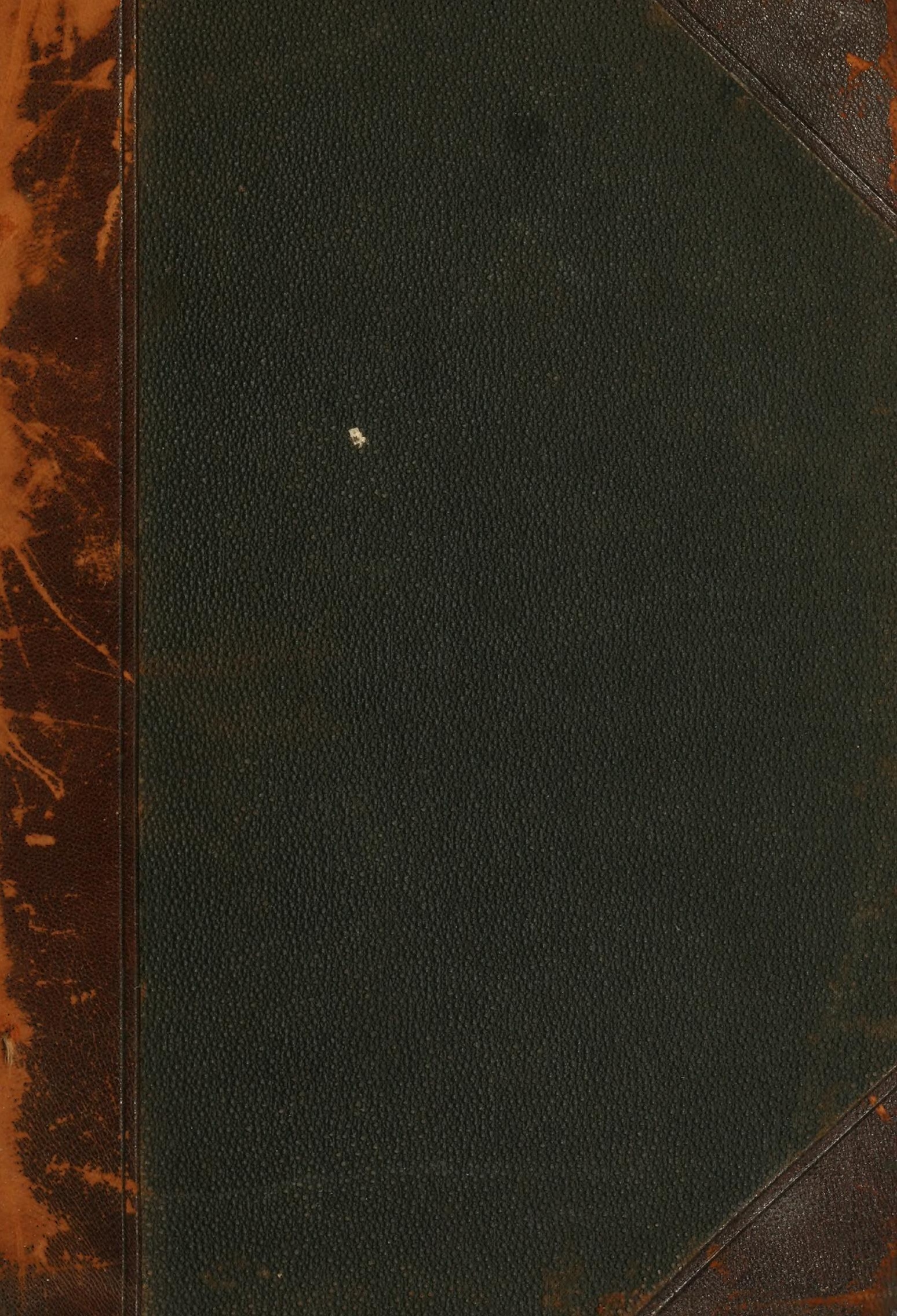




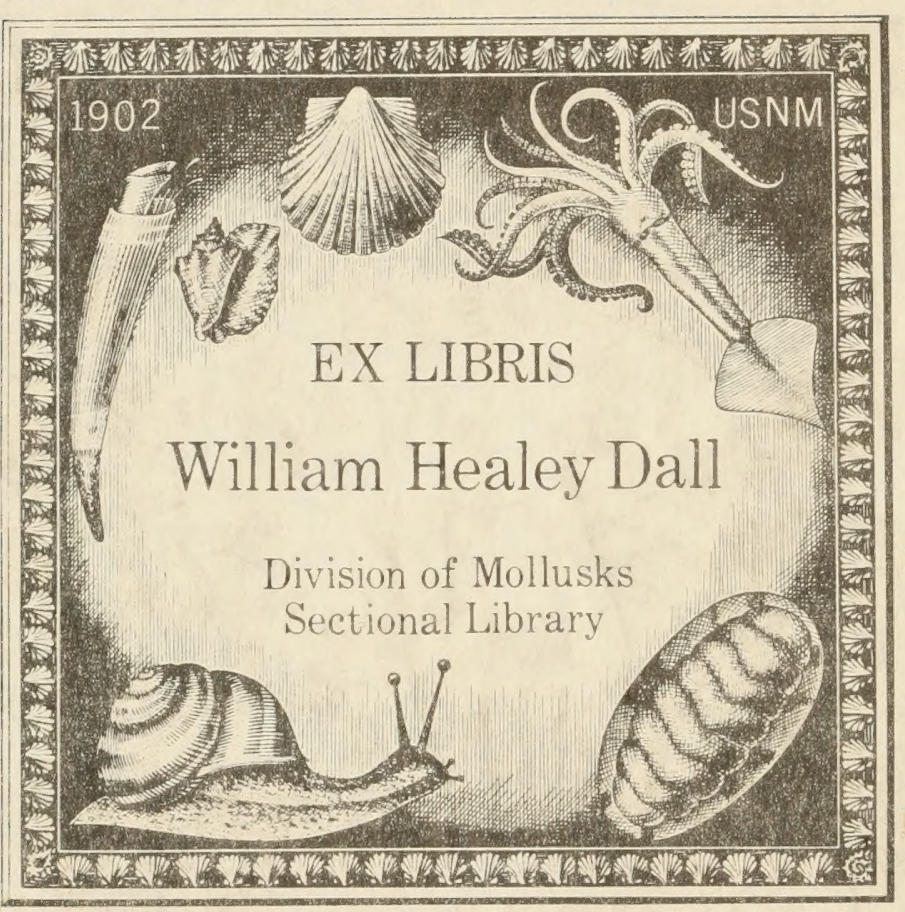




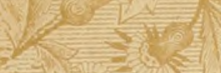

3

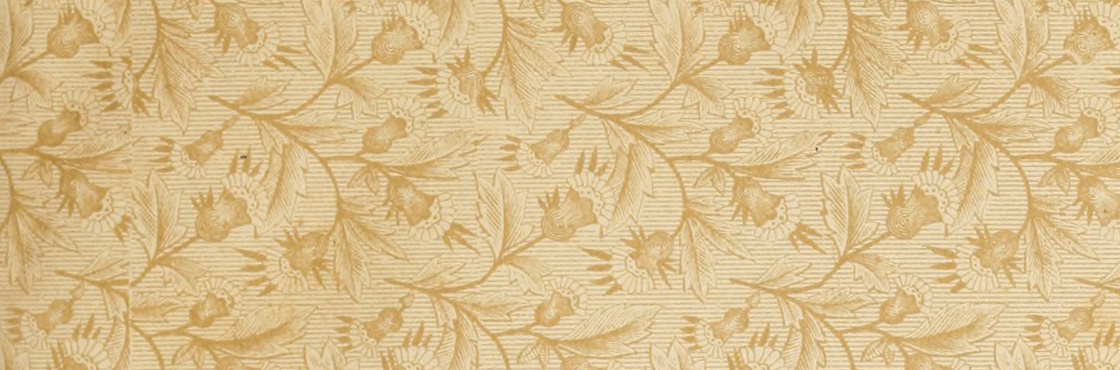

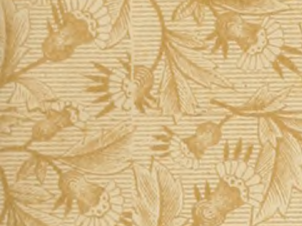

\section{$x=2 x$}

$3 0 \longdiv { 1 }$
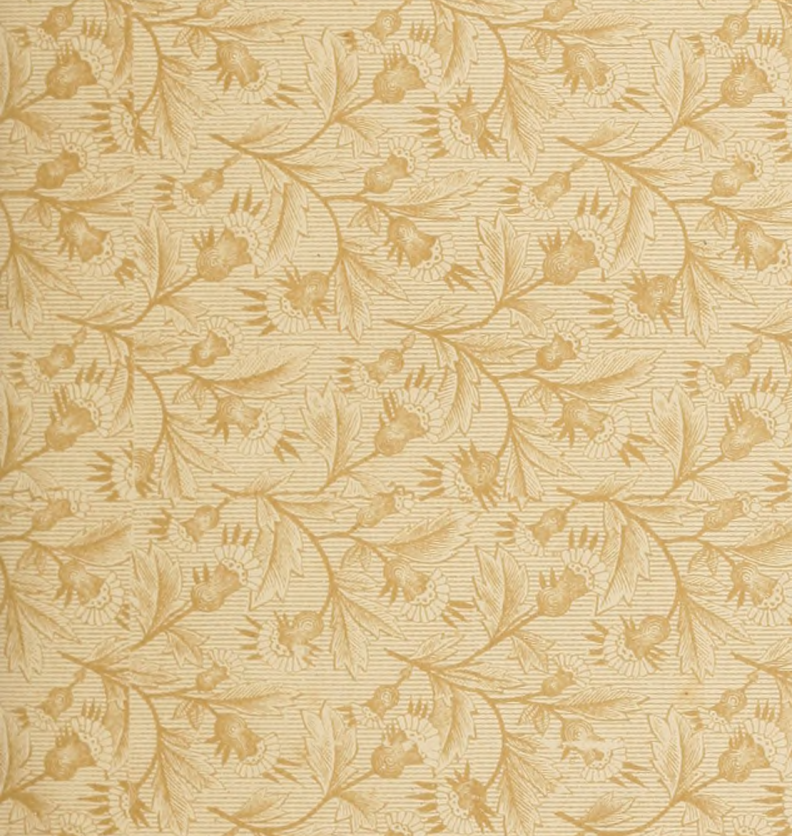

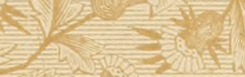
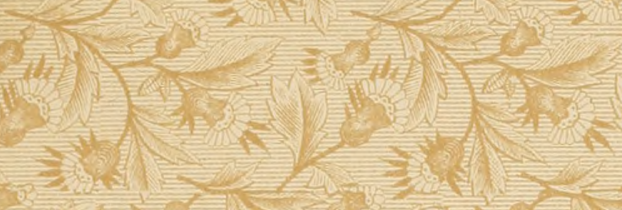

Cx 




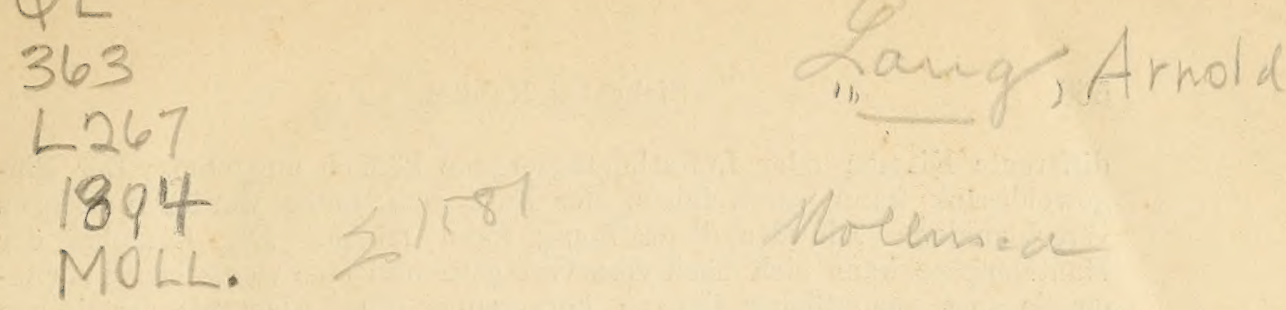

\section{KAPITEL.}

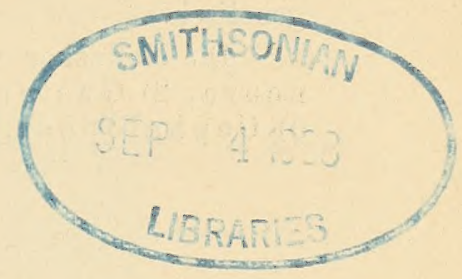

\section{Kreis oder Stamm des Thierreiches.}

\section{Mollusca. Weichthiere.}

Von Haus aus bilateral symmetrische Thiere mit ungegliedertem Körper. Die Bauchwand ist musculös verdickt und bildet den zur Locomotion dienenden Fuss, der die verschiedensten Formen annehmen kann. Eine Duplicatur der Leibeswand bildet eine am Körper herunterhängende Ringfalte, den Mantel, welcher die Mantelhöhle bedeckt. Die Mantelhöhle ist ursprünglich hinten am tiefsten und geräumigsten und beherbergt hier zu Seiten des medianen Afters symmetrisch gruppirt die beiden Kiemen, die beiden Nierenöffnungen und die Geschlechtsöffnungen. Der meist zu einem Eingeweidesack auswachsende Rücken ist bis zum Mantelrande von einer schützenden Schale bedeckt. Der Mund liegt am Vorderende des Körpers und führt in den meist mit Kiefern und einer Reibplatte (Radula) bewaffneten Pharynx. Mitteldarm mit einer voluminösen Verdauungsdrüse (Leber). Secundäre (eigenwandige) Leibeshöhle reducirt, jedoch immer als Pericard erhalten. Blutgefässsystem offen, meist grossentheils lacunär. Herz dorsal, ursprünglich mit zwei symmetrischen Vorhöfen, arteriell. Nephridien ursprünglich paarig, stehen mit dem Pericard in offener Communication. Das Centralnervensystem besteht aus den paarigen Cerebral-, Pleural-, Pedal- und Visceralganglien. Getrenntgeschlechtliche oder hermaphroditische Thiere. Gonade meist unpaar mit paarigen oder unpaaren Leitungswegen. In der Entwickelung entsteht aus der Gastrula eine modifizirte Trochophora, die für die Mollusken charakteristische Veligerlarve.

Diese kurze und allgemeine Charakteristik des Mollúskenkörpers müsste für jede einzelne Klasse modifizirt werden. In jeder Klasse giebt es Formenreihen, die in diesem oder jenem wichtigen Punkte der Organisation oder in mehreren Punkten zugleich abweichen. Die Schale kann verloren gehen, ebenso der Mantel. Von den beiden Kiemen kann die eine und schliesslich auch die andere verschwinden. Neue, morphologisch 
differente Kiemen oder Luftathmungsorgane können auftreten. Der Eingeweidesack kann verstreichen, der Fuss rudimentär werden und ganz verschwinden. Die Mundbewaffnung kann fehlen. Der Complex der Mantelorgane kann sich nach vorn verlagern und eine weitgehende Asymmetrie fast sämmtlicher Organe hervorrufen etc. Aber nie verwischen sich alle Molluskencharaktere derart, dass nicht die Zugehörigkeit einer Thierart zu den Mollusken in doppelter Weise nachgewiesen werden könnte, 1) vergleichend-anatomisch und systematisch durch Uebergangsreihen, die zum wohlausgeprägten Molluskentypus führen, 2) ontogenetisch.

Die Mollusken werden in folgende 5 Klassen eingetheilt: 1) Amphineura, 2) Gasteropoda, 3) Scaphopoda, 4) Lamellibranchia, 5) Cephalopoda.

\section{Systematische Uebersicht.}

\section{Klass e. Amphineura.}

Bilateral-symmetrische Mollusken. Das Nervensystem weist zwei seitliche und zwei ventrale durch zahlreiche Commissuren verbundene, in ganzer Ausdehnung mit Ganglienzellen besetzte Nervenstränge auf, welche vorn in das Cerebralganglion einmünden. Spezielle Sinnesorgane reducirt. Meeresbewohner.

I. Ordnung. Placophora sive Chitonidae.

Auf der Rückenseite 8 hintereinander liegende, dachziegelförmig übereinander greifende Schalenstücke. Gesonderte Schnauze. Zahlreiche Kiemen jederseits in einer Längsreihe in der Furche zwischen Fuss und Mantelzone. Fuss (mit Ausnahme von Chitonellus) stark entwickelt, mit grosser flacher Kriech- oder Haftsohle. Paarige Geschlechtsgänge und paarige Nephridien. Getrenntgeschlechtlich. Herz mit 2 Vorhöfen. Radula

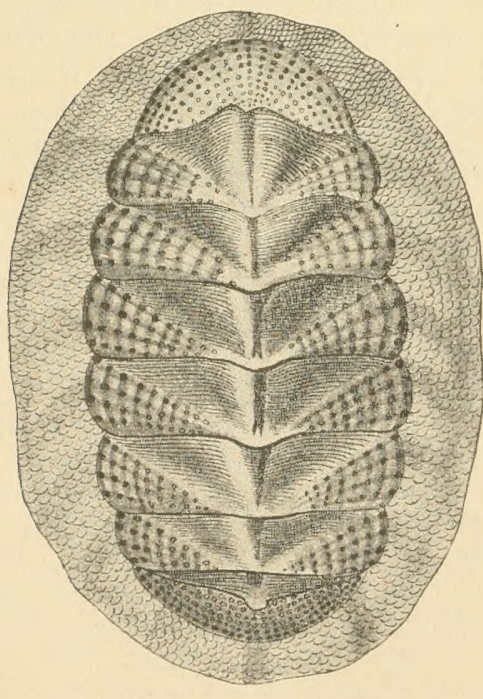

$(3+1),(2+1),(1+1+1),(1+2)$, $(1+3)$. Chiton (Fig. 385), Chi tonellus.

\section{Ordnung. Aplacophora sive Solenogastres.}

Körper annähernd cylindrisch, meist wurmförmig. Keine Schalen. Der stark verdickten Cuticula sind Kalknadeln eingebettet. Fuss rudimentär, Mantelhöhle reducirt auf eine Furche zu beiden Seiten des rudimentären, leistenförmigen Fusses und auf eine Höhle (Kloake) am hinteren Körperende, in welche Darm und Nephridien münden, und in welcher die rudimentären Kiemen

Fig. 385. Chiton, Habitusbild, nach Prétre (in: Voyage de l'Astrolabe). 
liegen, wenn solche vorhanden sind. Als Ausführungsgänge der Geschlechtsproducte fungiren die Nephridien.

\section{Familie. Neomeniidae.}

Fuss eine Längsleiste, die sich im Grunde einer medio-ventralen Längsfurche erhebt. Hermaphroditen. Proneomenia (Fig. 386), N e omenia, Lepidomenia, Dondersia.

2. Familie. Cha etodermidae.

Fuss und Fussfurche gänzlich verkümmert, Geschlechter getrennt. Cha etoderma.

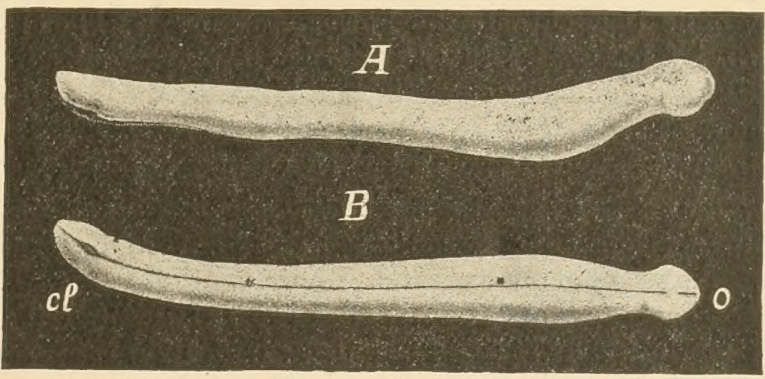

Fig. 386. Proneomenia Sluiteri, Original, $\frac{2}{3}$ Grösse. $\boldsymbol{A}$ von der rechten Seite, $\boldsymbol{B}$ von unten. o Mund, $c l$ Kloake.

\section{Klass e. Gasteropoda (Cephalophora). Schnecken.}

Körper asymmetrisch. Tentakel- und augentragender Kopf vom Körper meist gesondert. Fuss wohl entwickelt, meist mit flacher Kriechsohle. Der bruchsackartig hervortretende, grosse Eingeweidesack kann in allen Gruppen secundär wieder verstreichen. Er ist von einer aus einem einzigen Stück bestehenden Schale (Gehäuse) bedeckt, in welche sich das Thier zurückziehen kann. Doch kommt - meist im Zusammenhang mit dem Verstreichen des Eingeweidesackes — in allen Abtheilungen (doch bei den Prosobranchien nur ganz ausnahmsweise) Rudimentation der Schale vor, die zum völligen Schwunde derselben führen kann.

Mantelcomplex auf der rechten (selten linken) Seite oder dieser entlang ganz nach vorn verschoben. Eingeweidesack und Schale spiralig aufgewunden.

Die Asymmetrie prägt sich überall, mit alleiniger Ausnahme der niedersten Prosobranchier, in dem Schwunde der einen Kieme, der einen Niere, des einen Vorhofes des Herzens aus.

Radula immer vorhanden.

\section{Ordnung. Prosobranchia. Vorderkiemer.}

Die Pleurovisceralconnective gekreuzt. Mantelcomplex an die Vorderseite des Eingeweidesackes verlagert. Bei den meisten Formen nur eine Kieme, diese vor dem Herzen, und am Herzen der Vorhof vor der Kammer. Getrenntgeschlechtliche Thiere, die vorwiegend im Meere leben. Fuss meist mit Deckel zum Verschluss der Schale. Eine Schale fehlt nur bei Titiscania (einer Neritaceengattung). 


\section{Unterordnung. Diotocardia.}

Herz mit 2 Vorhöfen (excl. Docoglossa). 2 Nieren. Anstatt der Pedalganglien der übrigen Gasteropoden 2 durch zahlreiche Quercommissuren verbundene gangliöse Längsnervenstränge im Fuss. Kiemen zweizeilig gefiedert, mit der Spitze frei vorragend. Epipodium wohl entwickelt: ein Kranz von zahlreichen oder weniger zahlreichen Tentakeln um die Fussbasis. Kein Rüssel, kein Penis, kein Sipho.

a) Zeugobranchia (Rhipidoglossa, Aspidobranchia). 2 Kiemen, beide Vorhöfe gut ausgebildet. Herz vom Rectum durchbohrt. Schale mit marginalem Schalenschlitz, oder mit apicalem Loch oder von einer Reihe von Löchern durchbohrt. Meist ohne Deckel. Marine Formen. Fam. Hali otidae, Radula $\infty$ 1. (5. 1. 5.) 1. $\infty$, Fis s urellida e (Fissurella, Rad. $\infty$ 1. (4. 1. 4.) 1. $\infty$, mit secundär-symmetrischer Schale, Emarginula, Scutum $=$ Parmophorus), Pleurotomaridae (Pleurotomaria, Scissurella, Polytremaria), Bellerophontidae (ausschliesslich fossil).

b) Azygobranchia. Eine Kieme, die linke der Zeugobranchier. Rechter Vorhof blind geschlossen. Herz vom Rectum durchbohrt. Fam. Turbonidae, Rad. $\infty$ 0. (5. 1. 5.) $0 . \infty$, Trochidae (Fig. 387), Stomatiidae, Neritopsidae, Rad. $\infty$ 1. (2.0.2.) 1. $\infty$, marin, Neritidae, Rad. $\infty 1$. (3. 1.3.) 1. $\infty$ (marin, können an der Küste in der Luft leben), Neritina e im süssen Wasser).

Fig. 388 .
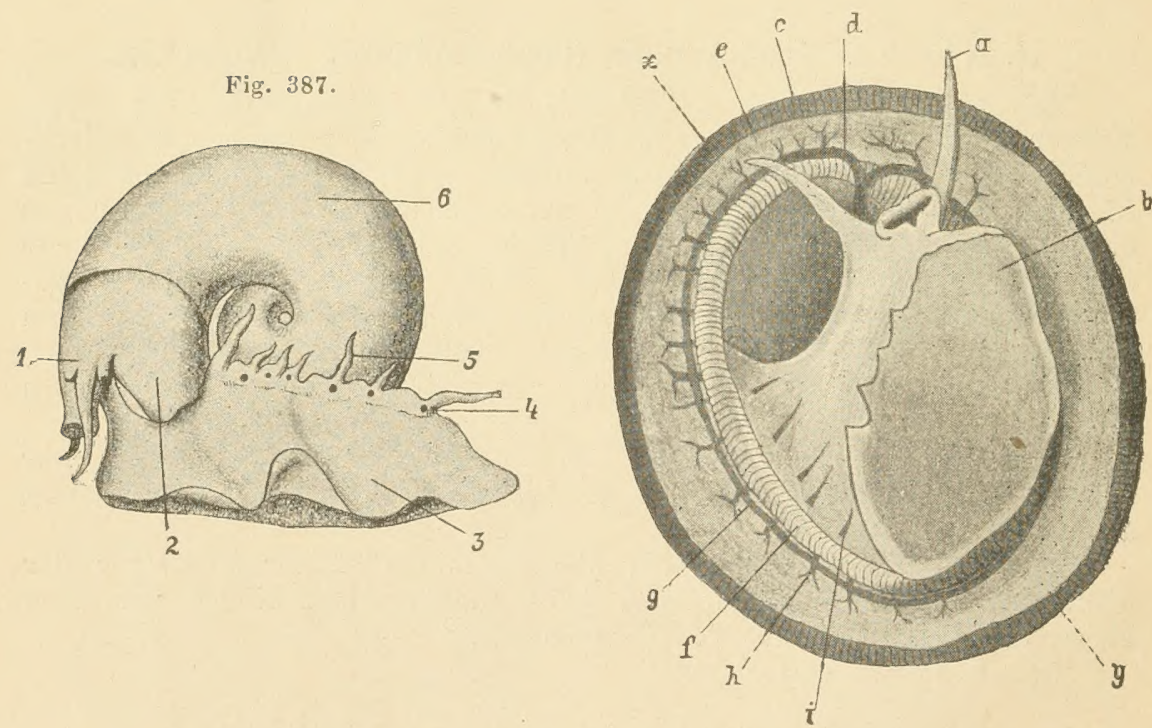

Fig. 387. Margarita groenlandica (Trochide), nach Pelseneer. 1 Kopf, 2 vorderer Epipodiallappeı, 3 Fuss, 4 pigmentirte Höcker an der Basis der Epipodialtentakel 5, 6 Eingeweidesack.

Fig. 388. Patella vulgata, von der Unterseite, nach LANkkster, a Tentakel, $d$ abführendes Kiemengefäss, $c$ freier Schalenrand, $e$ freier Mantelrand, $x-y$ Medianlinie, $g a b$ führendes Kiemengefäss, $f$ Kiemenlamellen, $h$ eines der zuführenden Gefässe, $i$ Zwischenräume $z$ wischen Schalenmuskel, $b$ Fuss. 
Die Hydrocoenidae, Rad. $\infty$ 1.(1.1.1.) 1. $\infty$, und Helicinidae, $\infty$ 1.(4.1.4.) 1. $\infty$, sind kiemenlos und besitzen eine derjenigen der Pulmonaten ähnliche Lunge. Die Helicinidae sind Landthiere.

c) Docoglossa. Herz mit einem Vorhof, nicht vom Rectum durchbohrt. Linke Niere auf die rechte Seite des Pericards gerückt. Eingeweidesack und Schale secundär-symmetrisch, letztere meist napfförmig. Operculum fehlt. Marin.

1. Linke ächte Kieme (Ctenidium) vorhanden. A c ma e ida e, Rad. 1. 2. (1.0.1.) 2.1, mit zahlreichen accessorischen Kiemen in der Mantelfurche: Scurria; ohne solche Kiemen: Acmaea (Tectura).

2. Aechte Kiemen (Ctenidien) fehlen ganz, accessorische Kiemen in der Mantelfurche in grosser Zahl vorhanden. Fam. Patellida e (Fig. 388), Rad. 3. 1. (2. 0.2.) 1.3.

3. Weder Ctenidien noch accessorische Kiemen vorhanden (Lepetid a e), Rad. 2. 0.1. 0.2.

2. Unterordnung. Monotocardia (Pectinibranchia).

Herz mit einem Vorhof. Eine einzige ächte Kieme, welche einzeilig gefiedert ist und deren Spitze nicht frei vorragt (excl. Valvata). Pedalstränge bilden die seltene Ausnahme, Pedalganglien die Regel. Nur eine Niere. Sipho und Penis sind meist vorhanden. Epipodium schwach entwickelt oder fehlend. Sehr formenreiche Abtheilung vorwiegend mariner Schnecken.

a) Architaenioglossa. Pedalstränge. Bei Cypraea (und anderen Formen?) besteht noch ein Rudiment des rechten Vorhofes. Fam. Cypraeidae, Rad. 3.1.1.1.3, Paludinidae (Süsswasser), Cyclophoridae (Landbewohner, lungenathmend).

b) Taeniogloss a. Typische Radula 2.1.1.1.2. Semiproboscidifera. Fam. Naticidae (Fig. 480), Lamellaridae. R ostrifera.

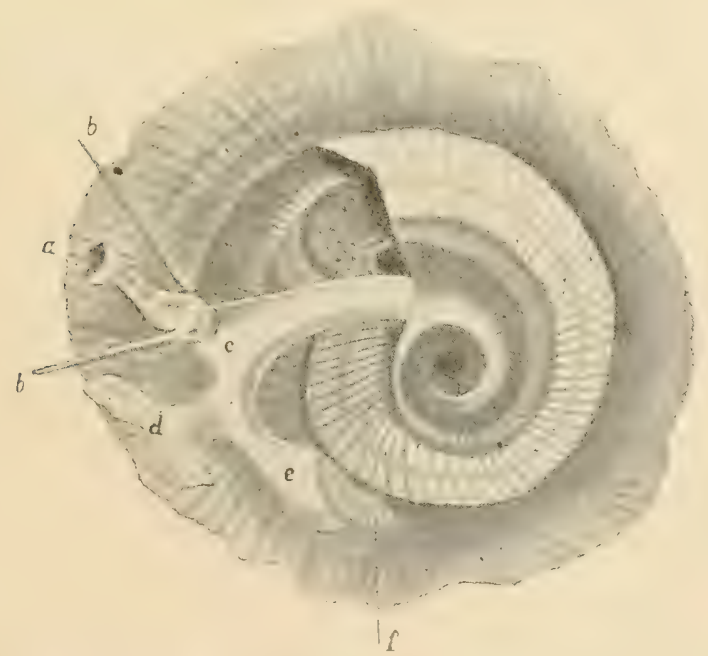

Fig. 389. Phorus exutus, nach LANKESTer. a Rüsselförmige Schnauze, $b$ Tentakel, c Auge, $d$ Fuss, e Metapodium mit Deckel $f$. 
Fam. Talvatidae (Süsswasser), Ampullaridae (Süsswasser), Littorinidae, Cyclostomidae (Landbewohner), Planaxidae, Hydrobiidae (Süsswasser), Aciculidae (Landbewohner), Truncatellidae (z. Th. Landbewohner), Hipponycidae, Capulidae, Calyptraeidae, Pseudomelanidae, Melanidae, Cerithiidae, Vermetidae, Turritellidae, Xenophoridae (Fig. 389), Struthiolaridae, Chenopidae, Strombidae (Fig. 390).

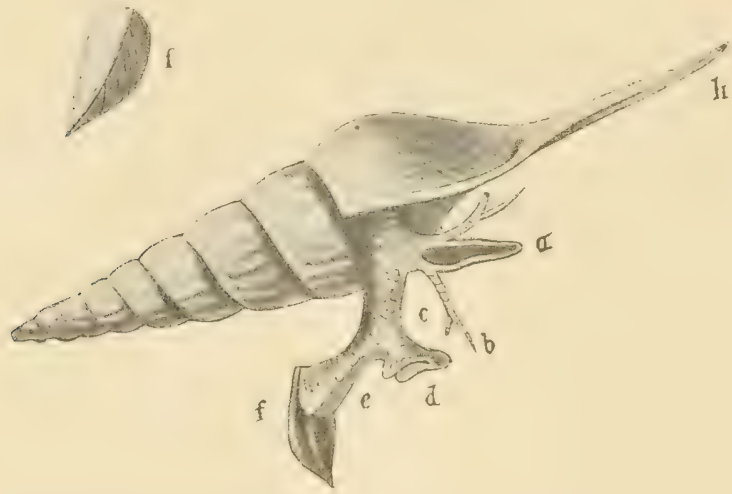

Fig. 390. Rostellaria rectirostris, nach Owen, $a$ Schnauze, $b$ Tentakel, $c$ gestielte Augen, $d$ Fuss, $e$ Metapodium mit Deckel $f, h$ Schnabel (Sipho).

Proboscidifera holostomata. Fam. Scalaridae, Rad. n, 0, n, Solaridae, Rad. n, 0, n, Pyramidellidae, Rad. 0, Eulimidae, Rad. 0. Proboscidifera siphonostomata. Fam. Colombellinidae, Tritoniidae, Cassidiidae (Fig. 391), Doliidae. I anthinida e, Rad. n, $0, n$. Heteropoda (pelagische Taenioglossa mit zu einer senkrechten Ruderflosse umgewandeltem Fusse). Fam. Atlantidae (Fig. 392), Pterotrachaeidae (Fig. 393).

c) Stenoglossa. Normale Rad. 1.1.1. Rachiglosssa. Fam. Turbinellidae, Fusidae, Mitridae, Buccinidae, Muricidae, Purpuridae, Haliadeae, Cancellariidae, Volutidae, Olividae, Marginellidae, Harpidaè. Toxiglossa. Fam. Pleurotomidae, Terebridae, Conidae.

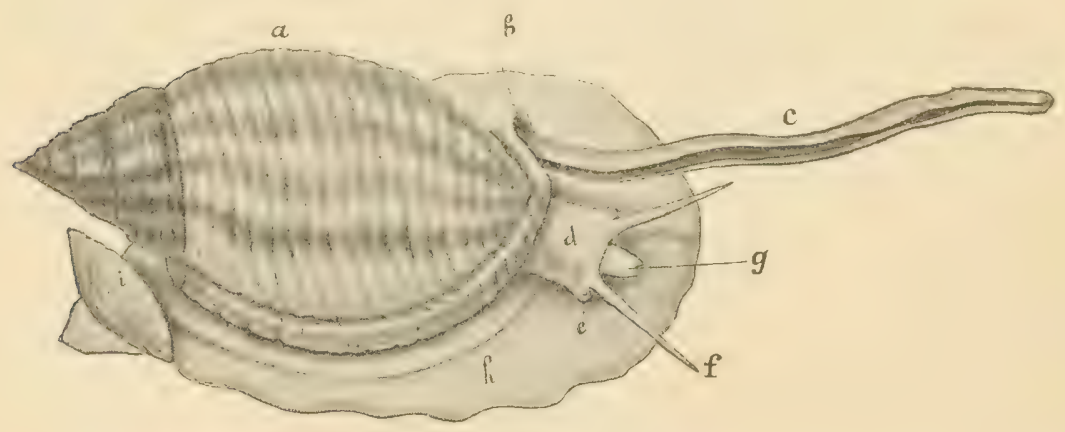

Fig. 391. Cassis sulcosa, nach PoLr. a Schale, $b$ Schnabel, $c$ Sipho, $d$ Kopf, $g$ Rüssel, e Auge, $f$ Tentakel, $h$ Fuss, $i$ Deckel. 


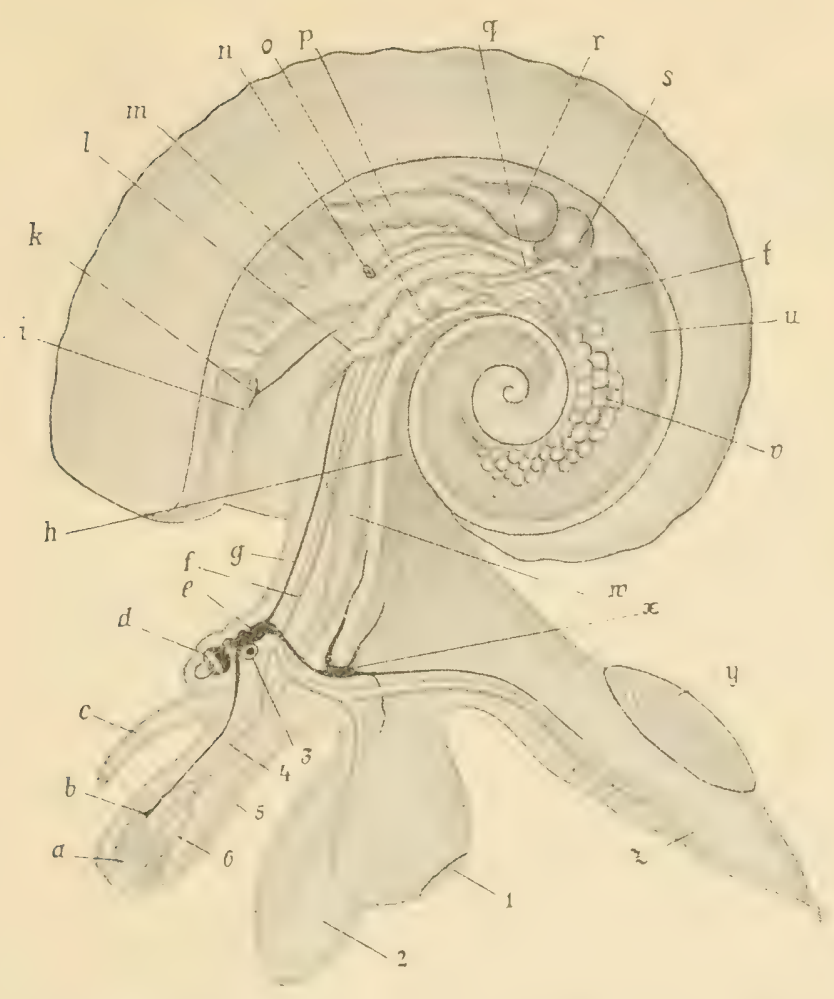

Fig. 392. Atlanta Peronii, nach Gegendaur. a Pharynx, $b$ Buccalganglion, $c$ Tentakel, $d$ Auge, $e$ Cerebralganglion, $f$ Aorta cephalica, $g$ Pleurovisceralconnectiv, $h$ Spindelmuskel, $i, k$ Osphradium, $l$ Vagina, $m$ Ctenidium, $n$ Anus, $o$ Uterus, $p$ Nephridium, $q$ Aorta cephalica, $r$ Vorhof, $s$ Herzkammer, $t$ Aorta visceralis, $u$ Verdauungsdrüse (Leber), $v$ Ovarium, w Mragen, $x$ Pedalganglion, $y$ Operculum, $\approx$ Metapodium, 1 Saugnapf des Flossenfusses (= rudimentäre Kriechsohle), 2 Fuss, 3 Gehörorgan, 4 Oesophagus, 5 Schnauze, 6 SpeicheIdriise.

\section{Ordnung. Pulmonata. Lungenschnecken.}

Pleurovisceralconnective ungekreuzt. Aus dem Mantelcomplex ist die Kieme geschwunden und durch eine Lunge, das heisst durch ein respiratorisches Gefässnetz an der Innenfläche des Mantels ersetzt. Pallealcomplex ursprünglich rechts vorn am Eingeweidesack. Mantelrand bis auf ein rechts liegendes Athemloch mit dem Integument des Nackens verwachsen. Bei Landpulmonaten ist das Verstreichen des Eingeweidesackes und die Rudimentation der Schale (Nacktschnecken) eine häufige Erscheinung. Das Operculum fehlt fast immer. Herz mit einem Vorhof, welcher fast immer vor der Kammer liegt. Hermaphroditen mit Zwitterdrüse und complicirtem ausführenden Apparate. Land- und Süsswasserschnecken.

1. Unterordnung. Basommatophora (Süsstrasserpulmonaten).

Augen an der Basis der (nicht einstülpbaren) Augententakel. Geschlechtsüffnungen getrennt, rechts vorn, die männliche ror der weiblichen. 


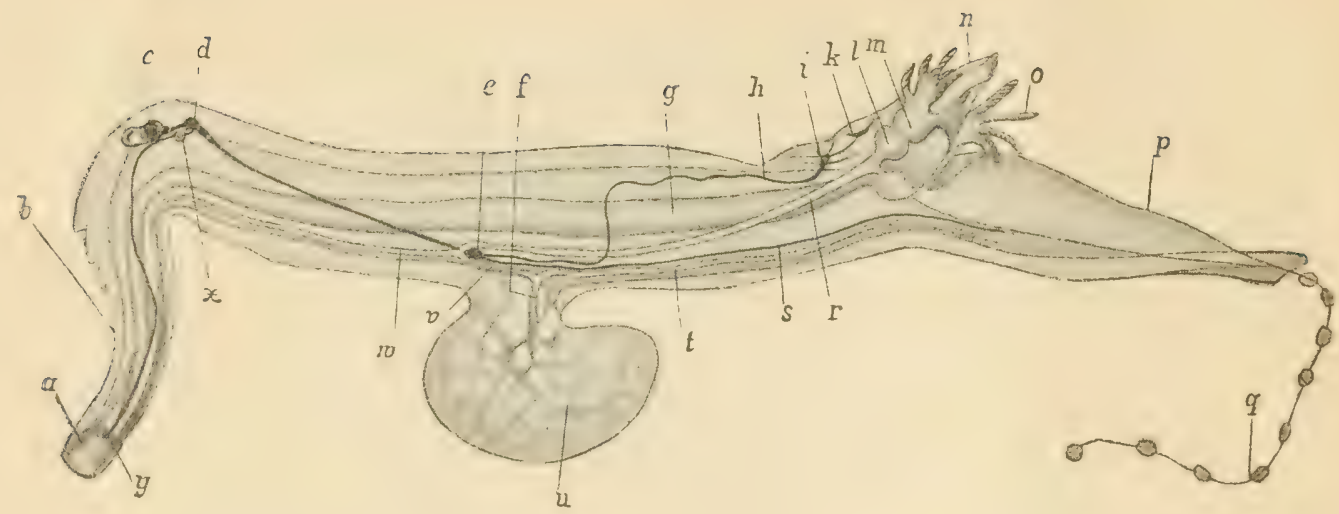

Fig. 393. Pterotrachea (Firola) coronata, nach Leuckart. $a$ Pharynz, $b$ rüsselförmige Schnauze, $c$ Auge, $d$ Cerebralganglion, $e$ Pedalganglion, $f$ Pedalarterie, $g$ Darm, $h$ Pleurovisceralconuectiv, $i$ Parietovisceralganglion, $k$ Osphradium, $l$ Herzkammer, $m$ Vorhof, $n$ After, o Ctenidium, $p$ Metapodium, $q$ Anhang, $r$ Aorta cephalica, 8 Nerv zum Metapodium verlaufend, $t$ Arterie, $u, v$ gemeinsame Fussarterie, $w$ Kopfarterie, $x$ Gehörorgan, $y$ Buccalganglion.

Fan. Li mu n e i da e (Limnaea, Amphipeplea [Fig. 394], Pliysa [Fig. 395], Planorbis, Ancylus), A u riculidae.

2. Unterordnung. Stylom mat ophora.

Augen an der Spitze der Augententakel. Tentakel einstülpbar.

a) Monogonopora. Mit einer einzigen rechtsseitigen Geschlechtsöffnung. Fam. Helicidae (Helix [Fig. 396 A], Arion [Fig. 396 D],

Fig. 395 .

Fig. 394.
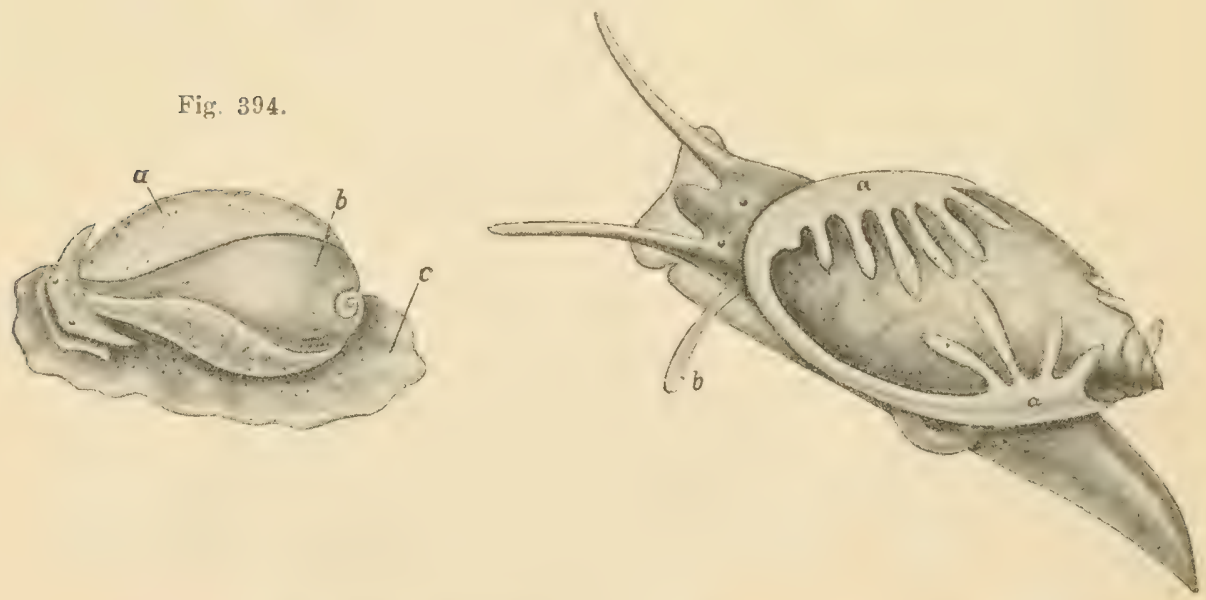

Fig. 394. Amphipeplea leuconensis, nach ADAss. a Auf die Schale zurückgeschlagener Nantellappen, $b$ unbedeckter Schalentheil, $c$ Fuss.

Fig. 395. Physa fontinalis, nach L. REEve. a Auf die Schale zurückgeschlagener Mantellappen, $b$ ausgestilipter Penis. 
Bulimus). Testacellidae (Daudebardia [Fig. 396 B], Testacella [Fig. 396 C]), Lim acida e (Ariophanta, Limax, Vitrina, Zonites, Helicarion), Bulimulidae (Fig. 397), Pupidae (Buliminus, Pupa, Clausilia), Succineidae.

b) Digonopora. Nacktschnecken mit getrennter männlicher und weiblicher Geschlechtsöffnung. Die männliche vorn rechts, die weibliche rechts am hinteren Körperende. Pallealcomplex am hinteren Körperende, Lungenhöhle reducirt. Fam. Vaginulid a e (Landbewohner), Oncidiidae (marine oder amphibische Formen; die Respiration geschieht theilweise durch respiratorische Rückenanhänge).

III. Ordnung.

Opisthobranchiata.

Hinterkiemer.

Pleurovisceralconnective ungekreuzt. Ein Vorhof des Herzens und dieser hinter der Kammer. Hermaphroditen. Schale vorhanden oder (häufiger) fehlend. Deckel fast immer fehlend. Athmen durch ächte Ctenidien, oder durch

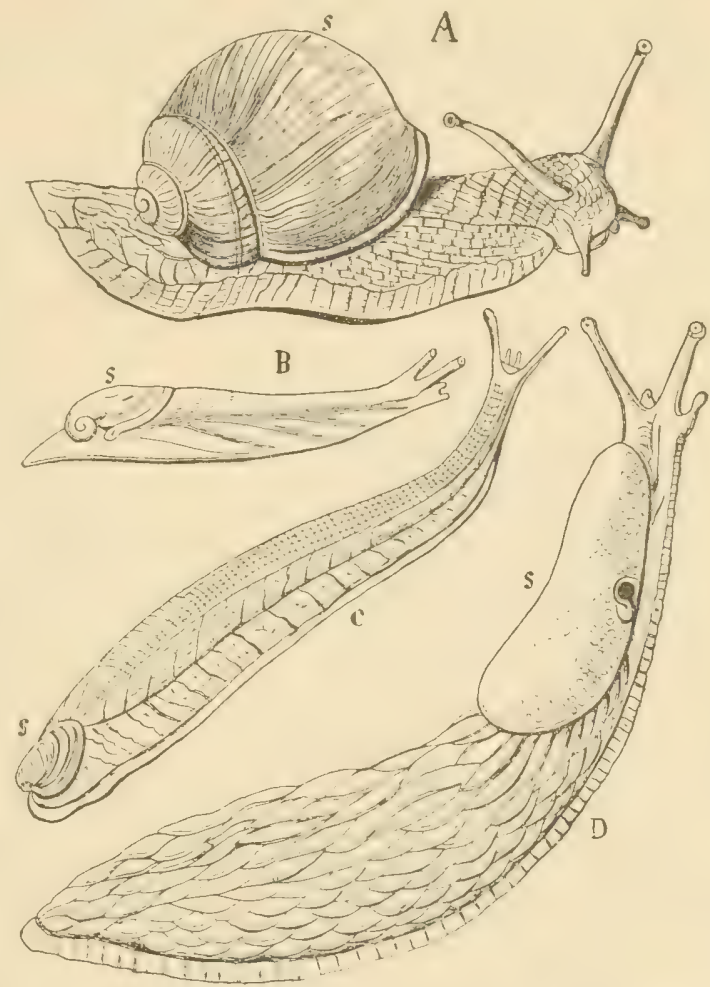

Fig. 396. A Helix pomatia, $\boldsymbol{B}$ Daudebardia (Helicophanta) brevipes, $\boldsymbol{C}$ Testacella haliotidea, $\boldsymbol{D}$ Arion ater. $s$ Schale, in $\boldsymbol{D}$ : Schild, aus LANkester.

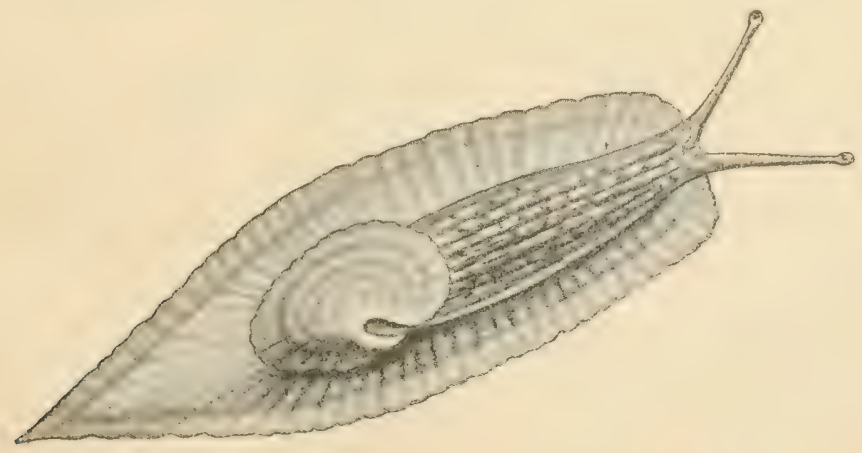

Fig. 397. Peltella palliolum (Bulimulide), nach FÉrussac. 
adaptive Kiemen, oder durch die Haut. Der Eingeweidesack sehr häufig verstrichen. Hermaphroditen mit Zwitterdrüse. Meeresbewohner.

1. Unterordnung. Tectibranchiata.

Pallealcomplex auf der rechten Körperseite von der auf dieser Seite entwickelten Mantelfalte mehr oder weniger bedeckt. Immer hat sich in der Mantelhöhle eine (die ursprünglich linke) ächte Kieme erhalten, welche vom Mantel oft nur sehr unvollständig bedeckt ist. Eingeweidesack mit Tendenz zum Verstreichen. Schale immer vorhanden, aber mit Tendenz zur Rudimentation. Meist mit Parapodien und die Schale bedeckenden Mantellappen.

\section{I*. Reptantia.}

a) Cephalaspidea. Mit Stirnscheibe. Fam. Acta eonidae (mit Deckel), Scaphandridae, Bullidae (Bulla, Acera), Gasteropteridae (Fig. 398), Philinidae, Doridiidae.

Fig. 398.

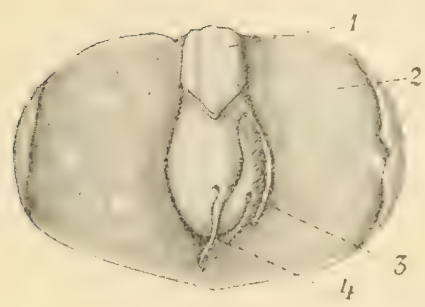

Fig. 399.

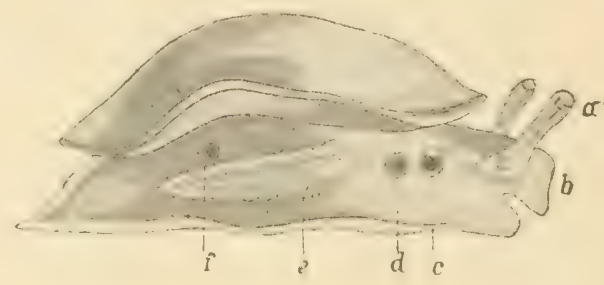

Fig. 398. Gasteropteron Meckelii (mit innerer Schale), nach VAISSIE்re. 1 Kupfschild (Stirnscheibe), 2 Parapodium, 3 Ctenidium, von der rudimentären Mantelfalte fast unbedeckt, 4 Flagellum = Anhang der Mantelfalte.

Fig. 399. Pleurobranchus aurantiacus (mit innerer Schale), nach LEdCKART, Wandtafeln, von der rechten Seite gesehen. $a$ Rhinophoren, $b$ Lippensegel, $c$ Genitalöffnung, $d$ Nephridialöffnung, $e$ Ctenidium, $f$ Anus.

b) Anaspidea. Kopf keine Stirnscheibe bildend. 4 zipfel- oder ohrförmige Tentakel. Fam. Aplysiidae (Aplysia, Dolabella, Notarchus).

c) Notaspidea. Kopf kurz, mit oder ohne Tentakel. Der Rücken bildet eine grosse Scheibe (Notaeum), in oder auf welcher eine Schale liegen kann. Fam. Pleurobranchidae (Pleurobranchus [Fig. 399], Pleurobranchaea, Oscanius), Umbrellidae (Umbrella, Tylodina), Peltidae.

II*. Natantia sive Pteropoda. Flossenschnecken.

Diese früher zu einer besonderen Molluskenklasse vereinigten Thiere sind jetzt als an die freischwimmende pelagische Lebensweise angepasste Tectibranchiata erkannt. Die Parapodien der Tectibranchia sind als Flossen oder flügelförmige Schwimmorgane ausgebildet.

a) Pteropoda thecosomata. Beschalte Flossenschnecken. Diese sind näher mit den Cephalaspidea verwandt. Mantel, Mantelhöhle, Schale vorhanden. Kopf nicht gesondert. 
Nur ein Paar Tentakeln. Flossen an ihrem vorderen Rande übor dem Munde verschmolzen. Anus auf der linken Seite. Fam. Limacinidae. Aeussere links gewundene Kalkschale mit einem spiraligen Operculum. Anus rechtsseitig (Limacina [Fig. 400], $\mathrm{Pe}$ raclis). Fam. Cavoliniidae. Aeussere Kalkschale symmetrisch (Clio, Cavolinia). Fam. Cymbuliidae. Innere Knorpelschale (Cymbulia, Cymbuliopsis, Gleba). Die Thecosomata ernähren sich vorwiegend von kleinen Protozoen und Algen.

Fig. 400 .

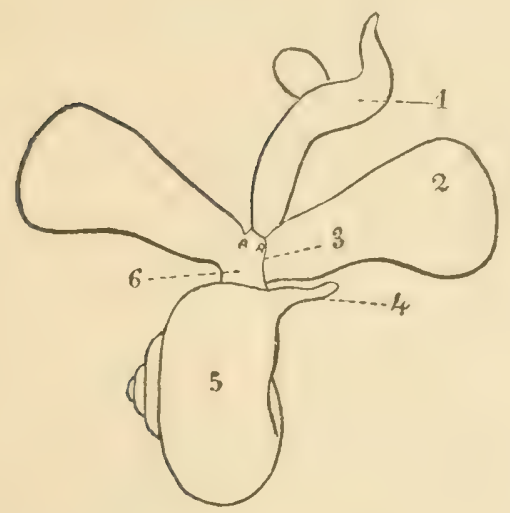

Fig. 400. Limacina Lesueuri, von der Dorsalseite, nach Pelseneer, 1 Penis, 2 Flosse (Parapodium), 3 Samenfurche, 4 Mantelfortsatz (,balancer"6), 5 Eingeweidesack, 6 Kopf mit 2 Tentakeln und der Samenfurche (3).

Fig. 401. Pnoumoderma, schematisch, von der rechten Seite, nach PelseneER. 1 Rechter ausgestülpter Hakensack, 2 Rüssel, 3 rechter Buccaltentakel, 4 Lage des rechten Nackententakels, 5 rechte Flosse (Parapodium), 6 Samenfurche, 7 Geschlechtsöffnung, 8 Lage des Kiefers, 9 ventrale Rüsselpapille, 10 rechter saugnapftragender Buccalanhang, 11 Kopf, 12 Penisöffnung, 13 rechter vorderer Fusslappen, 14 Anus, 15 hinterer Fusslappen, 16 Ctenidium, 17 hintere adaptive Kieme, $d, v, a, p$ dorsal, ventral, vorn, hinten.
Fig. 401.

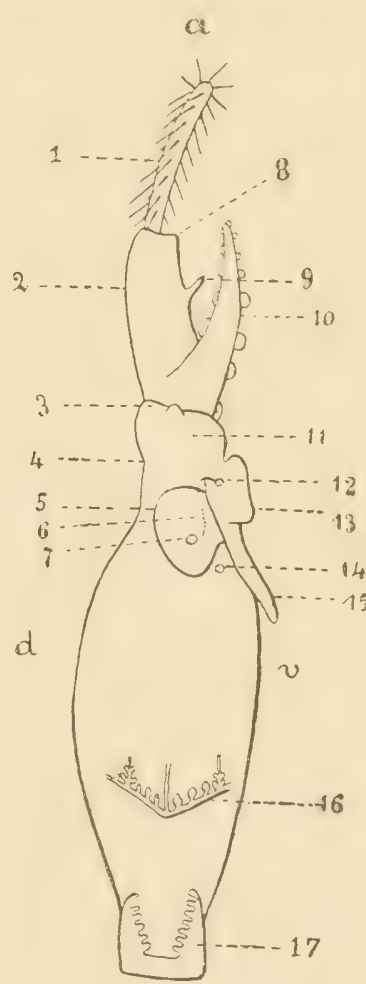

10

b) Pteropoda gymnosomata. Nackte Flossenschnecken. Diese sind näher verwandt mit den Anaspidea. Ohne Mantel, Mantelhöhle und Schale. Kopf gesondert. 2 Paar Tentakeln. Flossen getrennt. Anus auf der rechten Seite. Fam. Pneumodermatidae. Ein rechtsseitiges Ctenidium vorhanden (Dexiobranchaea, Spongiobranchaea, Pneumoderma [Fig. 401]). Bei den zwei letzteren Gattungen ausserdem noch eine adaptive hintere Kieme. Fam. Clionopsidae und Notobranchaeidae. Kein Ctenidium. Eine adoptive hintere Kieme. Fam. Clionidae. Weder ein Ctenidium noch adaptive Kiemen vorhanden. Alle Gymnosomata sind räuberische Thiere, die sich vorwiegend von Thecosomata ernähren. 


\section{Unterordnung. Ascoglossa.}

Charakterisirt dadurch, dass die verbrauchten Zähne der langen und schmalen, aus einer einzigen Reihe von Zahnplatten bestehenden Radula in einer Tasche am vordern Ende der Radula aufbewahrt werden. Keine Kiefer. Anus fast immer dorsal. Mit Ausnahme der Steganobranchia fehlt mit dem Mantel und der Mantelhöhle auch das einzige Ctenidium der Tectibranchiata.

I. Section. Steganobranchia.

Mit rechtsseitigem. Mantel, Mantelhöhle, Ctenidium und mit Schale, mit Parapodien. Fam. Oxynoidea e (Oxynoe, Lobiger).

II. Section. Cirrobranchia.

Auf den Seitentheilen des Rückens blatt- oder keulenförmige Fortsätze. Fam. Hermaeidae, Phyllobranchidae.

\section{Section. Pterobranchia.}

Seitentheile des Kürvers lappenfürmig ausgezogen. Die Verästelungen der Mitteldarmdrüse breiten sich in diesen Lappen aus. Fam. Elys ia da e, Placobranchidae.

\section{Section. Abranchia.}

Weder ein Ctenidium, noch Rückenanhänge, noch blattförmige seitliche Verbreiterungen des Körpers. Athmung durch die Haut. Körper fast planarienäbnlich. Fam. Lim apontiidae.

\section{Unterordnung. Nudibranchia.}

Ohne Mantelfalte, ohne Schale, ohne Ctenidium. Kiefer fast immer vorhanden. Radula meist wohl entwickelt, mit Zähnen, die abfallen und verloren gehen. Adaptive Kiemen sehr verschieden ausgebildet, bisweilen $\mathrm{O}$.

\section{Section. Holohepatica.}

Eine grosse compacte, keine Aeste abgebende Verdauungsdrüse (Leber). Fam. Phyllidiidae. Zahlreiche Kiemenlamellen rings in einer Furche um den Körper herum. Ohne Kiefer und ohne Radula. Pharynx zu einem Saugapparat umgewandelt. Doridopsidae. Ebenfalls ohne Kiefer und Radula, Pharynx ein Saugapparat. Kiemen in einer Rosette um den dorsalen After. Dorididae cryptobranchiatae. Mit Kiemenrosette um den dorsalen After. Kiemenrosette in eine Höhle zurückziehbar (Bathydoris, Archidoris, Discodoris, Diaulula, Kentrodoris, Platydoris, Chromodoris etc.). Dorididae phanerobranchiatae. Kiemenrosette nicht rückziehbar (Goniodoris, Polycera, Acanthodoris, Idalia, Ancula, Euplocamus, Triopa etc.).

\section{Section. Cladohepatica.}

Verdauungsdrüse ganz oder theilweise in verästelte, gesonderte Kanäle aufgelöst; welche sich im Körper weit verbreiten. Auf dem Rücken verschieden gestaltete, vornehmlich im Dienste der Respiration stehende Anhänge. After gewöhnlich rechtsseitig. Fam. A e olidiadae (Aeolidia [Fig. 402], Berghia, Tergipes, Galvina, Coryptella, Rizzolia, Facellina, Flabellina, Fiona, Glaucus, Janus, Hero). 'T ethymelibidae (ohne 
Radula) (Tethys, Melibe). Lomanotidae, Dotonidae, Dendronotidae, Bornellidae, Scyllaeidae, Phyllirhoidae (Fig. 403). (Pelagische freischwimmende Thiere, mit schmalem, seitlich zusammen-

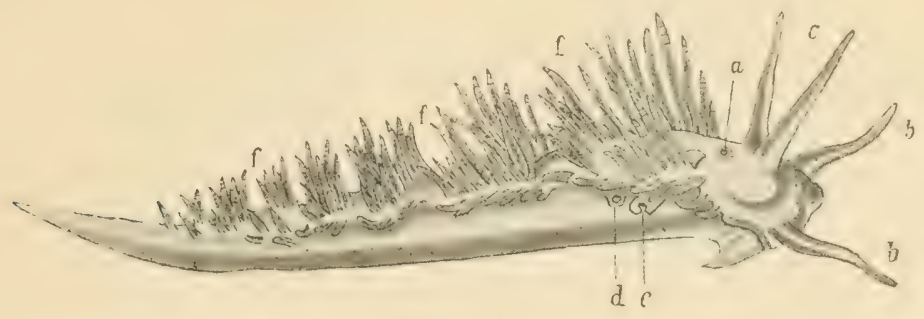

Fig. 402. Aeolis rufibranchialis, von der rechten Seite, nach ALDER und HANcock. $a$ Auge, $b$ Mundtentakel, $c$ Kopftentakel, $d$ Anus, $e$ Genitalöffnung, $f$ respiratorische Rückenanbänge (cerata).

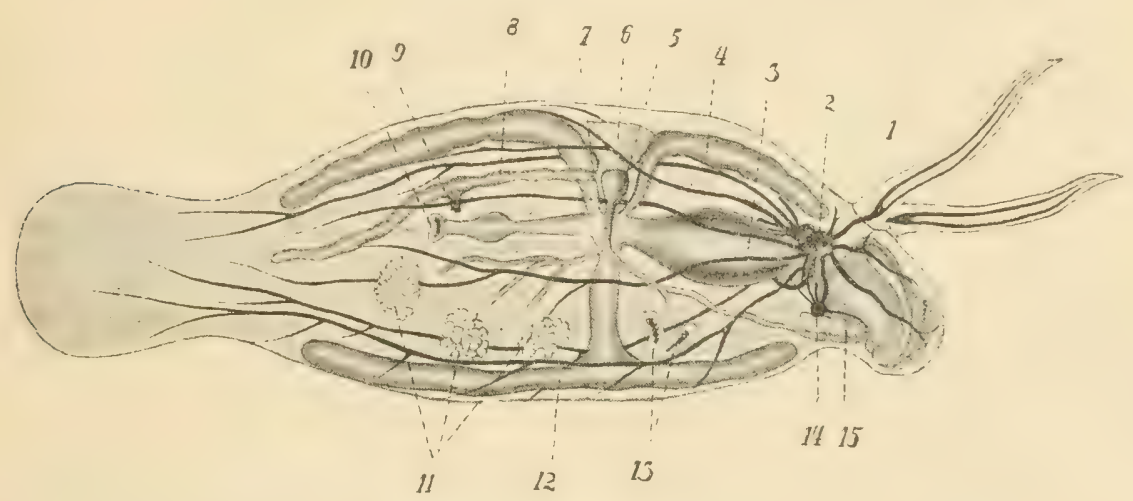

Fig. 403. Phyllirhoë bucephalum, von der Seite, nach Soulerex, modifizirt. 1 Tentakel, 2 Cerebralganglion, 3 Mrgen, 4 und 12 Darmcoeca (die Verdauungsdrüse bildend), 5 Herzkammer, 6 Vorhof, 7 Pericardialöffnung der Niere, 8 Niere, 9 äussere Oeffnung der Niere, auf der rechten Seite, 10 After, auf der rechten Seite, 11 Zwitterdrüsen, der ausleitende Apparat ist nicht dargestellt, 12 Coecum der Verdauungsdrüse, 13 Geschlechtsöffnungen, 14 Buccalganglion, 15 Speicheldrüse.

gedrücktem Körper ohne Fuss und ohne respiratorische Anhünge.) Pl europhyllidiidae (jederseits in einer Furche zwischen Rückenschild und Fuss zahlreiche in einer Längsreihe angeordnete Kiemenlamellen [Fig. 404]). Pleuroleuridae, Tritoniadae (Tritonia, Marionia).

\section{K l a s se. Scaphopoda.}

Körper symmetrisch, in dorsoventraler Richtung verlängert. Der Mantel einen röhrenförmigen Sack, mit dorsaler engerer und ventraler weiterer Mündung, bildend. Mantelhöhle sich auf der Hinterseite des Körpers bis zum apicalen Loch erstreckend. Schale hoch kegel-röhrenförmig, wie der Mantel mit apicaler kleinerer und ventraler grösserer Oeffnung. Ctenidien fehlen. Nieren paarig. Eigenwandiger Theil des 


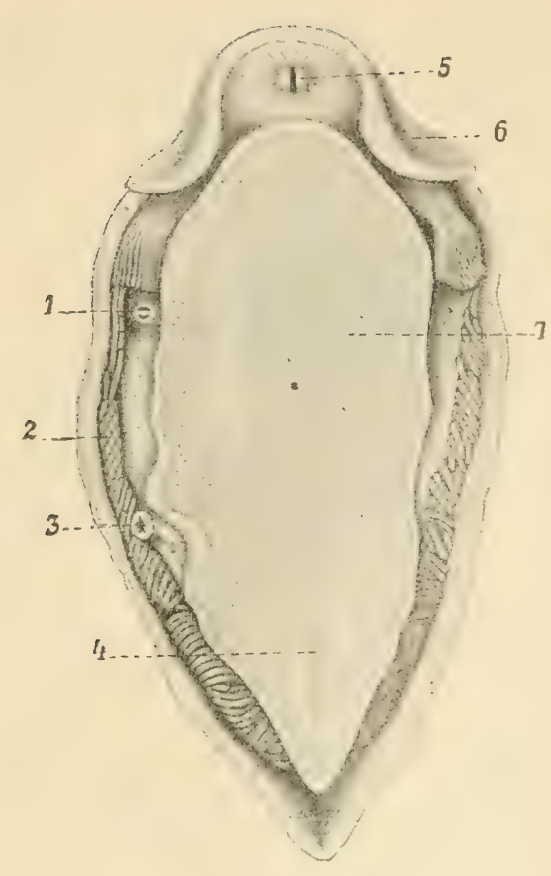

Circulationssystems auf eine Herzkammer ohne Vorhöfe reducirt. Trennung der Geschlechter. Besondere Leitungswege der Geschlechtsproducte fehlen. Letztere werden durch die rechte Niere entleert. Mund an der Spitze einer tonnenförmigen Schnauze, von einem Kranz blattförmiger Anhänge umgeben. An der Basis der Schnauze entspringen zahlreiche fadenförmige Anhänge, welche aus der untern Mündung der Schale und des Mantels vorgesteckt werden können. Fuss gestreckt, ventralwärts verlängert. Radula vorhanden. Limicole Meeresbewohner. Dentali u m (Fig. 483) (Fuss relativ kurz, am Ende fast eichelförmig, mit einem conischen Mittel- und zwei Seitenlappen). Siphonodentalium (Fuss wurmförmig verlängert, am Ende scheibenförmig verbreitert, mit Papillen am Scheibenrande).

Fig. 404. Pleurophyllidia lineata, von unten, nach SoulEyet. 1 Geschlechtsöffnungen, 2 Kiemenblättchen, 3 Anus, 4 Fussdruise, 5 Mund, 6 Tentakelschild, 7 Fuss.

\section{Klas se. Lamellibranchia (Pelecypoda, Bivalva, Acephala, Aglossa). Muscheln.}

Körper symmetrisch, in transversaler Richtung mehr oder weniger abgeplattet, mit zwei grossen seitlichen, blattartig ausgebreiteten Mantellappen, welche eine gerüumige Mantelhöhle begrenzen, in welcher der meist beil- oder keilförmige Fuss Platz finden kann. Zwei seitliche Schalenklappen, die nur am dorsalen Schlossrand miteinander verbunden sind. Zum Verschluss der Schale zwei quer von der einen zur andern Schalenklappe verlaufende Schliessmuslieln (Dimyarier), hier und da durch Reduction des vorderen nur ein Schliessmuskel (Monomyarier). Jederseits in der Mantelhöhle ein Ctenidium. Ohne Pharynx, ohne Kiefer, ohne Radula und ohne Tentakel - ohne gesonderten Kopfabschnitt. Nieren paarig, Geschlechtsorgane paarig, münden gesondert oder durch Vermittelung der Nephridien. Herz mit zwei Vorhöfen. Jederseits vom Munde ein Paar Mrundappen. Theils getrenntgeschlechtlich, theils hermaphroditisch. Im Meere und im siissen Wasser. Limicol oder festsitzend.

\section{Ordnung. Protobranchia.}

Kieme im hinteren Theil der Mantelhöhle, zweizeilig, gefiedert, dem Ctenidium der Zengobranchien durchaus entsprechend, mit der Spitze frei nach hinten in die Mantelhöhle vorragend. Fuss mit Kriechsohle. Pleural- 
ganglion vom Cerebralganglion unterscheidbar. Fam. Nuculida e (Nucula [Fig. 405], Leda, Yoldia), Solen om yid a e.

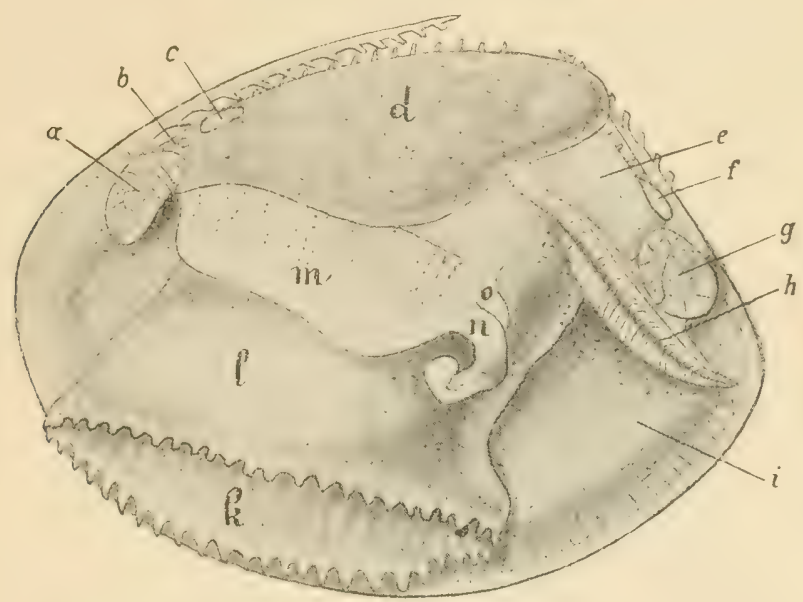

Fig. 405. Nucula nucleus, von der linken Seite nach Entfernung der linken Schale und des linken Mantels, nach Pelseneer. a Vorderer Schliessmuskel, $b$ vorderer Rückziehmuskel des Fusses, $c$ Heber des Fusses, $d$ Genitalmasse, $e$ Hypobranchialdrüse, $f$ hinterer Rückziehmuskel des Fusses, $g$ binterer Schalenmuskel, $h$ Ctenidium, $i$ Mantelhöhle, $k$ Kriechsohle des Fusses $l, n$ Mundlappen mit hinteren Anhången $n$ und 0 .

\section{Ordnung. Filibranchia.}

Die Kiemenblättchen des Ctenidiums haben sich zu langen Fäden verlüngert, welche weit in die Mantelhöhle herunterhängen und aus zwei Schenkeln besteher, einem basalen absteigenden und einem terminalen aufsteigenden.

Fam. A n o miidae. Mantel offen ohne Siphonen; Monomyarier. Fuss klein. Körper und Schale asymmetrisch. Festsitzende Muscheln. Kiemenfäden vollständig frei (Anomia, Placuna). Fam. A rcidae. Kiemenfäden einer jeden Reihe mit einander durch Wimperscheiben verbunden. Dimyarier. Keine Siphonen. Fuss gross. (Arca, Pectunculus.) Fam. Trigoniid a e. Kiemen wie bei den Arcidae. Dimyarier. Keine Siphonen. (Trigonia.) Fam. Mytilida e (excl. Aviculidae). Kiemenfäden mit einander durch nicht vascularisirte Suturen verbunden. Vorderer Schalenmuskel ist kleiner als der hintere (Heteromyarier). Siphonen vorhanden. Fuss gestreckt. (Mytilus [Fig. 406], Modiola, Lithodomus [Bohrmuscheln], Modiolaria.)

III. Ordnung: Pseudolamellibranchia.

Die aufeinander folgenden Kiemenfäden einer Reihe sind mit einander durch Wimperscheiben oder durch vascularisirte Brücken verbunden, ebeuso der aufsteigende mit dem absteigenden Schenkel eines jeden Filamentes.

Fam. Pectinidae. Monomyarier, mit ganz offenem Mantel und Augen am Mantelrand. Ohne Siphonen. Fuss klein, zungenförmig. Schale gleichklappig oder uugleichlklappig. Können schwimmen. (Pecten [Fig. 407], Chlamys.) Fam. Aviculidae. Monomyarier oder Heteromyarier ohne 
Siphonen. Schale gleich- oder ungleichklappig. (Avicula [Meleagrina], Malleus, Vulsella, Perna, Inoceramus, Pinna, Meleagrina margaritifera: Perlmuschel.) Fam. Ostreidae. Monomyarier ohne Fuss mit ganz offenem Mantel ohne Siphonen. Schale ungleichklappig, mit der linken Klappe an der Unterlage befestigt. (Ostrea: Auster [Fig. 408].)

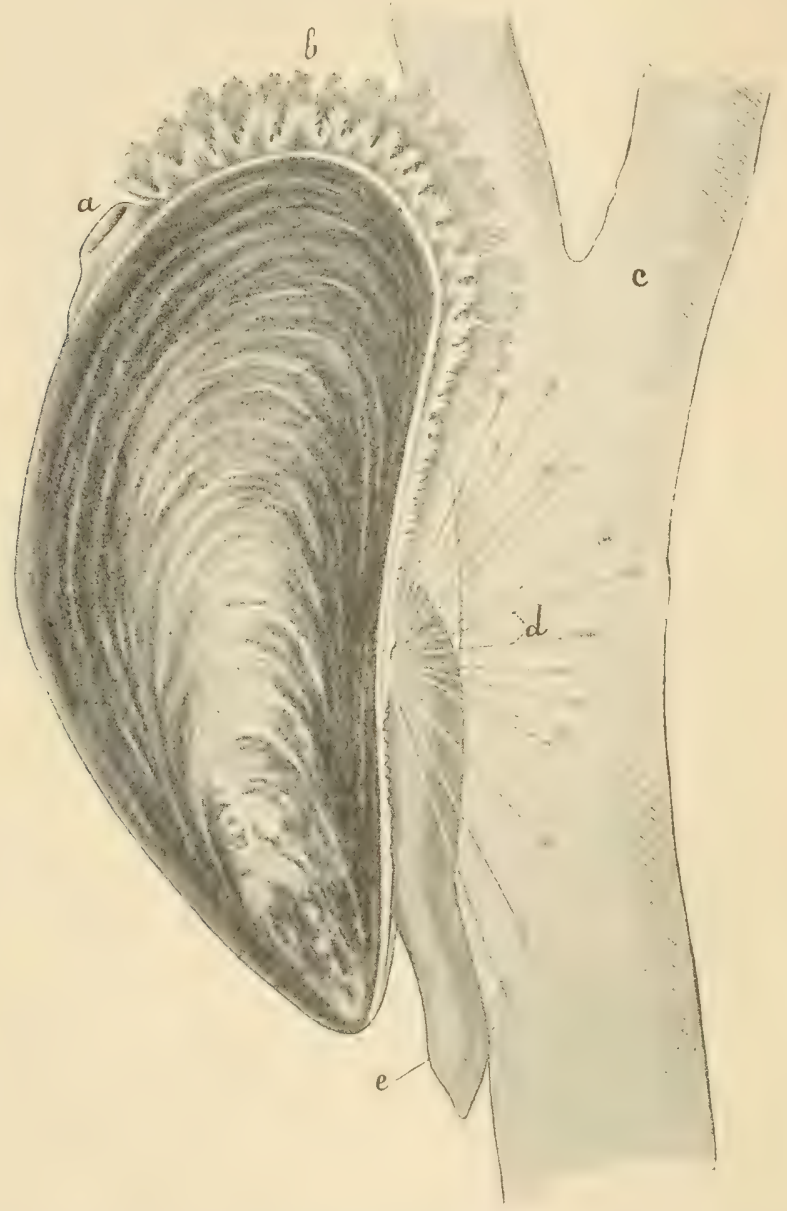

Fig. 406. Mytilus edulis, nach Merer und MöBtus. Das Thier von der linken Seite mit ausgestrecktem einen Byssusfaden befestigenden Fuss $e, d$ Byssusfäden, $a$ Ausströmungsöffnung (An̊lsipho), $b$ gefranster Mantelsaum der Einströmungsöffnung, $c$ Unterlage.

\section{Ordnung. Eu'lamellibranchia.}

Die Kiemen bestehen nicht aus erkennbaren Filamenten. Es sind vielmehr die Filamente einer Reihe, und die beiden Schenkel eines Filamentes derart mit einander durch vascularisirte Brücken oder Suturen verbunden, dass jede Filamentreihe wie eine gitterförmig durchbrochene Lamelle aussieht. So existiren jederseits zwei solche Kiemenlamellen (daher der Name Lamelliluranchier), die in Wirklichkeit den beiden Reihen von Blättchen eines einfachen zweizeilig gefiederten Ctenidiums entsprechen. Hieher die grosse Mehrzahl der Lamellibranchier. 


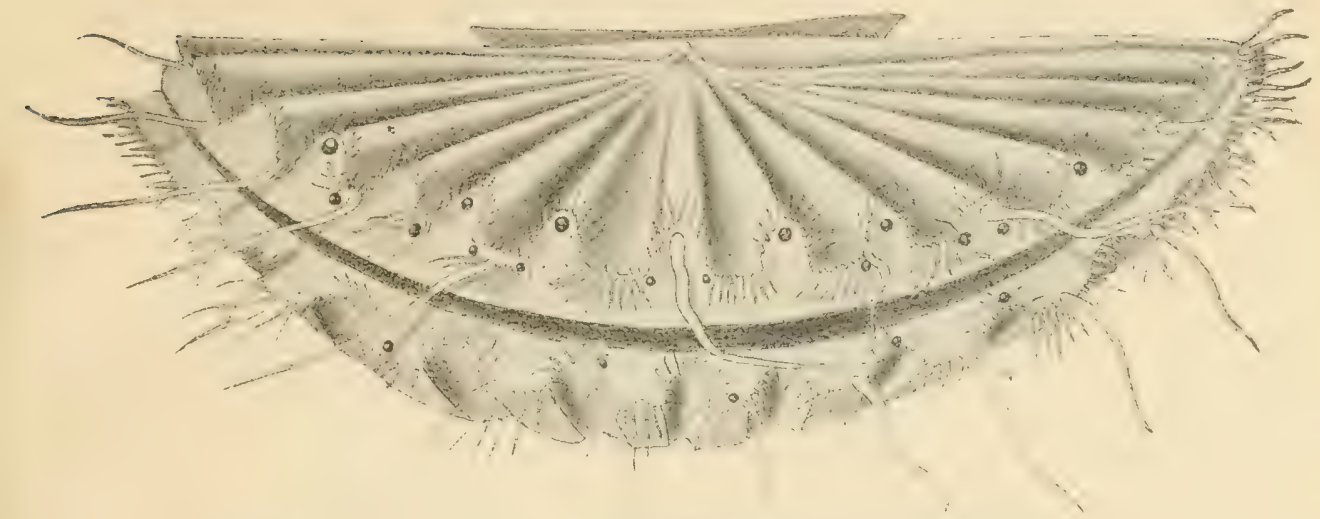

Fig. 407. Pecten Jacobaeus, von der Bauchseite, Schale geöffnet. Man sieht die Mantelspalte zwischen den beiden mit zahlreichen Tentakeln und Augen besetzten Mantelvorhängen. Nach Leuckart und Nitsche, Zool. Wandtafeln.

\section{Unterordnung. Submytilacea.}

Kiemenlamellen glatt. Mantel gewöhnlich nur zwischen Ein- und Ausströmungsöffnung verwachsen. Dimyarier. Fam. Carditidae. Dimyarier mit offenem Mantel und grossem Fuss (Cardita, Venericardia).

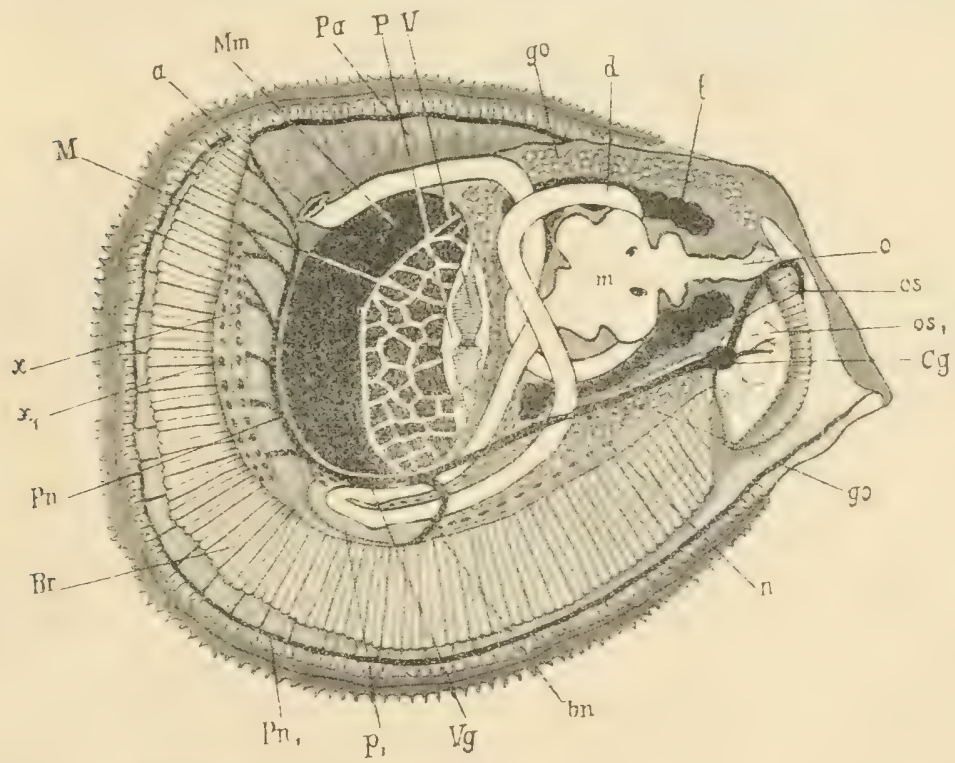

Fig. 408. Anatomie der Auster (Ostrea edulis), von der rechten Seite, nach MöвıUs (in Leuckart und Nitsche, Zool. Wandtafeln). Br Kieme, $P n$ hinterer Mantelnerv, $x, x_{1}$ Oeffnungen der Hohlräume zwischen den verwachsenen Platten der beiden linken Kiemen, $M I$ grosser Schliessmuskel, a Anus, $M / m$ hinterer Abschnitt des Schliessmuskels, Pa Mantel, $P$ Pericard, $V$ Herz, go Gonade (Zwitterdrüse), d Darm, $l$ Verdauungsdrüse (Leber), o Mund, os, $0 s_{1}$ Mundlappen der linken Seite, $C g$ Cerebralganglion, $n$ Niere, $b n$ Kiemennerv, $\nabla g$ Visceralganglion, $P_{1}$ Abdominalfortsatz, $P_{n_{1}}$ Mantelrandnerv, $m$ Magen mit den Oeffnungen der Verdauungsdrüse. 
Fam. L u cinid a e mit einfachen Siphonalöffnungen des Mantels. Fuss oft wurmförmig verlängert. Fam. Erycinidae. Mantel bis auf die beiden Siphonal- und die Fussöffnung geschlossen. Fuss lang. (Erycina, Kellya, Lasaea, Lepton, Galeomma.) Fam. Crassatellidae. Mantel offen, ohne Siphonen. Fuss entwickelt. Fam. Cyrenidae. Mantel offen. Zwei Siphonen. Fuss gross. Süsswasser- oder Brackwasserformen. (Cyrena, Corbicula, Sphaerium, Pisidium, Galatea.) Fam. Dreiss ensiidae (in Flüssen). Fam. Unionidae, im süssen Wasser, Fuss gross, beil- oder keilförmig, zwei einfache Siphonalöffnungen oder Spalten. Mantel offen (Unio [Fig. 409], Malermuschel, Anodonta, Teichmuschel, Mutela).

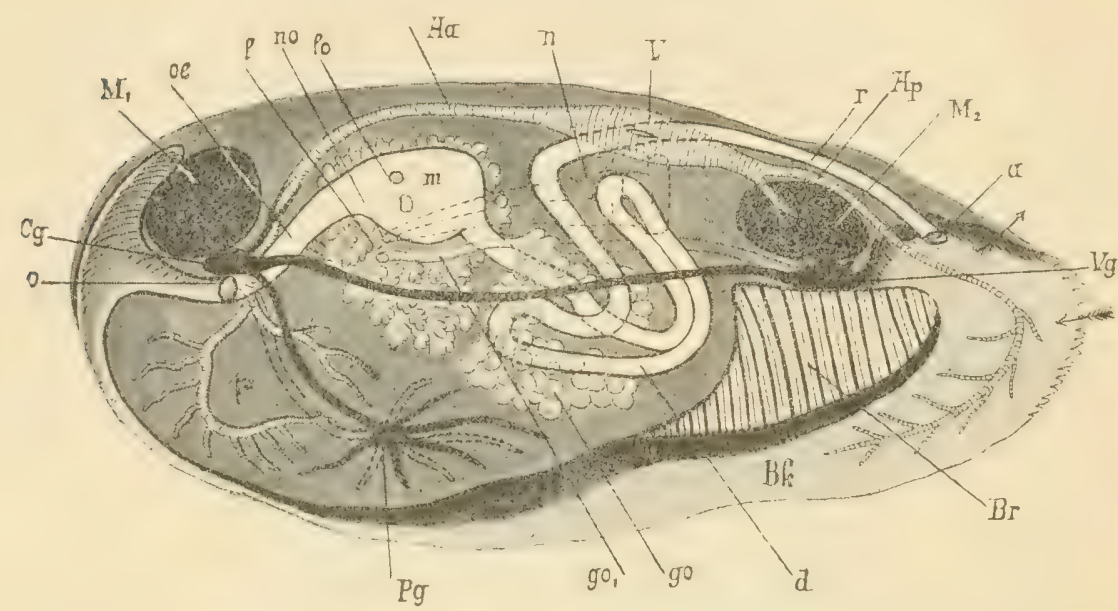

Fig. 409. Anatomie von Unio (Margaritana) margaritiferus, von der linken Seite, nach Ledckart und Nitsche. o Mund, $O g$ Cerebralganglion, $M_{1}$ vorderer Schliessmuskel, oe Oesophagus, $l$ Verdauungsdrïse (Leber), no Nephridialöffnung, lo Oeffnungen der Verdauungsdrüse in den Magen $m$, Aa Aorta anterior, $n$ Nephridium, Konturen durch punktirte Linien angegeben, $V$ Herz, $r$ Enddarm, $d p$ Aorta posterior, $H_{2}$ hinterer Schliessmuskel, $a$ After, $V g$ Visceralganglion, $B r$ Kieme, $B l$ Mantelhöhle, go Gonade mit Ausführungsgang $g o_{1}, F_{g}$ Pedalganglion, $p$ Fuss. Die Pfeile deuten die Richtung an, in welcher das Wasser in die Mantelhöhle ein- und aus ihr austritt.

\section{Unterordnung. Tellin a c e a.}

Dimyarier mit vollständig gesonderten Siphonen. Fuss gross. Kiemen glatt. Fam. Tellinidae (Tellina). Fam. Don acidae (Donax), Mactridae (Mactra).

\section{Unterordnung. Veneracea.}

Dimyarier. Kiemenlamellen etwas gefaltet. Siphonen gesondert. Fuss ansehnlich. Fam. Veneridae (Venus, Meretrix [Cytherea], Tapes). Fam. Petric olidae (Bohrmuscheln).

\section{Unterordnung. C a r d i a c e a.}

Dimyarier oder Monomyarier. Kiemenlamellen stark gefaltet. Mantel mit zwei Siphonal- und einer Pedalöffnung sonst verwachsen. Fam. Cardicae. Dimyarier. (Cardium [Fig. 410].) Fam. Chamidae. 
Dimyarier. Schale ungleichklappig. (Chama, Diceras, Requienia.) In die Nähe gehören wahrscheinlich die fossilen Monopleuridae, Caprinidae, Hippuritidae, Radiolitidae. Fam. Trid a cnid a e. Monomyarier. (Tridacna, Hippopus.)

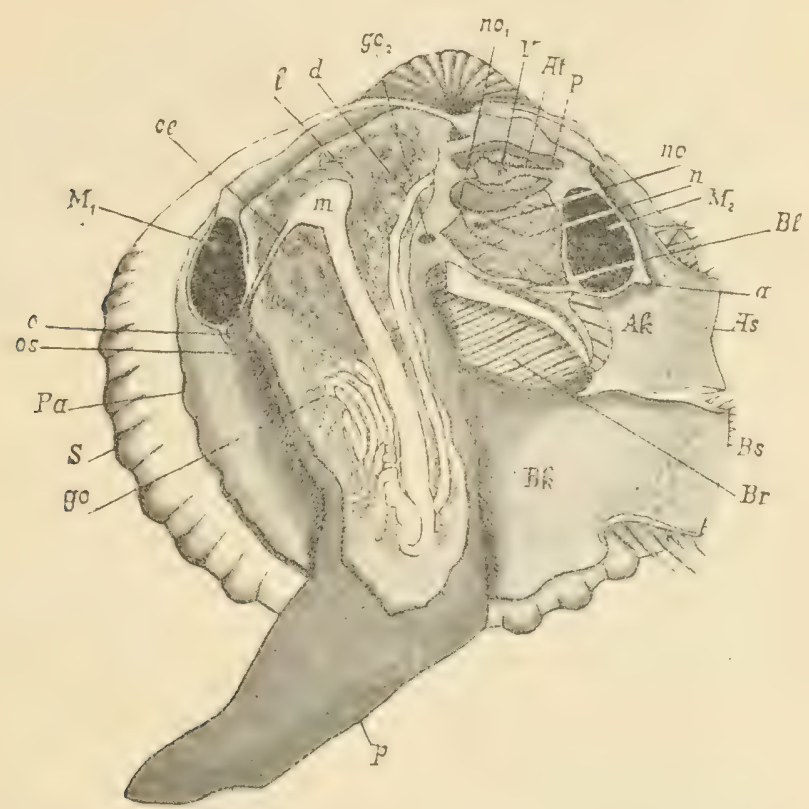

Fig. 410. Anatomie von Cardium tuberculatum, von der linken Seite, nach GroBBEN (in LeUckArt und Nitscue, Zool. Wandtafeln). $p$ Fuss, go Gonade, S Schale, Pa Mantel, os Mundlappen, o liund, $M l_{1}$ vorderer SchalenmuskeI, oe Oesophagus, $m$ Magen, $l$ Verdauungsdrüse, $d$ Darm, $g o_{2}$ Genitalöffnung, $n o_{1}$ Pericardialöffnung der Niere, $V$ Herzkammer, At Vorhof, $P$ Pericard, no Oeffunng der Niere in die Mantelhöhle, $n$ Niere, $M_{2}$ hinterer Schliessmuskel, $B l$ Verwachsungsstelle des rechten mit dem linken Ctenidium hinter dem Fusse, $a$ Anus, $A K$ Analkammer der Mantelhöhle mit Analsipho $A s, B k$ Branchialkammer der Mantelhöhle mit Branchialsipho Bs, Br Ctenidium (Kieme).

\section{Unterordnung. M y a c a.}

Dimyarier mit gefalteten Kiemenlamellen. Tendenz zum Verwachsen des Mantels. Siphonen sehr lang. Fuss gross. Fam. P s a m o bi id a e. Fussschlitz des Mantels noch sehr gross. (Psammobia.) Fam. Mesodesmatidae. Lutrariidae, Myiidae (Mya, Corbula). Glycymerida e (Glycymeris, Saxicava [Bohrmuschel]), Solenidae. Schale vorn und hinten klaffend, Fuss sehr gross. (Solenocurtus, Cultellus, Ensis, Solen.)

\section{Unterordnung. P holod acea.}

Dimyarier mit verwachsenem Mantel und wohl ausgebildeten Siphonen. Fuss verschieden, bisweilen rudimentär. Schale klaffend, häufig mit accessorischen Stücken. Fam. Pholadidae. Bohrmuscheln. (Pholas, Pholadidea [Fig. 411], Jouannetia [Fig. 412], Xylophaga.) Fam. Ter edinidae, Bohrmuscheln (Teredo [Fig. 413]). Fam. Clavagellidae (Clavagella, Brechites [Aspergillum, Fig. 414]). 


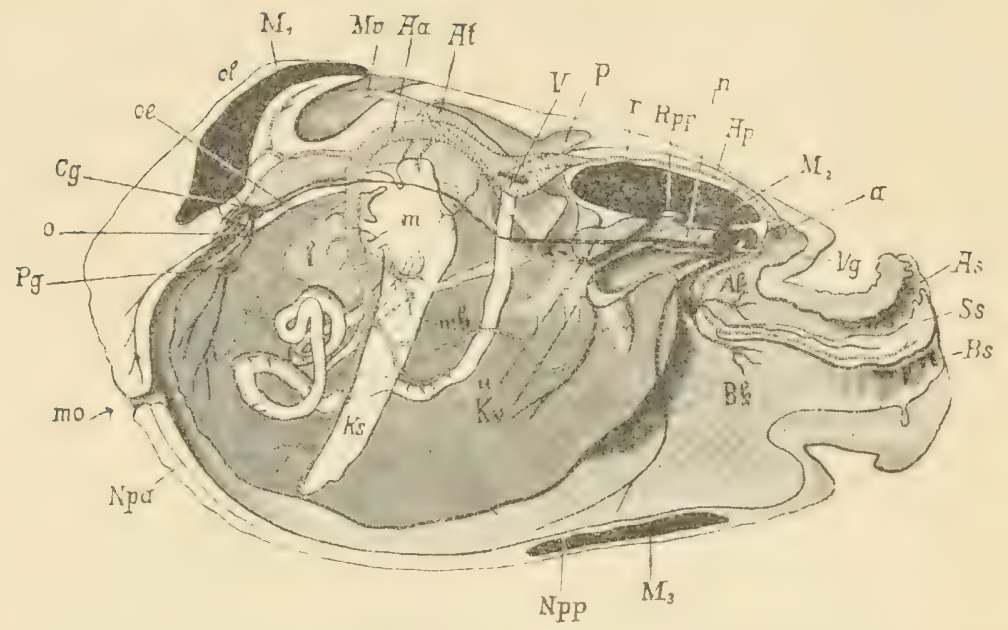

Fig. 411. Anatomie vou Pholadidea sp, von der linken Seite, nach EGGER. Bedeutung der Buchstabenbezeichnungen wie in den vorhergehenden Figuren. Ausserdem: $N p a, N_{p p}$ vorderer und hinterer Mantelrandnerv, mo vordere Mantelöffnung, Ks Krystallstielsack, $K v$ Kiemenvene, ol vorderer oberer Mantellappen, $R p p$ hinterer Rückziehmuskel des Fusses, $S_{s}$ Scheidewand zwischen den beiden Siphonen, $M_{3}$ accessorischer Schliessmuskel, $m b$ Magenblindsack, $x$ Pericardialabschnitt der Niere, welcher sich bei $u$ durch den Nierentrichter in das Pericard öfnet.

\section{Unterordnung. A n a t in a c e a.}

Mantel in grosser Ausdehnung verwachsen. Mit Siphonen. Hermaphroditen. Fuss vorhanden. Fam. Pandoridae, Lyonsiidae, Anatinidae (Anatina, Thracia).

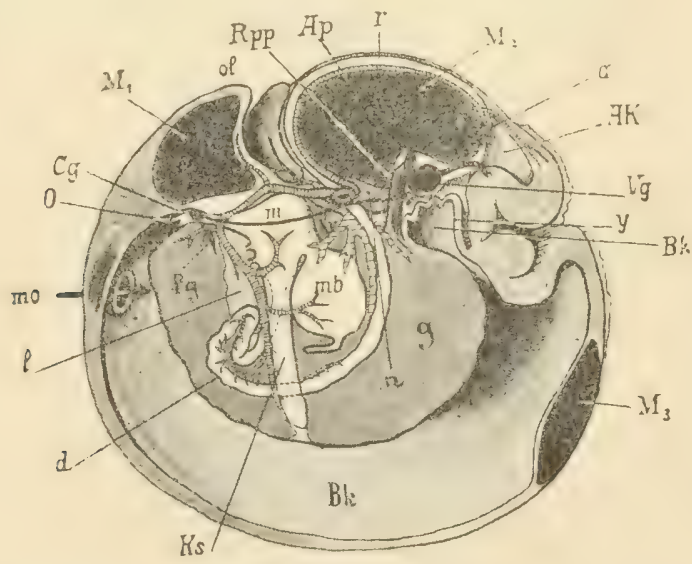

Fig. 412. Anatomie von Jouannetia Cumingii, von der linken Seite, nach EGGER. Bedeutung der Buchstabenbezeichnungen wie in den vorhergehenden Figuren. 
V. Ordnung. Septibranchia.

Die Kieme ist jederseits zu einer musculösen, von Spalten durchbrochenen Scheidewand umgewandelt, welche die Mantelhöhle in zwei übereinander liegende Etagen theilt. Hermaphroditen. Fam. Poromyidae, Cuspidaridae (Fig. $415 \mathrm{~A}$ und B).

\section{Klasse. \\ Cephalopoda. ('Tintenfische, Kraken, Kopffiisser.)}

Körper symmetrisch, mit hohem Eingeweidesack. Um den Mund herum Tentakel oder Fangarme, die als Theile des Fusses, welche nach vorn um den Mund herum gewachsen sind, betrachtet werden. Ein weiterer Theil des Fusses ist der Trichter. In der hinteren ständigen Mantelhöhle 2 oder 4 Ctenidien. Herz mit 2 oder 4 Vorhöfen, 2 oder 4 Nieren. Unpaare Gonade mit paarigem oder unpaarem Ausführungsgang. Sinnesorgane, speciell die vorn und seitlich am Kopffuss gelegenen Augen, hoch entwickelt. Kräftige Kiefer und starke Radula. Mit äusserer oder innerer Schale, oder schalenlos. Meist mit Tintenbeutel. Grosse, hochentwickelte, räuberische Meeresthiere getrennten Geschlechts.

I. Ordnung. Tetrabranchiata.

Mit äusserer gekammerter Schale, in deren letzter (grösster) Kammer das Thier sitzt. Schale symmetrisch, exogastrisch aufgerollt. Zahlreiche auf grösseren Lappen sich erhebende, in besondere Scheiden zurückziehbare, saugnapflose Tentakel um den Mund. 4 Kiemen, 4 Vorhöfe des Herzens,

Fig. 413. Teredo navalis in seiner Holzröhre, von der Baucbseite, nach MEYER und Möвхus. Das Mittelstück weggelassen. Kalkröhre grösstentheils unverletzt.
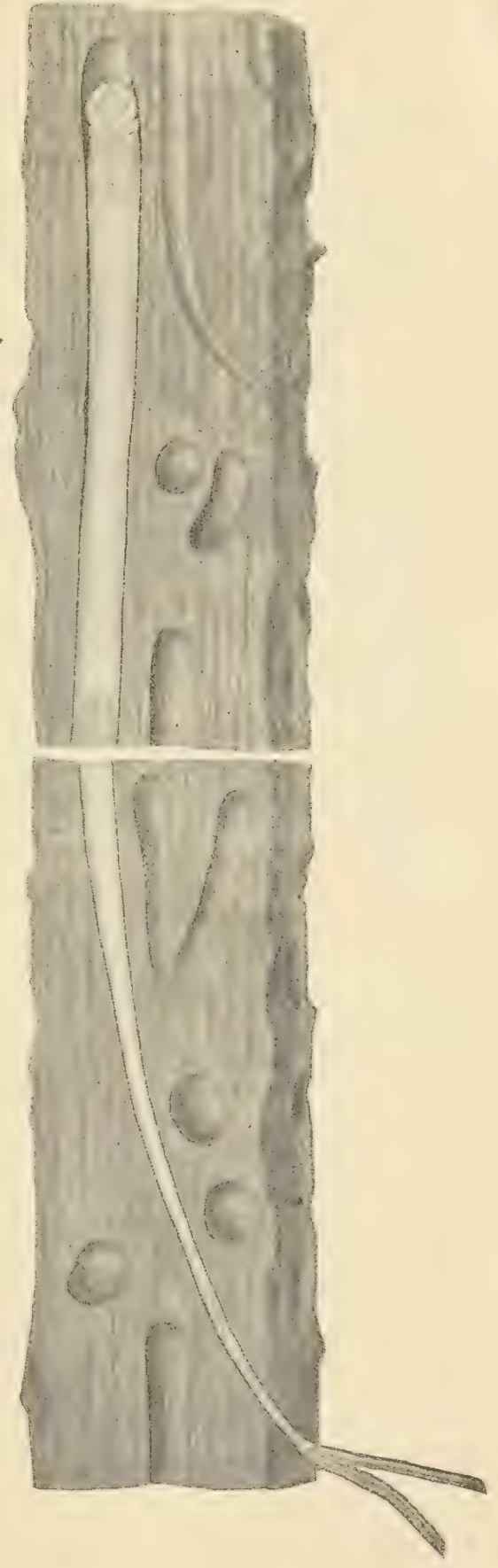
Fig. 414.

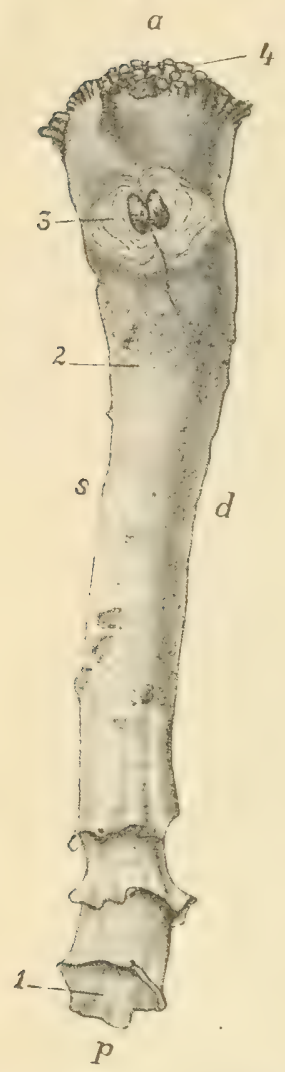

Fig. 415
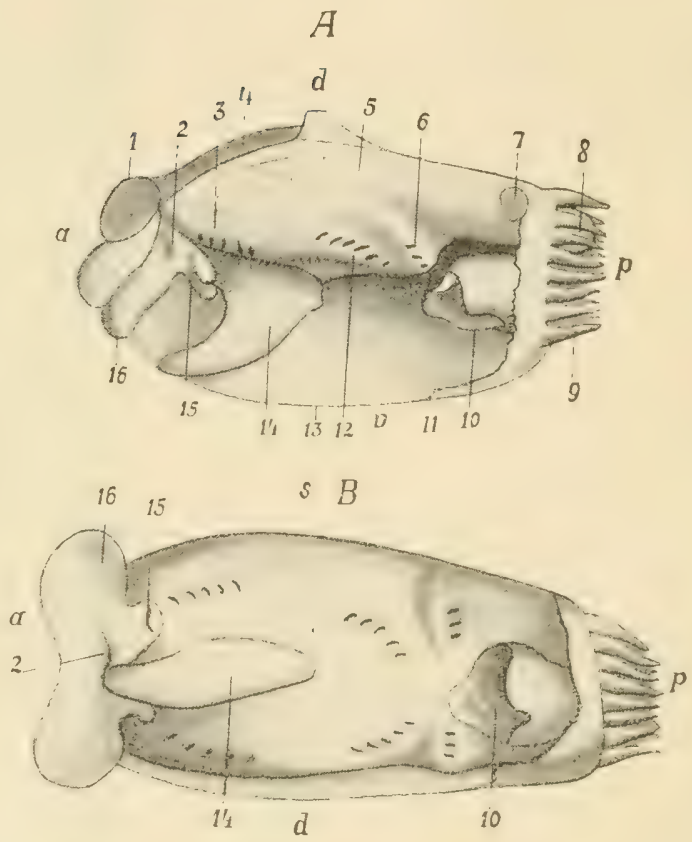

Fig. 414. Schale $\nabla 0 n$ Aspergillum (Brechites) vaginiferum, von der Dorsalseite. $a$ Vorn, $p$ hinten, $d$ rechts, $s$ links, 1 Siphonalöffnung der Pseudoconcha, 2 Pseudoconcha (Kalkröhre), 3 echte Schale, in der Pseudoconcha eingebettet, 4 vordere Oeffnungen der Pseudoconchs.

Fig. 415. Weichkörper von Silenia Sarsii (Cuspidaride), nach Pelseneer. $\boldsymbol{A}$ Von der linken Seite, nach Entfernung des Mantels, $\boldsymbol{B}$ von der Ventralseite, nach Entfernung des grössten Theiles des Mantels. $a, p$ Vorn, hinten, $d, v$ dorsal, ventral, $d, s$ rechts, links, 1 vorderer Schliessmuskel, 2 Mund, 3 vordere Gruppe von Kiemenspalten, 4 Lebermasse, 5 Kiemenscheidewand, 6 hintere Gruppe von Kiemenspalten, 7 hinterer Schliessmuskel, 8 Analsipho, 9 Siphonaltentakel, 10 Klappe der Branchial- oder Einströmungsöffinung, 11 Stelle, wo die beiden die Fussöffnung begrenzenden freien Mantelränder verschmelzen, 12 mittlere Gruppe von Kiemenspalten, 13 freier Mantelrand, 14 Fuss, 15 hintere Mundlappen.

4 Nieren. Trichter aus zwei seitlichen, getrennten Lappen bestehend, die, sich mit ihrem freien Rand ïbereinanderschiebend, eine Röhre bilden. Ohne Tintenbentel. Nit Grubenaugen. Einzige lebende Form $\mathrm{Na}$ u tilus, Radula 2.2.1.2.2 (Fig. 416). Fossil die beiden grossen Abtheilungen der $\mathrm{N}$ a utiloidea und Ammonitidea.

\section{Ordnung. Dibranchiata.}

Mit innerer Schale oder mit rudimentärer Schale, oder ohne Schale. Dio Schale ist selten und dann endogastrisch aufgerollt. 2 Kiomen. 
2 Vorhöfe des Herzens, 2 Nieren. 8 oder 10 mit Saugnäpfen besetzte Fangarme um den Mund. Die beiden Lappen des Trichters am freien Rande verwachsen. Blasenaugen. Mit Tintenbeutel.

Fig. 416 .
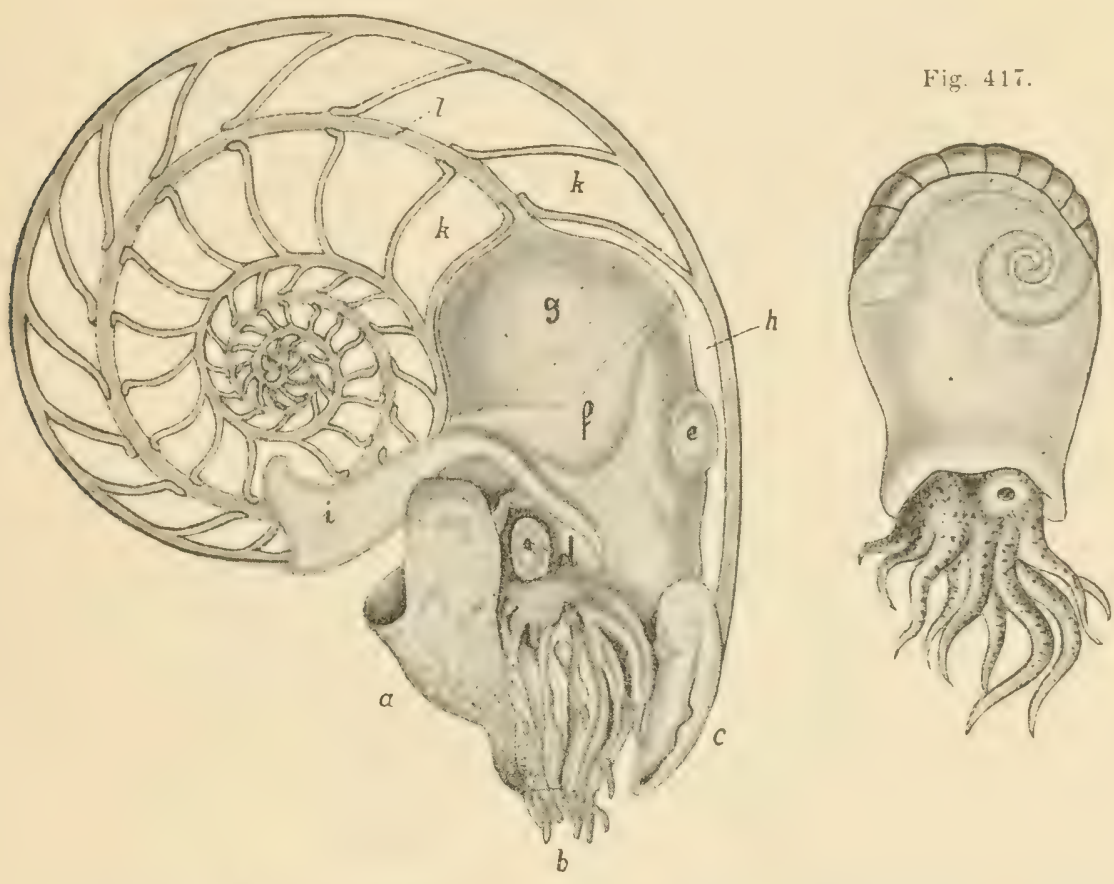

Fig. 416. Nautilus Pompilius, nach OWEN. Schale im Medianschnitt dargestellt. $a$ Kopfkappe, $b$ Tentakel, $c$ Infundibulum, $d$ Auge, $e$ durchschimmernde Nidamentaldrüse, $f$ Ansatzstelle des Schalenmuskels, $g$ oberer Theil des Eingeweidesackes, $h$ letzte (Wohn.) Kammer der Schale, $k$ vorletzte Kammer, $l$ Sipho.

Fig. 417. Spirula prototypos, von der rechten Seite, nach ChUN und Otven (LEUCKART und Nitsche, Zool. Wandtafeln). Man sieht die beiden Theile der Schale, der innere ist durch den Mantel durchschimmernd dargestellt. Das Auge müsste weiter vorn am Kopffuss gezeichnet sein.

\section{Unterordnung. Dec a poda.}

Mit innerer, oft rudimentärer Schale. Mit 10 Armen, von denen das 4 te Paar zu langen, in besondere Kopfhöhlen zurückziehbaren Fangtentakeln entwickelt ist. Gute Schwimmer mit dorso-ventral gestrecktem, mit seitlichen Flossen ausgestattetem Körper. Eileiter unpaar. Fam. Spiruli d a e. Mit innerer, spiralig gewundener, endogastrisch aufgerollter Schale. Spirula (Fig. 417). Fam. B elemnitida e. Fossile Formen mit innerer gekammerter, meist gerade gestreckter Schale. (Belemnites, Spirulirostra, Belemnotenthis.) Fam. Oigo psidae (Ommastrephes, Rad. 3. 1. 3, Loligopsis, Cranchia, Chiroteuthis, Owenia, Thysanoteuthis, Onychoteuthis, Ommatostrephes). Fam. My o sidae (Rossia, Sepiola, Sepiadarium, Idiosepion, Loligo [Fig. 418], Sepioteuthis, Belosepia [fossil], Sepia, Rad. 3. 1.3). 


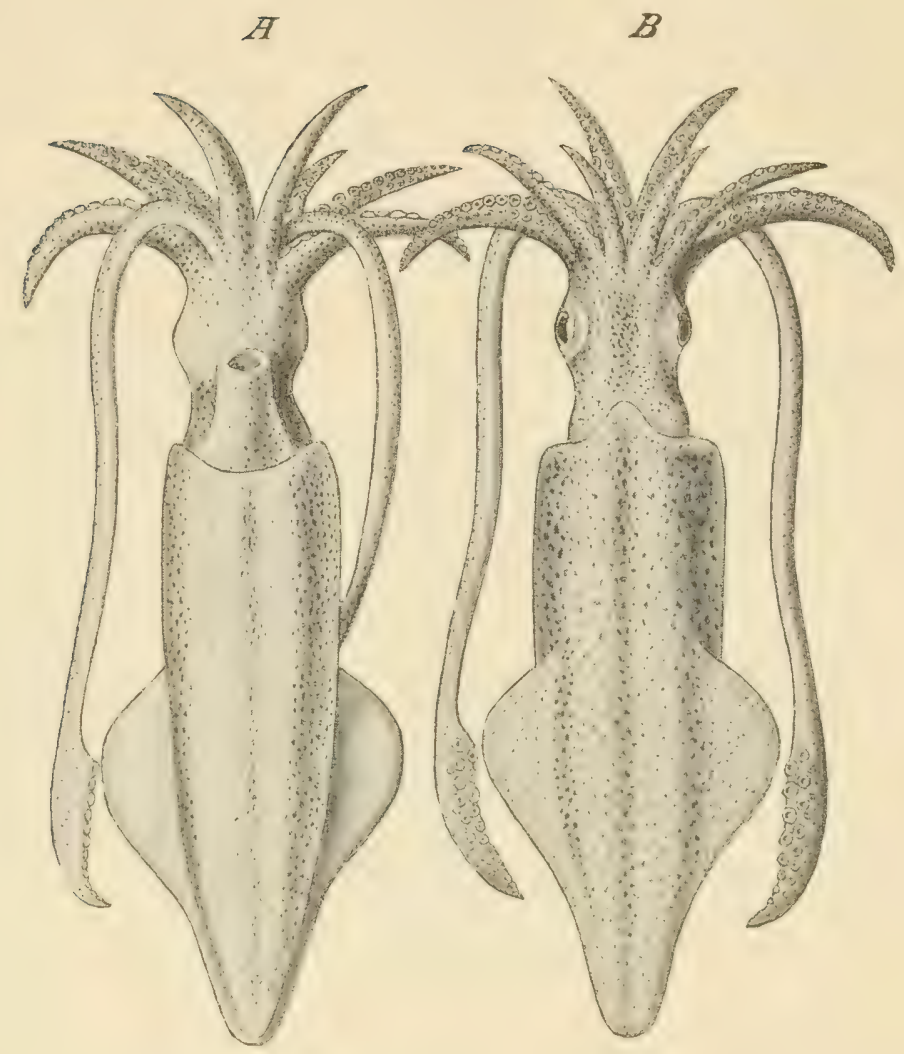

Fig. 418. Loligo vulgaris, nach D'OrBIGNY. $\boldsymbol{A}$ Von der Hinterseite (physiologisch Unterseite), $\boldsymbol{B}$ von der Vorderseite (physiologisch Rückseite). Man sieht die 10 Mundarme, von denen die des 4. Paares als lange Fangtentakel ausgebildet sind, ferner die - Augen, den Mantelrand, die Flossen und in der Haut die Chromatophoren.

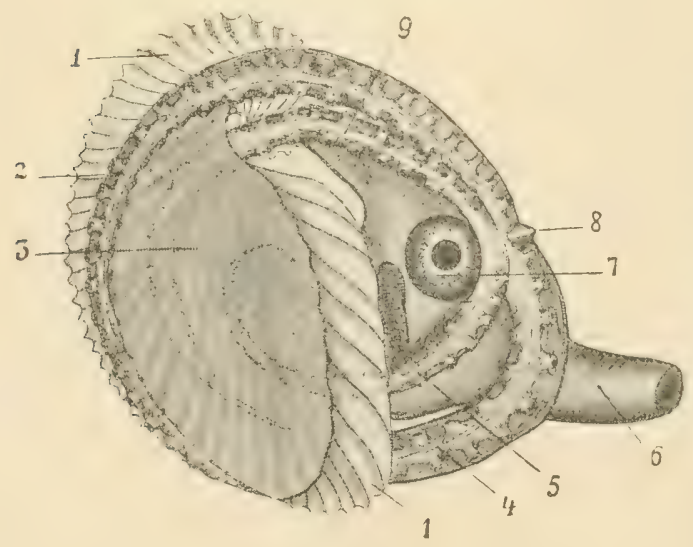

Fig. 419. Weibchen von Argonauta, in schwimmender Stellung, von der rechten Seite, nach LACAZE-DUTHIERS, 1 Unbedeckter Theil der Schale, 2 der rechte Arm des ersten, vorderen Armpaares, mit seiner einen grossen Theil der Schale von aussen bedeckenden lappenförmigen Verbreiterung (Segel) 3, 4 4. rechter Arm, 5 3. rechter Arm, 6 Trichter, 7 Auge, 8 Kiefer, 9 2, rechter Arm. Die Arme des 2., 3. und 4. Parres ins Imnere der Schale zurückgestreckt. 
2. Unterordnung. Octo p od a.

Ohne Schale oder Schulpe. Mit 8 Armen, ohne Fangtentakel. Körper plump, meist ohne Flossen, der Schwimmbewegung wenig angepasst.

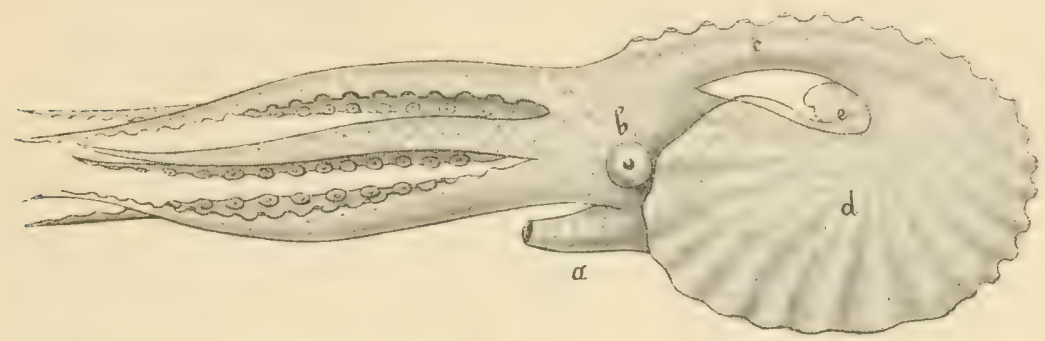

Fig. 420. Weibchen von Argonauta Argo, nach VérdNy. 2, 3. und 4. Armpaar nach unten gestreckt, $a$ Trichter, $b$ Auge, $c$ erstes Armpar, mit seinem Segel $d$ die Schale $e$ fast ganz bedeckend.

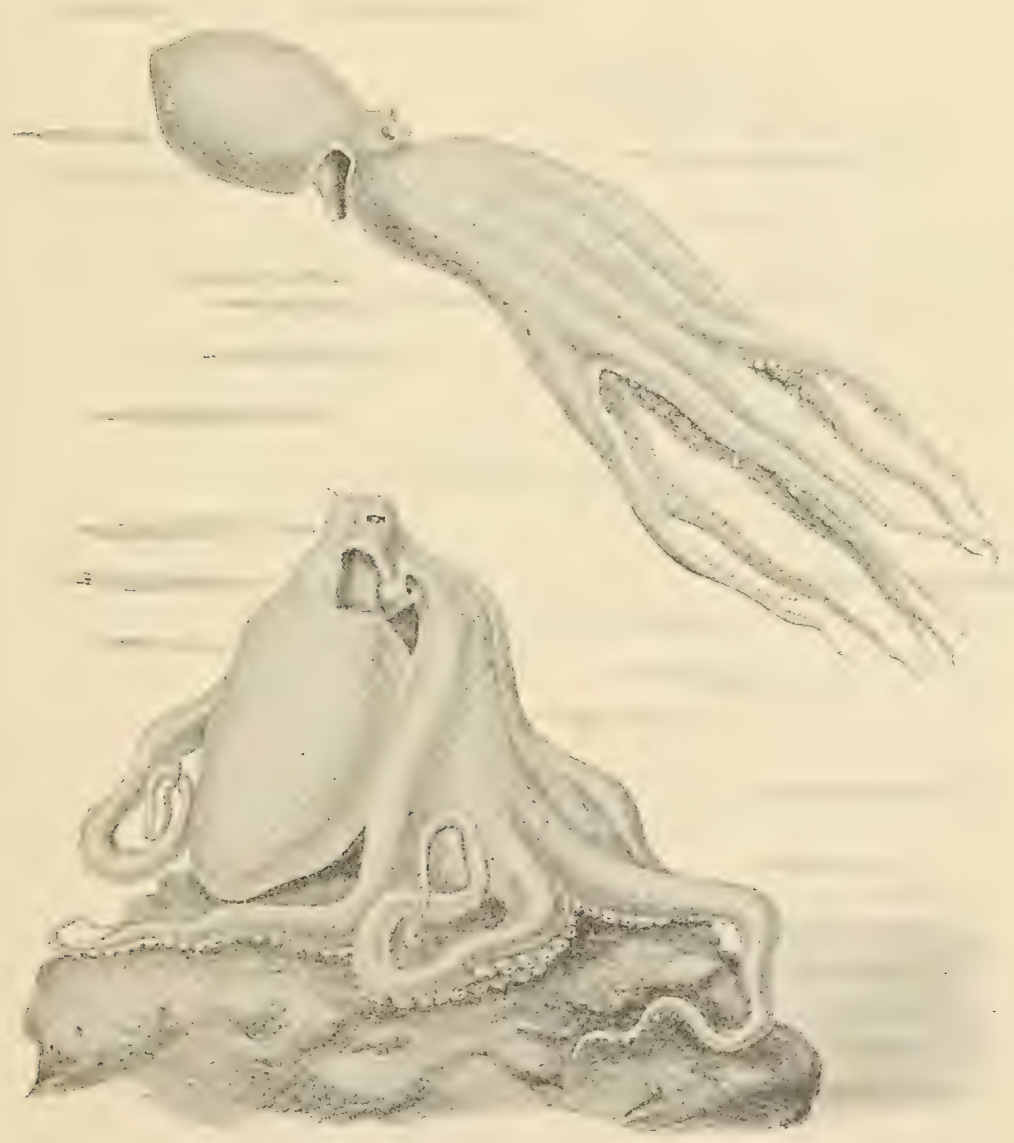

Fig. 421. Octopus vulgaris, nach Mercultaxo (in „Aquarium neapolitanum"), oben in schwimmender, unten in sitzender und lauernder Stellung. 
Eileiter paarig. Fam. Cirrhoteuthidae. Mit Flossen. Fam. Philonexid a e. Argonauta (Fig. 419, Fig. 420, Fig. 581) (Weibchen mit äusserer ungekammerter Schale), Philonexis, Tremoctopus. Fam. Octop odida e (Octopus, Rad. 1.3.1 [Fig. 421], Eledone).

\section{Schema der ursprimglichen Molluskenorganisation.}

Wenu wir versuchen, gestützt auf die Ergebnisse der morphologischen Durchforschung des Molluskenstammes, einen hypothetischen Urmollusken zu construiren, so wird das Bild desselben etwa folgendermaassen ausfallen.

Der Köruer ist bilateral-symmetrisch, mit gewölbter Rückenseite, das Vorderende trïgt den Mund, die Augen und Tentakel und ist als $\mathrm{Kopf}$ vom übrigen Körper abgesetzt. Die Bauchseite bildet eine stark musculöse, vom Rumpfe abgesetzte Platte, den Fuss, mit flacher Kriechsohle.

Das weiche Integument der gewölbten Rückenseite bildet rings um den Rumpf herum eine Duplicatur, eine nach allen Seiten herunterbängende Falte, den Mantel (Pallium). Der Mantel bedeckt rings um den Rumpf herum eine ringförmige Höhle, die Mantelhöhle, welche unter dem freien Raude des Mantels hindurch, zwischen diesen und dem Fusse, mit dem umgebenden Medium frei communicirt. Das dorsale Integument des Rumpfes und seine Fortsetzung, das äussere Integument des Mantels, sondert eine dicht anliegende Schale ab, die aus einer chitinartigen Grundsubstanz (Conchyliolin) mit eingelagertem kohlensauren Kialk besteht. Diese Schale wiederholt die Gestalt der Rückenseite des Rumpfes, sie ist also bilateral-symmetrisch, gewölbt. Denken wir uns dieselbe losgelöst und auf die gewölbte Rückenseite gelegt, so würde sie sich uns napf- oder tellerförmig präsentiren. Indem diese Rückenschale den ganzen liörper oder doch den grössten Theil desselben vom Rücken her bedeckt, gereicht er diesem einerseits zum wirksamen Schutze und dient anderseits als Skelet, an welchem in den Fuss und in den Kiopf verlaufende, im allgemeinen eine dorsoventrale Richtung einschlagende Muskeln sich als an einem festen Anheftungspunkte ansetzen.

Der Mantel hat noch seine ganz besondere Bedeutung bei der Bildung der schiitzenden Schale. Abgesehen davon, dass es der Mantelrand ist, welcher den grössten Theil der Schalensubstanz absondert und welcher beim fortschreitenden Wachsthum des Thieres auch für die Vergrösserung der Schale sorgt, bedeckt er die zarten Ki emen, die nun auch des Schutzes der von ilın abgesonderten Schale theilhaftig werden. Es handelt sich hier um Einrichtungen, wie sie in ganz analoger Weise in andern Abtheilungen des Thierreiches wiederkehren. Wir erinnern nur an die die Kiemenhöhle bedeckende Duplicatur des Hautpanzers der höhern Kirebse und an den Kiemendeckel der Fische. - Die Beziehungen zwischen Kiemen, Mantel und Schale bei den Mollusken sind äusserst wichtige, und man soll diese Bildungen nie anders als im innigen Zusammenhange betrachten. 
Die in der Nantelhöhle liegenden Ki iemen sind paarig und symmetrisch. Wir wollen unentschieden lassen, ob mehrere Paare solcher Tíemen oder ob nur zwei líiemen anzunehmen sind. In letzterem Falle müssten wir uns vorstellen, dass je eine Kieme im hinteren Theile der jederseitigen Mantelhöhle liegt. Im ersteren Falle hüitten wir es jederseits mit einer Reihe hintereinander liegender Kiemen zu thun.

Eine jede Kíeme ist ihrer Form nach einer Feder vergleichbar, mit einem Schaft und zahlreichen zweizeilig angeordneten Seitenfiederchen. Der Schaft erhelt sich frei vom Rumpfe in die Nantelhöhle. In unmittelbarer Nähe der Basis einer jeden Kỉeme liegt ein als Geruchsorgan gedeutetes Sinnesorgan, ein Osphradium. Eine solche Kieme mit einem Osphradi u m nahe ihrer Basis hat einen ganz bestimmten morphologischen Werth. Um sie von analogen, aber nicht homologen Athmungsorganen oder Kiemen, die bei gewissen Mollusken vorkommen, zu unterscheiden, hat man sie als Cten idium bezeichnet.

Fig. $4 \geq 2$

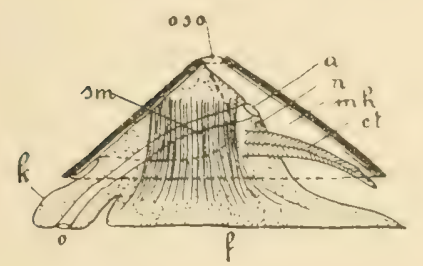

Fig. 422. Urmollusk, Schema von der linken Seite. o Mund, $k$ Kopf, $s m$ Schalenmuskel, oso obere Schalenöffnung, a Anus, $n$ Nierenöffnung, mh Mantelhöhle, ct Ctenidium, $f$ Fuss.

Fig. 423. Hypothetischer Urmollusk, von oben. o Mund, ulc, ulpl, ulp ursprünglich linkes Cerebral-, Pleural- und Pedalganglion, ulpa, urpa ursprünglich linkes und ursprünglich rechtes Parietalganglion, ula ursprünglich linker Vorhof des Herzens, uos, uros ursprünglich linkes und ursprünglich rechtes Osphra-

dium (SPExGEL's Organ), ulct, urct ursprünglich linkes und rechtes Ctenidium (Kieme), $m b$ Mantelbasis, $m r$ Mantelrand, $m$ Mantelböhle, $v$ Visceralganglion, ve Herzkammer, $a$ Anus.

Der Kopf trägt ein Paar Tentakel und ein Paar A ugen. An seiner Vorder- und Unterseite liegt der Mund. Die übrigen Oeffnungen innerer Organe liegen am hinteren Ende des Rumpfes ülser dem Fusse. In der Mittellinie liegt hier der A fter, und auf jeder Seite desselben, zwischen ihm und dem Ctenidium der betreffenden Seite (wenn wir annehmen, dass nur ein Paar Ctenidien vorhanden sei), finden sich zwei () effnungen, nümlich eine für die Geschlechtsorgane und eine für die Niere ( Tephridium). Alle diese Oeffnungen werden vom Mantel bedecht, liegen also in der Mantelhöhle. Wir finden also, um zur recapituliren, im hinteren Theile der Mantelhöhle 2 Ctenidien, 2 Osphradien und 5 Oeffnungen, nämlich die mediane Afteröffnung und die paarigen symmetrischen Geschlechts- und Tephridialöffnungen. Alle diese Theile bilden zusammen den pallealen () rgancomplex. 
Ich will jetzt kurz die innere Organisation charakterisiren. Der Darmkanal. Der Mund führt in einen musculösen Pharynx, mit hornigen Kicfern. An seinem Boden liegt fermer eine Reibplatte, Zunge oder Radula genannt, welche in mehreren hintereinander liegenden Querreihen spitze, chitinige Zähnchen trägt. In den Pharynx münden paarige Speicheldrüsen. Der Pharyux setzt sich durch einen Oesophagus in einen Mitteldarm fort, welcher - wir wollen annehmen unter Bildung von ITindungen - den lï̈rper von vorn nach hinten durchzieht, um hinten vermittelst eines sehr kurzen Enddarmes durch den medianen After wach aussen zu münden. Der Mitteldarm hesitzt ansehnliche paarige, drüsige Ausstülpungen (Vitteldarmdrüse, Verdauungsdrüse, Hepatopancreas, Leber).

Musculatur. Kräftige Musculatur des Fusses, in der für die Kriechbewegung geeigneten Anordnung. Muskeln, welche von der Unterseite der Schale in den Fuss und zum liopfe verlaufen (Spindelmuskel, Schalenmuskel). Musculatur der einzelnen Organe.

Nervensystem. Zwei wohlentwickelte Gehirnganglien (Cerebralganglien) liegeu dorsalwärts im liopfe und sind miteinander durch eine kurze, über den Oesophagus verlaufende Quercommissur, die Cerebralcommissur, in Verbindung gesetzt. Von jedem Cerebralganglion gehen zwei kräftige, in ihrer ganzen Länge mit Ganglienzellen versehene Nervenstïmme ab, welche den Körper von vorn nach hinten seiner ganzen Länge nach durchziehen. Es finden sich also 2 Paar solcher Längsstamme. Die zwei Stämme des einen Paares, die Pedalstränge, verlaufen rechts und links m Fusse; die zwei des andern Paares, die Visceralstä $1 n$ me, liegen mehr dorsalwärts und sind tiefer gelagert, indem sie in der Leibeshöhle verlaufen. Die beiden Visceralstämme verbinden sich hinten miteinander.

Würden wir die Amphineuren und Diotocardier nicht kennen, so würden wir folgendes modificirte Bild des Nervensystems entwerfen: 2 Cerebralganglien, 2 Pedalganglien, 2 zu Seiten des Pharynx liegeude Pleuralganglien, 2 im hinteren Theile der Leibeshöhle liegende Visceralganglien. Bezeichnen wir die die Gangrlien einer und derselben Kïrrperseite, also ungleichnamige Ganglien verbindenden Nerven mit dem Namen von Connectiven, und die Nerven, welche die gleichnamigen Ganglien der beiden Körperseiten verbinden, mit dem Namen Comm is suren, so können wir folgendes Schema des Systems der Connective und Commissuren aufstellen. Commissuren existiren: 1) zwischen den beiden Cerebralganglien (über dem Vorderdarm), 2) zwischen den beiden Perlalganglien (unter dem Vorderdarm), 3) zwischen den beiden Visceralgauglien (unter dem Enddarm). Es existiren jederseits folgende Connective: 1) Cerebropedalconnective, 2) Cerebropleuralconnective, 3) Pleuropedalconnective, 4) Pleurovisceralconnective.

Es existirt eine mit Endothel ausgekleidete, secundäre Leibes höhle, welche mindestens in zwei Abschnitte zerfällt. Im vorderen Abschnitt, der Geschlechtskanmer, entstehen aus dem Endothel die Geschlechtsproducte. Sie steht durch zwei lianäle (Leitungswege der Geschlechtsproducte) mit der Nantelhöhle in Verbindung. In hinteren Abschnitt (dem Herzbeutel oder Pericard) liegt mindestens das Herz. Fr steht mit der Mantelhöhle durch zwei Nephrid ialka näle oder Nephridialsäcke in Verbindung. 
Das Blutgefässsystem ist theilweise lacunär. Das $\mathrm{Herz}$ ist arteriell und liegt im Pericard über dem Enddarm. Es besteht aus der Kammer und zwei seitlichen Vorhöfen.

\section{Cehersicht der iusseren Oroanisation. Zur Orientirung innerhalb der Hauptgruppen der Mollusken.}

Nachdem im vorhergehenden Abschnitt ein allgemeines Schema der Molluskenorganisation gegeben worden ist, empfiehlt es sich, zu untersuchen, wie sich die verschiedenen Molluskenabtheilungen in ihrer äusseren Organisation zu diesem Schema verhalten. Dabei wollen wir bei jeder Gruppe zunächst nur diejenigen Merkmale hervorheben, die nach dem gegenwärtigen Stande der Forschung als für die betreffende Klasse typisch, als charakteristisch gelten können. Mit andern Worten, wir wollen für jede Molluskenklasse wieder ein Schema der äusseren Organisation der zu ihr gehörigen Formen zu entwerfen versuchen, damit diese specielleren Schemata mit dem allgemeinen Schema der Molluskenorganisation verglichen werden können. Weiteren Abschnitten bleibt es vorbehalten, jedes einzelne der für die äussere Morphologie in Betracht kommenden Organe nicht nur durch die verschiedenen Klassen hindurch, sondern auch innerhalb einer und derselben Klasse in seinen verschiedenen Gestaltungsformen $\mathrm{zu}$ verfolgen.

\section{A) Placophora (Chitonidae).}

Der Körper der Placophoren ist bilateral-symmetrisch, von der Rücken- oder Bauchflache betrachtet länglich-oval, dorsoventral abgeplattet. Auf der Bauchseite findet sich ein ansehnlicher musculöser Fuss mit flacher Sohle, lessen Konturen anuähernd denen des Körpers parallel laufen. Vor dem Fuss setzt sich ebenfalls an der Unterseite des Körpers ein Kopfabschnitt (Schnauze) ab, der in der Mitte seiner ventralen Fliche die Nundöttnung trägt. Augen und Tentakel fehlen am Kopfe. Zwischen der peripheren Zone des Körpers (Mantel) einerseits, dem Fusse und Kopf anderseits findet sich eine Furche. Im Grunde dieser Furche finden sich zahlreiche lanzettförmige Kiemen, die jederseits in einer Reihe angeordnet sind. Die beiderseitigen Reihen stossen entweder vorn und hinten fast zusammen, so dass ein fast completer Kranz von Kiemen um deu Fuss herum zu Stande kommt, odel sie verkürzen sich jederseits in verschieden hohem Maasse, his schliesslich bei gewissen Formen die Kiemenreihe jederseits nur das hintere Drittel der Kiemenfurche besetzt. Der After liegt am hinteru Körperende in der Medianlinie, ventralwärts unmittelbar hinter dem Fusse. Die beiden äusseren Oeffnungen der Ausführungsgänge der Nephridien haben ihre Lage in der Kiemenrinme, rechts und links neben und etwas vor dem After. Die beiden Geschlechtsöftinumgen finden sich dicht vor den Nephridialöffnungen, ebenfalls in der Kiemenrinne.

Die mittlere Zone des Rückens wird bedeckt von 8 hintereinander liegenden kilkigen Schalenstücken, die dachziegelförmig übereinander greifen. Die periphere Region aber - zwischen dem Rande des Körpers und den Schalenstücken - trägt Kialkstacheln, Kalkknollen etc. Sie entspricht der peripheren Region auf der Bauchseite, deren 
innerer Theil die Kiemenfurche begrenzt, und kann als Mantel bezeichnet werden.

\section{B) Solenogastres.}

Der Körper der Solenogastres ist bilateral-symmetrisch, wurmförmig, mit rundem Querschnitt, bald gestreckt und schlank, bald ansehnlich verkürzt, gedrungen. Die grosse Nundöffinung liegt in Form einer Lüngsspalte an der Ventralseite des vorderen Körperendes. Ventralwärts an hinteren liörperende liegt die Kloakenöffnung (gemeinsame Oeffnung für den Darm und den Urogenitalapparat). In der Mittellinie der Bauchseite verlüuft eine enge Furche, welche hinten in die Kloakenöffinung münlet, vorn in kurzer Entfernung vor der Jundöffinung aufhört. Am Boden dieser Fussfurche erhelt sich ('ine bewimperte, auf dem ( nucrschnitt dreieckige Leiste oder Falte, welche in der ganzen Länge der Fussfurche verläuft: der reducirte Fuss. Bei Chaetoderma fehlt sowohl der Fuss als die Fussfurche. Eine gesonderte, compacte Schale fehlt den Solenogastriden und wird ersetzt durch der Haut eingelagerte Kalkspicula.

\section{C) Gasteropoda (Cephalophora).}

Trotzlem an der Zusammengehörigkeit der zu dieser Klasse vereinigten Mollusken kaum gezweifelt werden kann, ist es doch fast unmöglich, die ganze Klasse ihrer äusseren Morphologie nach zu charakterisireu. Die lï̈rpergestalt im Allgemeinen zeigt die grössten Verschiedenheiten. Der lï̈rper ist bald äusserlich bilateral-symmetrisch, bald in hohem Grade asymmetrisch. Algesehen davon sind formen wie z. B. Fissurella, Oliva, Turritella, Cleodora, I'terotrachea, Phyllirhö̈, Limax, Pleurobranchus, Thetys etc. ausserlich so verschieden, dass man auf den ersten Blick nicht an ihre Verwandtschaft glauben würde. Die Schale kamm vorhanden und dann ausserordentlich mannigfaltig geformt sein, oler sie ist rudimentär oder sie fehlt im erwachsenen /ustande ganzlich. Auch der liuss tritt in den verschiedensten Formen auf und kaun sogar ebenfalls fehlen. Dasselbe gilt vou der Mantelfalte, den Kiemen etc.

Im Allgemeinen, von den ganz einseitig differeuzirten Formen abgesehen, kann man sagen, dass die Gasteropoden die ihren Körper schützende, aus einem Stück bestehende Schale in ausgiebiger Weise derart ausnutzen, dass der die Eingeweide enthaltende dorsale Körpertheil eine sackförmige Gestalt (Eingeweidesack) annimmt, sich vom Fuss und Kopf fast bruchsackartig abschnürt, sich zum Zwecke der Obertlïchenverkleinerung spiralig aufrollt und mit einer seine Gestalt wiederholenden Schale ungiebt, in welche der bei der freien Locomotion aus der Oeffuung der Schale hervortretende Kopf und Fuss zurückgezogen werden können. Der ansehnliche gestreckte Fuss besitzt meist eine Hache Kriechsohle. Der Kopf ist deutlich abgesetzt, mit Teutakeln und Augen ausgestattet. An irgend einer Stelle des Körpers bildet das Integument des Eingeweidesackes eine gegen den unteren Rand desselben herabhängende II antelfalte, welche die Athmungsorgane deckt und schützt und an ihrer ausseren Oberfäche, gleich dem übrigen Integumente des Eingeweidesackes, an der Bildung der Schale oder des Gehäuses theilnimmt. 
Es empfiehlt sich nun, für die Hauptgruppen der Gasteropoden besondere Schemata der äusseren Organisation zu entwerfen.

\section{Prosobranchia.}

Der ansehnliche Eingeweidesack ist in einer meist rechts gewundenen Spirale aufgerollt, desgleichen natürlich die Schale. Der wohlentwickelte Fuss mit platter Kriechsohle. Auf der Rückenseite des hinteren Fusstheiles eine kalkige Platte, der Deckel (Operculum), welcher, wenn das Thier den liopf und den Fuss zurückzieht, die Mündung des Gehïuses verschliesst. Die Mantelf alte hängt an der Vorderseite des Eingeweidesackes herunter. Sie bedeckt die geräumige Kiemen- oder Mantelhöhle, in welcher verschiedene, für die Morphologie der Prosobranchier äusserst wichtige Organe, die $\mathrm{M}$ a $\mathrm{n-}$ telorgane, ihren Platz finden, nämlich bei als ursprünglich zu betrachtenden Formen : 1) der A f t e r', der also nicht am Hinterende des Thieres, sondern dem Munde genähert, an der Vorderseite des Eingeweidesackes liegt; 2) die zwei ïusseren $\mathrm{M}$ ündungen der paarigen Nephridien, zu beiden Seiten des Anus; 3) zwei K i emen, eine rechte und eine linke; 4) zwei Osphradien in der Nähe der Kiemenbasis. Bei den allermeisten Prosobranchiern werden aber die cben citirten paarigen Organe unpaar, indem sich nur die auf

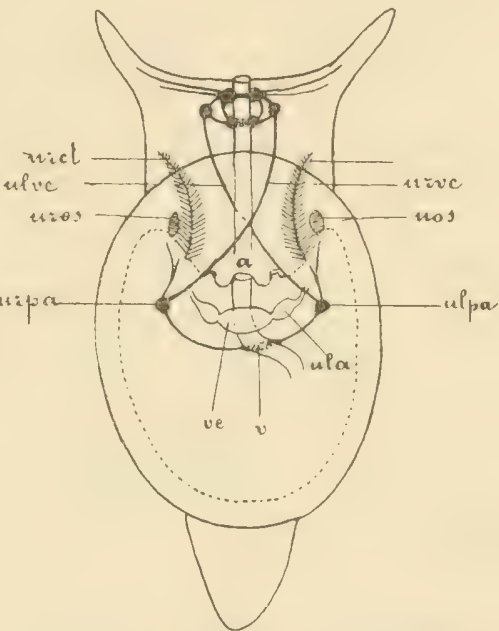

Fig. 424. Schema der Organisation eines zeugobranchiaten Diotocardiers. $a$ Anus, ve Herzkammer, ula rechter Vorhof, urct linkes Ctenidium, uros linkes Ospliradium. der linken Seite des Anus gelegene Kieme, Nephridialöffinung und das linksseitige Osphradium erhält, während der Enddarm mit dem After auf die rechte Seite der Mantelhöhle rückt. Die umpaare Geschlechtsöffinung liegt auf der rechten Seite, am Kopfe oder auf dem Boden der Mantelhöhle. (Die Prosobranchier sind gitreuntgeschlechtlich.) Dadurch, dass ursprünglich paarige Organe, wie die Kiemen, Nephridien und Osphradien, unpaar und asymmetrisch werden, wird die Asymmetrie des ganzen Körpers eine recht auffällige. Prosobranchier heissen die Thiere, weil die Kiemen vor dem Herzen liegen.

\section{Pulmonata.}

Typus: Helix pomatia. Der Eingeweidesack ist wohlentwickelt, rom übrigen Kö̈rper deutlich bruchsackartig alogesetzt, in rechtsgewundener Spirale aufgerollt, mit einer entsprechendeu Schale. Fuss gross, gestreckt, mit flacher Kriechsohle. Kopf mit zwei Paar Fühlern, vou deuen das eine die Augen trägt. Die Mantelfalte hängt an der Vorderseite des Eingeweidesackes herunter und bedeckt eine geräumige Mantelhöhle (Athemhöhle, Lungenhöhle). Der freie Rand der Mantelfalte ver- 
wächst mit dem benachbarten Integumente des Nackens bis auf eine rechts gelegene unverwachsene Stelle, das Athemloch, das zum Einund Austritt der Luft in die Athemhöhle dient. Der After und die unpaare äussere Nephridialöftinung liegen in nächster Nähe des Athemloches, also rechtsseitig. Die Mantelhöhle entbehrt der Kiemen, sie ist

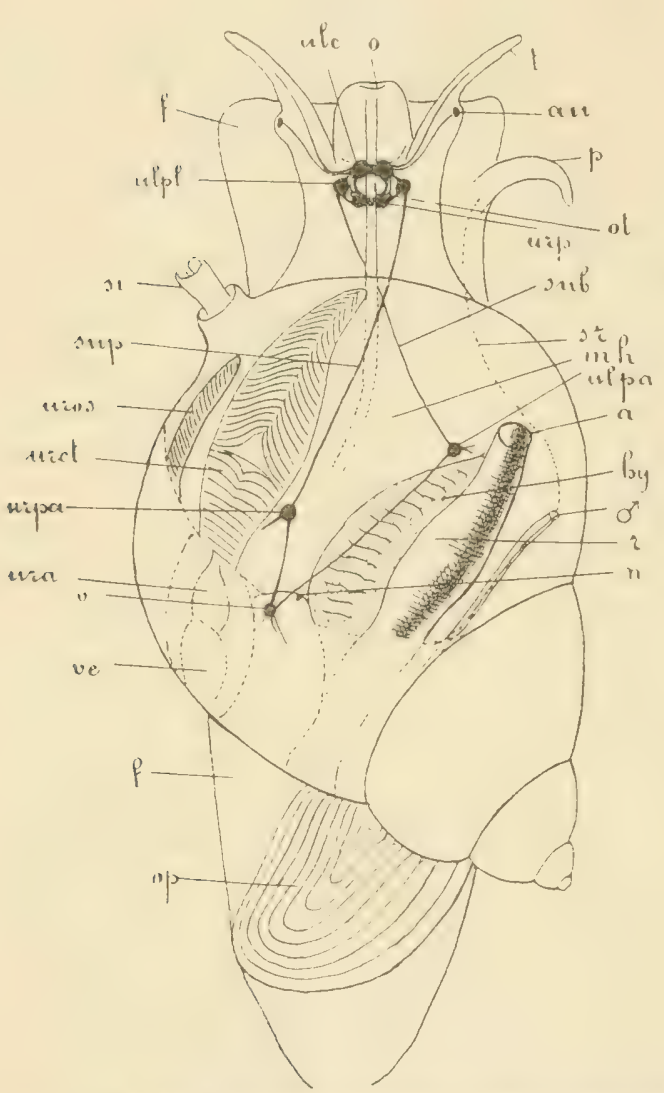

Fig. 426.

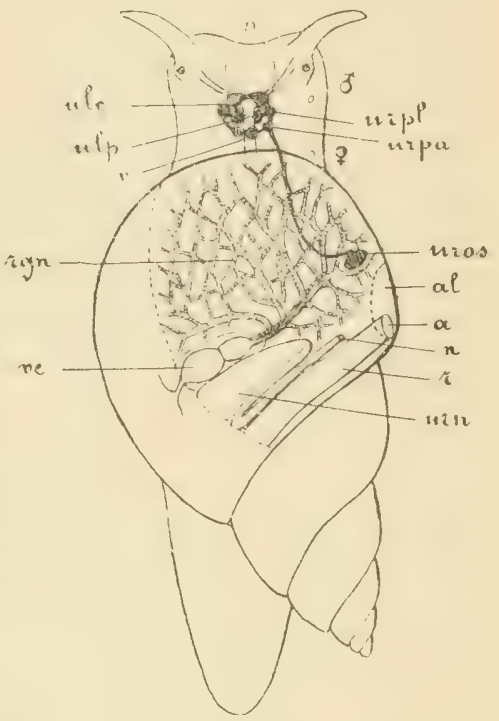

Fig. 426. Schema eines Pulmonaten aus der Abtheilung der Basommatophoren. al Athemloch, rgn Gefässnetz au der Innentläche des Mantels. Niere unrichtig gezeichnet. Uebrige Bezeichnungen wie in Fig. 423 u. 425.

Fig. 425. Schematische Darstellung eines Prosobranchiaten aus der Abtheilung der Monotocardier. Berücksichtigt sind die äussere Form, die Schale, der Mantel, der Pallealcomplex, das Herz und Pericard, das Nervensystem und das Operculum. Die meisten Bezeichnungen wie in Fig. 423. Ausserdem: $f$ Fuss, si Sipho, sup, sub Supra- und Subintestinalconnectiv, op Operculum, ot Gehörorgan, $p$ Penis, $s r$ Samenrinne, $m h$ Mantelhöhle, hy Hypobranchialdrüse, $\delta$ männliche Geschlechtsöffnung, $r$ Rectum, au Auge, $t$ Tentakel.

mit Luft erfüllt. Die Athmung geschieht an der inneren Oberfläche der Mautelfalte, an der sich ein zierliches Netz von Gefässen ausbreitet, das vor dem Herzen liegt. Der Fuss besitzt im Gegensatz zu den Prosobranchieru keinen Deckel. Gemeinsame Geschlechtsöffnung (die Pulmonaten sind Hermaphroditen) rechts am Nacken vor dem Athemloch.

Zahlreiche Pulmonaten weichen in ihrer äusseren Organisation sehr stark von dem Typus Helix ab. 
Opisthobranchia.

Die Athmungsorgane liegen hinter dem Herzen.

a) Tectibranchiata.

Der Eingeweidesack ist gewöhnlich nicht umfangreich. Er liann spiralig aufgerollt oder auch symmetrisch sein und ist von einer verschieden gestalteten Schale bedeckt. Der Fuss ist gross, gewöhnlich mit flacher Kricchsohle. Der Kopf verschieden gestaltet, oft mit Tentakeln oder Rhinophoren und mit ungestielten Augen. Die unanselnliche Mantelfalte hängt an der rechten Seite des Eingeweidesackes herunter und vermag häufig nicht die unter ihr liegende unpaare Kieme ganz zu bedecken. After in grösserer oder geringerer Entfernung hinter der Kieme. Geschlechtsöffnung (die Tectibranchien sind wie alle Opisthobranchien Hermaphroditen) und äussere Nephridialöftinung auf der rechten Körperseite vor dem After.

Fig. 427. Schema eines 0pisthobranchiaten aus der Abtheilung der Tectibranchiata. Bezeichnungen wie früher. Ausserdem: $g g$ Ganglion genitale, $s$ Schale, $q$ weibliche Genitalöffnung, lpp, rpp linker und rechter Parapodiallappen, der rechte auf die Seite gelegt.

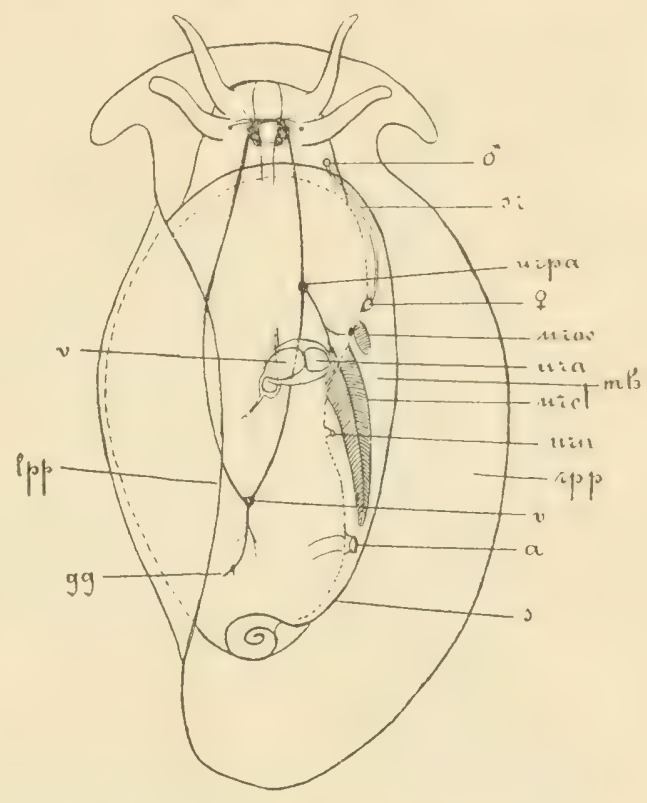

b) Nudibranchiata.

Der Körper ist äusserlich symmetrisch, der Eingeweidesack nicht bruchsackartig vom Körper abgesetzt, sondern dem mit einer flachen Kíriechsohle versehenen Fusse in seiner ganzen Länge aufgelagert und von ihm oft nicht deutlich abgesetzt. Eine deutliche Mantelfalte und eine derjenigen der Tectibranchien entsprechende Kieme fehlt ebenso wie die Schale. Der Kopf ist mit 'T'entakeln oder Rhinophoren und ungestielten Augen ausgestattet. Der After liegt entweder in der dorsalen Mittellinie oder rechts seitlich. Geschlechtsöffnung und Nierenöffuung anf der rechten Körperseite vor dem After. Die Kiemen finden sich in sehr verschiedener Form, Zahl und Anordnung auf dem Rücken oder an den Seiten des Köropers und haben mit dem typischen Molluskenctenidium morphologisch nichts gemein.

\section{D) Scaphopoda.}

Körper symmetrisch, langgestreckt, d. h. Eingeweidesack in dorsoventraler Richtung verlïngert, vom röhrenförmigen Mantel complet eingehüllt. Die Mantelböhle liegt hinten am Körrper und verlängert sich 
ventralwärts noch so weit, dass die Schnauze und der zurückgezogene Fuss vollständig in ihr geborgen liegt. Die Mantelhöhle steht ausser durch die grössere ventrale Oeffinung noch durch eine dorsale engere Oeffnung mit der Aussenwelt in Verbindung. Schale wie der Mantel röhrenförmig oder besser hoch-kegelförmig, etwas nach vorn gekrümmt, mit den Mantelöffuungen entsprechenden grösserer ventraler und kleinerer dorsaler Oeffinung. Der als tonnenförmige Schnauze entwickelte Kopfabschnitt entbehrt der Augen. Die an seinem ventralwärts

Fig. 428

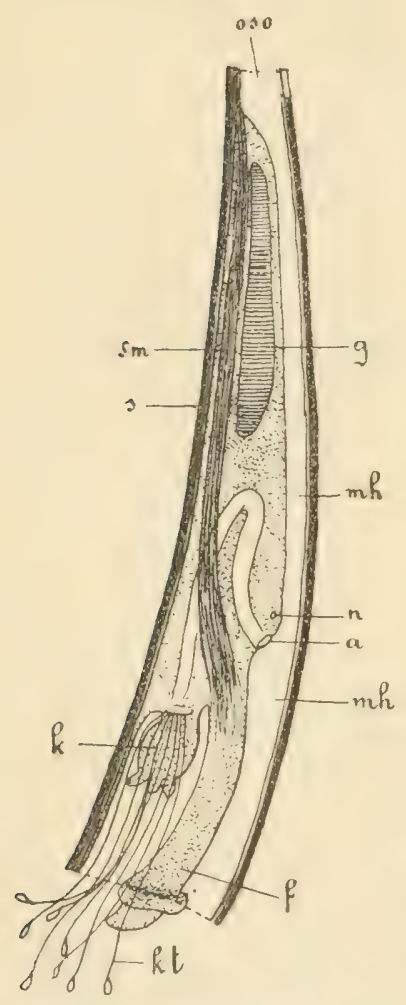

Fig. 429 .

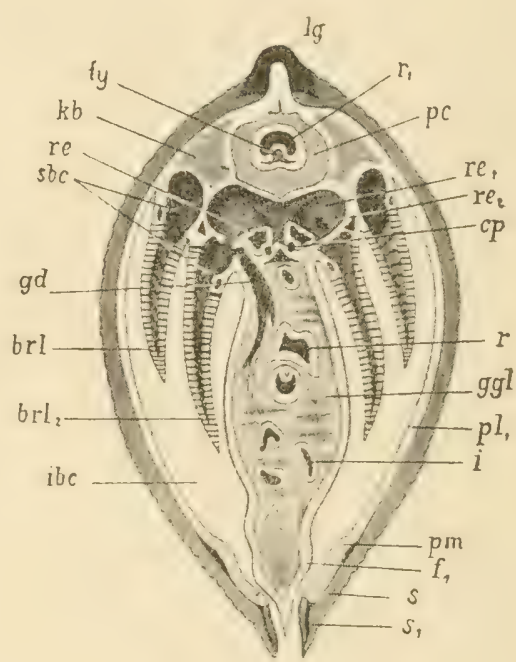

Fig. 428. Dentalium, schematisch, von der linken. Seite, $g$ Geschlechtsdriise, kt Kopftentakel. Uebrige Bezeichnungen wie früher.

Fig. 429. Querschnitt durch Anodonta cygnaea. (gewöhnliche Süsswassermuschel), nach G. B. Howes. lg Ligament, ty Typhlosolis, $k b$ Pericardialdrüse (KEBER's Organ), re Niere (drüsiger Theil), sbc Kammern an der Kiemenbasis, gd Ausführungsgang der Gonade, $b r \cdot l, b r l_{2}$ äussere und innere Kiemenlamelle, $i b c$ Mantelhöhle, $s$ Schale mit Schalenrand $s_{1}, f_{1}$ Fuss, $p m$ Muskel des Mantelrandes, $i$ Darm, $p l_{1}$ rechte Mantelfalte, $g g l$ Gonade, $r$ Rectum, $c p$ Cerebropedalconnectiv, $r e_{1}$ nicht-drüsiger Raum der Niere, re $e_{2}$ Nierenöffnung, $p c$ Pericard.

gerichteten Ende gelegene Mundöffuung ist von einem líranz von blattförmigen Tentakeln ungeben. An der Basis der Schnauze erheben sich zwei Quasten langer, fadenförmiger, contractiler Tentakel, welche nach unten in die Mantelhöhle herunterhängen und aus der ventralen Nantelöffnung weit vorgestreckt werden kömnen. Hinter der Schnauze entspringt vom liörper der cylindrische, musculöse, nach unten vorstreckbare Fuss. Ki liemen fehlen. Der After liegt hinten, median üher dem Fuss. Die beiden Nephridialötfinungen zu beiden Seiten des Afters. Besondere Geschlechtsöffnungen fehlen (Fig. 428 u. 4\$3). 
E) Lamellibranchia.

Der Körper ist bilateral-symmetrisch; von vorn nach hinten etwas verlängert. Das Integument bildet an der rechten und an der linken Seite eine Mantelfalte, welche blattartig ventralwärts weit auswächst, wälureud ihre Basis sich am Rumpfe in seiner ganzen Länge befestigt. Betrachtet man den von der Schale losgelösten Kiörper einer Muschel von der Seite, so werden die Contouren desselben bei zurückgezogenem Fusse gebildet: dorsalwärts von der dorsalen Mittellinie des Rumpfes, vorn, hinten und unten von dem freien Rande der Mantelfalte. Beide Mantelfalten begrenzen zusammen einen Raum, dessen grösster Querdurchmesser fast immer bedeutend kürzer ist als der dorsoventrale oder

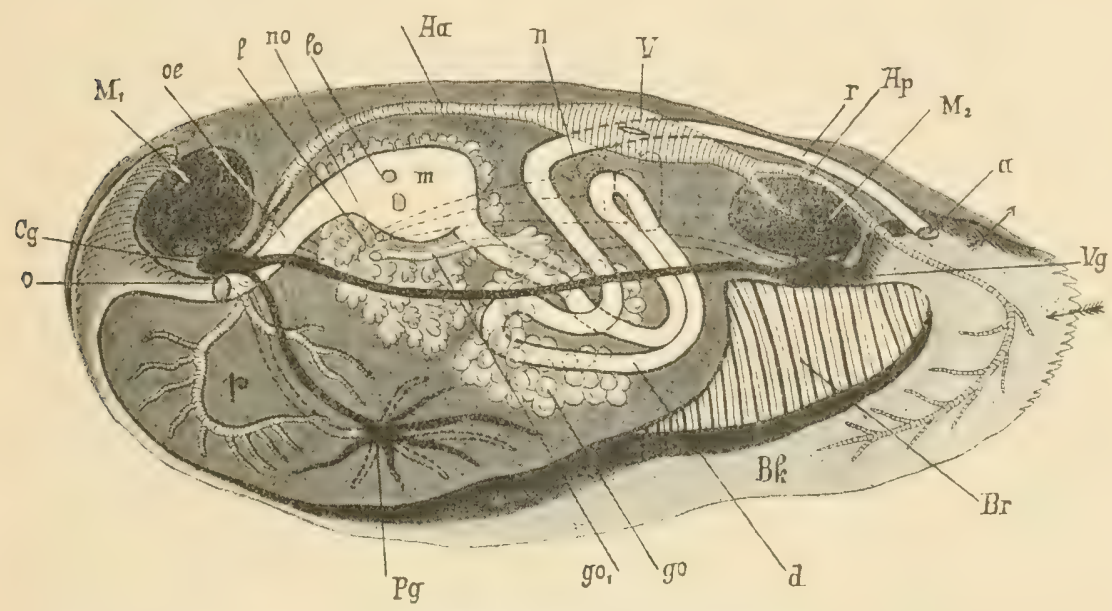

Fig. 430. Anatomie von Unio (Margaritana) margaritiferus, von der linken Seite, nach Leuchart und Nitsche. o Mund, $O g$ Cerebralganglion, $M$ vorderer Schliessmuskel, oe Oesophagus, $l$ Verdauungsdrüse (Leber), no Nephridialöffnung, lo Oeffinungen der Verdauungsdrüse in den Magen $n$, Aa Aorta anterior, $n$ Nephridium, Konturen durch punktirte Linien angegeben, $V$ Herz, $r$ Enddarm, Ap Aorta posterior, $D_{2}$ hinterer Schliessmuskel, a After, $\mathrm{Vg}$ Visceralganglion, $B r$ Kieme, $B k$ Mantelhöhle, go Gonade mit Ausführungsgang $g o_{1}, F g$ Pedalgauglion, $p$ Fuss. Die Pfeile deuten die Richtung an, in welcher dus Wasser in die IIantelhöhle ein- und aus ihr austritt.

der Längsdurchmesser; das heisst, das Thier mit dem Mantel ist seitlich zusammengedrückt. In die erwähnte Mantelhöhle ragt vom Rumpfe herunter ein grosser, etwas nach vorn gerichteter, musculöser Fortsatz, der zwischen den freien Mantelrändern vorgestreckt werlen kann, der Fuss. Auch der Fuss ist seitlich abgeplattet. Sein freies Ende ist in gewissen Fällen, die, obschon die Ausnahme bildend, besonders hervorgehoben zu werden verdienen, abgeplattet, d. h. er besitzt dann eine Hache Sohle. Der Rumpf mit seinen zwei Mantelfalten sondert an der äusseren Oberfläche eine zweiklappige Schale ab, welche den ganzen Körper bedeckt. Die eine Schalenklappe liegt rechts. die andere links von der Medianebene. Buide sind einander spiegelbildlich gleich. Eine jede hat dieselben Unrisse wie der Rumpf mitsammt der Mantelfalte ihrer Körperseite. Die beiden Schalenklaypen articuliren mit einander an Rücken und klaffen vorn unten und hinten. Zwei starke Muskeln 
(Adductoren, Schliessmuskel der Schale) verlaufen quer von der einen Schalenklappe zur gegenüberliegenden. Sie dienen bei ihrer Contraction zum vollständigen Verschliessen der Schale. Der eine liegt vorn, der andere hinten am Rumpfe. Beide erzeugen an der Innenfläche der Schalenklappen, wo sie sich anheften, Findrücke, die an losgelösten Schalen immer deutlich zu erkennen sind.

Der Mund liegt unter dem vorderen Schliessmuskel, zwischen diesem und der vorderen Basis des Fusses. Der After liegt hinter dem hinteren Schliessmuskel. Ein gesonderter Kopfabschnitt fehlt. Jerlerseits neben dem Mund trägt der Rumpf zwei blattförmige Fortsätze, die Mundlappen. An der Insertionslinie des Fusses, in der Mantelhöhle, verläuft jederseits am Rumpfe in seinem mittleren und hinteren Theile eine Längsleiste, auf welcher in zwei Längsreihen zahlreiche lange Kiemenblättchen sich erheben. Es liegt also jederseits in der Mantelhöhle eine Kieme, von der Gestalt einer Feder, deren Schaft der Länge nach am Körper befestigt wäre (Fig. 429, 430 u. a.).

Die äussere Organisation kann sich in den verschiedenen Abtheilungen der Lamellibranchier sehr weit von diesem Schema entfernen.

\section{F) Cephalopoda.}

Der Körper ist bilateral-symmetrisch. Der Eingeweidesack ist gross, hïufig in dorsoventraler Richtung stark verlängert, mehr oder weniger deutlich abgesetzt von dem Kopfe, der seinerseits von dem in eigenthümlicher Weise umgestalteten Fusse allseitig zur Bildung eines Kopffusses umwachsen ist. Der Fuss ist nämlich in verschieden zahlreiche Fortsätze (Arme, Tentakel) ausgezogen, die den Mund in einem Kranze umstellen und die hauptsïchlich zum Erhaschen und Festhalten der Beute dienen. Man muss den Kï̈rper eines Cephalopoden so orientiren, dass die Spitze des Eingeweidesackes (die ein Laie für das hintere liörperende halten würde) zu oberst liegt, also den höchsten Punkt des Rückens bildet, der Kopf mit seinen Fangarmen aber zu unterst liegt. Man kann also am Eingeweidesack sowohl als an dem mit dem hopfe vereinigten, in die Fangarme ausgezogenen Fusse ein Voru (dem Laien ist das oben), ein Hinten (dem Laien ist das unten), ein Rechts und Links unterscheiden. Dem in die vergleichende Anatomie der Mollusken nicht Eingeweihten wird diese Art der Orientirung deshall) anfangs paradox erscheinen, weil die normale Stellung einiger bekannter Cephalopoden im Wasser damit nicht übereinstimmt. Eine Sepia z. B. schwimmt so im Wasser oder liegt so auf dem Grunde, dass die vordere, stärker pigmentirte Seite des Eingeweidesackes und des Kopffusses oben, die hintere unten liegt. Beistehende schematische Zeichnung dient zur morpholog is chen Orientirung des lï̈rpers. Vergleichend-anatomisch ist diese natürlich allein maassgebend (Fig. 431).

Am Kopffuss befindet sich rechts und links ein hoch entwickeltes Auge und in seiner Nähe eine Geruchsgrube.

Die Mantelfalte häugt hinten vom Eingeweidesack herunter und bedeckt eine geräumige Mantel- oder Kiemenhöhle, die über dem Kopffuss am freien Rande der Mantelfalte durch dic Mantelspalte mit der Aussenwelt communicirt. Im Grunde der Mantelhöhle finden sich 2 oder 4 symmetrisch angeordnete Kiemen. In die Mantelhöhle öffnen sich ferner der median gelegene After und die Oeffinungen der Ge- 
schlechtsorgane und Nephridien. An der hinteren und unteren Seite des Eingeweidesackes erheben sich zwei symmetrisch gestaltete Lappen, die sich so aneinanderlegen, dass sie zusammen ein Rohr bilden, den sogenannten Trichter, dessen eine Oeffnung in der Mantelböhle liegt, während die andere ausserhalb der Mantelhöhle unter der Mantelspalte frei zu Tage tritt. Das Athemwasser, das in die Mantelhöhle durch die Mantelspalte eingedrungen ist, gelangt durch die in der Mantelhöhle liegende Oeff̈nung des Trichters in diesen letzteren hinein und durch dessen untere freiliegende Oeffnung wieder nach aussen. Den Weg des Trichters benutzen auch die Fäcalmassen, die Excrete und Geschlechtsproducte und das Secret des Tintenbeutels, um den Körper zu verlassen.

Ursprünglich besassen wohl alle Cephalopoden eine Schale, welche den ganzen Eingeweidesack mitsammt der Mantelfalte bedeckte. Bei den heute lebenden Cephalopoden ist die Schale selten in dieser Weise entwickelt, vielmehr meist rudimentär oder gänzlich in Wegfall gekommen. Die lebenden Cephalopoden zerfallen in zwei scharf getrennte Abtheilungen, die Tetrabranchiata und die Dibranchiata.

Fig. 431. Schema von Sepia, Medianschnitt von der linken Seite. $v$ Ventral (physiologisch vorn), $d$ dorsal (physiologisch hinten), an vorn (physiologisch oben), po hinten (physiologisch unten), 1, 2, 3, 4, 5 die 5 Arme der linken Seite, au Auge, co innere Schale, go Gonade, $d$ Farbstoffdrüse $=$ Tintenbeutel, $m$ Magen, $n$ Niere, ct Kieme (Ctenidium), a After, $m h$ Mantelhöhle, in Trichter. Die Pfeile bezeichnen den Weg des Athemwassers.

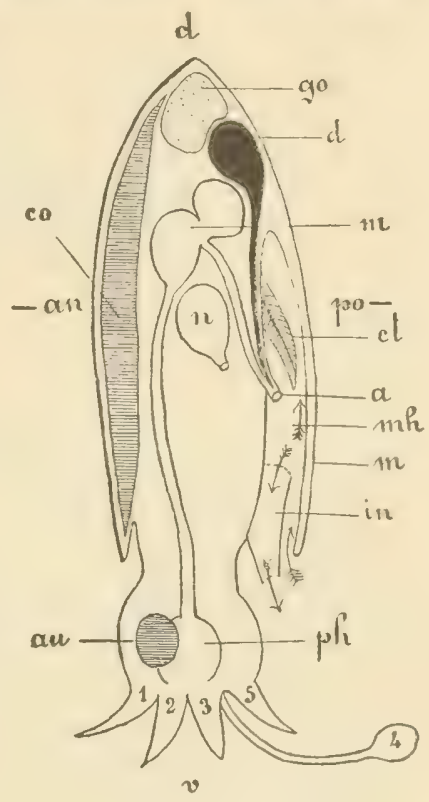

Die Tetrabranchiat a (Nautilus, Fig. 432)

besitzen eine in der Symmetrieebene, und zwar nach rorn (exogastrisch), eingerollte Schale, die durch Scheidewände in anfeinander folgende Kammern zerfällt. Das Thier sitzt in der grössten, letzten Kiammer. Die übrigen Kiammern enthalten Gas. Die Scheidewände, welche die aufeinander folgenden Kammern trennen, sind in ihrer Mitte durchbohrt zum Durchtritt eines Sipho, welcher alle Kammern durchzieht und sich am Eingeweillesack des Tautilus befestigt. Der Theil des Fusses, welcher den llund umgiebt, ist in zahlreiche Tentakel ausgezogen, welche in besondere Scheiden zurückgezogen werden können.

Der vorderste Theil des Fusses, der vor und über dem Kopfe liegt, ist zu einem concaven Lappen, der sogenannten Kopfkappe, verbreitert, welche dem vorderen Theil der Wohnkammer der Schale aussen anliegt und welche bei zuriekgezogenen Tentakeln die Mündung der Schale verschliessen kann. Die Kopfkappe trägt 2 'T'entaliel. Jederseits am Kopfe liegt das Auge.

Die Mantelfalte geht üher dem liopffuss um den ganzen Körper herum. 'Zu Seiten des Körpers ist sie nur kurz, vorn und oben aber 
bildet sie einen ansehnlichen Lappen, welcher in der in der Fig. 416 dargestellten Weise auf die Schale zurückgeschlagen ist. Hinten bedeckt die Mantelfalte eine sehr tiefe, die ganze hintere Seite des Eingeweide-

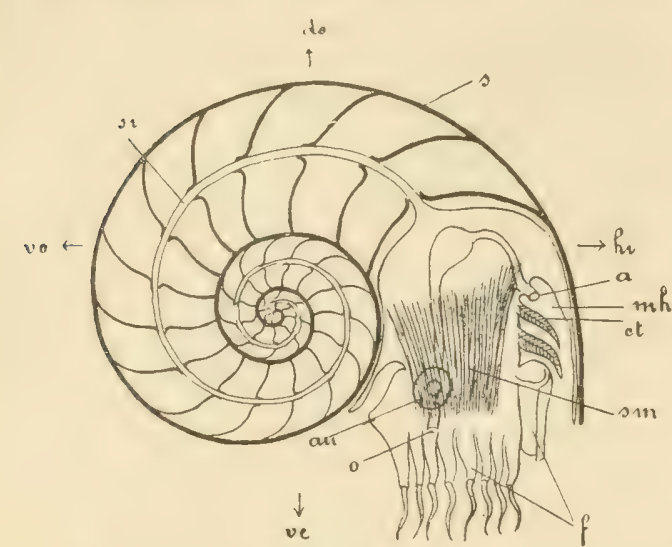

Fig. 432. Schema von Nautilus, von der linken Seite. ve Veutral, do dorsal, io vorn, hi hinten, $f$ Fuss (Tentakel + Trichter), $s m$ Schalenmuskel, ct Ctenidien, $m h$ Mantelhöhle, $a$ After, $s$ Schale, si Sipho, au Auge, o Mund. sackes einnehmende Mantelhöhle. Der Trichter besteht aus zwei völlig getrennten seitlichen Lappen (Epipodiallappen), von denen der eine mit seinem freien Rande sich so über den freien Rand des andern hinwegschiebt, dass beide eine unten und oben offene Röhre bilden, ähnlich einem von einem Blattwickler zusammengerollten Pflanzenblatte. Wie wir später sehen werden, stellt dieser 'Trichter einen Theil des Fusses dar. In der Tiefe der Mantelhöhle erheben sich auf dem Eingeweidesack zwei Paar federförmige Kiemen, ein oberes und ein unteres Paar. Ferner finden sich hier 9 Oeffnungen innerer Organe, eine unpaare Oeffinung in der Mitte: die Afteröftnung, und paarige Oeffnungen: namlich die 2 Oeffnungen der Geschlechtsorgane, die $t$ Oeffungen der Nephridien und rie 2 Visceropericardialötfnungen. Die Lage dieser Oeffnungen illustriren die Abbildungen Fig. 460 u. 461.

\section{Die Dibranchiata}

besitzen - mit Ausnahme des Weibchens von Argonauta, welchem eine äussere ungekammerte Schale zukommt - entweder nur eine innere Schale, welche an der Vorderseite des Eingeweidesackes, von einer Duplicatur des Integumentes bedeckt, liegt, oder sie besitzen überhaupt keine Schale. Der Eingeweidesack ist bald plump, beutelförmig - bei den Formen mit vorwiegend kriechender Lebensweise (Fig. 421) - bald in dorsoventraler Richtung stark verlängert, von vorn nach hinten abgeplattet, oben zugespitzt auslaufend - bei den guten Schwimmern (Fig. 418). Bei diesen ist er überdies meist von einem flossenartigen Hautsaume umgürtet, welcher die Grenze zwischen der vorderen und hinteren Seite des Eingeweidesackes markirt.

Der Kopffuss ist meist vom Eingeweidesack deutlich abgesetzt, er trägt rechts und links die wohl entwickelten Augen. Den Mund umstellen $s$ oder 10 Fangarme, die an ihrer unteren, dem Munde zugekehrten Seite mit Saugnäpfen besetzt sind.

Die Mantelfalte bedeckt fast die ganze hintere Fliiche des Eingeweidesackes, so dass hier eine sehr tiefe und geräumige Mantelhöhle zu Stande kommt. Auf die Seitentheile und auf die Vorderseite des Eingeweidesackes setzt sich die Mantelfalte nur als wenig breiter Saum fort, der unmittelbar über dem Kopffuss eine nicht tiefe Rinne oder Furche bedeckt. 
Die beiden Seitenlappen des Trichters der Tetrabranchiaten sind bei den Dibranchiaten an ihren freien Rändern zu einem oben und unten offenen Rohre verwachsen. In der Mantelhöhle liegen nur 2 Kiemen, eine auf der rechten und eine auf der linken Seite. Auf dem Eingeweidesack - immer in der Mantelhöhle - finden wir in der Nühe der oberen Oeffnung des Trichters die Oeffnungen der inneren Organe: After, Mündung des Tintenbeutels, Genital- und Nephridialötfnung. Näheres über Zahl und Lage dieser Oeffnungen weiter unten.

\section{Haut, Mantel, Eingeweidesack.}

Den ganzen Körper überzieht ein einschichtiges Körperep it he l, welches an den nicht von der Schale bedeckten Theilen überall oder doch in grosser Ausdehnung bewimpert sein kann. Es ist sehr reich an Drüsen, die fast ausschliesslich dem einzelligen Typus angehören und theils im Epithel selbst liegen, theils aus demselben in das darunterliegende Gewebe verlagert sind, ihren Ausführungsgang aber zwischen die Epithelzellen hineinschicken.

Man unterscheidet als Led erhaut die unmittelbar unter dem Körperepithel liegenden Gewebe (Bindegewebe, Muskelfasern). Doch ist diese Lederhaut gegen die tiefer liegenden Gewebe und Organe durchaus nicht scharf abgegrenzt. Das Pigment findet sich fast immer in subepithelialen Bindegewebszellen.

Fig. 433. Schnitt durch die Haut von Daudebardia rufa, nach Plate. 1 Körperepithel, 2, 3, 9 verschiedene Fornien einzelliger Drüsen, 4 kuglige Pigmentzellen, 5, 7 unpigmentirte Bindegewebszellen, 6 Muskelfasern, 8 verästelte und anastomosirende, pigmentführende Bindegewebszellen.

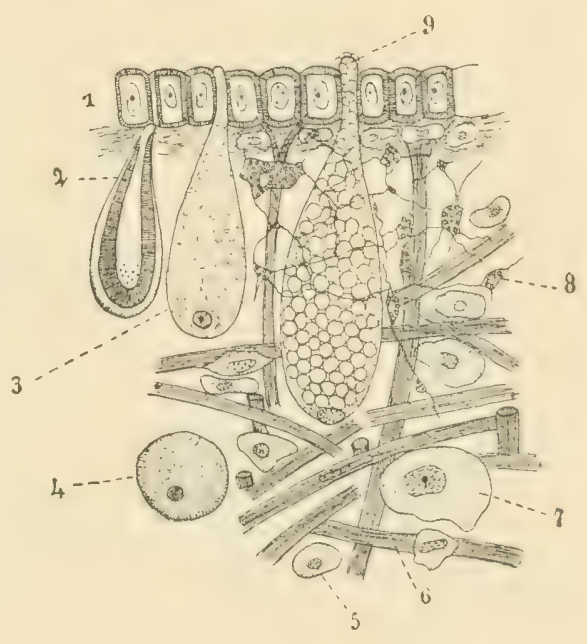

A) Placophora.

Schema der äusseren Organisation p. 595.

Auf dem Rücken von Chiton finden sich 8 hintereinander liegende $S$ chalenstücke (Fig. 385), die dachziegelförmig so übereinander greifen, dass der hintere Rand eines Stückes den vorderen Rand des nächst hinteren bedeckt. Jedes Schalenstück besteht aus zwei übereinander liegenden Schichten. Die äussere, d. h. obere, welche am Rücken frei zu Tage tritt, hat den Namen des Tegmentum erhalten, die untere, verborgene heisst Articulamentum. Gewöhnlich ist das Tegmentum nur am vordersten Schalenstück so gross wie das ihm unten anliegende Articulamentum. Bei den folgenden Schalenstücken ist das Articulamentum grösser und ragt seitlich und vorn über das darüber liegende Tegmentum hinats. Diese zwei Terlängerungen, als Apophysen bezeichnet, schieben sich unter 
das nächstvorhergehende Schalenstück. Zwischen beiden Schichten findet sich eine Gervebslage, welche eine Fortsetzung des Rückenintegumentes darstellt. Das Tegmentum ist von grösseren und kleineren Kanälen durchsetzt, welche sich an seiner Oberfläche durch in charakteristischer Weise angeordnete Poren öffnen. (Ueber die Beziehungen dieser Kanäle und Poren zu eigenthümlichen Tastorganen und Augen auf der Schale der Chitonen vergleiche das Kapitel: Simnesorgane.) Das 'Tegmentum besteht aus einer hornigen oder chitinigen Grundsubstanz, die als Cuticularbildung $\mathrm{zu}$ betrachten ist und die mit Kalksalzen imprägnirt ist. Das Articulamentum ist compact, nicht von Kanälen durchsetzt, mit wenig organischer Grundsubstanz und viel Kalksalzen. Es allein entspricht der Schale der ïbrigen Mollusken, während das Tegmentum als eine verkalkte, sich den Chitonschalen (Articulamenta) auflagernde Cuticula, als eine Fortsetzung der Cuticula des Integumentes der Z one, welche die 8 Schalenstücke rings umgiebt, aufzufassen ist. Die Zone trägt chitinige oder verkalkte Stacheln, Borsten, Schuppen, Körner etc. in für die verschiedenen Arten und Gattungen verschiedener Form und Anordnung.

Jeder Stachel nimmt gewöhnlich als rundes Bläschen seinen Ursprung im Innern einer Epithelpapille des Integumentes über einer sich durch besondere Grösse auszeichnenden Bildungszelle (Fig. 434). In dem Maasse als der Stachel wächst, wird er von den neu sich erzeugenden Schichten der Caticula in die Höhe gehoben. Dic Bildungszelle erhält sich an seiner Basis, bleibt aber mit der Epithelpapille durch einen sich immer mehr verlängernden Plasmafortsatz in Zusammenhang, der sich mit einer hesondern kernhaltigen Scheide umgeben kann. Bei den ausgebildeten Stacheln findet man den Rest der Bildungszelle immer noch als sogenanntes Endkölbchen an ihrer Basis.

Es giebt aber auch Stacheln und ganz besonders flachere, schuppen- oder plattenartige Kalkbildungen im Integument der Chitonen, welche nicht je von einer einzigen grossen Bildungszelle, sondern wahrscheinlich von mehreren im Grunde einer Epithelpapille erzeugt werden.

Fig. 434. A, B, $C$ Stadion der Stachelentwickelung von Chiton, nach BLUMrich, schematisirt. st Stachel, $b z$ Bildungszelle des Stachels, e Körperepithel, $c$ dicke, vom Körperepithel abgesonderte Cuticula, ek Endkölbchen (Rest der Bildungszelle).

Wie wir vorhin das Tegmentum nur als einen besonderen, dem Articulamentum aufgelagerten Theil der allgemeinen Körpercuticula aufgefasst haben, so können wir in dem letztern selbst ein Homologon der Kalkstacheln, Kalkschuppen etc. erkennen, welche in dem Mantelintegument zur Entwickelung gelangen. Die Articulamenta wären dann nur stark vergrösserte und verbreiterte Kalkschuppen.

Diese Ansicht führt schliesslich zu der Annahme, dass die Schale (wenn der Ausdruck für diesen Fall erlaubt wäre) der Mollusken ursprünglich aus isolirten Kalknadeln oder Stacheln bestand, die in einer dicken Cuti- 
cula eingeschlossen und aus dieser hervorragend in ähnlicher Weise entwickelt waren, wie bei Proneomenia, Neomenia etc., vergl. p. 608.

Bei Cryptochiton ist die Schale eine innere, $d . h$. vollständig von einer über ihr von allen Seiten zusammenwachsenden Duplicatur des Integumentes bedeckt. Sie besteht ausschliesslich aus dem Articulamentum, indem das ganze Integument des Rückens von einer gleichmässigen Cuticula überzogen ist, welche also kein Tegmentum bildet.

Wenn wir bei Chiton von einer Mantelfalte sprechen wollen, so können wir darunter nur die Randzone des Körpers verstehen, welche auf der Bauchseite den Kopf und Fuss umkreist und im Umkreis des Kopfes und Fusses die Kiemenrinne begrenzt, durch welche sie scharf von diesen Organen abgegrenzt wird. Wie dieser Mantel (dessen Rückenseite man Zone nennt) dorsalwärts grössere Stacheln, Borsten, Schuppen etc. trägt, so kann er auf der Unterseite mit kleinen, dichtstehenden Stacheln besetzt sein. Der übrige Theil des Integumentes ist nackt und von einem einfachen Epithel bedeckt.

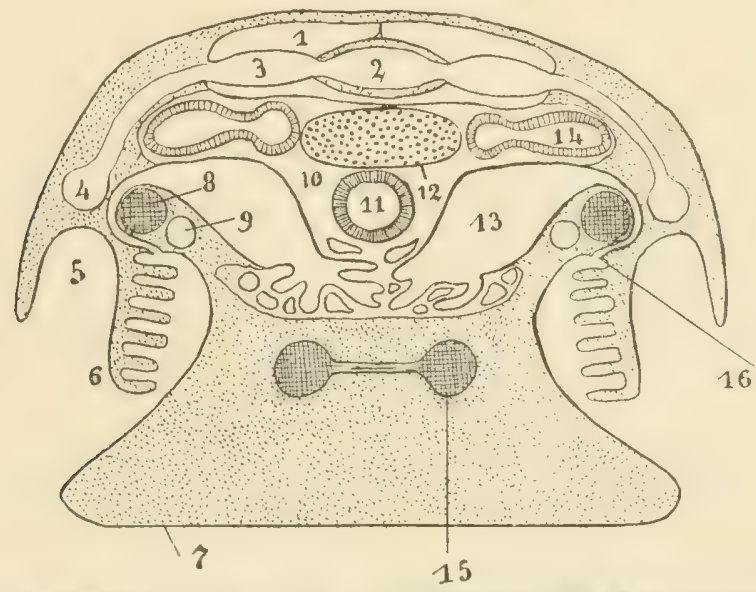

Fig. 435. Querschnitt durch Chiton, in der Gegend der Nephridialöffnungen, sehr stark schematisirt, nach SEDGWICK, etwas modificirt. 1 Pericard, 2 Herzkammer, 3 Vorhof, 4 ,Kiemenvene", 5 Kiemenfurche (Mantelhöhle), 6 Kieme (Ctenidium), 7 Fuss, 8 Pleurovisceralstrang, 9 ,Kiemenarterie ${ }^{6,}, 10$ secundäre Leibeshöhle, 11 Darm, 12 hinterster, sich dem Pericard unterlagernder Theil der Gonade, 13, 14 die beiden hintern Schenkel des Nephridiums, von denen der eine (13) in die Kiemenfurche (bei 16) mündet, der andere mit dem Pericard in (nicht dargestellter) Verbindung steht, 15 Pedalstränge.

Von grosser Bedeutung für den Vergleich der äusseren Organisation der Placophoren mit derjenigen der Solenogastres ist die Gattung Chitonellus. Der Körper von Chitonellus ist nicht dorsoventral abgeplattet wie der von Chiton, sondern annähernd cylindrisch, immerhin mit abgeflachter Bauchseite (Fig. 436), in deren Medianlinie eine Längsfurche verläuft. Ein Fuss ist äusserlich nicht sichtbar, er befindet sich nämlich in stark reducirtem Zustande in der Tiefe der medianen Furche und besitzt selbst in seiner ventralen Mittellinie eine Furche, welche seine schmale, contrahirte Sohle darstellt. Die flache Bauchseite stellt also den Mantel dar. In der engen Spalte jederseits zwischen Mantel und Fuss liegen in der hinteren Körperhälfte die Kiemen. Der seitliche Körperrand der Chitonen ist bei Chitonellus nur noch an einer stumpfen 
Kante kenntlich, welche, wie man auf dem Querschnitt sieht, fast ausschliesslich durch eine hier vorhandene starke Verdickung der Cuticula hervorgerufen wird.

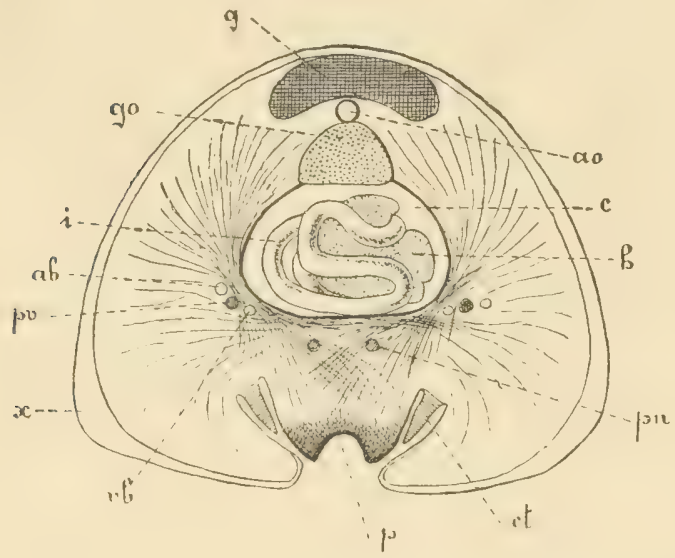

Fig. 436. Querschnitt durch Chitonellus, schematisch. Unter Benutzung von Figuren von Pelsenter und Blumrich. $g$ Schale (Articulamentum), go Gonade, $i$ Darm, $a b, v b$ Kiemenvenen und Kiemenarterien, $p v$ Pleurovisceralstrang, $x$ seitliche, ventrale Verdickung der Cuticula, $p$ Fuss, ct Ctenidium, $p n$ Pedalstränge, $h$ Verdauungsdrüse (Leber), $c$ secundäre Leibeshöble, ao Aorta.

B) Solenogastres.

Bei den Solenogastres (Aplacophoren), deren äussere Organisation p. 596 schon hinreichend geschildert worden ist, fehlt die Schale vollstandig. Dagegen ist die vom Körperepithel abgesonderte Cuticula rings um den Körper herum meist ausserordentlich dick (Fig. 437). Sie enthält Kalkspicula, die frei nach aussen vorragen können. Aehnlich wie die Stacheln der Polyplacophoren stecken sie mit ihren basalen Enden in zelligen Bechern, die durch einen kernhaltigen Stiel mit dem an der Basalflïche der Cuticula liegenden Körperepithel zusammenhängen. Die Bildung und das Wachsthum der Spicula geht zweifellos von diesen Bechern aus. Der Fuss ist, wie wir gesehen haben, auf eine schmale,

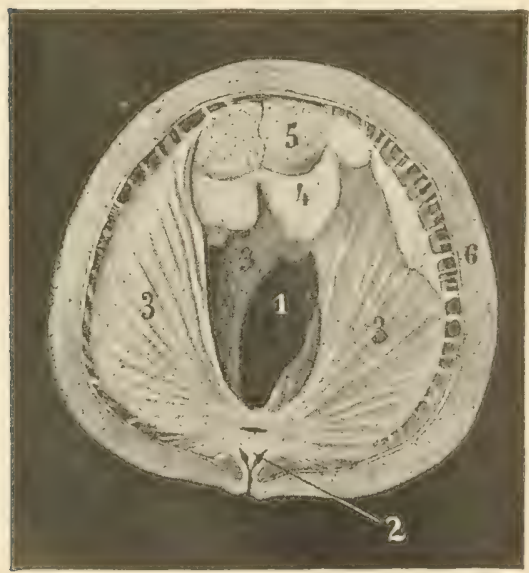
bewimperte Längsleiste reducirt, welche sich im Grunde der medioventralen Längsfurche erhebt. Von einem Mantel können wir hier kaum mehr sprechen, wenn wir nicht die die Längsfurche seitlich begrenzenden Integumenttheile mit diesem Namen belegen wollen.

Bei Chaetoderma schliesslich ist der Fuss ganz verkümmert und auch die medio-ventrale Furche fehlt vollständig.

Wir werden noch öfter Golegenheit haben, zu zeigen, dass man die Placophoren und die Solenogastres wegen einer ganzen

Fiu 437. Querschnitt durch Proneomenia Sluiteri in der Gegend des Mitteldarmes. 1 Mitteldarm, 2 rudimentärer Fuss, 3 in Uen Mitteldarm vorspringende Septen, 4 Hodentheil der Gonade, 5 Ovarialtheil der Gonade, 6 dicke, vom Körperepithel abgesonderte Cuticula. 
Reihe zweifellos ursprünglicher Organisationsverhältwisse an den Anfangspunkt des Molluskenstammes stellen muss. In einigen Beziehungen zeigen die Solenogastres vielleicht noch ursprünglichere Verhältnisse als die Polyplacophoren, und man glaubte auch in der wurmförmigen Körpergestalt, in der geringen Entwickelung des Mantels, des Fusses und der Kiemen ursprüngliche Verhältnisse erblicken zu dürfen. Mit neueren Autoren sind wir anderer Meinung und erblicken in den erwähnten äusseren Organisationsverhältnissen eher die Folge einer secundüren Anpassung des Körpers an die Lebensweise im Schlamme. (Die meisten Solenogastres sind Schlammthiere.) Schale, Mantel, Kiemen und Fuss sind für die Mollusken so absolut charakteristisch, dass wir sie bei einer gemeinsamen Stammform annehmen müssen.

Die Reihe Chiton, Chitonellus, Neomenia, Chaetoderma ist daher für uns eine Reihe, welche nicht das Auftauchen und die Weiterentwickelung, sondern das fortschreitende Sichverwischen und Verschwinden typischer Molluskencharaktere illustrirt.

\section{C) Gasteropoda.}

Vergleiche die Schemata der äusseren Organisation p. 596-599.

\section{$\mathrm{Ha} \mathrm{u} \mathrm{t.}$}

Ganz besonders reich an Drüsen: Schleimdrüsen, Farbdrüsen und $\mathrm{Kalkdrüsen,}$, ist der freie Mantelrand, von welchem ganz vorwiegend die Bildung und das Wachsthum der Schale ausgeht.

Das Körperepithel trägt besonders bei den im Wasser lebenden Schnecken auf grösseren oder kleineren Bezirken Cilien. Bei manchen Nacktschnecken unter den Opisthobranchiern ist sogar die ganze Körperoberfläche bewimpert.

Die besonders bei Nudibranchiern auffällige Färbung und Zeichnung der Haut wird hervorgerufen durch Pigmentzellen, die seltener im Epithel, häufiger in der Cutis ihren Sitz haben.

Wo eine compacte Schale fehlt, können Kalkkörper, Kalknadeln etc. zerstreut in der Cutis vorkommen.

Bei mehreren Nudibranchiern hat man Nesselzellen in der Haut beobachtet.

\section{Mantel, Eingeweidesack.}

Die Mantelfalte ist im allgemeinen bei den Gasteropoden wohl entwickelt und bedeckt eine gerïumige Mantelhöhle. Wo sie unansehnlich ist oder ganz fehlt, handelt es sich nicht sowohl um ursprïngliche, als vielmehr um abgeleitete Verhältnisse.

\section{Prosobranchiata.}

Bei den Prosobranchiern entwickelt sich die Mantelfalte an der Vorderseite des Eingeweidesackes und bedeckt hier eine geräumige Mantelhöhle. Sie erstreckt sich ausserdem meist noch als eine kragenförmige, wenig breite Ringfalte rings um die Basis des Eingeweidesackes herum.

Bei den symmetrischen Fissurelliden ist die Mantelhöhle kurz. Sie öffnet sich in ihrem hinteren und dorsalen Theil durch ein Loch in der Mantelfalte, welches dem auf der Spitze der Schale befindlichen Loche entspricht, nach aussen. Der Mantel bildet um das Loch herum eine kurze aus der Schalenöffnung hervortretende Ringfalte, die gefranst ist. Die Fransen sind Sitz eines feinern Tastgefühls. Das Athemwasser tritt 
durch die schlitzförmige Oeffnung unter dem freien Rande der Mantelfalte, über dem Nacken, in die Mantelhöhle ein und strömt durch das eben erwähnte Loch wieder nach aussen ab. Denselben Weg nehmen die Excremente, welche aus dem unmittelbar hinter dem Loche in der Mantelhöhle liegenden Rectum heraustreten. Bei Rimula ist das Loch in Schale und Mantel etwas nach vorne gerückt und liegt auf der Vorderseite der Schale zwischen Spitze und Schalenrand. Bei Emarginula ist die Mantelfalte vorne gespalten. Die diesen Mantelspalt umgebenden Ränder legen sich aber beim lebenden Thier so in Falten, dass sie einen röhrenförmigen Sipho bilden, der aus dem marginalen Schalenschlitz vorgestreckt wird. Parmophorus hat keine zweite Oeffnung der Mantelhöhle mehr. Der seitliche Mantelrand ist bei dieser Gattung stark verbreitert und vom Schalenrande her dorsalwärts auf die äussere Oberfläche der Schale zurückgeschlagen, so dass also der grösste Theil der Schale aussen von den zwei seitlichen Verbreiterungen der Schale bedeckt ist.

Bei Haliotis ist die Mantelhöhle durch die colossale Entwickelung der rechtsseitig gelegenen Colummellarmuskeln auf die linke Seite verschoben. Die Mantelfalte zeigt einen tiefen Schlitz oder Spalte, die vom freien Rande her bis gegen den Grund der Mantelhöhle reicht. Dieser Mantelschlitz liegt unter der für Haliotis charakteristischen Reihe von Schalenlöchern, durch welche das Athemwasser nach aussen abfliesst. Die Ränder des Mantelschlitzes legen sich in den Intervallen zwischen den aufeinander folgenden Schalenlöchern aneinander, weichen dagegen unter jedem Schalenloche zur Herstellung einer freien Communication der Mantelhöhle mit der Aussenwelt auseinander. Sie tragen 3 tentakelförmige Fortsätze, welche aus den Schalenlöchern frei nach aussen vorgestreckt werden. Der After liegt immer unter dem hintersten, offenen Schalenloch. Der den Körper umsäumende Mantelsaum weicht in zwei frei vorstehende, wenig breite Lamellen auseinander, so dass ein Falz zur Aufnahme des Schalenrandes gebildet wird.

Den Trochiden, Turbiniden, Neritiden und fast allen Monotocardiern fehlt eine zweite Mantelöffnung oder ein Mantelschlitz.

Bei den Docoglossa (Patella etc.) bildet die Mantelfalte einen Ringsaum um den Hach-kegelfürmigen Eingeweidesack herum. Dieser Mantel bedeckt rings den Rand des fast kreisrunden, breitsöhligen Fusses. Sie ist auch bei den Docoglossen vorn, wo sie Kopf und Nacken bedeckt, am breitesten, d. h. hier ist die von ihr bedeckte Mantelhöhle oder Mantelfurche am tiefsten.

Der Eingeweidesack der Monotocardier ist fast durchgängig vom übrigen Körper deutlich bruchsackartig abgeschnürt und spiralig aufgerollt. Die Mantelhöhle hat die typische Lage. Auf der linken Seite verlängert sich der freie Rand der Mantelfalte bei zahlreichen Monotocardiern derart, dass er eine mehr oder weniger weit (oft sehr weit) nach vorn vorragende Falte bildet, deren Ränder sich nach unten zur Bildung einer Röhre oder Halbröhre zusammenkrïmmen, die als Sipho bezeichnet wird. Durch den Sipho strömt das Athemwasser in die Mantelhöhle. Meist lässt sich schon an der Schale erkennen, ob ein Sipho vorhanden ist oder nicht, indem bei den meisten mit einem Sipho ausgestatteten Monotocardiern der Schalenrand an der Spindel einen Einschnitt besitzt oder sich hier zu dem sogenannten $\mathrm{K}$ anal oder $\mathrm{Schnabel}$ verlängert, in welchem der Sipho seinen Platz findet. Die Länge des Schalenkanals braucht übrigens nicht der Länge des Siphos zu entsprechen. 
Man hat sogar die Monotocardier nach dem Vorhandensein oder Fehlen eines Sipho in die beiden Gruppen der Siphoniata oder Siphonostomata und der Asiphoniata oder Holostomata eingetheilt, eine künstliche Classification, da bei unstreitig nahe verwandten Formen Siphonen vorkommen oder fehlen können.

Bei der Mehrzahl der Monotocardier ist die Schale äusserlich nicht vom Mantel bedeckt. Doch giebt es auch Abtheilungen, bei denen die Mantelränder sich auf die Aussenseite der Schale umschlagen und schliesslich so weit über die Schale nach dem Rücken zu emporwachsen, dass sie über der Schale verwachsen. Dann ist aus der äusseren Schale eine innere geworden.

Bei den Harpidae unter den Rhachiglossa ist der Mantel über den Spindelrand der Schale zurückgeschlagen. Bei deu Marginelliden bedeckt er einen grossen Theil der äusseren Oberfäche der Schale. Dasselbe gilt unter den Taenioglossa für Pirula, die meisten Cypraeiden und die Lamellariden. Speciell bei Lamellaria ist die Schale vollständig vom Mantel umwachsen. Auch bei Stilifer unter den Eulimiden ist die Schale äusserlich in geringerer oder grösserer Ausdehnung von einer Ausbreitung des Mantels bedeckt.

Der Mantehand kann gefranst oder gekerbt oder (Cypraeidae) mit warzenförmigen, tentakelförmigen oder verästelten Anhängen versehen sein.

\section{Pulmonata.}

Die Verhaitnisse des Eingeweidesackes und der Mantelfalte bieten, chenso wie die damit eng zusammenhängenden Schalenverhältnisse, bei den Pulmonaten grosses Interesse. Auf der einen Seite Formen, wie Helix, mit grossem, bruchsackartig entwickeltem, spiralig aufgerolltem Fingeweidesack und ansehnlicher, eine geräumige Mantelböllle bedeckender Mantelfalte - auf der andern Seite Formeu, wie Onchidium, ohne gesonderten Eingeweidesack, ohne deutliche Mantelfalte, ohne Schale: Schalenschnecken mit spiralig gewundener Schale (Gehäuse), in welcher (ler ganze Körper Platz finclen kann, schalenlose Nacktschnecken ohne Eingeweidesack. Zwischen beiden Extremen zahlreiche Uebergänge. Solche Uebergänge von Schalenschnecken zu Nacktschnecken finden sich sogar innerhalb verschiedener natürlicher Abtheilungen der Pulmonaten. Ich will einige charakteristische Typen herausgreifen.

Helix (Fig. 396 A, 455). Eingeweidesack gross, spiralig aufgerollt, von einer spiraligen Schale bedeckt, die geräumig genug ist, um den ganzen Körper mit Leichtigkeit beherbergen zu können. Die Mantelfalte bedeckt eine vorn am Eingeweidesack liegende Athemhöhle (Lungenhöhle). Thr freier, verdickter, drüsiger Rand verwächst - und das ist charakteristisch für die Pulmonaten - mit dem benachbarten dorsalen Integument des Nackens, bis auf eine rechts gelegene, offen bleibende Stelle, das A th $\mathrm{h}$ m loch, durch welches die Communication zwischen Athemhöhle und Aussenwelt hergestellt wird. (Bei den Pulmonaten mit linksgewundener Schale liegt das Athemloch links.) In unmittelbarer Nähe des Athemloches, mit demselben, öffnet sich der Enddarm und die Niere nach aussen.

Bei manchen Arten der Gattung Vitrin a vermag die Schale nicht das ganze zurückgezogene Thier in sich aufzunehmen. Die Mantelfalte überragt vorn die Schale und besitzt einen nach rückwärts auf die Schale zurückgeschlagenen Fortsatz, der zum Reinigen der Schale dient. 
Bei D a u de bardia (Helicophanta) (Fig. 396 B) ist der Eingeweidesack und mit ihm die Schale im Vergleich zum übrigen Körper sehr viel kleiner als bei Vitrina. Das Thier kann nicht in der Schale geborgen werden. Der Eingeweidesack beginnt sich zu verstreichen, gewissermaassen in die Rückenseite des Fusses aufgenommen $\mathrm{zu}$ werden. Er liegt woit hinten am Körper, das Athemloch befindet sich auf seiner rechten Seite.

Aehnliche Verhältnisse zeigt die Gattung Ho malon yx, deren ganz niedriger Eingeweidesack auf der Mitte des Rückens liegt. Das Athemloch liegt am rechten Mantelrande. Die ohrförmige flache Schale steckt nit ihrem Rande in der Mantelfalte. Daudebardia und Homalonyx haben schon ganz den Habitus von Nacktschnecken.

Bei Testacella (Fig. 438 u. 439) kann man kaum noch von einem Eingeweidesack sprechen. Das Einzige, was von ihm übrig geblieben ist, ist ein kleiner Mantel am Hinterende des Körpers auf der Rückenseite, welcher von einer ohrförmigen Schale bedeckt ist. Unter dem Mantel

$A$

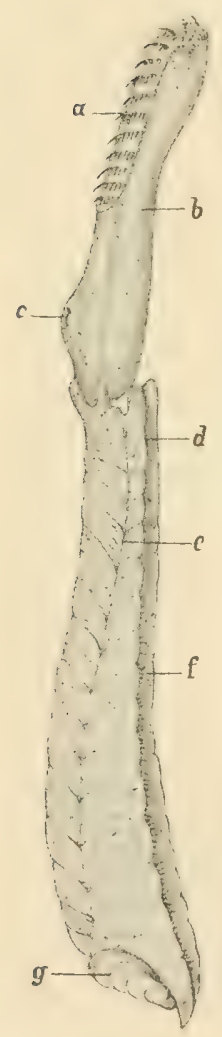

$B$

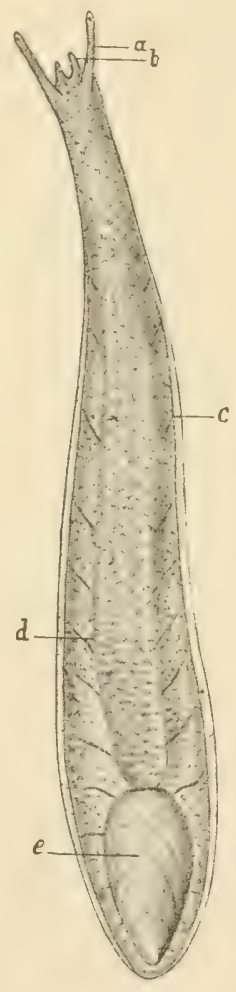
liegt eine reducirte Athemhöhle. Das Athemloch liegt hinten rechts unter dem Schalenrand. Die Eingeweide sind in die Rückenseite des Fusses verlagert.

Bei unsern gewöhnlichen Landschnecken Limax und Arion (Fig. 396 D) finden sich ähnliche Verhältnisse wie bei Testacella, nur liegt hier der an der Stelle des fehlenden Eingeweidesackes liegende Mantel (sogenannte Schild) vorn, hinter dem Kopfe. An seinem rechten Rande liegt das Athemloch. Bei Limax findet sich eine kleine, rudimentäre, rundliche, innere Schale, d. h. sie ist vollständig von einer Mantelfalte umhüllt oder ïberwachsen. Bei Arion wird diese Schale durch isolirte Kalkkörperchen vertreten.

Bei Onchidium und Vaginulus fehlt jede Spur eines Eingeweidesackes und - beim erwachsenen Thier - einer Schale. Der Eingeweidesack hat sich gewissermassen auf die ganze Rückenseite des Fusses ausgedehnt und verstrichen. Es fehlt ferner eine äusserlich erkennbare, vom übrigen Integument des Rückens sich ab-

Fig. 438. Testacella haliotidea, nach LAcaze-Duthiens. $\boldsymbol{A}$ Von der rechten Seite. $b$ Durch die Mundhöhle ausgestülpter, riesiger Pharynx, auf welchem die Radula $(a)$ zu Tage tritt, $c$ Mündung des Pharynx in den Oesophagus, $d$ Lage der Geschlechtsöffnung, $e$ latero-dorsale Körperfurche, $f$ latero-ventrale Körperfurche, $g$ Mantel, Rudiment des Eingeweidesackes. $\boldsymbol{B}$ Von der Rückenseite $a, b$ Die beiden Tentakelpaare, $c$ die lateroventrale Furche, $d$ die latero-dorsale Furche, $e$ Schale. 
hebende Mantelfalte. Immerhin trennt eine Längsfurche den Rückentheil des Körpers vom Fusse.

Das Athemloch mit dem After liegt am Hinterende des Körpers in der Medianlinie.

Fig. 439. Testacella haliotidea, hinterer Körpertheil von der rechten Seite, nach LACAzEDuthiers. Die Schale ist entfernt, man sieht den entblössten, rudimentären Eingewcidesack. $a$ Latero-dorsale Furche, $b$ lateroventrale Furche, $c$ Ende des an die Schale sich anheftenden Schalenmuskels, e Mantelrand des Eingeweidesackes, $g$ Athemloch.

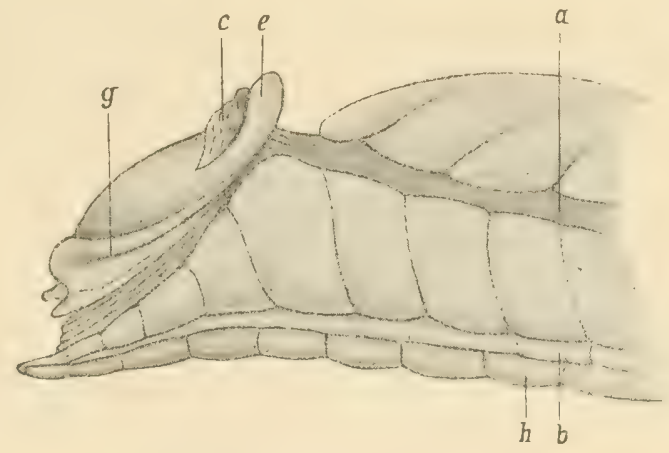

Bei der Gattung Physa (Fig. 395) setzt sich.der um den Rand der Schale herumgebogene Mantelrand in lappige oder fingerförmige Fortsätze fort, die sich der Aussenseite der Schale anlegen können. Bei A m phijpeplea (Fig. 394) ist der Mantel sehr stark verbreitert und bedeckt, wenn auf die Schale zurückgeschlagen, einen grossen Theil derselben bis auf eine ovale Stelle auf der Rückenseite der letzten Windung.

Das Rückenintegument der $\mathrm{On}$ chidien bildet Warzen oder Höcker, oder gar (Peronia) verzweigte Anhänge. Diese Bildungen sind reich vascularisirt und stehen im Dienste der Respiration. Bei Peronia finden sich ausserdem auf dem Rücken augentragende Höcker.

Das Rückenintegument setzt sich rings am Körper über den Fuss hinaus fort und bildet so, ähnlich wie bei Chiton, eine periphere Zone, welche ventralwärts vom Fusse durch eine diesen umkreisende Furche gesondert ist. Der Rand dieser Zone, d. h. der seitliche Körperrand ist bei Oncidiella gezähnelt oder gefranst.

\section{Opisthobranchiata.}

Die typische äussere Organisation der Schnecken erleidet in dieser formenreichen Abtheilung noch mannigfaltigere und tiefergreifende Modificationen als bei den Pulmonaten. Auf der einen Seite Gasteropoden mit Liopf, Fuss, Eingeweidesack, Schale, Mantel und Kieme - auf der andern Seite Formen ohne Fuss, ohme Schale, ohne Mantel, ohne Kiemen, die aber trotzdem Schnecken und zwar Opisthobranchiaten sind. Bei der einen Hauptabtheilung der Opisthobranchier, den Palliata oder 'Tectibranchiern, erhält sich die Mantelfalte auf der rechten Körperseite und beleckt hier - wenigstens theilweise - eine typische Molluskenkieme (Ctenidium), bei den anderen Abtheilungen tehlt mit dieser Kieme die Mantelfalte. Wenn wir hier von der Mantelfalte sprechen, so vernachlässigen wir dabei jene den Körper rings um die Ansatzstelle des Fusses und des Liopfes umziehende Falte oder Saum des Rüickenintegumentes, welche, bei deu meisten Opisthobranchiern in verschiedenem Grade entwickelt, eine deutliche Sonderung des Fusses und liopfes vom übrigen liörper, vom Rücken, berlingt. Wir verstehen darunter nur eine etwas breitere Falte, welche eine Mantelhöhle bedeckt, in der eine typische Molluskenkieme liegt. Der Mantelrand bildet bei den Opistho- 
branchiern nie einen deutlichen Sipho. Eine Andeutung eines solchen kommt bei Ringiculiden vor.

Wir wollen die Tectibranchier und die Nudibranchier betrachten.

\section{A) Tectibranchiata.}

a) Reptantia.

Wir finden in dieser Abtheilung zunächst noch Formen mit deutlichem, bruchsackartig sich abhebendem Eingeweidesack, dessen Integument eine gewundene Schale absondert, in die sich der ganze Körper des Thieres zurückziehen kann. Am andern Ende stehen Formen, bei denen der abgeflachte Eingeweidesack sich auf der ganzen Rückenseite des Fusses ausgebreitet hat, mit rudimentärer, innerer Schale.

Opisthobranchier, die zu der ersterwähnten Kategorie gehören, finden wir in der Abtheilung der Cephalaspidea, z. B. die Actaeonidae, Tornatinidae, einige Scaphandridae (Atys, Cylichna, Amphisphyra), einige Bullidae (Bulla), die Ringiculidae.

Bei Scaphander unter den Scaphandriden, Acera unter den Bullidae ist der Körper nicht oder nicht vollständig in die Schale zurückziehbar.

Bei den bis jetzt erwähnten Cephalaspiden ist die Schale eine ä ussere.

Bei Gasteropteron ist der Mantel rudimentär, hinten mit einem fadenförmigen Anhang versehen. Er bedeckt eine innere, zarte, häutige Schale, in die der Körper nicht zurückgezogen werden kann. Dasselbe
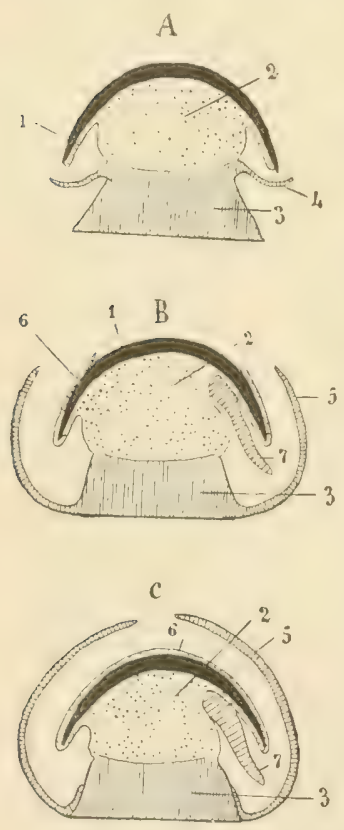
gilt für Philine und Doridium, wo ebenfalls eine dünne und zarte innere Schale vorhanden ist, welche nur einen kleinen Theil der Eingeweide bedeckt und bei Doridium sich hinten in zwei Lappen verlängert, von welchen der linksseitige sich in einen fadenförmigen Fortsatz auszieht.

Bei den An aspidea ist ein im Vergleich zur Grösse des Thieres kleiner, aber deutlich sich abhebender Eingeweidesack vorhanden, welcher von einer gewöhnlich zarten und dünnen, unansehnlichen Schale bedeckt ist. Der Mantel und die Schale schützen die Kieme oft nur unvollständig. Bei Aplysia ist die Schale eine innere, d. h. ganz vom Mantel umwachsen, bei Dolabella ist diese Umwachsung nicht ganz vollständig, indem der Mantel auf der Rückenseite der Schale in der Mitte eine kreisrunde Unterbrechung oder Oeffnung besitzt, an der die Schale frei zu Tage tritt. Der Mantel bildet bei Dolabella hinten einen kleinen Analsipho.

Notarchus hat eine mikroskopisch kleine Schale. Bei gewissen Arten dieser Gattung bildet das Integument Warzen oder zart verzweigte Anhänge.

Fig. 440. Schematische Querschnitte durch Gasteropoden, zur Demonstration der Verhältnisse von Schale (schwarz 1), Eingeweidesack (punktirt 2), Mantel und Fuss (schraftirt 3). $\boldsymbol{A}$ Prosobranchiat mit äusserer Schale und Epipodium (4). $\boldsymbol{B}$ Tectibranchiat mit auf die Aussenfläche der Schale zurückgeschlagenem Schalenlappen (6) des Mantels. Die Schale dorsalwärts noch frei, unbedeckt. 5 Parapodien, 7 Ctenidium. $C$ Tectibranchiat mit innerer Schale, d. h. der Schalenlappen des Mantels hat die Schale aussen ganz überwachsen. 
Bei den Oxynoiden ist die Schale nur theilweise vom Mantel bedeckt und ebeufalls lange nicht gross genug, um den Körper zu beherbergen.

Unter den Notaspidea besitzen die Umbrellen einen flachen Eingeweidesack, der dem mächtigen Fusse so aufsitzt wie eine kleine, flache Mütze einem grossen Kopfe. Der Eingeweidesack ist von einer Mantelfalte umgeben, welche auf der rechten Seite die Kieme bedeckt. Das Integument des Eingeweidesackes und des Mantels ist von einer flachen, scheibenförmigen Schale bedeckt.

Bei Pleurobranchaea ist der Eingeweidesack im Vergleich zum Fuss grösser. Während sein rechter und linker Rand als kurze Mantelfalte vorspringt, verstreicht diese Falte vorn und hinten vollständig, so dass sich hier der flache Eingeweidesack nicht vom übrigen Körper absetzt. Bei Pleurobranchus breitet sich das Integument des flachen Eingeweidesackes zu einer grossen fleischigen Scheibe aus, welche allseitig über den grossen breitsohligen Fuss hervorragt, so dass der Rand (Mantelfalte) von dem Fuss durch eine tiefe Furche rings um den Körper herum getrennt ist, in welcher auf der rechten Körperseite die grosse Kieme liegt. Während Pleurobranchus noch eine kleine, häutige, dünne, flache innere Schale besitzt, kann diese bei verwandten Formen fehlen. Häufig wird das Integument des Rückens durch Einlagerung von Kalkkörperchen verstïrkt.

b) $\mathrm{Natantia.}$

Pteropoda thecosomata.

Die Limacinidae besitzen einen wohl entwickelten, linksgew undenen Eingeweidesack mit entsprechender Schale, die durch ein echtes Operculum verschlossen werden kann. Die Mantelfalte bedeckt eine vorn am Eingeweidesack gelegene Mantelhöhle. After rechts. Thier in die Schale zurückziehbar. Bei den Cavoliniidae sind der Eingeweidesack und die Schale bilateral-symmetrisch, nicht gewunden. Der Körper kann ganz in der Schale geborgen werden. Die Mantelhöhle liegt hier an der hintern (gewöhnlich als untere bezeichneten) Seite des Eingeweidesackes. Die symmetrische Cymbuliidenschale entspricht nicht der Schale der übrigen Thecosomata, sie ist eine knorpelige "Pseudoconcha" und ist vom Körperepithel überzogen. Auch bei den Cymbuliidae liegt die Mantelhöble hinten. Die verschiedene Lage der Mantelhöhle bei den Thecosomata wird später noch besprochen werden.

Der Mantel der Gattung Cavolinia zeigt Besonderheiten, welche am besten im Anschluss an die Schilderung der Schale besprochen werden. An dieser letzteren unterscheidet man zwei Flächen, eine wenig gewölbte vordere (gewöhnlich als obere bezeichnete) und eine gewölbte hintere. Die vordere Schalenfläche überragt vorn und unten die hintere um ein Drittheil ihrer Länge. Die Schale hat drei schlitzförmige Oeffnungen, eine vordere und untere, durch welche die Fussflossen vorgestreckt werden können, und zwei seitliche, die sich weit nach oben erstrecken, so dass die ganze Schale fast zweiklappig erscheint. Der Mantel schlägt sich an diesen seitlichen Schalenspalten, durch welche das Athemwasser in die Mantelhöhle eintritt, auf die Aussenfläche der Schale um, diese zum grössten Theil bedeckend, und setzt sich am obern Winkel dieser Spalten noch in zwei frei nach aussen vorragende Fortsätze fort.

\section{Pteropoda gymnosomata.}

Der gestreckte, äusserlich symmetrische Körper ist nackt, ohne Mantel, der Fuss findet sich in reducirtem Zustande auf der Bauchseite des vordersten Körpertheiles. 
Ascoglossa und Nudibranchiata.

Eine Schale kommt bei den erwachsenen Ascoglossen und Nudibranchiaten mit allenniger Ausnahme der Steganobranchien niemals vor, ebensowenig ein vom übrigen Körper sich bruchsackartig abhebender Eingeweidesack. Dieser ist vielmehr auf die ganze Rückenseite des Förpers vertheilt, ausgebreitet. Das Rückenintegument bildet wohl noch eine Ringfalte (Mantelfalte), welche vom Fusse durch eine bald tiefere, bald seichtere Furche oder Rinne abgesetzt ist, aber in dieser Rinne finden sich mit Ausnahme der Phyllidiidae keine Kiemen. Wenn die Furche zwischen Rücken und Fuss fast vollständig verstreicht, so können die Nacktschnecken einen völlig planarienähnlichen Habitus erlangen.

Phyllidiidae. Die Mantelfalte ist deutlich und trägt an ihrer Unterseite rechts und links eine Reihe von Kiemenblättern. Hierdurch erinnern diese Thiere an die Patellen und Chitonen.

Die Gattung Dermatobranchus gehört der Organisation nach hieher, besitzt jedoch keine Kiemen.

Dorididae. Das den Körper schildförmig bedeckende, vom Fuss und vom Kopf meist deutlich abgesetzte Rückenintegument (Notaeum) enthält zahlreiche Kalkkörıer, die demselben eine festere Consistenz verleihen. Vorn trägt es zwei, von den Kopftentakeln wohl zu unterscheidende, fühlerartige Gebilde, die Rhinophoren, die meist in besondere Scheiden oder Gruben zurückgezogen werden kömnen. In seiner Mittellinie; gewöhnlich hinter der Körpermitte liegt der After, von einem zierlichen Kranze gefiederter Kiemen umstellt. Das Notaeum ist häufig mit Warzen oder Höckern besetzt und kann bei einzelnen Gattungen am Rande verschieden gestaltete Fortsätze tragen.

Clad ohepatica. Analkiemen fehlen. Das Rückenintegument trägt verschieden gestaltete, conische, fingerförmige, lappenförmige, keulenförmige oder verästelte Anhänge in verschiedener Anordnung. Diese Anhänge sind meist auffallend gefürbt und gezeichnet. An ihrer Spitze befindet sich meistens ein Sack mit Nesselkapseln, und in ihr Inneres dringen vom Körper her blindsackartige Fortsätze des Darmkanals (Verästelungen der Verdaumgsdrüse, hinein. Diese Rückenanhänge, die wie der übrige Körper bewimpert sind, haben wenigstens zum Theil eine respiratorische Function. Sie fallen bei manchen Formen leicht ab und werden nachher wieder regenerirt (Fig. 402, p. 579).

Haben schon viele Cladohepatica eine gewisse äussere Aehnlichkeit mit Planarien, deren Rücken mit Zotten besetzt ist (Thysanozoon), so steigert sich die Planarienähnlichkeit noch mehr bei manchen

Ascoglossa. Bei diesen fehlen Analkiemen und fehlen meistens auch Rückenanhänge. Der ganze Körper ist nackt, bewimpert. Der Rücken vom Kopfe undeutlich abgesetzt.

Am meisten ist die typische äussere Molluskenorganisation unter den Opisthobranchiern verwischt bei dem Nudibranchiatengenus.

Phyllirho ë. Der Körper ist hier nackt, seitlich zusammengedrückt, mit scharfem dorsalen und ventralen Rande. Fuss und Kiemen fehlen (Fig. 403, p. 579). 
D) Scaphopoda.

Vergl. Uebersicht der äusseren Organisation p. 599.

E) Lamellibranchiata.

Wir müssen hier als ursprüngliche Verhältnisse folgende hetrachten. Vom Rumpfe hängt jederseits eine grosse, blattartige Mantelfalte herunter, welche die gleiche Form hat, wie die von ihr gebildete Schalenklappe. Diese beiden Mantelfalten überragen den Rumpf nach vorn, nach unten und nach hinten und umgrenzen eine Mantelhöhle, die überall, mit Ausnahme am Rücken, durch die zwischen den freien Mantelrändern liegende Mantelspalte nach aussen mündet. Durch diese einzige grosse Mantelspalte kann von allen Seiten her Nahrung und Wasser in die Mantelhöhle eindringen, wird der Fuss vorgestreckt, werden die Excremente, Excrete, Geschlechtsproducte entleert, wird das Athemwasser ausgestossen. Einen solchen Mantel nennt man vollständig offen, seine Räurler sind vollständig frei, nirgends verwachsen. Der Mantelrand ist einfach, ohne Duplicaturen, ohme Papillen, ohne Tentakel, ohne Augen.

So finden wir den Mantel bei Nucula unter den Protobranchiern.

Nun treten bei den meisten Lamellibranchiern am Mantelrand besondere Differenzirungen auf: Falten, Verdickungen, Warzen, Papillen, Tentakel, Drüsen, Augen u. s. w. und zwar bei Formen mit offenem, wie bei solchen mit partiell geschlossenem Mantel.

Der Mantel kann sich partiell schliessen, indem der freie Rand der rechten Mantelfalte mit dem freien Rand der linken Mantelfalte an einer oder an mehreren Stellen verwächst.

Wir wollen den Mantel zuerst von diesem Gesichtspunkte aus betrachten.

A) Einen vollständig offenen Mantel, eine einzige grosse Mantelspalte, d. h. vollständig getremnte Mantelränder finden wir:

a) unter den Protobranchiern bei Nucula,

b) unter den Filibranchiern bei den Anomiidae, Arcidae, Trigoniidae und einigen Mytilidae ( $\mathrm{P}$ inna),

c) bei allen Pseudolamellibranchiern excl. M e l e a g r in a,

d) unter den Eulamellibranchiern einzig und allein bei einzelnen Crassatellaarten.

B) Die beiderseitigen Mantelränder verwachsen an einer Stelle.

In diesem Falle liegt die Verwachsungsstelle fast immer hinten und oben, sie grenzt von dem ursprünglich einheitlichen Mantelschlitz, der sich in grosser Ausdehnung von vorn und oben dem ganzen Mantelrand entlang bis hinten und oben erhält, eine kleinere hinten und oben liegende Oeffnung ab, an welcher die beiden Mantelränder wieder auseinanderweichen: die in der Höhe des Afters gelegene Ausströmungs-oder Analöffnung des Mantels. Der Mantelrand dieser Oeffnung kann nach hinten mehr oder weniger weit zu einem contractilen Analsipho auswachsen, der zwischen den Schalenklappen vorgestreckt werden kann.

Meist legt sich eine kurze Strecke unter der Analöffnung der Mantelrand der einen Seite an einer Stelle an denjenigen der gegenüberliegenden 
Seite an, ohne jedoch mit ihm zu verschmelzen. Ueber dieser Stelle, zwischen ihr und dem Analsipho, weichen die beiden Mantelränder zur Bildung einer Einströmungs- oder Branchialöffnung auseinander. Der Mantelrand dieser Oeffnung kann ebenfalls nach hinten zu einem Branchialsipho auswachsen, der aber dann seiner ganzen Länge nach an der Unterseite einen Schlitz hat, welcher sich in den grossen Mantelschlitz fortsetzt.

Der Branchialsipho ist dann einem Blatt Papier vergleichbar, das man zur Bildung einer Röhre zusammenkrümmt, ohne die beiden sich berührenden Ränder zu verkleben. Einen solchen Analsipho besitzt z. B. die Gattung Malletia unter den Protobranchiern.

Eine von dem grossen Mantelschlitz durch eine Verwachsungsstelle getrennte Analöffnung besitzt der Mantel folgender Lamellibranchier:

a) Protobranchia. Malletia,

b) Filibranchia. Die meisten Mytiliden,

c) Pseudolamellibranchia. Aviculidae, Gattung Meleagrina,

d) unter den Eulamellibranchiern die Carditidae (Venericardia Cardita Milneria), die Astartidae, die meisten Crassatellidae, unter den Cyrenidae das Genus Pisidium, unter den Unionidae die Unioninae (Unio, Anodonta), unter den Lucinacea Cryptodon Moseleyi.

Auch bei Solenomya unter den Protobranchiern sind die beiderseitigen Mantelränder nur an einer Stelle verwachsen, nümlich in grosser Ausdehnung in der ganzen hinteren Hälfte des ventralen Mantelrandes. Dadurch ist der ursprünglich einheitliche Mantelschlitz in zwei getheilt, einen vorderen, durch welchen der Fuss vorgestreckt wird, und einen hinteren, der die Ein- und Ausströmungsöffnung, d. h. die Anal- und Branchialöffnung zugleich darstellt. Unter sämmtlichen Muscheln findet sich dieses Verhalten nur bei Solenomya.

C) Die beiderseitigen Mantelränder verwachsen an $\mathrm{zwei}$ Stellen; der Mantel hat drei Oeffnungen.

Dieses Verhalten kommt dadurch zu Stande, dass sich auch die Respirationsöffumng vollständig algrenzt, indem zwischen ihr und dem ïbrig bleibenden srossen vorderen Mantelschlitz die gegenüberliegenden Ränder der Mantelfalten mit einander verwachsen. Die Anal- und Respirationsöffnungen künnen sitzend sein oder zu kürzeren oder längeren Anal- und Respirationssiphonen auswachsen. Der grosse vordere und untere Mantelschlitz dient zum Austritt des Fusses und wird als Fussschlitz bezeichnet.

Hieher a) Protobranchia. Yoldia, Leda.

b) Die meisten Eulamellibranchier, nämlich die meisten Luciniden, die meisten Cyrenidae, unter den Unionidae die Mutelinae, ferner die Donacidae, Psammobiidae, Tellinidae, Scrobiculariidae, unter den Veneracea die Veneridae, ferner die Cardiidae, die Mactridae, Mesodesmatidae, die Solenidae excl. Solen und Lutraria.

c) Alle Septibranchia (Poromyia, Cuspidaria).

Bei den hier erwähnten Formen ist der Mantel noch weit offen, d. h. die Verwachsungsstellen sind klein, localisirt. Nun können aber die Verwachsumgsstellen sich auf grössere Strecken des Mantelrandes ausdehnen. So liegen bei den Chamacea, ganz besonders aber bei 
den Tridacnidae unter den Eulamellibranchiern die drei Mantelöffnungen in grösseren Abständen von einander, d. h. sie sind durch längere Verwachsungsstrecken des Mantelrandes von einander getrennt.
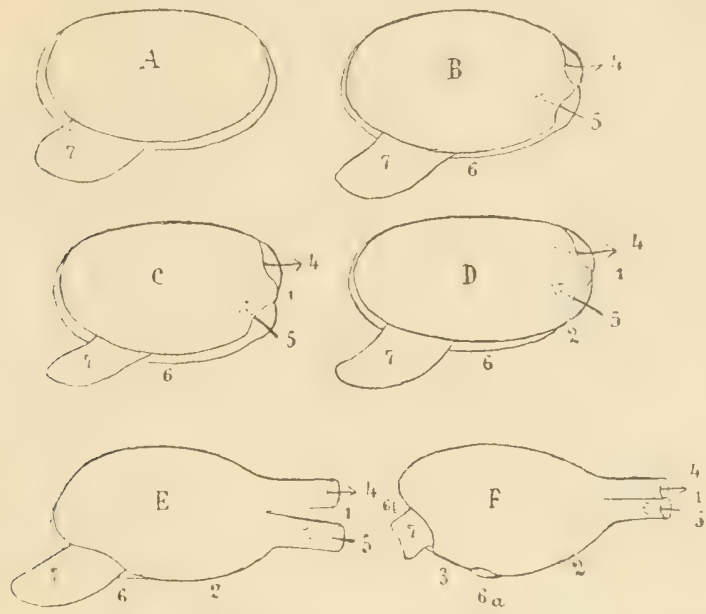

Fig. 441. 6 Schemata zur Darstellung der verschiedenen Formen der Mantelverwachsung und Siphonenbildung bei Lamellibranchiern. $7=$ Fuss, aus der Mantelspalte nach vorne vorgestreckt. $\boldsymbol{A}$ Mantel ganz offen. $\boldsymbol{B}$ Mantel ganz offen, seine Ränder legen sich aber af zwei Stellen aneinander, so dass unvollständig gesonderte Anal- und Respirationsöffnungen zu Stande kommen. $\boldsymbol{C}$ Mantelränder an einer Stelle (1) verwachsen, Analöffnung, Ausströmungsöfinung des Mantels (4) gesondert. $\boldsymbol{D}$ Mantelränder an zwei Stellen (1, 2) verwachsen. Auch die Branchial- oder Einströmungsöffnung (5) gesondert. Mantel im ganzen mit 3 Oeffnungen. $\boldsymbol{E}$ Mantel geschlossen durch stärkere Ausdehnung der Verwachsungsstelle 2, es bleiben 3 beschränkte Oeffnungen: Analöffnung, Branchiฉlöffinung und Fussöffnung. Die erstern beiden zu gesonderten Siphonen verlängert. $\boldsymbol{F}$ Es tritt eine dritte Verwachsungsstelle (3) auf. Mantel mit 4 Oeffnungen (4, 5, 6a, 6b), die vorderste (6b) zum Durchtritt des Fusses. Siphonen verschmolzen.

Bei einigen Gruppen von Lamellibranchiern bleibt die Verwachsungsstelle zwischen Anal- und Athemöffnung resp. Sipho kurz, d. b. die beiden Oeffnungen liegen direct untereinander, dafür aber verwächst der Mantelrand vor der Athemöffnung in grosser Ausdehnung, so dass die Fussspalte sich schliesslich auf ein kleines vorderes Loch reducirt. Man nennt dann den Mantel geschlossen.

Hieher

Eulamellibranchia. Modiolarca, Dreissensia. Petricola, sämmtliche Phol adida e (Pholas, Pholadidea, Jouannelia [das Fussloch soll bei alten Thieren ganz zuwachsen], Xylophaga, Martesia), die Teredin id ae, unter den Pandoriden Pandora, ferner die Verticordiidae und Lyonsiidae (Anatinacea).

D) Es giebt eine Reihe von Lamellibranchiern mit geschlossenem Nantel, bei denen ausser den :̈ Oeffnungen der vorhergehenden Gruppe noch eine 4. Oeffnung vorkommt, d. h. bei welchen der Mantel 3 Ver wa chs ungstellen aufweist. Die 4. Mantelöffumng ist immer klein und liegt zwischen der Fussöffnung und der Branchialöfthung und entspricht wahrscheinlich einer rudimentären Oeffuung für den Byssus. 
Eulamellibranchiata. Unter den Solenidae Solen und Lutraria. Unter den Pandoriden Myochama. Ferner Glycimeris. Unter den Anatinacea die Gattung Thracia; die Pholadomyidae und die Clavagellidae (Clavagella und Brechites [Aspergillum]). Schliesslich Lyonsia norvegica.

Die Analöffnung ist häufig, die Athemöffinung fast immer gefranzt, oder in verschiedener Weise von Warzen, Papillen, Tentakeln umstellt, und zwar gleichviel, ob diese Oeffinungen sitzend sind oder ob sie sich am Ende kürzerer oder längerer Siphonen befinden.

Ueber die Siphonen sei noch Folgendes mitgetheilt. Sie sind contractil und ausdehnbar. Durch besondere Muskeln könneu sie entwedler ganz oder theilweise in die Schale zurückgezogen werden. Diese Muskeln setzen sich hinten rechts und links an die Innenfläche der Schalenklappe an. Dadurch entsteht die Mantelbucht, von welcher später die Rede sein wird.

Die Länge der Siphonen ist sehr verschieden. Durch besonders lange Siphonen zeichnen sich aus die Mactridae, Donacidae, Psammobiidae, Tellinidae, Scrobiculariidae, manche Veneracea und Cardiidae, die Mesodesmatidae, Lutraria, die Pholadidae, Teredinidae, Anatinidae und Clavagellidae.

Die Siphonen können in ihrer ganzen Länge getrennt (oft divergirend) sein. Beispiel Galatea unter den Cyrenidae, die Donacidae, Psammoliiidae, Tellinidae, Scrobicularidae (Fig. 441 a), Mesodesmatidae, Pharus etc. Bei andern sind sie ihrer ganzen Länge nach verwachsen und sehen aus wie die beiden Läufe einer Doppelflinte. Sie können sogar äusserlich den Eindruck einer einheitlichen Röhre machen, die aber immer im Innern durch eine longitudinale Scheidewand in einen obern (analen) und einen untern (branchialen) Kanal zerfällt. Der gemeinsame Sipho kann hie und da, besonders bei Formen, bei denen er nicht in die Schale zurückgezogen werden kann, durch eine besondere Epidermisscheide geschützt sein. In ihrer ganzen Länge vereinigte Siphonen besitzen z. B. die Mactridae, einige Veneracea, Lutraria, Solenocurtus, Solen, die Pholadiden, viele Anatinidae, die Clavagellidae.

Hie und.da können die Siphonen eine Strecke weit (an ihrer Basis) vereinigt sein, gegen das Ende sich aber trennen und sogar divergiren, z. B. Petricola unter den Veneraceen, Teredo u. s. w.

Die beiden Siphonen sind häufig ungleich lang. Bei Modioloria (Mytilidae) ist sogar nur der eine, nämlich der anale ausgebildet, während die Branchialöffnung noch nicht von der grossen Mantelspalte getrennt ist. Im Gegensatz hiezu ist der Branchialsipho bei Dreissensia und Scrobicularia viel länger als der Analsipho.

In den .Siphonen können Klappen vorkommen, häufiger im Anal-, seltener im Branchialsipho.

Bedeutung der Ausbildung der Anal- und Branchialöffung, des Anal- und Branchialsipho.

Die meisten Muscheln sind Schlammthiere. Sie stecken mit dem Vorderende nach unten im Schlamm, in welchem sie sich vermittelst des zwischen den Schalenklappen nach vorn und unten vorgestreckten Fusses hewegen. Das zum Baden der Kiemen, zum Zweeke der Athmung, nöthige 
Athemwasser kann nur durch die Mantelspalte des hinteren, frei ins Wasser vorragenden Endes des Thieres in die Mantelhöhle aufgenommen und wieder nach aussen abgegeben werden. An dieser Stelle müssen auch die aus dem ganz naheliegenden After austretenden Fäcalmassen aus dem Mantelraume nach aussen entleert werden. Da eine beständige, geregelte Zu- und Abfuhr von Wasser zum Zwecke der Respiration, sowie zum Zwecke der Zuführung von im Wasser suspendirten Nahrungspartikelchen zum Munde nöthig ist, so verstehen wir die Ausbildung localisirter Stellen für das Ein- und Ausströmen von Wasser. Als Stelle des Ausströmens ist die Stelle des Mantelschlitzes die günstigste, welche unmittelbar hinter der Afteröffinung liegt.

Die Ausbildung von Siphonen steht damit in Zusammenhang, dass viele Muscheln tiefer im Schlamm, im Sande, in Holz, ja in verschiedenem Gestein versteckt leben. Vermittelst der Siphonen stehen sie dann mit der Oberfläche ihres Versteckes und damit mit dem Wasser in Verbindung, so dass, wenn das Thier ungestört bleibt, ein beständiger Strom durch den Branchialsipho in den Mantelraum ein- und dann wieder durch den Analsipho austritt.

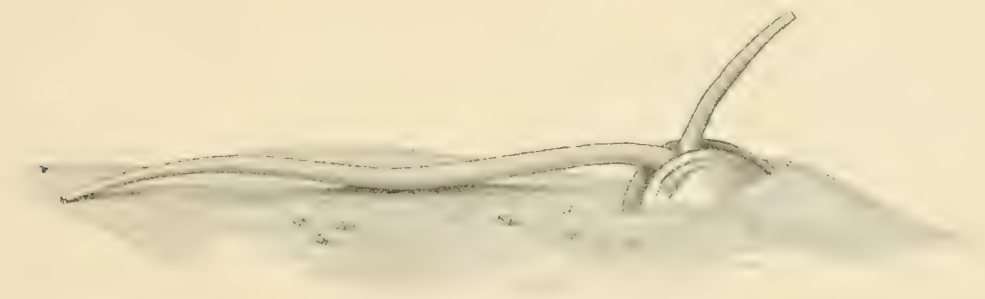

Fig. 441 a. Scrobicularia piperata, im Schlamm eingegraben. Der Einströmungssipho nimmt Schlamm als Nahrung ein, der Analsipho steht in die Höhe. Nach MEYer und Mönius.

Wo die beiderseitigen Mantelränder in grosser Ausdehnung verwachsen sind (geschlossener Mantel), sind die Siphonen immer wohl entwickelt. Ein solcher Verschluss des Mantels findet sich hauptsächlich bei Muscheln, welche in Holz, Lehm, Gestein u. s. w. bohren und bei denen der Fuss im erwachsenen Zustande schwach entwickelt oder ganz rudimentär ist. Es zieht die Verkümmerung des Fusses hier die Verengerung der ursprünglich zu seinem Durchtritt dienenden Mantelspalte (Fussschlitz) nach sich.

Einen weit offenen Mantel mit nicht oder wenig ausgebildeter Analund Branchialöffnung finden wir bei Muscheln, die weder im Schlamm, noch in Holz oder Gestein leben, die vielmehr, allseitig vom Wasser bespült, festsitzend oder frei dem Boden der Gewässer aufliegen. Hier kann das Wasser von allen Seiten durch die meist offene Mantelspalte hindurch zwischen Mantelhöhle und Aussenwelt circuliren. Warzen, Papillen, Tentakel, Träger von Sinnesorganen finden wir hier der ganzen Länge des freien Mantelrandes entlang, während sie bei Schlamm- und Bohrmuscheln vorzugsweise am Rande der Branchial- und Analöffnung angehäuft sind.

Beschaffenheit des Mantelrandes.

Der freie Mantelrand der Muscheln weicht sehr häufig in eine verschiedene Zahl von Falten auseinander, die auf Querschnitten wie finger- 
förmige Fortsätze desselben erscheinen. Die äusserste Falte liegt immer der Schale dicht an. Der Mantelrand kann mit einer oder mehreren Reihen von Warzen, Papillen, Tentakeln besetzt sein. In ihm finden sich häufig ein- oder mehrzellige Drüsen, Schleimdrüsen und solche, die als Giftdrüsen (Schutzdrüsen des Mantelrandes) betrachtet worden sind. Weit verbreitet sind Tastzellen am Mantelrand. Selten kommen hier Augen zur Entwickelung. (Vergleiche den Abschnitt Sinnesorgane.)

Bei den Pectiniden, Spondyliden und Limiden bildet die innere Mantelfalte einen ziemlich breiten Saum, der vom Mantelrande her bei geöffneter Schale gegen die Medianebene des Körpers zu vorragt (Fig. 407, p. 583). Die freien gegenüberliegenden Ränder dieser von rechts und links rorspringenden Falte (Klappe, Vorhang) können sich bei geöffneter Schale berïhren, so dass sie den Mantelraum selbst bei geüffneter Schale abschliessen, mit Ausnahme von vorn und hinten.

\section{F) Cephalopoda.}

$\mathrm{H}$ a u t.

Die Haut der Cephalopoden besteht aus einem äusseren Cylinderepithel und einer dicken darunter liegenden bindegewebigen Cutis. In dieser Cutis unweit unter dem Epithel und über einer das Licht reflectirenden, häufig silberglänzenden Schicht bindegewebiger Platten finden sich grosse Farbzellen oder Chromatophoren, welche durch abwechselnde Contractionen und Expansionen den berühmten $\mathrm{F}$ a $\mathrm{r}$ b e nw e c h s el hervorrufen.

Diese Chromatophoren sind einzellig und enthalten bald gelben, bald braunen, schwarzen, violetten oder carminrothen Farbstoff, und zwar sowohl in gelöstem, als in an kleine Körnchen gebundenem Zustande. Sie liegen in einer einfachen oder in einer doppelten Schicht. Im letzteren Falle hat das Pigment der Chromatophoren in den beiden Schichten eine verschiedene Farbe. An jede Chromatophore setzen sich radiü in das nmgebende Bindegewelse ausstrahlende Faserbündel an und zwar an ihren der Hautoberfläche parallel liegenden Aequator. Contrahiren sich die von einer besonderen, vielleicht elastischen Membran umgebenen Chromatophoren, so werden sie fast kugelig. Die Farbkürperchen sind dann dicht zusammengedrängt. Dehnen sich die Chromatophoren aus, so geschieht dies in der Richtung des Aequators, so dass der Abstand von $\mathrm{Pol} z u \mathrm{Pol}$ ein sehr geringer wird, das heisst die Chromatophoren sehr flach werden. Dabei nimmt jede Chromatophore sehr häufig eine zierlich verästelte Gestalt an, und es vertheilen sich die Farbkörperchen auf eine grosse Fläche. Früher glaubte man, dass die Ausdehnung der Chromatophoren durch Contraction der als musculös gedeuteten radiären Faserbündel erfolge. Nach neueren Untersuchungen wären aber diese Faserbündel bindegewebiger Natur. Das Farhenspiel, welches von grossem biologischen und physiologischen Interesse ist und zum Theil unter dem Einflusse des Willens der Thiere steht, kommt durch abwechselndes Contrahiren und Ausdehnen verschieden gefärbter Chromatophoren zu Stande.

\section{Mantel, Eingeweidesack.}

Das Wichtigste über den Eingeweidesack und Mantel ist schon oben, p. 602-605, gesagt worden.

Bei Nautilus heftet sich der Körper an der Innenseite der Schale der Wohnkammer rechts und links durch einen kräftigen Muskel an, der 
auf der Schale einen schwachen Eindruck zurücklassen kann. Zwischen diesen beiden seitlichen Muskelansätzen ist das Integument des Eingeweidesackes in einer schmalen ringförmigen Zone ebenfalls mit der Innenfläche der Wohnkammerschale verwachsen (Verwachsungsband), so dass das im gekammerten Gehäuse befindliche Gas nicht nach aussen entweichen kann. Während Integument und Mantel unter dem Verwachsungsrand (d. h. gegen die freie Oeffnung der Wohnkammer zu) derb, fleischig, musculös sind, ist das Integument des über dem Verwachsungsband liegenden Theiles des Eingeweidesackes (welcher sich an die letzte Scheidewand anlegt) zart und weich. Der Sipho, der vom dorsalen Ende des Eingeweidesackes ausgeht und sämmtliche Scheidewände durchbohrt, ist membranös, hohl, mit Blut erfüllt. Seine Höhlung soll mit dem Pericard communiciren. Beim Nautilusweibchen liegt die Nidamentaldrüse (siehe Geschlechtsorgane) in der freien Mantelfalte, freilich nahe der Stelle, wo sie sich vom Eingeweidesack abhebt. Es treten also hier Theile, welche sonst im Eingeweidesack liegen, aus diesem in die Mantelfalte ein.

Floss en finden sich bei den besseren Schwimmern unter den Dibranchiata. Den Octopoden, die sich durch plumpe, gedrungene Gestalt des Eingeweidesackes auszeichnen, fehlen sie mit Ausnahme der merkwürdigen Gattung Cirroteuthis. Bei den Decapoden sind sie ganz allgemein verbreitet und von sehr wechselnder Form, Anordnung und Ausdehnung.

Bei Sepia (Fig. 462) und Sepioteuthis inseriren die Flossen am seitlichen Körperrand und zwar in der ganzen Höhe (Länge) des Eingeweidesackes. Sie bezeichnen also hier die Grenze zwischen Vorder- und Hinterseite (physiologische Rücken- und Bauchseite) des Eingeweidesackes. Bei Rossia, Sepiola und Sepioloidea sind sie annähernd halbkreisförmig und inseriren als deutlich abgesetzte Anhänge auf der Vorderseite des Eingeweidesackes, ungefähr in seiner halben Höhe. Aehnlich verhält sich Cirroteuthis, wo die rundlichen Flossenlappen mit stielförmig verschmälerter Basis dem Rumpfe aufsitzen. Am dorsalen Ende des Eingeweidesackes, auf dessen Vorderseite, inseriren die dreieckigen oder halbkreisförmigen Flossen bei Cranchia, Histioteuthis, Onychoteuthis, Loligo (Fig. 418, p. 590), Loligopsis, Ommastrephes etc.

Bei manchen Dibranchiaten kommt es zu einer Verwachsung des freien Randes der Mantelfalte mit dem darunter liegenden Integumente des Kopffusses. Diese Verbindung geschieht durch ein über den Nacken hinwegziehendes musculöses Band, das $\mathrm{Nackentand.} \mathrm{Den} \mathrm{meisten}$ Decapoden fehlt eine solche Kopfnackenverbindung, so dass hier der Mantelrand rings um den Körper herum frei ist. Ausnahmen bilden die Gattungen Sepiola, Cranchia und Loligopsis, wo eine im allgemeinen schmale Kopfnackenverbindung besteht. Eine solche kommt allen Octopoden zu, wo sie, von Argonauta ausgehend, bei Philonexis und Octopus immer breiter wird, bis sie schliesslich bei Cirroteuthis sich auch auf die Hinterseite (physiologische Bauchseite) erstreckt, so dass der Mantelrand hier nur an einer beschränkten Stelle frei bleibt und eine in die Mantelhöhle führende Oeffnung umsäumt, durch welche der Trichter hervortritt.

Sehr verbreitet sind Einrichtungen, welche dazu bestimmt sind, die Mantelfalte an der unter ihr liegenden Körperwand zu befestigen. Diese Befestigung ist entweder eine vorïbergehende oder cine dauernde. Im ersteren Falle handelt es sich um die sogenannten Mantelschliesseinrichtungen, den, appareil de résistance", im letzteren 
Falle um häutige oder musculöse Verlöthungen zwischen Mantel und Leibeswand.

1. Mantelschliesseinrichtungen. Wir unterscheiden paarige und unpare. Die ersteren treffen wir an der Hinterseite des Körpers in der Mantelhöhle nahe an ihrem unteren Ende, rechts und links an der Trichterbasis und an den gegenüber liegenden Stellen der inneren Oherfläche der Mantelfalte. Die mpare Mantelschliesseinrichtung hingegen finden wir an der Vorderseite am Nacken. Da alle diese Einrichtungen dazu dienen, die Mantelhöhle von der Aussenwelt abzuschliessen, so bedarf die Thatsache keiner besonderen Erläuterung, dass ihre Ausbildung in umgekehrten Verhätniss zur Ausdehnung der Eopfnackenverbindung steht. Wo letztere fehlt, wie z. B. bei Sepia, da sind die Mantelschliesseinrichtungen hoch entwickelt; wo sie sehr breit ist, wie z. B. bei Octopus, kann der Mantelschliessapparat gänzlich fehlen. Im allgemeinen handelt es sich um knorpelige Vorsprünge (und häufig dazukommende Vertiefungen) an der der Mantelhöhle zugekehrten inneren Seite der Mantelfalte, welche genau zu entsprechenden knorpeligen Vertiefungen (und ihnen häufig anliegenden Vorsprüngen) der gegenüber liegenden Leibeswand passen (vergl. Fig. 462). Die besondere Gestalt der Mantelschliessknorpel und Nackenknorpel ist von systematischer Bedeutung:

Die bei den Decapoden fast allgemein vorhandenen knorpeligen Schliesseinrichtungen (sie fehlen nur bei Owenia und Cranchia) erhalten sich noch bei einigen Octopoden in fleischigem und überdies mehr oder weniger modificirtem Zustande (Argonauta, Tremoctopus). Zuerst verschwindet selbstverständlich mit dem Auftreten der Kopfnackenverbindung der Nackenschliessapparat. Dieser fehlt z. B. schon unter den Decapoden bei der Gattung Sepiola, welche eine feste Kopfnackenverbindung besitzt.

2. Fixe Verbindugen zwischen Mantelfalte und darunter liegender Leibeswand durch die Mantelhöhle hindurch finden sich nur bei solchen Cephalopoden, denen ein Mantelschliessapparat fehlt. So ist bei Octopus und Eledone der Mantel durch einen medianen Muskel über dem Trichter an die Leibeswand befestigt. Dieser Muskel besteht aus zwei einander eng anliegenden Lamellen, die den After zwischen sich fassen. Bei Cranchia ist der freie, dorsale Trichterrand (an der sogenannten 'Trichterbasis) rechts und links durch ein häutiges Band mit der Mantelfalte verwachsen. Aehnliches findet sich bei Loligopsis.

W asserporen. In der Umgebung des Mundes oder an der Basis der Arme oder seitlich am Kopfe kommen bei vielen Cephalopoden Oeffnungen vor, welche in kleinere oder grössere Taschen der Haut hineinführen. Die Function dieser Organe ist unbekannt.

\section{Die Schale.}

A) Allgemeines.

Formverhälnisse der Schale. Beziehungen derselben zum Weich kör per.

Wir kimmen die verschiedenen Schalenformen der Molluslien von einer napf- oder tellerförmigen Schale ableiten, welche den Körper vom Rïcken her loedeckt. Eine solche schale bietet hinreichenden Schutz bei 'Thieren, welche wie Fissurella, Patella etc. mit ihrem scheibenförmigen, wic cin Saugnajf wirkenten Fusse einer harten Unterlage 
fest und fast unloweglich aufsitzen. Der Weichkörper ist dann einerseits durch die Schale, anderseits durch die Unterlage geschützt. Bei beweglichen Mollusken zeigt sich aber die Tendenz, den ganzen Körper ausschliesslich durch die eigene Schale zu schützen.

Diese Tendenz kommt in verschiedener Weise zur Geltung.

Bei den Chitoniden gliedert sich die Schale in aufeinanderfolgende, gegen einander verschiehlare Stücke. Diese gegliederte Schale vermag den Gesammtkörper zu schützen, indem sie dem Chiton gestattet, sich nach Art eines Gürtelthieres oder einer Assel einzurollen.

Bei den Muschehn wird der Schutz des gesammten Weichkörpers erreicht durch Ausbildung einer zweiklappigen Schale, aus welcher der Fuss vorgestreckt werden kann, und welche, wenn die beiden Klappen sich schliessen, den anzen Weichkörper mitsammt dem zurückgezogenen Fuss allseitig vollkommen umschliesst.

Bei den Gasteropoden, Scaphopoden und Cephalopoden herrscht cin anderes Princip bei dem möglichst allseitigen und vollständigen Schutz des Körpers durch die Schale. Die Schale ist nämlich hoch thurmförnig ausgezogen und in Folge dessen so geräumig, dass nicht nur der Eingeweidesack in inr Platz findet, sonderu auch der Kopf und Fuss in sie zurïckgezogen werten können. Auch die einzige noch übrig bleibende unbesetzte ()effnung, die schwache Stelle des Panzerthurmes, kann sehr häufig durch einen harten Deckel vollständig verschlossen werden.

Eime hoch thurmförmig ausgezogene Schale ist eiuem freibeweglichen Thiere eine unbequeme Bürde. Sic ist wegen der grossen OberHaiche ein Hinderniss der Locomotion. Eine Verkleinerung der Oberfliche wird bewirkt dadurch, dass sich bei den in Betracht kommenden Gasteropoden und Cephalopoden die Schale aufrollt, sei es in einer Ebene, sei es in einer Kegelspirale.

Im letzteren Falle ist die Schale fast immer rechts gewunden. Um zu hestimmen, ob eine schale rechts oder links gewunden ist, stellt (ler Beobachter dieselbe (Fig. 443, p. (629) so vor sich hin, dass ihre Spitze nach oben, ihre Mündung nach unten gerichtet und dem Beolachter zugekehrt ist. Liegt dann die Mündung rechts, so ist die Schale rechts gewunden, liegt sie links, so ist die Schale links gewunden.

Eine ebenso auffillende, wie in den meisten Fällen unerklärte Erscheinung ist das Rudimentärwerden und schliessliche vollständige Schwinden der Schale, welches in fast allen Molluskenklassen, ja sogar innerhall, kleinerer Molluskengrupen constatirt werden kann. (Die Solenogastres immerlalb der Amphineuren, einzelne Heteropoden und 'Titiscania unter den Prosobranchieri, manche Pulmouaten, sehr viele ()pisthobranchiata und die meisten heute lebenden Cephalopoden.)

Der Nachweis ist in fast allen Fällen sicher erbracht, dass die Formen mit rudimentïrer oder fehlender Schale von Formen mit wohl entwickelter Schale alogeleitet werden müssen. Alle Nacktschnecken hesitzen wenigstens auf jungen Entwickelungsstadien eine Schale.

Die Rudimentation der Schale in den verschiedenen Reihen vollzicht sich häufig unter folgenden Erscheinungen, auf die weiter unten nälıer eingegangen wird. 1) Die Schale wird zunächst eine innere, dann nimmt sie 2) an Grösse ab, so dass sie nicht mehr den ganzen Weichkiörper bergen kann. 3) Der Eingeweidesack verstreicht. 4) Die Schale fundet sich nur noch als isolirte Kalkkörperchen im Rückenintegunent, 5) auch diese fehlen, und die Schale kummt nur noch embryonal vor. 
Den Grund oder mit andern Worten den Nutzen des Rudimentärwerdens der dem Körper so eminent zum Schutze gereichenden Schale, welche in so hohem Grade bestimmend auf die Gesammtorganisation der Weichthiere zurückwirkt, vermag man nur in wenigen Fällen deutlich zu erkennen. Wie in jeder grösseren Abtheilung des Thierreiches, so vermag sich auch in den verschiedenen Molluskengruppen die Organisation den verschiedensten Verhältnissen anzupassen.

Ich will einige Fälle, in deneu der Nutzen der Schalenrudimentation einigermaassen einleuchtet, citiren :

1) Bei freischwimmenden pelagischen Thieren. Die Schale beschwert den lï̈rper zu sehr und bietet zu grossen Reibungswiderstand.

2) Bei T'estacella und Verwandten, Regenwurmjägern, welche die Würmer bis in ihre engen Gänge und Röhren verfolgen.

3) Bei Schnecken, die im dichten Kínallen-, Bryozoen-, Hydroidoder Algengestrüpp weiden. (Viele Nudibranchier.)

Bei Verlust der Schale treten meist compensatorische Schutzeimrichtungen auf: grosses Regenerationsvermögen besonders der leicht abfallenden Körperanhänge, Selbstamputation, Schutz durch Nesselzellen, Schutzfarben(?), Schreckfarben(??).

Die rüuberischen Cephalopoden sind geschützt durch die mit einer sehr hoch entwickelten Organisation im Einklang stehenden Geschicklichkeit im Schwimmen, das gut ausgebildete Sehvermögen, die grosse Muskelkraft, die starken Kiefer, das entleerte Secret des Tintenbeutels, den zum Theil mimetischen Farbenwechsel u. s. w.

Bei verschwundener Schale erhalten sich immer gewisse Organisationsverhailtnisse, die nur als Reminiscenzen eines beschalten Zustandes verstiindlich sind. (Beispiel: seitliche Lage der Geschlechtsöff̈nung, der Nierenöfthung und zum Theil auch des Afters bei den Nudibranchien.)

Chemische Zusammensetzung der Schale.

Die Molluskenschale besteht zum grössten Theil aus kohlensaurem Kalk mit Spuren von phosphorsaurem Kalk und einer dem Chitin verwandten organischen Grundlage, dem Conchiolin. Ausserdem können verschiedene Farbstoffe in der Schale vorkommen.

\section{Structur der Schale.}

Die Schale der Lamellibranchier besteht aus drei geschichteten Lagen, einer äusseren, einer mittleren und einer inneren, der äusseren Oberfläche des Mantels anliegenden. Die ganze Schale ist als eine Cuticularbildung aufzufassen.

Die ä ussere Schicht (Schalenoberhant, Epidermis, Cuticula, Periostracum) ist der physikalischen Beschaffenheit nach hornartig und entbehrt der Kalksalze. An den älteren Theilen der Schale geht sie gewöhnlich verloren.

Die mittlere Schicht (Säulenschicht, Prismenschicht, Porzellanschicht) besteht aus meist auf der Schalenoberfäche senkrecht stehenden, dicht gedrängt stehenden, schlanken Kalkprismen (Kalkzellen, Kalksäckchen).

Die innere Schicht (Perlmutterschicht) hat ein fein-blättriges Gefüge. Die sehr dünnen, durchscheinenden Kalkblätter, welche sie zusammensetzen, sind zart wellenförmig gefältelt. Dadurch werden an der inneren, dem Mantel aufliegenden Oberfäche dieser Schicht dicht gedrängte, wellenförmig verlaufende Linien erzeugt, welche durch Inter- 
ferenz den Perlmutterglanz bedingen. Die Perlen der Perlmuscheln bestehen aus der Substanz dieser Schicht.

Im einzelnen bietet die Beschaffenheit der drei Schichten hier und bei den übrigen Mollusken grosse Verschiedenheiten.

Die äussere und die mittlere Schicht werden am freien Mantelrande, die innere vom Epithel der ganzen äusseren Oberfläche des Mantels gebildet.

Was die Structur der Schalen der Gasteropoden und Cephalopoden anbetrifft, so besteht die Hauptmasse derselben aus der mittleren oder Porzellanschicht, die aber eine von der der Lamellibranchier sehr abweichende Structur besitzt. Nur selten (bei einigen Gasteropoden) ist diese Schicht aussen von einem Schalenhäutchen überzogen. Auch die innere Perlmutterschicht fehlt sehr häufig.

Wachsthum der Schale.

Es ist lehrreich, das Wachsthum der Molluskenschale mit dem Wachsthum des Arthropodenexoskeletes zu vergleichen. Bei den Arthropoden entwickelt sich das mit der Molluskenschale vergleichbare chitinige Exoskelet an der gesammten Oberfläche des Körpers und seiner Anhïnge. Dieses Skelet, eimmal gebildet und erhärtet, sargt den Körrver allseitig ein, weist ihm eine bestimmte Auslehnung an, ist nicht wachsthumsfïhig. Daher bei den Arthropoden die das Wachsthum des Körpers allein ermöglichenden $\mathrm{Häutungen.} \mathrm{Die} \mathrm{Schale}$ der Mollusken hingegen ist eine oftene. Sie hat bei den Gasteropoden und Cephalopoden die Gestalt eines um eine Axe herum gewundenen Kegelmantels. Die Oeffinung liegt an der Basis des Kegels. Indem hier zum Mündungsrande der Schale immer neue Schalentheile hinzugrefügt werden, wächst die Schale, ohne im Wesentlichen ihre Form zu verändern, mit dem fortwachsenden 'Thier. Die Zuwachsstreifen an der Oberfläche der Schale verrathen uns noch bei der erwachsenen Schnecke die Wachsthumsphasen ihrer Schale. Bei dem Wachsthum les Thieres bleiben entweder die ältesten obersten Windungen immer noch vom obersten Ende des Eingeweidesackes erfüllt, wie das bei den meisten Schnecken der Fall ist, oder sie werden vom Thier aufgegeben, das sich also beim Wachsthum der Schale immer weiter von der Spitze derselben zurückzieht. Dabei bleiben die verlassenen, ältesten und obersten Windungen entweder leer, oder sie werden ganz oder theilweise mit Schalensubstanz ausgefüllt. In diesem letzteren Falle können die obersten Windungen successive verloren gehen, abgeworfen werden. Nautilus und Verwandte bilden beim Wachsthum periodisch in immer grösser werdenden Abständen quere Scheidewände, so dass die verlassene Schale gekammert und mit Gas erfüllt ist, wälırend das Thier in der zuletzt gebildeten grössten, nach aussen oftenen Wohnkammer sitzt.

In ganz ähnlicher Weise erfolgt das mit dem Wachsthum des Körpers gleichen Schritt haltende Wachsthum der Schale der Muscheln dadurch, dass dem freien Rande der Schalenklappen vom Mantelrande her immer neue Schaleusubstanz (Oberhäutchen und Prismenschicht) zugefügt wird, währeud die ganze äussere Mantelfläche der Innenfläche der so gebildeten Schale neue Lagen der Perlmutterschicht von iunen hinzufügt. Auch an der Oberfläche der Muschelschale können wir an den concentrischen Zuwachsstreifen dic aufeinanderfolgenden Phasen ihres Wachsthums verfolgen. 
B) Specielles.

1. A m phine ura. Vergleiche den vorhergehenden Abschnitt p. 605-608.

\section{Gasteropoda.}

$\mathrm{Zu}$ dem oben über die Gasteropodenschale Gesagten wollen wir hier nur noch Weniges hinzufügen. Die Schale ist spiralig um eine Axe aufgerollt, das ist die Regel. Selten ist die Spirale so stark niedergedrückt, dass, wie z. B. bei Planorbis, die Windungen fast in eine Ebene zu liegen kommen und eine fast symmetrische Schale zu Stande kommt. - Es
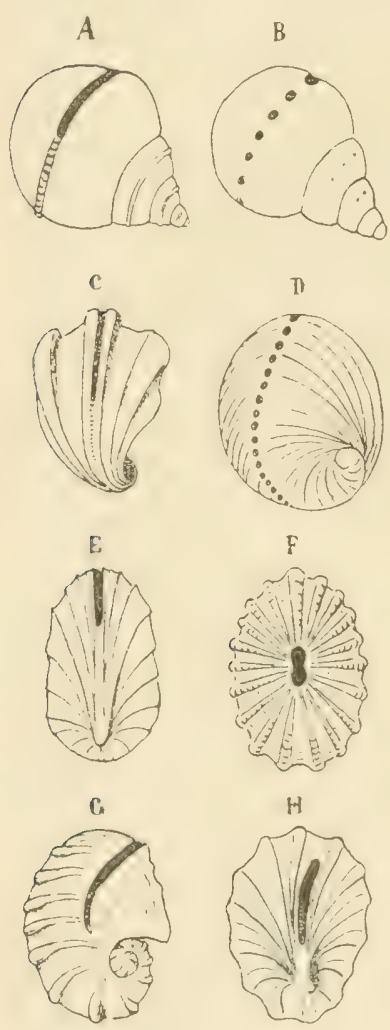

H
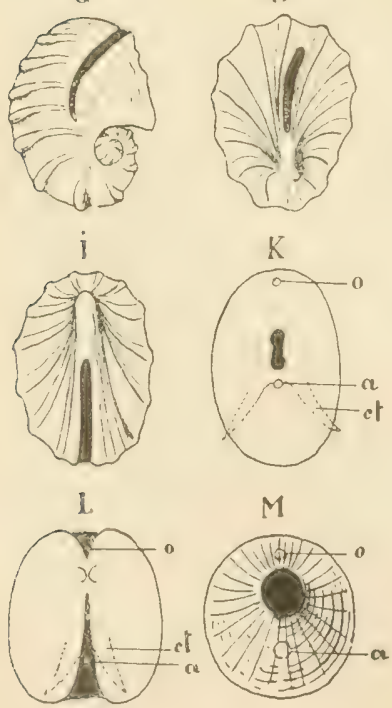

M

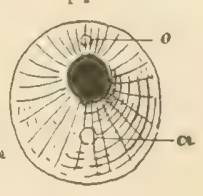

giebt aber auch nicht gewundene, symmetrische Gasteropodenschalen, und diese erheischen unsere besondere Aufmerksamkeit. Es sind dies vor allem die napfförmigen oder ziemlich flach-kegelförmigen Schalen der Patelliden und Fissurellen. Da wir 1) die Gasteropoden von bilateral-symmetrischen Stammformen mit symmetrischer Schale ableiten müssen, da 2 ) die Fissurelliden unter allen Gasteropoden in ihrer Organisation zweifellos der Stammform am nächsten stehen, und sie 3 ) in dieser Organisation eine auffallende Symmetrie zur Schau tragen, so läge der Gedanke nahe, ihre symmetrische Schale für eine ursprünglich-symmetrische zu halten. Gewisse Verhältnisse des Nervensystems, besonders die Kreuzung der Pleurovisceralconnective, im Verein mit andern Umständen, die später eingehend erörtert werden sollen, machen es sicher, dass die napfförmige Fissurellaschale eine s e cu n där-s y m m etrische ist, das heisst, dass die Fissurella von Formen abstammt, welche eine spiralig gewundene Schale besassen. Das Gleiche gilt für die Patellen. Damit stimmt die wichtige Thatsache überein, dass die junge Schale von Fissurella asymmetrisch und gewunden ist und nur ganz allmählich in die symmetrische Form übergeht (Fig. 442 G, H), dass ferner die scheinbar symmetrische Schale gewisser naher Verwandter von Fissurella und Patella bei genauerem Zusehen etwas asymmetrisch ist, indem besonders die Spitze excentrisch oder etwas schief gerichtet ist und dass schliesslich

Fig. 442. Schalen von $\boldsymbol{A}$ Pleurotomaria, $\boldsymbol{B}$ Polytremaria, $\boldsymbol{C}$ und $\boldsymbol{E}$ Emarginula, $\boldsymbol{D}$ Haliotis, $\boldsymbol{F}$ Fissurella, $\boldsymbol{G}$ und $\boldsymbol{H}$ Entwickelungsstadien der Fissurellaschale, I Schale der umgedrehten Gasteropodenstammform mit marginalem Schalenschlitz, II idem mit apicalem Schalenloch, $\boldsymbol{L}$ Muschelschale, $\boldsymbol{M}$ Dentaliumschale, vom apicalen Schalenschlitz aus gesehen. Die Löcher und Schlitze der Schale schwarz gezeichnet. o Mund, a After, ct Ctenidium. 
andere nahe Verwandte von Fissurella, wie Haliotis, Scissurella, Pleurotomaria, spiralig gewundene Schalen besitzen (Fig. 442 A, B, C, D).

Die Fissurelliden, viele Pleurotomariidae und die Haliotid a e, also gerade die ursprünglichsten Gasteropoden, zeigen eigenthümliche Durchbrechungen der Schale, die vereinzelt auch in andern Abtheilungen vorkommen und welche unsere Beachtung verdienen. Diese Durchbrechungen liegen über dem für diese Abtheilungen charakteristischen Mantelschlitz, der schon früher besprochen wurde, und sie stellen überall eine Communication zwischen Mantelhöhle und Aussenwelt dar, speciell auch für den Fall, dass die Mündung der Schale, d. h. der Schalenrand der Unterlage dicht aufliegt. Bei Scissurella, Pleuroto maria, Emarginula handelt es sich um einen medianen Einschnitt am vorderen Schalenrand, der dem Defecte, d. h. dem Einschnitt im Mantel entspricht. So verhält sich Fissurella in der Jugend, bei weiterer Entwickelung aber wächst die Schale ganzrandig fort, so dass bei der erwachsenen Fissurella die Oeffnung oben ganz in der Nähe der Spitze der Schale liegt. Unter ihr liegt der oben in der Mantelhöhle befindliche After. Würde der Schaleneinschnitt vom vorderen und hinteren Rande ausgehen und sehr tief sein, so würde eine zweitheilige Schale entstehen, die sich mit der zweiklappigen Schale ter Lamellibranchier vergleichen liesse. Es ist in der That wahrscheinlich, dass dem Schaleneinschnitt eine grössere phylogenetische Bedeutung zukommt. Bei Haliotis handelt es sich um eine Reihe solcher die Schale durchbrechender Löcher, indem sich der Vorgang der Bildung des Fissurellaloches beim Wachsthum der Haliotis vielfach wiederholt, wobei aber die älteren Oeffnungen immer wieder durch Schalensubstanz verschlossen werden, und die jüngeren nur so lange offen bleiben, als sie über der Athemhöhle liegen.

Bei zahlreichen Prosobranchiern (den früheren Siphoniaten) findet sich am Spindelrand der Schale eine Furche, welche eine Rinne des Mantelrandes aufnimmt. Diese Rinne ermöglicht eine Communication der Mantelhöhle mit der Aussenwelt auch dann, wenn die Schale durch den Deckel verschlossen ist. Häufig zieht sich die Rinne in einen kürzeren oder längeren Fortsatz, den Schnabel aus, welcher einen entsprechenden rinnenförmig ausgehöhlten Fortsatz des Mantels, den Sipho, in sich aufnimmt. Dieser letztere kann dadurch, dass sich die Ränder der Rinne aneinanderlegen, zu einem Rohre werden.

Wie schon erwähnt, sind die Schalen der meisten Gasteropoden rechtsgewunden. Doch giebt es einzelne Familien, Gattungen oder Arten,

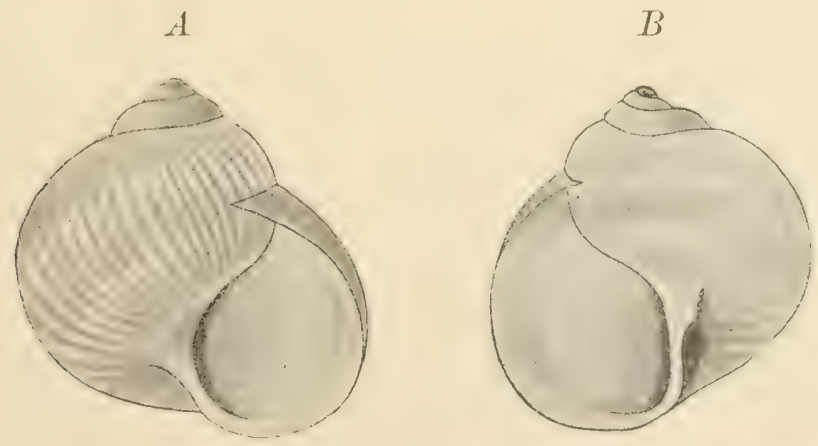

Fig. 443. $\boldsymbol{A}$ Rechtsgewundene, $\boldsymbol{B}$ linksgewundene Schale von Heliz pomatia. 
bei denen die Schale linksgewunden ist. Bei rechtsgewundenen Arten giebt es hier und da linksgewundene Individuen und umgekehrt. Interessant ist, dass gewisse linksgewundene Arten im Weichkörper die Asymmetrie der rechtsgewundenen, andere die entgegengesetzte, der Schale entsprechende, aufweisen. Darüber später.

Was das Wachsthum der Schalen anbetrifft, bei welchem $u$. a. die Fähigkeit der Thiere, früher gebildete Schalensubstanz wieder aufzulösen, von Interesse ist, so muss auf die Handbücher der Conchyliologie verwiesen werden, ebenso für alles, was die specielle Gestalt der Schale, ihre Altersunterschiede, den Deckel etc. anbetrifft.

Fortschreitende Rudimentation der Schalen kommt in jeder der 3 Hauptabtheilungen der Gasteropoden vor. Während sie aber unter den Prosobranchiern nur bei den pelagisch lebenden, freischwimmenden Heteropoden und bei Titiscania beobachtet wird, ist sie bei den Pulmonaten schon viel häufiger und gar bei den Opisthobranchiern so verbreitet, dass die meisten Vertreter dieser Abtheilung mit Bezug auf die Schale auf irgend einer Stufe der Rudimentation stehen. Zahlreiche Opisthobranchier haben sogar im erwachsenen Zustande jede Spur einer Schale eingebüsst (Pteropoda gymnosomata, Nudibranchia, die meisten Ascoglossa), aber auch diese besitzen wenigstens in der frühesten Jugend eine gewundene Schale, zu deren Verschluss sogar noch ein, wie bei den Prosobranchiern, vom Fusse gebildeter Deckel dienen kann.

Die Rudimentation der Schale erfolgt in den verschiedenen Reihen $h a ̈ u f i g$ in folgenden Hauptetappen und unter folgenden Begleiterscheinungen:

a) Die wohl entwickelte Schale ist nicht mehr geräumig genug, um den ganzen Körper zu bergen.

b) Die kleiner und dünner werdende Schale wird dorsalwärts von Verbreiterungen des Mantels theilweise oder ganz umwachsen.

c) Bei kleiner (zugleich napf-, schild-, ohrförmig) werdender Schale beginnt der ursprïnglich bruchsackartig hervortretende Eingeweidesack zu verstreichen, sich nicht mehr deutlich vom übrigen Körper abzuheben. Die in ihm enthaltenen Eingeweide vertheilen sich gewissermaassen in und auf der Rückenseite des Fusses.

d) Die äussere Asymmetrie des Körpers macht immer mehr einer äusseren Symmetrie Platz, während die innere Asymmetrie nie ganz verschwindet.

e) Die Schale reducirt sich auf eine Ansammlung isolirter Kalkkörner im Integument des verstrichenen Eingeweidesackes.

f) Keine Spur eines besondern Eingeweidesacks mehr; Kalkkörper im Rückenintegument der langgestreckten Nacktschnecke.

g) Auch keine isolirten Kalkkürperchen mehr im Rückenintegument.

Ueber die Rudimentation der Schale bei Opisthobranchiern und Pulmonaten vergleiche auch den Abschnitt über den Mantel.

Hübsch ist auch die Heteropodenreihe:

Atlanta. Schale zwar sehr dünn und leicht, aber gross und spiralig gewunden (mit Einschnitt an der Mündung), das Thier kann sich vollständig in dieselbe zurückziehen und dieselbe vermittelst eines am deutlich gesonderten Metapodium entwickelten Deckels verschliessen.

Carinaria. Schale dünn, zart, leicht, napfförmig, bedeckt den noch grossen, gestielten Eingeweidesack, ist aber nicht im Stande, den 
langen und dicken cylindrischen Körper und den Fuss zu beherbergen. Kein Deckel.

Pterotrachea. Eingeweidesack klein, keine Schale, kein Deckel.

3. Lamellibranchiata.

Die beiden seitlichen Schalenklappen der Lamellibranchier sind dorsalwärts, am sogenannten Schlossrand, durch das Schlossband (Liga$\mathrm{mentum}$ ) und durch das $\mathrm{Schlos}$ verbunden. Das Schlossband wirkt als Antagonist der Schalenmuskeln, von denen später die Rede sein wird, und die, wenn sie sich contrahiren, die Schale schliessen. Das Schlossband besteht gewöhnlich aus zwei Schichten, einer äussern nicht elastischen und einer innern elastischen. Die äussere nicht elastische geht in die Oberhaut (Periostracum) der Schale über. Diese Continuität beider Schalen durch das Schlossband auf der Rückenseite des Körpers lässt auch die Muschelschale streng genommen als aus einem einzigen dorsalen Stück bestehend erscheinen, welches rechts und links ventralwärts zu den Schalenklappen ausgewachsen ist. Die innere

Fig 444. Schemata zur Demonstration des Oeffnungsund Schliessungsmechanismus der Muschelschale. 1, 2, 3 Die drei Schichten der Schale, 1 Prismenschicht, 2 Cuticula oder Periostracum, 3 Perlmutterschicht. A Schale geschlossen iturch Contraction des Schliessmuskels 6 , wobei der elastische innere Theil des Schlossbandes (5) comprimirt wird. $\boldsymbol{B}$ S Schale bei Erschlaffen des Schliess: muskels durch Druckelasticität des inneren Theiles des Schlossbandes geöffnet. 4 Nicht-elastischer äusserer Theil des Schlossbandes, welcher sich in das Periostracum fortsetzt.

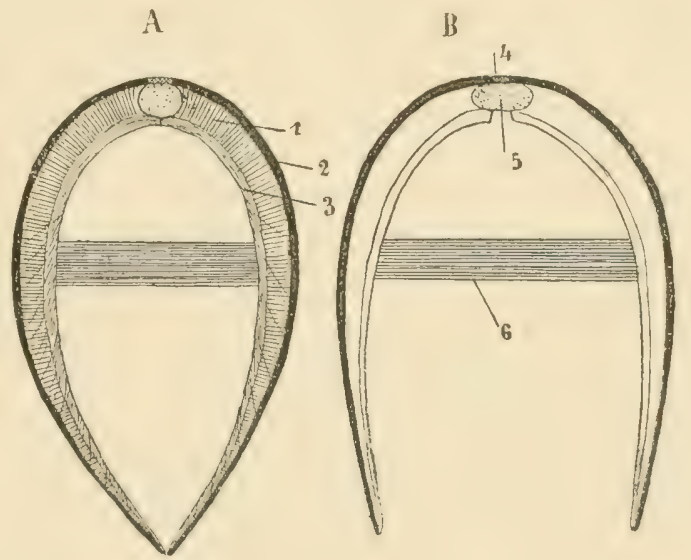

Schicht ist elastisch, kalkhaltig und wird als Knorpel bezeichnet, unlassenderweise, da sie histologisch mit Knorpelgewebe nichts zu thun hat. - Das Band ist entweder ein äusseres, wenn es dorsalwärts zwischen Vorsprüngen des Schlossrandes der Muschel frei zu Tage tritt, oder ein inneres, wenn es sich zwischen den aneinanderliegenden Schlossrändern selbst ausspannt, die dann jederseits eben zur Aufnahme des Schlossbandes grubenförmig vertieft sind. Diese Vertiefungen kann man dadurch leicht von den Vertiefungen des Schlosses unterscheiden, dass sie rechts und links an gegenüberliegenden Stellen am Schlossrand vorkommen, während den Gruben, Löchern, Furchen des Schlos ses selbst, die sich an dem einen Schlossrand finden, Zähne, Leisten etc. am gegenüberliegenden Schlossrand entsprechen.

Befindet sich der elastische Knorpel in der Ruhelage, wie dies bei der todten Muschel oder bei erschlafften Schalenschliessmuskeln des lebenden Thieres der Fall ist, so klafft die Muschel an ihrem ventralen freien Rande. Contrahiren sich die Schalenschliesser, so wird - wie es scheint in allen Fällen - der Knorpel comprimirt, während stets beim. 
Erschlaffen der Schalenschliesser die Schale durch Druckelasticität des Bandknorpels wieder geöffnet wird (Fig. 444).

Die Beschaffenheit von Band und Schloss liefert systematisch wichtige Charaktere.

Für die besondere Gestalt der Schale verweisen wir auf die systematisch-zoologischen Werke und begnügen uns mit folgenden Bemerkungen.

Die Schale der Lamellibranchier ist ursprünglich symmetrisch, $d . h$. beide Schalenklappen sind einander - abgesehen von der fast immer asymmetrischen Beschaffenheit des Schlossrandes - spiegelbildlich gleich. Dieser Zustand erhält sich bei den meisten Lamellibranchiaten. Die beiden Schalenklappen künnen aber ungleich, d. h. die Schale (und mit ihr der Weichkörper, doch dieser letztere in viel geringerem Maasse und in nebensächlichen Dingen) kann asymmetrisch werden. Diese Asymmetrie ist wohl - soweit sich dies zur Zeit. beurtheilen lässt — ursprünglich bedingt durch festsitzende Lebensweise.

Bei der Auster ist die linke Schalenklappe mit der Unterlage fest. verkittet. Diese Klappe ist dicker und gewölbter, bauchiger, sie dient. gewissermaassen als Becken zur Aufnahme des Weichkörpers, während die rechte Schalenklappe nur mehr als Deckel functionirt und dünner, abgeplattet erscheint. Die linke Schalenklappe wird hier zur unteren, die rechte zur oberen. Dass diese Bezeichnungen oben und unten m or pho$\mathrm{log}$ isch ebensowenig Gültigkeit haben, wie etwa bei den Pleuronecten unter den Fischen, braucht wohl nicht noch besonders hervorgehoben zu werden. Bald ist die linke, bald die rechte Schalenklappe die festsitzende, und dies oft innerhalb einer und derselben Gattung (Chama) oder sogar Art (Aetheria). Festsitzende, ungleichklappige Muscheln sind z. B. ausser den schon genannten: Spondylus, Gryphaea p. p., Exogyra p. p. und ganz besonders auch die fossilen Hippuriten (Rudisten), bei denen die rechte Schalenklappe die Gestalt eines hohen, mit der Spitze aufgewachsenen Kegels annimmt, während die linke Klappe wie ein Deckel aussieht. Aber die kegelförmige rechte Klappe ist innen nicht entsprechend ausgehöhlt, sondern fast ganz mit Schalensubstanz ausgefüllt, so dass der vom Thiere bewohnte Raum zwischen unterer und oberer Klappe trotz der Gestalt der Schale ein sehr niedriger ist.

Aehnliche Verhältnisse finden sich bei gewissen fossilen Chamaceen. Bei Requienia ist die linke Schale spiralig ausgewachsen und mit der Spitze festgewachsen, während ihr die spiralig gewundene, flache rechte Schale deckelartig aufliegt und so die ganze Schale einem durch einen Deckel verschlossenen Gasteropodengehäuse ausserordentlich ähnlich wird.

Es giebt aber auch freie, nicht festsitzende Muscheln, die ungleichklappig sind, z. B. manche Pectiniden. Zahlreiche Eigenthümlichkeiten der Organisation (rudimentärer Fuss, Beschaffenheit des Mantelrandes, Fehlen der Siphonen) weisen aber darauf hin, dass diese Formen von sedentären abstammen. Für andere inäquivalve Formen lässt sich freilich lieine Beziehung zu einer früheren sedentären Lebensweise darthuu.

Als Beispiel einer inäquivalven Muschel, bei der die der Unterlage aufliegende Schalenklappe flach, die obere aber etwas gewölbt ist, citire ich die interessante Form Anomia. Die untere Schalenklappe ist hier die rechte; sie schmiegt sich in ihrer Gestalt ganz genau der Gestalt der Unterlage an, so dass sie z. B. die Sculptur der Pecten- und Austerschalen, auf denen Anomia häufig festsitzt, genau wiederholt. In der rechten, aufliegenden Schalenklappe findet sich ein Loch, in welches das sogenannte Schliessknöchelchen (verkalkter Byssus) hineinpasst, vermittelst 
dessen die Muschel mit der Unterlage verkittet ist. Die Entwickelungsgeschichte klärt die Bedeutung dieses Loches auf, welches anfänglich ein einfacher Ausschnitt am Schalenrande ist, wie er auch bei andern Muscheln vorkommt und zum Durchtritt des Byssus dient. Bei weiterem Wachsthum der Schale wird dieser Ausschnitt von der Schale gewissermaassen umwachsen und entfernt sich so scheinbar vom Rande, mit dem er aber in Wirklichkeit immer noch zusammenhängt (Fig. 445). Bei verwandten Formen (Carolia) wird schliesslich dieses Loch ganz durch homogene Kalkmasse verschlossen.

Fig. 445. 3 Entwickelungsstadien der rechten Schalenklappe von Anomia. $\boldsymbol{A}$ Sehr junge schale. $\boldsymbol{B}$ Aeltere Schale mit Byssusausschnitt. $C$ Noch ältere Schale, Byssusausschnitt von der schale umwachsen und zu einem Loch in der rechten Schalenklappe geworden. Nach Morse.

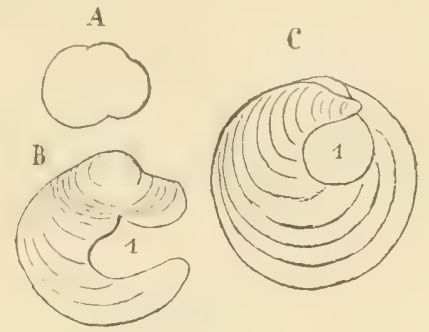

Schaleneindrücke. Verschiedene Organe der Muscheln, welche sich an die innere Oberfläche der Schale anheften oder ihr dicht anliegen, rufen auf derselben mehr oder weniger deutliche Eindrücke hervor, welche man an den leeren Muschelschalen erkennen kann. Die Kenntniss dieser Eindrücke ist aus naheliegenden Gründen besonders für den Paläontologen von grosser Bedeutung. Sie erlauben einen sicheren Rückschluss auf gewisse Organisationsverhältnisse des Weichkörpers, der sich nicht erhalten konnte.

1) Die deutlichsten Eindrücke sind die, welche die Schalenschliessmuskeln hervorbringen. Wo zwei kräftige Schalenschliesser vorhanden sind, ein vorderer und ein hinterer (bei den sogenannten Dimyariern), finden sich auf der Innenseite einer jeden Schalenklappe in entsprechender Lage auch zwei Schaleneindrücke (Fig. 446). Wo der vordere Schalenschliessmuskel rudimentär, dafür aber der hintere ausserordentlich kräftig wird und nach vorn gegen die Mitte der Schale hinrückt (Monomyarier), findet sich nur eiu grosser Muskeleindruck (Fig. 447). Immer liegt der After in unmittelbarer Nähe des (bei den Monomyariern einzig vorhandenen) hinteren Schalenschliessers.

A

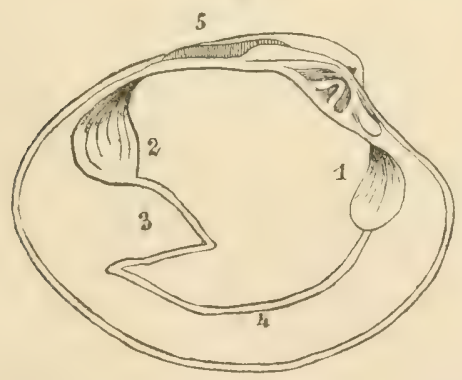

B

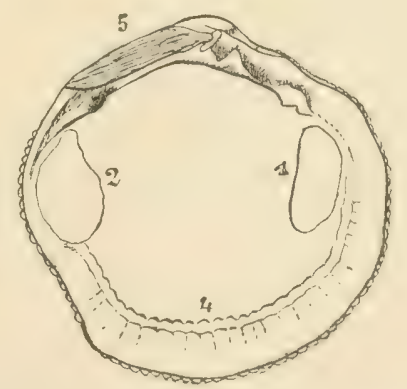

Fig. 446. Dimyarier, Innenseite der linken Schalenklappe, $\boldsymbol{A}$ von Cytherea chione (Sinupalliata), $\boldsymbol{B}$ von Lucina pennsylvanica (Integripalliata). I Eindruck des vordern, 2 des hintern Schliessmuskels, 3 Sinus der Mantellinie 4, 5 Schlossband. 
2) Dem Schalenrand parallel, in geringerer oder grösserer Entfernung von demselben, sieht man an der Innenseite der Schalenklappen die sogenannte Mantellinie hinziehen, welche durch die den Mantelrand an den Schalenklappon befestigenden Muskelfasern hervorgerufen wird.

Der Verlauf dieser Mantellinie erfährt bei den mit Siphonen ausgestatteten Muscheln eine charakteristische Modification, indem die Linie im hinteren Theile der Muschel plötzlich nach vorn und oben umbiegt, um dann wieder nach hinten und oben zum unteren Rande des hinteren Schalenmuskels hinzuziehen. Es bildet also die Mantellinie hier eine nach hinten offene Bucht, den Mantelsinus, die man systematisch verwerthet hat (Simupalliata, Integripalliata) (Fig. 446). Diese Bucht kommt in folgender Weise zu Stande. Die Siphonen können durch besondere

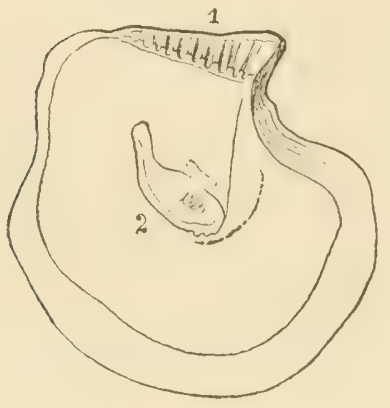
Muskeln verkürzt und zurückgezogen werden, welche sich jederseits mit einer der Gestalt des Mantelsinus entsprechenden Basis an die Innenfläche der Schalenklappen ansetzen. Der Mantelsinus entspricht eben dem Eindrucke dieser Siphoretractoren und ist um so grösser und deutlicher, je kräftiger diese Retractoren und je besser ausgebildet die Siphonen selbst sind.

Fig. 447. Monomyarier, Innenseite einer Schalenklappe von Perna Ephippium. 1 Schlossrand, 2 schliessmuskeleindruck.

3) $\mathrm{Zu}$ den sub 1 und 2 erwähnten Schaleneindrücken, welche die deutlichsten und constantesten sind, können noch andere hinzukommen, welche von den Retractoren und Protractoren des Fusses, von den Muskeln oder Bändern, die den Eingeweidesack an die Schale befestigen u. s. w., herrühren, auf deren Beschreibung wir aber verzichten müssen.

Bei den meisten Lamellibranchiern passen die Ränder der beiden Schalenklappen bei geschlossener Schale genau aufeinander, so dass der Weichkörper des Thieres dann vollständig von der Aussenwelt abgeschlossen ist (geschlossene Schalen). Es giebt aber auch Schalen, die im geschlossenen Zustande hinten oder, was der häufigere Fall ist, hinten und vorn mehr oder weniger weit klaffen (z. B. Myadae, Glycymeridae, Solenidae). Der Grund dieser Erscheinung liegt in der starken Entwickelung der Siphonen (und des Fusses), die nur mit Mühe oder nur zum Theil (Myadae, Solenocurtus) in die Schale zurückgezogen werden können. Solche offene $\mathrm{Schalen}$ besitzen auch die meisten Bohrmuscheln, deren Schalenverhältnisse, zumal bei Aushildung accessorischer Schalenstücke oder von Kalkrühren, sehr interessant sind. Unsere besondere Aufmerksamkeit verdient die Reihe Pholas - Jouannetia. Die wichtigsten Etappen in der Reihe sind Pholas, Pholadidea und Jouannetia.

Die Schale von $\mathrm{Pholas}$ ist in der Längsrichtung gestreckt, sie klafft vorn und unten zum Durchtritt des kurzeu, stempelförmigen Fusses und hinten zum Durchtritt der stark entwickelten Siphonen. Auf der Rückenseite der Schale entwickeln sich bis drei accessorische Schalenstücke (Prosoplax, Mesoplax, Metaplax). 
Die Schale von $\mathrm{Phol}$ adidea sieht der von Pholas ziemlich ähnlich. Sie klafft beim jungen Thier vorn zum Austritt des Fusses ganz wie bei Pholas. Hinten setzt sich jede Schalenklappe in einen hornigen Fortsatz fort, auf den ein accessorisches, trogförmig ausgehöhltes Schalenstiick (Siphonoplax) folgt. Das Siphonoplax der einen Schalenklappe bildet mit dem der anderen Klappe eine häufig durch Verschmelzung ganz einheitlich werdende Röhre zur Aufnahme der Siphouen. 2 Prosoplaxstücke sind vorhanden; Meso- und Metaplax rudimentär. Im erwachsenen Zustand sistirt die Bohrthätigkeit, und die vordere klaffende Oeffnung wird durch Ausscheidung eines accessorischen $\mathrm{Stückes,} \mathrm{des} \mathrm{sogenannten} \mathrm{Ca} / \mathrm{lum}$, vollständig geschlossen. Der ausser Function gesetzte Fuss atrophirt. Die Muschel kann sich in dem Material, in das sie sich gebohrt hat, nicht mehr bewegen.

Die Schale der erwachsenen Jou annetia ist in der Längsrichtung stark verkürzt, $\mathrm{kugelig}$, das Thier kann sich in dem kugelrunden Loch, das es sich in einem Korallenblock ausgehöhlt hat, nicht bewegen. Eine für das Thier fatale Lageveränderung im Loche würde auch verhindert durch den hinteren Zungenfortsatz der Schale, der aber nur der rechten Schalenklappe zukommt. Dio Schale ist vorne vollständig geschlossen; der Fuss fehlt (vergl. auch die Fig. 411, 412 und 449).

Zum Verständniss dieser Verhältnisse bei Jouannetia verhilft uns die Entwickelungsgeschichte. Die Schale des jungen Thieres stellt eine Kugelcalotte dar, deren Höhe kaum die Hälfte des Radius der ganzen Kugel beträgt. Sie bedeckt den hinteren und oberen Theil des Weichkörpers, ihre freien Ränder umgrenzen somit eine ausserordentlich grosse Oeffuung, welche der vorderen, zum Durchtritt des Fusses dienenden klaffenden Oeffnung von Pholas entspricht. In der That besitzt Jouannetia auf diesem "Pholasstadium" einen Fuss. Mit Hülfe des vorderen Schalenrandes das Gestein unter Drehungen des Körpers "raspelnd", höhlt sie sich ein Loch, das vermöge der Kugelcalottengestalt der Schale kugelig wird. Ist dieses fertig, so scheidet das Thier am freien Rande der Schale neue accessorische Schalensubstanz, das "Callum", ab und "indem der Mantelrand den Wandungen des Wohnloches folgt, wird auch hier (wie bei Teredo) die Form der accessorischen Schale durch die des Loches bedingt, sie ergänzt deshalb nothwendiger Weise die ursprüngliche Calotte zur Kugelform".

Ich gehe num unter Vernachlässigung einiger verwandter Formen (Martesia, Teredina, Xylophaga, Gastrochaena, Fistulana), die ähnliche Verhältnisse darbieten, zum Schiffsbohrwurm Teredo (Fig. 413) über. Das Thier besitzt einen langgestreckt röhrenförmigen Mantel, der sich nach hinten in zwei lange Siphonen verlängert. Der Rumpf liegt im Vorderende des Mantels. Teredo bohrt cylindrische Gänge im Holz. Die beiden Schalenklappen sind im Verhältniss zum Körper sehr klein und umfassen als dreilappige Stïcke reifenförmig das Vorderende des Mantels. Die so gestaltete rudimentäre Schale klafft vorn (zum Durchtritt des stempelförmigen Fusses) und hinten sehr stark. Der Mantel sondert ausserdem an seiner ganzen Oberfläche eine das Bohrloch von innen austapezirende kalkige Röhre aus, welche mit den Schalenklappen nicht verschmilzt. Zwei kleine accessorische Schaleustücke, die sogenannten Paletten, liegen an der Stelle, wo sich die Siphonen trennen. Wenn das Thier mit seinem Vorderende in das umgebende Wasser vorragt, so schliesst sich die Kalkröhre vorn calottenförmig. 
Aehnliche Verhältnisse finden sich bei Aspergillum (Brechites) (Fig. 414 u. 448) und Clavagella. Wir können hier an der keulenförmigen Schale, welche mit dem vorderen dickeren Ende in Felsen, Muschelschalen, Korallen oder im Sande steckt, die ächte und die falsche unterscheiden. Die falsche bildet weitaus den grössten Theil der Schalenröhre, sie entspricht der von Teredo abgesonderten Kalkröhre und ist auch zu ver-

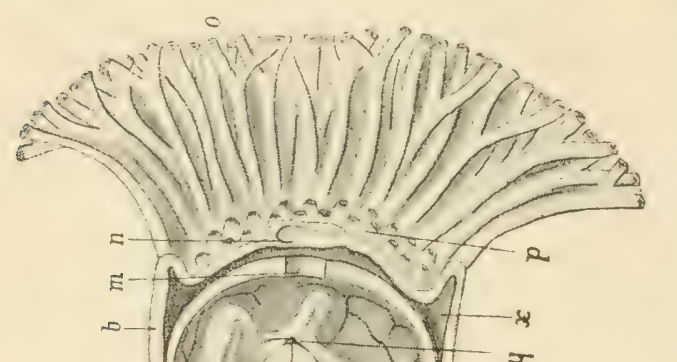

gleichen dem Callum der Pholaden. Die ächte aber ist sehr klein und zeigt sich ganz vorn an der Schale. Die beiden Schalenklappen dieser ächten, aber rudimentären Schale sitzen bei A spergillum fast sattelförmig über dem vorderen Ende der Röhre (Fig. 414), in deren Substanz sie fest eingeschmolzen sind. Isolirt würden sie nicht nur vorn und hinten, sondern auch unten ausserordentlich weit klaffen. Die Schalenröhre ist am hinteren Ende offen, entsprechend den Oeffnungen der Siphonen, am vorderen aber durch eine der Lage nach dem Callum der Pholadiden entsprechende runde Scheibe verschlossen, welche ähnlich wie der Schwamm einer Giesskanne von Löchern durchbohrt ist. Diese Löcher

Fig. 448. Anatomie ron Aspergillum dichotomum, Schale und Mantel der rechten Seite entfernt, nach LACAzE-DUTHIERS. $a$ Mündung des Analsipho, $b$ die Siphonen umschliessende Kalkröhre, c Analsipho, $d$ Branchialsipho, $e$ linkes Ctenidium, $f$ Enddarm mit After, $g$ Visceralganglion, $h$ rechtes Ctenidium, $i$ Herz, $k q$ Gonade, $l$ Cerebralganglion, $m$ vordere Mantel- und $n$ vordere Schalenöffnung (der Fussöffnung des Mantels anderer Muscheln homolog), $o, p$ zu Röhren verlängerte Löcher im vorderen Verschlussstück der Schale, $x$ Hohlraum zwischen Mantel und Schale, $y$ Pedalganglion an der Basis des rudimentären Fusses, $r$ Rumpf (enthaltend die Eingeweidemasse), s Mantelnerv, $t$ 4. Mantelöffnung, $u$ Kiemennerv, $v$ Analkammer, $w$ Branchialkammer der Mantelhöhle; $y$ äussere Oeffnung des Athemsipho. 
können sich am Rande oder auch auf der ganzen Fläche der Scheibe zu sich bisweilen dichotomisch theilenden Kalkröhrchen ausziehen. In der Mitte der Scheibe erhält sich bisweilen eine enge, spaltförmige Oeffnung, welche der darunter liegenden Fussöffnung des Mantels entspricht, hüufig aber vollständig verschlossen ist. Seltener erhält sich vorn in der ventralen Mittellinie noch eine Oeffnung, welche der früher besprochenen 4. Mantelöffnung entspricht.

Aspergillum steckt mit dem vorderen Ende im Schlamm oder Sand, aber die ganze Organisation des Thieres und besonders die Beschaffenheit des Gehäuses deuten auf eine frühere bohrende Lebensweise hin.

Clavagella, eine nahe Verwandte, bohrt in Gestein und Kalkschalen verschiedener Thiere. Das Gehäuse unterscheidet sich von dem des Aspergillum wesentlich dadurch, dass die Klappen der ächten Schale etwas grösser sind und dass nur die linke Klappe mit der Kalkröhre (falsche Schale) verschmolzen ist, während die rechte frei im Innern der Röhre liegt.

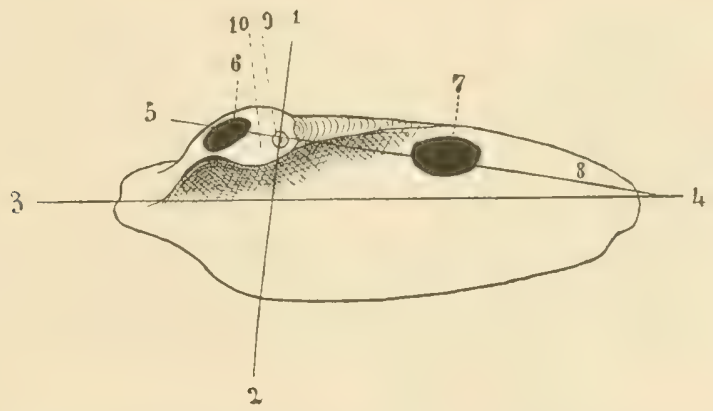

Fig. 449. Pholas dactylus, rechte Schale von innen, nach EGGER. 1-2 Drehaxe der Schalenbewegung, 3-4 Längsaxe der Schale, 5-8 Verbindungslinie der Schalenmuskeln, 6 vorderer Schalenmuskel, 7 hinterer Schalenmuskel, 9 Drehpunkt der Schalen, 10 nach aussen umgeschlagener, vorderer und oberer Schalenrand, an den sich der Schalenmuskel 6 anheftet, 6-9 kürzerer vorderer, 9-7 längerer hinterer Hebelarm.

Bei den Pholadiden spielt das zwar noch vorhandene Schlossband nicht mehr die Rolle eines Schalenöffners. In Folge einer eigenthümlichen Anordnung des vorderen Schalenschliessers wird hier das Oeffnen der Schale, soweit es möglich ist, durch Muskelthätigkeit ausgeübt. Der vordere und obere Rand der Schalenklappen ist nämlich nach aussen umgeschlagen, und der vordere Schalenmuskel setzt sich au dieso ausseren Umschlagsränder an. Die Ansatzstellen sind also jetzt äussere, nicht innere, und die gesammte Schale ist einem zweiarmigen, die Lüngsrichtung des Körpers einnehmenden Hehel zu vergleichen, dessen Angelpunkt an der Stelle des Schlosses der übrigen Muscheln liegt. Contrahirt sich der vordere Schalenmuskel, so werden die beiden kürzeren, den vor dem Schloss liegenden Schalenpartien entsprechenden Hebelarme einander genïhert, die längeren, hinteren und unteren Schalenpartien, als die längeren Hebelarme, von einander entfernt, $d$. h. die Schale klatft daun hinten und unten. Contrahirt sich der hintere Schalenschliesser, so werden die langen Hebelarme einander genähert, die Schale wird geschlossen. 


\section{Cephalopoda.}

Die Cephalopoden sind wohl alle von uralten Formen abzuleiten, welche eine g e kammerte $\mathrm{Schal}$ e besassen, in deren letzter, grösster Kammer das Thier sass, während die übrigen Kammern leer, d. h. mit Gas erfüllt und nur von einem Fortsatz des Thieres, dem sogenannten Sipho, durchzogeu waren. Unter allen heute noch lebenden Cephalopoden besitzt einzig und allein noch der lebende Vertreter der Tetrabranchiaten,

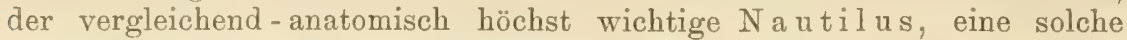
Schale. Zahlreiche fossile Verwandten des Nautilus, die man zu der Ordnung der $\mathrm{N}$ a utiloide a vereinigt hat, besassen eine ähnliche Schale, und das Gleiche gilt für die ungeheuer formenreiche Ordnung der A m monoidea, die man, mit Recht oder Unrecht, als nahe Verwandte der Nautiloidea, d. h. als Tetrabranchiaten betrachtet. Bei fast allen diesen Thieren ist die Schale - im Gegensatz zu der Gasteropodenschale - wenn sie überhaupt gewunden ist, nach vorn (exogastrisch) eingerollt.

Eine Gruppe von Nautiloiden, zu der nur sehr alte Formen gehören (Cambrium - Untersilur), die Endoceratida e, zeichnete sich dadurch aus, dass bei gerader (d. h. nicht eingerollter) Schale die Luftkammern nicht hinter der Wohnkammer, sondern neben ihr lagen. Ein eigentlicher Sipho war nicht vorhanden, sondern es erstreckte sich das obere Ende des Eingeweidesackes, durch die Gaskammern eingeengt, bis hinauf in die Spitze der Schale.

Bei den Nautiloiden liegen, wie bei Nautilus, die Luftkammern immer über der Wohnkammer, und werden von einem häutigen, dünnen Sipho durchsetzt, der nur bei älteren Formen noch dick war und den oberen eingeengten und verlängerten Theil des Eingeweidesackes darstellte (Fig. 416).

Es giebt unter den Nautiliden Formen mit endogastrischer Einrollung der Schale. Diese Einrollungsrichtung kommt aber nie bei Formen mit vollständiger Spiraleinrollung vor.

Die Sutur- oder Lobenlinie, welche der Insertionsstelle der Scheidewände an der Innenwand der Schale entspricht, ist bei den Nautiloiden im Vergleich zu den Ammonoidea einfach.

Folgende Tabelle giebt einen Ueberblick über die Hauptformen der Schalen der Natiloidea ${ }^{1}$ ):

„a) Orthoceras-Gruppe. Schale gerade oder unbedeutend gekrïmmt. Silur - Trias.

b) Cyrtoceras-Gruppe. Schale hornartig gekrümmt, aber nicht regelmässig spiral eingerollt. Cambrium - Perm.

c) Gyroceras-Gruppe. Schale regelmässig spiral eingerollt; Windungen sich nicht berührend. Silur - Perm.

d) Nautilus-Gruppe. Schale regelmässig spiral eingerollt; Windungen sich berührend oder umfassend. Silur - Gegenwart.

e) Lituites-Grup pe. Schale anfangs regelmässig spiral eingerollt, später sich gerade streckend. Silur."

Der Sipho verläuft bald durch die Mitte, bald durch die Vorder-, bald durch die Hinterseite der Scheidewände.

1) Steinmann-Döderlein, Elemente der Paläontologie, 1890. 
Die Schalen der fossilen Ammonoidea zeichnen sich durch die hohe Complication der Lobenlinie aus, die zickzackförmig gewunden verläuft. Diese Windungen können so complicirt werden, dass sie die Umrisse stark dendritisch verzweigter Blätter oder von Moosen etc. nachahmen. Dieses Verhalten wird hervorgerufen durch den entsprechend wellenförmigen Verlauf und die Fältelung des peripheren Theiles der Scheidewände, der sich an die Innenseite der Schale anheftet. Der Sipho ist bei den Ammonoidea immer sehr dünn und durchbohrt die Scheidewände fast immer an ihrer Hinterseite.

Ueber die Form der Ammonoidenschale sei folgende übersichtliche Zusammenfassung citirt $^{\mathbf{1}}$ ):

"Die Schale bildet in der Regel eine geschlossene, symmetrische Spirale mit sich berührenden oder umfassenden Windungeu. Die ältesten Formen sind zum Theil gerade, oder in der Jugend noch nicht vollständig eingerollt. In verschiedenen Zweigen des Ammonoidea-Stammes macht sich zu verschiedenen Zeiten (Trias, Jura, Kreide) die Tendenz zum Aufgeben der geschlossen symmetrischen Spirale und zur Bildung sogenannter $\mathrm{Neb}$ enformen geltend. Dieser Process geht in der Mehrzahl der Fälle auf die Weise vor sich, dass zuerst die Wohnkammer sich vom vorhergehenden Umfange abhebt und nach und nach auch die inneren Windungen sich von einander lösen, wobei die Umgänge aber in einer Ebene bleiben - Crioceras-Stadium. Häufig wächst die Schale eine Strecke weit in gerader Richtung, biegt dann aber hakenförmig um Ancyloceras-, Hamites-, Scaphites-Stadium, wenn sich die Ablösung auf die Wohnkammern beschränkt. Schliesslich entstehen ganz gestreckte Gehäuse - B a culites-Stadium. Weit seltener ist der Fall, in welchem die Windungen aus der Symmetrieebene heraustreten und sich nach Art einer Schneckenschale aufrollen, wobei die Windungen entweder mit einander in Berührung bleiben oder sich von einander ablösen - Turrilites-Stadium."

Die Schale aller bekannten. Dibranchiaten, sowohl der ausgestorbenen wie der lebenden, befindet sich in einem mehr oder weniger rudimentären Zustande, insofern sie nirgends mehr das Thier auch nur in geringem Maasse heherbergen kann. Es handelt sich ausserdem immer um eine innere Schale, welche, auf der Vorderseite des Eingeweidesackes gelegen, von oiner Falte des Integumentes überwachsen und bedeckt wird. Nur bei Spirula (Fig. 417) ist diese Umwachsung keine vollständige, indem die Schale an der Spitze des Eingeweidesackes noch eine Strecke weit frei zu Tage tritt.

Wir wollen zunächst die fossile Belemnitenschale (Fig. $450 \mathrm{C}$ ) betrachten. Diese Schale ist kegelförmig, gerade, gekammert, mit nahestehenden Scheidewänden, welche an ihrer Hinterseite (Bauchseite) zum Durchtritt des fadenförmigen Sipho durchbrochen sind, der von kurzen Kalkdüten umschlossen ist. Die Spitze dieser eigentlichen Schale (Phragmocon) steckt in einer kegelförmigen Kalkscheide (Rostrum), welche sich gewöhnlich allein erhalten hat. Die vordere Wand der letzten Kammer verlängert sich nach unten zu einem dünnen, breiten Fortsatz, dem sogenannten Proostracum.

1) Steinmand-Döderlein, Elemente der Paläontologie, 1890. 
Bei Spirulirostra (Fig. 450 D) beginnt die Schale (Phragmocon) sich nach hinten (endogastrisch) einzukrümmen. Das Rostrum ist dreieckig, nach oben spitz.

Bei Spirula (E) geht die Krümmung in eine spiralige, endogastrische Einrollung über. Der Sipho ist dick, in seiner ganzen Ausdehnung von Septaldüten umgeben. Das Rostrum ist rudimentär. Ein Proostracum fehlt.

Wieder von Belemnites ausgehend, können wir die Modification der Schale nach einer anderen Richtung verfolgen. Der Phragmocon wird immer kleiner und kürzer im Verhältniss zu dem immer länger werdenden Proostracum (Beispiel Ostracoteuthis F). Auch die Scheide wird dünner und unansehnlicher. Schliesslich reducirt sich die Schale auf einen sehr kleinen hohlen Kegel am Ende einer langen, schmalen, hornigen Lamelle, die dem Proostracum entspricht und bei den lebenden Decapoden als Gladius oder Calamus bezeichnet wird (Loligo, Ommastrephes G, Onychoteuthis). Bei Dosidicus ist dieser Endkegel schon fast solid,

A

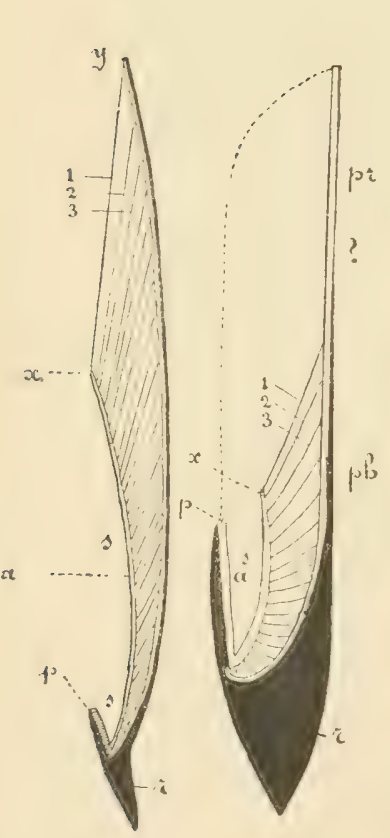

c

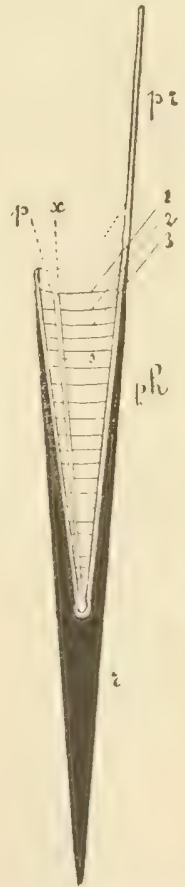

D

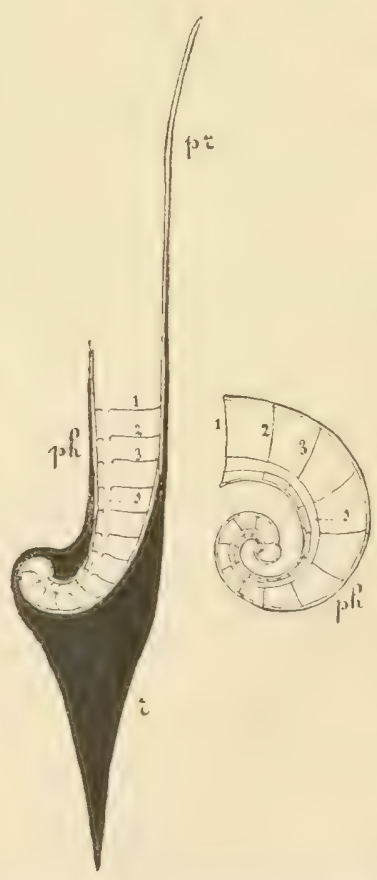

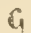

$H$

Fig. 450, $\boldsymbol{A}-\boldsymbol{H}$ Schematische Medianschnitte durch die Schalen $\nabla 0 n$ lebenden oder fossilen Dibranchiaten, von der rechten Seite. Oben in der Figur ist unten im Eingeweidesack, unten in der Figur entspricht der dorsalen Spitze des Eingeweidesackes, links und rechts in der Figur ist Hinter- und Vorderseite der Schale (vergl. die Orientirung des Cephalopodenkörpers p. 602) $\boldsymbol{A}$ Sepia $\boldsymbol{B}$ Belosepia (fossil). $\boldsymbol{C}$ Belemnites (fossil). $\boldsymbol{D}$ Spirulirostra (fossil). $\boldsymbol{E}$ Spirula. $\boldsymbol{F}$ 0stracotenthis (fossil). $\boldsymbol{G}$ 0mmastrephes. $\boldsymbol{H}$ Loligopsis. $p r$ Gekammerte Schale $=$ Phragmocon, $p h$ Proostracum, $r$ Rostrum $=$ Scheide, $s$ Siphonalkanal, Siphonalraum, welcher den Sipho beherbergt, 1, 2, 3 letzte, vorletzte und drittletzte (jüngste) Scheidewand, $a$ vordere Wand des Sipho, $p$ hinterer, $x$ vorderer Rand der ersten Septal- oder Siphonaldute $=$ vorderer oder hinterer Mündungsrand des Siphonalkanales. 
bei Loligopsis (H) stellt er nur noch eine Verdickung am oberen Ende des Gladius dar, und bei anderen Decapoden ist er am Gladius überhaupt nicht mehr nachweisbar. Bei den Octopoden ist die Schale völlig verschwunden.

Wieder von Belemnites ausgehend, entwickelt sich die Schale nach einer dritten Richtung, nach der Richtung der Sepienschale oder-schulpe hin. Die Zwischenform ist Belos epia (B) aus dem Eocän (wenn ich die Schale richtig interpretire). Die Schale ist etwas gekrümmt, die Scheidewände dicht gedrängt und schief von oben und hinten nach unten und vorn gerichtet. Sie sind hinten von einem ausserordentlich dicken Sipho durchsetzt, der in seiner ganzen Ausdehnung von einer vorn sehr dickwandigen Düte umgeben ist. So erscheint der allseitig geschlossone Hohlraum des Sipho als ein weiter, in die gekammerte Schale an ihrer Hinterseite eingeseukter Trichter. Die Schale (Phragmocon) steckt in einem dicken, stark entwickelten Rostrum, und ihre vordere und seitliche Wand setzt sich nach unten in einen breiten und nach hinten concaven Schulp (Proostracum?) fort.

Diese Verhältnisse erscheinen bei der lebenden Sepia auf die Spitze getrieben (Fig. 450 A, Fig. 451). Der Siphonalraum breitet sich muldenförmig über dem Eingeweidesack aus. Der vor ihm liegende Theil der Scheidewände der gekammerten Schale zieht noch viel steiler von hinten und oben nach vorn und unten, so dass bei Betrachtung der Sepienschulpe von hinten die letzte Scheidewand in ihrer ganzen Ausdehnung frei zu Tage tritt (Fig. 451, 1). Die Scheidewände sind dünne Kalklamellen, die dicht übereinander liegen und nur durch sehr niedrige gasführende Spalträume (Luftkammern) getrennt sind, welche von senkrechten Pfeilerchen durchsetzt werden. So wird diese Schulpe oder Schale sehr leicht, specifisch leichter als Wasser. Hinter dem Siphonalraum, an der hinteren, ausserordentlich verkürzten Schalenseite, liegen die kurzen Scheidewände fest aneinander, ohne sie trennende Gasräume.

Das dorsale Ende der Schale steckt in einem kleinen, spitzen Rostrum. Ihre ganze Vorderseite ist bedeckt von einer dünnen Conchyolinlamelle, die überall seitlich über ihren Rand hinausragt und selbst wieder von einer Kalkschicht, einer unteren und vorderen Ausbreitung des Rostrums, bedeckt ist.

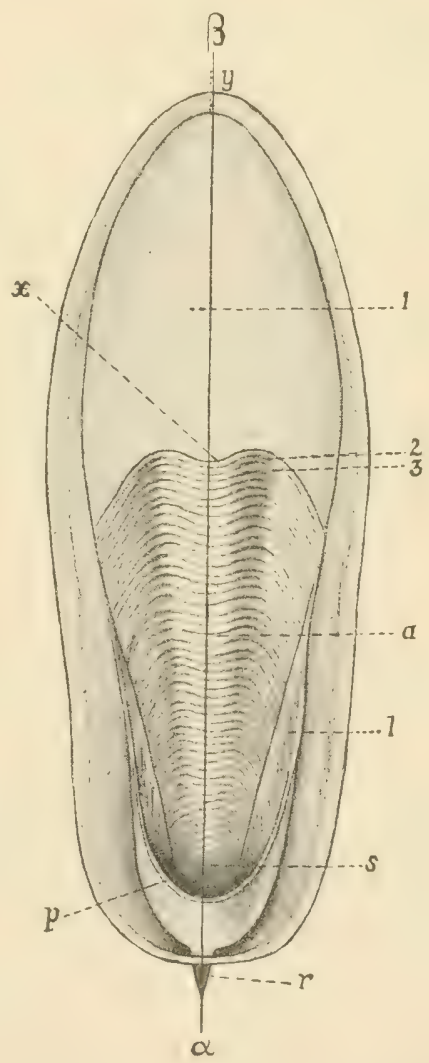

Fig. 451. Schale einer Sepia (aculeata), von der Hinterseite (physiol. Bauchseite). Bezeichnungen wie in Fig. 450. Man sieht die letzte Scheidewand 1 in ihrer ganzen Ausdehnung und man siebt in die fast pantuffelförmig erweiterte Siphonalböhle hinein. $l$ Lateralwand der Siphonalhöhle, $\alpha-\beta$ Richtung des Schnittes, wolcher in Fig. $450 \boldsymbol{A}$ schematisch abgebildet worden ist. Man vergleiche die beiden Figuren. Im Wesentlichen nach D'ORBIGNY. 
Wir haben oben gesagt, dass bei den Octopoden die Schale verschwunden ist. Eine Ausnahme von dieser Regel macht das Weibchen von Argonauta, welches eine spiralig nach vorn (exogastrisch) eingerollte, leichte und dủnne äussere Schale besitzt, welche nirgends mit dem Thier fest zusammenhängt und welche, wohl mehr als zum Schutze des Körpers, zur Aufnahme der Eier dient (Fig. 419, 420). Diese Schale wird festgrehalten und umfasst von dem lappenartig verbreiterten vorderen Armpaar. Sie entbehrt der Perlmutterschicht, ist porzellanartig und wird, wie es scheint, wesentlich rom Integument des Eingeweidesackes und des Mantels erzeugt. Das dorsale Armpaar soll nur die sogenannte schwarze Schicht auf deren Aussenfläche ablagern.

Die herrschende Ansicht über die Argonautaschale ist die, dass sie der Schale der übrigen Cephalopoden nicht homolog, sondern eine besondere Bildung des Argonautaweibchens sei. Dem entgegen wird neuerdings die Ansicht mit Geschick vertreten, dass die Argonautaschale eine Ammonitenschale sei, welche die Scheidewände und mit ihnen die Siphonalöffnungen, ferner die Perlmuttersubstanz verloren habe. - Sollte sich diese Auffassung als richtig erweisen, so müssten die Hauptabtheilungen der Cephalopoden anders als bisher gruppirt werden. Die Eintheilung in Tetra- und Dibranchiaten müsste fallen, da wir nicht wissen, ob nicht die fossilen Ammonoidea Vierkiemer waren und wann sie aus Vierkiemern zu Zweikiemern geworden sind. Man müsste dann die Cephalopoden eintheilen in: 1) Nautiloidea mit der lebenden Gattung Nautilus, 2) Ammonoidea mit den noch lebenden Octopoden, und 3) Belemnoidea mit den noch lebenden Decapoden.

Zweiklappige, als Aptychen bezeichnete Schalenstücke, die theils in der Wolnkammer von Ammonoiden, theils für sich isolirt aufgefunden werden und deren Zugehörigkeit zum Körper bestimmter Ammonoidenarten nachgewiesen ist, hat man bald als Schutzapparate der Nidamentaldrüse, bald als Deckel zum Verschluss des Gehäuses, bald als Analoga oder Homologa der Trichterknorpel der Decapoden gedeutet, ohne dass bis jetzt eine dieser drei Ansichten zu allgemeiner Anerkennung gelangt wäre.

\section{Uebersicht iiber die Anordnung der Organe der Mantelhöhe und der in ihl liegenden äusseren IIindungen innerer Organe.}

Wir halten es für zweckmässig, dieses Kapitel in die vergleichende Anatomie der Mollusken einzuschieben. Es dient in erster Linie dazu, das Verständniss der Asymmetrie der Gasteropodenorganisation zu erleichtern und eine Vereinfachung der Darstellung in späteren Kapiteln zu erzielen.

Der Nutzen einer solchen Uebersicht leuchtet ein, wenn man erwägt, dass zahlreiche wichtige Organe in der Mantelhöhle auf einen relativ engen Raum zusammengedrängt sind, und dass mit Ausnahme der Mundöffnung des Darmkanals alle Oeffuungen der wichtigen innern Organe in der Mantelhöhle liegen. Man spricht deshalb wohl auch von einem circumanalen Organcomplex, dieser Ausdruck ist besonders für die Gasteropoden passend. Passender, weil für fast sämmtliche Mollusken gültig, erscheint mir der Ausdruck pallealer Organcomplex, worunter nicht nur die Mantelorgane selbst, sondern auch die in der 
Mantelhöhle liegenden Ausmündungen innerer Organe verstanden sein sollen.

Die wichtigsten Theile des pallealen Complexes sind: das C tenidium (Ki e m e), das Osphradium (Spenger'sches Organ, Geruchsorgan, Nebenkieme), die Hypobranchialdrüse, der After und oft auch das Rectum, die Nephridialöffnungen und oft auch die Niere; die Geschlechtsöffnungen, ferner häufig das Pericard mit dem eingeschlossenen $\mathrm{Herzen}$.

Wir müssen von den Verhältnissen der ursprünglichsten aller lebenden Molluskenformen, der Chitoniden, ausgehen, welche schon p. 595 geschildert worden sind.

Der After liegt am hinteren Körperende median in der Mantelrinne, jederseits davor die Nephridialöffnung und wieder jederseits vor dieser die Genitalöffnung.

\section{A) Prosobranchiata.}

a) Diotocardia. Bei Fissurella ist der palleale Organcomplex noch vollständig symmetrisch; aber wir finden ihn, ebenso wie die Mantelfalte und die Mantelhöhle, anstatt hinten, wie dies bei Chiton der Fall war, vorn am Eingeweidesack. Wir haben uns vorzustellen, dass der gesammte Complex sich von hinten dem rechten Körperrand entlang nach vorn verschoben hat, so dass die ursprünglich linke Kieme jetzt vorn rechts, die ursprünglich rechte jetzt vorn links zu liegen kommt. Dasselbe gilt auch von den übrigen Organen des Complexes.

Um eine Verwechselung mit den übrigen Gasteropoden und den übrigen Mollusken überhaupt zu vermeiden, werde ich in diesem Kapitel die hypothetische ursprüngliche Lage eines Organes durch ein in Klammer gesetztes ur - ursprünglich rechts - oder ul - ursprünglich links bezeichnen.

Oben in der Mantelhöhle von Fissurella, unter dem Loch in Mantel und Schale in der Mittellinie des Körpers, liegt der After, dicht rechts davon die rechte (ul), links davon die linke (ur) Nephridialöffnung und ebenso symmetrisch rechts und links die rechte (ul) und linke (ur) Kieme. Gesonderte Osphradien fehlen. Genitalöffunugen fehlen, da die Geschlechtsdrüse in das rechte Nephridium einmündet.

$\mathrm{Haliotis.} \mathrm{In} \mathrm{der} \mathrm{nach} \mathrm{links} \mathrm{verschobenen} \mathrm{Mantelhöhle} \mathrm{verläuft,} \mathrm{an}$ der Mantelfalte befestigt, der Enddarm ziemlich weit nach vorn, so dass der After eine beträchtliche Strecke weit vom hinteren Grunde der Höhle entfernt ist. Rechts vom Enddarm das rechte (ul), links davon das grössere linke (ur) Ctenidium, beide am Mantel befestigt, weit nach vorn ziehend. Unweit der Basis der Kiemen, im oberen und hinteren Grund der Mantelhöhle rechts und links die rechte und linke Nephridialöffnung. Zwischen dem Enddarm und der linken Kieme, ebenfalls auf dem Mantel, die langgestreckte, stark ausgebildete Hyporanchialdrüse (Schleimdrüse), die soweit nach vorn reicht, wie die Kieme. Nur ein kleiner Theil der Drüse liegt rechts zwischen Rectum und rechter Kieme, soweit das Rectum reicht. Es existiren zwei Osphradien, welche als zwei Streifen dem freien, der Mantelhöhle zugekehrten Rande der Kiemenaxe entlang laufen.

Turboniden und Trochiden. Nur die linke Haliotiskieme (ur) erhält sich, sie liegt weit links an der Decke der Mantelhöhle (Mantel). 
Das Rectum geht an dieser Decke weit nach vorn. Zwei Nephridialöffn ung $\mathrm{n}$ im Grunde der Mantelhöhle auf Papillen zu beiden Seiten des Rectums. Die Hy pobranchialdrüse zeigt sich auf verschiedenen Stadien der Entwickelung, am besten ist sie bei den Turboniden ausgebildet. Ihre grösste Entfaltung nimmt sie zwischen Rectum und Kieme, also rechts von der Kieme und links vom Rectum. Doch kommt bei Turboniden auch noch ein Theil rechts vom Rectum vor. Osphradium diffus auf der Kiemenaxe.

Neritina. Nur eine Kieme (linke Haliotiskieme ur), welche ziemlich weit nach rechts herübergerückt ist. End d a rm asymmetrisch ganz rechts in der Athemhöhle, sich in der Mantelhöhle weit nach vorn erstreckend, so dass der After nahe dem rechten Rande der Mantelspalte liegt. Nur eine Nephridialöffnung links von der Basis der Kieme ganz oben im Grunde der Mantelhöhle. Die Innenfläche des Mantels zwischen Rectum rechts und Kieme links ist drüsig und stellt die wenig differenzirte Hypobranchialdrüse dar. Die Geschlechtsöffnung dicht neben dem Anus.

Docoglossa. Bei den Patelliden (Fig. 452, 453) ragt vom Mantelgrunde ein kurzes Stück Enddarm kegelförmig in die wenig ansehnliche Mantelhöhle vor. Dieser Analkegel liegt nicht in der Mittellinie, sondern ist merklich nach rechts verschoben. Rechts und links von ihm liegen auf kurzen, kegelförmigen Papillen die Oeffnungen der beiden Nephridien. Eine gesonderte Geschlechtsöffnung fehlt. Bei einigen Formen (Tectura, Scurria, Acmaea) finden wir links in der Mantelhöhle eine Kieme, welche am Mantel befestigt ist. Ueber die sonstigen Kiemenverhältnisse der Patelliden rergleiche weiter unten. Auf dem Boden der Kiemenhöhle treffen wir ferner rechts und links ein Osphradium, in Form eines kleinen Flecks von Sinnesepithel, das auf einem kleinen Höcker liegen kann. Ob bei Patella ein dicht an jedem Osphradium liegender Höcker, der einen von Scheidewänden durchsetzten Blutraum enthält, als rudimentäre Kieme gedeutet werden

Fig. 452 .

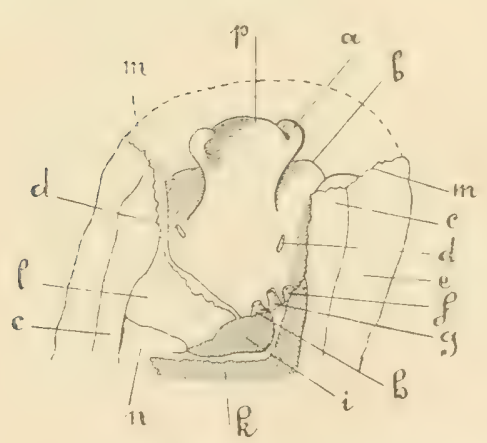

Figr. 453 .

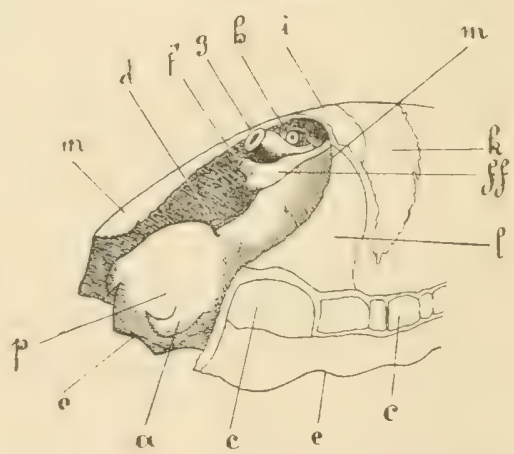

Fig. 452. Vorderer Theil von Patella von oben, nach Entfernung der Mantelfalte, nach RAY-LANkester. a Tentakel, $b$ Fuss, c Fussmuskeln (Schalenmuskel), $d$ Osphradien, $\varepsilon$ Mantelfalte, $f$ Mündung des rechten Nephridiums, $g$ Afterpapille und After, $h$ Papille und Oeffnung des linken Nephridiums, $i$ linkes Nephridium, $k$ rechtes Nephridium, $l$ Pericard, $n$ Verdauungsdrüse (Leber), $m$ Schnittrand des abgeschnittenen Mantels, $p$ Schnauze.

Fig. 453. Dasselbe Präparat von der linken Seite. Bezeichnungen wie in der vorhergehenden Figur. $o$ Mund. 
kann, erscheint namentlich aus dem Grunde zweifelhaft, weil die zwei Höcker auf dem Boden der Mantelhöhle sich erheben, während z. B. bei Tectura, wo linkerseits noch eine ächte Kieme vorkommt, diese Kieme weit entfernt von dem linksseitigen Osphradium und in der gewöhnlichen Lage an der Decke der Mantelhöhle (Innenfläche des Mantels) liegt.

b) Monotocardier. In dieser formenreichen, aber der Organisation nach sehr einheitlichen Abtheilung ist die Anordnung des pallealen Organ-

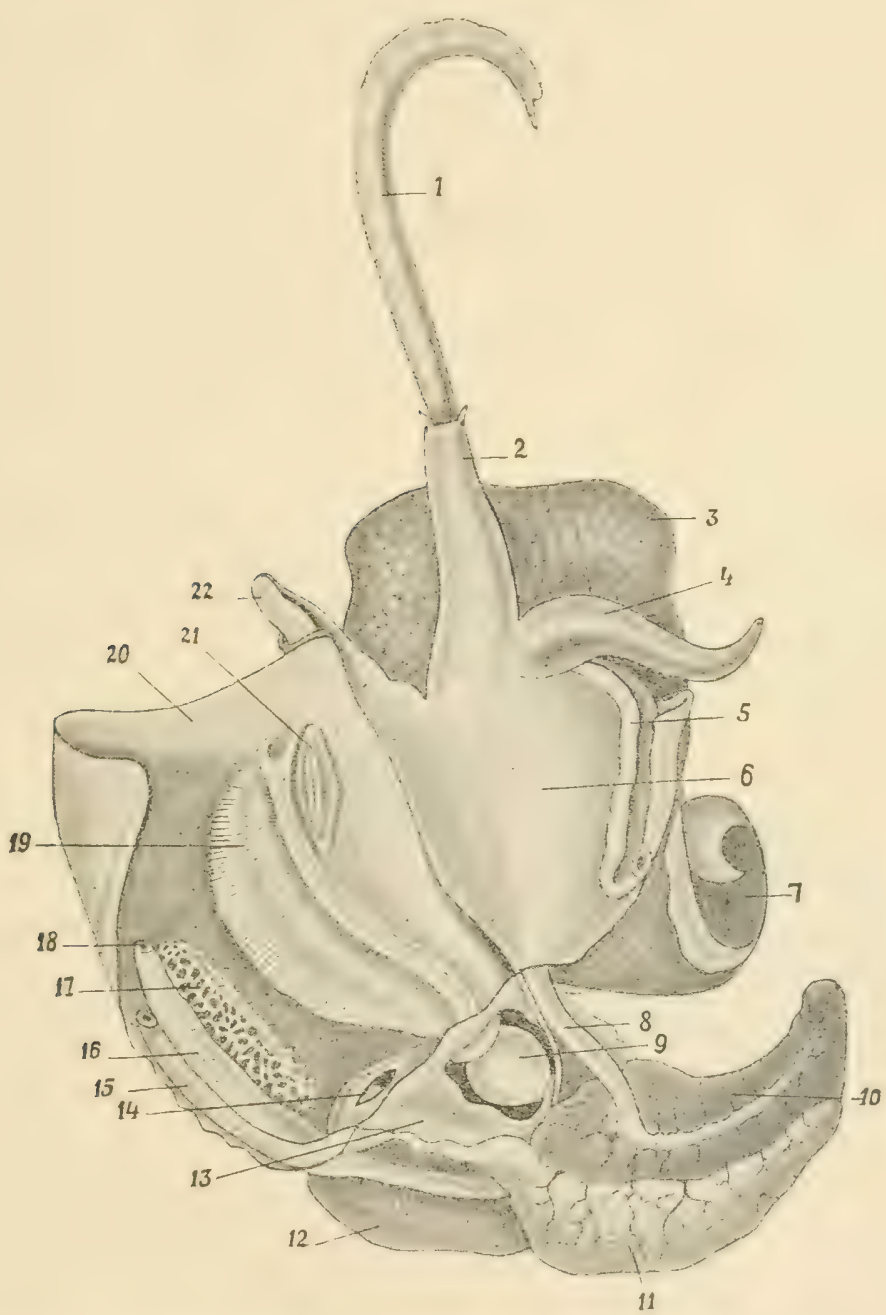

Fig. 454. Pyrula tuba, Månnchen, aus der Schale herausgenommen, nach SouLEYET. Mantel an der Basis und rechts aufgeschnitten und auf die linke Seite gelegt. Die Pallealorgane liegen deshalb invers. 1 Rüssel, 2 Schnauze, 3 Fuss, 4 Penis, 5 Samenleiter, Fortsetzung bei 15, 6 Boden der Mantelhöhle = Nackenintegument, 7 Spindelmuskel, 8 Darm, 9 Herz im aufyeschnittenen Pericard, 10 Verdauungsdrüse (Leber), 11 Hoden, 12 und 13 Niere, 14 Nierenöffnung, 15 Samenleiter, 16 Enddarm, 17 Hypobranchialdrüse, 18 After, 19 Ctenidium (Kieme), 20 Mantel, 21 Osphradium, 22 Athemsipho. 
complexes im Ganzen eine sehr einförmige. Immer ist die einzige Geschlechtsöffnung von der einzigen Nephridialöffnung getrennt. Die Lage der Organe in der geräumigen Mantelhöhle (Fig. 454) ist von rechts nach links folgende:

1) Zu äusserst rechts der Ausführungsgang der Geschlechtsproducte (Eileiter oder Samenleiter), der in der Mantelhöhle mehr oder weniger weit nach vorn verläuft.

2) Ihm links dicht anliegend, doch schon ganz an der Decke der Mantelhöhle, das Rectum.

3) Links vom Rectum ganz hinten und oben im Grunde der Mantelhöhle in der Scheidewand, welche diese von der darüber und dahinter liegenden Niere trennt, die spaltförmige Nephridialöffnung. Eine Ausnahme hiervon machen Paludina und Valvata, bei welchen diese Oeffnung an das Ende eines am Mantel nach vorn verlaufenden Harnleiters verschoben wird.

4) Es folgt auf der Decke der Mantelhöhle (innere Oberfläche des Mantels) die verschieden stark entwickelte Hypobranchialdrüse (Schleimdrüse, Purpurdrüse), dann

5) schon ganz links ebenfalls auf der Decke der Mantelhöhle das einzeilig gefiederte $\mathrm{Ctenidium} \mathrm{(das} \mathrm{linke} \mathrm{Ctenidium} \mathrm{[ur]} \mathrm{von} \mathrm{Haliotis}$ und Fissurella), an dessen Basis, am Grunde der Mantelhöhle, oft noch das Pericard mit der durchschimmernden Herzkammer und den Vorhof sichtbar wird.

6) Schliesslich zu äusserst links das Osphradium, als immer wohl ausgehildetes, scharf umschriebenes, fadenförmiges oder zweizeilig gefiedertes, der Decke der Mantelhöhle aufsitzendes Organ.

Die Topographie des pallealen Organcomplexes der Heteropoden, die sich mit Formen wie Atlanta eng an die übrigen Monotocardier anschliessen, bedarf einer neuen genauen Untersuchung. Das Osphradium liegt an der Basis der Kiemen.

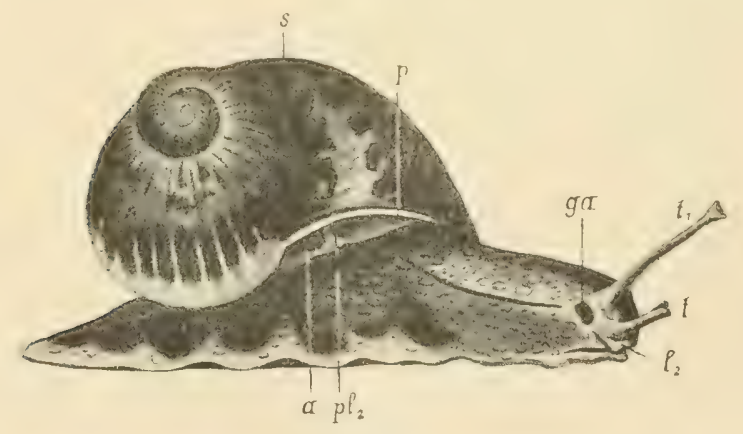

B) Pulmonata.

Fig. 455. Helix pomatia, ganz ausgestreckt, von der rechten Seite, nach HowEs. a Anus, im Athemloch $p l_{2}$ zu Taye tretend, s Schale, $p$ Mündungsrand der Schale, ga Geschlechtsöffnung, $t_{\mathrm{t}}$ Augententakel, $t$ vordere Teutakel, $l_{2}$ Oberlippe.

Bei den Pulmonaten ist die einfache oder doppelte ( $q$ und $\delta$ ) Geschlechtsöffnung (Fig. 455) aus dem pallealen Organcomplex ausgeschieden, sie lieģt ausserhalh der Mantelhöhle seitlich rechts am Kopfe oder Nacken. Bei Onchidium liegt die männliche Oeffnung vorn unter dem rechten Tentakel, die weibliche am hinteren Körperende in der Nähe des Afters.

Die Anordnung der übrigen Theile des pallealen Organcomplexes ist typisch, d. h. abgesehen von aberranten Formen wie Daudebardia, Testacella, Onchidium, folgende: 
(Wir erinnern uns dabei, dass die Mantel- oder Lungenhöhle nur durch das rechts liegende Athemloch mit der Aussenwelt communicirt.)

1) Ganz rechts in der Lungenhöhle liegt das Rectum, wolches mit dem After in das Athemloch ausmündet.

2) Im hinteren Grunde der Höhle, an der Decke lerselben liegt das. Nephridium (Niere).

3) Links neben der Niere, ebenfalls am hinteren und oberen Grunde. und an der Decke der Lungenhöhle liegt der Herzbeutel, mit der Herzkammer und der Vorkammer in seinem Innern. Die Vorkammer liegt vor der Herzkammer. Aus der Kammer entspringt nach oben und hinten der Aortenstamm, aus der Vorkammer die an der Decke der Lungenhöhle nach vorn verlaufende Lungenvene.

4) An der ganzen, von den bisher citirten Organen frei gelassenen Decke der Lungenhöhle (innere Oberfläche des Mantels), also vor der Niere und vor dem Pericard breitet sich das respiratorische Gefässnetz aus.

5) Ein Osphradium ist bis jetzt nur bei den Basommatophoren (Planorbis, Physa, Limnaeus) in der Nähe des Athemloches und unter den Stylommatophoren bei Testacella im hintersten Winkel und am Boden der Lungenhöhle beobachtet worden.

Der Boden der Lungenhöhle (Rückenintegument des Nackens) ist glatt, ohne Organe.

Eine besondere Besprechung verdient das verschiedene Verhalten des Nierenausführungsganges (Fig. 456).

1) Es öffnet sich die Vorderseite des Nierensackes auf einer einfachen Papille in die 1 [antelhöhle (Bulimus oblongus, Planorbisarten) (Fig. $456 \mathrm{~A}$.

2) Die Papille verlängert sich in einen gerade nach vorn verlaufenden Ureter (primärer Ureter). Die meisten Basommatophoren. Arten von Bulimus, Cionella, Pupa, Helix (B).

3) Der Ureter verläuft neben der Niere zurück und öffnet sich im Grunde der Lungenhöhle. Testacella, Helixformen (C).

4) Zu dem primären Harnleiter gesellt sich ein secundärer, der sich von der Wand der Lungenhöhle abschnürt und zunächst eine bald offene, bald mehr oder weniger geschlossene Rinne bildet, in welcher die Excrete aus dem Grund der Lungenhöhle zum Athemloch befördert werden. Arten von Bulimus und Helix (D).

5) Der geschlossene Ureter mündet allein oder mit dem After zı-

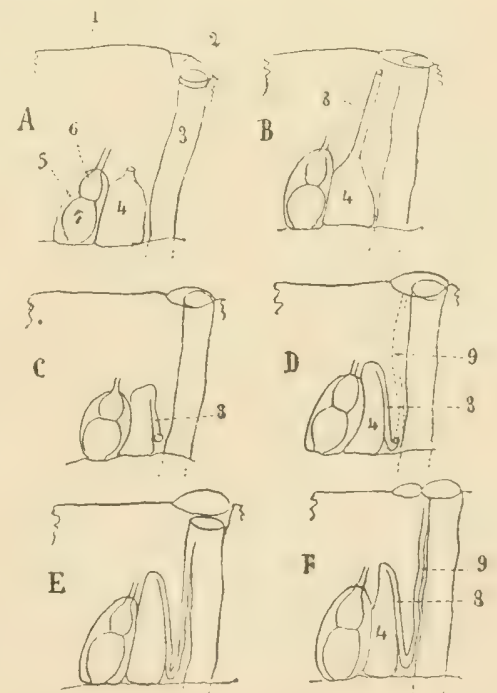

Fig. 456. 6 Schemata zur Demonstration der verschiedenen Ausmündung der Niere bei Pulmonata. Die Mantelorgane so gezeichnet, als ob sie durch den von oben betrachteten Mantel hindurch sichtbar wären. 1 Freier Mantelrand, 2 Athemloch, 3 Rectum, 4 Niere, 5 Pericard, 6 Vorhof, 7 Herzkammer, 8 primärer Harnleiter, 9 secundärer Harnleiter, in $\boldsymbol{D}$ eine Furche. Weitere Erläuterung im Text. 
sammen in die Lungenhöhle. Arten von Bulimus, Helix, Daudebardia, Vitrina, Hyalina, Zonites, Arion etc. (E).

6) Das Ende des secundären Ureters und das Ende des Rectums. bilden zusammen eine Kiloake, welche gesondert von der Lungenhöhle am Athemloch ausmündet. Limax, Amalia, Spec. von Daudebardia (F).

Der primäre Ureter ist, wo er an der Niere zurückläuft, äusserlich nicht von der Nierensubstanz zu unterscheiden, so dass es oft den Anschein hat, als ob der Harnleiter vom hinteren Ende der Niere entspringe.

Ganz besonders grosses Interesse beanspruchen die Lageveränderungen, welche die Organe des Mantelcomplexes in der Reihe der räuberischen Pulmonaten erleiden. Diese Reihe, deren Anfangspunkt wahrscheinlich in der Nähe der Hyalinen unter den Stylommatophoren zu suchen ist, geht durch die Daudebardien zu der merliwürdigen Gattung Testacella. In dieser Reihe finden wir eine fortschreitende Verkleinerung des Eingeweidesackes, eine Verlagerung desselbeu an das hinterste Leibesende, Vereinfachung und Verkleinerung der Schale, Zurückverlagerung der Leber und Geschlechtsorgane aus dem Eingeweidesack in den Nackentheil der Leibeshöhle, der sich streckt und nun gewissermaassen auf die ganze Länge der Rückenseite des Fusses zu liegen kommt. Bei Testacella und gewissen Daudebardien schliesslich ist der Eingeweidesack verschwunden, und an seiner Stelle liegt nur noch die von der Schale bedeckte Lungenhöhle, die sich bis in die Spitze der Schale hinauferstreckt. Der Boden dieser Höhle und mit ihm die ganze Lungenhöhle mit Mantel und Schale sinkt in den Körper ein, so dass Testacella, welche ihre Beute, die Regenwürmer, bis in deren Röhren in die Erde verfolgt, in ihrer schlanken Gestalt vorzüglich dieser Lebensweise angepasst ist und auch nicht mehr durch die ziemlich flache Schale am Hinterende des Körpers, welche nicht über die umgebende Obertï̈che des Körpers hervorragt, in ihren Bewegungen gehindert ist.

Mit diesen Veränderungen aber, hauptsächlich mit der Verlagerung des Eingeweidesackes an das Hinterende des Körpers, gehen wichtige Umlagerungen im pallealen Organcomplex Hand in Hand, die schliesslich zur Opisthopneumonie führen.

Es muss betont werden, dass der Mantel überall mit dem darunter liegenden Rückenintegument verwachsen ist, bis auf das rechts gelegene Athemloch, das mit Bezug auf die Lungenhöhle immer weiter nach $\mathrm{h}$ inten rückt, bis es schliesslich bei Testacella fast terminal liegt.

Den ersten wichtigen Schritt in der Verlagerung des pallealen Organcomplexes sehen wir bei $\mathrm{Daudebardia} r u f a$ verwirklicht. $\mathrm{D}$ as Pericard liegt nämlich hier, anstatt weit hinten im Grunde der Lungenhöhle, weit vorn an ihrer Decke, so dass weitaus der grösste Theil des vascularisirten Lungengewebes an der Decke hinter dem Pericard liegt (Fig. 457 A). Daudebardia rufa ist also in Wirklichkeit schon opisthopneumon. Aber diese Opisthopneumonie hat die gegenseitige Lage von Herzkammer und Vorkammer noch nicht beeinflusst. Die Vorkammer ist nach wie vor vor der Herzkammer gelegen, so dass die Lungenvene von der Vorkammer aus nach hinten, die Aorta aber, die fast ausschliesslich zu der den weitaus grössten, vor dem Eingeweidesack liegenden vorderen Körpertheil versorgenden vorderen oder Kopfarterie wird, von der Herzkammer nach vorn $\mathrm{zu}$ verlaufen genöthigt ist. 
Bei einer anderen D a u d bardia, D. sa ulcyi, finden sich ähnliche Verhältnisse, nur bilden Niere und Herzbeutel zusammen eine Art Sack, welcher von der Decke der Lungenhöhle in diese herunterhängt. In diesem Sacke liegt der Harnleiter dorsalwärts, das Pericard ventralwärts von der Niere. Der Boden der Höhle senkt sich rechts und links tief in die darunter liegende Körperpartie ein.
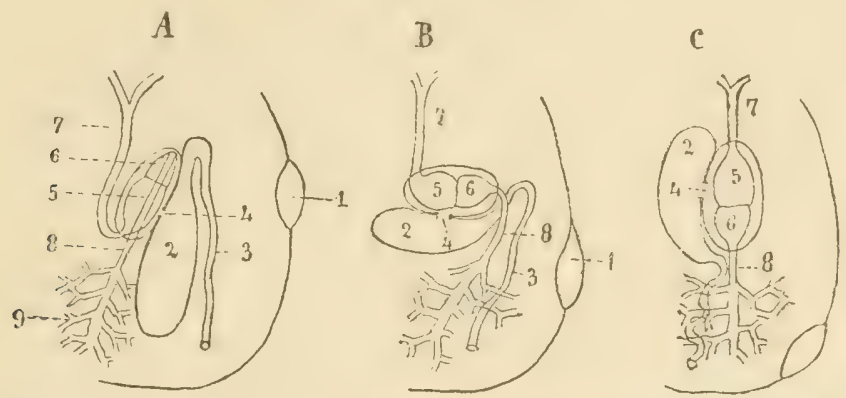

Fig. 45\%. Schemata zur Demonstration der Lagerungsverhältnisse der Mantelorgane bei Daudebardia und Testacella (unter Benutzung von Figuren von PLATE). Mantelorgane gezeichnet wie bei Fig 456. A Daudebardia rufa. $B$ Hypothetisches Stadium, Palleal. complex von $\boldsymbol{A}$ um $90^{\circ}$ gedreht. $\boldsymbol{C}$ Testacella. 1 Athemloch, 2 Niere, 3 Harnleiter, 4 Rezopericardialöftinung (Nierentrichter), 5 Herzkammer, 6 Vorhof, 7 Aorta, 8 Lungenvene, 9 Lungengefässnetz.

Man hat sich nun vorzustellen, dass an der vorn gelegenen Vorkammer die nach hinten verlaufende Lungenvene, an der hinter der Vorkammer liegenden Kammer die nach vorn verlaufende Aorta einen Zug ausüben, so dass diese Theile, welche in der geraden Flucht von Aorta und Vene eine Knickung hervorrufen, in e in e Flucht mit diesen Gefässen zu liegen kommen. Dann kommt die Kammer vor die Vorkammer zu liegen. Die Kiemenvene mündet dann hinten in die Vorkammer ein, diese in die vor ihr liegende Kammer, und letztere giebt vorn die nach vorn ziehende Aorta ab. Mit einem Wort, das Pericard (mit Herzkammer und Vorkammer) hat sich um $180^{\circ}$ gedreht. Dieser Drehung ist auch die mit dem Pericard durch die Renopericardialöffnung zusammenhängende Niere gefolgt, so dass sie jetzt nicht mehr an der rechten, sondern an der linken Seite des Pericards liegt, während die Mündung des Harnleiters an der alten Stelle verblieb. Der ganze Reno-Pericardialcomplex hat gegenüber der typischen Lage desselben bei den Pulmonaten eine vollständig inverse Stellung erlangt, wie sie für Testacella charakteristisch ist. Von Testacella ist ferner noch zu bemerken, dass der Boden der Lungenhöhle sich vorn in Form eines grossen Luftsackes in den darunter liegenden Körper einstülpt. Die Wandungen dieses Luftsackes sind nicht vascularisirt, und es dient derselbe wahrscheinlich nur als Luftreservoir. Bei vielen Testacellen hängt der Reno-Pericardialcomplex in Form eines Sackes von der Decke der Lungenhöhle in den Luftsack herunter.

Noch viel abweichender als bei Testacella ist das Verhalten der zum ursprünglichen pallealen Complex gehörenden Organe bei den Vaginuliden und Onchidien. Eine Schale fehlt im erwachsenen Zustande, 
und auch der Mantel und mit ihm die Mantel- oder Lungenhöhle scheint vollständig verschwunden zu sein. Der Herzbeutel liegt rechts hinten in der Tiefe des Integumentes, die Herzkammer wie bei Testacella vor der Vorkammer. Die Athmung findet vorwiegend durch die Haut - bei den amphibischen Onchidien mit Hülfe der Rückenpapillen - statt. Bei Vaginulus verbindet sich der Harnleiter mit dem Enddarm zu einer röhrenförmig, an der Vereinigungsstelle etwas erweiterten $\mathrm{Kloake}$, die ganz am Hinterende des Körpers nach aussen mündet. Aehnlich verhalten sich die meisten Onchidien, wälrend bei Onchidium celticum Harnleiter und Enddarm getrennt, aber dicht neben einander am hinteren Körperende nach aussen münden. Dicht neben diesen Oeffnungen liegt übrigens überall auch die weibliche Geschlechtsöffnung, während die männliche weit vorn am Körper rechts unter den Tentakeln sich befindet.

Die oben erwähnte, mit Luft erfüllte Kloake hat zu interessanten Discussionen Veranlassung gegeben. Die Wand zeigt gegen das Lumen zu vorspringende, dicht gedrängte Falten, die sich übrigens auch auf den hinteren Theil des Harnleiters fortsetzen können. Man hat deshalb die Kloake auch für eine rudimentäre Lungenhöhle gehalten, in welche Harnleiter und Enddarm einmünden. Wir halten vor der Hand den betreffenden Abschnitt für eine durch Vereinigung der Endabschnitte des secundären Harnleiters und des Enddarmes entstandene Kloake, wie sie auch bei anderen Pulmonaten vorkommt, die aber, bei vollständigem Schwunde der Lungenhöhłe, nicht mehr durch das Athemloch, sondern direct nach aussen mündet.

Nach einer dritten Ansicht wären die Verhältnisse von Onchidium und Vaginulus ursprüngliche. Die Lungenhöhle trete hier zuerst als eine unbedentende Erweiterung des Endahschnittes des primären Harnleiters auf.

An dieses Verhalten würde sich dann anschliessen das oben sub 1 bezeichnete Verhalten von Bulimus oblongus, wo die Niere direct auf einer Papille in den hinteren Grund der Lungenhöble einmündet, die dann als der stark erweiterte primäre Harnleiter aufzufassen wäre. Dann kämen in diesem primären Harnleiter (Lungenhöhle) die successiven Stadien der Ausbildung des secundären Harnleiters, zuerst offene Rinne, dann theilweise geschlossene Rinne, dann geschlossenes Rohr, so dass zuletzt, wie z. B. bei Helix pomatia, der primäre Harnleiter vollständig in zwei Abtheilungen getheilt wäre, nämlich in die stark erweiterte Lungenhöhle und in den secundären Harnleiter. Für die Limnaeen aber z. B. würde zugegeben, dass ihre Lungenhöhle der Mantelhöhle der ïbrigen Gasteropoden entspricht. Consequenter Weise würden die Pulmonaten in zwei Gruppen zerfallen, in die Nephropneusten (Stylommatophoren), Lungenhöhle = erweiterter primärer Harnleiter, und die $\mathrm{Br}$ anchiopneusten (Basommatophoren p. parte), Lungenhöhle $=$ Mantelhöhle der übrigen Gasteropoden.

Wir halten diese Ansicht für unrichtig, angesichts der einheitlichen Gesammtorganisation aller Pulmonaten und angesichts hauptsächlich der Thatsache des Vorkommens eines Osphradiums in der Lungenhöhle eines Stylommatophoren (Nephropneusten), der Gattung Testacella nämlich. Denn das Osphradium ist immer ein Organ der Mantelhöhle, ursprünglich an das Ctenidium gebunden und nie und nimmer ein im Harnleiter liegendes Organ. 
C) Opisthobranchiata.

Hier kann man nur bei den Tectibranchiata von einem pallealen Organcomplex sprechen, da nur bei diesen eine deutliche, rechts gelegene Mantelfalte entwickelt ist. Die Lage der Organe in der Mantelhöhle (Fig. 458) ist im Allgemeinen folgende:

1) $\mathrm{Zu}$ hinterst, oft kaum oder nicht vom Mantel bedeckt, bisweilen auf der Spitze eines Kegels, der After, in dessen Nähe mitunter eine Analdrüse.

2) Davor, zwischen diesem und dem Ctenidium, die Nephridialö ffnung, auf diese kann folgen

3) eine Hypobranchialdrïse, ferner

4) das Ctenidium und an dessen Basis oder auf dessen Axe

5) das Osphradium.

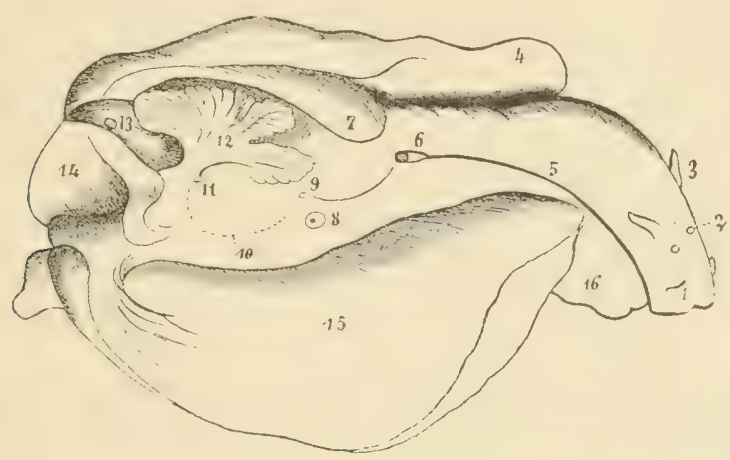

Fig. 458. Aplysia von der rechten Seite, das rechte Parapodium (15) nach unten umgeschlagen; man sieht den Pallealcomplex unter der Mantelfalte 7, nach LANKESTER. 1 Vordere Tentakel, 2 Augen, 3 hintere Tentakel (Rhinophoren), 4 linkes Parapodium, 5 Samenfurche, 6 Geschlechtsöffnung, 7 Mantelfalte, 8 Drüse, 9 Osphradium, 10 Contour der durchschimmernden Niere, 11 Nephridialöffnung, 12 Ctenidium, 13 After, 14 Eingeweidesack, 15 rechtes Parapodium, 16 vorderer Theil des Fusses.

Würden wir diesen Complex dem Körperrand entlang nach vorn schieben, so wïrde dasselbe Lagerungsverhältniss entstehen, wie bei den Monotocardia unter den Prosobranchiern. Diese Uebereinstimmung wird wenigstens scheinbar gestört durch die Lage

6) der Geschlechtsöffnung, welche bei den Opisthobranchiern am weitesten vorn liegt.

Bei den übrigen Opisthobranchiata löst sich mit dem Schwunde der Mantelhöhle und des ächten Ctenidiums der palleale Organcomplex auf. (Aehnliche Verhältnisse wie bei den Tectibranchiaten finden sich, abgesehen von der Kieme, nur noch bei den Phyllidiidae.) Die einfache oder doppelte Geschlechtsöffnung liegt immer asymmetrisch auf der rechten Seite und immer vor dem After, der bald asymmetrisch auf der rechten Seite, bald in der Mittellinie des Rückens zwischen der Mitte und dem Hinterende des Körpers sich befindet. Die Nierenüffnung fiudet sich zwischen After und Geschlechtsöffnung, der letzteren bisweilen dicht angelagert.

Bei den Pteropoda gymnos omata (Fig. 459), fehlen Schale und Mantel. Wo ein Ctenidi um sich erhalten hat, wie bei Dexiobranchaea und Pneumoderma, liegt dasselbe ziemlich weit hinten auf der rechten Körper- 
seite, weit hinter dem After. Es hat sich das Ctenidium mit dem Schwunde des Mantels offenbar von der ursprüuglichen Stelle zwischen After und Geschlechtsöffnung nach hinten verlagert, während das $\mathrm{Osphra-}$ d i um, welches sonst in unmittelbarer Nähe des Ctenidiums liegt, da, wo man es beobachtet hat, die ursprüngliche Lage beibehalten hat.

Der After liegt vorn hinter der rechten Flosse; die Nephridialöf f $n u n g$ in seiner unmittelbaren Nähe, getrennt von ihm oder vereinigt mit ihm, im Grund einer gemeinsamen Vertiefung (Kloake). Unmittelbar vor dieser liegt das $\mathrm{Osphradium}$. Dann folgt in einiger Entfernung weiter vorn am Nacken, auf der rechten Seite hinter der Basis der rechten Flosse, die Geschlechtsöffnung, von welcher aus, wie bei vielen Tectibranchien, eine Flimmerfurche an der Oberfläche des Körpers nach vorn zu der vor dem Fusse auf der rechten Seite gelegenen Oeffnung des Penis verläuft.

Alle The c os o mat a besitzen einen Mantel und eine Mantelhöhle und häufig auch eine Schale, die bei den Cymbuliidae durch oine knorpelige Pseudoconcha, eine subcutane Bildung des Mantels, ersetzt wird.

Unter den Thecosomata weisen die Limacini d en die ursprünglichen Verhältnisse auf: dorsale oder vorderständige Mantelhöhle, gewundene Schale, Operculum. Freilich fehlt das Ctenidium. Links im Grunde der Mantelhöhle liegt das Pericard, dicht vor diesem die $\mathrm{Niere}$ mit der engen Oeffuung in die Mantelhöhle, dann folgt das Osphradium (wo es beobachtet ist) und schliesslich ganz an der rechten Seite der Mantel-

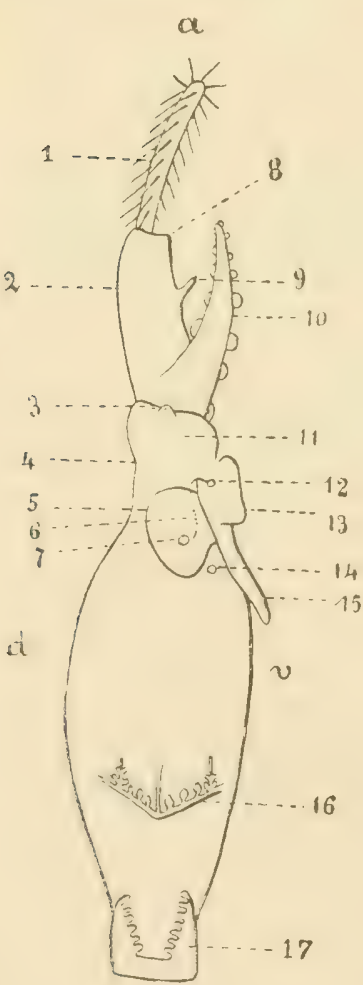

$\lambda$

höhle der After mit der Afterdrüse. An der Decke der Mantelhöhle findet sich eine Manteldrüse (Hypobranchialdrüse, Schild). Die Geschlechtsöffnung liegt vorn rechts an der Kopfregion; von ihr aus setzt sich eine Wimpergrube dorsalwärts zu der vorn zwischen den Flossen gelegenen Oeffinung des Penis fort.

Gegenüber den Limaciniden, d. h. den Thecosomata mit gewundener Schale, zeigen die Thecosomata mit gerader Schale, die Cavoliniidae und Cymbuliidae eine sehr abweichende. Anordnung des pallealen Organcomplexes, die erlklärt wird, wenn man annimmt, dass der grössere hintere Körpertheil (der Eingeweidesack) der Limaciniden mit dem ganzen ihm angehörigen pallealen Complex sich gegenüber der Kopfregion und der ihr angehorenden Genital-

Fig. 459. Pneumoderma, schematisch, von der rechten Seite, nach PelseneEr. 1 Rechter ausgestiulpter Hakensack, 2 Rüssel, 3 rechter Buccaltentakel, 4 Lage des rechten Nackententakels, 5 rechte Flosse (Parapodium), 6 Samenfurche, 7 Geschlechtsöffnung, 8 Lage des Kiefers, 9 ventrale Rüsselpapille, 10 rechter saugnapftragender Buccalanhang, 11 Kopf, 12 Penisöffnung, 13 rechter vorderer Fusslappen, 14 Anus, 15 hinterer Fusslappen, 16 Ctenidium, 17 hintere adaptive Kieme, $d, v, a, p$ dorsal, ventral, vorn, hinten. 
öffnung um $180^{\circ}$ (um die Längsaxe des Körpers) g edreht habe. Es ergeben sich dann die thatsächlichen Lagerungsverhältnisse bei den Cavoliniiden und Cymbuliden: hintere (ventrale) Mantelhöhle; in ihr der After links, Pericard, Niere und Osphradium rechts; Genitalöffnung in der ursprünglichen Lage rechts. Grund und Bedeutung dieser Drehung sind zur Zeit noch nicht erkannt.

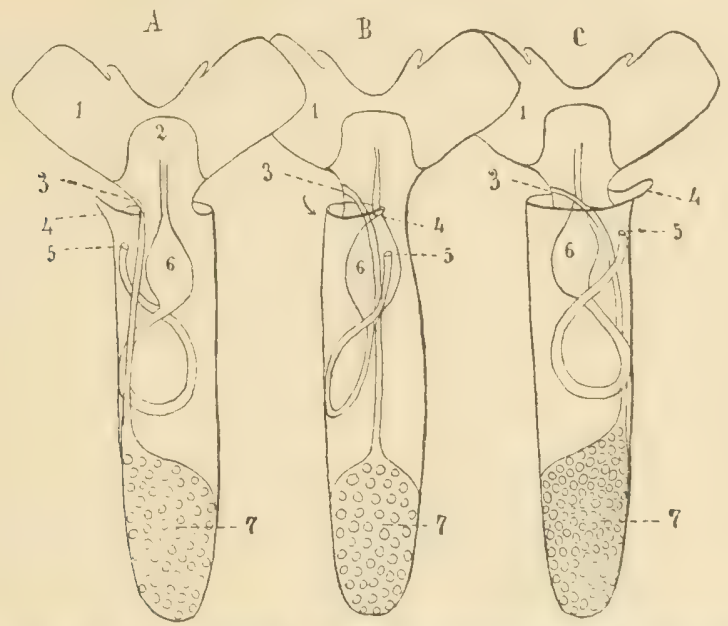

Fig. 459 a. $\boldsymbol{A}, \boldsymbol{B}, \boldsymbol{C} \mathbf{3}$ Schemata zur Demonstration des Verhältnisses der Limacinidae zu den Cavoliniidae, nach BoAs $\boldsymbol{A}$ Limacinidae. $\boldsymbol{B}$ Hypothetisches Zwischenstadium zwischen Limaciniden und Cavoliniiden. Der Eingeweidesack um $90^{\circ}$ gedreht. $\boldsymbol{C}$ Caroliniidae. Alle 3 von der Ventralseite, resp. Hinterseite. Bei $\boldsymbol{A}$ ist der Eingeweidesack gerade, nicht gewunden gezeichnet, während er in Wirklichkeit gewunden ist. 1 Rechte Flosse (Parapodium), 2 Fuss, nach vorn umgeklappt, 3 Geschlechtsöffnung, 4 tentakelartiger Anhang des Mantelrandes, 5 After, 6 Kaumagen, 7 Gonade.

\section{D) Scaphopoda.}

In der hinterständigen Mantelhöhle fehlt die Kieme. Der After liegt median über dem Fusse, zu seinen beiden Seiten die Nephridialöffnungen. Gesonderte Geschlechtsöffnungen fehlen.

\section{E) Lamellibranchiata.}

Die allgemeine Anordnung der Körpertheile in der Mantelhöhle der Lamellibranchiaten ist schon früher geschildert worden. Es sei hier nochmals auf die strenge Symmetrie des Muschelkörpers hingewiesen. Alle ursprünglich paarigen Organe bleiben hier paarig und symmetrisch.

Bezüglich der Lage der zwei Nephridialöffnungen ist Folgendes zu bemerken. Sie liegen seitlich am Rumpfe über der Basis des Fusses oder weiter hinten, dem hinteren Schliessmuskel genähert, ferner gowühnlich unter der Ansatzstelle der Kiemenaxe zwischen dieser und der Verwachsungslinie der (inneren) aufsteigenden Lamelle des inneren Kiemenblattes mit dem Fusse, da nämlich, wo überhaupt eiue solche Verwachsung stattfindet. Bei den Septibranchiern hingegen münden die Oeffunngen in die obere Mantelkammer.

Aeussere Genitalöffnungen können fehlen, und dann werden die Geschlechtsproducte durch die Nephridialüfuungen entleert primitives 
Verhalten). Wo sie vorhanden sind, finden sie sich bei den getrenntgeschlechtlichen Muscheln immer in der Zweizahl, sie liegen dann jederseits dicht vor den Nephridialöffnungen, bisweilen im Grunde einer gemeinsamen Grube oder Furche; seltener weiter von ihnen entfernt. Besondere Begattungsapparate fehlen.

Bei den hermaphroditischen Muscheln können folgende Fälle eintreten :

1) Beiderlei Geschlechtsproducte werden jederseits durch eine einzige gemeinsame Oeffnung entleert (Ostrea, Pecten, Cyclas, Pisidium etc.).

2) Es existiren jederseits zwei getrennte Oeffnungen, eine männliche und eine weibliche (Anatinacea).

3) Samenleiter und Eileiter verbinden sich vor ihrer Ausmündung zu einem kurzen, gemeinsamen Endstück (Septibranchia).

Das Osphradium der Muscheln ist paarig und liegt immer in der Nähe des hinteren Schliessmuskels über dem Visceralganglion der betreffenden Seite, an der Insertionsstelle der Kiemenaxe am Rumpfe.

Paarige Sinnesorgane liegen bei vielen Muscheln zu beiden Seiten des Afters (abdominale Sinnesorgane) oder rechts und links am Mantel an der imneren Oeffnung der Siphonen (palleale Sinnesorgane) der Siphoniaten.

Hypobranchialdrüsen sind bei den Protobranchien (Nuculiden und Solenomyidae) beobachtet worden. Sie liegen als anselmlich entwickelte, dem Mantel angehörige Drüsen im hinteren Körpertheile jederseits ïber der Kiemenbasis, rechts und links vom Pericard vor dem hiuteren Schalenmuskel.

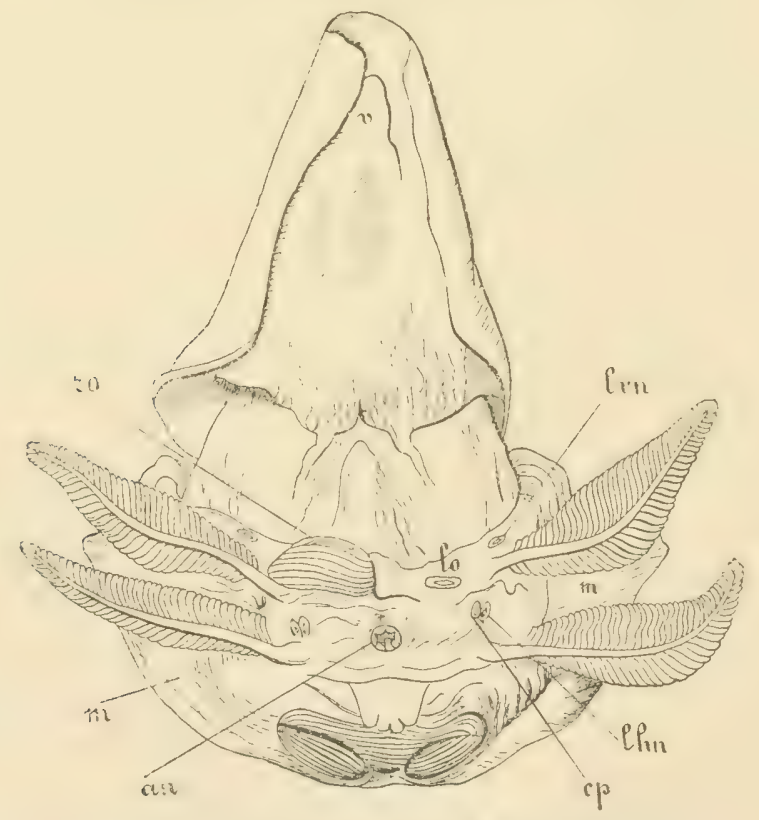

Fig. 460. Pallealcomplex und Trichter von Nautilus pompilius $q$, nach BourNe und LANKESTER. $v$ Klappe des Trichters, ro rechte Geschlechtsöffnung, $m$ die zurückgeklappte Mantelfalte mit der Nidamentaldrüse, an After, $c p$ linke Oeffnung der secundären Leibeshïhle, thn linke obere Nephridialöfnung, lo Oeffnung des linken rudimentären Eileiters, Ivn linke untere Nephridialöffnung. Die 4 Ctenidien siud nicht bezeichnet. 
Unter den Mantelorganen der Muscheln sind noch zu erwähnen die Mundlappen oder M undsegel; es sind jederseits neben dem Munde, zwischen diesem und dem Vorderende der Kiemenbasis, zwei blattförmige Anhänge, die noch besonders besprochen werden sollen.

F) Cephalopoda.

Bei den Cephalopoden hat sich die ursprüngliche Symmetrie des pallealen Organcomplexes im Allgemeinen erhalten.

Schneiden wir den Mantel von $\mathrm{N}$ a utilus (Fig. 460, 461), der die hinten am Eingeweidesack liegende Mantelhöhle bedeckt, auf und legen wir ihn allseitig zurück, so sehen wir in der geöffneten Mantelhöhle folgenden Complex:

1) Jederseits $2 \mathrm{~K}$ i eme $\mathbf{n}$, ein oberes und ein unteres Paar.

2) In der Mitte, zwischen der Basis der 4 Kiemen, auf dem Eingeweidesack, der After.

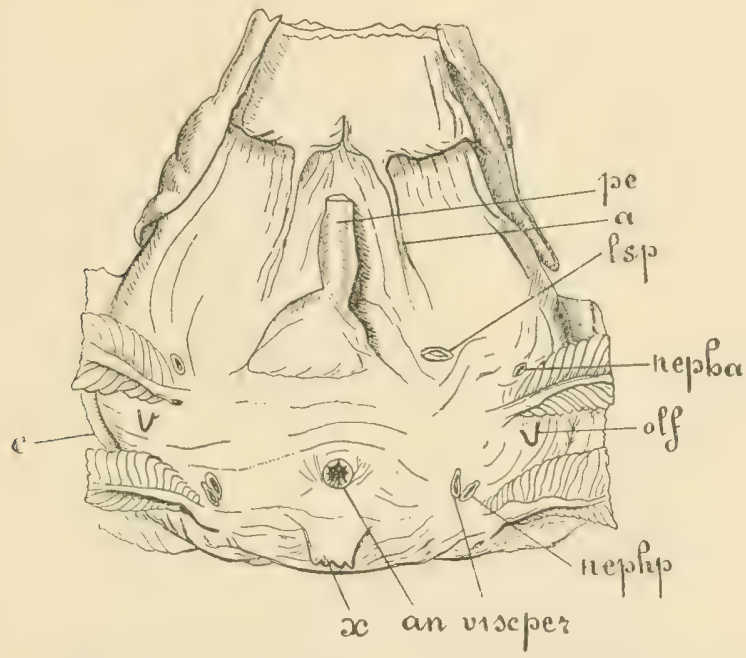

Fig. 461. Pallealcomplex von Nantilus pompilius $\delta$, nach Bourne und LANKester. pe Penis, a Muskelband des Trichters, lsp Oefinung des linken rudimentären Samenleiters, nepha, nephp untere und obere Nephridialöffnung der linken Seite, olf linkes Osphradium, viscper linke Oeffnung der secundären Leibeshöhle, an After, $x$ supraanale Papille von unbekannter Bedeutung, $c$ Mantel, abgeschnitten.

3) Jederseits vor der Basis einer jeden Kieme eine Nephridialöffnung, also im Ganzen 4.

4) Dicht neben den zwei oberen Nephridialöffnungen liegen die zwei sogenanten $\mathrm{V}$ is cero-Pericardialöffnungen.

5) Zwischen der Basis der unteren Kiemen in jedem Geschlecht zwei Genitalöffnungen, von denen aber nur die der rechten Seite functionirt. Beim Männchen setzt sich die Oeffuung in einen röhrenförmigen Penis fort.

6) Ueber der Basis der unteren Kieme jederseits auf einer Papille ein Osphradium.

7) Ueber dem After eine mediane, grössere Papille unbekannter Bedeutung.

8) Im Mantel dorsalwärts die Nidamentaldrüse. 
Vergleichen wir damit den pallealen Complex eines dibranchiaten Cephalopoden, etwa von Sepia (Fig. 462), so zeigen sich folgende Verhältnisse :

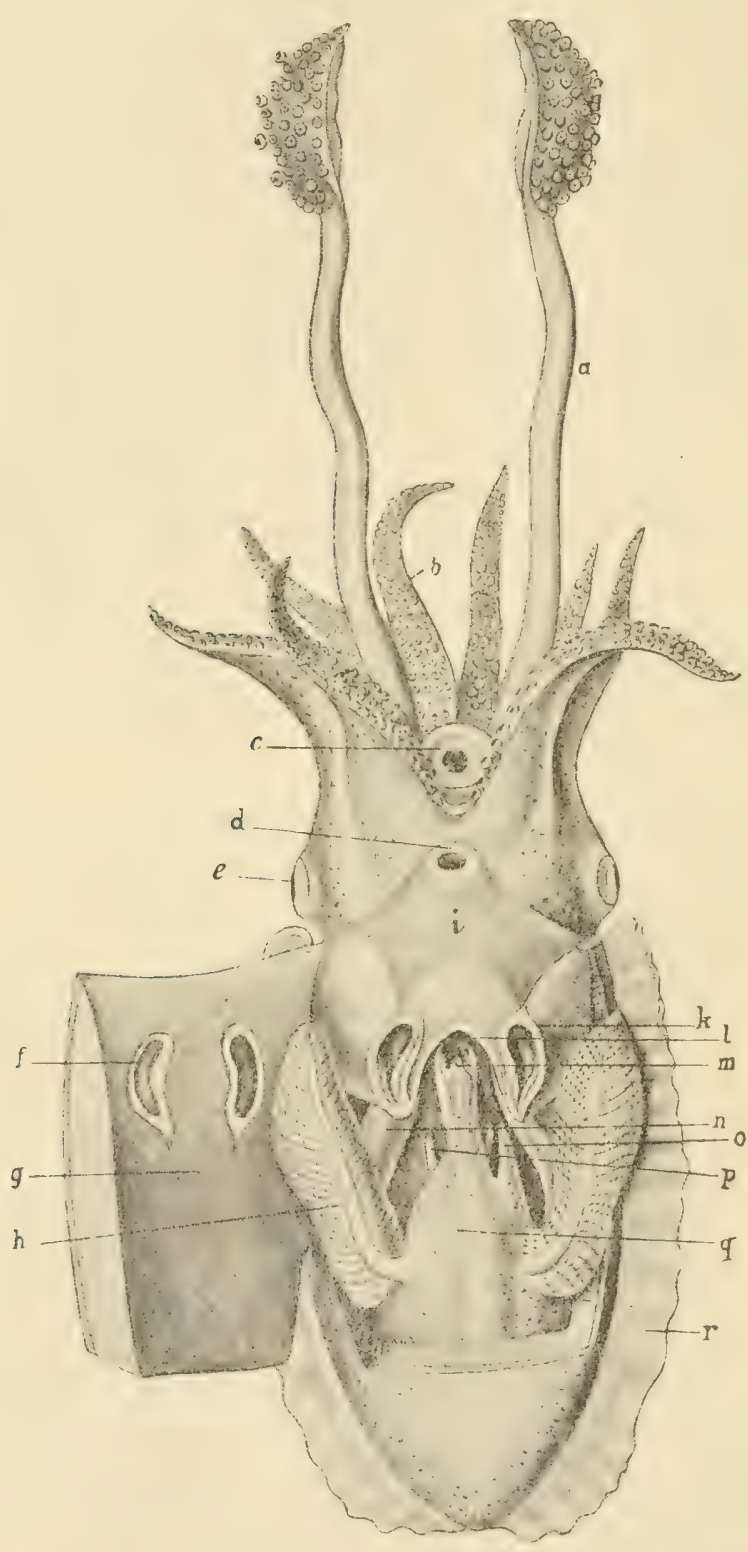

Fig. 462. Sepia Savignyana, von hiuten, nach Savigny. Der Mantel zum grössten Fif die rechte seite (links in der Figur) zurüickgeklappt. $a$ FangMitern, $d$ untere Trichteröffnung, e Auge, $f$ MantelMantel $g, h$ rechtes Ctenidium, $i$ Trichter, $l$ Mantelschliessknorpel am

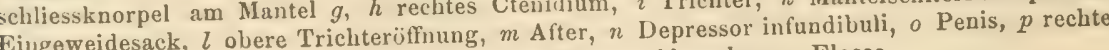

Nephridialöffnung, $q$ hinteres Integument des Eingeweidesackes, $r$ Flosse 
1) Jederseits eine $\mathrm{K}$ i e m e.

2) In der Medianlinie auf dem Eingeweidesack steigt mit dem Rectum der Ausführungsgang des Tintenbeutels herunter, um mit gemeinsamer Oeffnung auf der Spitze einer Papille an der Basis des Trichters auszumünden.

3) Jederseits neben dem Enddarm, über dem After, auf der Spitze einer Papille, die Nephridialöffnung.

4) Von den zwei paarigen Genitalöffnungen hat sich bei Sepia und vielen anderen Cephalopoden nur die linke erhalten, welche links nelen der linken Nephridialöffnung auf der Spitze einer grossen Papille (Penis) liegt. Bei dem Weibchen der Octopoden sind die Geschlechtsöffnungen paarig und symmetrisch und liegen rechts und links vom Enddarm.

5) Die zwei Nidamentaldrüsen (bei Decapoden) liegen im Eingeweidesack symmetrisch zur Mittellinie, sie münden oberhallo der Nephridialöffnungen in die Mantelhöhle.

\section{Die Respirationsorgane.}

A) Die ächten Kiemen oder Ctenidien.

Das wichtigste Organ der Mantelhöhle der Mollusken ist die Kieme, denn zum Schutze der Kieme hat sich der Mantel und mit ihm die Mantelhöhle gebildet. Die in der Mantelhöhle gelegene Kieme ist durch alle Abtheilungen hindurch ein homologes Organ, das von der Kieme einer gemeinsamen Stammform abgeleitet werden kann. Da diese Kieme gewissen Mollusken (z. B. vielen Opisthobranchiern) fehlt, dagegen functionell durch neu auftretende Organe ersetzt wird, die aber mo r ph o$10 \mathrm{~g}$ isch nichts mit ihr zu thun haben, so war es zweckmässig, die ursprünglich allen Mollusken zukommende Kieme mit einem besonderen Namen, dem des Ctenidiums zu bezeichnen. Diesem Namen entspricht also ein ganz bestimmter morphologis cher Begriff.

Die Ctenidien der Mollusken sind ursprünglich paarige, symmetrisch angeordnete, zweizeilig gefiederte (federförmige), bewimperte Fortsätze der Leibeswand, welche vom Rumpfe in die Mantelhöhle vorragen. In die Kiemen führen zuführende Gefässe (Kiemenarterien) venöses Blut und aus ihnen leiten abführende Gefässe (Kiemenvenen) das bei der Athmung arteriell gewordene Blut wieder in den Körper, zunächst zum Herzen. An der Basis eines jeden Ctenidiums oder in der Nähe derselben liegt immer ein als Geruchsorgan gedeutetes Sinnesorgan, das sogenannte Osphradium (SPENGEL's Organ).

Paarig, symmetrisch angeordnet, zweizeilig gefiedert treffen wir die Ctenidien zunächst bei derjenigen Gruppe, welche von allen bekannten Mollusken wohl zweifellos an meisten ursprüngliche Charaktere beibehalten hat, nämlich bei den Chitoniden unter den Amphineuren, und ferner bei allen übrigen Mollusken, welche die ursprüngliche bilaterale Symmetrie des Körpers beibehalten haben, den Lamellibranchiern, Cephalopoden und - was von grosser Wichtigkeit ist -- auch bei den ursprünglichen Gasteropodenformen, den Z e ugobranchiern. Nur ist hier, worauf später ausführlich zurückzukommen 
sein wird, die linke Kieme die ursprünglich rechte und die rechte die ursprünglich linke.

Was die Zahl der ursprünglich vorhandenen Ctenidien anbetrifft, so kann man der Ansicht huldigen, dass ursprünglich jederseits mehrere vorhanden gewesen seien. Dafür spricht das Verhalten von Chiton, wo jederseits in der Kiemenfurche (Mantelhöhle) zahlreiche Ctenidien in einer Lüngsreihe hintereinander liegen, und das Verhalten derjenigen Cephalopodenform, die wohl mit Recht als die ursprüinglichste aller lebenden Cephalopoden gilt, von Nautilus nämlich, wo 4 Kiemen
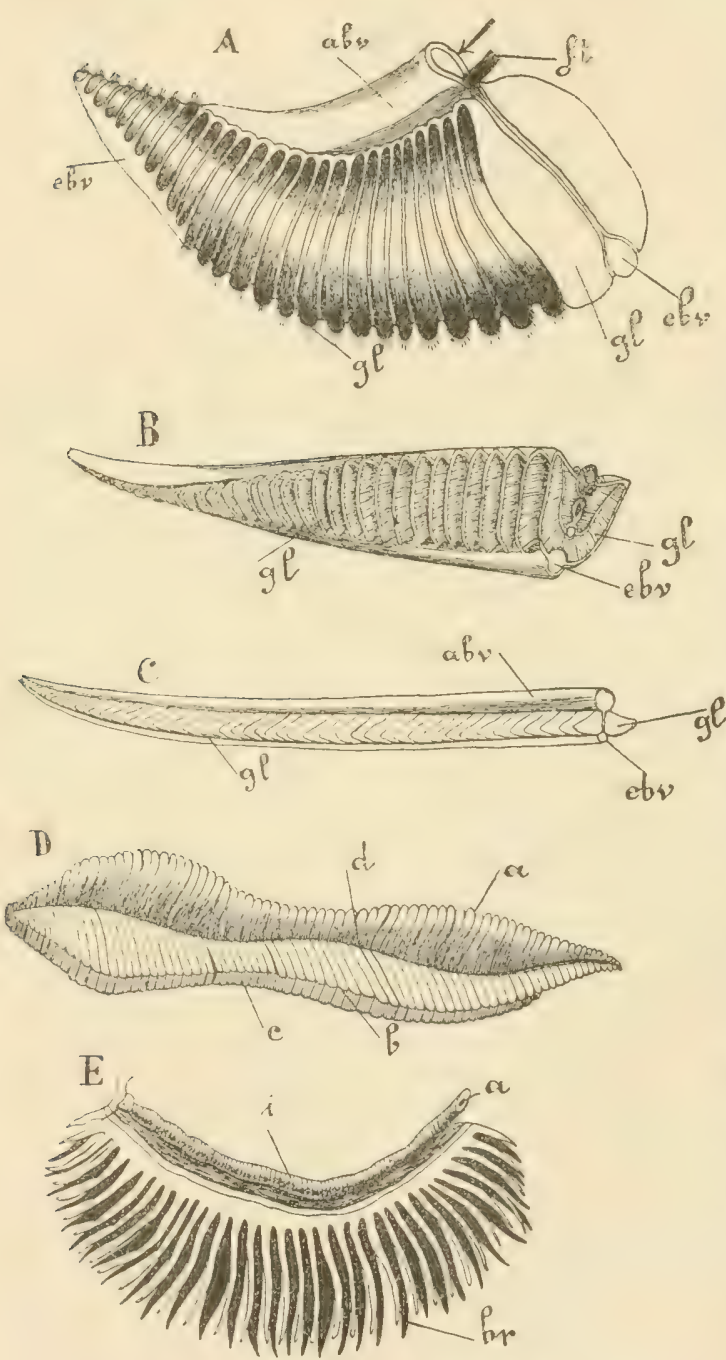

Fig. 463. Ctenidien verschiedener Mollusken, nach RAY-LANkEster, $\boldsymbol{A}$ Chiton. $B$ Sepia $C$ Fissurella. $\boldsymbol{D}$ Nucula. $\boldsymbol{E}$ Paludina. $f t$ Kiemenläıgsmuskel, abv zufiihrendes Kiemengefäss, $e b v$ ausführendes Kiemengefäss (Kiemenvene), $g l$ parrige Lamellen (Blättchen) der $\mathbf{z w e i z e i l i g ~ g e f i e d e r t e n ~ K i e m e ; ~ i n ~} D: a$ Lage der Axe, $a$ innere, $\zeta$ und $c$ äussere Reihe von Kiemenlamellen; in $\boldsymbol{E}$ bedeutet: $i$ Enddarm, or Kiemenfäden. branchiaten). Aus später zu erörternden Gründen ist aber die Ansicht mindestens ebenso berechtigt, dass die Mollusken ursprünglich nur ein Ctenidienpaar besessen haben.

Bei allen übrigen Mollusken mit paarigen Ctenidien sind dieselben in der That - auch bei den Lamellibranchiaten - stets nur in einem Paar vorhanden, das hinten am Körper liegt. Auch für die Stammformen der Prosobranchier ist die Lage der Kiemen in einer hin ten am Körper gelegenen Mantelhöhle anzunehmen, die sich dann mit den Kiemen nach vorn verlagert hat, wo wir sie schon bei den noch mit zwei Kiemen ausgestatteten 'Zeugobranchiern antreffen.

Bei der grossen Mehrzahl der Prosobranchier zeigt sich die Asymmetrie des Körpers auch an den Kiemen, indem sich von den beiden Kiemen der Fissurelliden und Halioti- 
den nur die linke erhïlt, die rechte aber völlig verschwindet. Bei denjenigen Formen, die sich noch am meisten an die Fissurelliden und Haliotiden anschliessen, den einkiemigen Diotocardiern (Turboniden, 'Trochiden etc.) ist (lie Kieme noch zweizeilig gefiedert, bei allen Monotocardiern aber nur einzeilig.

Bei einem Theile der Opisthobranchier, den Tectibranchiern, erhält sich noch ein Ctenidium, das der rechten Seite. Die übrigen sind mit der Mantelhöhle auch der ächten Ctenidien verlustig gegangen, die daun durch analoge (nicht homologe) Athmungswerkzenge (adaptive Kiemen) ersetzt sein können.

Bei den Pulmonaten sind die Ctenidien in Folge der Anpassung an die Luftathmung verloren gegangen.

Das Blut, das in den Ctenidien arteriell geworden ist, gelangt bei den Mollusken durch die Vorkammern in das Herz, vou wo aus es durch die Arterien im Körper vertheilt wird. Es ist deshalb verständlich, dass gewisse, wichtige Beziehungen zwischen Kiemen und Vorhöfen des Herzens vorhanden sind. Diese Beziehungen lassen sich kurz so resumiren: paarige Kiemen - paarige Vorkammern; unpaare einzige Kieme - unparre einzige Vorkammer, an derjenigen Seite, auf welcher die Kieme sich erhält. Wo die Kiemen paarig sind, sind sie fast immer nur in ein em Paar vorhanden, und es findet sich dam eine rechte und eine linke Vorkammer des Herzens. Nautilus hat 4 Kiemen und dementsprechend zwei rechte und zwei linke Vorkammern am Herzen. - Hingegen haben die Chitoniden trotz ihrer zahlreichen Kiemenpare nur eine rechte und ein e linke Vorkammer.

Die Scaphopoden besitzen weder ächte Ctenidien, noch andere localisirte Kiemen. Die Athmung mag an den verschiedenen, mit dem Wasser in Contact kommenden, weichhäutigen Oberflächen des Körpers (Innenfläche des Mantels, Tentakel etc.) stattfinden.

\section{A) Amphineura.}

Die Ctenidien der Amphine uren. Ich will zunächst den Bau eines einzelnen Chitonetenidiums (Fig. 464) beschreiben, das als 'Typus einer zweizeilig gefiederten Molluskenkieme dienen mag. Das federförmige Ctenidium erhebt sich frei auf dem Grunde der Kiemenfurche (Mantelhöhle). Man unterscheidet an ihm eine $\mathrm{Axe}$, welche hier in Form einer dünnen Scheidewand auftritt. Auf jeder Breitseite der Scheidewand erheben sich von der Basis bis zur Spitze derselben in einer Reihe zahlreiche fast wie die Blätter eines Buches dicht gedrängt stehende, zarte, sehr flache, im Umriss rundliche Kiemenblättchen. Das Epithel ist an der ganzen Oberfläche der Kieme bewimpert. Die Wimpern sind auf dem Epithel der Axe auffallend lang. In der dem Fuss zugekehrten Seite der Axe verläuft von der Basis bis an die Spitze ein Blutgefäss, welches der Kieme venöses Blut zuführt (zuführendes Kiemengefäss). Auf der entgegengesetzten, dem Mantel zugekehrten Seite der Axe verläuft ein Gefäss (Kiemenvene) von der Spitze bis an die Basis der Kieme, welches das in der Kieme bei der Athmung arteriell gewordene Blut der allgemeinen Kiemenvene und durch diese der Vorkammer des Herzens zuführt. Diese Gefässe besitzen keine besondere Endothelwand, sie sind von Ringmuskelfasern umgeben. Die Kiemenvene begleitet ein starker Längsmuskel. An der Basis eines jeden Kiemenblättchens strömt das Blut durch eine Oeffnung aus der Kiemenarterie in den schmalen Hohlraum dieses Blättchens, um an der gegenüber liegenden Seite der Axe 

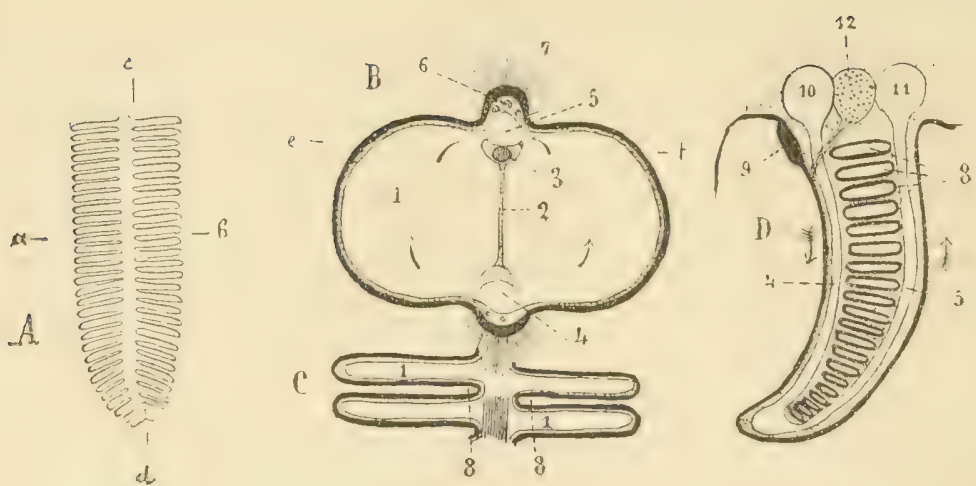

Fig. 464. Bau eines Chitonctenidiums, nach B. Haller. A Einzelkieme mit den zweizeilig angeordneten Kiemenblättchen. $\boldsymbol{B}$ Querschnitt der Kieme in der Richtung $a-b$ in Fig. A. 1 Schmaler Blutraum in den Kiemenblättchen, 2 Scheidewand in der Axe, 3 Längsmuskel, 4 zuführendes Kiemengefäss, 5 abführendes Kiemengefäss, 6 Nerven, 7 lange Cilien auf der Kiemenaxe. $\boldsymbol{C} 2$ Paar Kiemenblättchen, senkrecht auf ihre Fläche in der Richtung $e-f$ der Fig. $\boldsymbol{B}$ durchschnitten, horizontal, mit Bezug auf die Einzelkieme. 1 wie in Fig. $\boldsymbol{B}, 8$ Zwischenraum zwischen zwei aufeinanderfolgenden Kiemenblättchen. $\boldsymbol{D}$ Längsschnitt durch die Kieme, etwas seitlich von der Axe, parallel zu ihrer Scheidewand, in der Richtung $c-d$ der Fig. $\boldsymbol{A}$. Der Schnitt ist ein Theilstiick eines Querschnittes durch den Körper. Bezeichnungen wie in Fig. $\boldsymbol{B}$ und $\boldsymbol{C}$, ausserdem: 9 Riechwulst des Kiemenepithels, 10 allgemeines zuführendes, 11 allgemeines abfülırendes Kiemengefäss, 12 Pleurovisceralstrang des Nervensystems. Das Kiemenepithel ist überall durch eine dicke schwarze Contourlinie angedeutet.

durch eine ebensolche Oeffnung in die Kiemenvene einzutreten. Von dem in unmittelbarer Nähe der Kiemenbasis verlaufenden Pleurovisceralstrang treten Nerven in das Ctenidium ein.

Die Zahl der Kiemen in jeder Kiemenreihe ist bei den verschiedenen Chitonarten eine sehr wechselnde, von 75-14. Die Kiemenreihe erstrekt sich jederseits in der ganzen Länge der Kiemenfurche (Fig. $465 \mathrm{~A}$ ), oder (Chiton laevis, Ch. Pallasii, Chitonellus, sie beschriinkt sich auf die hintere Hälfte derselben $(\mathbf{B}, \mathrm{C})$.

\section{Fig. 465 .}

A

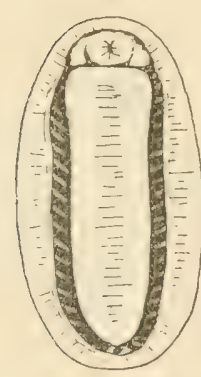

$\mathrm{B}$

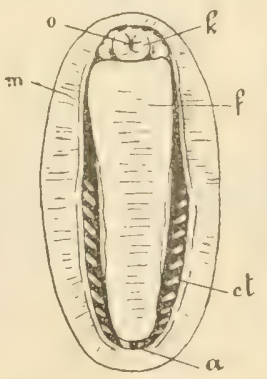

Fig. 466 .

C

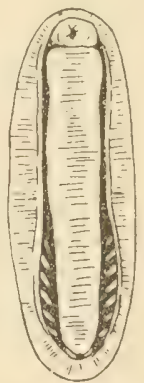

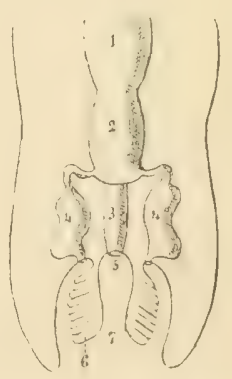

Fig. 465. Schematische Darstellung der Kiemenverhältnisse bei den Chitoniden. $m$ Mantel, o Mund, $k$ Schnauze, $f$ Fuss, ct Ctenidien, a Anus.

Fig. 466. Hinteres Leibesende von Chaetoderma, schematisch, nach HUBRECHT. 1 Gonade, 2 Pericard, 3 Rectum, 4 Nephridium, 5 After, 6 Ctenidium, 7 Kloake. 
Was die Solenogastres (Proneomenia, Neomenia, Chaetoderma) anbetrifft, so ist daran $\mathrm{zu}$ erinnern, dass die Mantelhöhle bei diesen Formen ausserordentlich reducirt ist, nämlich auf die Rinne jederseits neben dem rudimentären Fuss, die sich hinten in die Kloakenhöhle öffnet oder besser zur Kloakenhöhle erweitert. Die Kloake ist also der hintere Theil der Mantelhöhle. Bei Chaetoderma (Fig. 466) ist der Fuss verschwunden und die Mantelhöhle auf die Kloake reducirt, in welcher rechts und links vom After eine zweizeilig gefiederte Kieme liegt. Man fasst diese Kiemen als Ctenidien auf, als die letzten Ctenidien der Ctenidienreihen der Chitonen, die schon bei Chitonellus und gewissen Chitonarten auf die hintere Körperhälfte beschränkt sind. Bei Neomenia ist diese Kieme nicht mehr doppelt, sondern besteht aus einem Büschel von Fäden, die sich auf der Wand der Kloakenhöhle erheben, und bei Proneomenia finden wir nur noch unregelmässige Falten der Wand der Kloakenhöhle.

Ueber die Beziehungen der Chitonidenkiemen zu vielleicht als Osphradien zu deutenden Epithelstrecken siehe den Abschnitt über die Osphradien.

\section{B) Gasteropoda.}

Der Urform stehen am nächsten die Fissurelliden (Fig. $467 \mathrm{~A}$ u. B) unter den Prosobranchiern. In die vorderständige Mantelhöhle ragen von hinten und oben zwei symmetrisch zur Mittellinie, rechts und links vom After gestellte, zweizeilig gefiederte, langgestreckt-federförmige Kiemen vor, deren Axe höchstens in ihrem hinteren Theile mit dem Boden der Athemhöhle durch ein Band verbunden ist, während der vordere, zugespitzte Theil jeder Kieme frei vorsteht.

Die Duplicität der Kiemen der Fissurelliden (und verwandten Formen) und ihre Symmetrie ist von grosser Bedeutung. Es liegt darin ein sehr ursprünglicher Charakter, der uns erlaubt, die Kiemen mit denen niederer Lamellibranchier, der Protobranchien und miț denen der Cephalopoden zu vergleichen. Nur muss hier wieder betont werden, dass man mit gutem Recht annimmt, dass die linke Kieme von Fissurella der rechten der Lamellibranchier und Cephalopoden, und die rechte der linken dieser ursprünglich symmetrischen Mollusken entspricht. Das wird plausibel, wenn man sich vorstellt, dass die Mantelhöhle mit den Mantelorganen ursprünglich hinten am Körper lag und sich erst secundär der rechten Körperseite entlang nach vorn verschob.

An die Fissurelliden schliessen sich die $\mathrm{Haliotiden}$ an. Bei diesen ist die geräumige Mantelhöhle durch die starke Entwickelung des Columellarmuskels auf die linke Seite gedrängt. Von den zwei, zweizeiliggefiederten Kiemen ist die rechte etwas kleiner als die linke. Die Axe beider Kiemen ist fast in ihrer ganzen Länge mit der Innenwand des die Mantelhöhle bedeckenden Mantels verw achsen, und nur das vordere Ende ist zipfelförmig, frei und ragt sogar etwas aus der Athemhöhle hervor.

Besitzen die Fissurelliden und Haliotiden noch zwei Kiemen, so exhält sich bei den übrigen Diotocardiern nurnoch die bei Haliotis grössere linke Kieme (also die ursprüglich rechte). Diese ist aber noch $z_{w}$ izeilig gefiedert, wenn auch dirser zweizeilig gefiederte Zustand in Folge eigenthümlicher Verhältnisse etwas verdeckt erscheint. Die Scheidewand nämlich der Kieme (ihre Axe), auf deren Breitseiten die beiden Reihen von Kiemenblättchen sitzen und 
die schon bei Haliotis an der einen Kante mit der inneren Mantelwand verwachsen ist, verwächst nämlich auch mit der anderen Kante (in welcher die Kiemenarterie verläuft) etwas rechts von der ersteren Verwachsungslinie ebenfalls mit dem Mantel. Dadurch wird in einer Weise, die am besten durch die folgenden schematischen Querschnitte (Fig. 468) erläutert wird, die Mantelhöhle durch die Kiemenscheidewand in zwei ungleich grosse Abtheilungen getrennt, welche sich beide vorn ineinander öfthen.

Fig. 467 .
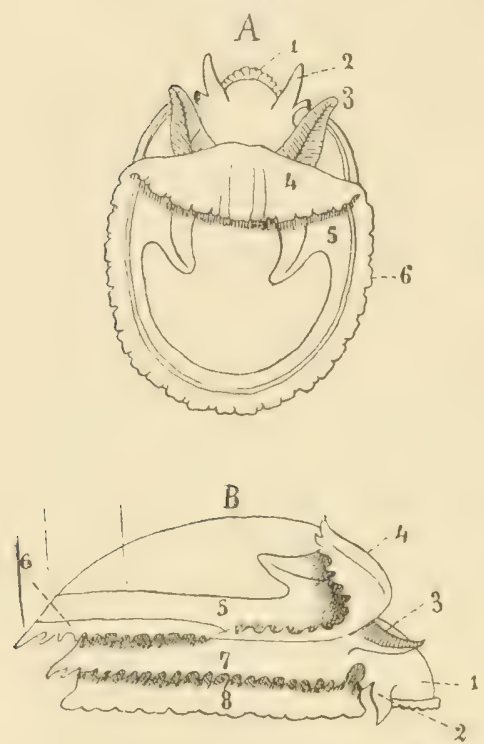

Fig. 468
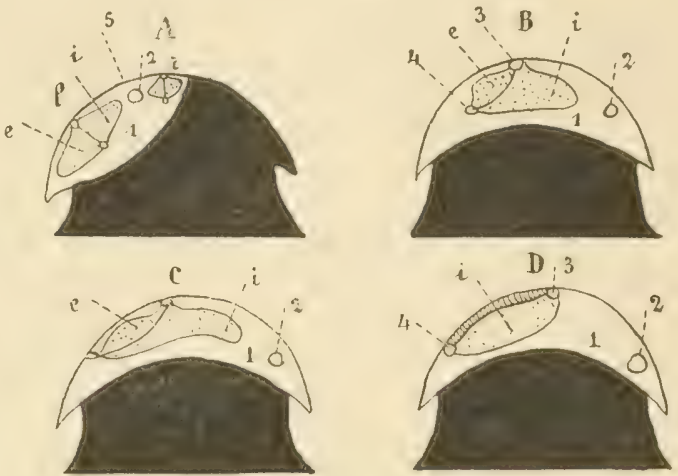

Fig. 467. Subemarginula nuch Eutfernung der Schale, nach Erscher. $\boldsymbol{A}$ Von oben. $\boldsymbol{B}$ Von der rechten Seite. Die Mantelhöhle ist durch Zurïckklappen der Mantelfalte 4 geöffnet. 1 Schnauze, 2 Tentakel, dahiuter die kurzgestielten Augen, 3 rechtes Ctenidium, 4 Mantelfalte, 5 Schalenmuskel, 6 Aantelsaum rings um den Körper, 7 Epipodium, 8 Fuss.

Fig. 468. Allgemeine Morphologio der Prosobranchierkieme. Schematische Querschnitte in der Gegend der Mantelhöhle, von hinten. $\boldsymbol{A}$ Haliotis. $\boldsymbol{B}$ Trochus, vorderer Theil der Mantelhöhle. $C$ Trochus, mittlerer oder hinterer Theil der Mantelhöhle. $\boldsymbol{D}$ Monotocardior. 1 Nantelhöhle, 2 Rectum resp. Anus, $r$ rechte, $l$ linke Kieme von Haliotis $(\boldsymbol{A})$, einzige vorhandene Kieme der Azygobranchier $(\boldsymbol{B}, \boldsymbol{C})$ und Monotocardier $(\boldsymbol{D})$, $\boldsymbol{i}$ Kiemenblättchen der inneren, $e$ Kiemenblättchen der äusseren Reihe, zwischen beiden die Kiemen. axe oder Scheidewand mit dem zu- und abführenden Kiemengefäss ( 3 und 4), 5 Lage des Mantelschlitzes von Haliotis. Weitere Erklärung in Text.

In die viel kleinere obere Abtheilung ragt die eine Reihe der Kiemenblättchen (die hier kleiner sind) vor, während in die untere grosse Kammer der Mantelhöhle die der gegenüber liegenden Reihe angehörigen grossen Kiemenblättchen hinunterhängen. Am vorderen Ende ist jedoch die Kieme noch frei und ragt zipfelförmig vor (Trochiden, Turboniden, Neritiden).

Bei den Docoglossen (Patelliden im weiteren Sinne) finden wir mit Rücksicht auf die Kiemen sehr verschiedene Verhältnisse. Während nämlich die Lepetiden gar keine Kiemen besitzen, treffen wir bei Patella zahlreiche kleine Kiemenblättchen in einer Reihe rings um den Körper herum, auf der Innen- oder Unterseite der kurzen den Körper umkreisenden Mantelfalte, zwischen dieser und dem Fuss. Diese Reihe ist nur an einer vorn und links liegenden Stelle unterbrochen. Dass aber diese Kiemenblättchen, deren Anordnung ein wenig an die Kiemen der Chitonen erinnert, keine wahren Ctenidien sind, wird einwurfsfrei bewiesen durch die Thatsache, dass es Docoglossen giebt, welche neben 
der marginalen Reihe von Kiemenblättchen eine ächte, zweizeilig gefiederte Kieme (Ctenidium) besitzen, welche vollstindig derjenigen der T'urboniden, Trochiden etc. entspricht (einige Tecturaformen, Scurria). Wieder andere Formen (Acmaea) besitzen ausschliesslich das ächte Ctenidium und keine marginalen Kiemenblättchen.

Bei der grossen zweiten Prosobranchierabtheilung der Monotocardier sind die Kiemenverhältnisse im Grossen und Ganzen ausserordentlich einförmig. Es existirt nur eine meist in ihrer ganzen Länge mit dem Mantel verwachsene, einzeilig gefiederte Kieme (Fig. 454, p. 615), welche der linken Fissurella- und Haliotis-Kieme, der einzigen Kieme von Turbo, Trochus etc. entspricht. Sie liegt gewöhnlich ganz links in der Mantelhöhle.

Die Entstehung dieser Kieme kann man sich am besten vorstellen, wenn man sich der bei Turbo, Trochus etc. vorhin geschilderten Verhältnisse erinnert. Man braucht nämlich nur anzunehmen, dass die dem Mantel zugekehrte Reihe der kleinen Kiemenblättchen von Turbo verschwindet, und dass die Kiemenscheidewand mit dem Mantel in ihrer ganzen Breite verwächst, um die bei den Monotocardiern bestehenden Verhältnisse zu erhalten (Fig. 468 C, D). Formen.

Eine besondere Besprechung erheischen nur wenige abweichende

1) Bei einer Reihe auf dem Lande lebender Monotocardier hat die Wasserathmung der Luftathmung Platz gemacht und ist das Ctenidium verschwunden (Acicula, Cyclostoma, Cyclophorus etc.).

2) Die Ampullarien sind amphibische Prosobranchier. Durch eine Verdoppelung des Mantels entsteht bei ihnen ein sehr geräumiger Lungensack, an dessen Innenwand sich ein reiches, respiratorisches Gefässnetz ausbreitet. Die untere Wand dieses Lungensackes (welche zugleich die Decke der Mantelhöhle bildet) ist von einer Oeffnung zur Aufnahme und Abgabe von Luft durchbrochen. Die Kieme ist auf die äusserste rechte Seite der Mantelhöhle verlagert, was wohl mit der starken Entwickelung des Lungensackes in irgend einem Zusammenhang steht. Trotzdem entspricht sie der sonst links gelagerten Monotocardierkieme, wie die Innervationsverhältnisse zeigen.

3) Die Gattung Valvata steht dadurch im Gegensatz zu allen iibrigen Monotocardiern, dass ihre Kieme zweizeilig gefiedert und allseitig frei ist. Sie kann aus der Mantelhöhle vorgestreckt werden.

4) Unter den Heteropoden liegt die Kieme bei Atlanta noch wohl geborgen in der geräumigen Mantelhöhle. Bei Carinaria ist sie nur wenig geschützt durch die gering entwickelte Mantelfalte. Bei Pterotrachea fehlt die Mantelfalte, und die fadenförmigen Kiemenblättchen ragen hier frei und unbedeckt vor. Firoloides ist kiemenlos.

Opisthobranchiata. Hier erhält sich ein ächtes Ctenidium nur bei den Tectibranchiern und den Steganobranchiern unter den Ascoglossa. Es liegt, oft nur unvollständig bedeckt, in der rechtsseitig entwickelten Mantelhöhle und ist, wenigstens in einigen Fällen (z. B. Pleurobranchus), deutlich zweizeilig gefiedert.

Bei den Pteropoden, die wir von tectibranchiaten Opisthobranchiern ableiten müssen, ist das Ctenidium, wenn es überhaupt vorhanden ist, wenig entwickelt und liegt rechts am Körper. Es entspricht dem Ctenidium der 'lectibranchier. 
Bei den Gymnosomata erhält sich diese ächte Kieme nur bei den Pneumodermiden als ein einfacher, seltener (Pneumoderma) gefranster Fortsatz an der rechten Körperseite (Fig. 459, p. 652). Dagegen können sich neue Kiemen am hinteren Ende des Körpers entwickeln, die entweder mit dem ächten Ctenidium zusammen (Spongiobranchaea, Pneumoderma) oder allein vorkommen (Clionopsis, Notobranchaea), bis sie auch ihrerseits wieder verschwinden (Clione, Halopsyche).

Unter den 'Thecoso-

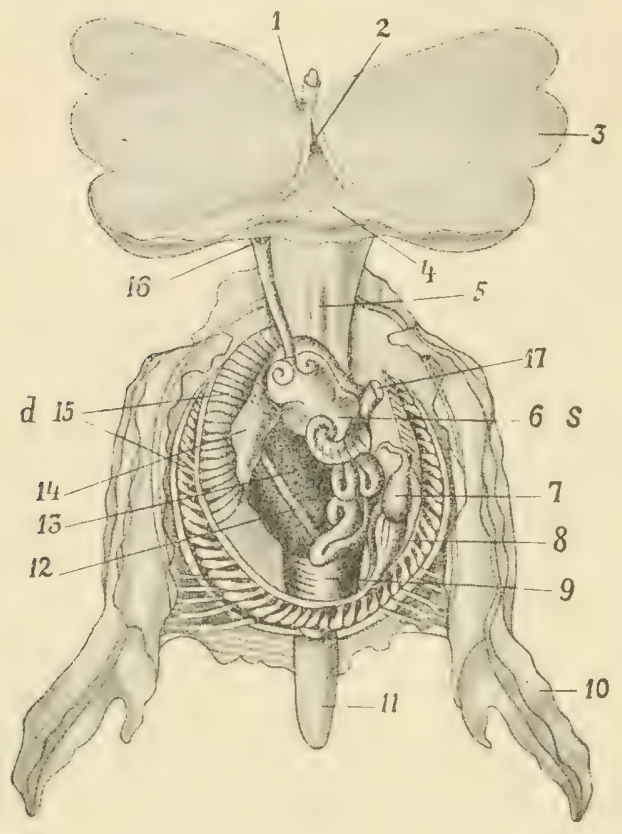
m a t a besitzen nur die Cavoliniiden (Fig. 469) eine Kieme, welche als eine Reihe faltenförmiger Erhebungen der Leibeswand in der Mantelhöhle auftritt und in wellenförmigen Biegungen so verläuft, dass sie einen nach vorn offenen Halblkreis bildet, dessen grössere Hälfte auf der rechten Körperseite liegt.

Fig 469. Anatomie von Carolinia tridentata, nach SOULEYET. schale und Mantel entfernt, Eingeweidesack zum Theil geöffnet, Ansicht von hinten und unten. $d$ Rechts, $s$ links; 1 Mündung des Penis, 2 Mund, 3 linke Flosse (Parapodium), 4 Fuss, 5 Oesophagus, 6 Theile des ausfiihrenden Geschlecbtsapparates, 7 Herzkammer, 8 Vorhof, $9 \mathrm{Zwitterdriise,} 10$ seitliche Fortsätze des Mantels, 11 Spindelmuskel, 12 Darm, 13 Verdauungsdrüse (Leber), 14 Magen, 15 Ctenidium, 16 Geschlechtsöffinung, 17 Anus.

C) Lamellibranchiata.

Auch die Lamellibranchier besitzen von Haus aus zwei symmetrisch gelagerte, zweizeilig gefiederte Kiemen. Die bis vor kurzem allgemein verbreitete Ansicht, dass die Muscheln jederseits in der Mantelhöhle zwei Kiemen besitzen, hat sich nämlich als irrthümlich herausgestellt, indem diese zwei Kiemen in Wahrheit den zwei Reihen von Kiemenblättchen einer zweizeilig gefiederten Kieme entsprechen.

Es verlohnt sich, die interessante Reihe von Modificationen, welche die ursprünglich zweizeilig gefiederte Kieme innerhalb der Klasse der Lamellibranchior erleidet, Schritt für Schritt zu verfolgen.

a) Die ursprünglichsten Verhältnisse findet man bei den Protobranchiern. Betrachten wir z. B. Nucula (Fig. 405, p. 581). Hier finden wir die Kieme in einem ähnlichen Zustand, wie bei Fissurella, eine Axe, in welcher die Kiemenarterie und die Kiemenvene verläuft und welche durch ein kurzes, häutiges Band mit dem hinteren und oberen Theil des Rumpfes oder Eingeweidesackes und dem hinteren Schliessmuskel verbunden ist. Dieser Axe sitzen zwei Reihen von kurzen, flachen Kiemenblättchen auf. Die beiden federförmigen Kiemen convergiren nach hinten, wo sie mit einer freien, zipfelförmigen Spitze in die Mantelhöhle vorragen. Die Blättchen der beiden Reihen sind etwas nach unten gerichtet, so dass 
sio aufeinander senkrecht stehen. Bei Malletia und Solenomya hingegen liegen sie noch in einer Ebene, so dass die beiden Reihen an der Axe gegenständig sind. Diese Ebene liegt bei Malletia horizontal, bei Solenomya von aussen und oben nach unten und innen geneigt. Die Zahl der Blätchen ist an der sehr schlanken Kieme von Malletia eine viel geringere als bei Nucula, sie sind in Folge dessen noch nicht so dicht gedrängt und noch nicht so abgeplattet. Jedes Blättchen enthält einen Blutraum, welcher eine Fortsetzung der Kiemenarterie ist. Zwei bindegewebige Stäbchen verlaufen am unteren Rande eines jeden Kiemenblättchens von der Axe bis zur Spitze und dienen ihm zur Stütze. Aehnliche Stützstäbchen finden sich fast bei allen Lamellibranchiern und zahlreichen Gasteropoden.

Das Epithelium der Kiemenblättchen ist an folgenden Stellen mit langen Cilien besetzt: 1) am ventralen Rande; 2) auf ihren boiden (vorderen und hinteren) Flächen, nahe am ventralen Rande.

Die ersteren Cilien bilden also mit Rücksicht auf die ganze Kieme je eine Längsreihe von Cilien an der freien, ventralen Kante einer jeden Blättchenreihe, und sie erzeugen einen Wasserstrom längs dieser Kante von hinten nach vorn. Die letztern stellen, indem sie wie die Borsten zweier ineinandergedrückter Bürsten ineinandergreifen, eine freilich lockere Verbindung der hintereinander liegenden Blättchen einer Reihe dar.

b) Bei den Filibranchiern (Fig. 470 B) werden die Blättchen in jeder der zwei Reihen sehr lang, und sie hängen weit in die Mantelhöhle herunter. Man bezeichnet sie jetzt als Ki emenfä den. Die Kiemenfäden beider Reihen sind auf sich selbst zurückgeknickt, so dass man an jedem Faden einen absteigenden und einen a ufsteigenden Schenkel unterscheiden kann. Die Verlängerung der Kiemenfädeu entspricht eimer zum Zwecke der Athmung nützlichen Oberflächenvergrösserung. Die Grösse der Mantelhöhle setzt ihr eine Grenze, die dadurch umgangen wird, dass der Kiemenfaden auf sich selbst, gegen seine Ansatzstelle an der Axe zurückläuft. An der äusseren, dem Mantel zugekehrten Reihe ist jeder Kiemenfaden nach aussen, an der inneren nach innen zurïckgeknickt.

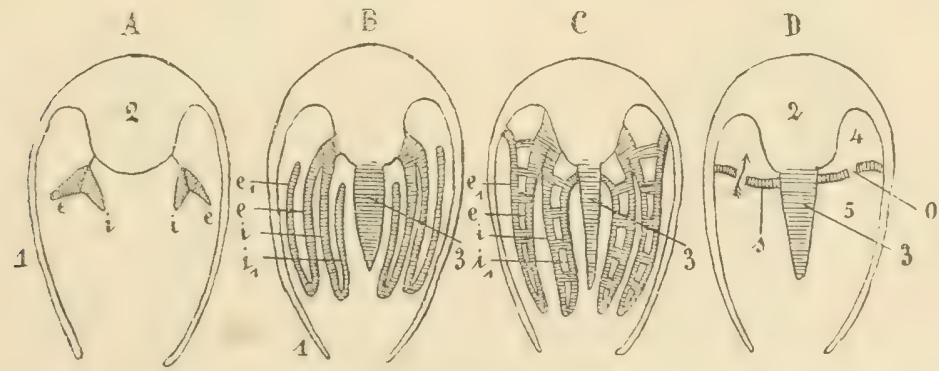

Fig. 470. Morphologie der Lamellibranchiatenkieme, schematische Querschnitte. 1 Protobranchiata. $B$ Filibranchiata, $C$ Eulamellibranchiata. $D$ Septibranchiata. 1 Mantel, 2 Rumpf (Eingeweidesack), 3 Fuss, $e$ in $\boldsymbol{A}$ Kiemenblättchen der äusseren Reihe der zweizeilig gefiederten Kieme, in $\boldsymbol{B}$ Kiemenfaden der äusseren Reihe, in $\boldsymbol{C}$ äusseres Kiemenblatt, $i$ Kiemenblättchen resp. Kiemenfaden der inneren Reihe, resp. inneres Kiemenblatt, $e_{1}$ aufsteigender Ast resp. Lamelle des äusseren Kiemenfadens resp. Kiemenblattes, $i_{1}$ aufsteigender Ast resp. Lamelle des iuneren Kiemenfadens resp. Kiemenblattes. In $D$ bedeutet $s$ die zu einem musculösen Septum umgewandelte Kieme, welche die Mantelhöhle in eine obere (4) und in eine untere Etage (5) theilt, die miteinander dureh Spalten (o) in der Scheidewand communiciren. Die weitere Erklärung im Text. 
In jeder Reihe stehen die Kiemenfäden dicht hintereinander, so dass die ganze Reihe das Aussehen eines Blattes oder einer Franse bekommt. Dieses Kiemenblatt besteht aus zwei $\mathrm{Lamellen}$, die einander dicht anliegen, einer absteigenden und einer a ufsteigenden, die am unteren Rande des Blattes ineinander übergehen. Die absteigende Lamelle wird gebildet von den absteigenden, die aufsteigende von den aufsteigenden Schenkeln der Kiemenfäden. Die aufsteigende Lamelle liegt am äusseren Blatte aussen, am inneren innen von der absteigenden.

Bei den Filibranchiern behalten die einzelnen Kiemenfäden ihre volle Selbständigkeit, sie sind frei, das heisst die aufeinander folgenden Fäden eines Blattes (einer Reihe) sind weder unter sich - noch sind die aufsteigenden und absteigenden Schenkel eines und desselben Kiemenfadens miteinander fest verbunden. Immerhin finden sich an den Vorder- und den Hinterseiten der Fäden oder Filamente Stellen mit ausserordentlich dicht stehenden, langen Cilien. Ich will diese dicht gedrängten Cilien Cilien bürsten nennen. Die Cilienbürsten der aufeinander folgenden Kiemenfäden greifen ineinander, und so kommt ein gewisser Zusammenhang zwischen den Fäden eines Kiemenblattes zu Stande.

Bei den Mytiliden kommen ferner schon Verwachsungen zwischen den ab- und aufsteigenden Schenkeln der Kiemenfäden vor, sogenannte

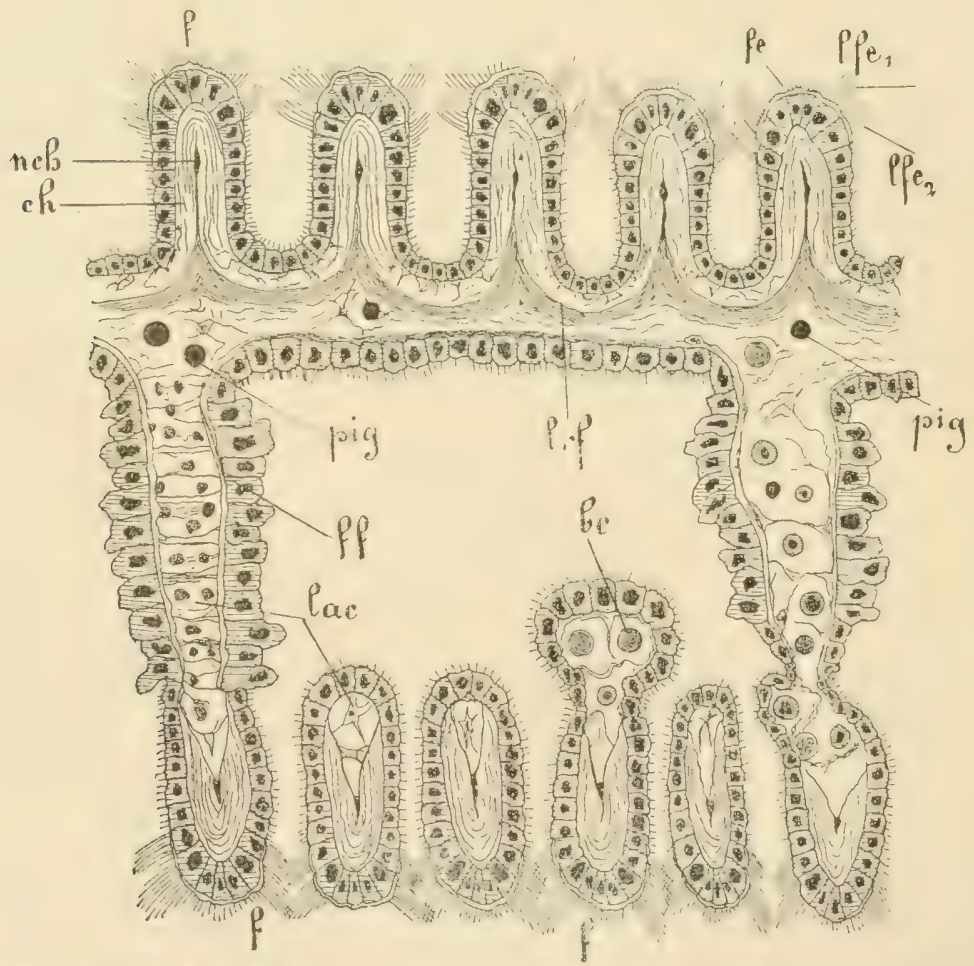

Fig. 471. Stũck eines Querschnittes durch das äussere Kiemenblatt von Dreissensia polymorpha, nach PECK, $f$ Die einzelnen Kiemenfäden, ff subepitheliale Fasern, ch Stützsubstanz der Fäden, lac Lacunengewebe, pig Pigmentzellen, bc Blutkörperchen, fe Epithelium des freien Randes der Kiemenfäden, $l f e_{1}$ und $l f e_{2}$ zwei Reihen von lateralen Epithelzellen der Kiemenfäden, welche lange Cilien (Cilienbürsten) tragen, lrf Gewebe der in terfila m entär en Verbindungsbrïcken. Es sind zwei i nterfoliäre Verbindungsbrücken getroffen. 
interfoliäre Verwachsungen; aber diese Verwachsungen enthalten keine Blutkanäle.

Bei Anomia sind die dorsalen Enden der aufsteigenden Schenkel des äusseren Blattes frei, bei den Arciden sind sie miteinander verwachsen, doch ohne innere Communication. In diesen Fällen ist der Binnenraum eines jeden Kiemenfadens durch eine Scheidewand in zwei Kanäle getheilt. In dem einen strömt das Blut von der Basis des Kiemenfadens bis an das Ende desselben, in dem anderen von dem Ende bis zur Basis (zur Axe) zurück. Bei den Mytiliden sind die dorsalen Enden der aufsteigrenden Schenkel der Kiemenfäden eines Blattes miteinander verwachsen, und ihre Blutkanäle communiciren an diesen Verwachsungsstellen, also am oberen Rande der aufsteigenden Lamelle miteinander.

Fig. 472, Stücke von Querschnitten durch die Kie. menblätter von Anodonta, nach Реск. $\boldsymbol{A}$ Aeusseres, $\boldsymbol{B}$ inneres Kiemenblatt; man sieht bei jedem Kiemenblatt die Querschnitte seiner beiden Lamellen und die interfoliären sowohl als die interfilamentären Verbindungsbrïcken. $\boldsymbol{C}$ Ein Theil von $\boldsymbol{B}$ sterk vergrössert. ol Aeussere, il innere Lamelle eines Kiemenblattes, $v$ Blutkanäle, $f$ die einzelnen Kiemenfäden, aus denen die Kiemenlamelleu bestehen, lac Lacunengewebe, ch Stuitzgewebe der Kiemenfäden mit festeren Stützstäben chr.

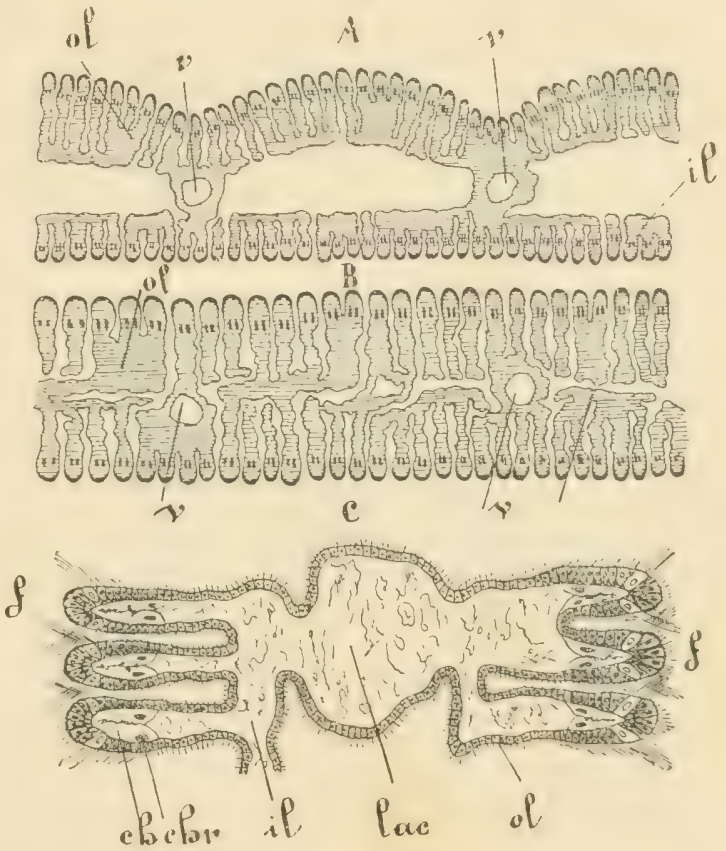

c) Pseudolamellibranchier. Bei diesen ist jedes Kiemenblatt im Sinne einer weiteren Oberfächenvergrösserung gefaltet. Die Falten verlaufen in der Längsrichtung der Kiemenfäden, sind also annähernd dorsoventral. Man kann also regelmässig alternirende Wülste und Furchen, vorspringende und einspringende $\mathrm{K}$ ante $\mathrm{n}$ an jedem Blatt, und zwar an beiden Flächen desselben unterscheiden, so dass immer ein vorspringender Wulst auf der Aussenfläche einem solchen auf der Innenfläche, eine Furche auf der Aussenfläche einer solchen auf der Innenfläche gegenüberliegt. Die ein- und vorspringenden Kanten werden je von einem Kiemenfaden gebildet. und der Kiemenfaden der einspringenden Kante zeichnet sich als Hauptfaden in irgend einer Weise, z. B. durch grössere Breite, vor den übrigen aus. Die beiden Lamellen eines Kiemenblattes sind stellenweise durch Querbänder verbunden, welche Blutkanäle enthalten können oder njcht. Diese Verbindungen finden sich entweder zwischen den gegenüberliegenden einspringenden oder zwischen den gegenüber- 
liegenden vorspringenden Kanten eines Blattes, mit anderen Worten, zwischen dem aufsteigenden und dem absteigenden Schenkel der Hauptfäden, die entweder an den einspringenden oder an den vorspringenden Kanten eines Blattes liegen. Der obere Rand der aufsteigenden Lamelle des äusseren Blattes kanu mit dem Mantel verwachsen. Die aufeinanderfolgenden Kiemenfäden eines und desselben Blattes sind miteinander nur durch Cilienbürsten verbunden.

d) Eulamellibranchier (Fig. 471-473). Die Kiemenblätter sind glatt oder gefaltet. Immer aber stehen sowohl die absteigenden und aufsteigenden Lamellen eines und desselben Kiemenblattes, als auch die aufeinanderfolgenden Kiemenfäden eines Blattes miteinander durch zahlreiche vascularisirte Verbindungsbrücken in orgauischer Verbindung. Diese Verbindungsbrücken sind also sowohl interfoliär als interfilamentär. Dieses Verhalten bedingt ein vollständiges Verwischen des ursprünglichen filamentären Baues jedes Kiemenblattes. Es ist dasselbe wirklich zu einem Blatt geworden, welches an beiden Flächen Löcher oder Spalten (die nicht verwachsenen Stellen zwischen deu aufeinanderfolgenden Filamenten)

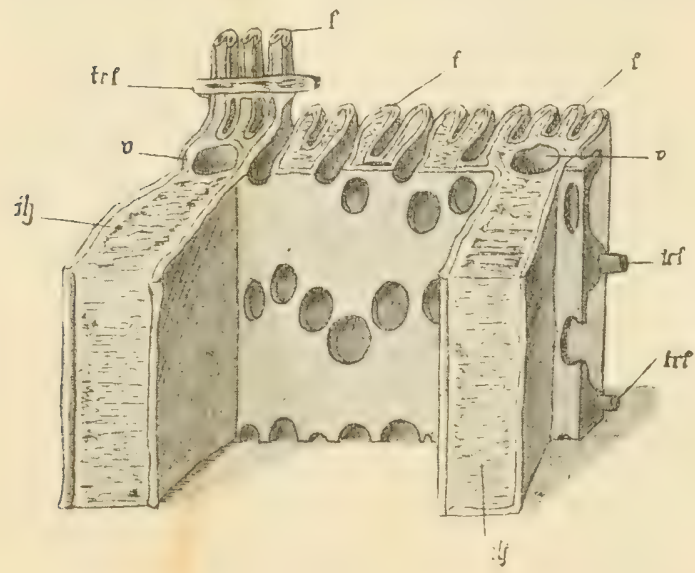

Fig. 473. Herausgeschnittenes Fragment der aufsteigenden Lamelle des äusseren Kie. menblattes von Anodenta, sche. matisch, nach PECK, $f$ Die einzelnen Kiemenfäden, verbunden durch interfilamentäre Verbindungsbrücken, trf Bindegewebe derselben, $v$ Blutkanäle, ilj interlamelläre Verbindungsbrücken, die (schwarz gehaltenen) Löcher in der Kiemenlamelle sind die übrig gebliebenen Lïcken zwischen den Kiemenfäden und ihren Verbindungs brücken, durch welche das Athemwasser strömen kann.

aufweist, die in ein Lücken- oder Kanalsystem im Inneren des Kiemenblattes führen, welches den nicht verwachsenen Stellen zwischen absteigender und aufsteigender Lamelle eines und desselben Kiemenblattes entspricht. Diese Beschaffenheit wurde früher als für die Muscheln typisch gehalten, hat ihnen den Namen Lamellibranchiaten verschafft und zu der Ansicht geführt, dass diese Thiere durch den Besitz von zwei blättrigen Kiemen jederseits in der Mantelhöhle, also im Ganzen vier, ausgezeichnet seien. Wir wissen jetzt, wie die zwei Kiemenblätter jederseits entstanden sind und dass sio nur den modificirten zwei Reiheu von Kiemenblüttchen der ursprünglichen, zweizeilig gefiederten Kieme der Protobranchier entsprechen. Die Lamellibranchier haben in Wirklichkeit jederseits nur eine Kieme in der Mantelhöhle.

Das Blut strömt jetzt nicht mehr durch die ursprünglichen Kiemenfäden in die Lamellen der Kiemen und aus diesen zurück, sondern die zu- und abführenden Blutwege liegen in dem Balkennetz zwischen den beiden Lamellen eines Kiemenblattes, welches eben diese beiden Lamellen zu einem Blatte verbindet. 
Das äussere Blatt einer Kieme kann, anstatt dass es dem inneren Blatt parallel in die Mantelhöhle herunterbängt, dorsalwärts in die Mantelhöhle emporragen, so dass inneres und äusseres Blatt in eine Ebene zu liegen kommen (bei Telliniden und Anatinacea).

Die aufsteigende Lamelle des äusseren Blattes kann fehlen (Anatinacea, Lasaea); ja das ganze äussere Blatt kann fehlen (Lucina, Corbis, Montacuta, Cryptodon).

Bei allen Lamellibranchiern mit Ausnahme der Protobranchier, ferner der Arcidae, Trigoniidae und Pectinidae, kommt es zu einer Verwachsung zwischen Kieme und Mantel, derart, dass der dorsale Rand der aufsteigenden (äusseren) Lamelle oder, wo diese fehlt, der freie Rand der einzig vorhandenen Lamelle des äusseren Kiemenblattes mit dem Mantel verschmilzt. In ähnlicher Weise kann der dorsale Rand der aufsteigenden (inneren) Lamelle des inneren Kiemenblattes mit dem oberen Theile des Fusses verschmelzen (Fig. $470 \mathrm{C}$ ). Wenn nun beide Kiemen, die im Bereiche des Fusses mit diesem verschmelzen, hinten, wo der Fuss aufhört, von beiden Seiten her in der Mittellinie der Mantelhöhle mit ein ander verschmelzen, so bilden sie eine Scheidewand, welche, indem sie sich mit der vom Mantel gebildeten Scheidewand zwischen Einströmungs- und Ausströmungssipho verbindet, die Mantelhöhle in eine obere und in eine untere Abtheilung trennt. Durch den unteren (Einströmungs-)Sipho strömt das Wasser in die grosse, untere Mautelhöhle, badet die Kiemen, kommt nach vorn, giebt die mitgeschwemmten Nahrungspartikelchen an den Mund ab, fliesst dann jederseits neben dem Fuss in dem oberen Theil der Mantelhöhle, die durch die Ansatzstelle der Kieme in zwei Kanäle getheilt wird, in die hinter dem Fuss einheitliche hintere und obere Abtheilung, und von da durch den oberen (Ausströmungs-) Sipho nach aussen (vergl. Fig. 410, p. 585).

e) Septibranchier (Fig. 415 A u. B, p. 588 u. Fig. 470 D). Diese Muscheln wurden irrthümlich für kiemenlos gehalten. In Wirklichkeit hat sich bei ihnen die eben erwähnte Kiemenscheidewand unter starker Veränderung ihres Baues zu einem musculösen Septum umgewandelt, welches die Mantelhöhle in horizontaler Richtung quer durchzieht und sich hinten an das Siphonalseptum anschliesst, weiter vorn den Fuss rings umgiebt. Dieses Septum ist in je nach den Gattungen verschiedener Weise von Spalten oder Löchern durchbrochen, durch welche eine Communication zwischen oberer und unterer Abtheilung der Mantelhöhle stattfinden kann.

\section{D) Cephalopoda.}

Die Kiemen der Cephalopoden sind durchgängig zweizeilig gefiedert. Ihr Bau ist bei den Dibranchiaten genauer untersucht. Beispiel Sepia. Jede Kieme hat im Ganzen die Gestalt eines schlanken Kegels, welcher der Länge nach dem Eingeweidesack in der Mantelhöhle aufliegt, so dass die Basis dorsalwärts (gegen die Spitze des Eingeweidesackes), die Spitze ventralwärts, gegen den freien Rand der Mantelfalte, d. h. gegen die Mantelspalte gerichtet ist (Fig. 462, p. 656). Die beiden Kiemen divergiren mit ihren Spitzen.

Die zwei Reihen von flachen, dreieckigen, zipfelförmigen Kiemenblaittchen Fig. 174) werden getragen von den beiden Kiemengefïssen, so dass sich jedes Kiemenblättchen mit dem einen Ende seiner Basis an der Kiemenarterie, mit dem anderen an der Kiemenvene befestigt. So kommt in der Axe der Kieme ein zwischen den beiden Gefässen und auch zwischen 
den beiden Reihen von Kiemenblättchen verlaufender Kanal zu Stande, welcher zwischen je zwei aufeinander folgenden Blättchen durch eine Oeffnung mit der Mantelhöhle communicirt und also vom Athemwasser durchströmt werden kann. Diese Oeffnungen oder Spalten, welche in den Axenkanal der Kieme hineinführen, sind zu beiden Seiten der Axe alternirend angeordnet, ebenso wie die Kiemenblättchen, zwischen deren Basis sie liegen. Die Kiemenvene bildet die hintere, dem Mantel zugekebrte, die Kiemenarterie die vordere, dem Eingeweidesack zugekehrte Stütze der Kieme. Die Kiemenarterie ist in ihrer ganzen Ausdehnung durch eine bindegewebige Membran mit dem Integumente des Eingeweide-

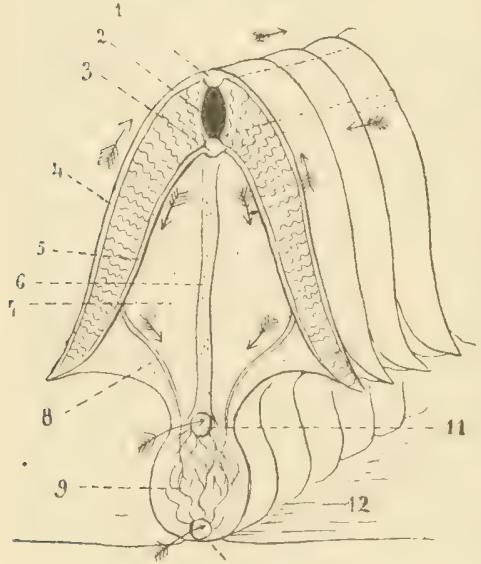

10

Fig. 474. Schematische Darstellung des Baues der Sepiakieme, nach der Darstellung von JoUbin. 1 Kiemenvene (enthält arterielles Blut), 2 Kiemenkanal, 3 Kiemenarterie (enthält venöses Blut), 4 specielle Kiemenvene (Vas efferens) eines jeden Kiemenblättchens, 5 specielle Kiemenarterie (Vas afferens) eines jeden Kiemenblättchens, 6 Aufhängeband der Kieme, welches speciell die Kiemenarterie (3) am hinteren Integument (12) des Eingeweidesackes befestigt, 7 specielles Aufhängeband eines jeden Kiemenblättchens am allgemeinen Aufhängeband 6,8 eine der Communicationen der Kiemenarterien mit der Blutdrüse 9, welche von venösem Blut durchspült wird. Die Gefässe 10 und 11 führen das venöse Blut, welches die Blutdrüse durchspült hat, wieder in den an der Kiemenbasis gelegenen venösen Sinus zurück. Die Pfeile deuten die Richtung des Blutstromes an.

sackes verwachsen. Der vordere (dem Eingeweidesack zugekehrte) Rand eines jeden Kiemenblättchens ist mit dieser Membran, die ich als Aufhängeband der Kieme bezeichnen will, selbst wieder durch eine dreieckige, dünne Haut verbunden. Am hinteren, freien Rande eines jeden Kiemenblättchens verläuft die sjecielle Kiemenvene dieses Blättchens und mündet in die Vene der Gesammtkieme ein, am vorderen, mit dem Aufhängeband verbundenen Rande verläuft die specielle Arterie des betreffenden Blättchens. Jedes Blättchen ist selbst wieder gefaltet, und zwar auf beiden Flächen alternirend. Jede solche Falte ist ferner selbst wieder germzelt. Alle diese Faltensysteme stehen senkrecht aufeinander. Sie dienen zur Oberflächenvergrösserung.

Da, wo das Aufhängeband der Kieme in das Integument des Eingeweidesackes übergeht, birgt er in seinem Innern einen Zellkörper, der ron einem System von blutführenden, intercellulären Kanälen durchzogen ist und vielleicht eine Blutdrüse darstellt. Dieser Zellkörper bezieht venöses Blut aus Verästelungen der Haupt-Kiemenarterie und der Kiemenarterien der Blättchen und giebt dasselbe wieder ab an zwei Venen, die bis zur Basis der Kieme zurückverlaufen, um dort wieder mit anderen Gefässen in den venösen Sinus der Niere einzumünden, von wo es zum zweiten Male durch die Kiemenarterie in die Kieme gelangt. Es gelangt also nicht alles venöse Blut, das durch die Kiemenarterie der Kieme zugeführt wird, in die Kiemenblättchen und zur Athmung, sondern ein Theil desselben durchströmt die "Blutdrüse", um, wieder ungeathmet, zum venösen Kiemenherzen zurückzukehren. Gewisse feine 
Verästelungen der Kiemenarterien dienen ferner zur Ernährung der Kieme und ihrer Aufhängemembranen. Ihr Blut kehrt durch ein besonderes Gefäss, das der Kiemenarterie an ihrer Vorderseite parallel läuft, zum venösen Sinus zurück.

Ein kräftiger Nerv tritt von der Basis in die Kieme ein und verästelt sich in ihr. Ein Muskel breitet sich auf der Oberfläche der Blutdrüse aus, und eine besondere Musculatur ermöglicht die Contractionen der Hauptkiemenvene.

Die Kiemen der Octopoden weichen in ihrem Bau beträchtlich, doch nicht wesentlich, von denen der Decapoden ab. Der Kiemenkanal ist viel geräumiger. Die Kiemenblättchen sind nicht nur gefaltet, sondern selbst wieder mit auf beiden Seiten alternirenden $\mathrm{Lamellen}$ besetzt, die selbst wieder auf beiden Flächen alternirend stehende Lamellen 2. Ordnung und diese 3. Ordnung und so fort, bis zu Lamellen 7. Ordnung tragen. So wird jedes Kiemenblättchen zu einem sehr complicirt gefalteten oder gefiederten Gebilde mit ausserordentlich stark vergrösserter Oberfläche.

\section{B) Adaptive Ki emen.}

Die Scaphopoden und viele Gasteropoden besitzen keine ächten Ctenidien. Die Ctenidien sind, als Wasserathmungsorgane, verschwunden bei den wenigen luftathmenden Prosobranchiern und bei den Pulmonaten. Welches aber die Ursache ihres Verschwindens bei den im Wasser lebenden $\mathrm{O}$ p is thobranchiern (incl. die ctenidienlosen Formen der Pteropoden) war, lässt sich zur Zeit nicht sagen, um so weniger, als bei den meisten Opisthobranchiern an Stelle der verschwundenen C te nidien neue, mit diesen morphologisch nicht vergleichbare, ad a p t ve K i e men auftreten. Ja es können (Pneumoderma) solche Kiemen schon auftreten, bevor die ächten Ctenidien geschwunden sind. Manche Opisthobranchier und die Scaphopoden besitzen überhaupt keine Kiemen, werler adaptive noch ächte. Hier erfolgt die Athmung offenbar an verschiedenen, geeigneten Stellen der Körperoberflïche, und viclfach, wo neben Kienen grössere Epiporlial-, Parapodial- oder Mantelausbreitungen vorkommen, mögen diese eine accessorische Rolle bei der Athmung spielen.

Adaptive Kiemen finden wir bei den meisten Ascoglossa und den Nudibranchiata und, wie oben schon gesagt wurde, bei einigen gym nosomen Pteropoden. Bei letzteren bestehen sie aus unansehnlichen gefransten oder ungefransteu Leisten am hinteren Körperende von verschiedener Form, deren Besprechung kein genügendes vergleichend-anatomisches Interesse darbietet.

Die Hauptformen der adaptiven Kiemen der Nudibranchier sind: 1) die Analkiemen rer Dorididae;2) die rechts - und linksseitigen Längsreihen von Kiemenblättchen unter der Mantelfalte der sogenannten Phyllidiidae; 3) die Rückenanhänge oder Cerata der Nudibranchiata und der meisten A s coglossa.

\section{Die Analkiemen (Fig. 475)}

sind zierliche, meist zweiseitig gefiederte Kiemenbliittchen, welche rosettenförmig den in der Mittellinie des Rückens hinter der Körpermitte gelegenen After der Dorididae umstellen. Zugleich mit diesen Analkiemen können noch Cerata vorkommen (Polyceridae). Die Ansicht, nach 
welcher die Analkiemen Ctenidien sind, entbehrt zur Zeit hinreichender Begründung.

2. Die rechts- und linksseitigen Längsreihen von Kiemenblättchen (Fig. 404, p. 580)

der Phyllidiidae und Pleurophyllidiidae stehen zu dem (fehlenden) Ctenidium in einem ähnlichen Verhältnisse, wie die entsprechenden, früher schon besprochenen Bildungen der Patelliden zu dem ächten

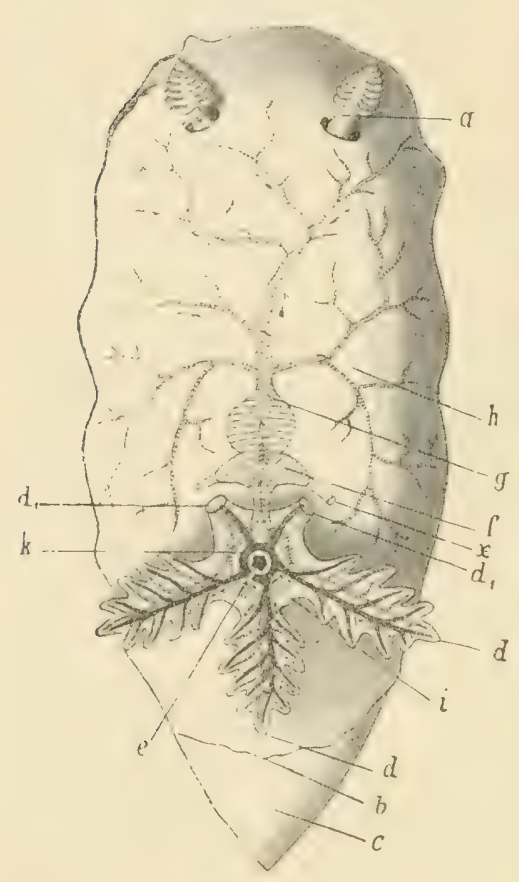
(bald fehlenden, bald vorhandenen) Ctenidium. Es handelt sich um zahlreiche kleine, von der Unterseite der den Körper umziehenden Mantelfalte in die niedrige Mantelhöhle vorspringende Lamellen, die entweder in einer einzigen, sich in der ganzen Länge der Mantelfalte erstreckenden, nur vorn unterbrochenen Reihe stehen (Phyllidia), oder die Reihe ist auch hinten unterbrochen (Pleurophyllidia), oder die Kiemenblättchen sind jederseits auf das Hinterende der Mantelfalte beschränkt (Hypobranchiaea). Dermatobranchus ist eine kiemenlose Gattung.

Fig. 475. Doris, Respirations- und Circulationssystem, nach LEUCKART, Wandtafeln. a Rhinophoren, $b$ hinterer Rand des Eingeweidesackes, $c$ Fussende, $d$ Kiemenfeder, $d_{1}$ zwei abgeschnittene Kiemenfedern, e After, $f$ Vorhof, $g$ Kammer des Herzens, $h$ Aorta, $i$ Ringvene um den After, enthâlt das aus der Kieme zurückströmende arterielle lilut und führt es durch die Kiemenvene in den Vorhof, $k$ Ringarterie, enthält aus dem Körper kommendes venöses Blut, $x$ zwei Gefässstämme, welche venöses Blut direct zum Herzen führen.

3. Die Rückenanhänge (Cerata) (Fig. 402, p. 579)

sind sehr verschieden gestaltete, bald einfache und bald verästelte, in grösserer oder geringerer Anzahl vorhandene, verschiedenartig angeordnete Fortsätze. An ihrer Spitze findet man häufig eine Cnidophorentasche, eine Einstülpung des Ectoderms, in welcher Nesselzellen mit Nesselkapseln zur Ausbildung gelangeu. Hüufig erstrecken sich Divertikel des Darmes (der Verdauungsdrüse) in die Cerata hinein und können sogar an ihrer Spitze nach aussen münden. Die Cerata sind meist schön und auffallend gefärbt und gezeichnet. Sie mögen bald, vermöge ihrer Farbe und Form, die Rolle von schützenden, verbergenden Einrichtungen, bald bei dem Zusammentreffen von auffallenden Farben und Nesselzellentaschen die Rolle von Warnzeichen spielen. Häufig brechen sie an ihrer Basis leicht $\mathrm{ab}$ (Schutzeinrichtung), und immer werden sie leicht wieder regenerirt. Sie spielen gewiss auch bei der Athmung, wie übrigens die gesammte übrige Körperoberfläche, eine Rolle, besonders wo sie stark verästelt und reich vascularisirt sind.

Gewisse Opisthobranchier sind gänzlich kiemenlos, so die Elysiidae, Limapontiidae und Phyllirrhoidae. 
Unter den Pulmonaten hat die schalenlose Gattung Onchidium adaptive Kiemen ausgebildet. Die Arten dieser Gattung leben amphibisch am Meeresstrande, an Stellen, die von der Fluth bedeckt werden. Ihre Lungenhöhle ist sehr klein; dafür findet die Athmung am reich vascularisirten Rückenintegument der Thiere und ganz besonders auf den hier befindlichen einfachen oder verästelten Rückenpapillen statt, in deneu ein reiches Gefüssnetz vorkommt, welches das Blut von einem zuführenden Gefäss erhält und an ein abführendes abgiebt.

\section{C) Lungen.}

Für die Pulmonaten ist der gämzliche Verlust des typischen Molluskenctenidiums charakteristisch, der mit der Lebensweise dieser luftathmenden Thiere zusammenhängt. Anstatt Wasser wird Luft in die vorn oder seitlich am Eingeweidesack liegende Mantelhöhle aufgenommen und aus ihr entleert. Die Mantelhöhle wird zu einer L ungenhöhle.

Fig. 476. Etwas schief und vor der Columella geführter Querschnitt durch Helix, nach Howes. $p g l$ Fussdrüse, $f s$ seitlicher Blutsinus des Fusses, ao Kopfaorta, gd Uterus, rp Rückziehmuskel des Penis, $p l m$ Muskel des Mantelrandes, welch letzterer mit dem Nackenintegument verwachsen ist, $s l$ Speicheldrüse, $c r$ Kropf, erweiterter Oesophagus, $s$ Schale, ms Boden der Lungenhöhle $=$ dorsales Integument des hinteren rom Mrantel bedeckten Nackenab. schnittes, $8 p$ Stiel des Receptaculum seminis, $p l_{1}$ Lungenhöhle, $p v$ zuführende Lungengefässe, re Harnleiter, r Rectum, $h g$. Z Zitterdrïse, $l$ Verdauungsdrüse, hd Z $\mathbf{Z}$ wittergang, $r m$ Spindelmuskel, $a g l$ Eiweissdrüse, $i$ Darm, st Magen.

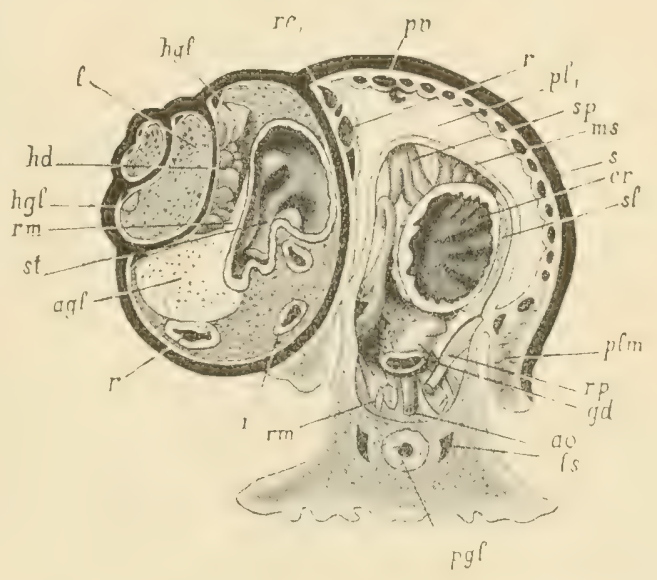

Der freie Rand der Mantelfalte, welche die Decke der Lungenhöhle bildet, verwächst mit dem darunter liegenden Körperintegument des Nackens bis an eine rechts liegende Stelle, welche offeu bleibt, und welche als ein verschliessbares $\mathrm{A}$ the $\mathrm{mloch}$ die $\mathrm{Zu}$ - und Abfuhr der Luft der Lungenhöhle ermöglicht. Längs der Verwachsungslinie ist der Mantelrand stark wulstförmig verdickt ( M a n t elwulst) und enthält hier ausserordentlich zahlreiche Kalkdrüsen. An der inneren, zarthïutigen Oberflïche des Mantels (Decke der Lungenhöhle) breitet sich ein dichtes respiratorisches Blutgefässnetz aus. Eine Vene, die Ringvene, verläuft dem Mantelwulst entlang. Aus ihr entspringen zahlreiche am Mantel sich ausbreitende, feine, anastomosirende Gefässe. Aus dem Netzwerk dieser feineren Gefässe sammeln sich wieder grössere Stänme, welche in die grosse, dem Rectum ungefähr parallel verlaufende Lungenvene eintreten, die auf der rechten Seite der Lungendecke, links vom Rectum nach oben und hinten verlïuft, um in den Vorhof des Herzens einzumünden. Die Ringvene enthält venöses Blut, die Lungenvene enthält Blut, das in dem Gefässnetz der Lungendecke bei der Athmung arteriell geworden ist und num dem Vorhof des Herzens zugeführt wird. 
Da bei den meisten Pulmopaten, wie bei den Prosobranchiern, das Athmungsorgan (mit der Nantelhöhle, in der es liegt) vor dem Herzen gelegen ist, so sind diese Pulmonaten prosopneumon. Ueber die Opisthopneumonie, welche bei einigen Pulmonaten in Folge der Verlagerung des Eingeweidesackes und des Mantels an das hintere Körperende entstanden ist, vergleiche Abschnitt V, p. 648.

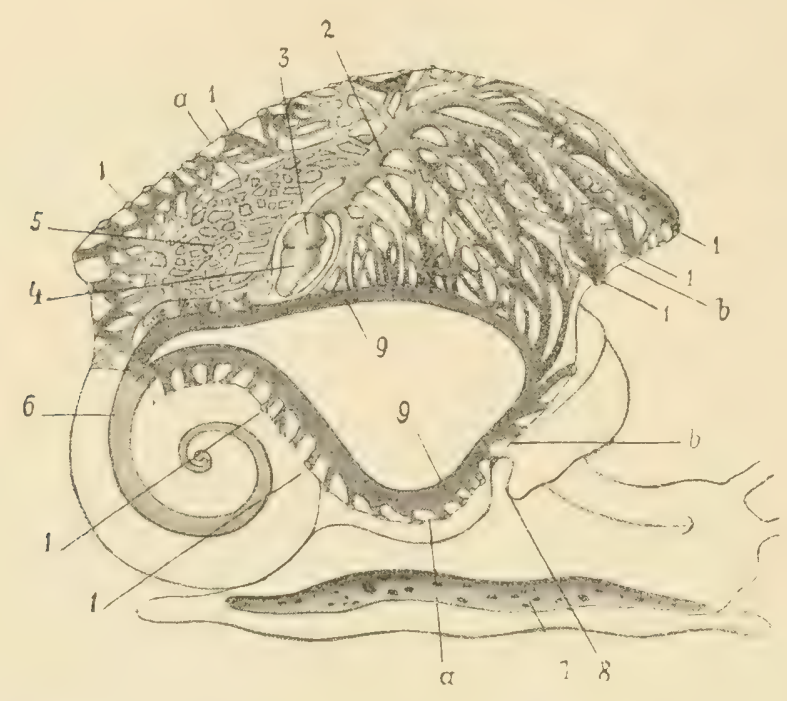

Fig. 477. Helix. Die Lungendecke dem Rectum und ihrem mit dem Nacken verwachsenen Rand entlang durchschnitten und zurückgeklappt, zur Demonstration des Blutgefässsystems, nach HowEs. Die Lungenvenen sind hell, die zuführenden Lungengefässe und venösen Sinusse dunkel gehalten. $a a, b \quad$ Zusammengehörige Schnittränder, 1 zuführende Lungengefässe, welche ihr (venöses) Blut aus dem grossen venösen Ringsinus 9 beziehen. Dieser letztere erhält sein Blut aus den grossen Körpersinussen, von denen der des Eingeweidesackes 6 und der rechte Fusssinus 7 dargestellt sind. Die abführenden Lungengefässe sammeln das an der Lungendecke arteriell gewordene Blut und führen es durch die Lungenvene 2 zum Vorhof 3 des Herzens." 4 Herzkammer, 5 Nierenkreislauf.

Gewisse Pulmonaten (Limnaeiden) haben sich wieder an das Leben im Wasser angepasst, aber sie athmen wie die Landformen und steigen von Zeit zu Zeit zum Luftholen an die Oberfläche des Wassers. Immerhin ist ihre Athemhöhle in der Jugend mit Wasser erfüllt, und sie sind dann wasserathmend. Bei einer Tiefseeform des Genfersees, Limnaea abyssicola, findet diese Wasserathmung zeitlebens statt; die in keiner Weise modificirte "Lungenhöhle" ist hier beständig mit Wasser erfüllt.

In ähnlicher Weise wie bei den Pulmomaten ist bei gewissen a uf dem Lande lebenden Prosobranchiern (Cyclostoma, Cyclophorus etc.) die Athemhöhle zu einer Lungenhöhle, ihre Decke durch Bildung eines respiratorischen Gefässnetzes zu einer Lungendecke geworden. Aber es kommt hier nicht zu einer Verwachsung des Mantelrandes mit dem Integument des Nackens. Cyclostoma hat noch ein Rudiment der Prosobranchierkieme, Cyclophorus hat auch dieses verloren. Die amphibischen Ampullarien besitzen zugleich eine Kiieme und einen Lungensack, und sie könmen nach Belieben Luft oder Wasser athmen. 


\section{Die Hypobranchialdruise.}

(Schleimdrüse der Prosobranchier, Epithelschild der Pteropoden etc., Analdrüse etc.)

ist bei den Mollusken ein weit verbreitetes Mantelorgan, welches überall in der Nähe des Ctenidiums, an dessen Basis oder zwischen ilım und rlem Rectum, vorkommt. Nan vergleiche bezüglich ihrer Lage und Verbreitung den Abschnitt $\mathrm{V}$.

Im Einzelnen ist die Driise von selı wechselnder Gestalt, sie ist aber nie eine vielzellige folliculäre oder tubulöse Drüse mit Ausführungsgang, sondern sie stellt ursprünglich nur eine geringere oder grössere Strecke des Epithels der Mantelhöhle (gewöhnlich an der Innenfläche (les Mantels) dar, in welcher besonder's zahlreiche epitheliale Drüsenzellen vorkommen. In diesem Zustande ist sie von der Ungebung wenig scharf abgegrenzt. Sie kann sich aber schärfer localisiren, eine bestimmte Gestalt aunehmen, und dann kamn sich das Drüsenepithel behufs Vergrösserung der secernirenden Oberfläche in Falten legen, die bald dichter, bald weniger dicht gerlrängt in die Mantelhöhle vorragen. Die Drüse sondert eine oft sehr reichliche Masse von Schleim ab. Die Purpurdrü se gewisser Prosobranchier (Purpura, Murex, Mitra) ist eine Hypobranchialdrüse, deren ummittelbar nach der Entleerung farbloses oder schwach gefärbtes Schleimsecret unter dem Einfluss des Lichtes violett orler roth wird. Bei Purpura zerfällt die Hypolranchialdrüse in 2 Theile von etwas verschiedener Structur.

\section{Der Kopf.}

Wenn man unter Kopf einen vorderen, vom Rumpfe mehr oder weniger deutlich al)gesetzten lïirpertheil versteht, welcher den Mund und specifische Simesorgane trägt, so besitzen unter den Mollusken die Lamellibranchier keinen Kopf. Sie sind deshalb auch als Acephala den übrigen kopftragenden Mollusken gegenïbergestellt worden. Das Fehlen eines Kopfes bei den Lamellibranchiern darf nicht als ein primärer /ustand betrachtet werden, sondern ist auf Rechnung ihrer im Allgemeinen limicolen Lebensweise, ganz besonders aber auf Rechnung der starken und eigenthümlichen Entfaltung des Mautels und der Schale zu setzen, welche das von ihnen eingeschlossene vordere Körperende mit dem Munde der directen Beziehung mit der Aussenwelt entrïcken und specifische Simnesorgane an dieser Stelle unnütz machen. Bei solchen Mollusken, die ihre Nahrung anfsuchen und direct erfassen und zerkleinern, leistet ein vorragender kopf als Träger von Simesorganen aussen und einer Hundbewaffinung innen gute Dienste. Die Muscheln aber sind auf kleine, in die Mantelhöhle hineingestrudelte Nahrungspartikelchen, die durch Flimmerbewegung dem Munde zugeführt werden, angewiesen, so dass eine Mundbewaffnung unnütz ist.

Bei den Cephalopoden verstärkt sich der Kopf durch Incorporation des zum Erfassen der Beute zweckdienlich umgestalteten Fusses (Armkranzes) zum Kiopf fuss, an welchem jederseits vorn das grosse, hoch entwickelte Auge liegt. Der Kopffuss ist durch den Nacken vom limpfe (Eingeweirlesack) melur oder weniger deutlich algesetzt.

Alle Gasteropoden mit sehr wenigen Ausnahmen besitzen einen Koppf, der vorn und unten die Mundöffinung, oben Tentakeln und Augen, 
und häufig asymmetrisch auf der einen (meist rechten Seite) eine Geschlechtsöffinung oder ein Begattungsorgan trägt. Dieser Kopf ist ventral von dem hinter ihm liegenden Fusse durch eine Furche deutlich abgesetzt, wäln'end er dorsal allmählich, ohne scharfe Grenze in den Nacken übergeht.

Der Kopf der Gasteropoden erheischt eine nähere Besprechung.

A) Prosobranchiata.

Der Kopf trägt überall Tentakel, welche solide, nicht einstülpbare, sondern einfach contractile Fortsätze der Kopfwand darstellen. Wir dürfen annehmen, dass ursprünglich 2 Paar 'Tentakel vorhanden sind, ein vorderes und ein hinteres. Das hintere trägt als A u genträger oder Ommatophor an der Spitze die Augen. Die meisten Diotocardier besitzen vordere Tast- und hintere und äussere A g gententakel.

Die Kopftentakel werden immer vom Cerebralganglion aus innervirt und unterscheiden sich dadurch scharf von tentakelähnlichen Fortsätzen, die neben den Tentakeln am Kopfe oder Nacken vorkommen können, aber dem Epipodium angehören und vom Pedal-resp. Pleuralganglion aus innervirt werden.

Bei den Docoglossa und den meisten Monotocardiern erheben sich die Augententakel nicht gesondert am Kopfe, sondern sie scheinen

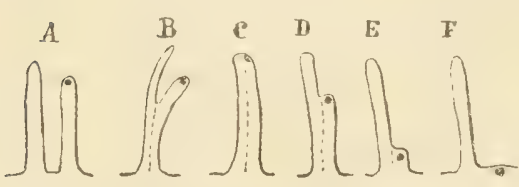

Fig. 478. Verhältniss der Tast- und Augententakel bei den Prosobranchiern. Erläuterung im Text. mit den Tasttentakeln in grösserer oder geringerer Ausdehnung verschmolzen zu sein. Zum Ausgangspunkt können wir Verhältnisse nehmen, wie sie bei Dolium, Strombus, Rostellaria existiren. Tasttentakel und Augententakel sind hier an der Basis eine Strecke weit verschmolzen, weichen dann aber mit ihren läıgeren oder kürzeren Enden frei auseinander (Fig. $478 \mathrm{~B}$ ).

Wären die beiden Tentakel jederseits gleich lang und ihrer ganzen Länge nach verschmolzen, so würde jederseits nur ein Tentakel entstehen, welcher an der Spitze das Auge tragen würde (Terebra) (C). Wenn aber der mit dem Tasttentakel verschmelzende Augententakel kürzer ist als dieser, so können wir das Auge an irgend einer Stelle zwischen der Spitze und der Basis des ersteren auf einem Absatze desselben antreffen (D und E), welcher der Spitze des verschmolzenen Augententakels entspricht. Das Auge kann schliesslich auch ganz sitzend werden, d. h. neben der Basis des Tasttentakels im Kopfintegument liegen (F).

Was nun den vor den Tentakeln befindlichen, den Mund tragenden Kopftheil, die Schnauze; anbetrifft, so zeigt derselbe bei den Prosobranchiern eine sehr verschiedene Ausbildung.

1). Die Schnauze ist kurz, abgestutzt bei den Diotocardiern und bei zahlreichen, vorwiegend pflanzenfressenden Taenioglossen.

2) Die Schnauze ist rüsselförmig verlängert (Rostrum), aber dabei nur contractil, nicht einstülpbar (Capulidae, Strombidae, Ctenopidae, Calyptraeidae), oder von der Spitze an einstülpbar (Cypraeidae, Lamellaridae, Naticidae, Scalaridae, Solaridae).

3) Die Schnauze ist zu einem langen $\mathrm{R}$ üs el (Proboscis) umgewandelt, an dessen vorderem Ende der Mund liegt. Dieser Rüssel ist so 
einstülpbar, dass die eingestülpte Basis desselben als Rüsselscheide den nicht eingestülpten vorderen Theil des Rüssels enthält. Hieher gehören fast ausschliesslich räuberische Schnecken (die Tritonidae, Doliidae und Cassididae, von den Taenioglossa die Rachiglossa und eine Anzahl Toxiglossa).

Die meisten Monotocardier besitzen im männlichen Geschlechte auf der rechten (selten linken) Seite des Kopfes oder des Nackens, unweit des rechten Tentakels einen verschieden gestalteten, nicht einstülpbaren Penis, der aber in den meisten Fällen morphologisch dem Fusse angehört (vom Pedalganglion aus innervirt wird), seltener einen Kopfanhang darstellt (und dann vom Cerebralganglion aus innervirt wird) (Fig. 454, p. 645).

Der Kopf der Heter opoden trägt zwei (selten rudimentäre: Pterotrachea, Firoloidea) Tentakel. Die Augen sind sitzend oder liegen auf kleinen Höckern neben der Tentakelbasis, an ihrer Aussen- und Hinterseite. Der Kopf verlängert sich vor den 'Tentakeln zu einer ansehnlichen, rüsselförmigen, nicht einstülpbaren Schnauze.

\section{B) Opisthobranchiata.}

In dieser Abtheilung der Gasteropoden zeigt der Kopf ausserordentlich verschiedenartige Formverhältnisse, die hier nicht im Einzelnen besprochen werden können. Er trägt gewöhnlich zwei Paar Tentakel, von denen die hinteren, als $\mathrm{Rh}$ in ophoren bezeichneten, vielleicht im Dienste der Geruchswahrnehmung stehen. Die Oberfläche dieser letzteren erscheint oft durch Bildung von Ringfalten u. S. w. vergrössert, und sie erheben sich oft auf dem Grunde von Gruben, in die sie zurückgezogen werden können. Der Kopf verlängert sich nur äusserst selten zı einem Rüssel oder einer rüsselartigen Schnauze. Die Augen sind sitzend.

Unter den Tectibranchien sind die Cephalaspidea durch eigenthümliche Verhältnisse des Kopfes ausgezeichnet. Der Kopf trägt nämlich auf der Rückenseite eine flache, fleischige Scheibe, die Ko pfoder Fühlerscheibe (Fig. 398, p. 570), die man als aus der Verschmelzung der Fühler hervorgegangen betrachtet und die in ihrer Gestalt vielfach an das Propodium der Naticidae oder Olividae unter den Prosobranchiern erinnert. Die Kopfscheibe trägt auf der Rückenseite die sitzenden Augen und schiebt sich mit ihrem bisweilen in zwei seitliche tentakelförmige Zipfel auslaufenden Hinterlappen hie und da über den Vordertheil der Schale hinüber. Im Einzelnen ist auch diese Kopfscheibe sehr verschiedenartig gestaltet.

Unter den $\mathrm{Nudibranchiern} \mathrm{wollen} \mathrm{wir} \mathrm{aus} \mathrm{der} \mathrm{Fülle} \mathrm{verschieden-}$ artiger Formen nur zwei Extreme herausgreifen: Tethys und Phyllirrhoë.

Bei Tethys bildet der Kopf eine grosse, annähernd halbmondförmige, flach ausgebreitete Scheibe mit gefranstem Rande, die auf der Oberseite die zwei conischen, in weite Scheiden zurückziehbaren Rhinophoren trägt.

Bei Phyllirrhoë (Fig. 403, p. 579) setzt sich der Kopf in eine kurze, rüsselförmige Schnauze fort. Er trägt nur zwei sehr lange, gebogene Fühler, deren Basis von einer Hautfalte umgeben ist und die als Rhinophoren betrachtet werden.

Pteropoda gymnosomata. Der Kopf ist gesondert und trägt 2 Paar Tentakel, nämlich ein Paar Lippen- und ein Paar $\mathrm{Nacken-}$ tentakel. Das erstere entspricht den vorderen, das letztere den hinteren 
Tentakeln oder Rhinophoren der Tectibranchia, speciell der Aplysidae. Die Nackententakel sind im Allgemeinen klein oder rudimentär, an ihrer Basis liegt ein Augenrudiment.

Fast alle Gymnosomen besitzen als exquisit räuberische Schnecken eine von der Spitze vollstündig einstülpbare, rüsselförmige Schnauze, die an ihrer Basis (im ausgestiulpten Zustande) Buccalanhänge trägt, welche vom Cerebralganglion aus innervirt werden. Es herrschen bestimmte compensatorische Beziehungen zwischen der rüsselförnigen Schnauze und den Buccalanhängen. nopsis).

1) Der Rüssel ist ausserordentlich lang, Buccalanhänge fehlen (Clio-

2) Der Rüssel ist mässig lang und trägt an der Basis Saugnäpfe oder ein Paar lange, mit Saugnäpfen besetzte Anhünge (Pneumodermidae) (Fig. 459, p. 652).

3) Der Rüssel ist kurz. Vordere Tentakel lang. An der Basis des (ausgestülpten) Rüssels 3 Paar conische Fortsätze (Kopfkegel) mit besonderen Nervenendigungen und Drüsen, deren klebriges Secret die Beute befestigt (Clionidae).

4) Der Rüssel fehlt. Jederseits vom Munde ein langer, dehnbarer Buccalanhang, der an seiner Basis den Lippententakel trägt.

Pteropoda thecosomata. Kopf meist undeutlich gesondert, ohne einstülpbare Schnauze; nur ein Paar Tentakel, die den Rhinophoren entsprechen und bisweilen an ihrer Basis in Scheiden stecken. Der linke Tentakel kann rudimentär werden. Bei den Thecosomata liegt das männliche Begattungsorgan auf der Oberseite des Kopfes in der Nähe der Tentakel.

\section{C) Pulmonata.}

Der Kopf der Pulmonaten ist ventralwärts vom Fusse abgesetzt, geht aber dorsalwärts und seitlich ohne Grenze in den Nacken über. Er trägt 2 oder 4 Tentakel. Die Stylommatophoren (Landpulmonaten) haben 4 Tentakel (Fig. 479), ein vorderes und ein hinteres Paar. Das hintere, gewöhnlich längere trägt an der Spitze die A ugen. Die Tentakel sind hohle Röhren, deren mit Blut erfüllter Hohlraum mit den Bluträumen des Kopfes communicirt. Sie sind von der Spitze an vollständig in den Kopf zurückstülpbar, indem besondere Muskeln als Retractoren wirken, die aus dem Kopf in die Tentakelhöhle eintreten und in dieser bis an die Spitze der ausgestülpten 'Tentakel verlaufen.

Die Basommatophoren (Wasserpulmonaten) haben nur ein Tentakelparar. Die Tentakel sind meist dreieckig-zipfelförmig, nicht hohl

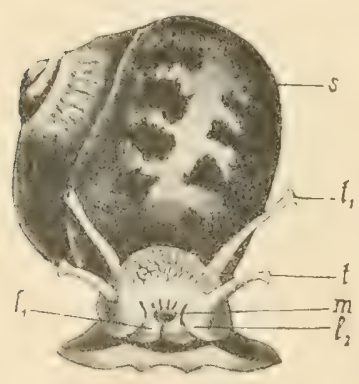
und nicht einstülpbar, sondern bloss contractil. Die Augen liegen an ihrer Basis, auf der inneren Seite.

Bei gewissen Pulmonaten (Glandina, Zonites, Oncidium) kann sich die Oberlippe jederseits in einen Lappen, den sogenannten Lippentaster ausziehen. Dieser Lippentaster ist z. B. bei Glandina sebr beweglich und der Sitz eines sehr feinen Tastgefühls.

Fig. 479. Kriechende Helix, von vorn, mit ausgestreckten Fiihlern, nach Howes. $s$ Schale, $t_{1}$ Augententakel, $t$ vordere Tentakel, $m$ Mund, $l_{1}, l_{2}$ Lippen. 
Rechtsseitig, hinter dem rechten Tentakel, liegt die gemeinsame Geschlechtsöffnung oder, wenn männliche und weibliche Oeffnungen getrennt sind, die männliche Geschlechtsöffnung.

$$
\text { Scapho poda (Fig. 483, p. 687). }
$$

Vor und über dem Fusse ragt vom Rumpfe eine ei- oder tonnenförmige, nicht einstülpbare Schnauze nach vorn und unten in die Mintelhöhle vor. An ihrem Ende liegt der Mund, ungeben von einem Kranze am Rande gezackter, eichblattförmiger Mundlappen, 4 jederseits.

An der Grenze zwischen der Basis des Fusses und der Basis dieser Schnauze, rechts und links vom Cerehralganglion, heht sich jederseits rom Körper ein schildfïrmiger Lappen ab, der in rler Mitte seiner Innenseite dn'ch einen kurzen, schmalen Stiel der Körperwandung aufsitzt und auch an seinem unteren Rande mit ihr verwachsen ist. Auf diesem Schilde erhelen sich zahlreiche faden-oder wurmförmige, drüsige, äusserst bewegliche 'I' entakel, die weit aus der unteren Mantelöfinung vorgestreckt werden können.

Das Ende der Tentakel ist löffelfö $\mathrm{r}$ mig angeschwollen und kann sich wie ein Saugnapf an fremde Gegenstände anlegen. Auf der concaven Seite trägt die Anschwellung lange Wimperhaare, und dieses Wimperkleid zicht sich auch als ein Wimperstreifen den Tentakeln entlang bis an ihre Basis hin. Ausser den ausgebildeten Tentakeln finden sich solche auf allen Stadier der Entwickelung. Diese erheben sich hauptsächlich auf der Innenfläche des Tentakelschildes. Die Tentakel fallen leicht ab oder werden bei schädigenden äusseren Einflüssen abgestossen und wieder regenerirt. Sie dienen wohl in erster Linie als Tastorgane und als Organe zum Ergreifen von Nahrungspartikelchen (Foraminiferen u. a.). Ausserdem mag die durch sie bedingte Oberflächenvergrösserung bei dem Mangel localisirter Kiemen der Athmung zu Gute kommen. Die Tentakel werden durch den Stiel des Tentakelschildes bindurch ron den Cerebralganglien aus innervirt.

$$
\text { Ceph a lopoda. }
$$

Bei Nautilus findet sich jederseits ein Tentakel über und ein Tentakel unter dem Auge. Es ist nicht unwahrscheinlich, dass diese T'entakel den zwei Tentakelpaaren der Gasteropoden entsprechen.

\section{Die Mundlappen der Lamellibranchier.}

Die Mundïfïnumg der Iannellihranchier setzt sich rechts und links in eine Rin ve fort, welche an der (Oberfläche des Rumpfes nach hinten verliuft bis an das vordene Ende der Kiemenbasis oder bis in die Nähe desselben. Diese Rinne wird begrenzt durch zwei vorspringende I, e is te 11 , eine obere und eine untere. Die beiden oberen Leisten bilden da, wo sie von den Seiten her am Nunde ineinander übergehen, eine Art Ober-, die zwei unteren eine Art Unterlippe. Die von den I.risten begrenzte Rinne dient dazu, die Nahrungspartikelchen, welche an clen hiemen durch Flimmerbewegung herbeigespïlt worden sind, dem Munde zuzuführen.

Die Rinne ist natürlich um so länger, je weiter das Vorderende der Kiemen vom Munde entfernt ist, um so kürzer, je geringer dieser Abstand ist. 
Nun verlängern sich die beiden Leisten, welche die Rinne zwischen sich fassen, bei den Muscheln in ihrem hinteren Theile zu dünnen Blättern, welche in die Mantelhöhle hineinhängen. Diese Blätter, zwischen denen die Rinne zu einer engen und tiefen Spalte wird, sind die M und la p pen oder M und s ege l der Lamellibranchier. Sie haben im Allgemeinen eine dreieckige Gestalt, wobei die eine Seite des Dreiecks die Basis darstellt, mit welcher der Mundlappen dem Rumpfe aufsitzt.

Wo die Kiemen weit hinter der Mundöffnung liegen, ist diese Basis lang, wo sie nahe hinter dem Munde ihren Anfang nehmen, ist diese Basis kurz und jeder Mundlappen hat dann meist die Gestalt eines langen, freien Zipfels. Die zwei an ihrer Oberfläche bewimperten Mundlappen jeder Seite sind an ihrer einander zugekehrten, d. h. den Spalt zwischen sich fassenden Oberfäche senkrecht zur Basis gestreift. Diese Streifung ist der Ausdruck von nebeneinander liegenden leistenförmigen Erhebungen und verleiht den Inundlappen häufig eine oberflüchliche Aehnlichkeit mit den Kiemen. Die Mundlappen werden von Blutlacumen durchzogen, und es ist wahrscheinlich, dass sie neben ihrer Hauptfunction als Zuleitungsorgan der Nahrung zum Munde auch eine Rolle bei der Athmung spielen.

Indem bei gewissen Formen am Munde der freie Rand der Oberlippe sich über den freien Rand der Unterlippe überschlägt (Ostrea, Tridacna), oder die beiden Ränder sich direct aneinanderlegen und durch Fortsätze, Falten ineinander greifen (Pecten, Spondylus), kann eine vor dem Munde liegende geschlossene Höhle entstehen, in welche von rechts und links her der offene Theil der Rinne die Nahrungspartikelchen hineinführt. Der freie Rand der Oberlippe kann sogar (Lima) mit dem freien Rand der Unterlippe verwachsen.

$\mathrm{N}$ u cula (Fig. 405, p. 581), bei der das Ctenidium weit hinten liegt und eine kleine Oberfläche darbietet, mag als Beispiel für sehr stark entwickelte (früher für die Kiemen gehaltene) Mundlappen gelten. Ihre Basis erstreckt sich fast in der ganzen Länge der Fussbasis, und sie verlängert sich hinten noch in einen rinnenförmig ausgehöhlten freien Anhang, welcher aus der Schale vorgestreckt werden kann und wahrscheinlich bei der Zufuhr der Nahrung betheiligt ist.

\section{Der Fuss und seine Driisen.}

Die Bauchseite des Molluskenkörpers ist charakterisirt durch die starke Entwicliclung der zur kriechenden Locomotion dienenden Musculatur, durch welche ein fleischiges, vom übrigen Kïirper, besonders auch vom hopf deutlich alogesetztes, mit einer flachen líriechsolıle ausgestattetes Organ, (ler Fuss, zur Aushildung gelangt. Diese starke ventrale Musculatur ist aufzufissen als ein Rest eines bei den Stammformen vorhandenen Hatutmuslielschlauches, der sich, in Anpassung an die kriechende Lebeusweise, auf der Banchflache starkes entwickelt hatte, wïhrend er auf dem Rücken, durch die Aushildung einer harten Schale functionslos und nutzlos gewordeu, sich rückbildete.

Die Form des Fusses mit flacher Kriechsohle, der Sohlenfuss, kann als die ursprüngliche betrachtet werden. Wir finden den Sohlenfuss hei den Chitoniden unter den Amphineuren, bei den meisten Gasteroporlen und bei gewissen Lanellibranchiern, besonder's den Protobranchiern, die man auch ans anderen goten Gründen für die ursprünglichsten Formen der Klasse halten muss. 
Die Musculatur des Fusses und aller Theile, die sich an und aus ihm differenziren können, wird von den Fuss-oder Pedalgangli en oder Fusssträngen aus innervirt.

Der Fuss kann seine Gestalt in Anpassung an verschiedenartige Lebens- und Bewegungsweisen des Thieres stark modificiren, so stark sogar, dass er keine Aehnlichkeit mehr mit dem ursprünglichen Organ darbietet. Er kann durch Einschnitte oder durch Lappen- oder Faltenbildungen in verschiedene Abschnitte zerfallen, von denen folgende die wichtigsten sind:

1) von vorn nach hinten ein vorn vom übrigen Fuss sich absetzender Theil, der Vorderfuss (Propodium), ein hinterer, selten scharf abgesetzter Theil, der Hinterfuss (Metapodium), welcher den Deckel trägt, wo ein solcher vorkommt;

2) von unten nach oben folgende Theile, die Parapodien, lappenartige Verbreiterungen des Randes der ventralen Kriechsohle;

3) das Epipordium, eine vorspringende Leiste oder Falte rings un die Basis, d. h. um den oberen Theil des Fusses herum. An dieser Leiste kommt es hüufig zur Bildung von tentakelartigen Fortsätzen.

Wir wollen nun den liuss in seinen verschiedenen Erscheinungsformen durch die verschiedenen Abtheilungen hindurch verfolgen und hei dieser Gelegenheit auch die Drïsen des Fusses, die Schleimdrü sen und Byssusdrüsen, besprechen.

\section{A) A mphineura.}

Das früher, Abschnitt II, p. 595 u. 596 Gesagte genügt. Es kommt weder zu einer Gliederung des Fusses in longitudinaler Richtung noch zur Ausbildung von Para- oder Epipodien.

\section{B) Gasteropoda.}

a) Prosobranchiata.

Mit seltenen Ausnahmen, die besonders besprochen werden sollen, besitzt der gewöhnlich gut ausgebildete Fuss eine flache einheitliche Kriechsohle.

Der vordere Theil des Fusses setzt sich in einzelnen Fällen als Propodium scharf vom übrigen Fuss ab. Es ist dies vornehmlich bei einigen Monotocardiern der Fall (Olividae, Harpidae, gewisse Pirula-Arten, Strombidae (Strombus, Pterocera, Terebellum [Fig. 390]), Xenophoridae [Fig. 389, p. 571], Naricidae, Naticidae).

Greifen wir einige Fälle heraus. Sehr schön ist das vom übrigen Fuss durch eine Querfurche getrennte Propodium als eine halbmondförmige Scheibe bei Oliva entwickelt.

Sehr deutlich ist auch am grossen Fusse von Natica (Fig. 480) die Abtrennung eines Vorderfusses ausgeprägt. Der Vorderfuss besitzt einen Lappen, welcher von vorn her sich auf die Schale zurückschlägt und dabei den Kopf bedeckt. Das Propodium bildet bald auf der linken Seite eine Art Sipho, bald zeigt der auf die Schale zurückgeschlagene Lappen eine Ausbuchtung. Beide Einrichtungen dienen wohl zur Zuleitung des Athemwassers zur Kiemenhöhle. Auch der im geschwellten Zustande weit ausgebreitete Hinterfuss trägt auf seiner Rückseite einen nach vorn auf die Schale umgeschlagenen Schalenlappen, der auf der der Schale zugekehrten Seite das Operculum trägt.

Bei den meisten Prosobranchiern trägt der Hinterfuss auf seiner 
Rückenseite ein horniges oder kalkiges $\mathrm{O}$ perculum, das zum Verschluss der Schale dient.

Epipodium. Ein solches kommt den Diotocardiern ganz allgemein zu. Am stärksten ist es entwickelt bei $\mathrm{Haliot}$ is (Fig. 487), wo es als eine ansehnliche Hautfalte die Fussbasis rings umzieht. Die Hautfalte, treffend als $\mathrm{Kr}$ a us e bezeichnet, zeigt gefranste oder fingerförmig zerschlitzte Anhänge neben langen, contractilen, tentakelartigen Fortsätzen. Die Tentakel sind hier, wie die entsprechenden Epipodialtentakel anderer Prosobranchier, Tastorgane und können an ihrer Basis

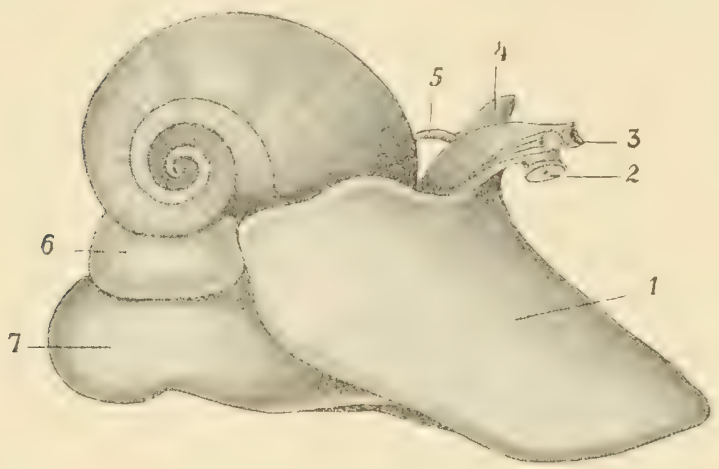

Fig. 480. Natica josephina, mit ausgestrecktem Rüssel, von der rechten Seite, nach Schiemenz. 1 Vorderfuss, 2 saugnapfähnlicher, zum Bohren dienender Anhang (mit Bohrdrüse) des Rüssels 3, 4 Sipho (hier vom Fusse gebildet), 5 Tentakel, 6 Schalenlappen des Hinterfusses, welcher gewöhnlich einen grossen Theil der Schale von hinten bedeckt und an seiner Innenseite den Deckel trägt, 7 Hinterfuss.

mit sogenannten Seitenorganen versehen sein. Bei den $\mathrm{F}$ is surelliden (Fig. 467, p. 662) wird diese Krause ersetzt durch eine Reihe zahlreicher Tentakel oder Papillen, welche jederseits sich auf dem Grunde der Furche zwischen Fusswurzel und Eingeweidesack erheben. Auch bei den übrigen Diotocardiern ist das Epipodium gut ausgebildet als ein einfacher oder gefranster Hautsaum, welcher meist kürzere oder längere Tentakel in geringerer Zahl (am häufigsten 4 jederseits) trägt (Fig. 387, p. 570). An der Basis eines jeden Tentakels findet sich ein Seitenorgan. Bei Eumargerita und Scissurella sollen Augen an der Basis der Epipodialtentakel vorkommen.

Das Epipodium fehlt im Allgemeinen bei den Docoglossa, doch existirt bei der Gattung $\mathrm{Helcion}$ ein mit Papillen besetztes, bei den Gattungen $\mathrm{Patinella}$ und $\mathrm{Nacell}$ a ein gefranstes Epipodium, welches der Lage nach ganz mit demjenigen der ïbrigen Diotocardier ïhereinstimmt.

Unter den Monotocardiern tritt ein wohl entwickeltes Epipodium selten auf. Doch zeigt Ianthin a einen typischen Epipodialsaum, und das Epipodium der Litiopidae und mancher Rissoidae besitzt sogar jederseits mehrere (1-5) Tentakel. Bei zahlreichen anderen Monotocardiern haben sich ferner entweder vordere oder hintere Theile des Epipodiums erhalten.

a) Vordere Epipodialreste, z. B. bei Vermetus 2 vordere Fusstentakel, bei Paludina und Ampullaria die beiden Nackenlappen (nicht zu verwechseln mit den Kopftentakeln), von denen bei Paludina der rechte, bei Ampullaria der linke durch Bildung einer Längsrinne zu einer Art Sipho wird.

Calyptraea besitzt jederseits unter dem Nacken eine halbkreisförmige Epipodialfalte. 
b) Hintere Epipodialreste. Lacuna hat jederseits hinten über dem Fusse eine Epipodialfalte mit einem Fortsatz. N a rica jederseits über dem Metapodium einen flügelförmigen Epipodiallappen.

c) Mittlere und hintere Epipodialreste. Choristes hat jederseits in der Mitte eine Papille und hinten unter dem Operculum jederseits einen Tentakel.

Das Epipodium wird immer von den Pedalsträngen oder den diesen gleichwerthigen $\mathrm{Pedalganglien}$ oder von den sich von diesen sondernden Ple u ralganglien aus innervirt.

Eine eigenthümliche Umwandlung erleidet der Fuss von Hipponyx, einer Monotocardiergattung mit conischer Schale. Die Thiere sitzen Felsen oder Molluskenschalen, die sie aushöhlen, fest auf, entweder direct oder vermittelst eines wahrscheinlich dem Operculum entsprechenden Schalenstückes. Die Sohle des Fusses hat in der Mitte die Muskelschicht verloren, und ihr Rand ist mit dem Mantelrand verwachsen mit Ausnahme von vorn, wo der Kopf hervortritt. Auf der Unterseite des Fusses bedingt der von der Schale heruntersteigende spindelmuskel einen hufeisenförmigen, die centrale, muskellose Partie umfassenden Muskelbezirk.

Ohne im Einzelnen auf die Art der Locomotion der Prosobranchier einzugehen, sei hier nur erwähnt, dass die meisten auf der flachen Sohle kriechen, oder sich mit ihr festheften.

Fuss der Heteropoden. Die Heteropoden sind pelagische Prosobranchier und zwar Monotocardier, welche die kriechende Lebensweise mit der schwimmenden vertauscht haben. Ihr Fuss ist dieser neueu Bewegungsweise in charakteristischer Art angepasst. Das Propodium ist nämlich zu einer schmalen, senkrecht stehenden $\mathrm{Ruder}$ flosse (Kielfuss) umgewandelt, welche in der Schwimmstellung der Thiere - Bauch nach oben, Rücken nach unten - nach oben gekehrt ist.

Wir können innerhalb der Heteropoden fast Schritt für Schritt die Ausbildung des Kielfusses verfolgen, wenn wir von Oxygyrus ausgehen und durch Atlanta und Carinaria bis zu Pterotrachea gelangen. Diese Reihe ist die nämliche, in welcher der typische, noch bei Oxygyrus und Atlanta bestehende Prosobranchierhabitus sich auch nach einer anderen Richtung hin (Schale, Eingeweidesack, Mantel, Kieme) allmählich verwischt.

Oxygyrus (Fig. 481 A) hat noch ganz Prosobranchiercharakter. Der Fuss besteht: 1) aus einem Propodium, das auf der Unterseite die vertiefte Kriechsohle besitzt, vorn aber einen flossenartigen Auswuchs zeigt, der als Ruderorgan beim Schwimmen gebraucht wird, und 2) einem deutlich gesonderten, schwanzartig nach hinten gerichteten deckeltragenden Metapodium. Diese Verhältnisse lassen sich leicht auf diejenigen gewisser Prosobranchier mit gesondertem Pro- und Metapodium, etwa der springenden Strombiden zurückführen. Die Kriechsohle von Oxygyrus wird, obschon das Thier auf derselben kriechen kann, schon als Saugnapf bezeichnet.

Bei Atlanta (B) finden wir ganz ähnliche Verhältnisse wie bei Oxygyrus, nur ist jetzt der flossenartige, bedeutend vergrösserte Auswuchs des Propodiums der ansehnlichste Theil desselben geworden, dem gegenïber die verkleinerte Fusssohle, der Saugnapf, nur als ein Anhang erscheint.

Bei Carinaria (C) haben sich die Fussverhältnisse mit dem Gesammthabitus des Thieres stark verändert. Das hier deckellose Meta- 


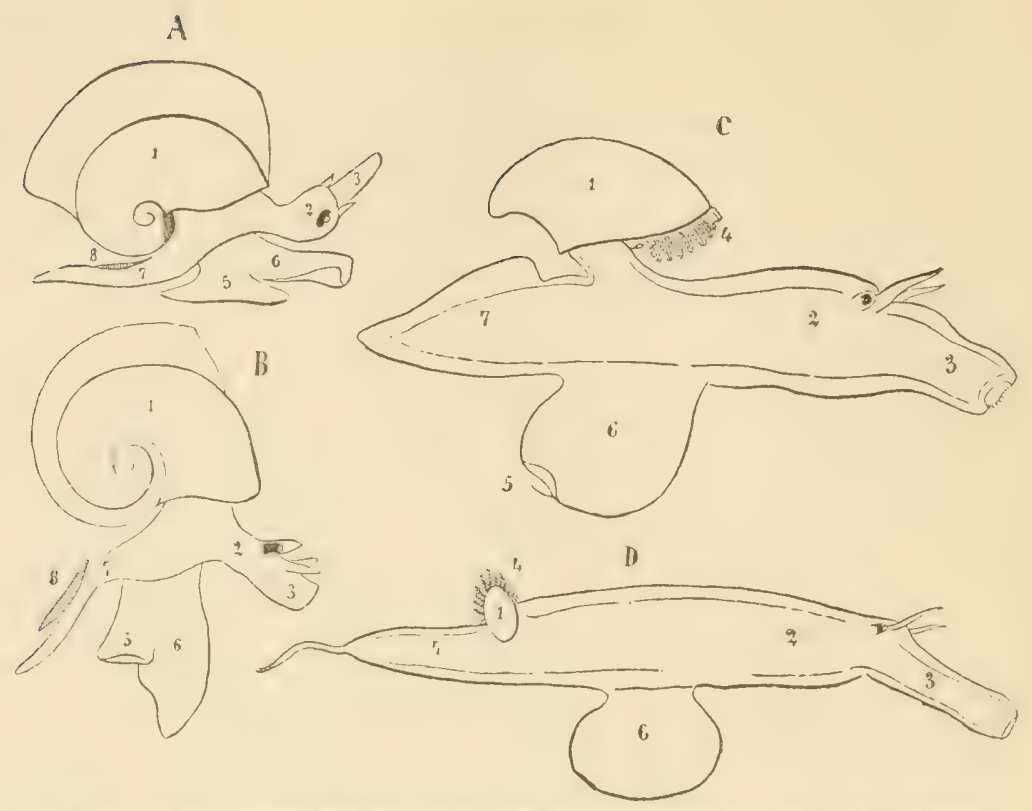

Fir. 481. Vergleichende Morphologie des Heteropodenkörpers. $\boldsymbol{A}$ 0xygyrus. $\boldsymbol{B}$ Atlanta. $C$ Carinaria. $D$ Pterotrachea $q$. Mit Benutzung von Figuren von SouLEYET. 1 Eingeweidesack, Schale, 2 Kopf mit Augen und Tentakeln und rüsselartig verlängerter Schnauze 3, 4 Kiemen, 5 Fuss mit Sohle, bei $\boldsymbol{B}$ und $\boldsymbol{C}$ zum, ,Saugnapf" reducirt, bei $\boldsymbol{D}$ fehlend, 6 Flossenanhang des Fusses, 7 Hinterfuss mit Deckel 8.

podium erscheint nur als die hintere, schwanzartige Verlängerung des Rumpfes, mit dem es in einer Flucht liegt. Die Flosse hat sich stark verbreitert und vergrössert, und der Samgnapf erscheint an ihrem freien Rand entlang nach hinten verschoben.

Bei den Pterotracheen (D) schliesslich ist der Saugnapf (die ursprüngliche Fusssohle) noch kleiner geworden und überdies nur beim Männchen vorhanden.

Die Heteropoden sollen sich gelegentlich mit dem Saugnapf an fremde Gegenstände anheften können.

b) Pulmonata.

Der Fuss der Pulmonaten ist fast überall einheitlich und mit grosser flacher Kriechsohle versehen. Nur bei einigen Auriculiden (Melampus, Leuconia, Blauneria, Pedipes) ist er durch eine vorübergehende oder bleibende Querfurche in einen rorderen und hinteren Abschnitt getheilt.

c) Opisthobranchiata.

Bei fast allen Opisthobranchiern ist eine flache Kriechsohle des Fusses wohl entwickelt. Der Fuss zeigt keine Gliederung in longitudinaler Richtung und trägt mit seltenen Ausnahmen (z. B. Actaeon) im erwachsenen Zustande keinen Deckel.

Ein Epipodium fehlt.

Dagegen siud Parapodien, d. h. seitliche lappen- oder faltenförmige Verbreiterungen der Kanteu oder Ränder der Kriechsohle bei manchen Opisthobranchiern sehr entwickelt. Wir citiren die Elysiadac 
unter den Ascoglossen und sehr zahlreiche Tectibranchier, so die Scaphandridae, Bullidae, Aplustridae, Gastropteridae (Fig. 398), Philinidae, Dorididae, Aplysiidae (Fig. 458), Oxynoeidae. Die Parapodien sind häufig nach oben zurückgeschlagen, wo sich ihre Ränder über der Schale berühren können, so dass letztere vollständig von den Parapodialfalten überdacht wird. Da bei zahlreichen mit Paraporlien ausgestatteten Formen (Gastropteridae, Philinidae, Doridiidae, Aplysiidae) sich auch der Mantel auf die Aussenseite der Schale, sie ganz oder theilweise bedeckend, zurückschlägt, so ist bei diesen Formen die Schale gewissermassen eine doppelt innere, indem sie zunächst vom Mantel und dann weiter aussen noch von den Parapodien bedeckt wird (Fig. 482).

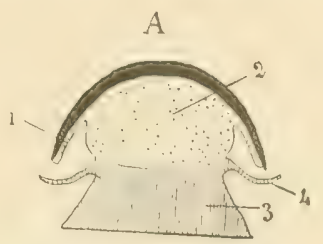

Die Parapodien können hinten mit ihrem freien, nach oben gerichteten Rande miteinander verschmelzen (Aplysiidae, Oxynoë). Bei Lobiger ist jedes Parapodium quer gespalten, so dass es jederseits zwei lange, flügelförmige Fortsätze bildet. Mehrere Opisthobranchier (Aplysiidae, Oxynoeïdae, Gastropteridae) vermögen durch Schwingungen ihrer Parapodien sich schwimmend fortzubewegen.

Phyllirhoë ist eine Nudibranchiate, die in der Weise der pelagischen, schwimmenden Lebensweise angepasst erscheint, dass ihr Körper seitlich comprimirt ist und so ein schmales, längliches Blatt mit scharfer dorsaler und ventraler Kante darstellt, das sich undulirend im Wasser bewegt (Fig. 403). Der Fuss ist vers chw unden.
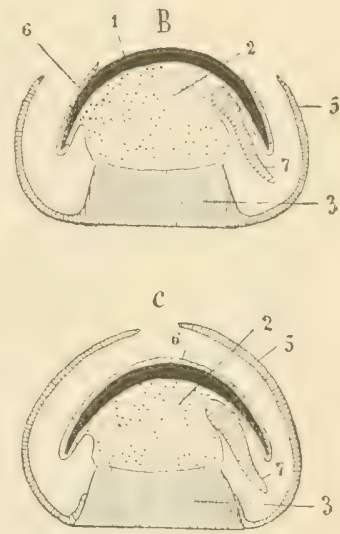

Fig. 482. Schematische Querschnitte durch Gasteropoden, zur Demonstration der Verhältnisse von Schale (schwarz 1), Eingeweidesack und Mantel (purktirt 2), Fuss (schraftirt 3). A Prosobranchiat mit ïusserer Schale und Epipodium (4). B Tectibranchiat mit auf die Aussenfäche der Schale zurüickgeschlagenem Schalenlappen (6) des Mantels. Die Schale dorsalwärts noch frei, unbedeckt. 5 Parapodien, 7 Ctenidium. $C$ Tectibranchiat mit innerer Schale, d. h. der Schalenlappen des Mantels hat die Schale aussen ganz ¿iberwachsen.

Der Fuss der Pteropoden. Wie die Heteropoden Prosobranchier sind, welche sich an die freischwimmende, pelagische Lebensweise angepasst hahen, so sind die Pteropoden Opisthobranchier aus der Abtheilung der 'Tectibranchier, welche pelagische Thiere mit schwimmender Bewegungsweise geworden sind.

Ist bei den Heteropoden das Propodium zu einer medio-ventralen, senkrechten Ruderflosse umgewandelt, so werden die parigen Parapodien der Tectibranchier, die schon bei diesen zum Schwimmen dienen können, zu den Schwimmorganen, den paarigen Flossen oder Flügeln der Pteropoden (Fig. 400, 401, 469).

Bei den Thecosomata (Fig. 469), die wir von Cephalaspiden (Bulloiden) ableiten müssen, deren Parapodien rechts und links in der directen Fortsetzung der Kriechfläche des Fusses liegen, ist der Fuss auf das vordere Ende des Körpers beschränkt und besteht aus drei Theilen, einem 
medianen unpaaren, dem Mittelfuss, und zwei seitlichen, den Parapodien oder Flossen. Der Mittelfuss ist klein und auf der Bauchseite, die der Sohle der Cephalaspiden entspricht, aber nicht mehr als Kriechfläche dienen kann, stark bewimpert. Die Wimperbewegung ist nach vorn, gegen die vorn am Fusse gelegene Mundöffnung gerichtet und dient offenbar dazu, kleine Nahrungspartikelchen, winzig kleine Meeresthierchen dem Munde zuzuführen. Auf der Rückenseite des nach hinten frei abstehenden Mittelfusses tragen die Limaciniden einen zarten, durchsichtigen, oft hinfälligen Deckel. Mit Hinblick auf die Ableitung der Thecosomata von Cephalaspidea, denen, wie überhaupt den Opisthobranchiern im erwachsenen Zustande, im Allgemeinen ein Deckel fehlt, muss hervorgehoben werden, dass die auch sonst in mancher Beziehung ursprüngliche Cephalaspidengattung Acta eon ein Operculum besitzt. Die Parapodien sind gross, flossen- oder flügelförmig, inseriren jederseits vorn am mittleren Fusstheile und gehen überdies noch vor und über dem Munde ineinander über.

Die Gymnosomata (Fig. 401) leiten wir von Aplysiidae ab, bei denen die Parapodien nicht direct in der seitlichen Verlängerung der Kriechfläche des Fusses liegen, sondern jederseits etwas oberhalb des Randes der Kriechfläche inseriren. Man kann sich das so vorstellen, dass die Parapodien an ihrer Basis eine Strecke weit mit der seitlichen Leibeswand verschmolzen sind.

Auch bei den Gymnosomata ist der Fuss scharf von den zwei seitlichen Flossen oder Parapodien getrennt.

Der von dem Kopfe deutlich gesonderte Fuss besteht selbst wieder aus drei Theilen, zwei vorderen paarigen Lappen, die sich nach vorn convergirend vereinigen, und einem mittleren hinteren Lappen, der sich nach hinten spitz auszieht.

Die Flossen vereinigen sich nie vor und über dem Kopfe.

Mittelfuss und Flosseninsertion liegen vorn auf der Bauchseite des Rumpfes hinter dem Kopfe.

Fussdrüsen der Gasteropoden. Abgesehen von den velschiedenen einzelligen Druisen, die an der Ober- oder Unterseite des Fusses zerstreut vorkommen, besitzen viele Gasteropoden, vor allem die meisten Prosobranchier und Pulmonaten noch grössere vielzellige, localisirte Fussdrüsen, die zu zwei morphologisch gesonderten Gruppen gehören.

1) Die unpaare vordere Fussdrüse mündet bei den Prosobranchiern am Vorderrande des Fusses, und zwar bei denjenigen Formen, bei denen dieser Vorderrand in einen oberen und einen unteren Lippensaum gespalten ist, zwischen den beiden Lippen (Lippendrüse). Bei den Pulmonaten öffnet sie sich zwischen Kopf und Fuss nach aussen. Sie stellt einen verschieden langen, nicht selten die Länge des Fusses erreichenden Epithelschlauch dar, welcher meist in die Fussbasis eingeschlossen, seltener ihr in der Leibeshöhle aufliegend, von ihrer Mündungsstelle median nach hinten zieht. In die Wandung des Schlauches, welcher als Reservoir und Ausführungsgang dient, münden zahlreiche einzellige Schleimdrüsen, die im umgebenden Fussgewebe liegen. Die Drüse sondert Schleim ab. Mit Unrecht ist sie als Geruchsorgan bezeichnet worden. Sie unterliegt, was ihre Grösse, die Gestalt ihres Querschnittes und was die Zahl, sowie Anordnung der Drüsenzellen anbetrifft, bedeutenden Modificationen. 
2) Die unpaare Fusssohlendrüse ist bei Prosobranchiern weit verhreitet. Ihre äussere, spaltförmige Oeffnung liegt hinter rlem Vorderrand des Fusses in der Mittellinie der Sohle und führt in eine als Reservoir fungirende in Fusse gelegene Höhle, deren Epithelwand in das Lumen vorspringende Falten bildet. Die Höhle ist allscitio von einzelligen Drüsen umlagert, welche ihr Secret vermittelst ihrer zwischen den Epithelzellen mündenden Ausfülırungsgänge in sie entleeren. Mit Recht ist diese Fussohlendrüse der Prosobranchier als ein der Byssusdrüse der Lamellibranchier homologes Organ betrach tet worden. Ihr Ausbildungsgrad ist sehr verschieden und nicht selten fehlt sie ganz. Ihr fadenziehendes Schleimsecret bildet Fäden, durch welche manche Prosobranchier sich an fremden Gegenständen im Wasser aufhängen können. Auch Landpulmonaten können sich vermittelst abgesonderter zäher Fäden aus der Höhe (von Pflanzen) herunterlassen.

Ausser den beiden erwähnten Fussdrüsen kommen gelegentlich noch andere vor. Es sei hier nur noch einer Fussdrüse Erwähnung gethan, welche sich bei einigen Opisthobranchiern(Pleurobranchus, Pleurobranchaea, Pleurophyllidia) findet. Sie liegt am hinteren Ende der Fusssohle und besteht aus Drüsenblindsäckchen, von denen jedes gesondert ausmündet.

Fig. 483. Anatomie von Dentalium entale, nach LEUCKART (Wandtafeln) und LACAzE-Duthiers. Rechte Hälfte der Schale und unterer Theil des Mantels entfernt. a Vom Visceralganglion nach oben ziebender Nerv (Mantelnerv), $b$ Schale, $c$ Raum zwischen Mantel und Schale, $d$ After, $e$ Visceralganglion, $f$ Mautelböhle, $g$ Mantel, $h$ unteres, $t$ oberes Buccalganglion, $i$ Gehörorgan, $k$ Pedılganglion, $m$ seitliche Falten des Fusses, $n$ Endkegel des Fusses, o Fadententakel, $l$ unterer Mantelrand, $p$ blattförmige Mundanhänge, $q$ Schnauze, $r$ Gehirnganglion, s Schalen- oder Spindelmuskel, durchschnitten, $u$ rechte Nephridial(zugleich Geschlechts-) Oeffinung, $v$ Verdauungshrüse (Leber), $v$ Gonade, $x$ oberes Ende des Spindelmuskels, $y$ oberes offenes Ende des Mantels.

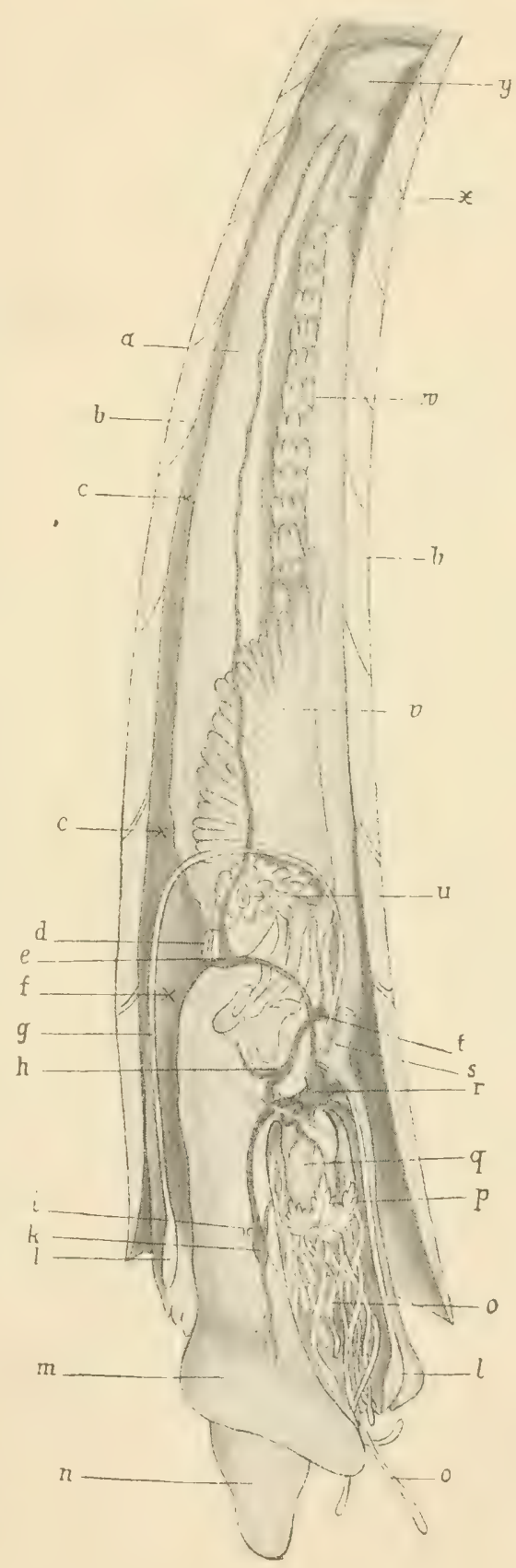




\section{C) Scaphopoda.}

Der Fuss von Dentalium (Fig. 483) ragt als ein fast cylindrischer Körper nach unten in dic löhrenförmig geschlossene Mantelhöhle vor, aus deren unterer Oeffinung er vorgestreckt werden kaun. Sein freies Ende ist kegelförmig zugespitzt und trägt an der Basis des Kegels rechts und links cine Falte oder einen Wulst, den man mit zweifelhaftem Rechte einem Epipodium verglichen hat. Die beiden seitlichen Falten oder Tïlste umfassen die Basis des liegelförmigen Fussendes, ohne vorn und hinten ineinander überzugehen. In der vorderen Mittellinie des ganzen Fusses verläuft eine Furche. Bei Siph onodentalium fehlen sowohl die Furche als die Seitenlappen, dagegen ist das Vorderende des Fusses zu einer runden, an Rande mit kleinen, conischen Papillen besetzten Scheibe verbreitert.

\section{D) Lamellibranchiata.}

Der Fuss der Muscheln ist im Allgemeinen seitlich zusammengedrückt, mit scharfer Kante, vom Rumpfe nach unten und vorn gerichtet, aus der Schale vorstreckbar. Einen solchen Fuss kann man als beilförmig (Pelecypoda) oder zungenförmig bezeichnen, und er ist vornehmlich zum Eindringen in den Schlamm bei abwechselnder Contraction und Schwellung geeignet.

Die eben erwähnte Beil- oder Zungengestalt des Fusses muss indessen als eine erworbene bezeichnet werden. Ursprünglich wird auch der Muschelfuss eine flache Iíriechsohle besessen haben. Und in der That, die Protobranchier besitzen einen Fuss mit ventraler Scheibe (Fig. 405), und ebenso Pectuuculus. Der Rand der Fussscheibe ist gezackt oder gezähnelt. Wird der Fuss zurückgezogen, so krümmen sich die seitlichen halbkreisförmigen Flächen der Scheibe gegeneinander, so dass sie nun im contrahirten Zustande eine Furche begreuzen.

Im Einzelnen ist der Fuss der Muscheln je nach Lebens- und Bewegungsweise und nach dem Verhalten des Byssus verschieden gestaltet.

Für den Muschelfuss ist die den Byssus ausscheidende Byssusd $r$ ü se charakteristisch. Der Byssus besteht aus resistenten, bald sehr dünnen, bald dickeren Fäden von (physikalisch) hornartiger Beschaffenheit, welche die Muscheln an fremden Gegenständen befestigen, so dass sie sich vermittelst des Byssus vor Anker legen. Die meisten byssusführenden Muscheln vermögen den Byssus abzustossen und jeweilen wieder durch eimen neuen zu ersetzen, und manche Formen können durch abwechselndes Anheften und Abstossen, bei Vorstrecken und Zurückziehen des byssusbefestigenden Fusses sich sogar an senkrechten, glatten Glaswänden fortbewegen.

Die erste Anheftung der wit einer Schalenklappe festsitzenden Formen geschieht mit Hilfe des Byssus, der im Allgemeinen auch den Jugendformen der im Alter byssuslosen Muschelı zukommt.

Ein completer Byssusapparat (Fig. 48t) besteht 1) aus der im Fusse gelegenen Byssushöhle, in welche die Byssusdrüsen einmünden ; 2) aus dem Kanal, durch welchen die Byssushöhle an der Fusskante nach aussen mündet; 3) aus der Byssusfurche, welche von der Oeffnung des Kanals der ventralen Fusskante entlang bis an die vordere Spitze des Fusses verläuft, und 4) aus einer an dieser Spitze selbst liegenden, hallomond- oder napförmigen E $\mathrm{r}$ w ite r ung der Fulche. 
1) Die Byssushöhle wird von zahlreichen Falten, die von den Seitenwänden der Höhle in ihr Lumen vorragen, in flache Fächer eingetheilt. Ausserdem ragt von ihrer Decke eine Scheidewand in sie herunter, welche sie in zwei seitliche Abtheilungen theilt. Das Byssussecret wird theils von den Zellen der epithelialen Wandung der Byssushöhle, theils von Drüsenzellen ausgeschieden, die im umliegenden Gewebe liegen und ihre Ausführungsgänge zwischen die Epithelzellen der Byssushöhlenwand entsenden. Die ausgeschiedene Byssussubstanz nimmt die Gestalt der Hohlrïume der Byssushöhle an, d. h. sie wurzelt mit zahlreichen Lamellen in den Fächern dieser Höhle. Diese Lamellen werden bei fortschreitender Absonderung rom Byssus in den Ausführungsgang der Byssushöhle, d. h. in den

2) Kanal hineingedrängt, wo sie sich zu dem Byssus t a m m vereinigen.

Die Wandungen der 3) Byssusfurche und 4) ihrer terminalen Erweiterung sind ebenfalls drüsig. Will eine Muschel den Byssus anheften, so erzeugt sie in der Furche einen Byssusfaden, der mit dem Ende des Stammes verschmilzt, drückt (Fig. 406) das Ende des Fusses mit der Furchenerweiterung auf die Unterlage, z. B. einen Felsen, und befestigt den Faden auf der Unterlage mit Hilfe des von der Furchenerweiterung abgesonderten, verkittenden Secretes. So kann der Fuss das Ende des Byssusstammes vermittelst zahlreicher in der Furche successiv abgesonderter Fäden fest an den Felsen anheften.

Fig. 484. Byssushöhle und Byssusgang (1) mit Byssus einer Muschel, schematisch. Querschnitt durch den Fuss. 2 Byssusstamm, 3 Endfäden, durch welche der Stamm an einem fremden Gegenstand befestigt wird.

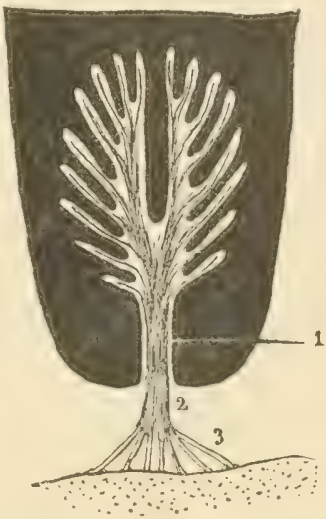

Die Beziehungen, welche zwischen der Ausbildung des Fusses und derjenigen des Byssusapparates existiren, lassen sich in grossen Zügen etwa folgendermaassen darstellen.

1) Fuss in ursprünglicher Form mit flacher Sohle ohne Furche, mit einer einfachen Einstülpung ohne Byssus (Solenomya).

2) Fuss ebenso. Im Grunde der einfachen Einstülpung eine wenig vorspringende Lamelle, Byssus sehr wenig entwickelt (Nucula, Leda).

3) Die Einstülpung gliedert sich in die Byssushöhle und den Kanal. Byssusdrüse und Byssus stark entwickelt. In Folge der starken Entwickelung des Byssus verliert der Fuss seine Bedeutung als Locomotionsorgan; seine flache Sohle verschwindet, er wird entweder fingerförmig oder zungenförmig, ist oft klein oder von mässiger Grösse und dient zum Anheften des Byssus. In sehr zahlreichen Fällen bildet sich vor der Oeffnung des Kanales die Byssusfurche und an der vorderen Spitze des Fusses die Erweiterung derselben aus. Hieher gehören sehr zahlreiche Muscheln, vorzugsweise Formen, die sich mit ihrem Byssus an Felsen, Steinen, Pflanzen, Muscheln, Schneckenschalen u. s. w. vor Anker legen. Dabei kann die Verankerung eine mehr dauernde oder eine mehr vorübergehende, festere oder losere sein (Limidae, Spondylidae, Pectinidae pp., Mytilidae, Arcidae pp., Carditidae pp., Erycinidae, Galeommidae, Tridacnidae, Cyprinidae pp., Veneridae pp., Glycimeridae, Myidae pp. etc.). 
Bei den Muscheln mit stark entwickeltem Byssus bildet sich ein Theil der Fussmuskeln, indem sie sich an die Byssushöhle ansetzen, zu Byssusretractoren aus.

4) Zahlreiche Muscheln besitzen im erwachsenen Zustande weder Byssus noch Byssusdrüse mehr, aber es können sich die Byssushöhle, der Kanal und sogar die Byssusretractoren (z. B. bei Trigonia) erhalten. Byssusapparate können bei nahen Verwandten bald mit, bald ohne Byssus vorkommen. Der Fuss nimmt gewöhnlich bei den mit einem byssuslosen Byssusapparat ausgestatteten Formen eine stärkere Entfaltung und dient als zungen-, keil- oder beilförmiges Organ zur Locomotion (Eindringen und Vorwärtsbohren im Sande oder Schlamme, Springbewegung bei Trigonia). Die meisten hieher gehörigen Formen sind Schlamm- oder Sandthiere (Arcidae pp., Carditidae pp., Cyprinidae pp., Tellinidae, Scrobiculariidae, Myidae pp., Cardiidae pp., Lucinidae [Fuss wurmförmig], Donacidae etc.).

5) Bei starker Entwickelung des zungen- oder beilförmigen, bisweilen knieförmig geknickten, fleischigen, stark schwellbaren Fusses ist jede Spur des Byssus und Byssusapparates im erwachsenen Zustande verschwunden (Unionidae, viele Veneridae, Cyrenidae, Psammobiidae, Mesodermatidae, Solenidae, Mactridae). Alle diese Muscheln sind Schlammbewohner. Ausserordentlich stark ist der fleischige, ganz nach vorn gerichtete Fuss bei den Soleniden entwickelt, wo er häufig nicht ganz in die Schale zurïckgezogen werden kann, so dass die Schale vorn klafft. Dick zungenförmig ist der Fuss bei Solenocurtus, kenlenförmigr, am Ende abgestutzt bei Pharus, Cultellus, Siliqua und Ensis, cylindrisch, am Ende eiförmig angeschwollen bei Solen.

6) Der Fuss kann bei fehlendem Byssus rudimentär werden (Chamacea) oder ganz verschwinden (Ostreiden) bei Formen, die festsitzend mit der einen Schalenklappe dem harten Untergrunde aufgewachsen sind; er ist ferner auf ein kleines, meist fingerförmiges Rudiment reducirt bei Formen, die im Schlamme oder in selbst gebohrten Höhlungen im Gesteine etc. lebend, ihren Körper mit einer accessorischen Kalkröhre umgeben (Gastrochaeniden, Clavagelliden). Besonders interessant ist die Reihe der bohrenden Pholadiden. Pholas besitzt einen stempel- oder saugnapfförmigen Fuss, der, zwischen den weit klaffenden Schalenklappen vortretend, sich beim Bohren anheftet. Bei Pholadidea und Jouannetia hingegen besitzen nur die Jugendstadien, so lange sie ihre Wohnlöcher bohren, einen solchen Fuss. Sind aber die Wohnlücher einmal ausgehöhlt, so verwächst der Fussschlitz des Mantels, die klaffende Vorderseite der Schale wird ebenfalls durch das mit dem Namen Callum bezeichnete accessorische Schalenstück geschlossen, und der Fuss verkümmert vollständig. Die Thiere sind dann keiner Locomotion mehr fähig.

Auch bei der festsitzenden Anomia ist der Fuss klein. Er hat aber hier trotzdem eine grosse Bedeutung als Träger des Byssusapparates. Das Schliessknöchelchen, durch welches diese Muschel mit der Unterlage verkittet ist und welches den tief in die rechte Schalenklappe hineingerïckten Byssusausschnitt ausfüllt, muss als ein rerkalkter Byssus betrachtet werden.

Manche Muscheln (Crenella, Lima, Modiola) spinmen mit ihren Byssus ein Byssusgeflecht, in dem sie sich, wie in einem Neste, aufhalten und zu dessen Verstärkung sie allerlei Fremdkörper mit Byssusfäden verkleben. 
E) Cephalopoda.

Man hat bis heute darüber discutirt und darüber Untersuchungen angestellt, ob und welche 'Theile des Cephalopodenkiorpers dem Fusse der übrigen Mollusken entsprechen. Als ziemlich sicher kann jetzt gelten, dass der Molluskenfuss bei den Cephalopoden bildet:

1) die Arme (Brachialschirm) und

2) den Trichter.

Die $A$ rme werden aufgefasst als seitliche fortsätze eines Molluskenfusses, der sich rechts und links an den hopf vorgeschoben und ror demselhen vereinigt hat, so dass der Kopf rings vom fiusse umgeben wird, und der Mund in die Mitte der Bauchseite des Fusses, d. h. in die Mitte des Armkiranzes oder Brachialschirmes gerüclit ist. Für die Fussnatur des Armkranzes sprechen wichtige anatomische und ontogenetische Thatsachen: 1) Die Arme werden vom Brachialganglion innervirt, welches, unter dem Schlunde gelegen, eine vordere Abgliederung des Perlalganglions dar'stellt. 2) Die Arme treten ontogenetisch nicht in ihrer definitiven Lage rings um den Nund auf, sondern auf der Bauchseite, hinter dem Inunde, zwischen diesem und dem After, jederseits in einer Reihe. Erst secundar schiebt sich die Doppelreihe um den Mund herum nach vorn und bildet den Armkranz des nunmehrigen Lopffusses. (Nach einer anderen Ansicht wären die Arme liopfauhänge, den Kopftentakeln iler Pteropoden vergleichbar.)

An der Fussnatur des Trichters ist selten gezweifelt worden. Er wird rom Pedalganglion innervirt. Seine zwei seitlichen, bei Tautilus zeitlebens getrennten, bei den Dibranchiaten sich getrennt anlegenden Lappen dürften als Epipodiallappen aufzufassen sein. Nebenstehende Abbildung eines Cephalopodenembryos, an welchem die Anlagen des Trichters in typischer Epipodiallage als zwei seitliche, über dem Fuss und unter dem Eingeweidesack von vorn nach hinten ziehende Falten auftreten, dürfte zur Rechtfertigung dieser Anschauung beitragen.

Bei Nautilus und den Decapoden (excl. Loligopsidae) findet sich im Innern des Trichters eine Trichterklappe.

Ueber die Form des Trichters vergl. p. 603 u. ft:

Fig. 485. Cephalopodenembryo, schief von hinten links, nach Grenacher, 1 Mantel, 2 Anus, 3 rechtes Ctenidium, 4 Trichteranlage, 5 Gehörorgan, 6 Arme, 7 Dottersack, 8 linkes Auge.

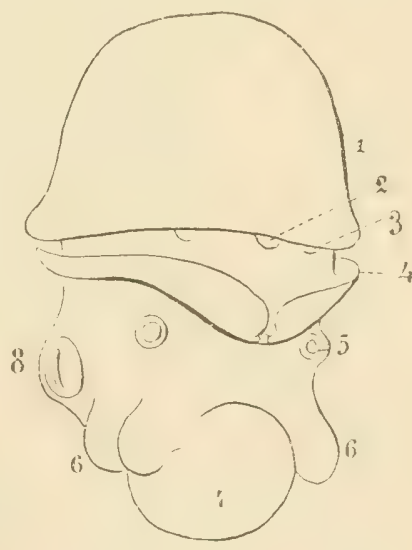

Die Arme der Tetrabranchiata (Nautilus).

Der Kopffuss ron Nautilus (Fig. 486) trägt zahlreiche rings um den Mund gestellte Tentakel, die sich aber nicht direct auf dem den Nund umgebenden Integumente erheben, sondern auf besonderen Lappen stehen, die in den beiden Geschlechtern in verschiedener Weise ausgebildet sind. Diese Lappen sind den Armen der Dibranchiaten vergleichbar; die Tentakel, die sie tragen, vielleicht den Saugnäpfen der Dibranchiatenarme. Jeder Tentakel kann in seinen eigenen Basaltheil wie in eine Scheide zurückgezogen rerden. 
Betrachten wir nun den Kopffuss von seiner Bauchseite, so dass wir den Mund in der Mitte des ausgebreiteten Lappen- und Tentakelcomplexes vor uns sehen, so bemerken wir beim Weibchen (untere Figur) unmittelbar an den Mund angrenzend drei Lappen, zwei seitliche und einen

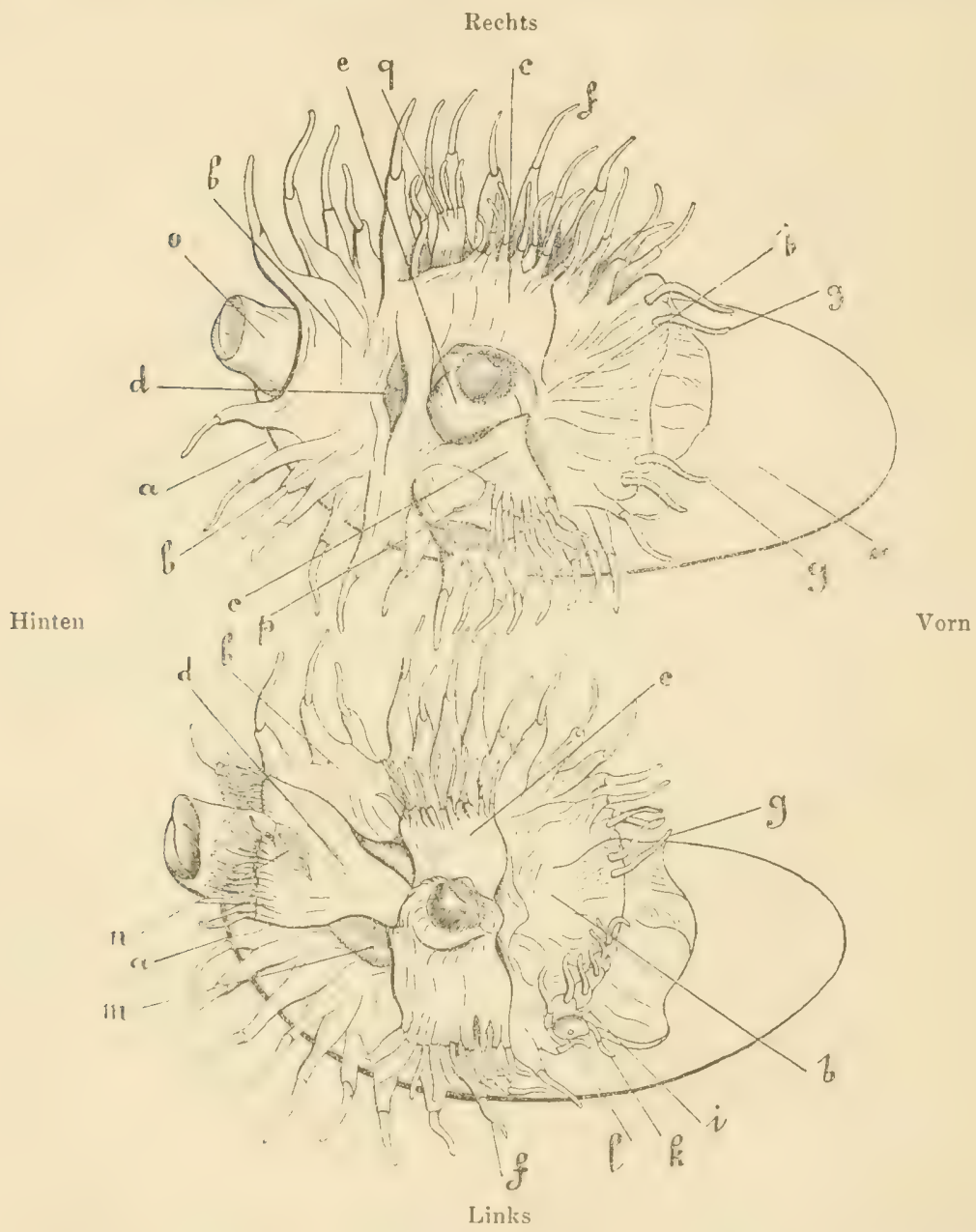

Fig. 486. Circumoraler Tentakelkranz von Nautilus pompilius, nach LANKester und BounNe. Von der oralen oder Bauchseite. Oben Männchen, unten Weibchen. a Schale, $b$ Ringfalte oder Kopfkappe mit ihren Tentakein $g, c$ die beiden seitlichen inneren Lappen, beim Männchen bildet der linke innere Lappen den Spadix oder Hectocotylus $p$ und auf der rechten Seite den Antispadix $q, a$ der hintere innere Lappen, beim Männchen reducirt, $n$ lamellöses Organ (Geruchsorgan?), e Kiefer im Mundkegel, $f$ die Tentakel der äusseren, musculösen Ringfalte, $m$ paariges lamellöses Organ, o Trichter.

hinteren, das sind (im Kranze der Lappen und Tentakel) die drei inneren Lappen. Der hintere innere Lappen besteht aus zwei verwachsenen, seitlichen Lappen, deren Grenze durch ein gefaltetes Organ (Geruchsorgan?) angedeutet wird. Er trägt 28 Tentakel, jederseits 14 . Jeder innere Seitenlappen trägt 12 Tentakel. Ausserhalb der drei inneren 
Lappen bildet der Fuss eine musculöse Ringfalte, die besonders vorn dick ist und hier einen Lappen bildet, die sogenannte $K$ opfkap e, welche bei eingezogenem Kopftuss die zurïckgezogenen Tentakel hedeckt und deckelartig die Mündung der Schale verschliesst. Die äussere Ringfalte trägt jederseits 19 Tentakel.

Ausser diesen dem Fusse angehörigen Tentakeln finden sich jederseits noch zwei, die wahrscheinlich zum Kopfe gehören, nämlich jederseits ein 'Tentakel unter und einer über dem Auge.

Beim Nautilusmännchen (obere Figur) ist der hintere, innere Fusslappen rudimentär. Die beiden inneren Seitenlappen sind jederseits in zwei Bezirke getheilt. Der rechte Lappen zeigt einen vorderen Bezirk mit 8 Tentakeln und einen hinteren (Antis padix) mit 4 Tentakeln, von denen 3 eine gemeinsame Scheide haben. Der linke Lappen hat ebenfalls einen vorderen Bezirk mit 8 Tentakeln und dahinter einen conischen Körper, Spadix, der keine Tentakel, aber sich dachziegelförmig bedeckende Lamellen trägt. Dieser Spadix wird als der hectocotylisirte Fusstheil von Nautilus betrachtet (siehe Geschlechtsorgane) und spielt wahrscheinlich irgend eine Rolle bei der Begattung.

\section{Dibranchiata.}

Die Dibranchiata besitzen entweder 8 oder 10 Arme, welche den Mund kranzförmig umstellen und auf ihrer Unterseite mit in einer oder mehreren Längsreihen stehenden Saugnäpfen bewaffnet sind. Zu diesen Saugnäpfen können sich noch Reihen von Cirren gesellen und sie können sich stellenweise zu Hacken oder Krallen (z. B. Onychoteuthis) umwandeln.

Bei manchen Octopoden sind die langen Arme an ihrer Basis, ja gelegentlich bis an ihre Spitze, durch eine Membran verbunden. Im letzteren Falle gleicht der Armkranz einem Regenschirm, seine Membran dem Tuch, die Arme den radiären Spangen. Wo die Spangen am Stock zusammentreffen, würde der Mund liegen. Die Octopoden können auf ihrem Armkranz bei erhobenem Eingeweidesack kriechen. In dieser Stellung sind sie am leichtesten mit Schnecken zu vergleichen, indem dann die ventrale Seite des Armkranzes, auf der sie kriechen, der Fusssohle der Schnecken ähnlich functionirt.

Die Decapoden haben 10 Arme, von denen 8 gleichartige den 8 Octopodenarmen entsprechen, nur dass sie kürzer und fast nie durch Membranen verbunden sind. Die 2 übrigen Arme, die Fangtentakel, inseriren zwischen dem 3. und 4. Octopodenarme jederseits und sind von ihnen abweichend gebaut, lang, wurmförmig, mit angeschwollenen, mit Saugnäpfen, Haken etc. bewaffneten Enden. Die Fangtentakel sind sehr contractil und bei zahlreichen Decapoden (z. B. Sepia) im Ruhezustande in besonderen Kopfhöhlen verborgen. Diese Höhlen entsprechen wahrscheinlich morphologisch den Wasserporen, welche häufig auch anderswo an der Basis der Arme oder am Kopfe vorkommen. Beim Verfolgen der Beute werden die Fangtentakel mit Vehemenz aus diesen Höhlen oder Scheiden vorgeschleudert.

Von den 8 oder 10 Armen der Dibranchiaten ist fast immer einer (seltener 2) im männlichen Geschlechte in besonderer Weise umgestaltet (hectocotylisirt) und spielt bei der Begattung eine Rolle. Bei einigen Oetopoden löst er sich sogar vom Körper los und wird wieder regenerirt.

Der hectocotylisirte Arm ist bei den Octopoden gewöhnlich der 3. Arm der rechten, bei den Decapoden der 4. Arm der linken Seite. (Man zählt die Arme von vorn nach hinten.) 
Beim Argona utaweitbchen ist das erste Armpar segelförmig verbreitert und schlägt sich auf die Aussenseite der Schale zurück.

Alle Cephalopoden, auch die plumperen Octopoden, sind gute Schwimmer. Beim Schwimmen spielen Mantel und Trichter die Hauptrolle. Wasser wird abwechselnd durch die Mantelspalte in die Mantelhöhle aufgenommen und durch den Trichter in kräftigem Strahl ausgestossen, wobei durch den Rückstoss der Körper in der Richtung des Eingeweidesackes fortgeschnellt wird. Beim Ausstossen des Wassers wird die Mantelspalte durch den Mantelschliessapparat verschlossen, so dass alles in die Mantelhöhle aufgenommene Wasser durch den Trichter ausströmen muss. Manche Decapoden können auch mit dem Kopffuss voran schwimmen, indem sie das untere Ende des Trichters aufwärts krümmen, so dass der Wasserstrahl in der Richtung des Eingeweidesackes austritt. Die Arme werden beim Schwimmen aneinandergelegt, damit der Reibungswiderstand möglichst gering werde. Octopoden, vornehmlich solche mit Interbrachialmembran, helfen ihren Schwimmbewegungen nach, indem sie ihren Armkranz öffnen und schliessen, wie einen Regenschirm.

\section{Wasseraufnalime.}

Der Euss vieler Muscheln und Schnecken kann geschwellt, dabei aus der Schale oder dem Gehäuse vorgestreckt und zur Locomotion verwendet werden. Wie die Schwellung geschieht, darüber herrschten bis vor kurzem noch die verschiedensten Ansichten. Die Annahme war viel verbreitet, dass von aussen Wasser in das Blut- oder in ein gesondertes Wassergefüsssystem aufgenommen werde. Auch über die Wege der Wasseraufnahme war man verschiedener Ansicht. Das Wasser sollte durch Oeffnungen oder Poren am Fusse aufgenommen werden. Es wurde num aber festgestellt, dass solche Poren entweder nicht existiren, oder dass sie die Oeffnungen von Fussdrüsen (Byssusdrüse, Fusssohlendrüse) sind. Das Wasser sollte durch Intercellulargänge zwischen den Epithelzellen des Fusses hindurch aufgenommen werden. Auch diese Annahme hat sich als irrig erwiesen. Das Wasser solite durch die Nephridien in das Pericard geleitet und von diesem aus dem Blutgefässsystem mitgetheilt werden. Aber das Pericard hat sich als ein vom Blutgefässsystem vollständig abgeschlossener Sack erwiesen. Auch noch_andere Ansichten über Wasseraufnahme wurden geäussert und später widerlegt.

Nach dem gegenwärtigen Stande unserer Kenntnisse bleibt mit Ausnahme eines einzigen, gleich zu besprechenden Falles nur die Annahme übrig, dass der Fuss durch Blutzudrang geschwellt wird, wobei ein Zurückfliessen des Blutes aus dem Fuss in den übrigen Körper durch Muskelsphincter verhindert wird (Blutstauung).

Der eben erwähnte Fall ist der von $\mathrm{Natica} J o s e p h i n a$. Hier kann nicht daran gezweifelt werden, dass Wasseraufnahme zum Zwecke der Schwellung des Fusses stattfindet. Sie geschieht sehr rasch, in weniger als 5 Minuten. Das auf Reize hin wieder abgegebene Wasser nimmt das doppelte, ja das dreifache Volumen der leeren Naticaschale ein. Das Wasser wird durch sehr kleine (makroskopisch nicht sichtbare) Spalten, welche am Fussrandẻ liegen (wahrscheinlich sogar durch eine einzige sehr enge, dem Fussrand entlang verlaufende Spalte), aufgenommen und 
in ein im Fusse liegendes System von Wasserräumen geführt, welches von allen übrigen Hohlräumen des Fusses, also namentlich auch von dem. (bei Natica geschlossenen) Blutgefüsssystem vollständig abgeschlnssen ist, so dass von einer directen Wasseraufnahme in das Blutgefässsystem durch Fussporen nicht die Rede sein kann. Die Wasserspalten am Fussrande können durch ein System von Schliessmuskeln, die sich vom oberen zum unteren Rande der Spalten erstrecken, geschlossen werden.

\section{Musculatur und Endoskelet.}

In diesem Kapitel soll gänzlich vernachlässigt werden die den einzelnen Organen eigene Musculatur, z. B. die Musculatur der einzelnen Theile des Darmkanals, die Musculatur des Herzens, der Begattungsapparate etc., ferner die Musculatur der Cutis und auch die für die Locomotion so wichtige Eigenmusculatur des musculösesten Organes, des Fusses, die entsprechend der so sehr verschiedenen Ausbildung und Functionsweise in unzähligen Nüancirungen auftritt.

Wir besprechen hier nur die allgemeine Körpermusculatur, und diese erhält ihr Gepräge durch die Ausbildung der Molluskenschale, die dem ganzen Weichkörper Schutz gewähren soll. Damit dieser Schutz ein vollständiger werde, ist im Allgemeinen die Molluskenorganisation, im Einzelnen in verschiedener Weise, so eingerichtet, dass alle Weichtheile im Imnern der Schale geborgen werden könmen, und dass die Schale selbst geschlossen werden kann. Die Schale fungirt dann als Skelet, als passives Bewegungsorgan, an welches sich diejenigeu Muskeln anheften, die bei ihrer Contraction dic Weichtheile in die Schale zurückzichen, und diejenigen, die bei ihrer Contraction die Schalt schliessen oder verschliessen.

Es liegt auf der Hand, dass die Musculaturverhältnisse sich di secundär wieder stark ändern, wo die Schale rudimentär wird oder ganz verschwindet.

Die Musculatur der Mollusken ist $\mathrm{n}$ icht quergestreift.

\section{A) Amphineura.}

Die Musculatur der $\mathrm{Ch}$ iton iden ist noch nicht genügend untersucht und in Zusammenhang dargestellt worden. Auf den Abbilduugen der Autoren erkennt man 1) jederseits über dem Fuss eine ansehnliche Lïursmuskelmasse, 2) zahlreiche Muskelfasern, die in dorsoventraler Richtung von den Seitentheilen des Rückens in den Fuss heruntersteigen, um genen seine Sohle auszustrahlen, und 3) dem Fins eigene Muskelfasern, die denselhen nach verschiedenen Richtungen durchsetzen. Die sul) 22 erwilhnten Muskelfisern entsprechen wohl dem Schalenm us kiel der Fissurellirlen etc., dem Spindelmuskel der übrigen Gasteropolen. I)ie von der einen Scite in den Fuss heruntersteigenden Fasern lireuzen sich theilweise mit den von rler gegenïl)erliegenden Seite heruntersteigenden. Die Hauptlireuzungsstelle liegt in der Mediane zwischen den zwei Pedalsträngen.

Unter den Solenogastres ist das Muskelsystem am genauesten hei Prone omeni a untersucht. Wohl in Zusammenhang mit der Rüchhililumg des Fusses und der Ausbildung der wurmförmigen lïrpergestalt hat sich eine Art Hautmuskelschlauch ausgebililet, in welchem wir einige 
im Vergleich zu der Dicke der Epidermis sehr dünne Schichten in verschiedener Richtung verlaufender Muskelfasern unterscheiden können. Der Hautmuskelschlauch liegt der Epidermis von innen dicht an. Zu äusserst liegt eine Schicht circulärer Muskelfasern (Ringfaserschicht), dann folgt eine Schicht von Diagonalmuskelfasern, die einander unter rechtem Winkel, die Ring- und Längsfasern aber unter einem Winkel von $45^{\circ}$ kreuzeu. Zu innerst liegt eine Schicht longitudinaler Fasern. Diese ist besonders auf der Bauchseite, rechts und links von der Bauchfurche, stark entwickelt. Aus der Ringmuskelschicht lösen sich beiderseits Fasergruppen ab, welche von beiden Seiten gegen die Basis des rudimentären Fusses convergiren und sich theilweise über demselben kreuzen. Dabei verlaufen die von der seitlichen und oberen Körperwand stammenden Faserbündel im Innern der Septen, welche die aufeinanderfolgenden Seitendivertikel des Darmkanals trennen.

Soweit zur Zeit ein Vergleich nit Chiton möglich ist und wenn man die Rudimentation des Fusses und Ausbildung einer wurmförmigen Körpergestalt (Zwischenstadium: Chitonellus) in Betracht zieht, kann man annehmen, dass die Ringmuskelschicht und besonders die gegen den Fuss convergirenden Fasergruppen den dorsoventralen Muskeln von Chiton, die Längsmuskelschicht den seitlichen Längsmuskelmassen von Chiton entsprechen.

\section{B) Gasteropoda.}

Der einzige, wichtige, in Petracht kommende Muskel ist der Spindelmuskel (Musculus columellaris). Er setzt sich im Inneren der Schale an die Spindel an, zieht an der rechten Seite des Eingeweidesackes und am rechten Rande der Mantelfalte der Spindel entlang herunter, tritt dann in die Rückenseite des Fusses ein, in welchem er ausstrahlt. Der Spindelmuskel ist der $\mathrm{Rückziehmuskel}$ des Thieres in die Schale.

\section{a) Prosobranchiata.}

Der Spindelmuskel ist überall in typischer Form entwickelt. Er setzt sich einerseits an die Spindel der letzten Windung der Schale, andererseits an das auf der Dorsalseite des Metapodiums liegende Operculum an.

Einige Prosobranchier, so die meisten Fissurelliden, Haliotiden und Docoglossen, benutzen ihren Fuss mehr als Sangnapf, um sich fest an einer harten Unterlage zu befestigen. Diese Formen besitzen keinen Deckel. Der Spindelmuskel steigt hier senkrecht in den Fuss hinunter und drückt bei seiner Contraction die Schale fest der Unterlage an. $\mathrm{Er}$ ist bei Haliotis (Fig. 487, dessen ohrförmige Schale noch gewunden ist, cylindrisch, übrigens ausserordentlich stark entwickelt, ungefähr in der Mitte des Thieres, etwas mehr rechts gelegen, senkrecht auf der Fussscheibe stehend. Die Mantelhöhle und die Eingeweide verdrängt er auf die linke Seite. Bei zahlreichen Fissurelliden und den Docoglossa ist die Schale napfförmig und symmetrisch geworden. Der Spindelmuskel, welcher dementsprechend stark verkürzt ist, steigt direct von der Innenfläche der Schale zum Fusse herunter, ist aber nicht mehr cylindrisch, sondern auf dem Querschnitt hufeisenförmig (Fig. 488), indem er die Visceralmasse von hinten umfasst. Er nimmt die Gestalt eines vorn offenen, niederen, abgestutzten Hohlkegels an, der sich mit seiner oberen, hufeisenförmigen 
Schnittfläche an der Schale anheftet, mit seiner ebenfalls hufeisenförmigen Basis aber in den saugscheibenförmigen Fuss eintritt und in seinem Innern die Visceralmasse birgt.

Ganz ähnliche Verhältnisse kehren überall da wieder, wo die Schale flach conisch, napf- oder tellerförmig wird, wie z. B. bei den Hipponyciden und Capuliden unter den Monotocardiern.

Fig. 487 .

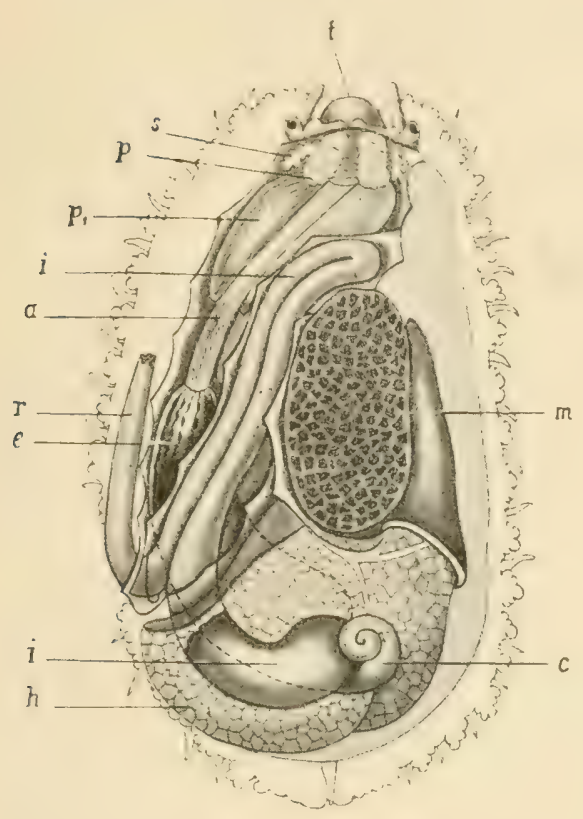

Fig 488 .

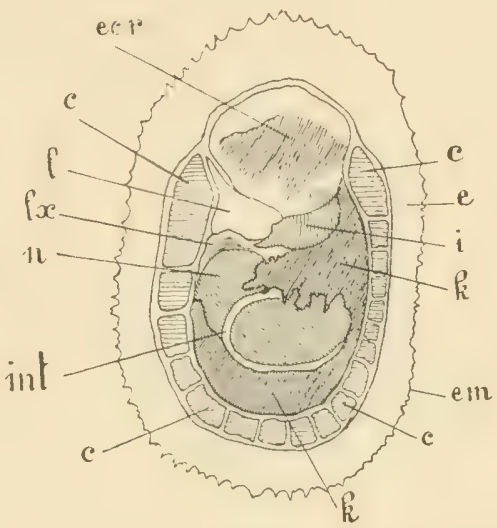

Fig. 488. Patella, von oben, nach Entfernung der Schale, nach LAANESTER. $c$ Die einzelnen, den auf dem Querschnitt hufeisenförmigen $\mathrm{S}$ c hale $\mathrm{n}$ muskel zusammensetzenden Muskelbündel, $l$ Pericard, $l x$ Scheidewand hinter dem Pericard, $n$ Verdauungsdrüse, int Darm, $k$ grösseres rechtes, $i$ kleineres linkes Nephridium, e Mantelsaum, sich vorne zu der Mantelfalte ecr verbreiternd, em Mantelrand

Fig. 487. Haliotis, von oben, nach Entfernung der Schale, des Mantels und des ganzen Rückenintegumentes, nach Wegmans. $t$ Schnauze, $s$ und $p$ Speicheldruisen, $p_{1}$ seitliche Taschen des Oesophagus, $i$ Mitteldarm, $a$ Oesophagus, $r$ Enddarm, $e$ Magen mit Coecum $c, h$ Verdauungsdrüse (Leber), ihr rechts neben dem grossen Schalenmuskel $m$ liegender Theil ist noch von der Genitaldrüse bedeckt. Rings um den Körper herum das gefranste Epipodium.

Heteropoden. Besondere Beachtung verdient die Musculatur der Heteropoden, wo wir die Rudimentation der Schale, Umwandlung des Fusses und fortschreitende Entfernung der Körpergestalt vom Schneckenhabitus Schritt für Schritt verfolgen können.

Bei Atlanta, deren Kopf und Fuss noch vollständig in die wohlentwickelte Schale zurückgezogen werden kann, erhält sich der Sp indelmuskel in typischer Form. Er steigt aus der Schale herunter und theilt sich dann in 3 Züge, von denen der stärkste mittlere in die Flosse und den Saugnapf, der hintere in das deckeltragende Metapodium, der vorderste kleinste in den Kopf und die Schnauze ausstrahlt.

Die Cutis ist bei Atlanta noch relativ dünn. Das dicht unter ihr liegende Hautmuskelnetz ist nicht stärker entwickelt, als bei anderen Schnecken. Ein besonderes System sich kreuzender Muskelfasern, unabhängig von der übrigen Hautmusculatur, liegt jederseits unter der Cutis der Flosse. Dies gilt für alle Heteropoden. 
Dis Dicke der Haut nimmt bei den typischen Heteropoden (Carinaria, Pterotrachea) sehr stark zu und mit ihr die Stärke des subcutanen Hautmuskelschlauches. Am Rumpfe besteht dieser aus zwei übereinanderliegenden Schichten sich kreuzender Diagonalmuskelfasern. In der äusseren Schicht verlaufen die Fasern von vorn oben nach hinten unten; in der inveren von vorn unten nach hinten oben. Am Kopfe mit der Schnanze, am. Eingeweidesack und am schwanzförmigen Metapodium nehmen die Diagonalfasern beider Schichten eine longitudinale Richtung an. Bei Caxinarił kommt noch am grössten Körpertheil, bei Pterotrachea nur an der Schnauze, eine äussere Ringmusculatur hinzu.

Erkundigen wir uns num nach dem Schicksal des Spindelmuskels. Bei Carinaris, wo noch eine zarte, hinfällige, den Eingeweidesack bedeckende Schale vorhanden ist, in die aber kein Theil des Körpers zurückgezogen werden kanu, ist noch ein Spindelmuskel vorhanden, der in Form von zwei Bändern vom Eingeweidesack in die Flosse heruntersteigt, um an deren Rond anszustrahlen.

Bei Prerotrachea, wo die Schale fehlt und der Eingeweidesack rudimentär isi, ist auch der Spindelmuskel reducirt. Er hat die Verbindung mii dem Eingeweidesack aufgegeben und beginnt jederseits erst etwa in der halben Höhe der Leibeswand als drei Muskelstümpfe, die nach unten in die Flosse hineintreten, um an ihren Rand auszustrahlen.

Aus dem Spindelmuskel, der ursprünglich dazu diente, den Fuss in die Schale murückzuziehen, ist ein Muskel geworden, der vorzugsweise die seitlichen schlagenden Bewegungen der dem Fusse bomologen senkrechten Ruderflosse hervorbringt.

b) Opisthobranchiata.

Der Spindelmuskel ist da gut entwickelt, wo eine Schale vorhanden ist, in welche der Körper ganz oder theilweise zurückgezogen werden liann. Wo aber die Schale rudimentär ist oder fehlt _- und das ist bei der Mehrzahl der Opisthobranchier der Fall - atrophirt der Spindelmuskel oder er bildet vielleicht einen Bestandtheil der Fussmusculatur. Dagegen entwickelt sich dann der subcutane Hautmuskelschlauch um so stärker, je bewegljcher die Thiere sind. Er besteht aus Längs-, Ringund Diagonalmuskeltasern, die bisweilen ein wahres Muskelnetz bilden. Die Museulatm des Fusses stellt sich nur als ein verdickter Theil dieses Hautmuskelschlauches mit prädominirenden Längsfasern dar. Im Einzelnen ist die Entfaltung der Musculatur sehr verschieden. Wo bewegliche oder entractile Rückenanhänge, Kiemen, Mundsegel, Parapodien, Mundscheiben u. s. w. zur Entwickelung gelangen, ist ihre Musculatur von der Hautmuskelschicht detachirt, und letztere stellt dann, im Verein mit der bisweilen derben Haut, das passive Stützorgan der ersteren dar.

Auch die beschalten Pteropoda thecosomata besitzen einen Spindelmuskel. Eis ist ventral bei den Limacinidae, dorsal bei den Cavoliniidae, deren Rumpf mit Bezug auf den Kopf, wie früher dargethan, um $180^{\circ}$ gedreht erscheint. Der Muskel theilt sich vorn in zwei seitliche Aeste, die in die Flossen ausstrahlen.

\section{c) Pulmonata.}

Der Sunntelunsskel ist bei deu beschaiten Puhmonaten stark entwickelt. Hir isf, padrig und setzt sich einerseits mit vielen Wurzeln an Fusse, bimral der Mundmasse, andererseits an der Spindel der erste? 
Schalenwindung an. Von dem Spindelmuskel detachire, sich 1) die Rückziehmuskeln der Tentakeln und Augenträger, 2) dif listractoren der Mundmasse, 3) Muskeln, die zu den Eingeweiden gehan.

Es ist von Interesse, den Spindelmuskel bei den Daudebardien und Testacellen zu untersuchen, bei denen der rudimenteir werdende Eingeweidesack mit der ihn bedeckenden Schale an das Hirterende des Körpers gerückt ist und bei denen von einem Zuriickziehen des Körpers in die Schale keine Rede sein kann.

Da ist nun vor allem die Thatsache zu constatireu, dass sich der Spindelmuskel nur theilweise erhält und selbstverständlich nur einen Theil seiner ursprünglichen Functionen beibebalten hat. Er hat sich in der That bei den Daudebardien und Testacellen erhalten 1) als Fühlerretractor und 2) bei Daudebardia als Schlundkopfretractor. Fühlerretractoren und Schlundkopfretractoren sind getrennt.

Fig. 489. Schale von Helix, so durchschnitten, dass die Spindel (Columella, Axe) der Länge nach getroffen ist, nach Howes. $c$ Columella, $r m$ Spindelmuskel, $p$ Mündungsrand.

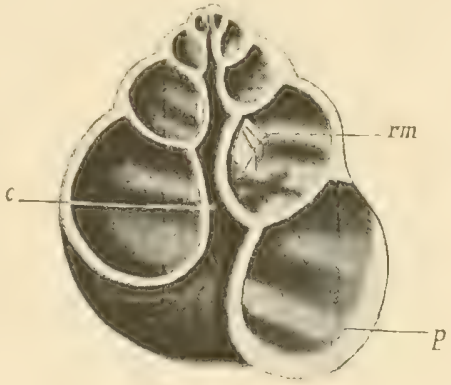

Die Fühlerretractoren durchziehen bei Daudebardia rufa getrennt die Leibeshöhle nach hinten bis an die Basis des Eingeweidesackes, wo sie, nicht in diesen eindringend, jederseits mit der Leibeswand verwachsen. Bei D. saulcyi laufen die Retractoren nicht so weit nach hinten, sondern dringen schon vor der Mitte des Körpers, die zwei rechtsseitigen und die zwei linksseitigen miteinander verschmolzen, in die Fussmusculatur ein. Aehnlich verhalten sich die Fühlerretractoren der 'T'estacellen.

Die Schlundkopfretractoren. Bei D. rufa entspringen am Schlundkopf zwei Retractoren, die, duch den Nervenschithirigr hindurchtretend, miteinander zu einem unpaaren Muskel verschmelzen, welcher am Boden der Schlundhöhle, der linken Körperwand gerkiff", nach hinten zieht, dann in den Eingeweidebruchsack hinaufsteigt, um sich in der letzten Schalenwindung an die Spindel auzuheften. Bei 1\%. sulcyi, wo kein Eingeweidebruchsack mehr vorhanden ist und die Schale nur noch eine Mantelhöhle bedeckt, steigen die hier nicht mit einander verschmolzenen Schlundkopfretractoren nicht mehr in die Schale hinauf, sondern endigen schon in der Mitte der Körperlänge, wo sie in die Flassmusculatur eindringen.

Die zahlreichen, in zwei asymmetrischen Reihen wngeordneten Schlundkopfretractoren von 'T estacella lassen sich aus verschiedenen Gründen nicht als Ueberreste eines Spindelmuskels auffassen.

Von Oncidium, welches im erwachsenen Zustande weder eine Schale noch einen Spindelmuskel besitzt, weiss man. dass es als beschalte Isarve einen solchen Muskel hat.

\section{C) Scaphopoda.}

Bei Dentalium (Fig. 483) verlaufen auf der Vorderseite des Runpfes jederseits zwei eng aneinanderliegende Muskelbander, die sich am dorsalen Ende der röhrenförmigen Schale voris anhetten. An der 
Basis des Fusses verschmelzen die beiden Bänder jederseits zu einem einzigen IIuskel, der, in den Fuss eindringend, in demselben in zahlreiche Längsmuskelbündel ausstrahlt. Wir haben es hier mit einem paarigen Spindelmuskel zu thun, welcher den Fuss verkürzt und den ganzen Unterkörper in den oberen Theil der Schale zurückzieht.

D) Lamellibranchiata.

Wir wollen bei den Lamellibranchiaten zwei Muskelgruppen in Betracht ziehen:

1) die Mantelmusculatur und

2) die in den Fuss verlaufende Musculatur.

Die Mantelmusculatur ist hauptsïchlich gegen den freieu Mantelsaum zu entwickelt und besteht aus 3 Systemen: 1) Muskelfasern, welche in der Ebene der Mantelfalte gegen ihren freien Rand verlaufen, auf dem sie senkrecht stehen, sie bilden den M a n telsaummuskel im engeren Sinne und lassen auf der Schale den Mantelsaumeindruck (Mantellinie) zurück. 2) Muskelfasern, welche dem Mantelsaum parallel verlaufen, :3) Muskelfasern, welche auf der Fläche der Mantelfalte mehr oder weniger senkrecht stehen und als kurze Fasern von der inneren zur äusseren Manteloberfläche verlaufen. Die nämlichen drei Systeme werden an den vom Mantel gebildeten Siphonen zu Ring-, Längs- und Radiärmuskeln. Eine besondere Differenzirung der Mantelmusculatur ist der Retractor der Siphonen, dessen Stärke zu der Grösse der Siphonen in directem Verhältnisse steht und dessen Insertion an der Innenseite jeder Schalenklappe die II an t e lbu ch t (vergl. p. 634) hervorruft. Als Differenzirungen der Mantelmusculatur müssen ferner die wichtigen Schliessmuskeln der Schalen betrachtet werden (Adductores, Schalen muskeln). Es sind ausserordentlich kräftige und dicke Muskeln, die quer von der Innenfläche der einen Schalenklappe zu der Innenfläche der gegenüberliegenden Schalenklappe ziehen. Sie wirken dem Schlossband entgegengesetzt, indem sie bei ihrer Contraction die beiden Schalenklappen einander nähern, sie aneinanderpresseu, die Schale schliessen. Auf der Innenfläche der Schalenklappen lassen sie die Schliessmuskeleindrü cke zurück. Typisch besitzen die Muscheln zwei Schliessmuskeln, einen vorderen und einen h interen (D imy a rier), die dem dorsalen Schalenraum nüher liegen, als dem ventralen. Bei den Mytilacea ist der hintere Schliessmuskel grösser, als der vordere (Heteromyarier, Is omyarier). Bei einer grossen Reihe von Formen schliesslich verkümmert der vordere Schliessmuskel gänzlich, während der um so stärker entwickelte hintere Schliessmuskel nach vorn gegen die Mitte der Schale rückt. Diese Formen werden zu der Abtheilung der It onomyarier vereinigt, einer nicht natürlichen Gruppe, da nahe verwandte Formen (z. B. innerhalb der Mülleriaceen) einen oder zwei Schliessmuskel besitzen können und weit entfernte Formen (z. B. Tridacna, Anomia, Mülleria, Aspergillum) in dem Besitz nur eines Schliessmuskels übereinstimmen. Monomyarier sind z. B. die Anomiidae, Ostreidae, Spondylidae, Limidae, Pectinidae, Aviculidae etc., Mülleridae etc.

Der Schliessmuskel besteht häufig (z. B. Pecten, Ostrea, Nucula) aus zwei verschieden aussehenden Partien, von denen die eine glatte, die andere solche MInskelfasern enthält, die quergestreift aussehen, ohne dass diese Querstreifung derjenigen der Arthropoden- und Vertebratenmuskeln entspricht. 
Die in den Fuss verlaufende Musculatur entspricht in ihrer Gesammtheit dem Spindelmuskel der übrigen Mollusken, speciell der Gasteropoden. Sie besteht aus symmetrischen Duskelpaaren, die sich einerseits an die Innenfläche der Schale anheften und hier Muskeleindrücke erzeugen, andererseits in den Fuss hineintreten. Dass diese Musculatur in ihrer Gesammtheit dem Spindelmuskel der Gasteropoden entspricht, ersieht man am besten bei einem Vergleich von Protobranchiaten mit Patella oder Fissurella z. B. Bei Nucula oder Leda nämlich bilden die Fussmuskeln jederseits vom vorderen zum hinteren Schliessmuskel eine fast continuirliche Reihe in den Fuss hinuntersteigender Bündel. Beide Reihen bilden zusammen eiue von oben oder unten betrachtet ovale Linie, welche dem hufeisenförmigen bis ovalen Querschnitt des Spindelmuskels von Patella oder Fissurella entspricht.

In der Mehrzahl der Fälle, wo der Fuss entwickelt ist, kann man jederseits von vorn nach hinten folgende Fussmuskeln unterscheiden, deren Anordnung Figur 490 erläutert: 1) der Protractor pedis; 2) der vordere Retractor pedis; 3) der Elevator pedis und 4) der hintere Retractor pedis.

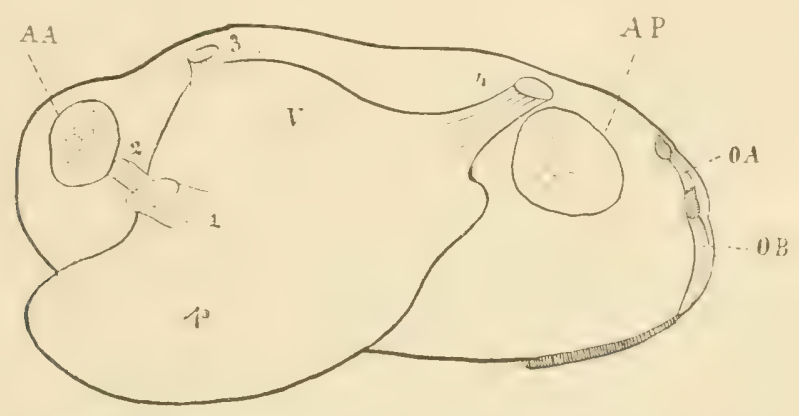

Fig. 490. Pliodon Spekei, von links, nach Pelsexeer. Schale, Mantel, Kiemen, Sundlappen linksseitig entfernt. AA Vorderer, $A P$ hinterer Schliessmuskel der Schale, $O A$ Anal-, $O B$ Branchialöffnung des Mantels, $V$ Eingeweidemasse, $p$ Fuss, 1 Protractor pedis, 2 Retractor pedis anterior, 3 Elevator pedis, 4 Retractor pedis posterior.

Wo ein Byssus vorkommt, wird der hintere Rückziehmuskel des Fusses zum Byssusmuskel. Er ist dann meist sehr kräftig entwickelt, reicht weit nach vorn und kann in mehrere Bündel zerfallen. muskeln.

Bei rudimentärem Fuss und fehlendem Byssus verkümmern die Fuss-

Bei P e cten inseriren die Fussretractoren asymmetrisch nur auf der linken Schale. Dasselbe ist der Fall bei Anomia, wo das dem Byssus entsprechende, in dem Byssusausschnitt der rechten aufliegenden Schalenklappe liegende "Schliessknöchelchen" durch zwei stark entwickelte Retractoren mit der (in physiologischer Stellung oberen) linken Schalenklappe verbunden ist. Diese zwei Muskeln lassen neben demjenigen des Schliessmuskels Eindrücke zurück, was zu der irrthümlichen Auffassung der Anomien als Trimyarier Veranlassung gab.

E) Cephalopoda.

Bei den Cephaloporlen kommt es zur Bildung eines knorpeligen Endo skelets, das einerseits verschiedenen Muskeln, Muskelgruppen, 
Muskelhäuten zur Anheftung, andererseits zum Schutze wichtiger Organe, vor allem der Centraltheile des Nervensystems und der Augen, dient. Von den verschiedenen, das Skelet bildenden Knorpeln ist allein der Kopfknorpel constant.

\section{a) Tetrabranchiata (Nautilus).}

I a u tilus besitzt nur den Knopfknorpel. Dieser ist annähernd X-förmig, wobei man sich die Schenkel dick vorzustellen hat. Zwischen den Schenkeln der einen Hälfte des X läuft der Oesophagus in die Höhe, während diejenigen der anderen Hälfte den Trichter stützen und seinen Muskeln zum Ansatz dienen.

Unter den Muskeln ist besonders hervorzuheben der grosse, paarige Schalenmuskel, welcher dem Columellarmuskel der ïbrigen II ollusken entspricht. Er entspringt vom Kopfknorpel und verliuft jederseits in jenes Verwachsungsband (annulus) hinein, durch welches der Körper des Nautilus mit der inneren Wand der Wohnkammer verbunden ist (vergl. Fig. 416), um sich, wie dieses Band selbst, an die Schale anzuheften, an welcher er in der Lobenlinie einen grosseu Muskeleindruck zurücklïsst. Von den Seitenrändern des Kopfknorpels und besonders seines Trichtertheiles zieht jederseits ein breites Muskelband, der M u s c ulu s collaris, nach vorn, den „Halstheil" des Körpers umgreifend, um sich am Nacken mit seinem Gegenüber in der musculösen Xackenplatte zu vereinigen. Die Unterseite des Kopfknorpels dient der Musculatur der Tentakel zur Insertion.

\section{b) Dibranchiata.}

Hier ist das Knorpelskelet viel reicher gegliedert, als bei Nautilus. Diese reichere Gliederung steht jedenfalls, zum Theil wenigstens, in ursächlichem '/usammenhang mit der innerhalb der Dibranchiaten erfolgenden Rudimentation der Schale. Flossen und mit ihnen Flossenknorpel entwickeln sich z. B. nur bei Formen mit innerer, rückgebildeter Schale.

Der Kopflknorpel (Fig. 491) ist überall wohl entwickelt. Er umschliesst alle rings um den Schlund zusammengedrängten centralen Theile des Nervensystems und bildet somit eine hohle, ringförmige Kapsel, die vom Schlunde durchbohrt wird. Fortsätze dieser Kapsel helfen die Augen stützen und bilden zusammen mit selbständigen A u gendeckelknorpeln eine Art knorpelige Augenhöhle. An der Basis der vorderen Arme findet sich bei einigen Decapoden ein Armknorpel. Weiter sind zu erwähnen bei den Decapoden die Knorpel der Mantelschliessapparate:

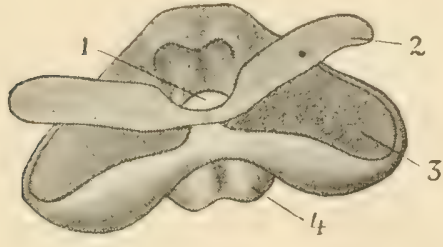

Fig. 491. Kopfknorpel von Sepia, von vorn. 1 Centrale Oeffnung zum Durchtritt des Schlundes, 2 Augendeckelknorpel, 3 Raum für das Auge, 4 knorpelige Gehörkapsel. der Nackenknorpel im Nacken und die Knorpel des Schliessapparates der Mantelhöhle, von denen früher schon die Rede war. Im Di a phragma, d. h. in der hinteren Wand des Eingeweidesackes, über welche der Mantel herunterhängt und die Mantelhöhle mit ihren Organen bedeckt, findet sich am Trichter bei Decapoden der Di a phragmaknorpel. Schliesslich ist noch des $R$ ückenknorpels Erwähnung zu thun, der besonders bei Sepia stark entwickelt ist. Er liegt an 
der Hinterseite des vorderen, auf den Nacken vorragenden Mantelsaumes und steht zu dem Nackenknorpel in einem ganz ähnlichen Verhältniss, wie beim Schliessapparat der Mantelhöhle der Knorpelvorsprung jederseits am Mantel zum napfförmigen Knorpel jederseits der Trichterbasis. Bei Sepia setzt er sich jederseits in einen Knorpelstab fort, welcher der rechten und linken Kante der Sepiaschale entlang aufsteigt. An der der Mittellinie zugekehrten Seite zeigen die Knorpelstäbe eine Furche, in welche die Schalenkante hineinpasst; oder, mit anderen Worten, sie bilden eine Art Falz um die seitlichen Kanten des Sepiaschulpes herum. Bei Octopoden liegt jederseits am Rücken im Integumente ein Knorpelstreifen, der den Rückenknorpelstäben von Sepia entsprechen dürfte. Vielleicht ist die innere Schale des einzigen Octopoden, bei dem eine solche gefunden worden ist, von Cirrhoteuthis nämlich, in Wahrheit nicht der Decapodenschale homolog, sondern entspricht den in der Medianlinie $\because$ erschmolzenen Knorpelstreifen von Octopus. Die Aufzïhlung der Knorpel im Dibranchiatenkörper vervollständigen wir durch die Erwähnung der Knorpel, die bei Decapoden ganz allgemein an der Basis der Flossen liegen, der Flossenknorpel.

Bei der Besprechung der Dibranchiatenmusculatur will ich die Musculatur des Mantels, der Flossen und der Arme nicht eingehend beschreiben, sondern nur erwähnen, dass sich die Mantelmusculatur vorzugsweise an die Schale oder an den Ruickenkuorpel, die Flossenmusculatur an den Flossenknorpel, die Armmusculatur an die Vorderseite des Kopfknorpels und theilweise, wo ein solcher vorhanden ist, an den Armknorpel anheftet.

Ueber die übrige Musculatur wollen wir uns an der Hand einer schematischen Zeichnung (Fig. 492), die aut Grund einer Beschreibung der Enoploteuthismusculatur entworfen worden ist, orientiren.

Der paarige, starke Depress or in fund i bu li, Herabzieher des Trichters (1), entspringt jederseits an der Schale (oder am Rückenknorpel) und verläuft nach unten und hinten an die Basis des Trichters und zum Schliessknorpel. Er liefert den grössten Theil der Muskeln der vorderen Trichterwand. Zusammen mit dem Depressor infundibuli entspringt der parige Retractor capitis lateralis (2), der in den Kopf verläuft und sich an den Kopfknorpel anheftet. Der Retractor

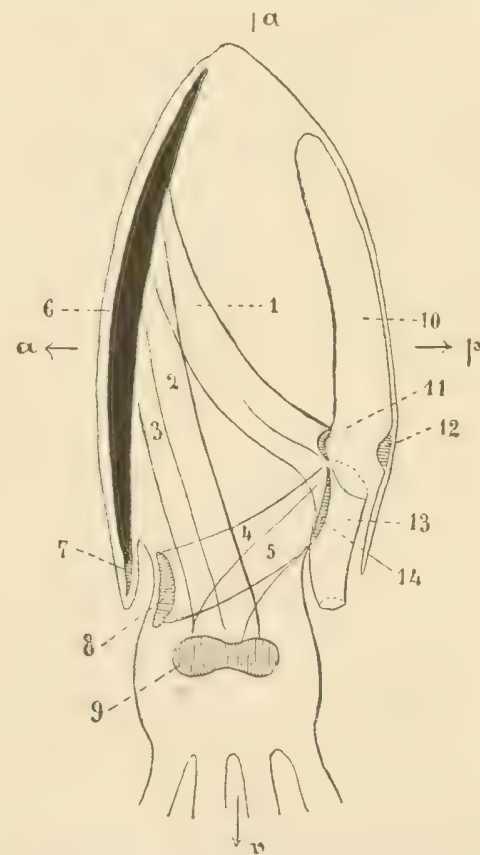

Fig. 492. Schematische Darstellung der wichtigsten Dibranchiatenmusculatur. Körper von der linken seite. $v$ Ventral, $d$ dorsal, $a$ vorn, $p$ hinten, 1 Depressor infundibuli, 2 Retractor capitis lateralis, 3 Retractor capitis medianus, 4 Collaris, 5 Adductor infundibuli, 6 Schale, 7 Rückenknorpel, 8 Nackenknorpel, 9 Kopfknorpel, 10 Mantelhöhle, 11 Schliessknorpel an der hinteren Wand des Eingeweidesackes, 12 gegenüberliegender Schliessknorpel an der Innenwand des Mantels, 13 Trichter (Infundibulum), 14 Diaphragmaknorpel. 
capitis medianus (3), ursprünglich parig, aber meist zu einem Muskel verschmelzend, entspringt an der Hinterseite (Innenseite) der Schale und verläuft ebenfalls in den Kopf, wo er sich an den Kiopfknorpel anheftet.

Zunächst verschmelzen nun bei den Dibranchiaten die medianen Kopfretractoren unter sich (Onychoteuthis), dann immer vollständiger auch mit den seitlichen Retractoren (Ommastrephes, Sepioteuthis, Loligo, Sepiola), so dass schliesslich (Sepia) die gesammte Schalenkopfmusculatur eine hinten offene Muskelscheide bildet, welche den unteren, hauptsächlich von der Verdauungsdrüse (Leber) erfüllten Theil der Eingeweidehöhle umschliesst und als musculöse Leberkapsel bezeichnet wird. Indem sich auch der Depressor infundibuli mit seinen vorderen Rändern an den medialen und hinteren Rand der musculösen Leberkapsel anschliesst und mit ihr verwächst, und indem er ferner zahlreiche Muskeln in das Diaphragma ausstrahlen lässt und so das Diaphragma musculare bildet, wird auch die hintere Lücke der musculösen Leberkapsel gänzlich ausgefüllt.

Die ganze musculöse Leherkapsel, alle Muskeln, aus der sie hervorgeht, also die Retractoren capitis und Depressores infundibili, dürften ohne Bedenken als Homologa der Colum ellarmuskeln der übrigen Mollusken aufgefasst werden können. Wie diese steigen sie von der Schale oder Schalengegend zum Kopfe und zu Theilen des Fusses (Trichter) herunter.

Von weiteren Muskeln des Dibrauchiatenkörpers sind noch zu elwähnen die Add uctoren (5) des Trichters. Sie entspringen vom Kopfkuorpel und ziehen nach oben und hinten zum Trichter. Ein starker Muskel ist schliesslich der Collar is (4), der aus der Trichterwand rechts und links nach vorn zicht und sich an die Seitenränder des Nackenknorpels anheftet. Bei den ()ctopoden und Sepiola, wo eine gelenkige lopfnackenverloindung und mit ihr ein Nackenknorpel fehlt, zieht der Collaris ohne Unterlorechumg sattelartig über den Nacken hinweg und bildet um den Halstheil des Körpers herum einen geschlossenen Ring.

\section{Nervensystem.}

Als Einleitung diene das in Abschnitt II über das Yervensystem der Mollusken Gesagte.

\section{A) A mp hineura.}

Die wichtigsten Eigenthümligkeiten des vergleichend-anatomisch bedeutungsvollen Nervensystems der Amphineureu lassen sich kurz dahin zusammenfassen :

1) Die Ganglienzellen finden sich nicht oder nicht bloss in Ganglienknoten localisirt.

2) Den Körper durchziehen von vorn nach hinten 4 Nervenstäm m e. Diese enthalten nicht nur Nervenfaseru, sonderu sind in ihrer ganzen Länge auch mit Gauglienzellen besetzt. Man könnte sie also passender Markstïmme nennen. Sie müssen zum Centralnervensystem gerechnet werden. Von diesen 4 symmetrischen Markstämmen verläuft ein Paar seitlich am Körper, die Lateral-oder Pleurovisceralstämme, ein zweites Paar ventral am Körper, die Fus oder Pedalstränge. Vorn vereinigt sich jederseits der Visceral- mit 
dem Pedalstrang. Die so jederseits vereinigten Längsstämme stehen durch einen vor und über dem Schlunde quer verlaufenden, ganglienzellenhaltigen Strang, den oberen Cerebrallual bring, in Verbindung. Die Pleurovisceralstïmme gehen binten $\ddot{b} b \mathrm{er}$ d em Enddarm schlingenförmig in einander über. Die Pedalstränge stehen sowohl unter sich, als mit den Pleurovisceralsträngen durch Anastomosen in Verbindung, so dass das Nervensystem auffallend an das Strickleit ernervensystem mancher Turbellarien und Trematoden erinnert.

a) Chit on idae (Fig. 493 und 435). Das Nervensystem vou Chitou wurde der vorstehenden schematischen Darstellung zu Grunde gelegt. Die typischen Ganglien des Centralnervensystems der Mollusken sind hier in der That noch nicht als durch Commissural- und Connectivnerven verhuudene Knoten gesondert, sondern es sind - was wahrscheinlich als ursprüngliches Verhalten aufzufassen ist - die Ganglienzellen gleichmässig auf die Connective und Commissuren vertheilt, so diass der obere Schlundhalbring den Cerebralganglien mitsammt der sie verbindenden Comm issur entspricht, und die Ped a lstränge den ganzen centralen Theil des Fussnervensystems, die Pleurovisceralstränge den centralen Theil des visceralen, pallealen und branchialen Nervensystems enthalten. Nur bei einer einzigen Chitonart (Chiton rubicundus) kommen im oberen Schlundhalbring zwei einander in der Mittellinie genäherte Ganglienknoten (Cerebralganglien) vor.

Wir wollen nun das Nervensystem der Chitonen etwas näher betrachten und successive ins Auge fassen: 1) die Anordnung des Schlundringes und der Markstämme; 2) die peripheren Ganglien; 3) die Nerven des Strickleiternervensystems; 4) die vom Centralnervensystem (Schlundring und Markstämme) abgehenden Nerven.

1) Form und Anordnung des Centralnervensystems. Der Visceralstrang zieht jederseits in der seitlichen Leibeswand über der Kiemenfurche nach hinten, um über dem After in den der anderen Seite überzugehen. Die Pedalstränge verlaufen im dorsalen Theile der Fussmusculatur einander ziemlich genähert von vorn nach hinten, um am Anfang des Afterdarms zu endigen, ohne dass sie in einander übergehen. Der Schlundring besteht zunächst aus dem schon erwähnten oberen Halbring, welcher in Folge der besonderen Gestalt des Chitonkörpers in derselben Ebene wie die beiden Visceralstränge liegt. Hinten theilt sich jeder Schenkel dieses Halbrings in den Pedal- und in den Pleurovisceralstrang der betreffenden Körperseite. An der Stelle, wo der Pedalstrang aus dem oberen Schlundhalbring entspringt, spaltet sich von ihm mit verdickter Basis nach innen ein Strang ab, welcher sich hinter dem Munde mit seinem Gegenüber zum unteren Schlundhalbring verbindet. Unterer und oberer Schlundhalbring bilden zusammen den geschlossenen Schlundring.

2) Ausser diesem centralen Nervensystem existiren noch periphere Ganglien, die mit ihm durch Nerven (Stränge, die nur aus Nervenfasern bestehen) verbunden sind.

a) Die Buccalganglien bilden zusammen eine hufeisenförmige Ganglienmasse unter dem Oesophagus, die jederseits durch ein Cerebrobuccalconnectiv mit dem verdickten Theile des unteren Schlundrings verbunden ist. Die Buccalganglienmasse zerfällt bei Ch. rubicundus in zwei 
paarige und ein mpaares Ganglion, die mit einander durch Connective verbunden sind. Die Buccalganglien innerviren den Oesophagus bis zum Magen und das Mundloch.

b) Aus dem unteren Schlundhalbring entspringt etwas nach innen vom Buccalconnectiv ein Nerv (Subradularconnectiv), welcher nach vorn und innen zu den beiden Subradularganglien geht, die in dem auf

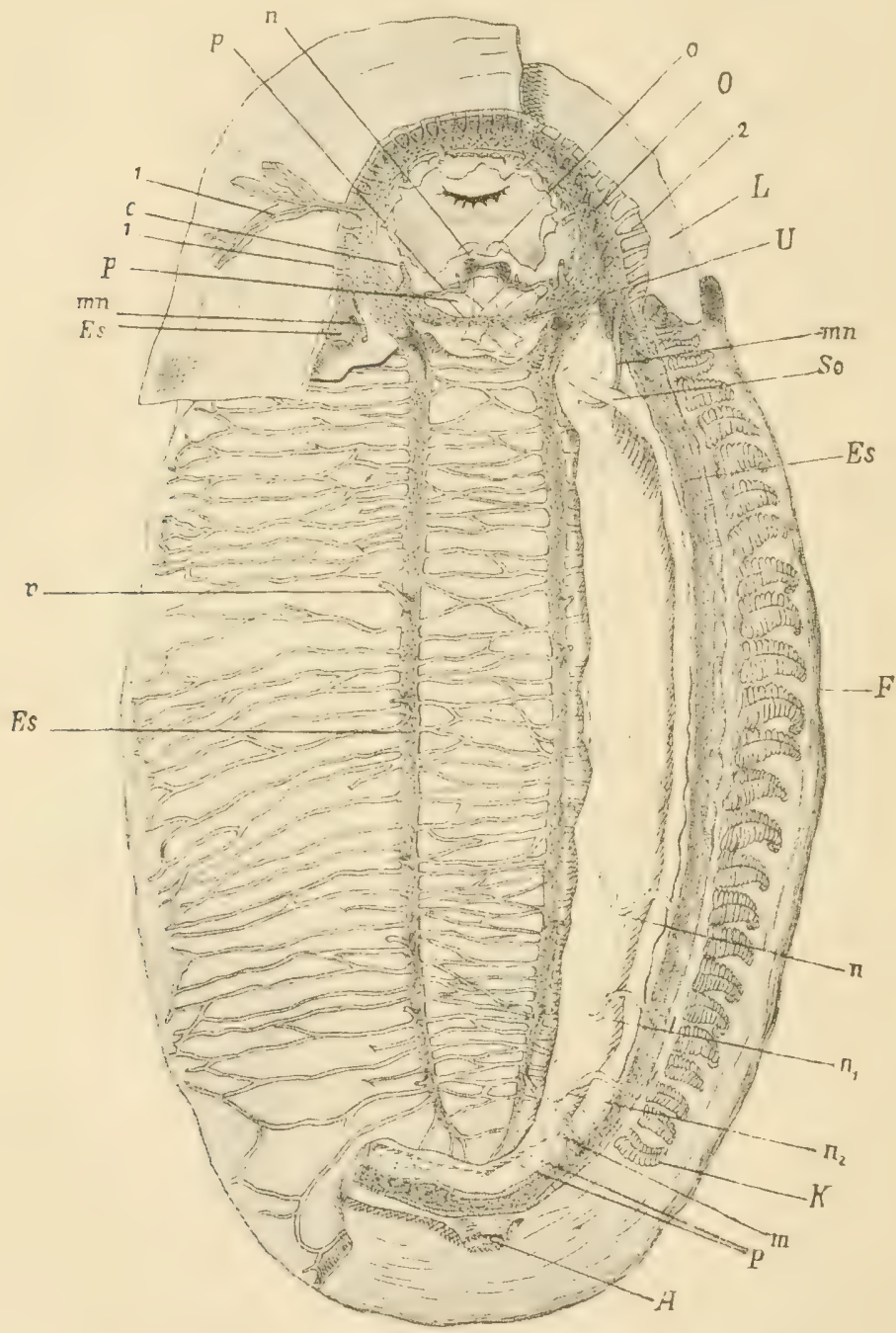

Fig. 493. Nervensystem von Chiton siculus, nach Béla Haller. Auf der rechten Seite der Mantel entfernt. In der Mitte und links der obere Theil des Fusses weggetragen, um das Fussnervensystem blosszulegen. $F$ Fuss, $K$ letzte Kieme, $A$ After, $O$ obere, $U$ untere Hälfte des Schlundringes, 1 und 2 Nerven des Schlundringes, $c$ Connectiv zu den vorderen Eingeweideganglien, $p$ Connectiv zu den Ganglien des Subradularorganes $n$, Es Pleurovisceral- und Pedalstränge, $m n$ Magennerv, So Ansatzstelle des Sphincter oris, $n, n_{1}, n_{2}$ Nierennerven, $m$ Mantelnerven, $p$ (rechts unten in der Figur) Herznerven, $v$ ein dorsaler Nerv eines Pedalstranges. Man sieht die Commissuren zwischen den Pedalsträngen und die von letzteren nach aussen abgehenden Nerven. 
dem Boden der Mundhöhle unter der Radula liegenden Subradularorgan liegen. Beide Ganglien sind durch eine kurze Commissur verbunden.

c) Zwei kleine, durch eine feine Commissur verbundene $\mathbf{M}$ a genganglien liegen am Vorderende des Magens und stehen jederseits mit dem Vorderende des Visceralstranges durch ein längeres Connectiv in Verbindung.

3) Die Nerven des Strickleiternervensystems. Die beiden Pedalstränge stehen in ihrer ganzen Länge durch anastomosirende Commissuren in Verbindung, von denen aber keine Nerven an die Fussmusculatur abgehen. Bei Chiton rubicundus stehen auch die Visceralstränge mit den Pedalsträngen durch zahlreiche Connective in Zusammenhang, die bei anderen Chitonarten zu fehlen oder auf eine einzige vordere oder hintere Anastomose reducirt zu sein scheinen.

4) Die vom Centralnervensystem abgehenden Nerven.

a) Nerven des Schlundrings. Zahlreiche Nerven entspringen aus dem oberen oder cerebralen Theile des Schlundrings und innerviren den Kopftheil des Mantels, die Schnauze, die Oberlippe, die Unterlippe, die Geschmacksknospen an der unteren Iundwand und die Musculatur der Buccalmasse. Der untere Theil des Schlundrings giebt ausser den Connectiven zu den Buccal- und Subradularganglien aus seinem Mittelstück noch ein Paar in den Boden der Mundhöhle verlaufende Nerven ab.

b) Nerven der Pleurovisceralstränge. Jeder Pleurovisceralstrang giebt an jede Kieme zwei Nerven ab. Ausserdem entspringen aus den Visceralsträngen zahlreiche Mantelnerven und in ihrem hinteren Theile Nerven, die in die Leibeshöhle, wahrscheinlich an die Nieren und an das Herz abgehen.

c) Nerven der Pedalstränge. Die Pedalstränge entsenden jederseits nach aussen etwa 7-8 Nerven zur lateralen Körpermusculatur, besonders zahlreiche Nerven aber (äussere und innere Fussnerven) nach unten in die Fussmusculatur. Diese Fussnerven verästeln sich erheblich und bilden, miteinander anastomosirend, ein wahres Nervennetzwerk im. Fusse.

b) Soleuogastres. Das Centralnervensystem der Solenogastren unterscheidet sich von demjenigen der Chitonen vornehmlich durch die 'Tendenz zur Bildung von Ganglienknoten, wobei aber trotzdem die Pedal- und Pleurovisceralstränge in ihrer ganzen Länge ihren Besatz mit Ganglienzellen beibehalten. Fig. 494 erläutert in ühersichtlicher Weise den Bau des Nervensystems von Proneomeni a sluiteri. Die in der Mittellinie verschmolzenen Cereloralganglien sini sehr voluminös. An den Markstämmen, sowohl an den Pleurovisceral-, wie an den Pedalsträngen lassen sich Ganglienanschwellungen unterscheiden. Wir unterscheiden:- 1) 3 Par hintere Visceralganglien, hinten im Körper; 2) zwei vordere Pedalganglien.

Die hinteren Visceralganglien sind mit einander durch quer üher dem Enddarm verlaufende Strïnge verbunden, welche wenigstens theilweise der Schlinge entsprechen, durch welche hei Chiton die heiden Visceralstränge hinten in einander übergehen.

Durch einen starken Querstrang sind die zwei vorkeren Pedalganwlien miteinander verlounden. Dieser Querstrang düfte der ventralen Hälfte des Schlundringes von Chiton entsprechen. 
Ausserdem sind sowohl die Pleurovisceralstränge mit den Pedalsträngen als die letzteren unter sich in ihrer ganzen Ausdehnung durch quere Connective verbunden, und auch die beiden Pleurovisceralstränge sind durch dorsale, bogenförmig verlaufende Quercommissuren verknüpft ${ }^{1}$ ).

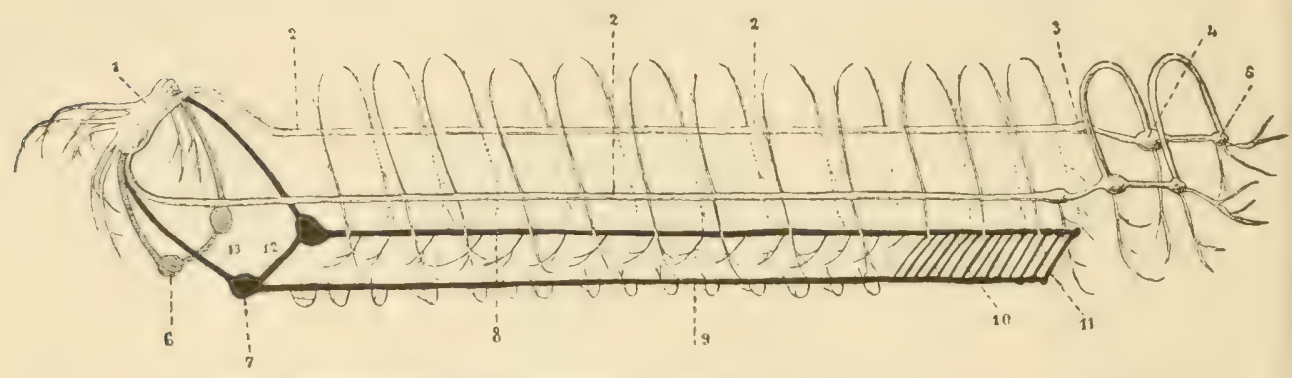

Fig. 494. Nervensystem von Proneomenia Sluiteri, Originalzeichnung von J. Heuscher. 1 Cerebralganglien, 2 Pleurovisceralstränge, 3, 4, 5 hintere Ganglien der Pleurovisceralstränge, 6 Sublingualganglien, 7 vordere Pedalganglien, 8 rechter Pedalstrang, 9 linker Pedalstrang, 10, 11 starke hintere Commissuren zwischen den Pedalsträngen, 12 vordere Pedalcommissur, 13 Sublingurlcommissur.

Jederseits entspringt vom Cerebralganglion ein Nerv, welcher zu einem jederseits unter dem Pharynx, hinter der Radulascheide gelegenen Ganglion, dem Sublingualganglion geht, das mit seinem Gegenüber durch eine kurze Quercommissur verbunden ist. Diese Sublingualganglien entsprechen wahrscheinlich den Buccalganglien von Chiton.

Dondersia ist besonders deshalb bemerkenswerth, weil bei dieser Form die Pedalstrïnge in regelmüssigen Abständen, und besonders dentich im vorderen Körpertheil, zu Ganglienknoten anschwellen. Die ebenso regelmässig sich wiederholenden Quercommissuren zwischen den Pedalsträngen und die Connective zwischen Pedal- und Visceralsträngen gehen von diesen Ganglienknoten ab.

Bei Lepidomenia hystrix kommt in jedem Längsstamm (sowohl in den Pleurovisceral-, als in den Pedalsträngen) vorn und hinten ein Ganglion vor, das mit seinem Gegenüber durch eine Quercommissur verbunden ist.

Bei $\mathrm{N}$ eomenia und Chaetoderma sind keine Connective zwischen den Visceral- und Pedalsträngen beobachtet worden, bei $\mathrm{Cha}$ etoderma fehlen nach den vorliegenden Beobachtungen auch die Commissuren zwischen den Pedalsträngen. Bezüglich Chaetoderma ist ferner noch zu bemerken, dass jederseits Pedalstrang und Visceralstrang sich hinten im Körper zu einem Strange vereinigen, der über der Cloake durch einen Querstrang in den der gegenüberliegenden Seite übergeht.

B) Gasteropoda.

Das Yerrensystem der Gasteropoden ist rergleichend-anatomisch in hohem Grade interessant. Was ihm dieses hohe Interesse verleiht, ist, um es hier gleich zu sagen, die hei den Prosobranchiern bestehende Kreuzung der Pleurovisceralconnective, welche in diesem Abschnitt eingehender besprochen werden soll.

1) Diese Connective und Commissuren scheinen aber nicht ununterbrochen von dem einen Markstrang zum andern zu ziehen. 
Typisch besteht das Gasteropodennervensystem aus jenen Theilen, die wir grösstentheils schon bei der Darstellung der schematischen Molluskenorganisation erwähnt haben, nämlich:

1) Zwei Cerebralganglien neben oder über dem Schlunde, die mit einander durch eine Cerebralcomm is $\mathrm{cur}$ verbunden sind.

2) Kwei Pedalganglien unter dem Schlunde, die mit einander durch eine quere Pedalcommissur und mit den Cerebralganglien durch zwei Cerebropedalconnective verbunden sind.

Die Cerebralganglien und Pedalganglien mit den zugehörigen Conmissuren und Connectiven bilden zusammen eimen den Schlund umgebenden Ring, der dem Schlundring der Annulaten und Arthropoden vergleichbar ist.

3) Zwei Pleural- oder Pallealganglien (zwischen Cerebralund Pedalganglien), die mit den Cerebralganglien durch zwei Ce rebrople u ra l-, mit den Pedalganglien durch zwei P l e uro p e d a l connective zusammenhängen.

4) Ein einfaches oder mehrfaches unter dem Darme liegendes V is ceralganglion, welches mit den Pleuralganglien durch zwei Pleurovisceralconnective verbunden ist.

5) Im Verlaufe eines jeden Pleurovisceralconnectives tritt fast immer ein Ganglion auf. Diese Ganglien mögen als Parietalganglien bezeichnet werden. Das Parietalganglion theilt das Pleurovisceralconnectiv in zwei Theile, ein vorderes, das Pleuroparietalconnectiv, und ein hinteres, das Visceroparietalconnectiv.

Die Cerebral-: Pedal- und Pleuralganglien sind mit zu vernachlïssigenden Ausnahmen bei allen Gasteropoden symmetrisch zur Medianebene angeordnet. Für die Pleurovisceralconnective und ihre Ganglien jedoch lässt sich dies nur bei einem Theile der Gasteropoden sagen. Die Pleurovisceralconnective mit ihren Ganglien sind in der That nur bei den Opisthobranchiaten (incl. Pteropoden) und den Pulmo naten in dem Sinne symmetrisch, dass das rechte Counectiv mit seinem Ganglion ganz auf der rechten, das linke ganz auf der linken Seite des Thieres liegt. Die Opisthobranchier und Pulmonaten sind euthyneure Gasteropoden.

Bei den Prosobranchiern sind die Pleurovisceralconnective in dem Sinne asymmetrisch angeordnet, dass sie einander kreuzen, und zwar derart, dass das vom rechten Pleuralganglion entspringende Connectiv über dem Darm hinweg auf die linke Seite hinüberzieht, bevor es das Visceralganglion erreicht, während umgekehrt das vom linken Pleuralganglion ausgehende Compectiv un ter dem Darm hinweg nach der rechten Seite hin verläuft. In Folge dieser Kreuzung wird das Parietalganglion des vom rechten Pleuralganglion stammenden Connectives zu einem Supraintestinalgangrion - es liegt auf der linken Seite - und das Parietalganglion des vom linken Pleuralganglion kommenden Connectives wird zum Subintestinalganglion - es liegt auf der rechten Seite. - Die Prosobranchier sind streptoneure Gasteropoden.

Iunervationsgebiete der verschiedenen Ganglien.

1) Die Cerebralganglien innerviren die $A$ ugen, die Gehörolgane, die Tentakeln, die Schnauze oder den Püssel, die Lippen, die Bewegungsmuskeln des Rüssels und der Buccal- 
masse und die an der Basis der Schnauze liegende Körperwand. Auch dann, wenn die Gehörorgane in unmittelbarer Nähe der Pedalganglie» sich befinden oder ihnen sogar dicht anliegen, erhalten sie ihren Nerven vom Cerebral- und nicht vom Pedalganglion.

2) Die Pedalganglien liefern die Nerven für die Musculatur des Fusses und gelegentlich (Patella) auch des Spindelmuskels.

3) Die Pleuralganglien innerviren besonders den Mantel, den Spindelmuskel und die hinter dem Kopf liegende Leibeswand.

4) Die Parietalganglien liefern die Nerven für die Ctenidien (Ki iemen), das Osphradium und theilweise auch für den Mantel.

5) Die Visceralganglien innervieren die Eingeweide. Auch die Connective und $\mathrm{Comm}$ issuren kömmen Nerven abgeben, die zum Innervationsgebiet der benachbarten Ganglien gehören.

6) Die weiter unten zu hesprechenden Buccalganglien immerviren die Muskeln des Pharynx, die Speicheldrüsen, den Oesophagus, die vordere Aorta etc.

Vergleichen wir das typische Nervensystem der Gasteropoden mit demjenigen der Amphineuren, so ergeben sich folgende Homologien:

1) Die Cerebralganglien der Gasteropoden entsprechen dem Schlundringe von Chiton mit Ausnahme des mittleren Stückes seiner unteren Hälfte; sie entsprechen den Cerebralganglien der Solenogastres.

2) Die Pedalganglien der Gasteropoden entsprechen den zu je einem Ganglion concentrirten Pedalsträngen der Amphineuren. Sehr in structiv sind in dieser Beziehung die Diotocardier, d. h. die ursprünglicheren Prosobranchier, indem sich bei diesen die Pedalganglien nach hinten in zwei ächte, wie bei den Amphineuren durch Quercommissuren verbundene Pedalstränge fortsetzen.

Schwieriger gestaltet sich ein Vergleich der Pleural-, Parietal- und Visceralganglien der Gasteropoden. Am meisten berechtigt erscheint die Auffassung, dass dieser ganze Gangliencomplex mitsammt seinen Connectiven den Pleurovisceralsträngen von Chiton entspricht. Der Innervationsbezirk ist identisch: Mantel, Ctenidien, Osphradien (Chiton?), Eingeweide. Ist diese Auffassung richtig, so hat man sich

3) die Pleuralganglien so entstanden zu denken, dass sich der palleale Ganglienzellentheil der Pleurovisceralstränge von Chiton auf ihr vorderes Ende, da wo sie aus dem Schlundring entspringen, zu einem Ganglion concentrirt hat, welches noch dem Seitentheil des Schlundringes angehört. Weichen nun die beiden Theile jeder Schlundringseite, der cerebropedale und der pleurale, auseinander, wobei zugleich am Schlundring die Cerebral- und Pedalganglien stärker als solche sich individualisiren, so kommt jederseits ein doppeltes Cerebropedalconnectiv zu Stande. Das eine zeigt in seinem Verlaufe kein Ganglion - es ist das wahre Cerebropedalconnectiv der Gasteropoden. In den Verlauf des zweiten aber ist das Pleuralganglion eingeschaltet, aus welchem immer noch die Visceralstränge entspringen und welches dieses zweite Connectiv in ein Cerebropleural- und in ein Pleuropedalconnectiv zerlegt.

4) Chiton hat zahlreiche Kiemen jederseits, von denen jede 2 Nerven aus dem nahen Pleurovisceralstrange bezieht. Die Gasteropoden haben höchstens zwei Kiemen, eine rechte und eine linke. Dem entsprechend 
dürfte sich der den Kiemennerven zukommende Antheil Ganglienzellen der Pleurovisceralstränge jederseits auf ein zu einer Kieme gehöriges Ganglion reducirt haben. Entstehung der Parietalganglien. Der zwischen dem Pleural- und dem Parietalganglion gelegene Theil eines jeden Pleurovisceralstranges wird zu einem ganglienzellenlosen Pleurop arie ta Iconnectiv.

5) Für das oder die Visceralganglien der Gasteropoden existirt bei Chiton kein Homologon, und hierin besteht die grösste Schwierigkeit des Vergleiches. Bei den Amphineuren gehen die Pleurovisceralstringe hinteu üb er dem Darm ineinander über; bei allen übrigen Mollusken liegt diese Verbindungsstelle (eben das Visceralganglion) un ter dem Darm.

Bemerkenswerth ist das Verhalten von Proneomenia, wo sich diese hinteren Commissuren zwischen den Pleurovisceralsträngen nur als stärker entwickelter 'Theil eines allgemeinen Commissurensystems darstellen.

\section{Entstehung der Kreuzung der Pleurovisceralconnective} (Chiastoneurie) (Fig. 495-498).

Die merkwürdige Chiastoneurie der Prosobranchier hat verschiedene Erklärungsversuche hervorgerufen, von denen hier einer, der, wenn auch nicht ganz, so doch in hohem Maasse befriedigt, dargelegt werden soll.

IVir müssen von einer supponirten Stammform ausgehen, die vollstandig, auch im Nervensystem, symmetrisch war und etwa die Organisation unseres schematischen Urmolluskes besass. Diese Organisation stimmt in den meisten wichtigen Punkten mit der der heutigen Chitonen sehr überein. Doch haben wir uns vorzustellen, dass hinten jederseits nur eine Kieme vorhanden ist.

Es ist ferner im Auge zu behalten, dass die Parietalganglien die Kiemen und das (Isphradium innerviren, dass sie also innig an diese Organe geknüpft sind.

Die Gasteropodenstammform mag von einem schmalen Mantelsaum umsüumt gewesen sein, der nur hinten breiter war, d. h. hier eine etwas tiefere Mantelhöhle bedeckte, welche den pallealen Organco $\mathrm{mplex}$ barg: in der Mittellinie den After, rechts und links davon das Ctenidium mit dem Osphradium, zwischen Cteuidium und After jederseits die Nephridialöf fnung.

Lassen wir jetzt diesen pallealen Organcomplex seine Lage verändern und von hinten der rechtsseitigen Mantelfurche entlang allmählich nach vorn sich verschieben, so zieht jedes Ctenidium se in Parietalganglion mit sich. Mit der Verschiebung des pallealen Complexes verschiebt sich auch das Herz und seine beiden Vorhöfe, die an die Ctenidien gebunden sind.

II enn der palleale (Grancomplex auf der rechten Seite noch wenig weit nach vorn acrüickt ist, so sind die Pleurovisceralconnective noch nicht gekreuzt, somlern nur auf die rechte Seite verschoben (Fig. 496). Auf diesem Stadium stehen (wenigstens scheinhar) die Tectibranchier unter den Opisthobranchiaten, nur dass sie schon a uf diesem Sta dium das ursprünglich linke Ctenidium und damit auch den ursprünglich linken Vorhof des Herzens verloren hätten (Fig. 427, p. 599)).

Geht nun die Verschiehung weiter, schieht sich der palleale Complex, immer in der Mantelfurche, ganz nach vorn (Fï. 497, 494$)$, bis er schliesslich vorn über und hinter dem Nacken, wieder symmetrisch zu liegen lionmt, so liegt damn das ursprünglich linke Ctenidium rechts, das 
ursprünglich rechte Ctenidium links in der vorderständigen Mantelhöhle. Das ursprünglich rechte Ctenidium aber hat dabei sein Parietalganglion über den D arm hinweg auf die linke Seite hinübergezogen. Letzteres wird zum Supraintestinalganglion. Das ursprünglich linke Ctenidium hingegen hat sein Parietalganglion unter dem Darm hinweg auf die rechte Seite hinübergezogen. So ist aus diesem Ganglion das $\mathrm{Sub}$ intestinalganglion geworden. Die Connective, in denen diese Ganglien liegen, die Pleurovisceralconnective, kreuzen sich jetzt; die Chiastoneurie ist gebildet. Das Visceralganglion, in welches die beiden Connective hinten einmünden, liegt nach wie vor unter dem Darme.

Fig. 495

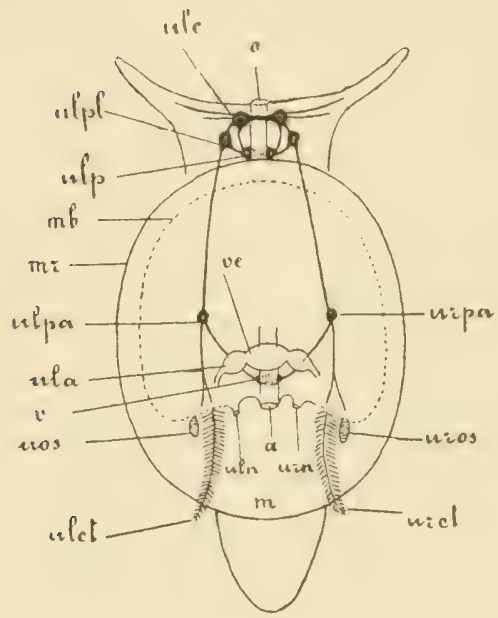

Fig. 497 .

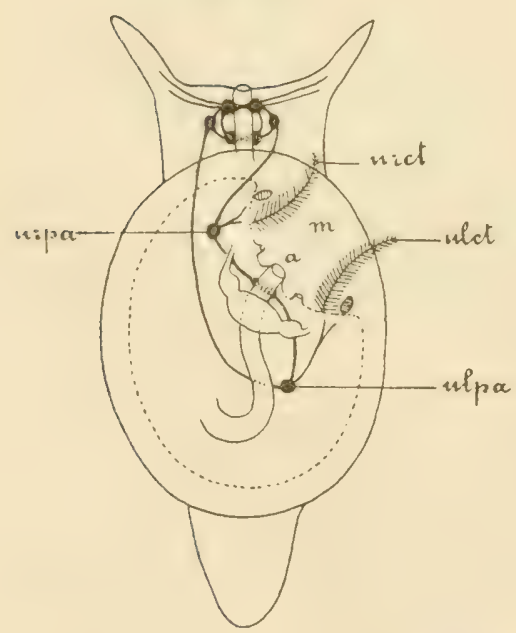

Fig. 496

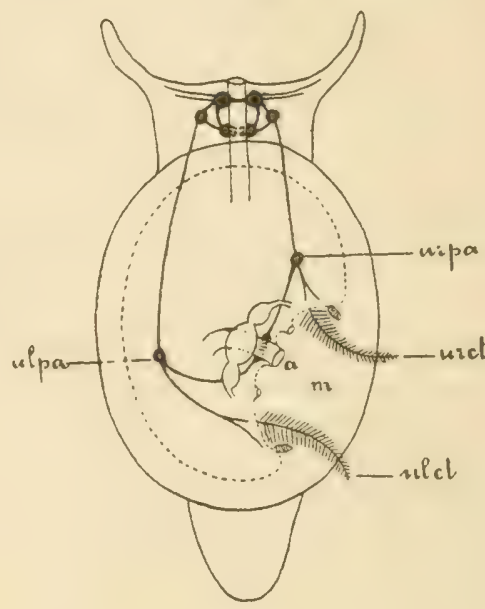

Fig. 498

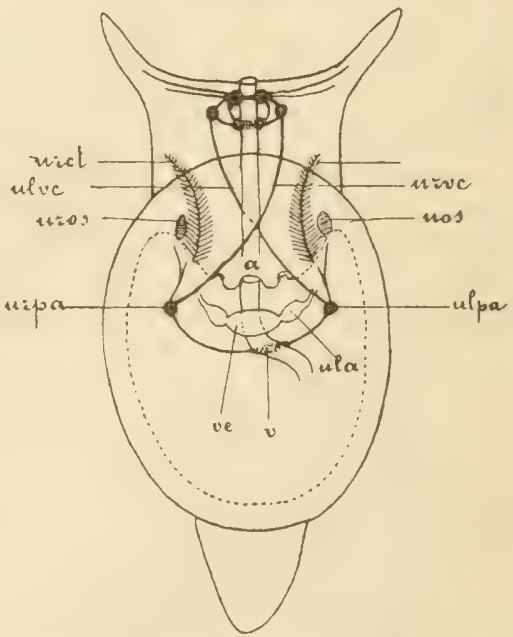

Fig. 495, 496, 497, 498. Schematische Figuren zur Veranschaulichung der Verlagerung des Pallealcomplexes von hinten nach vorn, der rechten Körperseite entlang. Ausbildung der Chiastoneurie. Bedentung der Buchstabenbezeichnungen wie in Fig. 423, p. 593. 
Es braucht nicht noch besonders betont zu werden, dass die Inversion auch das Herz mit seinen Vorkammern, die Osphradien und die Nephridialöffnungen betrifft.

Wenn nun auch die Erklärung der Chiastoneurie durch die besprochene Verschicbung des pallealen Organcomplexes befriedigt, so ist dabei doch sofort zu betonen, dass die Verschiebung selbst vor der Hand nicht erklärt ist. Es müsste die Ursache, der Grund der Verschiebung nachgewiesen werden (vergl. Abschnitt XIV, p. 726).

\section{Specielles über das Nervensystem der Gasteropoden.}

I. Prosobranchiata. a) Diotocardia. Diese bilden die ursprünglichste Gruppe der Gasteropoden. Die Ganglien sind noch nicht scharf abgegrenzt, hierin erinnern sie noch an die Amphineuren. Die Gehirnganglien sind durch eine vorn über den Pharynx verlaufende, lange Cerebralcommissur und durch eine vorn unter dem Schlunde verlaufende $\mathrm{Labialcommissur}$ verbunden. Die nicht scharf gesonderten $\mathrm{Buccalg}$ anglien bilden zusammen eine hufeisenförmige Figur und sind jederseits durch ein Connectiv mit der verdickten Wurzel der Labialcommissur verbunden. Die Pleuralganglien liegen den Pedalganglien dicht an, so dass gesonderte Pleuropedalconnective nicht zu unterscheiden sind. Die Pedalcommissur ist sehr kurz und enthält Ganglienzellen. Von den beiden Pedalganglien entspringen zwei lange, im Fuss nach hinten ziehende Pedalstränge, welche in ihrer ganzen Länge Ganglienzellen enthalten und durch Quercommissuren verbunden sind. Diese Pedalstränge mit ihren Quercommissuren weisen also dieselben Verhältnisse, wie bei den Amphineuren, auf. Die Pedalstränge innerviren die Musculatur des Fusses und das Epipodium. Es findet sich nur ein nicht scharf abgegrenztes Visceralganglion, welches mit den Pleuralganglien durch zwei in typischer Weise gekreuzte Pleurovisceralconnective in Verbindung steht. Nur bei Fissurella findet sich ein in das supraintestinale Pleurovisceralconnectiv eingeschaltetes Supraintestinalganglion. Sonst findet sich bei den Diotocardiern an der Stelle, wo der starke Kiemennerv von dem Pleurovisceralconnectiv abgeht, kein Ganglion. Dagegen bildet dieser Nerv ein Ganglion dicht unter dem Osphradium, an der Kiemenbasis das $\mathrm{Branchialganglion.} \mathrm{Wo} \mathrm{jeder-}$ seits ein Ctenidium oder auch bloss ein Osphradium vorhanden ist, findet sich jederseits ein Branchialganglion; wo nur die linke (ur) Kieme sich erhält (Turboniden, Trochiden), findet sich nur das linke Branchialganglion. Da im Allgemeinen den Diotocardiern Parietalganglien, den Monotocardiern aber Branchialganglien fehlen, so hat man auch die Branchialganglien der Diotocardier als von der Pleurovisceralcommissur weg- und an die Kiemenbasis gerückte Intestinalganglien betrachtet, eine Auffassung, für die Manches spricht. Da indessen Fissurella sowohl ein Supraintestinal-, als ein linkes Branchialganglion besitzt, so müsste man annehmen, dass sich hier ein ursprünglich einheitliches Ganglion in zwei getheilt habe.

Immer steht der symmetrische Mantelnerv (derjenige, der aus dem Pleuralganglion entspringt) mit dem as y m metrischen Mantelnerven (der aus dem Parietalganglion der betreffenden Seite oder aus dem Pleuroparietalconnectiv entspringt) der nämlichen Körperseite durch eine Mantelanastomose in Verbindung.

Die Neritidae und Helicinidae zeigen in ihrem Nervensystem 
eigenthümliche Verhältnisse, die sich kurz so charakterisiren lassen, dass ihnen das supraintestinale Pleurovisceralconnectiv mit dem entsprechenden Ganglion fehlt.

Docoglossa. Das Nervensystem von Patella (Fig. 499) unterscheidet sich von dem typischen Nervensystem der übrigen Diotocardier im Wesentlichen nux dadurch, dass das Pleuralganglion durch ein deut-

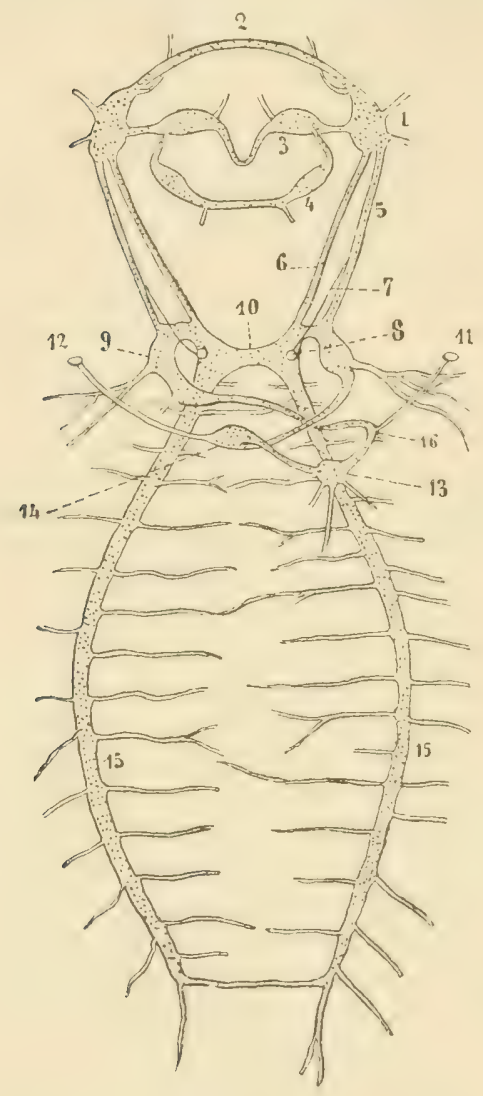

liches Pleuropedalconnectiv vom Pedalganglion getrennt ist.

b) Monotocardier (Fig. 500). Die Parietalganglien sind immer vorhanden. Die Cerebralcommissur ist kurz und liegt hinter dem Pharynx. Die Labialcommissur fehlt (excl. Paludinidae, Ampullaridae). Pedalstränge und Quercommissuren fehlen (excl. die Architaenioglossa: Paludinidae, Cyclophoridae, Cypraeidae). Die Zahl der Visceralganglien variirt von $1-3$.

Unsere besondere Aufmerksamkeit verdient die fortschreitende Ausbildung der sogenanten Zygoneurie. Schon bei den Diotocardiern existirt eine Anastomose zwischen dem symmetrischen und dem asymmetrischen Mantelnerven jederseits, die Mantelanastomose. Wenn diese Anastomose an den beiden Mantelnerven einer Seite

Fig. 499. Nervensystem von Patella. Die Figur ist nach Zeichnungen von Pelseneer und Bouvier combinirt. 1 Cerebralganglion, 2 Cerebralcommissur, 3 Labialganglion, 4 Buccalganglion, 5 Cerebropleuralconnectiv, 6 Cerebropedalconnectiv, 7 Nervus acusticus, 8 Gehörblåschen, 9 Pleuralganglion, 10 Pedalcommissur, 11 rechtes, 12 linkes Osphradium, 13 Visceralganglion, 14 Supraintestinalganglion, 15 Pedalstränge, 16 Andeutung eines Subintestinalganglions.

sich bis zu ihrem Ursprung, d. h. bis zu den Ganglien, aus denen diese Mantelnerven entspringen, verschiebt, so wird sie zu einem Mantelconnectiv, welches das Pleuralganglion der einen Körperseite mit dem Intestinalganglion der nämlichen Seite verbindet. Es entsteht also ein neues, accessorisches Pleurointestinalconnectiv, welches aber im Gegensatz zu dem schon bestehenden asymmetrischen gedrehten ein symmetrisches ungedrehtes ist. Die Zygoneurie besteht eben in dem Auftreten eines solchen Mantelconnectives. In der grossen Mehrzahl der Fälle, in denen die Zygoneurie auftritt, ist sie eine rechtsseitige (einige Rostrifera, nämlich ein Theil der Cerithiidae, Ampullariidae, Turitellidae, Xenophoridae, Struthiolariidae, Chenopidae, Strombidae, Calyptraeidae, ferner alle Proboscidifera siphonostomata und alle Stenoglossa). Seltener ist die Zygoneurie eine linksseitige (Ampullariidae, einige Crepidulidae, Naticidae, Lamellariidae, Cypraeidae). Bei den übrigen Prosobranchiern kommt jederseits, wie bei den Diotocardiern, nur eine Mantelanastomose vor; man sagt dann, das Nervensystem sei dialyneur. 
Schliesslich ist noch die mit der Ausbildung der Zygoneurie gleichen Schritt haltende, fortschreitende Concentration des centralen Nervensystems der Monotocardier zu betonen. Die Connective, welche die verschiedenen Ganglien miteinander verbinden, verkürzen sich immer mehr, so dass man schliesslich vorn am Schlunde einen Haufen von Ganglien antrifft, es sind dies die einander sehr genäherten Cerebral-, Pleural-, Pedal-, Subintestinal- und Supraintestinalganglien, zu denen sich noch die kleinen Buccalganglien gesellen. Nur die Visceralganglien bleiben im Eingeweidesack zurïck.

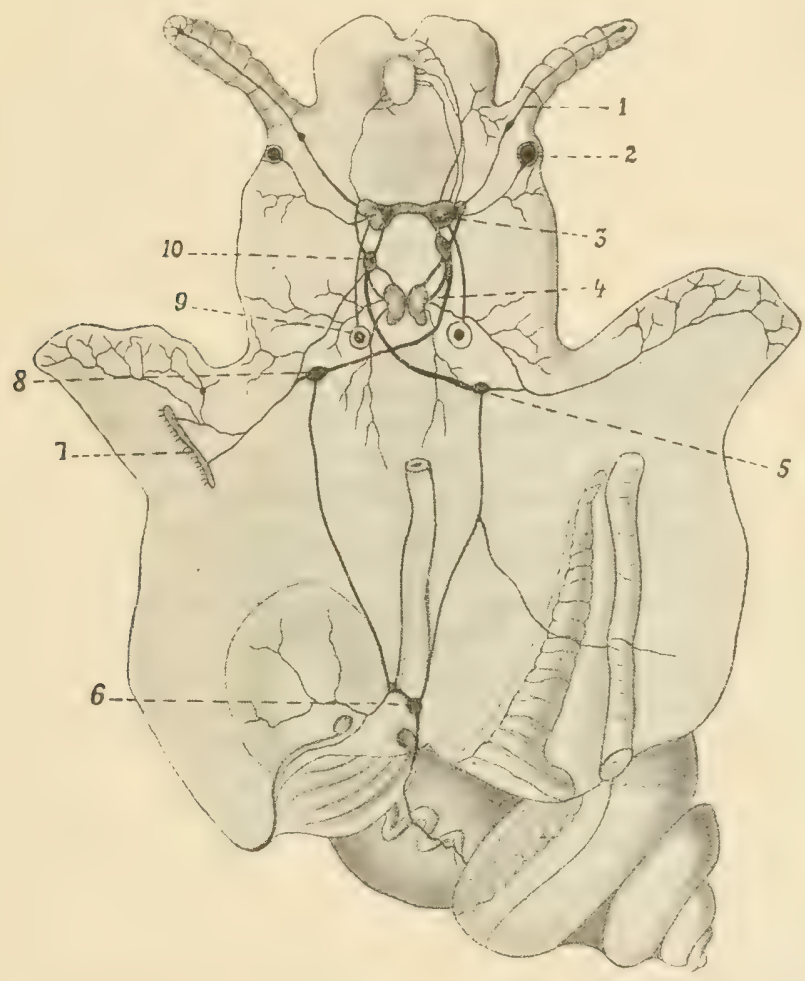

Fig. 500. Nervensystem von Cyclostoma elegans, nach LACAzE-Duthiers. 1 Tentakelnerv, 2 Auge, 3 Cerebralganglion, 4 Pedalganglion, 5 Subintestinalganglion, 6 Visceralganglion, 7 Osphradium, 8 Supraintestinalganglion, 9 Gehörbläschen, 10 Pleuralganglion.

Das Nervensystem der Heteropoden bedarf einer erneuten genauen Untersuchung. Doch ist nach den vorliegenden Beobachtungen so viel sicher, dass sie gekreuzte Visceralconnective haben, also Prosobranchier sind und zwar, wie die übrige Organisation zeigt, Monotocardier. Die Cerebralganglien und die Pedalganglien (Plenropedalganglien?') sind weit von einander entfernt, so dass die Cerebropedalconnective sehr lang sind.

II. Opisthobranchiata. Das die typischen Gasteropodenganglien aufiveisende Nervensystem ist in doppelter Weise charakterisirt, erstens durch das Fehlen der Chiastoneurie, d. h. die ungekreuzten Pleurovisceral- 
connective, und zweitens durch die ausgesprochene Tendenz zur Concentration der Ganglien um das hintere Ende des Pharynx herum.

a) Tectibranchiata. Gewöhnlich existirt nur das rechte Parietalganglion (bei Actaeon auch das linke). Aus ihm entspringt ein Nerv, welcher vorwiegend das Ctenidium, das Osphradium und den Mantel innervirt und an der Basis der Kieme ein Branchialganglion bildet. Eine zarte, unter dem Pharynx der Pedalcommissur entlang verlaufende untere Cerebralcom mis ur, der Labialcommissur der Diotocardier vergleichbar, ist vielfach nachgewiesen.

Wir wollen zwei 'Typen von Tectibranchiern herausgreifen: Bulla als Vertreter der Cephalaspidea, und Aplysia als Vertreter der An as pidea (Aplysiidae).

Beistehende Fig. 501 stellt das Nervensystem von Bulla hydatis dar. Sie bedarf keiner eingehenderen Erklärung. Nur drei Punkte mögen hervorgehoben werden: 1) Die Pleuralganglien sind unter Verkürzung des Cerebropleuralconnectives ganz dicht an die Cerebralganglien herangeriickt. (Bei Actaeon sind sie sogar mit ihnen verschmolzen, äusserlich nicht unterscheidbar.) 2) Es existiren 3 Visceralganglien. 3) Die Commissuren sind relativ lang. 4) Von den Pedalganglien aus werden auch die Parapodien innervirt.

Es ist ferner noch zu bemerken, dass bei manchen Cephalaspidea kein gesondertes rechtes Parietalganglion existirt. Dasselbe scheint ganz nahe an das rechte Pleuralganglion hinangerückt oder mit demselben rerschmolzen zu sein, so dass dann der zum Branchialganglion gehende Nerv direct vom rechten Pleuralganglion entspringt.

Das Nervensystem der Pteropoda thecosomata, die wir von Cephalaspiden herleiten, stimmt im Allgemeinen mit dem Nervensystem dieser letzteren überein, besonders darin, dass die Pleuralganglien dicht an die Cerebralganglien herangerïckt oder mit ihnen verschmolzen sind. Es sind die Pleurovisceralconnective so stark verkürzt, dass die in ihrem Terlaufe liegenden Ganglien dicht an die Cerebral- und Pedalganglien herangerückt sind. Gewöhnlich sind zwei solcher Ganglien vorhanden (das rechte Parietal- und ein Visceralganglion?), seltener drei (zwei Intestinal- und ein Tisceralganglion?). Die Pedalganglien innerviren auch die den Parapodien der Cephalaspidea entsprechenden Flossen.

Aplysia (Fig. 502) als Vertreter der Anaspidea: Die beiden Cerebralganglien sind in der Mittellinie dicht aneinander gerückt. Im Gegensatz zu den Cephalaspidea liegen die Pleuralganglien in nächster Nïhe der Pedalganglien, so dass die Pleuropedalconnective stark verkürzt sind. Die Pedalcommissur ist doppelt, die vordere Commissur ist relativ kurz und dick, die hintere länger und dünn. Von den Pleuralganglien ziehen die langen Pleurovisceralconnective nach hinten, um in zwei aneinander gelagerte Ganglien einzumünden. Das rechte stellt das rechtsseitige Parietalganglion dar, indem dasselbe hauptsächlich die Kieme und das Osphradium innervirt. Die bezüglichen Nerven bilden an der Basis eines jeden dieser Organe ein Ganglion. Das linke ist das Visceralganglion. Einer der Nerven, die von ihm abgehen, bildet an der Basis der Anhangsdrüsen der Geschlechtsorgane ein Genitalgangliou. Bei anderen Anaspidea, z. B. Notarchus (Fig. 503), sind die Pleurovisceralconnective so stark verkürzt, dass das Parietal- und Visceralganglion dicht an die periösophageale Gangliengruppe herangeriickt sind, die also besteht aus den 2 Cerebral-, 2 Pedal-, 2 Pleuralganglien, dem rechten Intestinal- und dem Visceralganglion. Die beiden Cerebralganglien sind auch durch eine dünne, un tere 
Commissur verbunden. Die Parapodien werden überall von den Pedalganglien aus innervirt. Das Nervensystem der Pteropoda gymnosomata, deren nächste Verwandte die Anaspidea sind, stimmt in allen wesentlichen Punkten mit dem Anaspidennervensystem vom Typus desjenigen von Notarchus überein.

Fig. 501.

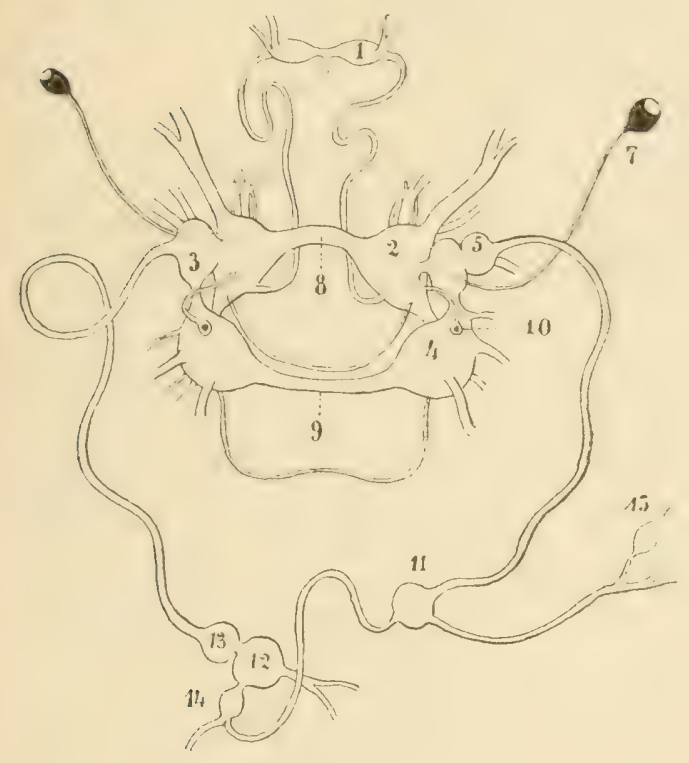

Fig. 502 .

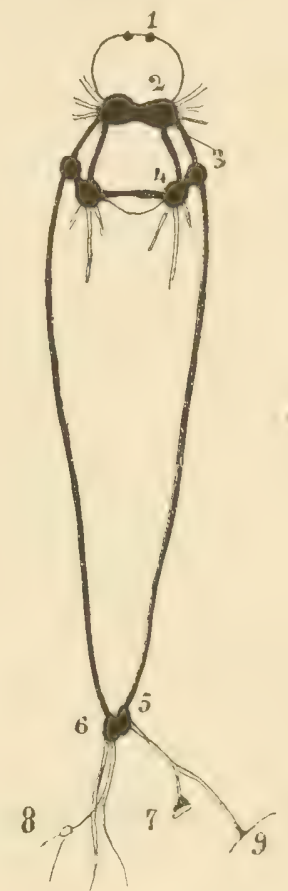

Fig. 501. Nervensystem von Bulla hydatis, uach VAYssière. 1 Buccalganglion, 2 Cerebralganglion, 3 Pleuralganglion, 4 Pedalganglion, 5 Theil des rechten Pleuralganglions? 7 Auge, 8 Cerebralcommissur, 9 Pedalcommissur, 10 Gehörbläschen, 11 rechtes Parietalganglion, 12, 13, 14 Visceralganglien, 15 Branchialganglion.

Fig. 502. Nervensystem von Aplysia, nach verschiedenen Angaben combinirt, schematisch. 1 Buccalganglion, 2 Cerebralganglion, 3 Pleuralganglion, 4 Pedalganglion, 5 rechtes Parietalganglion, 6 Visceralganglion, 7 Osphradium, 8 Genitalganglion, 9 Branchialganglion.

b) Nudibranchiata und Ascoglossa. Das Nervensystem ist charakterisirt durch die sehrstarke Concentration der typischen Molluskenganglien und durch die Tendenz zur Bildung zahlreicher accessorischer Ganglien (an den Wurzeln der Tentakelnerven, der Rhinophorennerven, an der Basis der Tentakeln und Rhinophoren, im Verlaufe des Genitalnerven u. s. w.) Das Pleuralganglion ist dicht an das Cerebralganglion gerïckt und kann mit demselben verschmelzen. Die Pedalganglien sind ebenfalls gegen die Cerebralganglien heraufgerïckt, so dass jetzt der gauze ösophageale Gangliencomplex fast ganz auf die Dorsalseite des Oesophagus zu liegen kommt. Dadurch wird die unter dem Schlunde rerlaufende Pedalcommissur, die hisweilen doppelt ist, in die Länge gezogen. Die Pleurovisceralconnective sind kurz und münden bisweilen in ein unpaares Visceralganglion, das ebenfalls in den 
Schlundgangliencomplex einbezogen erscheint. Auch dieses einzige Ganglion der Visceralconnective kann fehlen (Fig. 504), dann nehmen die beiden Visceralconnective den Charakter einer unter dem Schlunde verlaufenden Commissur zwischen den beiden Pleuralganglien an, die der Pedalcommissur parallel verläuft und sich mit ihr vereinigen kann. Sehr weit geht die Verschmelzung der Ganglien des gesammten circumösophagealen Complexes, z. B. bei Tethys, wo jederseits das Pleural- und Pedalganglion mit dem Cerebralganglion verschmolzen ist. Das so gebildete Pleurocerebro-pedalganglion legt sich seinerseits wieder in der dorsalen Mittel-

Fig. 503.

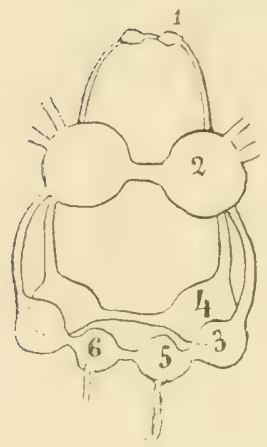

Fig. 504.

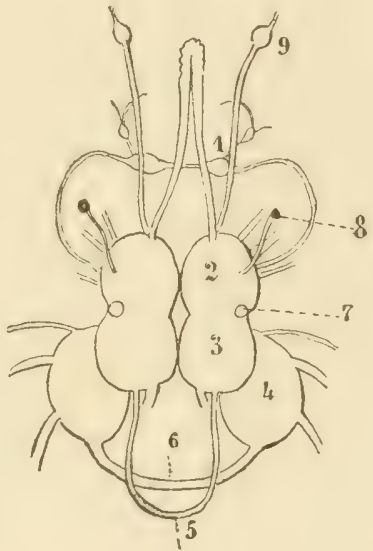

Fig. 503. Nervensystem von Notarchus punctatus, nach VAYSSIERE, schematisirt. 1 Buccalganglien, 2 Cerebralganglien, 3 Pleuralganglien, 4 Pedalganglien, 5 rechtes Parietalganglion, 6 Visceralganglion.

Fig. 504. Nervensystem von Janus, nach PeLseneer vereinfacht. 1 Buccalganglien, 2 Cerebralganglien, 3 Pleuralganglien, 4 Pedalganglien, 5 Commissur zwischen den zwei Pleuralganglien, welche den beiden Pleurovisceralconnectiven der übrigen Mollusken entspricht, 6 Pedalcommissur, 7 Gehörbläschen, 8 Auge, 9 Rhinophorenganglion.

linie dicht an das gegenüberliegende an, so dass eine grosse, supraösophageale Ganglienmasse zu Stande kommt, an der man aber immer noch in der Gruppirung der Ganglienzellen und in der Anordnung der Faserziige die Zusammensetzung aus den 6 typischen Ganglien erkennen kann. Von der supraösophagealen Ganglienmasse geht jederseits ein Nerv ab, der sich unter dem Schlunde mit seinem Gegenüber vereinigt. Es ist die Pedalcommissur, die sich bei genauerer Untersuchung als doppelt erweist. Ein dritter, zarter, infraösophagealer Verbindungsstrang zwischen den Seitentheilen der supraösophagealen Ganglienmasse stellt die Visceralcommissur dar, in welche ein kleines Visceralganglion eingeschaltet ist.

Ueberall bei den Nudibranchiern finden sich die zwei Buccalganglien an der hinteren und unteren Wand des Pharynx. Sie sind miteinander durch eine Buccalcommissur und mit dem Gehirn durch 2 Cerebrobuccalconnective verbunden, in deren Verlauf accessorische Ganglien eingeschaltet sein können.

Der gesammte circumösophageale Gangliencomplex ist bei den Nudibranchiern in eine bindegewebige Kapsel eingeschlossen.

III. P u lmonata (Fig. 505). Das Centralnervensystem besitzt alle typischen Gasteropodenganglien. Sie bilden zusammen, ähnlich wie bei so vielen Opisthobranchiern und manchen Prosobranchiern, unmittelbar hinter dem Pharyngealbulbus einen circumösophagealen Gangliencomplex, in welchen auch die Parietalganglien und das Visceralganglion einbezogen sind. Dabei haben die einander sehr genäherten Cerebralganglien eine dorsale, alle übrigen einander ebenfalls sehr genäherten Ganglien eine 
ventrale Lage. Dementsprechend sind die Cerebropedal- und Cerebropleuralconnective immer deutlich zu unterscheiden. Bei Testacella sind sie sogar, wohl in Anpassung an die besondere Gestalt und aussergewöhnlich starke Ausbildung des Pharyngealbulbus, langgestreckt. Alle übrigen Connective hingegen und alle Commissuren sind stark verkürzt, so dass die durch sie verbundenen Ganglien dicht aneinander liegen. Ein Visceralganglion existirt immer, und gewöhnlich auch in jedem Pleurovisceralconnectiv ein Parietalganglion. Das Osphradium wird, wenn es existirt (Basommatophoren), von dem Parietalganglion der betreffenden Seite innervirt. Bei den rechtsgewundenen Formen liegt es rechts, bei den linksgewundenen links, bei den ersteren ist das rechte Parietalganglion grösser als das linke, bei den letzteren umgekehrt. Das kleinere Parietalganglion kann auch mit dem benachbarten Pleuralganglion verschmelzen. An den Cerebralganglien treten häufig Lappen auf, in denen bestimnte Gruppen von Nerven ihren Ursprung nehmen. Die Pedalcommissur ist häufig doppelt. Buccalganglien existiren immer. Sie liegen, mit dem Cerebralganglion durch Cerebrobuccalconnective, unter sich durch die Buccalcommissur verbunden, hinten am Pharynx unter dem austretenden Oesophagus.

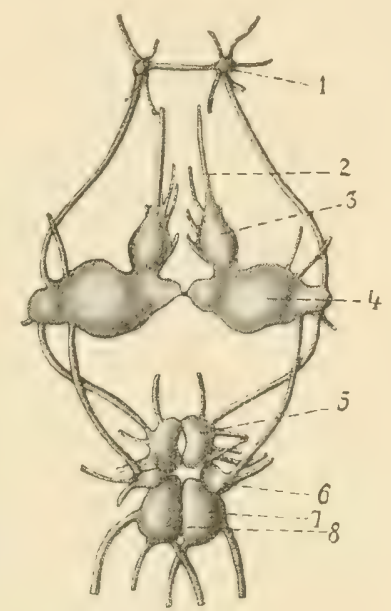

Fig. 505. Centraler Theil des Nervensystems von Helix pomatia, nach BöвMiG und LEUCKART, etwas schematisirt, indem die Abgrenzungen der Ganglien in Wirklicbkeit nicht so scharf sind. 1 Buccalganglien, 2 Augennerven mit verdickter Wurzel (3), aus den Cerebralganglien (4) entspringend, 5 Pedalganglien, 6 Pleuralganglien, 7 Parietalganglion, 8 Visceralganglion.

\section{C) Scaphopoda.}

Das Nervensystem (Fig. 483, p. 687) ist symmetrisch, die Visceralconnective ungekreuzt. Die beiden Cerebralganglien liegen einander sehr genïhert, vor (resp. bei horizontal gedachtem Darme üb er) dem Schlunde ïber der Schuauze, die beiden dicht aneinander liegenden Pedalganglien finden sich in der Vorderseite des Fusses, ungeführ in der Nitte seiner Länge und sind mit den Cerebralganglien durch zwei lange Cerebropedalconnective verbunden. Die zwei Pleuralgangli en liegen dicht an und über den Cerebralganglien, so dass das Cerebropleurocomnectiv sehr verkürzt ist. Das Pleuropertalconnectiv verschmilzt sofort mit dem Cerebropedalconnectiv, un mit diesem vereinigt das Pedalganglion zu erreichen. Hinten, rechts und links vom Enddarm, in der Nähe des Afters liegen zwei durch eine längere hinter dem Darm verlaufende Commissur verbundene Ganglien der Pleurovisceralcomnective (V is c e r a $l$ ga $n g l i$ e $n$ ). Von den Visceral-oder den Pleuralganglien gesonderte Parietalganglien kommen nicht vor.

Es existiren 4 Buccalganglien, 2 hinter dem Schlunde (bei horizontal gedachtem Schlunde die unteren), und 2 (obere) der Muskelmasse der Radula seitlich und vorn anliegende. Die vorderen sind mit den hinteren und diese mit den Cerebralganglien durch Connective, die 
beiden hinteren und die beiden vorderen mit einander durch hinter (unter) dem Schlund verlaufende Commissuren verbunden. Von den hinteren Buccalganglien verlaufen Nerven zu den kleinen Ganglien eines Subradularorgans.

\section{D) Lamellibranchiata.}

Das Nervensystem der Lamellibranchier (Fig. 506) ist, der Gesammtorganisation entsprechend, vollständig symmetrisch und besteht typisch aus drei Ganglienparen, 1) den Cerebropleuralganglien, 2) den Pedalganglien und 3 ) den Visceroparietalganglien. Diese drei Ganglienpaare sind im Allgemeinen weit voneinander entfernt, also durch lange Connective verbunden. Die beideu Pedalganglien liegen immer dicht aneinander, während die beiden Cerebropleural- und die beiden Visceroparietalganglien durch deutliche, mit Ganglienzellen besetzte Commissuren verbunden sind.

1) Die Cerebropleuralganglien sind aus der Verschmelzung: der Cerebralganglien mit den Pleuralganglien hervorgegangen. Doch sind die Pleuralganglien bei den Protobranchiaten noch gesondert; sie liegen ummittelbar hinter den Cerebralganglien am Anfang der Visceralconnective. Die Pleuropedalconnective verlaufen bei Nucula noch eine Strecke weit gesondert, um sich dann aber mit den Cerebropedalconnectiven zu vereinigen. Bei Solenomyia haben sie zwar noch eine gesonderte Wurzel, sind aber sonst in ihrer ganzen Länge mit den Cerebropedalconnectiven verschmolzen.

Die Cerebropleuralganglien sind supraösophageal und liegen dem vorderen Schaleumuskel an, wenn ein solcher existirt. Sie entsenden Nerven in die Mundlappen, den vorderen Schliessmuskel und den Mantel.

2) Die Pedalganglien liegen an der Basis des Fusses.

3) Hinten unter dem Enddarm, hinter dem Fuss, meist dem hinteren Schalenmuskel anliegend, doch bei den Protobranchiaten viel weiter vorn, liegt das dritte Ganglienpar, welches den Ganglien der Visceralconnective der Gasteroporden entspricht. Sein Innervationsgebiet entspricht demjenigen der vereinigten Parietal- und Visceralganglien der Gasteropoden, denu diese Visceroparietalganglien iunervieren in der That die beiden Ctenidien, die beiden Osphradien, den hinteren Manteltheil, den hinteren Schliessmuskel, die Eingeweide.

Das Buccalnervensystem (Nervensystem des Vorderdarmes) ist sehr reducirt, was mit dem Fehlen eines musculösen Pharynx und irgend einer Mundbewaffnung zusammenhängt. Der vordere Theil des Darmes erhält Nerven von den Visceralconnectiven. Da die Fasern dieser Nerven nachweislich aus den Cerebralganglien stammen, so ist die Annahme erlaubt, dass, bei verschwundenem Pharynx, die Buccalconnective sich mit den Visceralconnectiven vereinigt haben, so dass jetzt die Darmnerven aus diesen Connectiven und nicht direct aus dem Gehirn entspringen. Bei Pholadiden und Terediniden sind die Visceralconnective vor den Visceroparietalganglien durch eine weitere, unter dem Darm verlaufende Commissur verbunden, die vielleicht als eine weit nach hinten verlagerte Buccalcommissur zu deuten ist.

Der Mantel wird, wie schon aus dem Vorstehenden erhellt, einmal von den Cerebropleural- und dann von den Visceroparietalganglien aus innervirt. 
Die beiden aus den Cerebropleuralganglien entspringenden vorderen Mantelnerven verlaufen dem Mantelrand entlang nach hinten, um sich mit den beiden aus den Visceroparietalganglien stammenden hinteren Mantelnerven zu verbinden. Dadurch kommt jederseits ein dem Mantelrand parallel verlaufender Nerv, der Mantelrandnerv, zu Stande, der wie ein Connectiv das Cerebropleuralganglion vorn mit dem Visceroparietalganglion hinten verbindet. Ton diesem Manteliandnerven gehen

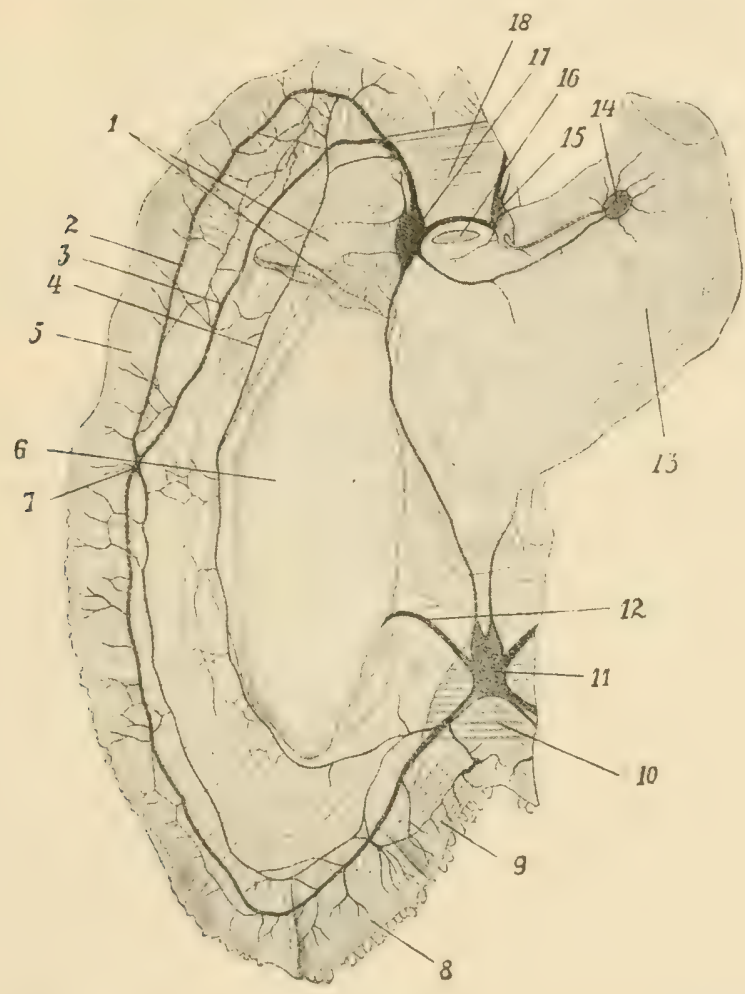

Fig. 506. Nervensystem von Cardium edule, nach Drost. Das Thier von der Bauchseite gesehen, der linke Mantel (in der Figur rechts) abgeschnitten, der rechte zurückgeschlagen, der Fuss auf die Seite gelegt. 1 MLundlappen, 2, 3, 4 Mantelnerven, welche annähernd dem Mantelrand parallel verlaufen, 2 der Mantelrandnerv, 5 Mantel, 6 Kieme, 7 Knotenpunkt der Hauptnerven des Mantels, 8 Mantelrand der Respirations-, 9 der Analöffnung, 10 hinterer Schliessmuskel, 11 Visceroparietalganglion, 12 Kiemennerv, 13 Fuss, 14 Pedalganglion, 15 linkes Cerebropleuralganglion, 16 Mund, 17 rechtes Cerebropleuralganglion, 18 vorderer Schliessmuskel.

Nervenzweige an die Organe des Mantelrandes und an die Siphonen ab, und ausserdem steht er in Verbindung mit einem in der Mantelfalte reich entwickelten Nervenplexus, in welchem sich noch andere, vom Mantelrande weiter entfernte, d. h. mehr dorsalwärts gelegene, aber dem Mantelrand parallel verlaufeude stärkere Verbiudungsstränge accentuiren können. Im pallealen Nervenplexus und im Siphonalnervensystem können noch mehr oder weniger zahlreiche, kleine, periphere Ganglien zur Ausbildung gelangen. 
E) Cep halopoda.

Das symmetrische Nervensystem aller Cephalopoden zeichnet sich durch die sehr starke Concentration der typischen Molluskenganglien, auch derjenigen der Visceralconnective aus.

Zum Verständniss der nachfolgenden Darstellung sei bemerkt, dass wir uns den Pharynx und Oesophagus horizontal verlaufend denken, während diese Organe in Wirklichkeit senkrecht stehen und der Oesophagus in den Eingeweidesack zum Magen emporsteigt. Der Enddarm biegt dann wieder nach unten und hinten um. Wenn wir die Bezeichnungen unten und oben, vorn und hinten für die Ganglien des Centralnervensystems gebrauchen, so denken wir uns dabei eben den Pharynx und den Oesophagus in der für die anderen Mollusken normalen horizontalen, nach hinten gerichteten Lage, setzen aber in Klammern die Bezeichnung der wirklichen Lage im Körper hinzu, z. B. das Cerebralganglion liegt über (vor), das Pedalganglion unter (hinter) dem Schlund, das Brachialganglion vor (unter) dem Infundibularganglion etc.

\section{I. 'Tetrabranchiata (Fig. 507, 508).}

An dem den Schlund hinter der mächtigen Mundmasse umgebenden und hier noch nicht vollständig vom Kopfknorpel umhüllten Gangliencomplex von $\mathrm{N}$ a u tilus sind die Ganglien nicht scharf von den Commissuren und Connectiven gesondert. Die Cerebralganglien (14) sind repräsentirt durch einen breiten, bandförmigen über (vor) dem Schlund verlaufenden Strang, von dem zwei deu Schlund unten (hinten) umfassende gaugliöse Strängre, ein vorderer (unterer) und ein hinterer (oberer), abgehen. Der vordere (3) stellt die Pedal-, der hintere (15) die vereinigten $\mathrm{Pl}$ e ural- und $\mathrm{V}$ isceralganglien dar.

Vom Cerebralstraug entspringen seitlich die starken Augennerven, die sofort zu einem Ganglion opticum anschwellen, ferner zahlreiche Nerven zu den Lippen, die Nerven für die Augententakel, die Hörnerven, die Geruchsnerven und die Cerebrobuccalconnective.

Vom Pedalstrang entspringen die Nerven für die den Mund umstellenden Tentakel und den Trichter. Beim Weibchen gehen die Terven, welche den inneren Ring von Tentakeln versorgen, von einem partiellen Brachialganglion (Fig. 508 a) ab, welches mit dem Pedalring durch ein Brachiopedalconnectiv verbunden ist.

Vom Pleurovisceralstrang gehen zahlreiche Nantelnerven ab (ein Ganglion stellatum fehlt) und ferner zwei starke der Mittellinie genäherte Visceralnerven, welche die Vena cava begleiten, die Kiemen, die Osphradien, die Gefïsse innerviren und oben im Eingeweidesack ein Genitalganglion bilden.

Das sympathische Nervensystem besteht aus einer vom Cerebralganglion ausgehenden, den Schlund in der Musculatur der Mundmasse infräisophageal umgreifenden Commissur, in deren Verlauf jederseits 2 Ganglien, ein Pharyngeal- und ein Buccalganglion, eingeschaltet sind.

\section{Dibranchia ta (Fig. 509, 510).}

Die circumösophageale Ganglienmasse, die das gesammte Centralnervensystem enthält, ist ganz vom liopfknorpel umschlossen. Die voluminösen, typischen Ganglien sind so stark zusammengedrängt, dass sie äusserlich nur undentlich voneinander abzugrenzen sind, und dass man 
die Connective und Commissuren äusserlich nicht sieht. Der ganze Complex besitzt eine ununterbrochene Rindenschicht von Ganglienzellen.

Charakteristisch für die Dibranchiata ist die mehr oder weniger (leutliche Sonderung der Pedalganglien in zwei Paare, ein vorderes (oder unteres) und ein hinteres (oder oberes). Das erstere ist das B racli i l 1ganglion und innervirt die als Fusstheile zu betrachtenden Arme,

Fig. 507 .

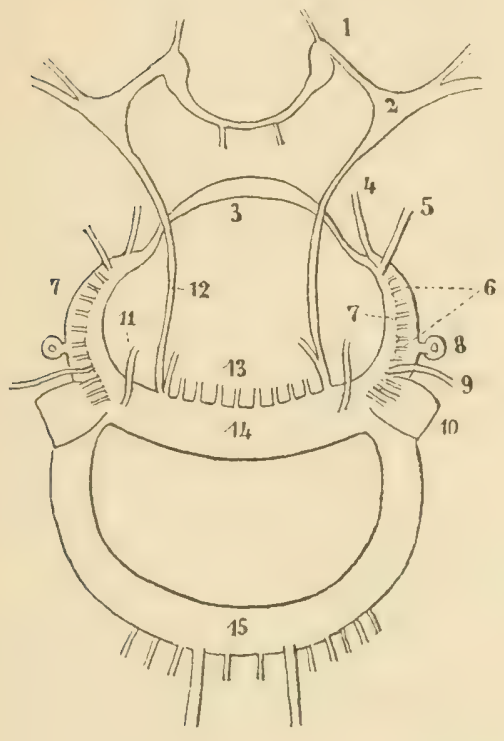

Fig. 508

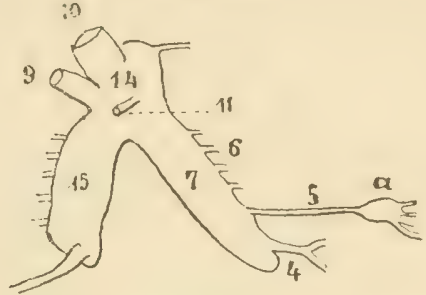

Fig. 507. Nervensystem von Nautilus, nach Jhering. 1 Buccalganglien, 2 Pharyngealganglien, 3 Pedalcommissur, 4 Trichternerv, 5 beim Weibchen Nerv für die Tentakel des hinteren und inneren Lappens; dieser Nerv schwillt bald $\mathrm{zu}$ einem Ganglion an (vergl. Fig. 508), 6 übrige T'entakelnerven, 7 Pedalstrang (=Pedalganglien), 8 Gehörorgan, 9 Riech. nerv, 10 Opticus, 11 Augententakelnerv, 12 Connectiv zu dem Pharyngealganglion, 13 Lippenuerven, 14 Cerebralstrang ( $=$ Cerebralganglien), 15 Pleurovisceralstrang.

Fig. 508. Nervensystem von Nautilus, von der rechten Seite. Bedeutung der Zahlen wie in voriger Figur, $a$ Ganglion für die Tentakel des hinteren und inneren Lappens beim Weibchen.

das letztere ist das Trichtergangliou und innervirt den als Epipodium zu deutenden Trichter. Diese Sonderung des Pedalganglions in ein Brachial- und in ein Trichterganglion ist auf die starke Entwickelung der den Kopf umwachsenden Fusstheile, d. h. der Arme zurïckzuführen, ähulich wie z. B. auch bei Natica, wo der vordere Fusstheil stark entwickelt ist und sich auf den Kopf zurückschlägt, sich von dem Pedalganglion ein Propedalganglion sondert. Bei den Dibranchiaten nun setzen sich die Brachialganglien mit den Cerebralganglien durch Cerebrobrachialconnective in Verbindung. Bei Eledone und Octopus stehen sie ausserdem noch durch eine dünne supraösophageale Commissur in Verbindung.

Die Pleuralganglien liegen seitlich in der circumösophagealen (imnglienmasse, während die Ganglien der Visceralconnective, d. h. die Parietal- und Visceralganglien, durch die grösstmögliche Verkiirzung dieser Connective dicht aneinandergeriickt, den hinteren (oberen) 'Theil der subösophagealen Ganglienmasse bilden.

Folgendes sind die Co nne $\mathrm{c}$ ive, die man auf Schnitten durch die circumösophageale Ganglienmasse nachweisen kann:

1) Zwei Cerebrobrachialconnective; 2) zwei Cerebroinfundibularconnective; 3) zwei Cerebropleuralconnective; 4) zwei Brachioinfundibular- 


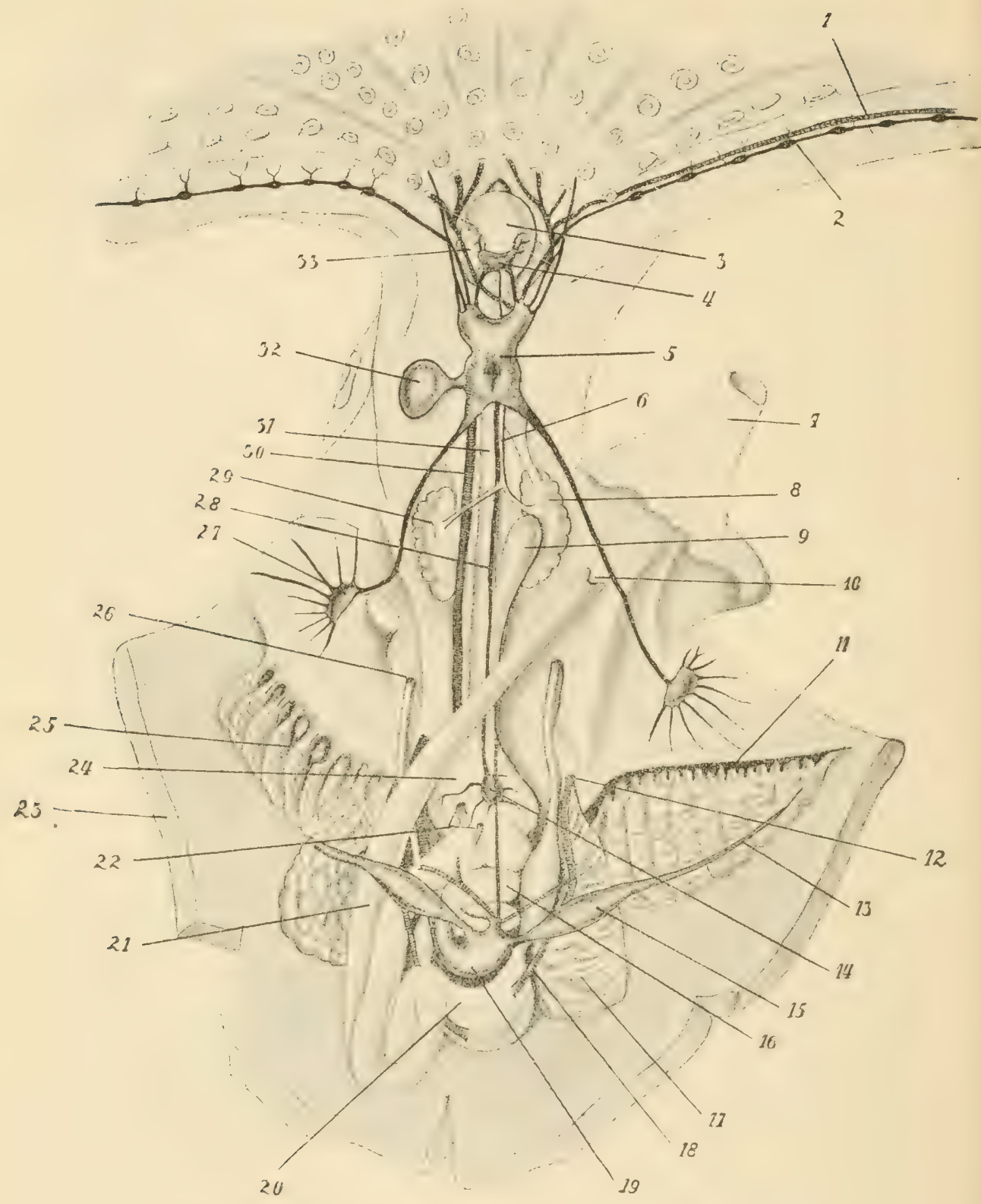

Fig. 509. Anatomie von 0ctopus, nach LEUChART und MiLNE EDTrards. Körper von hinten aufgeschnitten, Mantel nach rechts und links zurückgeklappt, Leber entfernt. 1 Armarterie, 2 Armnerv, 3 Pharyns, 4 Buccalganglion, 5 Cerebralganglion, 6 Ausführungsgang der oberen Speicheldrüsen, 7 Trichter, 8 obere Speicheldrüsen, 9 Kropf, 10 After, 11 zuführendes Kiemengefäss (Kiemenarterie), 12 Oeffoung der linken Niere, 13 abführendes Kiemengefäss (Kiemenvene), 14 Ganglion gastricum, 15 linker Vorhof des Herzens, 16 Spiralcoecum des Magens, 17 Nierensack, 18 Wasserkanal, 19 Herzkammer, 20 Ovarium, 21 Enddarm, 22 Ausführungsgänge der Verdauungsdrüse (Leber), nahe der Einmündung in den Darm abgeschnitten, 23 Mantel, 24 Magen, 25 rechtes Ctenidium, 26 Oeffnung des rechten Eileiters, 27 Ganglion stellare, 28 Nerv zum Ganglion gastricum, 29 obere Speicheldrüsen, 30 Aorta, 31 Oesophagus, 32 Ganglion opticum, 33 untere Speicheldruisen. 
connective ; 5) zwei Pleuroinfundibularconnective ; 6) zwei Pleurobrachialconnective. Die Visceralconnective sind durch dichte Anlagerung der Visceralganglien als solche unkenntlich geworden.

Nerven der Cerebralganglien sind die beiden Augennerven, die bald an der Basis der Augen zu den riesigen Ganglia optica anschwellen, die Gehörnerven, die Geruchsnerven (eine Strecke weit mit den Sehnerven verschmolzen) und die Connective der Buccalganglien.

Von den Brachialganglien gehen die gesonderten Nerven der Arme ab, welche an der Basis der Armkrone durch einen Commissurenring reifenförmig miteinander verbunden sind. In den Armen verlaufend, schwellen die Armnerven, den Querreihen der Saugnäpfe entsprechend, zu aufeinander folgenden Ganglien an.

Die Trennung des Pedalganglions in ein Brachial- und ein Infundibularganglion lässt sich ontogenetisch und vergleichend-anatomisch nachweisen. Beim Männchen von Nautilus existirt keine solche Trennung, sondern Arm- und Trichternerven entspringen aus einem und demselben Ganglion. Bei Argonauta (Fig. 510 F) ist die Trennung äusserlich noch nicht sichtbar, sie wird in den ersten Spuren äusserlich unterscheidbar bei Octopus (E), progressiv deutlicher bei Sepia (D), Loligo (C) und Sepiola (B), bis schliesslich bei Ommatostrephes (A) das deutlich gesonderte Brachialganglion, vom Infundibularganglion abgerückt, mit diesem durch ein auch äusserlich deutlich kenntliches, schlankes Connectiv verbunden ist.

Fig. 510. Centralnervensystem verschiedener Dibranchiaten, von der rechten Seite. Sämmtliche Figuren nach PELSEnevr. A 0mmatostrephes. $\boldsymbol{B}$ Sepiola. $\boldsymbol{C}$ Loligo. $\boldsymbol{D}$ Sepia. $\boldsymbol{E}$ Octopus. $\boldsymbol{F}$ Argonauta 1 Cerebralganglion, 2 Pedalganglion, 5 Visceralganglion, $4 \mathrm{Bra-}$ chialganglion, 5 oberes Buccalganglion, 6 Trichternerv, $7 \mathrm{Vi}$ sceralnerv, 8 durchschnittener Opticus, 9 Mantelnerv, 10 Armnerven. In Fig. $\boldsymbol{B}$ ist der Pharynx $p h$ und Oesophagus oe schwarz eingetragen.
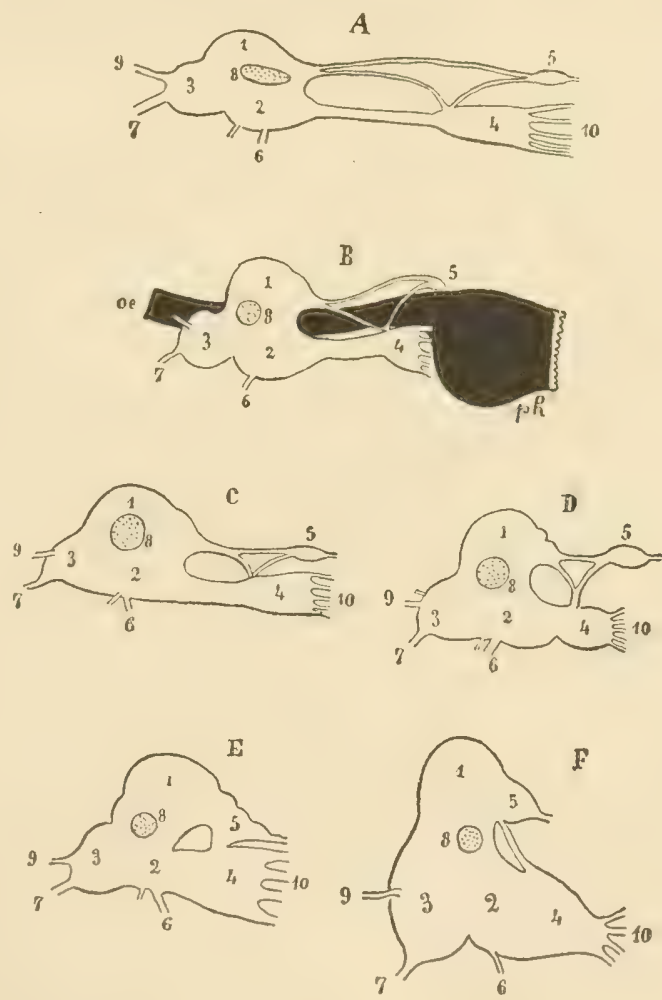

In derselben Reihenfolge, in welcher die Sonderung des Brachialganglions erfolgt, geschieht auch die Sonderung des sogenannten oberen Buccalganglions vom Cerebralganglion, wobei das Buccalganglion mit dem Brachialganglion durch das Brachiobuccalconnectiv in Verbindung bleibt.

Aus den $\mathrm{Parietalg}$ a $\mathrm{g}$ lie $\mathrm{n}$ entspringen die zwei grossen Mantelnerven. Jeder Mantelnerv zieht nach hinten und oben und tritt an der 
Innenfläche des Mantels in ein Ganglion, das Ganglion stellatum, von welchem zahlreiche Nerven in den Mantel ausstrahlen, von denen einer, dorsalwärts verlaufend, als die directe Fortsetzung des Mantelnerven über das Ganglion stellatum hinaus imponirt. Oft theilt sich der Mantelnerv früher oder später nach seinem Austritt aus dem Parietalganglion in zwei Aeste, von denen der eine zum Ganglion stellatum und über dasselbe hinaus zieht, um sich jenseits des Ganglions mit dem anderen zu verbinden, der am Ganglion vorbeigeht. Die beiden Ganglia stellata sind häufig durch eine Quercommissur verbunden. Aus den Visceralgan glien entspringen, der Mittellinie genähert, die zwei Visceralnerven, welche Enddarm, Tintenbeutel, Kiemen, Herzen, Geschlechtsapparat, Niere und Theile des Gefässsystems innerviren. Die beiden Genitalzweige der Visceralnerven stehen mitcinander durch eine Commissur in Verbindung.

Das sympathische Nervensystem besteht aus dem unter (hinter) dem Schlunde an der Mundmasse liegenden Buccalganglion, welches mit dem oberen Buccalganglion (Pharyngealganglion) durch ein Buccalconnectiv verbunden ist. Z Zwei am Schlunde nach oben verlaufende Nerven ziehen vom unteren Buccalganglion zu dem auf dem Magen gelegenen Ganglion gastricum, welches den grössten Theil des Darmes und die Verdauungsdrüse (Leber) innervirt.

\section{Versuch einer Erkliirung der Asymmetrie der Gasteropoden.}

1.

Die Chiastoneurie, d. h. die Kreuzung der beiden Pleurovisceralconnective der Prosobranchier lässt sich unter folgenden drei Voraussetzungen erklären:

1) Die Vorfahren der Prosobranchier waren symmetrische Thiere; ihre Mantelhöhle lag hinten am Eingeweidesack, somit natürlich auch der palleale Organcomplex, d. h. der Complex der in der Mantelhöhle liegenden Organe: Ctenidien (Kiemen), Osphradien (Geruchsorgane), Nephridialöffnungen, Genitalöffnungen und - im Centrum des Complexes in der Medianlinie - der After. Darm.

2) Die Visceralcommissur oder das Visceralganglion lag unter dem

3) Der Pallealcomplex wanderte allmählich von hinten nach vorn, und zwar der rechten Körperseite entlang (vergl. p. 711).

Als erklärt kann auch gelten die rechtsseitige Lage des Pallealcomplexes bei den Tectibranchiaten unter den Opisthobranchiaten. Bei diesen hat entweder der Pallealcomplex bei seiner Verschiebung nach vorn die vorderständige Lage noch nicht erreicht oder er ist von vorn wieder zurückverschoben. Die Visceralconnective sind in Folge dessen nicht gekreuzt.

Nicht erklärt bleibt:

1) diejenige Asymmetrie der Gasteropoden, die durch das Verschwinden des einen Ctenidiums, des einen Osphradiums, der einen Nierenöffnung bedingt wird;

2) die Aufrollung des Eingeweidesackes und der Schale, speciell die Aufrollung in einer rechts- oder linksgewundenen Spirale;

3) die Beziehungen zwischen der Art der Aufrollung des Eingeweidesackes und der Schale einerseits und der speciellen Asymmetrie 
der asymmetrischen Organe (Ctenidien, Osphradien, Nephridien, After, Genitalorgane) andererseits.

4) Die Ursache der Wanderung des Pallealcomplexes nach vorn bleibt unermittelt.

2.

Wir wollen zunächst die drei Voraussetzungen, unter denen der erwähnte Erklärungsversuch zutrifft, beleuchten.

Erste Voraussetzung. Dass die Vorfahren der Gasteropoden symmetrische Thiere waren, darüber wird wohl eine Discussion unnöthig sein. Alle Mollusken, mit Ausnahme eben der Gasteropoden, sind symmetrische Thiere: die Amphineuren, die Lamellibranchier, die Scaphopoden und die Cephalopoden.

Die Annahme, dass der Pallealcomplex hinten lag, ist ebenfalls wohl begründet. Bei allen symmetrischen Mollusken liegt der After als Centrum des Pallealcomplexes hinten in der Mittellinie. Bei allen symmetrischen Mollusken liegen die Nephridial- und Genitalöffnungen hinten, symmetrisch zu beiden Seiten des Afters. Wo bei den symmetrischen Mollusken die Ctenidien und Osphradien sich erhalten haben, liegen sie symmetrisch auf der Hinterseite des Eingeweidesackes. So bei den Cephalopoden, so bei denjenigen Lamellibranchiern, die als die ursprünglichsten gelten müssen, nämlich bei den Protobranchiata (Nucula, Leda, Solenomya), so selbst bei einigen Chitoniden und denjenigen Solenogastres, die noch Kiemenrudimente besitzen.

Entsprechend der hinterständigen Lage des Pallealcomplexes ist bei den symmetrischen Mollusken die Mantelfalte, welche die Basis des Eingeweidesackes rings umsäumt, hinten, wo sie den Pallealcomplex bedecken muss, am breitesten, $d . h$. hier vertieft sich die Mantelfurche zur eigentlichen Mantelhöhle.

Bezüglich der zweiten oben angeführten Voraussetzung besteht nach wie vor die unbeseitigte Schwierigkeit, dass bei den Amphineuren die Commissur zwischen den Pleurovisceralsträngen über dem Enddarm hinwegzieht. Dagegen ist hervorzuheben, dass bei allen anderen symmetrischen Mollusken das Visceralganglion, wie bei den Gasteropoden, unter dem Darm liegt.

Die dritte Voraussetzung wollen wir in einem besonderen Paragraphen erörtern.

3.

Ursache der Verschiebung des Pallealcomplexes von hinten nach vorn: Wenn sich der Pallealcomplex in der rechtsseitigen Mantelfurche von hinten nach vorn verschoben hat, so hat die Chiastoneurie zu Stande kommen müssen; die ursprünglich linke Hälfte des Complexes hat zur jetzigen rechten - und umgekehrt - werden müssen. Das rechte Pleurovisceralconnectiv hat zum Supraintestinalconnectiv, das linke zum Subintestinalconnectiv, das ursprünglich rechte Parietalganglion zum Supraintestinalganglion, das ursprünglich linke zum Subintestinalganglion werden müssen. W a rum aber hat die Verschiebung des Pallealcomplexes stattgefunden? Wir wollen versuchen, die Frage in befriedigender Weise zu lösen.

Wir haben uns die symmetrische Stammform der Gasteropoden (mit hinterstandigrer Mantelhöhle nud in dieser liegendem symmetrischen Pallealcomplex) als ein dorsoventral abgeplattetes Thier mit breiter Kriechsoble 
des Fusses, schnauzenförmigem Kopf mit Tentakeln und Augen und ziemlich flacher, napfförmiger, die Rückenseite des Körpers bedeckender Schale vorgestellt. Das äussere Aussehen glich also einer Fissurella oder einer Patella oder einem Chiton, wenn man sich bei letzterem die gegliederte Schale durch eine einheitliche ersetzt denkt. Der Körper dieser Stammform war also nur vom Rücken her durch die Schale geschützt. Den Schutz der Unterseite besorgte die harte Unterlage, auf der die Thiere langsam kriechend sich bewegten und welcher sie ihre Rückenschale durch die Contraction eines kräftigen, auf dem horizontalen Querschnitt hufeisenförmigen Schalenmuskels fest andrücken konnten. Bei fost angedrückter Schale vermittelte ein vom hinteren Mantel- und Schalenrand ausgehender Mantel- und Schalenschlitz die Communication der Mantelhöhle mit der Aussenwelt (Aus- und Einströmen des Athemwassers, Entleerung der Excrete, Excremente, Geschlechtsproducte).

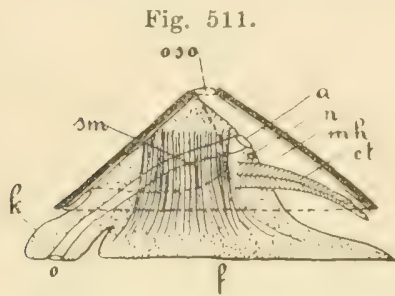

Fig. 511. Hypothetischer Urgasteropod, von der Seite. o Mund, $k$ Kopf, sm Schalenmuskel, oso obere Schalenöffnung, a Anus, $n$ Nierenöffinung, $m h$ Mantelhöhle, ct Ctenidium, $f$ Fuss.

Fig. 512. Hypothetischer Urgasteropod, von oben. o Mund, ulc, ulpl, ulp ursprünglich linkes Cerebral-, Pleural- und Pedalganglion, ulpa, urpa ursprünglich linkes und ursprünglich rechtes Parietalganglion, ula ursprünglich linker Vorhof des Herzens, uos, uros ursprüng. lich linkes und ursprünglich rechtes Osphradium (SPENGeL's Organ), ulct, urct ursprünglich linkes und rechtes Ctenidium (Kieme), $m b$ Mantelbasis, $m r$ Mantelrand, $m$ Mantelhöhle, $v$ Visceralganglion, ve Herzkammer, $\boldsymbol{a}$ Anus.

Im Gegensatz zu dieser Stammform zeichnen sich alle bekannten Gasteropoden (wenn man von solchen absieht, deren Körpergestalt, wohl meistens in Zusammenhang mit der Rudimentation der Schale, sich nachweislich secundär abgeändert hat) dadurch aus, dass das die Eingeweide bedeckende Rückenintegument hoch bruchsackartig als Eingeweidesack ausgestülpt und dementsprechend die in ihrer Gestalt mit dem Eingeweidesack übereinstimmende Schale hoch thurmförmig ist. Jede abgewickelte Schneckenschale ist in der That hoch thurmförmig.

Wir haben als Grund der Entwickelung einer solchen Schale und des von ihr beherbergten Eingeweidesackes den vermehrten Schutz des Körpers bei entwickelterem Kriechvermögen erkannt. Der ganze Weichkörper kann jetzt in der Schale geborgen, in sie zurückgezogen werden, und zur Vermehrung des Schutzes bildet sich häufig noch zum Verschluss der Schalenöffnung bei zurückgezogenem Thier der Deckel am Fusse aus. Der Schalenmuskel der Stammform dient jetzt nicht mehr dazu, die Schale an die Unterlage anzupressen, sondern 
dazu, Kopf und Fuss in die Schale zurückzuziehen. Er wird zum Sp in delmuskel (Fig. 513 sm).

Zum Zwecke vermehrter Schärfe bei der nun folgenden Beweisführung wollen wir die für die Gasteropodenschale in Betracht kommenden Momente gesondert behandeln.

Das erste und wichtigste ist die dorsalwärts gerichtete, hoch thurmförmige Verlängerung der Schale. Dadurch wird aus der Napfschale der Stammform eine hoch kegelförmige, ähnlich derjenigen von Dentalinm.

Würde nun eine solche Schale von der Schnecke senkrecht getragen (Fig. 513), so würde sie sich beim ruhenden Thiere im labilen Gleichgewicht befinden, das bei der Bewegung und bei den geringsten äusseren Druckeinwirkungen gestört würde. Ausserdem wäre die Lage einer senkrecht getragenen, hoch thurmförmigen Schale bei der Fortbewegung aus unmittelbar einleuchtenden Gründen so ungeschickt und unbehülflich wie möglich.

Nehmen wir nun an, die Schale wird gen eigt getragen, und discutiren wir die verschiedenen Möglichkeiten:

1) Die Schale wird nach vorn geneigt getragen (Fig. 514). Diese Lage ist die denkbar ungünstigste für die Locomotion, für die Function des Mundes und für die der Sinnesorgane am Kopfe.

Iig. 513

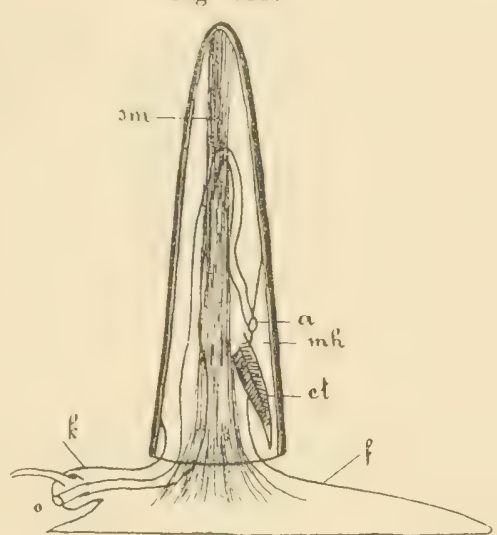

Diese Lage ist die denkbar günstigste für die Function der Organe des hinten, jetzt oben liegenden Pallealcomplexes. Denn diese Stelle ist diejenige des geringsten Druckes der Eingeweide und speciell des Spindelmuskels auf die Mantelhöhle. Der jetzt nach unten erfolgende Druck der Eingeweidemasse wäre im Gegentheil der Erweiterung der Mantelhöhle günstig.

Fig. 514

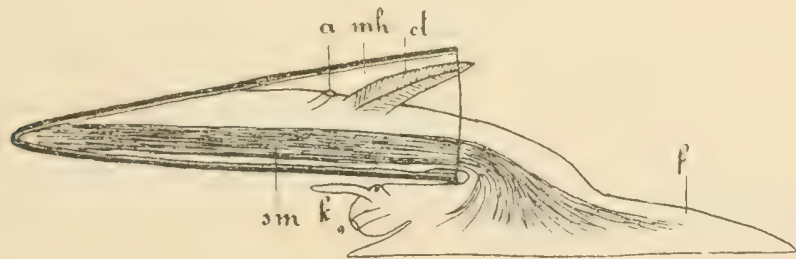

2) Die Schale wird nach hinten geneigt getragen (Fig. 515). Diese Lage ist die denkbar günstigste für die Locomotion und die Function der Organe des allseitig frei gewordenen Kopfes.

Sie ist die denkbar ungünstigste für die Function der Organe des hinten, jetzt aber unter dem Eingeweidesack liegenden Pallealcomplexes. Die Mantelhöhle hat den ganzen Druck der Eingeweidemasse mul hosonders des Spindelmuskels auszuhalten; sir wird zusammengedriekt, die Circulation des Athemwassers in der Mantelhöhle wird gehindert oder 
doch erschwert, ebenso die Entleerung der Excrete, Excremente und Geschlechtsproducte.

3) Es bleibt die Möglichkeit, dass die Schale nach der rechten oder linken Seite geneigt getragen wird (Fig. 516). Dies ist sowohl für den Kopf und die Locomotion, wie für den Pallealcomplex weder die günstigste noch die ungünstigste Lage. Es ist eine denkbare Mittellage.

Fig. 515 .

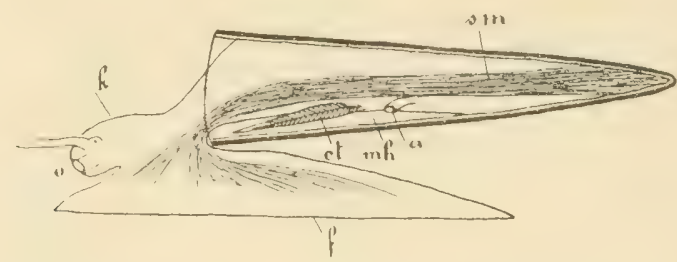

Bei Einnahme dieser Lage der Schale und des Eingeweidesackes ist zugleich ein todter Punkt überwunden. Es werden jetzt Verschiebungen möglich, durch welche die Schale die beste Lage für die Bewegung und für die Functionen der Kopforgane einnehmen und die Mantelhöhle die beste Lage für die Ausübung der Functionen des in ihr liegenden Pallealcomplexes gewinnen kann.

Nehmen wir an, die Schale wird nach der linken Seite geneigt getragen (Fig. 517), so ist der Druck, der auf der hinten liegenden Mantelhöhle lastet, in den verschiedenen Bezirken der Mantelhöhle ein un-

Fig. 516 .

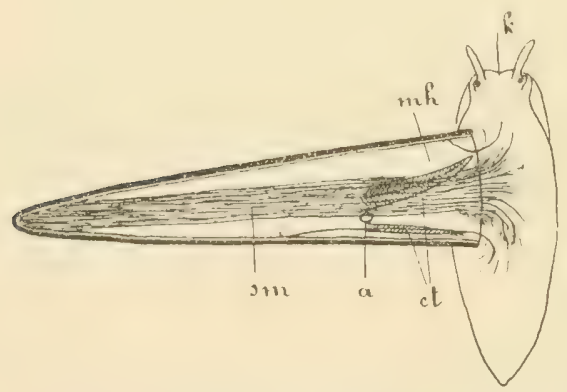
gleicher. Er ist am grössten an der linken Seite der Mantelhöhle und wird fortschreitend kleiner bis zur rechten Seite. Es wird auf die Mantelhöhle von links vorn ein Druck ausgeübt, welcher den Pallealcomplex nach rechts - sit venia verbo - herausquetscht. Dabei ist noch besonders zu betonen, dass jetzt die Stelle des geringsten Druckes, ja die Stelle des grössten Zuges nach unten, auf der rechten, jetzt oberen Seite

des Eingeweidesackes liegt. Hier wird es der Mantelfurche am leichtesten, sich zu vertiefen, geräumiger zu werden. Tritt dies ein, so bekommen jetzt die von links her verdrängten Organe des Pallealcomplexes Platz, um nach rechts und vorn auszuweichen. Dieses ist aber der erste Anfang einer Verschiebung des Pallealcomplexes in der rechtsseitigen Mantelfurche nach vorn. Bei der geringsten Verschiebung auf der rechten Seite nach vorn kann aber die Schale und der Eingeweidesack wieder um ein Weniges von der seitwärts nach links geneigten Lage in die nach hinten geneigte Lage übergehen, welche wir als die denkbar günstigste für die Locomotion und die Function der Kopforgane erkannt haben.

Lassen wir diesen Vorgang sich allmählich vollenden, so nimmt schliesslich die Schale und der Eingeweidesack in der That die denkbar günstigste, nach hinten gerichtete Lage ein und ebenso der allmählich 
in der rechten Mantelfurche nach vorn gerückte Pallealcomplex. Dieser letztere liegt also jetzt vorn an der Oberseite des nach hinten geneigten Eingeweidesackes, also an der Stelle des geringsten Druckes nach oben oder besser des grössten Zuges nach unten, an der Stelle, wo sich die Mantelfurche am leichtesten zur Mantelhöhle vertiefen und erweitern kamn, wo die Pallealorgane am leichtesten und ungehindertsten ihren Functionen obliegen können.

Fig. 517. Schematische Darstellung der Druckverhältnisse des Eingeweidesackes für den Fall, dass derselbe mit der Schale nach links geneigt getragen würde. Die Dicke der concentrisch verlaufenden Kreislinien solle die Stärke des Druckes andeuten. $a$ Stelle des grössten Druckes, $b$ Stelle des geringsten Druckes. Die Pfeile geben die Richtung der eintretenden Verschiebungen an. Man sieht, dass die linke Seite des Pallealcomplexes einem stärkeren Druck ausgesetzt wäre, als die rechte.

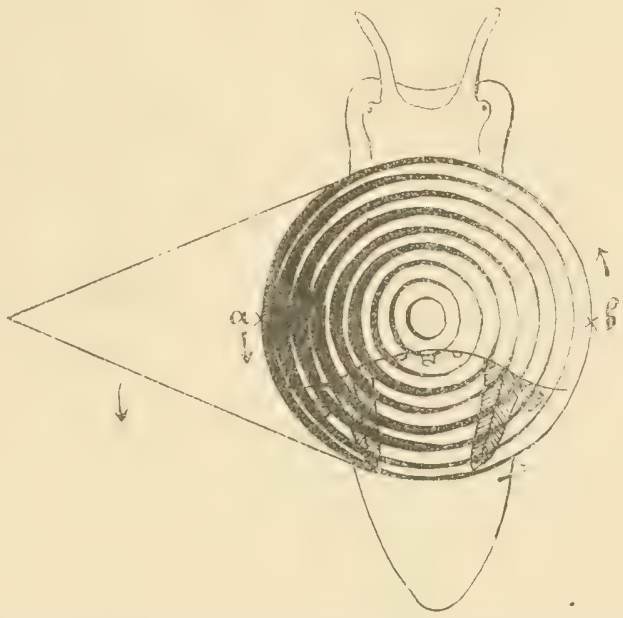

Die charakteristische Lage der Schale und des Pallealcomplexes der Gasteropoden ist jetzt erreicht. Zugleich hat sich die Chiastoneurie und die inverse Lage der Organe des Pallealcomplexes ausgebildet.

\section{4.}

Bildung eines in einer Ebene gekrümmten Eingeweidesackes und einer entsprechenden Schale. Dieses ist das zweite, zum Zwecke der Schärfe der Beweisführung gesondert zu betrachtende Moment.

Nimmt der Gasteropodeneingeweidesack die allein geeignete geneigte Lage ein, so wird sich, sollen nicht Knickungen und Zerrungen eintreten, seine Kegelgestalt verändern. Die nunmehrige Oberseite wird gewölbt werden, die Unterseite eingekrümmt. Diese Gestalt kommt durch stärkeres Wachsthum des Integumentes des Eingeweidesackes und des Mantels an der Seite zu Stande, welche bei der schief geneigten Lage des Eingeweidesackes der stärksten Streckung oder Zerrung ausgesetzt ist. Der Eingeweidesack wird in einer Ebene gekrümmt. Dieser Krümmung folgt natürlich auch die Schale, die den Contouren des wachsenden Eingeweidesackes folgt. Sie könnte auch aus dem Grunde nicht kegelförmig bleiben, weil ein grosser Theil des Rückenintegumentes (Basis des Eingeweidesackes) entblösst und bei der Grössenzunahme der von der Schale unbedeckten Körpertheile der Fall eintreten würde, dass diese Körpertheile nicht mehr vollständig in die Schale zurückgezogen werden könnten.

\section{5.}

Wachsthum der Gasteropodenschale. Bevor wir zur Discussion des dritten Momentes übergehen, müssen wir das Wachsthum der Gasteropodenschale betrachten. Dieses Wachsthum ist, von geo- 
metrischen Gesichtspunkten aus betrachtet, ein dreifaches, nämlich ein Höhenwachsthum, ein peripheres Wachsthum und ein radiäres oder Dickenwachsthum der Schalenwand. Das letztere fällt für uns ausser Betracht.

Das Höhenwachsthum der der Einfachheit halber kegelförmig gedachten Schale geschieht in der Richtung von der Basis (Mündung der Schale) nach der Spitze. Dieses Wachsthum erfolgt durch fortschreitende Ablagerung neuer Zuwachsstreifen an der Basis (am Mündungsrand) von Seiten des fortwachsenden Mantelrandes.

Das periphere Wachsthum bedingt die Vergrösserung der Peripherie der Basis, mit anderen Worten, die Vergrösserung der Mündung der Schale.

Ist die Intensität des Höhenwachsthums an allen Stellen der Peripherie der Basis des Hohlkegels gleich gross und gilt dasselbe für das periphere Wachsthum, so vergrössert sich der Hohlkegel, ohne seine Gestalt zu verändern.

Ist aber die Intensität des Höhenwachsthums an der Peripherie der Kegelbasis eine ungleiche, nimmt sie von einem Punkte der Peripherie der kreisrund gedachten Basis, als dem Minimalpunkte, bis zu dem diametral gegenüberliegenden Punkte der kreisrunden Peripherie der Kegelbasis als dem Maximalpunkte jederseits symmetrisch zu - wobei aber die Intensität des peripheren Wachsthums an der ganzen Peripherie dieselbe bleibt, d. h. wobei die Kegelbasis ihre kreisrunde Gestalt beibehält - so entsteht ein spiralig a ufgerollter Hohlkegel.

Liegen bei dieser Art des Wachsthums die Maximal- und Minimalpunkte bei fortschreitendem Wachsthum immer in einer und derselben Ebene, so entsteht eine in dieser Ebene, als der Symmetrieebene, aufgerollte s y mmetrische Schale.

Verschiebt sich aber bei fortschreitendem Wachsthum der Maximalpunkt des Höhenwachsthums aus der unmittelbar vorher bestehenden Symmetrieebene heraus, z. B. nach links (wobei der Minimalpunkt sich nach der entgegengesetzten Richtung nach rechts verschiebt), so bilden die Maximalpunkte (und natürlich auch die Minimalpunkte) an der spiralig aufgerollten Schale nicht eine gerade, sondern eine spiralig gebogene Linie, und die Kegelschale wird dann nicht in einer Ebene symmetrisch, sondern in einer Schraubenfläche asymmetrisch aufgerollt. In dem supponirten Falle würde nach der Terminologie der Conchyliologen eine rechts gew undene Schale entstehen.

Thatsächlich erfolgt das Wachsthum der Gasteropodenschale in dieser letzteren Weise.

\section{6.}

Das dritte Moment, das wir gesondert betrachten wollen, ist eben die Aufrollung der Gasteropodenschale in einer rechtsoder linksgewundenen Schraubenfläche. Nimmt der in einer Ebene gedrehte Eingeweidesack und die Schale bei fortschreitendem Wachsthum von der nach links g e neigten Lage fortschreitend eine nach hinten geneigte Lage ein, so ist das identisch mit einer fortschreitenden Verrückung des Maximalpunktes des Höhenwachsthums nach links und des Minimalpunktes nach rechts. Die nothwendige Folge davon ist die in einer rechtsgewundenen Schraubenfläche aufgerollte Gasteropodenschale. 
Dabei ist in Erinnerung zu bringen:

1) dass das periphere Wachsthum constant gleich bleibt, d. h. dass bei gleich bleibendem Contour des wachsenden Mantelrandes auch die sich vergrössernde Schalenmündung die gleiche Form beibehält;

2) dass die Vergrösserung der Schale vom Mantelrande aus geschieht durch Bildung von Zuwachsstreifen, wobei die schon gebildete Schale als starres Gebilde ihre Form nicht mehr verändert;

3) dass sich der fortwachsende (Schalensubstanz absondernde) Mantelrand beim Wachsthum und beim allmählichen Uebergang von der nach links zu der nach hinten geneigten Lage der Schale selbst nicht dreht, sondern seine Lage mit Bezug a uf den übrigen Körper beibehält, dass also nur die Maxima und Minima der Intensität des Höhenwachsthums sich am Mantelrand beim Wachsthum des Eingeweidesackes fortschreitend verschieben.

4) Nota bene, der stricte Beweis für die Entstehung einer rechtsgewundenen Schale ist bis jetzt nur für diejenige Zeit des ontogenetischen oder phylogenetischen Wachsthums der Schale geliefert, während welcher die Verlagerung der Schale nach hinten und die des Pallealcomplexes nach vorn erfolgt. Sind die für die Oekonomie des Thieres denkbar günstigsten Endstadien dieser Verlagerung, die vorderstündige Lage der Mantelhöhle und die nach hinten gerichtete der Schale, erreicht, so tritt eine weitere Verlagerung; welche einer fortschreitenden Verschlechterung der Verhältnisse gleichkäme, nicht mehr ein. Es ist dann aber nicht ohne weiteres ersichtlich, weshalb bei aufhörender Ursache die Wirkung noch fortdauert, d. h. weshalb von dem gegebenen Zeitpunkte an der Eingeweidesack und die Schale fortfahren, in einer rechtsgewundenen Spirale und nicht symmetrisch zu wachsen. Die Erklärung dieser Punkte weiter unten.

\section{7.}

Wir haben bis jetzt im Interesse einer schärferen Beweisführung drei wichtige, bei der Bildung des Eingeweidesackes und der Schale der Gasteropoden in Betracht kommende Momente gesondert betrachtet: 1) die Bildung einer hoch thurmförmigen Schale von kegelförmiger Gestalt; 2) die spiralige Aufrollung des Eingeweidesackes und der Schale, und 3) die specielle Art der Aufrollung in einer rechtsgewundenen Schraubenfläche. In Wirklichkeit kamen alle drei Nomente gleichzeitig zur Geltung, d. h. mit der fortschreitenden Hervorwölbung des Eingeweidebruchsackes ging Hand in Hand die Aufrollung in einer rechtsgewundenen Schraubenfläche als Folge der Drehung des sich nach links neigenden Eingeweidesackes in die nach hinten geneigte günstigste Lage, wobei der Pallealcomplex rechts nach vorn verschoben wurde.

\section{8.}

Auch die ontogenetischen Forschungsresultate lassen sich für die hier vorgetragene Theorie verwerthen. Vor allem ist die Thatsache hervorzuheben, dass der After (das Centrum des Pallealcomplexes) und die Mantelfalte anfänglich hinten liegen. Sie kommen ontogenetisch nach vorn zu liegen, nicht durch eine active Wanderung, sondern dadurch, dass die rechtsseitige Strecke zwischen Mund und After im Wachsthum zurückbleibt, während die linksseitige allein weiterwächst. Es liegt aber nicht die geringste Schwierigkeit vor, diese Art der ontogenetischen Erreichumg des Endzieles mit der Art der phylogenetischen in Einklang zu bringen. 
9.

Wir haben in unseren bisherigen Ausführungen die mechanischgeometrische Betrachtungsweise in den Vordergrund gestellt. Sie declit sich und muss sich decken mit der utilitarischen Betrachtungsweise. Jede Veränderung in der skizzirten Richtung bedeutete eine Verbesserung in der Organisation, einen Vortheil, und hatte Chancen, sich im Kampf ums Dasein zu erhalten. Die Ausbildung einer hoch thurmförmigen Schale, die wir als den Ausgangspunkt der Entwickelung der Asymmetrie der kriechenden Gasteropoden erkannt haben, ermöglicht allein einen ergiebigen Schutz des gesammten Körpers und muss unter den bestimmten Verhält-
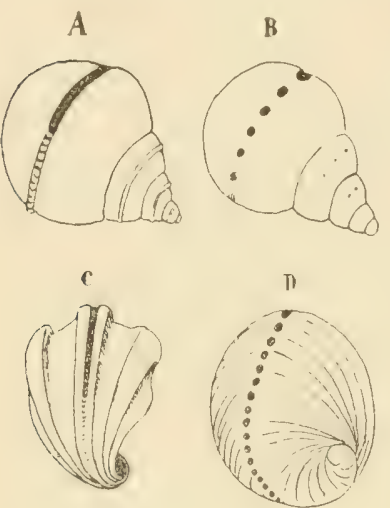

B

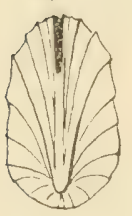

$\mathrm{F}$

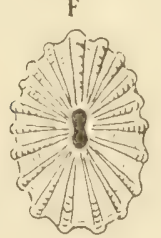

c.

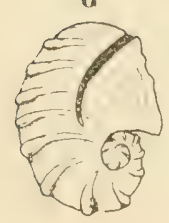

H
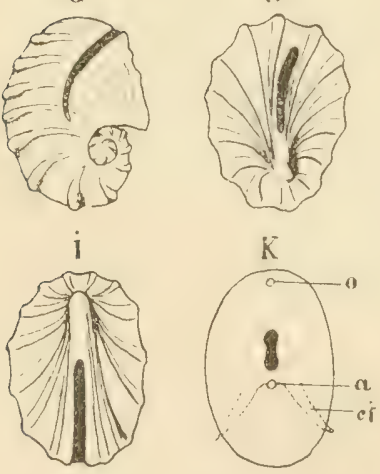

l.

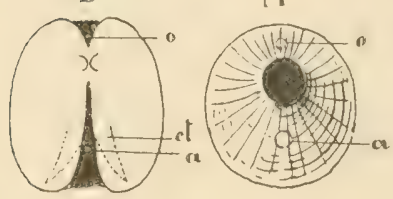
nissen als nützlich anerkannt werden, ganz abgesehen davon, dass die Gasteropoden sich thatsächlich hierin von ursprünglichen Mollusken, als welche mit vielem Recht die Chitoniden gelten, unterscheiden.

\section{0.}

Es könnte ein scheinbar gewichtiger Einwand gegen unsere Ansicht vorgebracht werden. Wenn die Asymmetrie des Gasteropodenkörpers in letzter Instanz von der Ausbildung einer hoch thurmförmigen Schale herrührt und wenn die specielle Asymmetrie im Nervensystem mit einer nach einer ganz bestimmten Richtung erfolgenden Aufrollung der Schale nothwendig zusammenhängt, wie verhält es sich dann mit Formen, wie z. B. Fissurella? Die Diotocardiergattung $\mathrm{F}$ is surella gehört in der That zu den ursprünglichsten Gasteropoden, weil sich die Symmetrie im Pallealcomplex noch vollständig erhalten hat. Aber Fissurella besitzt ein asymmetrisches Nervensystem, hat die typische Chiastoneurie der Prosobranchier und trotzd e m - eine flache, napfförmige, symmetrische Schale. Es gesellen sich also hier ursprüngliche Charaktere der inneren Organisation zu scheinbar ursprünglichen Schalencharakteren. Letztere sind aber in der That nur scheinbar ursprüngliche, was sich systematisch und ontogenetisch nachweisen lässt. Nächste Verwandte von F'issurella, wie z. B. die uralte Gattung Pleurotomaria (Fig. 518 A), dann Polytremaria (Fig. 518 B)

Fig. 518. Schalen von $\boldsymbol{A}$ Pleurotomaria, $\boldsymbol{B}$ Polytremaria, $C$ und $E$ Emarginula, $D$ Haliotis, $F$ Fissurella, $G$ und $\boldsymbol{H}$ Entwickelungsstadien der Fissurellaschale, I Schale der umgedrehten Gasteropodenstammform mit marginalem Schalenschlitz, $\boldsymbol{K}$ idem mit apicalem Schalenloch, $\boldsymbol{L}$ Muschelschale, $\boldsymbol{M}$ Dentaliumschale, vom apicalen Schalenschlitz aus gesehen. Die Löcher und Schlitze der Schale schwarz gezeichnet. o Mund, a After, ct Ctenidium. 
und Scissurella besitzen eine geräumige, spiralig aufgerollte, rechtsgewundene Schale. Die Schale wird flacher und die Aufrollung undeutlicher bei Haliotis (Fig. 518 D) und zum Theil auch bei Emarginula (Fig. $518 \mathrm{C}$ ), bis sie schliesslich bei $\mathrm{F}$ is surella (Fig. $518 \mathrm{~F}$ ) secundär wieder flach-napfförmig - und symmetrisch wird. Ja es durchläuft $\mathrm{F}$ is surella ontogenetisch noch ein deutlich spiralig gewundenes Emarginulastadium (Fig. 518 G, H). Daraus schliessen wir mit aller in morphologischen Fragen erreichbaren Sicherheit, dass die äusserlich symmetrische $\mathrm{F}$ issurella von Formen mit spiralig gewundener, hoher Schale abstammt. Thre Rückkehr zu einer flachen, symmetrischen mag in ähnlicher Weise auf der Anpassung an bestimmte biologische Verhältnisse beruhen, wie bei den Patelliden, Capuliden etc.

\section{1.}

Unser Erklärungsversuch scheint uns noch auf manche weitere bis jetzt nicht berührte Probleme der Molluskenmorphologie neues Licht zu werfen, so namentlich auf die Asymmetrie des Pallealcomplexes der meisten Gasteropoden. Viele Diotocardier, alle Monotocardier, alle Opisthobranchiata und alle Pulmo$\mathrm{n}$ a ta zeigen eine auffällige As y m metrie ihres Pallealcomplexes. Diese Asymmetrie besteht zumeist darin, dass eine Kieme, ein Osphradium und eine Nephridialöffnung fehlt. Auch in der inneren Organisation zeigen sich die Wiederklänge dieser Asymmetrie, so im Nervensystem, in dem Fehlen einer Niere und eines Herzvorhofes. Bei genauerem Zusehen stellt es sich heraus, dass die ursprünglich linke Hälfte des Pallealcomplexes fehlt (sie würde jetzt bei einem Prosobranchier in der Mantelhöhle rechts neben dem After liegen). Der After bildet also jetzt nicht mehr das Centrum der Pallealgruppe, sondern er liegt zu äusserst auf der einen Seite. Indem bei den Prosobranchiern z. B. die ursprünglich linke Hälfte (sie würde jetzt rechts liegen) des Pallealcomplexes verschwunden ist, rücken jetzt diejenigen Organe des Complexes (die ursprünglich rechten), die sich erhalten haben, von links her in die Lïicke. In Folge dessen finden wir den After nicht mehr vorn in der Mittellinie, sondern vorn auf der rechten Seite, hart auf der äussersten Rechten der Mantelhöhle.

Warum aber ist bei den Monotocardiern, Opisthobranchiern und Pulmonaten die ursprünglich linke Hälfte des Pallealcomplexes verschwunden?

Zur Beantwortung dieser Frage kehren wir zu Paragraph 3 zurück, in welchem wir gesehen haben, dass, wenn die thurmförmige Schale die einzig mögliche seitwärts geneigte Lage einnimmt, dabei die Mantelhöhle mit ihrem Pallealcomplex unter ungleiche Druckverhältnisse kommt. Wird die Schale nach links geneigt getragen, so ist die Stelle des grössten Druckes in der hinterständigen Mantelhöhle links, und der Druck nimmt von dieser Stelle nach rechts fortschreitend ab. Diese verschiedenen Druckverhältnisse erhalten sich auch während der ganzen Zeit, während welcher die Schale sich nach hinten, der Mantelcomplex nach vorn verlagert. Anders ausgedrückt, d. h. für unsere Theorie verwerthet, heisst das: Schon beim ersten Anfang der Ausbildung der Gasteropodenorganisition grerifthen die ursprünglich linksseitigen Organe des Pallealcomplexes in ungünstige Verhältnisse. In der linksseitig eingeengten Mantelhöhle musste vornehmlich das Ctenidium kleiner, rudimentär werden und es kounte ganz verschwinden. 
Bei manchen Diotocardiern (den sogenannten Azygobranchiern), bei allen Monotocardiern und bei den Opisthobranchiaten ist in der That die ursprünglich linke (sie würde jetzt rechts liegen) Hälfte des Pallealcomplexes völlig verschwunden. Dass bei den Pulmonaten auch noch die einzige ursprünglich rechte Kieme verschwunden ist, hat seinen Grund im Uebergang zur Lungenathmung. Um so interessanter ist es, dass sich bei den $\mathrm{Bas}$ am matophoren wenigstens noch das ursprünglich rechte Osphradium erhalten hat.

Wenn aber die ursprünglich linke Kieme nicht ganz verschwunden, sondern nur kleiner geworden ist, so müssen wir erwarten, dass bei denjenigen Diotocardiern, die noch zwei Kiemen besitzen, die ursprünglich linke (d. h. die nunmehrige rechte) die kleinere sei. Dies muss wenigstens für die ursprünglicheren Formen mit noch gewundener Schale gelten.

Uns sind nun die betreffenden Verhältnisse nur bei $\mathrm{H}$ aliotis und Fissurella bekannt. Bei Haliotis, dessen Schale noch gewunden ist, ist in der 'That die rechte (ursprünglich linke) Kieme kleiner als die linke. Bei Fissurella, Subemarginula aber, wo die Asymmetrie im Mantelraum sich ausgeglichen hat, hat sich auch wieder der Grössenunterschied in den Kiemen ausgeglichen.

12.

Wir kommen jetzt zu einem anderen unerledigten Punkte. Weshalb fährt die Schale auch dann noch fort asymmetrisch zu wachsen, sich in einer rechtsgewundenen Spirale aufzurollen, wenn die primäre causa efficiens, der Uebergang von der nach links geneigten Lage der Schale in die nach hinten geneigte bei gleichzeitiger Wanderung des Pallealcomplexes und Verschiebung der Mantelhöhle nach vorn, aufgehört hat zu wirken, d. h. wenn die Schale ihre definitive nach hinten geneigte Lage, der Pallealcomplex die vorderständige Lage eingenommen hat? Die Erklärung liegt eben in den so frühzeitig auftretenden asymmetrischen Raumverhältnissen der Mantelhöhle, die von Anfang an rechts (jetzt links) geräumiger wurde als links, so dass die ursprünglich linksseitige Hälfte des Pallealcomplexes verkümmerte. Die Asymmetrie des Pallealcomplexes und der Mantelhöhle blieb auch nach der definitiven Ordnung der Lageverhältnisse der Schale und des Pallealcomplexes der Prosobranchien bestehen, d. h. das asymmetrische Wachsthum und damit die fortdauernde Aufrollung des Eingeweidesackes und der Schale in einer rechtsgewundenen Spirale blieb bestehen.

Nur in Folge ganz besonderer Verhältnisse, die eine flache, napfförmige Schale nützlich erscheinen lassen, konnte die Ausgleichung der Asymmetrie des Pallealcomplexes und der Mantelhöhle resp. Mantelfalte sich als nützlich erweisen, indem dann ein symmetrisches Wachsthum der Schale und bei geringem Unterschied zwischen dem Maximum und Minimum der Intensität des Höhenwachsthums eine wenig aufgerollte Schale, bei starkem peripheren Wachsthum, bei geringem Höhenwachsthum eine flach-napfförmige Schale entstehen konnte (Haliotis, Emarginula, Fis surella, Patella etc.).

13.

Die Chiastoneurie kommt nur dann zu Stande, wenn die ursprünglich rechte Hälfte des Pallealcomplexes vorn die Mediane nach links hinüber ïberschreitet.

Diese Ueberschreitung der Symmetrieschwelle hat bei den Proso- 
branchiern wirklich stattgefunden. Bei ihnen liegt die ursprünglich rechte Kieme weit links in der Mantelhöhle. Dabei hat sich bei den Azygobranchiern und Monotocardiern der Enddarm mit dem After aus der Mediane heraus in die engere, kiemenlose, aber für die Aufnahme des Enddarmes genügend weite nunmehrige rechte (ursprünglich linke) Hälfte der Mantelhöhle verlagert. Die Prosobranchier sind Strepton e uren.

Bei den in Betracht kommenden Op is thobranchiern (den 'T'ectibranchiata) finden wir den Pallealcomplex auf der rechten Körperseite. Nirgends hat er vorn die Mediane überschritten. Die Opisthobranchier sind dementsprechend keine Chiastoneuren, ihre Visceralconnective kreuzen sich nicht.

Bei den $\mathrm{Pulmon}$ aten ist zwar der Pallealcomplex weit nach vorm grerïckt, aber er hat die Mediane mit keinem Organ überschritten, welches, das Parietalganglion und das rechte Visceralconnectiv mit sich ziehend, eine Chiastoneurie hätte hervorbringen können. Denn auch diejenige Kieme, die sich sonst allein erhält, die linke (ursprünglich rechte), ist bei den Pulmonaten (offenbar frühzeitig) verschwunden. Das Osphradium, welches sich bei Wasser-Pulmonaten erhält, ist das ursprünglich rechte und liegt thatsächlich noch rechts. Dabei ist es für die Auffassung der Verhältnisse des Nervensystems ziemlich gleichgültig, ob man annimmt, dass der Enddarm secundär wieder aus der Mediane nach rechts zurïckgeschoben und das Osphradium in die Nähe des Athemloches gerïckt sei, oder ob man annimmt, dass der Enddarm die Mediane überhaupt nie erreicht, das Osphradium die Mediane überhaupt nie überschritten habe.

Die Pulmonaten sind Euthyneuren.

14.

Wir haben oben in Paragraph 3 gesehen, dass bei der starken Entwickelung eines Eingeweidesackes und ursprünglich hinterständigem Pallealcomplex die nach vorn geneigte oder nach vorn eingerollte Schale un möglich ist bei einem kriechenden Thiere, einem Gasteropoden. Diese Unmöglichkeit besteht aber nicht bei einer anderen als der kriechenden Lebensweise. Wenn z. B. bei schwimmender Lebensweise die theilweise mit Gas erfüllte Schale zugleich als hydrostatischer Apparat dient, so ist nicht einzusehen, weshalb bei stark entwickeltem Eingeweidesack derselbe mitsammt der Schale nicht nach vorn eingerollt sein könnte, wobei zugleich die ursprüngliche Lage des Pallealcomplexes, die hinterständige, als die für diesen Fall günstigste, beibehalten werden konnte. Beispiel: N a utilus und alle Nautiliden und Ammonitiden mit ihrer "exogastrisch" d. h. nach vorn eingerollten Schale und ihrem hinterständigen Pallealcomplex (Fig. 519).

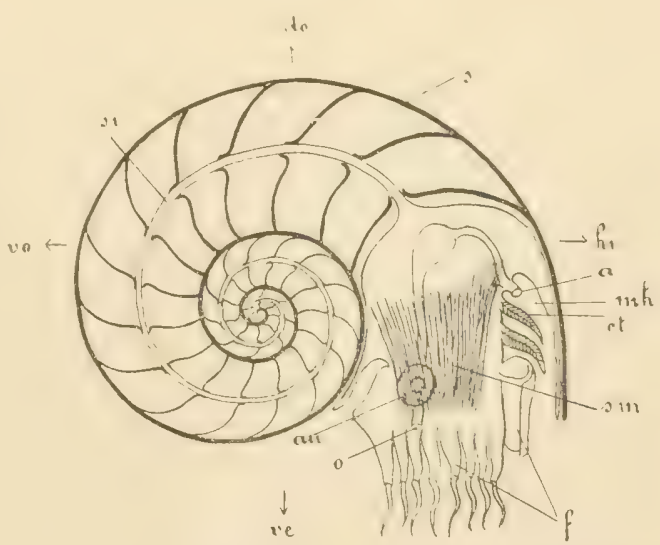

Fir. 519. Nautilus, schematisch. do Dorsal, ve ventral, vo vorn, hi hinten, 
Eine Ausnahmestellung scheint unter allen Mollusken einzig und allein Spirula einzunehmen, aber es ist zu bedenken, erstens, dass die Schale von Spirula eine innere rudimentäre ist, und dass ihre nach rückwärts gerichtete Aufrollung die hinterständige Mantelhöhle durchaus nicht beeinträchtigt; $\mathrm{z}$ we itens, dass nur die moderne Gattung Spirula eine endogastrisch gewundene Schale besitzt. Die miocäne Gattung Spirulirostra hat einen in endogastrischer Richtung gekrümmten,

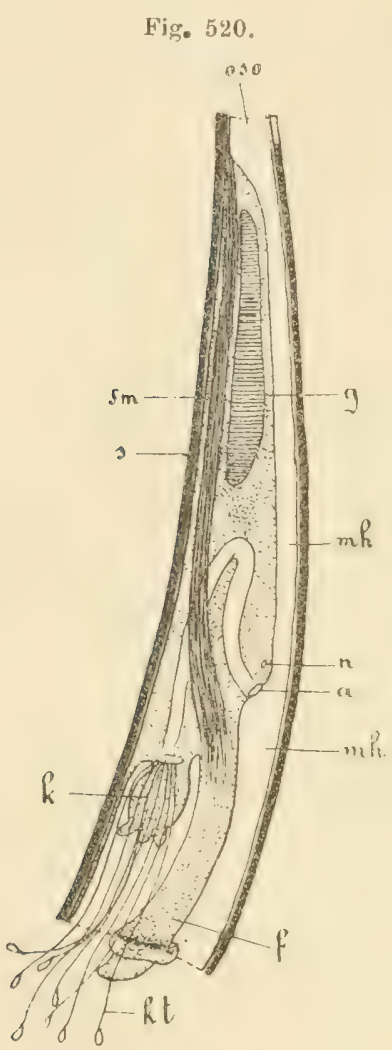
aber nicht aufgerollten Phragmokon, und die älteren $\mathrm{Belemmiten}$ besitzen überhaupt keine gekrümmate oder eingerollte Schale. Ausserdem kommt die Schale der ganzen Abtheilung als eine innere und mit Bezug auf den ursprünglichen $\mathrm{Z}_{\text {weck, }}$, das Thier zu schiitzen und $\mathrm{zu}$ bergen, rudimentäre überhaupt für uns gar nicht in Betracht.

Fig. 521.

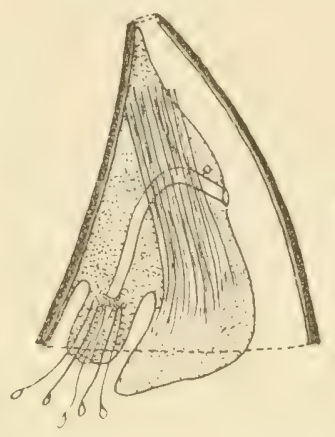

Fig. 520. Dontalium, schematisch, von der linken Seite. $g$ Geschlechtsdrüse, lt Kopftentakel.

Fig. 521. Supponirte Zwischenform zwischen Dentalium-(Fig. 520) und Gasteropodenstammform (Fig. 522), von der linken Seite.

Fig. 522. Supponirte Stammform der Gasteropoden, von der linken Seite.

15.

Wenn eine Schnecke eine Lebensweise führt, wie eine im Schlamme lebende Muschel, so ist nicht einzusehen, weshalb sich die Schale nicht einfach thurmförmig verlängern und weshalb der Mantelcomplex und die Mantelhöhle nicht hinten verbleiben sollte. Dentalium (Fig. 520) ist deutlich in dieser Lage, ist das an die Lebensweise im Schlamme angepasste symmetrische Urgasteropod mit thurmförmiger Schale und hinterständigem Pallealcomplex. Die am oberen, aus dem Schlamme hervorragenden Schalenende liegende, morphologisch äusserst wichtige Schalenöffnung entspricht physiologisch den Siphonen der Schlammmuscheln.

Auch von unserem Gesichtspunkte aus erscheint der Vergleich vou Dentalium mit einer Fissurella, deren Pallealcomplex zurückgedreht und deren Schale hoch thurmförmig verlängert wäre, in jeder Beziehung durchaus zutreffend. Eine solche zurückgedrehte Fissurella würde aber fast genau der supponirten symmetrischen Gasteropodenstammform 
entsprechen, bei der wir aber annehmen müssen, dass ein Mantel- und Schalenschlitz bis zum Mantel- und Schalenrande reichte.

Die in neuerer Zeit genauer bekannt gewordene Anatomie der Protobranchiaten, vornehmlich die hinterständige Lage der zwei Kiemen, die Kriechsohle am Fuss, das Vorhandensein der Pleuralganglien, erlaubt auch eine Zurückführung der Lamellibranchier auf die Gasteropodenstammform, wobei der Schlitzrand des Mantels dem hinteren oder Siphonalrand des Mantels der Lamellibranchier entspricht. Die betreffenden, in ähnlichen physiologischen Verhältnissen befindlichen Mantelränder der Fissurelliden, Haliotiden, Lamellibranchier weisen häufig in übereinstimmender Weise 'Tentakel, Papillen etc. auf.

Dentalium, als ein nicht frei kriechendes, sondern limicoles Thier, passt auch insofern in unsere Theorie, als die freilich nur schwach gekrümmte Schale nach vorn gekrümmt ist und der Spindelmuskel an der Vorderseite des Eingeweidesackes liegt.

\section{6.}

Rechts- und linksgewundene Schnecken. Die meisten Gasteropoden besitzen einen rechtsgew undenen Eingeweidesack und entsprechende Schale. Diese Windungsrichtung wurde bestimmt dadurch, dass der Eingeweidesack und die Schale sich ursprünglich auf die linke Seite und dann immer mehr nach hinten neigte, wobei der Pallealcomplex sich auf der rechten Seite in der Mantelfurche nach vorn verschob. Weshalb die linke Seite die bevorzugte war, lässt sich natürlich nicht sagen. Ebensogut konnte sich die Schale zuerst auf die rechte Seite und von da aus successive nach hinten neigen, wobei dann der Pallealcomplex sich auf der linken Seite des Eingeweidesackes in der Mantelfurche nach vorn verschob. Die Asymmetrie hätte dann gerade die entgegengesetzte werden müssen. Um einen concreten Fall herauszugreifen, hätte bei einem Monotocardier mit linksgewundenem Eingeweidesack und entsprechend gewundener Schale das ursprünglich linke Parietalganglion zum nunmehr auf der rechten Seite gelegenen Supraintestinalganglion werden müssen. Es wäre die ursprünglich rechte Hälfte des Pallealcomplexes verschwunden, und die sich erhaltende linke würden wir jetzt auf der rechten Seite des links gelegenen Afters oder Enddarmes antreffen.

Es giebt nun bekanntlich in der That linksgewundene Gasteropoden. Viele derselben haben die dieser Windungsrichtung entsprechende inverse Lage der asymmetrischen Organe, so unter den Prosobranchiern Neptunea contraria, Triforis und gelegentlich auftretende linksgewundene Exemplare von Buccinum; unter den Pulmonaten Physa, Clausilia, Helicter, Amphidromus und gelegentlich auftretende linksgewundene Individuen von Helix-oder Limnaeaarten. Bei Bulimus perversus, wo die Individuen indifferent rechts oder links gewunden sind, wechselt mit der Richtung der Schalenmündung auch die specielle Asymmetrie der asymmetrischen Organe.

\section{7.}

Falsch rechtsgewundene und falsch linksgewundene Gasteropoden. Wir wissen nun aber, dass es rechtsgewundene Schnecken giebt, welche die Organisation linksgewnudener besitzen. Hierher grehören unter den Prosobranchiern die linksgewundene Untergattumg Lanistes des Genus Ampullaria, unter den Pulmonaten Choa- 
nomphalus Macki und Pompholyx solida, unter den Opisthobranchiern diejenigen $\mathrm{P}$ teropode $\mathrm{n}$, welche, sei es im erwachsenen $\mathrm{Zu}$ stande (Limacinidae), sei es im Larvenzustande (Cymbuliidae) eine gewundene Schale besitzen. Diese Thatsache lässt sich mit unserem Erklärungsversuch der Asymmetrie der Gasteropoden absolut nicht vereinigen, denn dieser weist einen ursächlichen Zusammenhang zwischen der Richtung der spiraligen Aufrollung der Schale und des Eingeweidesackes einerseits und der speciellen Asymmetrie der asymmetrischen Organe anderseits nach. Nun wurden die eben erwähnten Ausnahmen in folgender durchaus plausiblen Weise erklärt. Die Spira einer rechtsgewundenen Schale z. B. kann sich immer mehr abflachen, so dass eine in einer Ebene - oder annähernd - aufgerollte Schale zu Stande kommt. Dann kann die Spira an der gegenüberliegenden Seite, wo ursprünglich der Nabel lag, wieder hervorbrechen, so dass jetzt an der Nabelseite eine falsche Spira, an der Spiraseite ein falscher Nabel zu Stande kommt.

A
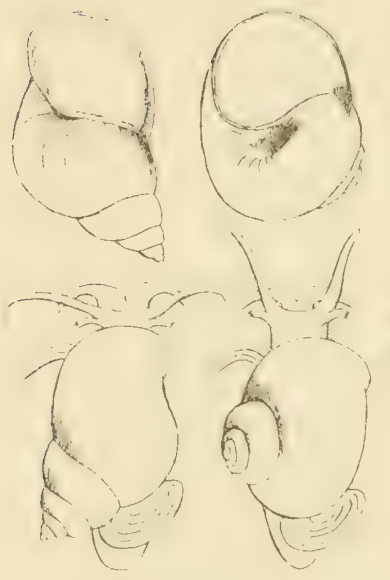

$\mathrm{C}$
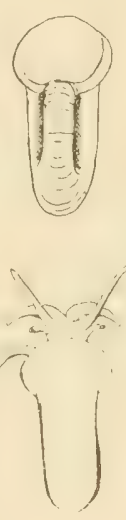

D

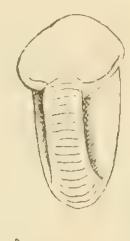

$\mathrm{E}$

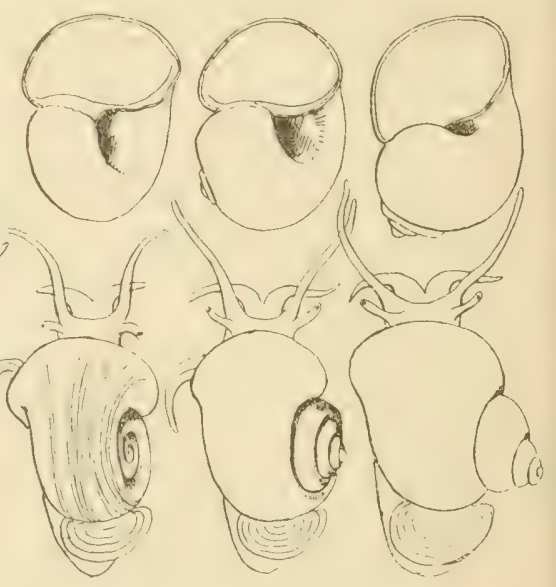

Fig. 523. 7 Formen von Ampullaria-Schalen (in verschiedenem Maasse verkleinert), in der oberen Reihe von der Schalenmuindung aus gesehen, in der unteren Reihe von der Rückenseite gezeichnet. Kopf, Fuss und Operculum sind willkü rli ch eingezeichnet, nur zu dem Zwecke, die rechts- und linksgewundenen Formen leichter vergleichen zu können.

Diese Uebergänge von einer rechtsgewundenen Schale zu einer falsch linksgewundenen, genetisch aber rechtsgewundenen, haben wir an der Hand von 7 Arten der Gattung A m pullaria bildlich dargestellt (Fig. 523). Ampullaria Swainsoni PH.? (G) und A. Geveana SAr. (F) sind rechtsgewunden mit deutlich vorragender Spira. Ampullaria crocostoma PH. (E) besitzt eine flache Spira, A. (Ceratodes) rotula Mss. (D) und A. (Ceratodes) chiquitens is D'OrB. (C) besitzen schon eine durchgedrückte oder vertiefte Spira, aber trotzdem noch einen ächten Nabel auf der Nabelseite. Bei A. (Lanistes) Bolteniana Chems. (B) und noch mehr bei A. purpurea Jos. (A) tritt die durchgedrückte Spira auf der Nabelseite als falsche Spira frei vor, und an der Spiraseite findet sich jetzt ein falscher Nabel.

So plausibel diese Erklärung auch sein mochte, der wirkliche Beweis, dass sie richtig ist, ist erst durch Feststellung folgender "Thatsachen ge- 
liefert. Wo ein spiraliges Operculum vorkommt, ist die Richtung der Spirale an diesem der Spiralrichtung der Schale entgegengesetzt (Fig. 524 A, B und C), und der Spiralenanfang ist immer der Nabelseite der Schale zugekehrt. Lanistes hat nun zwar kein spiralig gewundenes Operculum, aber die Pteropoden besitzen ein solches. Nun ist das Operculum bei den Pteropoden, die bei linksgewundener Schale die Organisation rechtsgewundener Gasteropoden haben, genau so wie bei einer rechtsgewundenen Schale. Das (immer von der freien Seite betrachtete) Operculum ist in der That bei Peraclis, bei den Larven der Cymbulijdae und bei Limacina retroversa Fleming linksgewunden, and die Anfangsstelle seiner Windung ist der (falschen) Spira zugekehrt, welche bei diesen falsch linksgewundenen Gasteropoden an der Stelle des ursprïnglichen
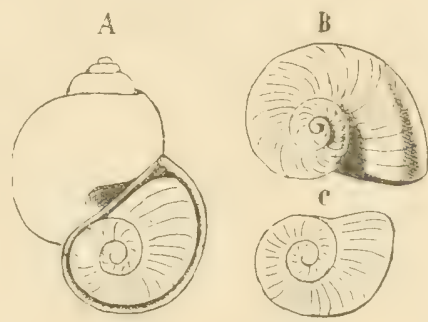

Fig. 524. Choristes elegans Corp. $A$ mit Operculum in situ (nach (VerRill), $\boldsymbol{B}$ Schale von der Spira. seite, $\boldsymbol{C}$ Deckel von der Aussenseite. Nabels liegt.

So sehen wir die scheinbaren Ausnahmen in willkommenster Weise die Regel bestätigen.

\section{Sinnesorgane.}

\section{A) Organe des Hautsinnes.}

In der Haut der Mollusken finden sich in verschiedener Auordnung und Zahl Epithelsinneszellen (Funumá'sche Zellen), die über grössere Strecken zerstreut sein kömmen. Ihrer Form nach können wir zwei Arten solcher Sinneszellen unterscheiden. Die einen finden sich, wie es scheint, nur bei Lamellibranchiern. Es sind grosse Epithelzellen mit grossem, an cler Begrenzung der äusseren Körperobertläche 'Theil nehmendem Endplateau, welches ein Büschel nach aussen vorragender Simneshaare trägt (Pinselzellen). Die zweiten kommen allgemein verbreitet vor. Es sind langgestrechte Faden- oder Spindelzellen, die nur an der Stelle, wo der Kern liegt, angeschwollen sind. Bald tragen sie ein Büschel von Simesharen, hald nicht. Beide Arten von Zellen setzen sich an ihrer Basis in eine Nervenfaser fort, welche in das Nervensystem hinein verläuft. Eine scharf umgrenzte, specifische Function dürfte diesen Fpithelzellen wohl kaum zuzuschreiben sein. Sie mögen noch emptindlich sein für sehr verschiedene lieize, hauptsächlich mechanische umd chemische, und sie mögen also in uubestimmter Weise die Rolle von 'Tast-, Geruchs- und Geschmackszellen spielen. Ihre Function mag sich nur da etwas mehr specialisiren, wo sie an hestimmten hörperzellen in griösserer Anzithl zusimmengedringt vorkommen und besondere Sinnesorgane darstellen. Zwischen den einzelnen Sinneszellen eines solchen Hautsinnesorganes erhalten sich aber immer noch andere Epithelzellen: Drüsenzellen, Flimmerzellen, Stützzellen etc.

\section{Tastorgane.}

An exponirten hïrperstellen wird wahrscheinlich die Tastfunction der Hautsinneszellen in den Vordergrumd treten: so an den T'entakelu, 
Epipodialfortsätzen, Siphonen, am Mantelrand der Lamellibranchien, am Fussrande etc. etc. Immerhin ist auch für diese Stellen nicht anzunehmen, dass die an ihnen befindlichen Sinneszellen n ur für mechanische Reize empfindlich sind.

\section{Geruchsorgane.}

a) Das Osphradium.

Wie bei Prosobranchiern nachgewieseu wurde, kommen Sinneszellen im ganzen, der Mantelhöhle zugekehrten, also inneren Epithel des Mantels zerstreut zwischen den anderen Epithelzellen vor. Es lassen sich nuimlich hier, wie auch an anderen Köryerstellen, drei Arten von Epithelzellen nachweisen: 1) I nd iffer en te E p i thelzellen. Diese könuen gelegentlich Pigment enthalten, sie sind meist bewimpert. 2) Drü s enzellen. 3) Sinn eszellen. Das numerische Verhältniss dieser drei Zellenarten kann in verschiedenen Bezirken des Mantels wechseln. Prïdominireu die Drüsenzellen, so nimmt der betreffende Bezirk einen vorwiegend drüsigen Charakter an und kann sich sogar zu einer scharf localisirten Epitheldrüse (z. B. Hypobranchialdrüse) ausbilden. An den líiemen prädominiren die indifferenten Wimperzellen. Prädominiren die Sinneszellen, so nimmt der betreffende Bezirk einen vorwiegend sensoriellen Charakter au. Er wird, wenn er sich scharf localisirt, und wenn die Simneszellen immer mehr vorherrschen, zu einem Sinuesorgane des Nantels. Die allmähliche Ausbildung und fortschreitende Differenzirung eines solchen pallealen Sinnesorganes lässt sich besonders schön bei den Prosobranchiern verfolgen. Das Sinnesorgan ist kein auderes als das () sphradi u m. Vermöge seiner Lage in der Mlautelhöhle und speciell in der Nöhe der Kíemen wird man geneigt sein, zu vermuthen, dass seine Hauptfunction die der Untersuchung der Beschaffenheit des Athemwassers sei, mit auderen Worten, dass es vorwiegend als Geruchsorgan functionire.

Das Osphradium ist unter den Prosobranchiern am wenigsten differenzirt bei den Diotocardiern. Bei den Fissurelliden existirt es noch gar nicht als scharf localisirtes Organ. Bei den Monotocardiern differenzirt es sich immer mehr, bekommt ein besonderes Ganglion und erreicht schliesslich bei den Toxiglossen das Maximum seiner Entwickelung.

Eine Uebersicht über die Lagerungs- und Zahlenverhältnisse des Osphradiums ist schon in einem anderen Kapitel (p. 642) gegeben worden. Auf eine ausführliche Darstellung der besonderen Form und des besonderen Baues des Osphradiums in den verschiedenen Abtheilungen der Mollusken müssen wir verzichten. Wir wollen uns darauf beschränken, das hoch entwickelte Osphradium eines 'Toxiglossen, der Cassidaria tyrrhena, zu beschreiben.

Das Osphradium von Cassidaria liegt als ein längliches, an beiden Enden zugespitztes Organ links vom Ctenidium am Mantel in der Mantelhöhle. Es sieht wie bei anderen stark specialisirten Monotocardiern aus (Fig. 454, p. 645) wie eine zweizeilig gefiederte Kieme und ist deshalb auch als "Nebenkieme" betrachtet und bezeichnet worden. Es besteht aus einem sich auf dem Mantel erhebenden, im Querschnitte annähernd viereckigen Wulste, welcher jederseits 125-150 flache Blättchen trägt, die auf der Fläche des Mantels senkrecht stehen und dicht gedrängt sind, so dass die Flächen der aufeinanderfolgenden Blättchen aneinauder liegen. Der Wulst wird fast ausschliesslich von einem gestreckten Ganglion, dem 
Osphradialganglion gebildet. Von diesem Ganglion erhält jedes Blättchen einen besonderen Nerven, der seiner unteren, gegen die Mantelhöhle vorragenden Kante entlang verläuft und 4 Hauptzweige in das Blättchen entsendet. An der dorsalen, dem Mantel zugekehrten Seite enthält jedes Blättchen Blutsinusse, die mit einem über dem Ganglion im Wulste liegenden Sinus communiciren. Die erwähnten Hauptzweige verästeln sich. Ihre letzten, feinsten Aestchen durchsetzen die Stützmembran zwischen Epithel und dem subepithelialen Gewebe und verbinden sich mit verästelten, im Epithel (interepithelial) liegende Ganglienzellen, von denen eine jede mit einer spindelförmigen Epithelsinneszelle in Verbindung steht. Die verästelten interepithelialen Nervenzellen stehen untereinander durch ihre Fortsätze im Zusammenhang.

Das beschriebene Sinnesepithel ist an der unteren, der Mantelhöhle zugekehrten Oberfläche der Osphradialblättchen entwickelt, und in dieser Gegend sind die indifferenten, cilienlosen Epithelzellen mit Körneru gellen Pigmentes erfüllt, während diese Zellen in der oberen Region eines jeden Blättchens pigmentlos und bewimpert sind. Auch Drüsenzellen sind in bestimmter Anordnung - im Epithel der Osphradialblättchen vorhanden.

Was die Innervation des Osphradiums anbetrifft, so entspringt der Osphradialnerv gewöhnlich aus dem Pleurovisceralconnectiv und zwar da, wo ein Parietalganglion vorhanden ist, aus diesem; bei den Lamellibranchiaten kommt er von dem Parietovisceralganglion. Meist ist der Osphradialnerv ein Seitenzweig des Kiemennerven.

Wichtig ist der bei Lamellibranchiaten erbrachte Nachweis, dass die Fasern der Osphradialnerven, obschon diese Nerven von dem Parietovisceralganglion kommen, nicht aus diesem selbst entspringen, dass sie sich vielmehr direct in die Pleurovisceralconnective fortsetzen und in den Cerebralganglien wurzeln.

b) Riechtentakel.

Gewisse, freilich nicht gauz einwandfreie Experimente scheinen zu zeigen, dass die grossen oder Augententakel der Landpulmonaten auch im Dienste der Geruchswahrnehmung stehen. Ebenso sollen nach einer allgemein verbreiteten, aber noch unbewiesenen Ansicht die hinteren oder dorsalen Tentakel (Rhinophoren) der Opisthobranchier Geruchsorgane sein. Diese Rhinophoren (Fig. 475, p. 672) zeigen häufig Oberflächenvergrösserungen, vielfach in Form von mehr oder weniger zahlreichen, ringförmigen Lamellen, welche den Tentakel kragenförmig umgeben. oft auch sind diese Rhinophoren ohrförmig oder dütenförmì̈ eingerollt. Nicht selten sind sie in besondere Gruben oder Scheiden zurückziehbar. Sie werden vom Gehirmganglion aus durch einen Nerven innervirt, welcher an ihrer Basis ein Ganglion bildet.

Am seitlichen und unteren Rande der Kopfscheibe der Cephalaspidea, welches Organ man als aus der Verschmelzung der Labialtentakel und Kopftentakel hervorgegangen betrachtet, finden sich als Geruchsorgane gedeutete Gebilde, die da, wo sie am besten ausgebildet sind, aus mehreren sich auf" der Kopfscheibe erhebenden parallelen "Riechlamellen" bestehen.

c) Riechgruben der Cephalopoden.

Bei den Dibranchiaten liegt jederseits über den Augen eine als Geruchsorgan gedeutete Grube, deren Epithelboden aus Wimperzellen 
und Sinneszellen besteht. Unter dieser Grube findet sich ein „Riechganglion", das dem Opticus dicht anliegt. Die zum Ganglion verlaufenden Nervenfasern kommen vom Ganglion opticum, stammen wohl aber in letzter Linie aus dem Cerebralganglion. Der Gedanke liegt nahe, diese Geruchsorgane als Reste der hinteren Tentakel der Gasteropoden aufzufassen, sie zu vergleichen mit den Rhinophoren der Opisthobranchier. An der Stelle der Geruchsgrube findet sich bei Nautilus der obere Augententakel. Wir haben schon früher gesehen, dass Nautilus noch echte Osphradien besitzt.

\section{d) Das palleale Sinnesorgan der Lamellibranchier.}

Bei mehreren Asiphoniaten sind ausser den Osphradien noch epitheliale Sinnesorgane nachgewiesen worden, welche auf kleinen Falten oder Höckeru rechts und links neben dem After, zwischen diesem und dem Hinterende der Kieme liegen. Sie werden von einem Kaweig des hinteren Mantelnerven innervirt.

Epitheliale Sinnesorgane von verschiedener Form (Platten von Sinnesepithel, Sinneslamellen, Simneswülste, Büschel von kleinen Tentakehn) finden sich auch bei Siphoniaten am Mantel, und zwar auf dem Rückziehmuskel der Siphonen, an der Basis des Branchialsiphos. Auch diese pallealen Sinnesorgane der Siphoniaten werden vom hinteren Pallealnerven imnervirt und dürften den analen Sinnesorganen der Asiphonier entsprechen. Ihre Function ist unbekannt. Man vermuthet, dass sie derjenigen des Osphradiums analog sei.

\section{e) Die Geruchsorgane der Chitonen.}

In der Mantelrinne der Chitonen existiren epitheliale Sinnesorgane, die als Geruchsorgane gedeutet worden sind. Es handelt sich um Leisten oder Wülste, an denen das ausserordentlich erhöhte Epithel aus Drüsenzellen und fadenförmigen Sinneszellen besteht. Bei Chiton laevis und Ch. cajetanus finden sich jederseits in der Mantelrinne zwei sich in der ganzen Länge der Kiemenreihe erstreckende Sinnesleisten, von denen die eine, die parietale, der äusseren Wand der Furche angehört, während die andere, die paraneurale Leiste, dem Boden der Furche entlang, also über der Kiemenbasis und unter dem Pleurovisceralstrang verläuft. Es setzt sich die Paraneuralleiste eine kurze Strecke weit auf die Innenseite einer jeden Kieme fort, so dass jede Kieme einen epibranchialen Sinneshöcker besitzt. Vor dem ersten Kiemenpaar und in der Gegend des letzten werden die Sinneszellen auf den paraneuralen Sinnesleisten im. Vergleich zu den Drüsenzellen viel zahlreicher. Chiton siculus, Ch. Polii und Acanthochiton (bei diesen reichen die zahlreichen Kiemen weit nach vorn) besitzen die parietalen und die paraneuralen Sinnesleisten nicht. Bei ihnen beschränlkt sich das Sinnesepithel auf je zwei Epithelwülste, welche paraneural hinter dem letzten Kiemenpaare gelegen sind und an welche sich ein hohes Epithel anschliesst, welches die Mantelwand des hintersten Raumes der Kiemenfurche überzieht.

Alle diese Sinnesepithelien scheinen von den Pleurovisceralsträngen aus innervirt zu werden.

Die Frage nach den Beziehungen dieser Sinnesepithelien der Chitoniden zu den Osphradien der übrigen Mollusken ist ebenso naheliegend, als schwer zu beantworten. Der Lage nach entsprechen den Osphradien 
am besten die epibranchialen Verlängerungen der Paraneuralleisten von Chiton laevis und Ch. cajetanus.

\section{Die "Seitenorgane" der Diotocardier.}

An der Basis der Epipodialtentakel von Fissurella und Trochiden, an der Basis der unteren Tentakel der Epipodialkrause von Haliotis und bei dieser letzteren Gattung noch an anderen Stellen in der Nähe der Krause finden sich Sinnesorgane, die mit den Seitenorganen der Ammeliden verglichen worden sind. Sie bestehen aus einem Hofe vou Sinnesepithel, der sich kugelförmig vorwölben und grubenförmig vertiefen kann. Das Epithel dieser Sinnesorgane, die an der Unterseite der Basis der Epipodialtentakel liegen, besteht aus je mit einer Sinnesborste versehenen Sinneszellen und pigmentführenden Stïtzzellen. Die Innervation geschieht für jedes Sinnesorgan durch den betreffenden Tentakelnerven, der vom Pedalstrange stammit und in der Basis eines jeden Epipodialtentakels ein Ganglion bildet.

\section{Gesch macks organ e.}

Falten und Wülste der Mundhöhle sind in einigen Abtheilungen der Mollusken als Geschmacksorgane gedeutet worden, doch immer ohne physiologische, fast immer ohne histologische Begrindung. Nur in wenigen Fïllen, bei Chitoniden und Diotocardiern (Haliotis, Fissurella, Trochus, Turbo und Patella) wurde das Vorhandensein von sogenannten "Geschmacksbechern" auf einem Wulste der Nundhöhle nachgewiesen. Dieser "Geschmackswulst" (bei Chiton am genauesten untersucht) liegt am Boden der Mundhöhle, dicht hinter der Lippe. In seinem Epithel finden sich wenige Geschmacksbecher, gegenüber dem umliegenden Epithel etwas vertieft. Sie bestehen aus Sinneszellen mit frei vorragendem Sinneskegel und Stützzellen.

Rechts und links vom Munde der Pulmonaten liegt ein Mundlappen, unter dessen hohem, von einer dicken Cuticula überzogenem Epithel ein Ganglion liegt. Kileinere Ganglien finden sich in den am oberen Mundrande liegenden Läppchen. Alle diese Ganglien erhalten Nerven, die von einem Zweig des vorderen Tentakelnerven ausstrahlen. Die erwähnten Lappen (SEnp'E's's ()rgan) werden als Geschmacksorgane aufgefasst.

\section{Subradulares Sinnesorgan von Chiton.}

Bei Chiton wurde ein in der Mundhöhle gelegenes Sinnesorgan als Subradularorgan von unbekannter physiologischer Bedeutung beschrieben. Es ist eine "unter und vor der Radula gelegene Erhabenheit" und hat die Gestalt zweier mit den concaven Rändern aneinandergelegter Bohnen, wobei die Spalte zwischen ihnen eine Rinne repräsentirt, wo eine kleine Drüse mündet. Unter dem Organ liegen zwei Ganglien: Subradularganglien, Lingualganglien (vergl. das Kapitel: Nervensystem). Das Epithel des Organes besteht aus grün pigmentirten Flimmerzellen und zwei Arten Sinneszellen. Ein ähnliches, nicht genauer untersuchtes Organ kommt auch bei Patella vor, und an der nämlichen Stelle findet sich anch bei verschiedenen Diotocardiern eine Erhabenheit, aber ohne Sinneszellen. Die Scaphopoden besitzen ebenfalls ein Subradularorgan.

\section{Die Sinnesorgane der Chitonschalen.}

Auf den Schalen der Chitoniden kommen in bestimmter Anordung zahlreiche Organe vor, die wohl mit Recht als Sinnesorgane, und zwar 
als Organe des Tastgefühls betrachtet werden (Fig. 525). Sie werden A e s the ten genannt und liegen in Poren des Tegmentums (vergl. p. 605). Die Aestheten sind von keulenförmiger und cylindrischer Gestalt. Jedes Aesthet trägt aussen eine tief becherförmige Chitinkappe. Vom Aesthet (Megalästhet) zweigt sich ein einfacher bis mehrfacher Kranz dünner Abzweigungen, Mikrästheten, ab, von denen eine jede mit einer Anschwellung endigt, welche ein kleineres Chitinkäppchen trägt. Der Körper der Aestheten besteht vorwiegend aus grossen, langen, drüsenähnlichen Zellen; er setzt sich in einen Faserstrang fort, der an die Basis des Tegmentums verläuft und von da an, zusammen mit den Fasersträngen der übrigen Aestheten einer Chitonschale, zwischen Tegmentum und Articulamentum hinziehend das umgebende Mantelgewebe erreicht oder das Articulamentum selbst durchsetzt.

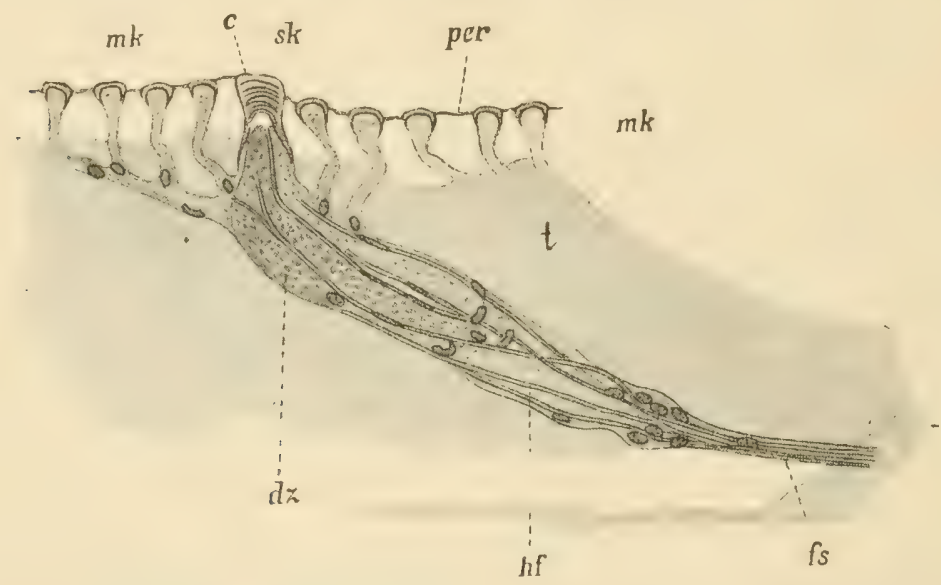

Fig. 525. Schnitt durch das Tegmentum von Chiton laevis zur Demonstration eines Aestheten, nach Blumich, $m k$ Mikrästheten, per Periostracum, sk Hauptästhet, $t$ Tegmentum, $d z$ drüsenähnliche Zellen, $h f$ helle Fasern, fs Faserstrang, $c$ Chitinkappe.

Die Deutung der einzelnen Formbestandtheile der Aestheten und ihrer Easerstränge ist noch nicht sicher. Es ist wahrscheinlich, dass sie von dorsalen Seitehästen der Pleurovisceralstränge innervirt werden. Vor allem weiss man nicht, ob die Faserstränge der Aestheten ihre Nerven sind oder ob die in ihrem Inneren verlaufenden hellen Fasern langgestreckte Sinneszellen sind, deren Kerne zwischen den Drüsenzellen des Aesthetenkörpers liegen würden und die mit Nervenfasern in Zusammenhang stünden.

Die Annahme erscheint gerechtfertigt, dass die Aestheten nur Modificationen der Stacheln mit ihren Papillen und Bildungszellen sind, welche im Integument der Chitonen so verbreitet vorkommen. Die Chitinkappen würden dann einem Theile der chitinigen Basis der Stacheln entsprechen.

Dafür, dass die Aestheten Sinnesorgane sind, spricht besonders auch der Umstand, dass bei einzelnen Chitonenarten einzelne Megalästheten zu Augen umgewandelt sind.

Jedes Auge ist von einer Pigmenthülle umgeben, welche von den Mikrästheten durchsetzt wird, und aussen bedeckt von einer gewölbten Lage des Tegmentums, welche die Corne a des Auges bildet. 
Unter der Cornea findet sich eine I.inse und unter dieser eine als Retin a betrachtete Zelllage, an welche sich ein demjenigen der Aestheten entsprechender Faserstrang (Opticus?) anheftet.

\section{B) Gehörorgane.}

Alle Mollusken mit einziger Ausnahme der Amphineuren besitzen Gehörorgane, welche ontogenetisch sehr frühzeitig auftreten. Es sind zwei, meist allseitig geschlossene $\mathrm{H}$ örbläsch en (O tocy s ten), deren Epitbelwand gewöhnlich aus Wimperzellen und Sinneszellen besteht. In dem von Flüissigkeit erfüllten Binneuraume des Bläschens sind Gehörsteinchen (Otolithen) in verschiedener Zahl (von 1 bis über 100), Grösse, Form und chemischer Beschaffenheit suspendirt und beim lebenden Thiere in zitternder Bewegung.

Was die Lage der beiden Otolithen ambetrifft, so finden sie sich gewöhnlich auf den Pedalganglien oder in deren Nähe, seltener weiter von ihnen entfernt. Trotzdem ist der sichere Nachweis vielfach geleistet, dass der $\mathrm{H} \ddot{\mathrm{r}} \mathrm{nerv}$ nicht aus dem Pedalganglion, sondern aus dem Cerebralganglion stammt, freilich aber oft dem Cerebropedalconnectiv dicht anliegt oder zusammen mit seinen Fasern verläuft.

In den meisten Fällen entstehen die Hörbläschen durch Einstülp ung vom äusseren Epithel aus. Nun ist der kürzlich geführte Nachweis von Interesse, dass bei ursprünglichen Lamellibranchiern (Nucula, Leda, Yoldia) jedes der beiden $\mathrm{Hörbläs} \mathrm{chen} \mathrm{noch} \mathrm{beim} \mathrm{erwachsenen}$ Thiere durch einen langen $\mathrm{Kanal}$ an der Oberfläche des Fusses a usm ündet. Die Gehörsteinchen sind hier von aussen aufgenommene Fremdkörper, Sandkörnchen. Bei Cephalopoden erhält sich wohl noch ein Rest des Einstülpungskanals als KöLuıKeR'scher Kanal; er ist aber blind geschlossen.

Die höchste Ausbildung erhalten die Gehörorgane innerhalb der Mollusken bei den guten Schwimmern, besonders den Cephalopoden und Heteropoden. Hier kommt es zur Bildung von Maculae und $\mathrm{Cr}$ is tae acusticae.

Heteropoden. Das genau untersuchte Gehörorgan von Pterotrachea (Fig. 526) hat folgenden Bau. Die Wand der Blase besteht zunächst aus einer structurlosen, von Muskel- und Bindegewebselementen umhüllten Membran. Im Innern der mit Flüssigkeit erfüllten Gehörblase ist ein kalkiger Otolith von concentrisch geschichtetem Bau suspendirt. Die Innenfläche der Blase ist von einem Epithel ausgekleidet, das aus drei verschiedenen Zellarten besteht: Hörzellen, Wimperzellen, Stützzellen. Die unbewegliche Sinneshaare tragenden Hörzellen finden sich an der der Eintrittsstelle des Hörnerven diametral gegenüberliegenden $W$ and der Hörblase (Macula acustica). Hier findet sich in Centrum eines von vielen Hörzellen gebildeten Hofes, von diesen durch 4 Stütz- oder Isolationszellen getrennt, eine grössere, centrale IÏ̈rzelle. An dem grösseren übrigen Theil der Hörbläschenwand finden sich zwischen indifferenten 'Lellen flachere Wimperzellen, welche sehr lange Wimpern oder Borsten tragen, die eigenthümliche Bewegungen zeigen. Sie könuen sich nämlich auf die Inneuwaud der Blase niederlegen und dann wieder (wie behauptet wird, bei stärkeren Schallreizen) aufrichten, so dass sie dann, gegen das Centrum der Blase vortretend, den Otolithen stützen.

Der Hörnerv, welcher an dem der Centralzelle diametral gegenüberliegenden Pol an dic Hörblase herantritt, strahlt sofort in Fasern 
aus, "welche, wie an einem Globus vom Pole aus die Meridiane, alle in einer Richtung über die ganze Wand der Gehörblase ausstrahlen" um schliesslich die Hörzellen an ihrem basalen Ende zu innervieren.

Noch complicirter sind die beiden Hörlläschen der Cephalopoden, welche in zwei geräumigen Höhlen des liopfknorpels liegen. Das Simesepithel findet sich hier auf einer Macula acustica und

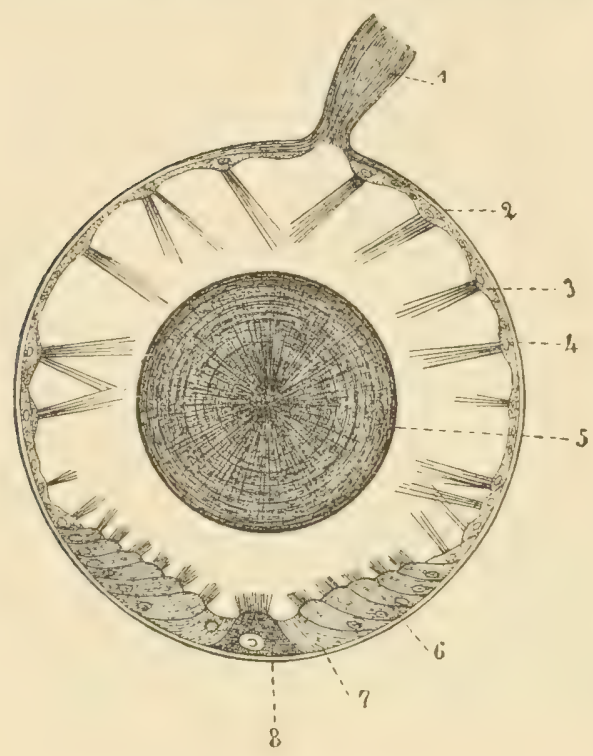
auf einer leistenförmigen, nach innen vorspringenden $\mathrm{Cr}$ is t a acustica. Otolithen finden sich nur auf der Macula acustica. Der Hörnerv theilt sich in zwei Aeste, von denen der eine zur Macula-, der andere zur Crista acustica geht. Als Rest der Einstülpungsöffnung findet sich der oben erwähnte, innen flimmernde, an dem einen Ende blind geschlossene, an dem anderen sich in das Hörbläschen öffnende KöLLIKERsche Kanal.

Fig. 526. Gehörorgan von Pterotrachea, nach Claus. 1 Hörnerv, 2 structurlose Membran, 3 und 4 Wimperzellen, 5 Otolith, 6 Hörzellen, 7 Stützoder Isolationszellen, 8 grosse centrale Hörzelle.

Experimentelle Untersuchungen an Cephalopoden haben dargethan, dass eine der Functionen der Gehörbläschen die ist, das Thier mit Bezug auf seine Gleichgewichtslage bei der Locomotion zu orientiren.

\section{C) Sehorgane.}

1. A ugengruben.

Es sind dies die einfachsten Sehorgane. Sie bestehen aus grubenförmigen, also nach aussen offenen, Einstülpungen des Körperepithels, das am Borlen der Grube die Retina bildet. Die Augengrube ist bald ziemlich Hach, bald tief, von der Gestalt einer weitbauchigen Flasche, die mit einem kuzen, engen Hals mündet. Der A u gennerv tritt an den Boden der Augengrube heran, um sich auf ihm auszubreiten. Die Epithelwand (Retina) der Augengrube besteht - und dies scheint für alle Gasteropodenaugen zu gelten - aus zwei Arten von langen, fadenförmigen Zellen: 1) aus hellen, pigmentlosen Zellen; 2) aus Pigmentzellen. Ob die hellen oder die Pigmentzellen oder beide Arten (?) Retinazellen sind, ist noch strittig. In den Pigmentzellen findet sich, dies ist für einige Fälle sicher nachgewiesen, das Pigment nur in der peripheren Zone, so dass die Axe der Zelle pigmentfrei ist und als erregbarer Theil betrachtet werden kömnte. Die hellen Zellen würden dann indifferente Zwischenzellen oder Secretzellen sein. - Die Retina wird gegen die Höhlung der Augengrube zu überzogen von einem dicken, gallertigen Cuticularüberzug, oder es ist die ganze Augengrube erfüllt von einem oft als Lins e bezeichneten Gallertkörper. Man hat 
die hellen oder Secretzellen als diejenigen betrachtet, welche diese Gallertmasse absondern. Neuerdings ist man eher geneigt, die hellen Zellen für die Retinazellen zu halten.

Augengruben finden sich innerhalb der Gasteropoden nur bei den ursprüngliche Charaktere aufweisenden Diotocardiern. Sie wurden beobachtet bei Haliotiden, Patellidae, Trochidae, Delphinulidae und Stomatiidae.

Mit Hinblick darauf, dass unter allen lebenden Cephalopoden $\mathrm{N}$ a u tilus (Fig. 527) als die ursprünglichste Form betrachtet werden muss, ist es interessant $\mathrm{zu}$ constatiren, dass die beiden $\mathrm{N}$ autilusaugen A ugengruben sind. Die Sinneszellen der Retina, das heisst der Epithelwand der Augengrube, besitzen eiu gegen die Augenhöhle vorragendes cuticulares Stäbchen. Zwischen die Ausbreitung des Sehnerven und der Retina ist eine Schicht von Ganglienzellen eingeschaltet.

Fig. 527.

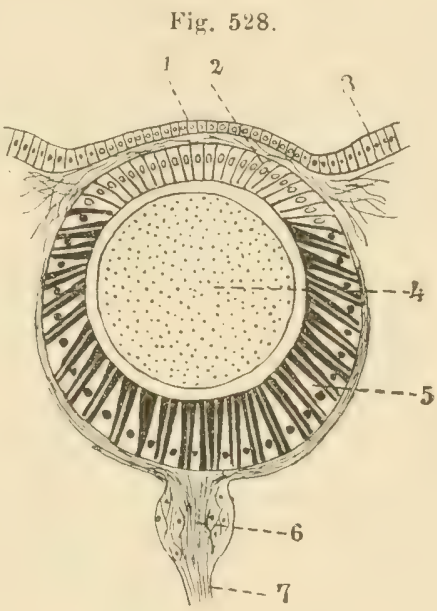

Fig. 527. Auge von Nautilus, nach HENsEN. 1 Augenhöhle (Grube), 2 Stäbchenschicht, 3 Pigmentschicht, 4 Sehzellenschicht, 5 Ganglienzellenschicht, 6 Aeste des Sehnerven.

Fig. 528. Auge eines Pulmonaten. 1 Aeussere Cornea, 2 innere Cornea, 3 Körperepithel, 4 Glaskörper, 5 Retina, 6 Ganglion opticum, 7 Sehnerv.

\section{A ugenblasen oder Bläschenaugen.}

Die Augenllasen gehen aus Augengruben ontogenetisch (und wohl auch phylogenetisch) dadurch hervor, dass die Ränder der Augengrube einander entgegenwachsen und schliesslich verschmelzen. Dadurch wird aus der Grube eine Blase, über welche das äussere Epithel continuirlich hinwegzieht (Fig. 528). Dieses äussere Epithel ist üler dem Auge pigmentfrei und wird als äussere Cornea bezeichnet, während die unmittelbar darunter liegende, ebenfalls pigmentfreie Epithelwand der Augenblase als innere Cornea bezeichnet wird. Der ursprüngliche Epithelboden der Augengrube bildet auch hier die Retina. Die Retinazellen besitzen deutliche, gegen die vom Gallertkörper erfüllte Höhle der Augenblase vorragende, St äb che n. Der Augennerv schwillt gewöhnlich, bevor er an die Retina herantritt, zu einem peripheren Ganglion opticum an. 
Die Tentakelaugen der meisten Gasteropoden, mit Ausnahme jener Diotocardier, welche Grubenaugen besitzen, zeigen den hier beschriebenen einfachen Bau.

\section{Das Auge der dibranchiaten Cephalopoden}

gehört zu den höehstentwickelten des ganzen Thierreiches. Es ist eine Weiterbildung des Gruben- und des Bläschenauges, und wir haben gesehen, dass das Auge der Tetrabranchiaten (Nautilus) zeitlebens ein Grubenauge bleibt.

In der Ontogenie (Fig. 529) werden diese Stadien durchlaufen. Es bildet sich zunächst eine Augengrube (primäre Augengrube), dann schnürt sich dieselbe zu einer Augenblase (primäre Augenblase) ab, deren innere Wand zur Retina, deren äussere (der inneren Cornea des Bläschenauges entsprechende) Wand zum inneren Corpus epitheliale wird. Dieses embryonale Bläschenauge complicirt sich nun zunächst dadurch, dass die über dem Auge hinwegziehende Haut (äussere Cornea des Bläschenauges) sich in Form eines Ringwalles erhebt und dann über dem Auge gegen die Axe desselben zu diaphragmaartig vorwächst. Das Diaphragma wird zur Iris, die Oeffnung in demselben zur Pupille. Die zwischen der kreisförmigen Irisbasis sich ausdehnende Haut liegt dem inneren Corpus epitheliale dicht an und wird zum äusseren Corpus epitheliale.

Das innere Corpus epitheliale bildet nach innen, gegen die Höhlung der primären Augenblase zu eine annähernd halbkugelige Lin se, ebenso

A

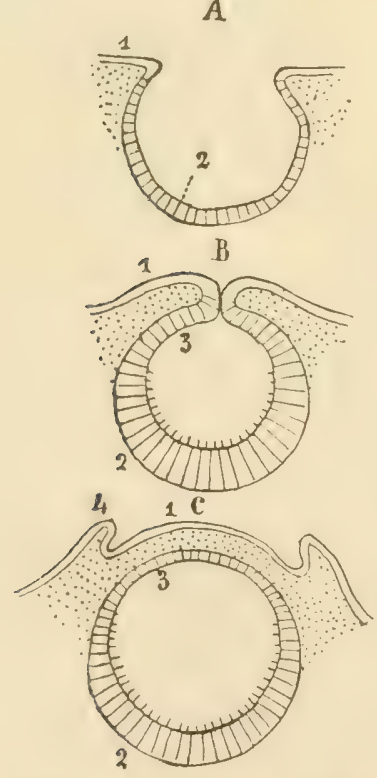

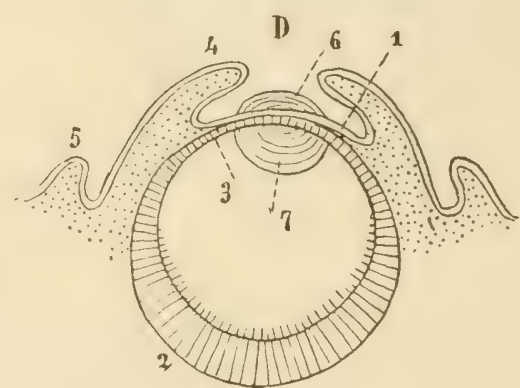

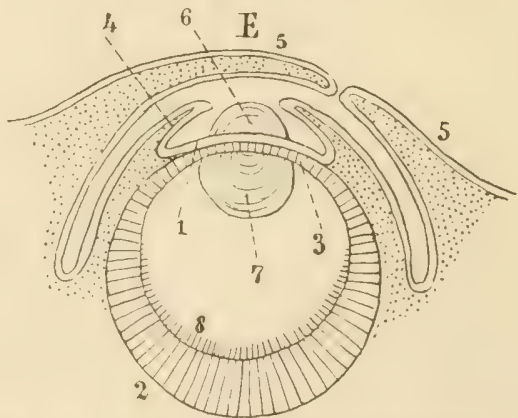

Fig. 529. Entwickelung des Áuges der dibranchiaten Cephalopoden. 1 Körperepithel, welches zum äusseren Corpus epitheliale wird, 2 innere Wand der Augengrube, welche zur Retina wird, $\mathbf{3}$ äussere Wand der Augenblase, welche zum inneren Corpus epitheliale wird, 4 Falte, welche die Iris bildet, 5 Falte. welche die secundäre Cornea bildet, 6 vom äusseren, 7 vom inveren Corpus epitheliale erzeugter Linsentheil, 8 Stäbchenschicht der Retina. 
erzeugt das äussere Corpus epitheliale nach aussen, gegen die Pupille $\mathrm{zu}$, eine halbkugelige Linse. Beide Halbkugeln liegen so, dass sie sich anuähernd zu einer Kugel ergänzen, an der aber immer die doppelte Zusammensetzung kenntlich bleibt, indem die kugelige Linse in ibrer Aequatorealebene von der Doppellamelle des Corpus epitheliale durchsetzt wird.

Schliesslich wächst über das so gebildete Auge eine neue Ringfalte der Haut hinweg, welche über dem Auge eine neue Augenhöhle bildet. Diese Falte bildet die secundäre Cornea des Dibranchiatenauges, welche also nicht mit der primären Cornea des Bläschenauges verwechselt werden darf, denn letztere ist im Dibranchiatenauge durch das Corpus epitheliale repräsentirt. Bei den meisten Formen gelangt die Ringfalte (Cornea) iiber dem Auge nicht vollständig zum Verschluss, sondern es bleibt eine Oeffnung übrig, durch welche die vordere Augenkammer mit dem Meereswasser communicirt. Bei einigen Formen aber bildet die Ringfalte über dem Auge eine vollständig geschlossene secundäre Cornea.

Diese entwickelungsgeschichtliche Skizze verschafft einen Einblick in den allgemeinen Aufbau des Dibranchiatenauges. Es mögen nun noch einige ergänzende Bemerkungen über die Structur des erwachsenen Auges folgen (Fig. 530 und 531).

1) Retina (Fig. 531). Die Retina besteht aus zwei Arten von Zellen, 1) pigmentführenden Seh-oder Stäbchenzellen und 2) Li mitanzellen. Dadurch, dass die Kerne der Sehzellen in der Retina in einer (mit Bezug auf das Centrum der Augenblase) äusseren, diejenigen der Limitanszellen in einer inneren Schicht liegen, und dadurch, dass zwischen beiden Schichten eine Grenzmembran die Zwischenräume zwischen den Retinazellen durchsetzt, erscheint die Retina scheinbar geschichtet, sie besteht aber in Wirklichkeit aus einer einzigen Zelllage. Die Stäbchen der Retinazellen liegen auf der inneren Seite der Grenzmembran, sind also der Lichtquelle und zugleich der Höhlung der primären Augenblase zugekehrt. Die Retina ist auf ihrer Innenseite von einer homogenen, ziemlich dicken Membrana limitans überzogen.

2) Das Auge ist, mit Ausnahme der der Körperoberfläche zugekehrten Seite, von einer der Sclera des Wirbelthierauges ähnlichen Knorpelkapsel umgeben, welche da, wo sie die Retina bedeckt, zum Durchtritt der Fasern des Sehnerven siehartig durchbrochen ist.

3) Unmittelbar unter dem Knorpelboden der Retina liegt ein sehr grosses Ganglion opticum, als ein mächtiger Hirnlappen. Aus ihm entspringen die eben erwähnten, die knorpelige Augenkapsel durchsetzenden, zur Retina verlaufenden Nervenfasern.

4) Die beiden Linsenhälften, die übrigens ungleich gross sind (die äussere ist kleiner), bestehen aus homogenen, zwiebelartig übereinander gelagerten Lamellen.

5) Die Höhlung der primären Augenblase (zwischen Retina und Linse) ist von glashell durchsichtiger Flüssigkeit erfüllt.

Es ist festgestellt, dass, ähnlich wie bei Arthropoden und Vertebraten, die Pigmentkörner der Stäbchenzellen sich verlagern können, indem sie sich in der Dunkelheit an die Basis, im Lichte an das freie Ende der Zelle begeben. 
4. Die Rückenaugen von Onchidium und die Augen des Mantelrandes von Pecten (Fig. 532) und Spondylus.

Man hat diese Augen als nach dem Typus der Wirbelthieraugen gebaute bezeichnet, weil bei ihnen die Stäbchen der Retina gegen das Innere des Körpers gerichtet, also von der Lichtquelle abgewendet sind.

\section{Fig. 530 .}

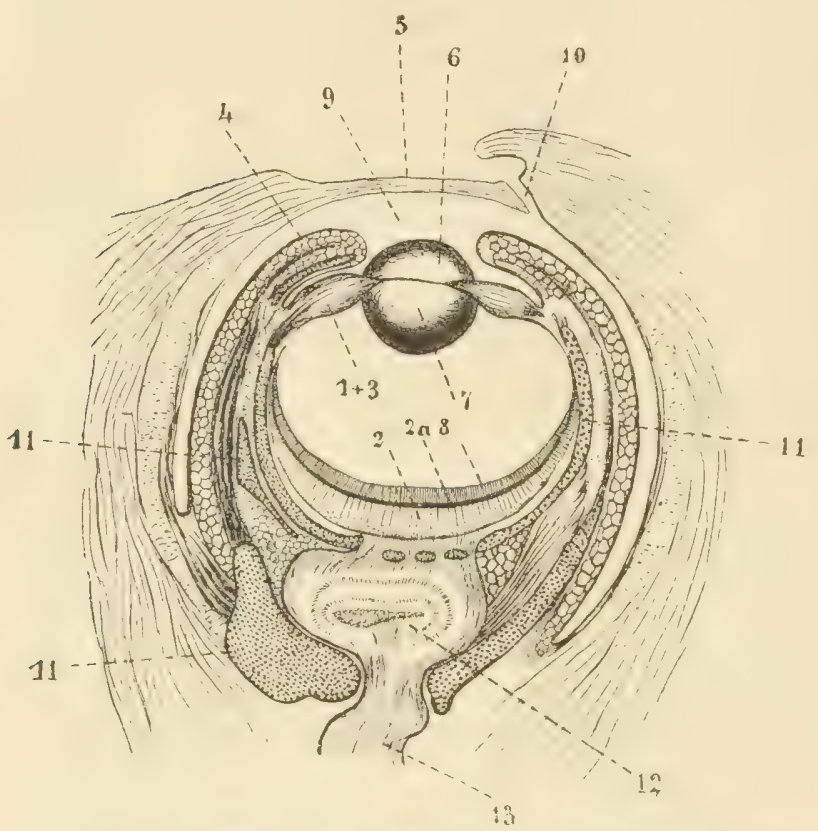

Fig. 530. Schnitt durch das Auge von Sepia officinalis, etwas schematisch, nach Hensen, $1-8$ wie in Fig. 529, $1+3$ Corpus epitheliale, 9 vordere Augenkammer, sich bei 10 nach aussen öffnend, 11 knorpelige Augenkapsel, 12 Ganglion opticum $=$ Retinaganglion, 13 Nervus opticus, 2a Pigmentschicht der Retina.

Fig. 531. Zwei Retinazellen von Cephalopoden, starl vergrössert, nach GreNaCHER. 1 Membrana limitans, 2 Pigment, 3 Secretfäden, 4 Nervenfaser, 5 Stäbchen, 6 Pigment, 7 Limitanszelle, 8 Grenzmembran, 9 Retinazelle, 10 Nervenfaser.

Sie gehören in die Kategorie der Bläschenaugen. Al)er es ist hier die äussere der Lichtquelle zugekehrte Wandung der Augenblase, welche zur Reti n wird, während die imnere (bei den anderen Molluskenaugen als Retina entwickelte) Wand ein Pigmentep it he l darstellt. Zugleich ist die äussere oder Retinawand gegen die innere oder Pigmentwand eingestülpt, wie bei der Gastrulabillung durch Invagination das Entoderm gegen das Ectoderm. Die Folge davon ist, dass die bei den anderen Molluskenaugen vom Gallertkörper (Linse) erfüllte Höhlung der Augenblase verschwindet und die Augenblase selbst zu einem flachen, aber dickwaudigen Teller (Pecten) oder Becher (Onchidium) wird, dessen Wandung aus Pigmentschicht und Retina besteht. Das über das Auge hinwegziehende Körperepithel ist über dem Auge pigmentlos, durch- 


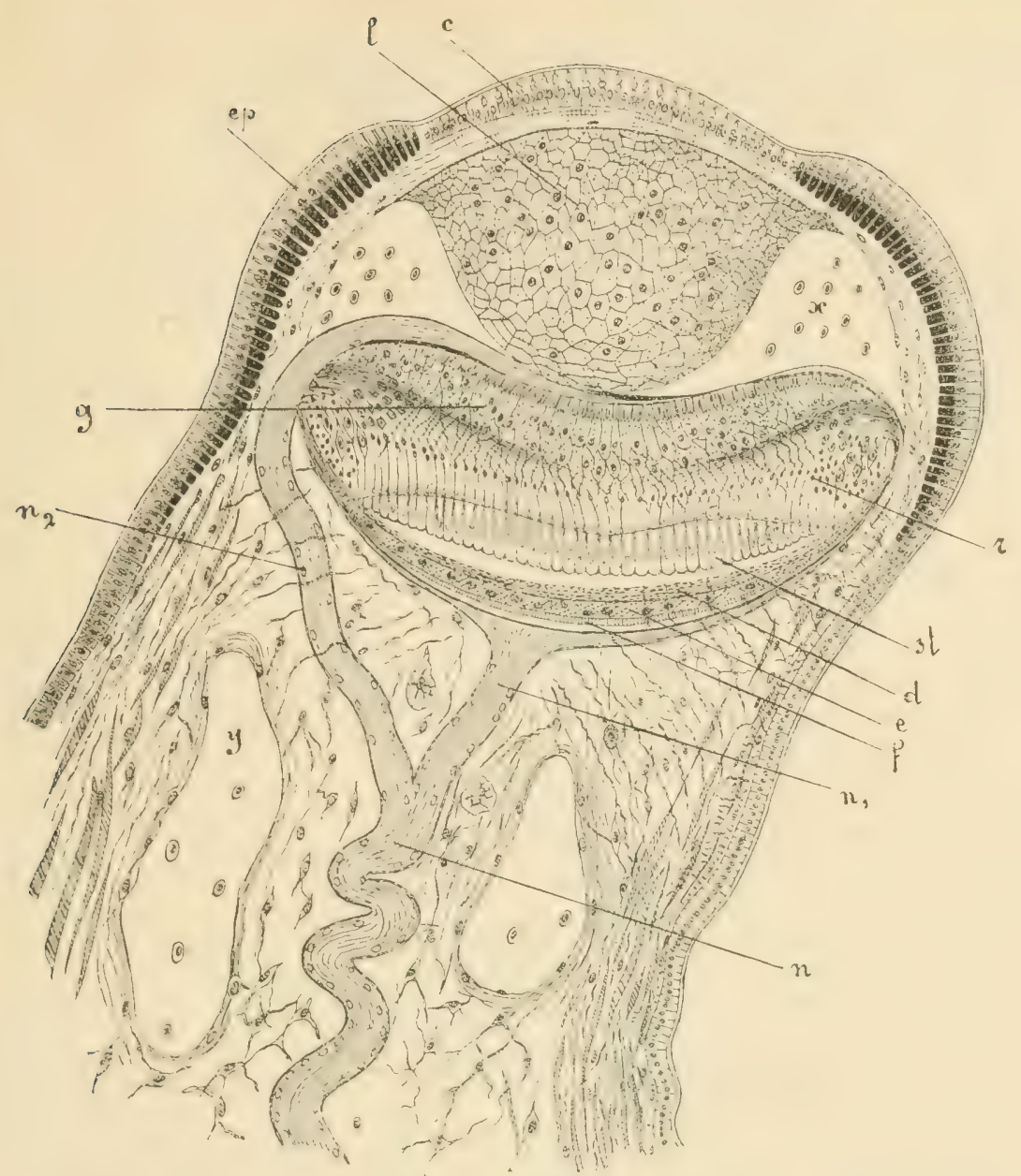

Fig. 532. Schnitt durch das Auge von Pecten, nach Patten. $c$ Cornea, $l$ Linse, ep pigmentirtes Körperepithel, $g$ Ganglienzellenschicht, $r$ Retina, st Stäbchenschicht der Retina, $d$ Tapetum, $e$ Pigmentepithel, $f$ Sclerotica, $n$ Nervus opticus, $n_{1}$ und $n_{2}$ seine beiden Aeste.

sichtig und wird hier zur Cornea. Unter der Cornea, in dem Augenhecher oder auf dem Augenteller liegt eine zellige Linse, die beim Rückenauge von Onchidium aus wenigen (5) grossen Zellen, beim Mantelauge von Pecten und Spondylus aus sehr zahlreichen Zellen besteht. Ihre Entwickelung ist unbekaunt. Vielleicht geht sie aus einer Verdickung oder Einstülpung des embryonalen Ectoderms hervor, welches das Auge überzieht.

Bei Onchidium durchsetzt der Sehnerv die Wand des Augenbechers (ähnlich wio beim Wirbelthierauge), um sich auf der (mit Bezug auf das Centrum der Augenblase) inneren Oberfläche der Retina auszubreiten und die Retinazellen zu innerviren.

Bei Pecten theilt sich der zu jedem Auge gehende, vom Mantelrand- 
nerven stammende Sehnerv in nächster Nähe des Auges in zwei Aeste. Der eine tritt an den Boden des Augentellers und löst sich hier in seine Fasern auf, welche, nach allen Seiten ausstrahlend, den Rand des Tellers erreichen, um hier, nach innen gegen die Retina umbiegend, einen Theil der Retinazellen zu innerviren. Der andere Ast verläuft direct bis an eine Stelle des Tellerrandes, um hier rechtwinklig umzubiegen und einen anderen Theil der Retinazellen mit seinen Fasern zu versorgen. Die Fasern dieses Astes verbinden sich aber nicht direct mit den Retinaoder Stäbchenzellen, vielmehr ist zwischen beide eine Schicht von Ganglienzellen, die miteinander anastomosiren, eingeschaltet. Zwisehen Pigmentschicht und Stäbchenschicht der Retina findet sich ein Tapetum luc i d um, welches dem Pectenauge seinen metallischen Glanz verleiht.

Die Rückenaugen von Onchidium finden sich bei vielen Species dieser Gattung. Sie liegen an der Spitze jener contractilen Papillen, welche das Rückenintegument dieser merkwürdigen Pulmonaten tragen kann, und zwar kommen auf jede Papille 3-4 solcher Augen. Daneben besitzt Onchidium noch die beiden normalen Kopfaugen der Gasteropoden.

Die Mantelaugen der Muscheln Pecten und Spondylus finden sich in grösserer Anzahl am Mantelrande dieser Thiere, zwischen den längeren Tentakeln, auf der Spitze kurzer Tentakel. Die Stäbchen der Pectenretina besitzen im frischen Zustande eine sehr vergängliche, rothe Färbung (Sehpurpur?).

\section{Die Schalenaugen der Chitonen}

sind schon p. 746 erwähnt worden. Ihre morphologische Deutung ist so lange noch unsicher, als ihr histologischer Bau nicht noch genauer untersucht und ibre Entwickelung unbekannt ist.

\section{Die zusammengesetzten oder Fächeraugen von Arca (Fig. 533) und Pectunculus.}

Sie finden sich in grossel Anzahl am Mantelrande dieser Muscheln und sind epitheliale Organe, die ihrem Baue nach keineswegs mit den Sehwerkzeugen anderer. Mollusken, vielmehr eher mit gewissen einfachen Arthropodenaugen übereinstimmen.

Sie haben die Gestalt einer nach aussen vorgewölbten Schale. Die einschichtige Epithelwand rer Schale setzt sich an ihrem Rande in das

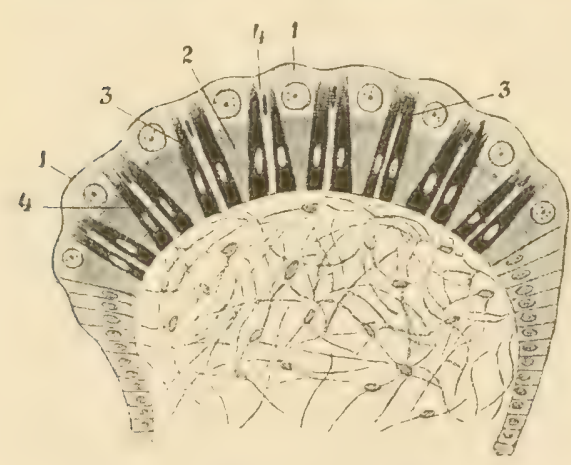
umgebende Mantelepithel fort. Auf einem Schnitte erscheinen die sie zusammensetzenden Elemente fächerförmig angeordnet (daher auch der Name Fächerauge). Diese Elemente sind dreierlei Art: 1) Conische Sehzellen, deren Basis nach aussen gerichtet ist. 2) Jede dieser Sehzellen ist umgeben von einer Scheide von 6 cylindrischen Pigmentzellen. Man kann jede Gruppe von einer Sehzelle und von umgebenden Pigmentzellen als ein Einzelauge, ein Ommatidium

Fig. 533. Schnitt durch das Auge von Arca barbata, nach den Angaben und Figuren von RAwitz gezeichnet. 1 Retinazelle mit stäbchenähnlichem Körper 2, 3 Pigmentzellen, 4 schlanke Füll- oder interstitielle Zellen. 
von einfachstem Bau betrachten, als ein Onmatidium, an welchem die Retinula durch eine einzige Sehzelle repräsentirt wäre. 3) Kwischen den Ommatidien stehen schlanke, fast fadenförmige "Füllzellen."

\section{Verkümmern der Kopfaugen.}

Es wird in der neuesten Zeit immer wahrscheinlicher, dass die Kopfaugen der verschiedenen Mollusken homologe Gebilde sind und dass sie von Haus aus allen Mollusken zukommen. Sie können aber unter bestimmten biologischen Verhältnissen rudimentär werden und auch ganz verschwinden, so namentlich bei Schlammthieren und Bohrmollusken, bei Mollusken der Tiefsee, bei parasitischen Mollusken. Auch die Lamellibranchier und Chitonen (?) besitzen vorübergehend auf Entwickelungsstadien Kopfaugen, die aber später ganz verschwinden, da sie, von der Schale bedeckt, nutzlos werden. Sie können durch an geeigneteren Stellen neu auftretende Sehorgane ersetzt werden: Augen am Mantelrande gewisser Muscheln, Schalenaugen der Chitonen.

\section{Der Darmkanal.}

Der Darmkanal ist bei allen Mollusken wohlentwickelt und zerfüllt in aufeinanderfolgende Abschnitte, als da sind: 1) Mundhöhle; 2) Pharynx oder Schlundkopf; 3) Oesophagus oder Vorderdarm; 4) Mitteldarm mit II agen; 5) Rectum oder Enddarm, mit dem After nach aussen mündend. Ursprünglich liegt der Muni am Vorderende, der After am Hinterende oder an der Hinterseite des Körpers, letzterer in der Mantelfurche oder Mantelhöhle. Ueberall verharrt der Mund in der ursprünglichen Lage, wälnrend der After bei den Gasteropoden als Centrum des Pallealcomplexes die ursprünglich hinterständige Lage verlïsst und auf der rechten (seltener auf der linken) Seite sich in der Mantelfurche mehr oder weniger weit nach vorn verschiebt.

Wo der Körper dorsalwärts zu dem Eingeweidesack auswächst, derart, dass die Längsaxe gegenüber der dorsoventralen Axe verkürzt erscheint, wie dies bei vielen Gasteropoden, den Cephalopoden und Dentalium der Fall ist, tritt zum mindesten der Mitteldarm mit seiner Anhangsdrüse, der sog. Leber in diesen Eingeweidesack empor, diesen zum grössten Theil ausfüllend. Der Darm bildet dementsprechend bei diesen Thieren eine dorsale Schlinge mit einem von Vorderdarm aufsteigenden und einem zum After absteigenden Schenkel. Der letztere biegt bei den Gasteropoden, wo die Afterötfinung mehr oder weniger weit nach vorn verschoben ist, auf der rechten (selten auf (ler linken) Seite nach vorn um, um den After zu erreichen.

Abgesehen von dieser Hauptschlinge, die durch die Ausbildung des Eingeweidesackes und zum Theil durch die Verschiebung des Pallealcomplexes bedingt wird, bildet der Darm bei fast allen Mollusken noch secundäre Schlingen oder Windungen, wodurch er sich verlängert. Diese Schlingen finden sich gauz vorwiegend an dem auf den Magen folgenden röhrenförmigen Theil des Mitteldarms. Sie sind im allgemeinen bei Pflanzenfressern an stärksten ausgesprochen und bedingen eine grössere Länge des Darmes als bei den Carnivoren.

In den Magenibschnitt des Mitteldarms der Mollusken mündet eine fast immer voluminöse Verda u ung gr r ü se, llie gewöhnlich als L, eb e r 
bezeichnet wird. Functionell stimmt diese Mitteldarmdrüse nicht oder nur zum geringsten Theil mit der Leber der Wirbelthiere, eher mit dem Pancreas überein. Sie vereinigt vielleicht die Functionen der verschiedenen specialisirten Verdauungsdrüsen der Vertebraten.

Ein durchgreifender Unterschied zwischen Lamellibranchiern einerseits und allen übrigen Mollusken andererseits besteht darin, dass bei letzteren der vordere, auf die Mundhöhle folgende Abschnitt des Vorderdarmes als musculöser Pharyux (Schlundkopf, Buccalmasse) entwickelt ist und an seinem Boden auf einem verschiebbaren $Z$ ungenwulst eine Reibplatte, Radula, trägt, die mit zahlreichen, harten, wohl aus Conchiolin oder Chitin bestehenden Z ähnen besetzt ist. Diese Zunge dient meist zum Zerkleinern der Nahrung, gelegentlich aber auch zum Packen, Festhalten und Verschlucken der Beute. Den Lamellibranchiern fehlt ein dermaassen bewaffineter Pharynx durchaus. Sie werden deshalb auch als Aglossa allen übrigen Mollusken, den Glossophor a, gegenübergestellt.

In der Mundhöhle der Gloss ophora finden sich fast immer harte K i efer aus Conchiolin in verschiedener Zahl und Anordnung. Solche Kiefer fehlen bei allen Lamellibranchiern.

In den Pharynx der Glossophora münden ein oder zwei Paar Drüsen, die gewöhnlich als Speicheldrüsen (Buccaldrüsen) bezeichnet werden, obschon sie physiologisch nicht oder nur wenig den gleichnamigen Drüsen der Vertel)raten entsprechen. Auch in die Mundhöhle können Drüsen münden. Die Lamellibranchier besitzen keine Speicheldrüsen.

Das Fehlen des Pharynx, der Zunge, der Kiefer und der Speicheldrüsen bei den Lamellibranchiern ist auf Rechnung ihrer Lebensweise zu setzen. Die Muscheln suchen ihre Nahrung nicht direct auf, sie sind zum Theil festsitzende Thiere, zum Theil Thiere, die sich nach Art festsitzender ernähren, indem sie durch Wimperbewegung die im einströmenden Athemwasser suspendirten kleinen Körperchen (kleinste Thierchen, mikroskopische Algen, Detrituspartikelchen) dem Munde zuführen. Die fein zertheilte Nahrung braucht nicht noch erst erfasst und zerkleinert $\mathrm{zu}$ werden.

In analoger Weise macht sich bei den Muscheln auch äusserlich der Einfluss der Lebensweise geltend, indem bei diesen ein Kopfabschnitt mit Tentakeln und Augen felit: Aglossa = Acephala, Glossophora $=$ Cephalophora.

Mit dem letzten Theil des Enddarmes steht bei einigen Gasteropoden (Aurex, Purpura) und bei Dentalium eine Analdrüse, bei den Cephalopoden (excl. Nautilus) die F a rb dr ü se (der sogenannte D in te nbeutel) in Verbindung.

Der Darmkinal der Mollusken verläuft durch die primäre und oft anch durch die secundïre Leibeshöhle, in verschiedener Weise durch hindegewelige Fasern oder Bänder befestigt. Seine Wandung besteht aus einem inneren, meist über weite Strecken flimmernden Epithel, einer äusseren Muskclschicht, in welcher Lüngs- und Ringfasern nicht immer deutlich zu Schichten angeordnet sind, und einer den Darm gegen die primïre Leibeshöhle zı überzichenden bindegewebigen Hülle.

Der Pharynx und vielleicht hie und da auch ein Theil des Oesophagus, ferner ein jedeufalls immer sehr kurzes Stuick des Enddarmes entstelen ontogenetisch aus dem ectodermalen Stomodateum resp. Procto- 
daeun. Doch ist man über die genauen Grenzen der entodermalen und ectodermalen Darmabschnitte nur wenig orientirt.

\section{A) Mundhöhle, Schnauze, Rüssel.}

Der Darmkanal beginnt mit einer von verschieden gestalteten Lippen begrenzten Mundöffnung und führt bei vieleı Glossophoren, so bei fast allen Gasteropoden, in eine von den Lippen überdachte Vorhöhle, die von einer Fortsetzung der Leibeswand des Kopfes ausgekleidet ist. An den Lippen sind nicht selten (manche Opisthobranchier, einige Prosobranchier) die Hautdrüsen als Lippendrüsen stärker entwickelt. Indem die Lippen auseinanderweichen, kann der Mund mancher Schnecken saugnapfähnlich fremde Körper, die zur Nahrung dienen, festhalten.

Bei kurzer Schnauze ist dieselbe einfach contractil. Dieses ist der Fall bei den Chitonen, den Diotocardiern, den meisten pflanzenfressenden Tänioglossen, vielen Pulmonaten und Nudibranchiern. Dabei ist meist die Umgebung des Mundes stärker contractil, so dass bei erfolgender Contraction der Mund etwas zurückgezogen wird, an den Grund einer Vertiefung zu liegen kommt. Eine Steigerung dieses Verhaltens bei gleichzeitiger Verlängerung der Schnauze führt zur Bildung der retractilen, einziehbaren oder $\mathrm{r}$ üsselförmigen $\mathrm{Schnauze}$. In diesem Falle kann die Schnauze von ihrer Spitze, d. h. von der Mundöffnung an in die Kopfhöhle zurückgestülpt werden, wo dann der Mund jm Grunde der eingestïlpten Schnanze liegt (manche Tectibranchier, Capulidae, Strombidae, Chenopidae, Calyptraeidae, Cypraeidae, Lamellariidae, Naticidae, Scalaridae, Solariidae).

Endlich kommt es bei manchen räuberischen Prosobranchiern (Tritoniidae, Doliidae, Cassididae, Rachiglossa und einige Toxiglossa) zur Bildung eines langen, oft sehr langen Rüssels (Fig. 454 und 534), welcher in einer besonderen $\mathrm{R} u ̈ \mathrm{sselscheide} \mathrm{eingeschlossen} \mathrm{ist,} \mathrm{die}$ selbst wieder in der Höhle des oft schnauzenförmig verlängerten Kopfes liegt und sich sogar noch weiter nach hinten in die Rumpfhöhle erstrecken kann. Am freien Vorderende des cylindrischen Rüssels liegt die Mundöffnung, und wir haben uns vorzustellen, dass der Rüssel mitsammt seiner Scheide eine ausserordentlich verlängerte Schnauze darstellt, die aber an ihrer Basis in dauernder Weise in sich selbst eingestülpt ist, so dass ein proximaler Theil der Schnauze die dauernde Rüsselscheide, der distale Theil mit der terminalen Mundöffnung den Rüssel bildet. Diese beiden Theile sind nicht aus- und nicht einstülpbar, nur eine zwischen ihnen liegende Zone wird beim Einziehen des Rüssels in die Leibeshöhle zurïckgestülpt und bildet dann eine vergängliche hintere Verlängerung der Rüsselscheide, während die nämliche Region beim Vorstrecken des Rüssels umgekrämpelt wird und am vorgestreckten Rüssel die Basalpartie desselben bildet. Die dauernde Rüsselscheide ist nämlich mit der Leibeswand des Kopfes, in dem sie liegt, durch Bänder verbunden, die eine A usstülpung derselben unmöglich machen, und die Wand des datıernden Theiles des Rüssels ist durch Bänder oder Muskeln mit dem in ihm liegenden Oesophagus verbunden, so dass dieser Theil des Rüssels nicht eingestülpt werden und der MIund niemals an den Grund der Rüsselscheide zu liegen kommen kann.

Wir beobachten also bei zurückgezogenem Rüssel am Vorderende der Schnauze oder des Kopfes eine Oeffnung, welche nicht die Mundüffnung ist, sondern die Mündung der Rüsselscheide. Wird nun der 
Rüssel vorgestreckt, so tritt er, mit der wahren Mundöffnung an seiner Spitze, aus der Mündung der Rüsselscheide hervor frei zu Tage.

Die Retraction des Rüssels wird bewirkt durch Muskeln, die sich einerseits an der Leibeswand, andererseits an die (einstülpbare) Basis des vorgestreckten Organes anheften. Bei dem Vorstrecken des Rüssels spielt wahrscheinlich Blutschwellung gegen die Schnauze zu die wichtigste Rolle, unterstützt von Contractionen der Ringmuskeln des Kopfes und des Rüssels.

Auch die Pteropoda gymnosomata (räuberische Thiere) besitzen einen mit sogenannten Buccalanhängen versehenen, vorstreckbaren Rüssel (Fig. 401). Bei ihren Verwandten, den Aplysiidae, ist er zwar

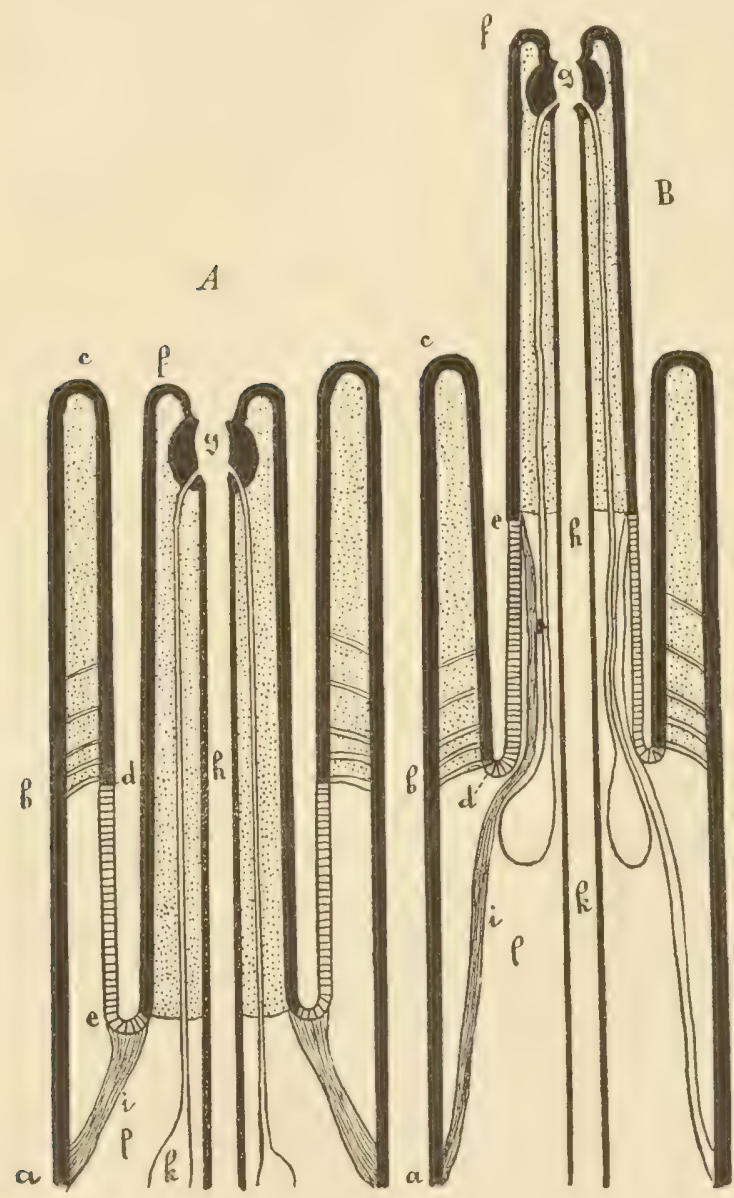
vorhanden, aber schwach entwickelt. Die Thecosomata haben keinen Rüssel.

Eine besondere Erwähnung verdient die Mundhöhle von Dentalium, welche sich in der ganzen Länge der frei vorragenden, eiförmigen, die blattförmigen Lippenanhänge tragenden Schnauze erstreckt. Jederseits der Mundhöhle liegt ein Sack, die sogenannte Backentasche, mit drüsiger Epithelwand, welche vorn in die Mundhöhle mündet.

Fig. 534. Schematische Darstellung des Rüsselapparates der Prosobranchier. $A$ Riissel zurückgezogeu; $\boldsymbol{B}$ vor. gestreckt. $a-c$ Kopfintegument, $c$ Mündungsrand der Rüsselscheide, $c-d$ nicht verschiebbare Wand der Rüsselscheide, $d-e$ verschiebbare (ausstülpbare und einstülpbare) Wand der Rüsselscheide, $e-f$ nicht verschiebbare Wand des Rüssels, $f$ Rand der Mundöffinung am vorderen Ende des Rüssels, $g$ Pharynx, $h$ Oesophagus, $i$ Rückziehmuskel, $t$ Speicheldrüsen, $l$ Kopfhöhle.

Eine genaue vergleichende Untersuchung des Mechanismus des Rüsselapparates, der contractilen Schnauze u. s. w. der Prosobranchier ist zur Zeit noch ein Postulat.

Es kommen ïbrigens noch sehr stark abweichende Formen des Rüsselapparates vor, z. B. bei Terebriden. 
Bei den Heteropoden ist der Kopf zu einer ansehnlichen Schnauze verlängert, welche oft als Rüssel bezeichnet ist. Wir können diese Bezeichnung nicht acceptiren, da die Heteropodenschnauze nicht retractil ist und der Mund immer an ihrem vorderen Ende liegt.

\section{B) Der Pharynx mit den Kiefern, der Zunge und den} Speicheldrüs en.

Auf den Mund (resp. Mundhöhle) folgt bei allen Mollusken wit Ausnahme der Lamellibranchier der musculöse Phary nx- oder Schlundkopf (Buccalmasse). Seine Höhle, die Pharyngealhöhle, öfrnet sich vorn in die Mundhöhle, hinten in den Oesophagus. Drei 'Theile sind für den Pharynx charakteristisch: in seinem vor'deren Theil, an der Grenze zwischen Mund- und Pharynxhöhle die Kiefer, an seinem Boden der Z ungenapparat und drittens die Speicheldr ü $\mathrm{sen}$, welche gewöhnlich in seinen hinteren Theil, zu beiden Seiten der Stelle münden, wo der Oesophagus aus ihm entspringt.

1) Die K i efer sind fast überall vorhanden, hie und da, besonders bei räuberischen Thieren, sehr stark entwickelt, seltener rudimentär oder 0 . Sie stellen harte Cuticularbildungen des Epithels rles vorderen Pharyngealabschnittes dar, welche wohl aus Conchiolin oder einer diesem verwandten Substanz bestehen und in einigen Fällen sich durch Auflagerung von Kalk verstärken (z. B. Nautilus).

Bezüglich der Zahl, Form und Anordnung der Kiefer herrschen grosse Verschiedenheiten, die von einem allgemeineren Gesichtspunkte aus beurtheilt werden könnten, wenn man zu der Annahme berechtigt wäre, dass ursprünglich ein geschlossener Kieferring am Eingang zum Pharynx vorhanden war, von dem sich bald nur obere und untere, bald nur seitliche Stücke erhielten.

Die Kiefer dienen zum Erfassen der Beute oder der Nahrungstheile

Ein geschlossener Kieferring am Eingange zum Pharynx findet sich z. B. bei Umbrella und Tylodina (Opisthobranchier).

Einen Oberkiefer und zwei Seitenkiefer besitzen die Süsswasserpulmonaten.

Zwei Seitenkiefer besitzen die meisten Prosobranchier und Opisthobranchier. Sie können sich einander an der Wand der Pharyngealhöhle bis zur Berührung nähern (Haliotis, Fissurella).

Die Landpulmonaten haben einen Oberkiefer, zu dem gelegentlich noch ein schwacher Unterkiefer hinzutreten kann.

Ausserordentlich stark sind die Kiefer, als Ober- und Unterkiefer, bei den Cephalopoden entwickelt, wo sie zusammen die Gestalt eines umgekehrten Papageischnabels annehmen.

Bei Opisthobranchiaten aus der Familie der Aplysiadae: Notarchus, Acera, Dolabella und Aplysiella, findet sich ausser den seitlichen Kiefern an der Decke der Pharyngealhöhle noch ein Besatz von zahlreichen Hacken oder Zähnchen. Von dieser Einrichtung dürften die gleich zu besprechenden $\mathrm{Hackensäcke} \mathrm{der} \mathrm{Pteropoda} \mathrm{gymnosomata,} \mathrm{die} \mathrm{nur} \mathrm{bei}$ Halopsyche fehlen, abzuleiten sein.

Diese Hackensäcke sind zwei paarige, längere oder kürzere Ausbuchtungen der dorsalen Pharyngealhöhle, vor der Radula. Ihre Wand trägt nach innen vorragende Hacken. Wird der Rüssel dieser rüuberischen Thiere vorgestreckt, so werden diese Säcke wie Handschuhfinger ausgestülpt, wobei die Hacken an die Aussenseite zu liegen kommen. 
Kiefer fehlen oder sind rudimentär bei den Amphineuren, den Scaphopoden, unter den Prosobranchiern bei den Toxoglossa, Pyramidellidae, Eulimidae, manchen Trochiden, den Heteropoden, ferner bei manchen Nudibranchiern (Tethys, Melibe, Doridopsis, Phyllidia), bei den Ascoglossa, bei gewissen Tectibranchiern (Actaeon, Doridium, Philine, Utriculus, Scaphander, Lobiger). Sie verschwinden unter den Pulmonaten in der Reihe der Testacelliden, wo sie bei Daudebardia rufa noch vorhanden sind, bei D. Saulcyi rudimentär werden und bei Testacella fehlen.

2) Der / ungenapparat (Fig. 535 und 536) ist für alle Mollusken mit Ausnahme der Lamellibranchier in hohem Maasse charakteristisch (Glossophora), so dass man sagen kann, jedes Thier mit einer von einer Reibplatte (Radula) bedeckten Zunge ist ein Mollusk.

Die ventrale und die Seitenwand des Pharynx ist stark musculös verdickt. Auf dem Boden der Pharyugealhöhle erhebt sich ein consistenter nusculöser Längswulst: die $Z$ un ge. Ihre Obertläche, die in die Pharyngealhöhle vorragt, wird üherzogen von einer derben, aus Chitin (oder Conchiolin?) bestehenden Cuticula, „ler Bas a l m e m l) r a n, und auf dieser erheben sich zahlreiche, oft viele tausend, harte $\mathrm{Ch}$ it inzähuchen, die dicht in Quer- und Längsveihen gestellt sind. Basalmembran und Zühnchen zusammen lilden die Reibplatte oder R a d u la der Zunge.

Das Vorterende der Zunge ragt frei in die Pharyngealhöhle vor, und die Reil)platte biegt um dieses Vorderende herum, um dasselbe auch von der Unterseite eine Strecke weit zu bedecken. Unmittelbar vor der 'Munge findet sich immer eine in die ventrale Pharyugealwand sich einsenkende Nische oder Tasche rer Pharyngealhöhle. Verfolgen wir die Reiloplatte nach hinten, so sehen wir, dass sie am hintersten Ende der Zuuge sich in die 'Tiefe eines engen, verschieden langen Schlauches einsenkt, welcher ehenfalls eine nach unten und hinten gerichtete Ausbuchtung der Pharyngealhöhle, die R a d ul as cheide, darstellt. Die Reilpplatte reicht, immer der vorderen order ventralen Wand der Radulascheide, die sich nach vorn zu der Zunge verdickt, aufliegend, bis in den Grund dieser Scheide, wo ihr Bildung sherd liegt.

Die Zunge mitsammt der ihr aufliegenden Radula kann in einer Weise bewegt werden, die in den meisten Fällen am besten der Bewegung der Zunge einer leckenden Katze verglichen werden kann, nur dass die Bewegung gewöhnlich eine langsanere ist. Bei dieser Bewegung, durch welche eine Zerreibung der von den Mandibeln gepackten, oft auch zerstückelten. Nahrung geschieht, wird die Zunge entweder nur innerhalb der Pharyngeal- und Mundhöhle bewegt, oder sie tritt in die Mundöffnung vor oder sie wird sogar mehr oder weniger weit aus der Mundöffnung vorgestreckt.

In oder unter der fleischigen Zunge findet sich sehr verbreitet ein Zungenknorpel, der aus 2 oder 4 oder noch mehr Knorpelstücken bestehen kann. Dieser Zungenknorpel bildet einmal ein festes Widerlager für die Reibplatte, und ferner gewährt er gewissen Muskeln des Zungenapparates festere Ansatzstellen.

Die in einzelne Bündel oder Züge zerfallende, oft recht complicirte Musculatur des Pharynx besteht erstens aus den die Muskelwand des Pharynx selbst bildenden Muskeln, welche, vornehmlich im Umkreise des Radularapparates, also in der ventralen und lateralen Pharyngealwand entwickelt, die Bewegung der Zunge (Leckbewegung, Reibbewegung etc.) bewerkstelligen, und z weit ens in Muskeln, welche den 
ganzen Pharynx oder doch den ganzen Zungenapparat bewegen, ihn vorstossen oder ausstülpen. Diese zweite Gruppe von Muskeln besteht im Allgemeinen aus Protractoren und Retractoren, die sich einerseits am Pharynx, andererseits, indem sie die Kopf- oder Leibeshöhle durchsetzen, an der Leibeswand ansetzen.

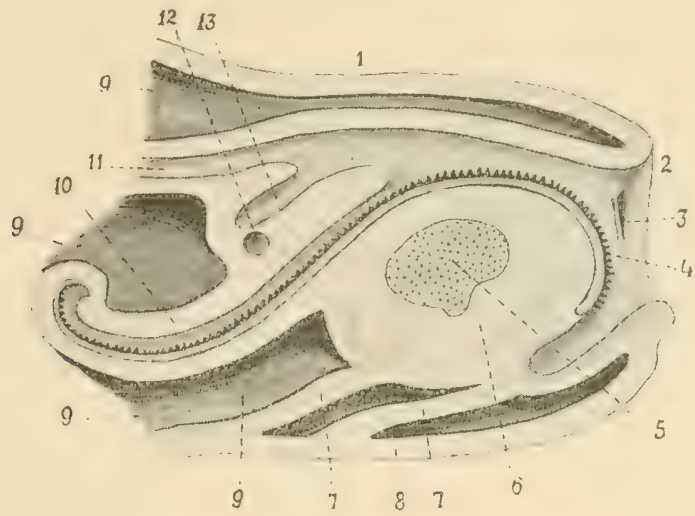

Fig. 535. Nicht ganz medianer Längsschnitt durch die Schnauze eines Prosobranchiers zur Demonstration des Pharyngealapparates. 1 Rückenwand des Kopfes, 2 Mund, 3 Kiefer, 4 Radula, 5 Zungenknorpel, 6 Muskelwand des Pharynx, 7 Muskeln, die sich einerseits an den Pharynx, anderseits an die Kopfwand ansetzen, 9 Kopfhöhle, 10 Radulascheide, 11 Oesophagus, 12 Mündung der Speicheldrüse, 13 Einfaltung hinter der Radulascheide.

Auch Blutschwellung mag beim Vorstülpen des Pharynx eine Rolle spielen.

Die Zunge mit ihrer Reibplatte dient übrigens in manchen Fällen, z. B. den räuberischen Heteropoden, auch als Organ zum Erfassen der Bente.

Die Radula oder Reibplatte ist ein Organ von grosser, systematischer Bedeutung. Für ihre genaue Kenntniss muss auf die Specialarbeiten und auf die Lehrbïcher der Conchyliologie verwiesen werden.

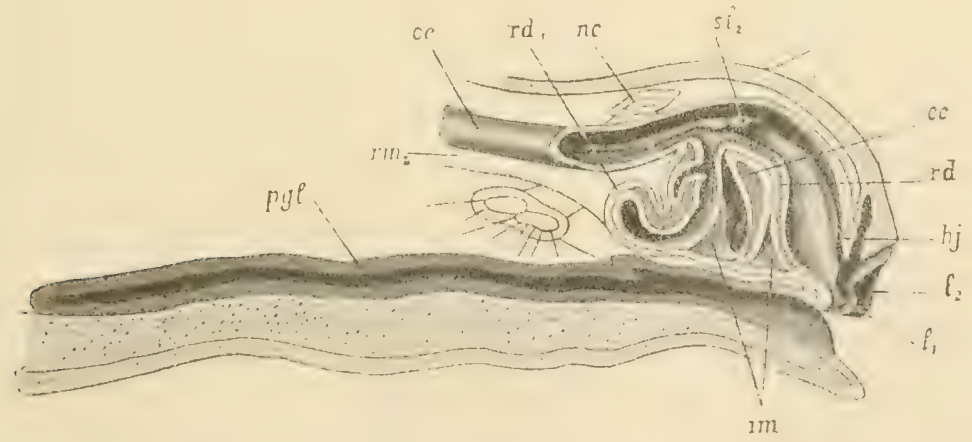

Fig. 535 a. Medianer Längsschnitt durch den Vorderkörper von Helix, nach Howes. oc Oesophagus, $r d_{1}$ Radulascheide. $n c$ Cerebralganglion, $s l_{2}$ Mündung der Speicheldrüsen, oc Muskelmasse in der ventralen Pharyngealwand, $r d$ Radula, $h j$ Oberkiefer, $l_{1}, l_{2}$ Lippen der Mundöffnung, im Pharyngealmuskeln, $r m_{2}$ Pharynxretractor, pgl Fussdrüse. 
Es kommt an: 1) auf die Grösse und Gestalt der ganzen Radula: 2) auf die Zahl der Längs- und Querreihen von Zähnchen, und 3) auf die Form der Zähne in jeder Quer- und Längsreihe. Im Ganzen gleicht eine Querreihe von Zähnchen der nächstvorhergehenden und der nächstfolgenden. Doch giebt es hiervon Ausnahmen, indem sich eine Querreihe ron bestimmtem Charakter erst nach einigen anders gestalteten Querreihen wiederholt.

Man unterscheidet im Allgemeinen drei Sorten von Zähnen. Erstens kommt gewöhnlich eine mediane Längsreihe von Zähnen auf der Radula

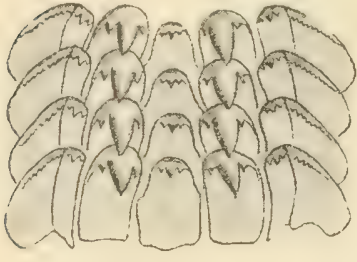

Fig. 536. Vier Querreihen von Radulazähnchen von Cyclo. stoma elegans, nach CLAPARÈDE. vor: die Reihe der centralen oder rachialen Zähne. Zu beiden Seiten dieser medianen Reihe zeichnen sich eine oder mehrere Längsreihen von Zähnen durch annähernd übereinstimmende Gestalt der Zähnchen aus: die Reihen der lateralen Zähnchen oder Pleurae. Schliesslich finden sich gegen die Seitenränder der Radula eine bis sehr zahlreiche Längsreihen von marginalen Zähnchen oder Uncin i.

Wie für die Zähne der Säugethiere, so gebraucht man auch zur Charakteristik der Bezahnung der Molluskenradula Zahnformeln, in welchen die Zahl der centralen, lateralen und marginalen Zähne einer Querreihe angegeben wird.

In der systematischen Uebersicht findet der Leser die Zahnformeln einiger Mollusken.

Die Gesammtzahl der Zähne auf der Radula schwankt ausserordentlich, von 16 bei Eolis Drummondi bis zu 39596 bei Helix Ghiesbreghti.

Im Allgemeinen finden sich die zahlreichsten und feinsten Zähne bei Pflanzenfressern. Was die räuberischen Mollusken anbetrifft, so lassen sich zwei Extreme unterscheiden: 1) starke Ausbildung eines Rüssels, schwache Entwickelung des Pharynx und der Radula, relativ geringe Anzahl von Zähnen (Beispiel: die räuberischen Prosobranchier); 2) Fehlen eines ausstülpbaren Rüssels, starke Entwickelung des Pharrngealapparates und der Radula, zahlreiche, oft grosse Zähne (Beispiele: die Heteropoden, die räuberischen Pulmonaten, die Cephalopoden).

Am stärksten ist der musculöse Pharynx bei den räuberischen Pulmonaten entwickelt, wo er fast halb so lang (Daudebardia) oder mehr als halb so lang (Testacella) als der Körper werden und einen sehr grossen Theil der Leibeshühle ausfüllen kann. Er wird derart vorgestülpt, dass die Zunge mit der Reibplatte das Vorderende des ausgestülpten Pharynx bildet (Fig. 438 A).

In sehr seltenen Fällen (abgesehen von den Muscheln) ist die Radula ganz verkümmert, so bei parasitischen Schnecken (Stilifer, Eulima, Thyca, Entoconcha), bei den Coralliophiliden (Coralliophila, Leptoconchus, Magilus, Rhizochilus), unter den Nudibranchiern bei Tethys und Melibe, unter den Amphineuren bei Neomenia und bei Arten der Gattungen Dondersia und Proneomenia. Bei Chaetoderma erhält sich von der Radula ein einziger Zahn.

Auch bei gewissen rüsseltragenden, räuberischen Prosobranchiern kann die oben angedeutete Reduction des gesammten Pharyngealapparates so woit gehen, dass die Radula fehlt (gewisse Terebraarten). 
Bildung der Radula. Bei den Reibbewegungen der Radula werden die Zähnchen ihrer vorderen, auf der Zunge aufsitzenden Querreihen fortlaufend abgenutzt und fortlaufend durch Nachschub von hinten ersetzt. Fortlaufend auch werden immer neue Querreihen von Zähnchen im hinteren, blinden Grunde der Radulas cheid e gebildet. Sie werden hier bei Pulmonaten und Opisthobranchiern als Cuticularbildungen von einigen Querreihen grosser Epithelzellen, den Od on to blasten (Fig. 537) der Radulascheide abgesondert, und zwar wird die Basalmembran, welche die Zähnchen trägt, von der vordersten oder den vordersten Zellreihen, die Zähnchen von den hinteren Querreihen abgesondert.

Die Odontoblastengruppe, welche einen Zahn erzeugt hat, wird nicht durch eine andere ersetzt, sondern bildet hinter den schon gebildeten immer neue Zähnchen, so dass am Grunde der Radulascheide für jede Längsreihe von Zïhnchen eine Gruppe von Odontoblasten nachzuweisen ist, welche alle ihre Zähnchen abgesondert hat. Auf die so gebildeten Zühnchen wird von der Epitheldecke der Radulascheide noch eine

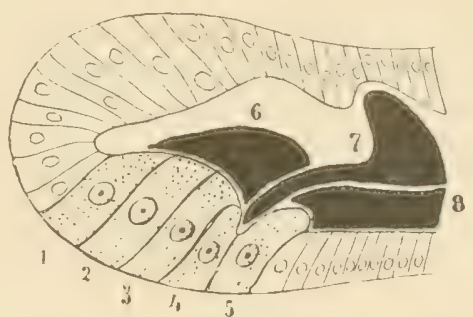

Fig. 537. Längsschnitt durch das hintere Ende der Radulascheide eines Pulmonaten, nach RössLER, schematisirt. $1,2,3,4$ Bildungszellen der Radulazähne, 5 Bildungszelle der Basalplatte der Radula, 6, 7 Zühne der Ra. dula, 8 Basalplatte. „Schmelzschicht" aufgelagert.

Bei den Chitoniden, Prosobranchiern und Cephalopoden sind die Odontoblasten schmale Zellen, aber sie sind sehr zahlreich und bilden am Grunde der Radulascheide ein Polster, welches in so viele zahnbildende Einzelabtheilungen zerfällt, als Zähnchen in einer Querreihe der Radula vorhanden sind.

Während die Radulascheide bei den Pulmonaten, Scaphopoden, Opisthobranchiern und Cephalopoden kurz und in der ventralen und hinteren Muskelwand des Pharynx enthalten ist, so dass sie nur selten nach hinten etwas aus derselben hervorragt, so ist sie bei sehr vielen Prosobranchiern lang und schmal und ragt nach hinten in die Kopfhöhle, ja sogar in die Leibeshöhle vor. Letzteres ist besonders bei den Diotocardiern der Fall, und speciell bei den Docoglossen (Patella) ist die über dem Fuss, am Boden der Leibeshöhle liegende Radulascheide sngar länger als der Körper (Fig. 539).

3) Speicheldrü sen (Buccaldrüsen, Pharyngealdrüsen) sind bei den Glossophoren, d. h. den mit einem Pharynx und einem Zungenapparat ausgestatteten Mollusken allgemeiu verbreitet. Ebenso allgemein fehlen sie den Lamellibranchiern. Sie können in einem oder in zwei Paaren auftreten. Das hintere Paar oder das einzige Paar liegt häufig den Wandungen des Oesophagus auf und entsendet nach vorn zwei Ausführungsgänge, welche seitlich in den Pharynx eimmünden, gewöhnlich etwas hinter der Stelle, wo sich die Radulascheide in die Pharyngealhöhle öffinet. Die Function der Speicheldrüsen ist so gut wie unbekannt. Auch ist eine strengere morphologische Vergleichung der verschiedenen Pharyngealdrüsen, z. B. ler Gasteropoden, zur Zeit noch nicht gut möglich. 
A m phineura. a) Chiton. Zwei kleine, zarte Buccaldrüsen liegen auf dem Dache der Mundhöhle und münden in den Mund. Sie dürfen deshalb wohl kaum als Pharyngeal- oder Speicheldrüsen aufgefasst werden. b) Solenogastres. Mit Ausnahme von Neomenia und Chaetoderma (?) kommen überall Speicheldrüsen vor. Ein Paar langgestreckter Drüsenschläuche mit hohen Drüsenzellen und kräftiger Muskelwand liegt im Vorderkörper unter dem Darm und setzt sich in zwei enge Ausführungsgänge fort, die gesondert oder mit einem gemeinsamen Endabschnitt an der Zunge in die Pharyugealhöhle münden. Ausserdem kommt bei einigen Arten (Paramenia impexa, Param. palifera, Proneomenia ragans, Dondersia flavens) noch ein Paar Speicheldrüsen vor, welche ohne gesonderten Ausführungsgang mit einem unpaaren Endabschnitt in der dorsalen Wand der Pharyngealhöhle münden, und zwar an der Spitze einer Papille, welche sich auf dem Grunde einer grubenförmigen Ausstülpung der dorsalen Pharyngealwand erhebt.

Gasteropoda. a) Prosobranchiata. In der Mehrzahl der Fälle ist nur ein Paar Speicheldrüsen vorhanden. Es sind gewöhnlich gelappte oder verästelte Drüsenmassen, die bei den Diotocardiern zu Seiten des Pharynx, bei den Monotocardiern zu Seiten des Oesophagus liegen. Im ersteren Falle sind die Ausführungsgïnge kurz und treten nicht durch den von den Nervencentren und ihren Comnectiven und Commissuren gebildeten Schlundring hindurch, denn dieser umgiebt hier das Vorderende des Pharynx. Im zweiten Falle (Monotocardia) sind die Ausführungsgänge lang und schlüpfen gewöhulich mit dem Oesophagus durch den Schlundring hindurch, der hinter dem Pharynx liegt, um an der hinteren und seitlichen Wand des Pharynx einzumünden.

Zwei Paar Speicheldrüsen kommen bei gewissen Diotocardiern (z. B. Haliotis, Fissurella), ferner bei Patella, den Scalariidae, Ianthinidae, gewissen Purpuriden, Muriciden und den Cancellariiden vor.

Eines der beiden Paare von Speicheldrüsen von Haliotis ist als ein Paar ansehnlicher, seitlicher Drüsentaschen entwickelt, die den Pharynx von rechts und links bedecken (Fig. 487).

Auch bei den Ampullariiden treten die Ausführungsgänge der Speicheldrüsen nicht durch den Schlundring hindurch, da dieser hier, wie bei den Diotocardiern, das Vorderende des Pharynx umgiebt.

Während die Speicheldrüsen im Allgemeinen verästelte tubulöse oder acinöse Drüsen sind, stellen sie in einigen Fällen (Scalariiden, Ianthinidae, Cancellariiden) einfache, röhrenförmige nder (Doliidae, Xenophoridae etc.) sackförmige Drüsenschläuche dar.

Das Hindurchtreten der Ausführungsgänge der Speicheldrüsen durch den Schlundring bei den Monotocardiern kann man sich so entstanden denken, dass der Schlundring, welcher bei den Diotocardiern das vordere Ende des Pharynx umgiebt und vor der Einmündungsstelle der Speicheldrüsen liegt, sich über den Pharynx hinweg nach hinten verschob, wobei nothwendigerweise auch die Speicheldrüsen, resp. ihre Ausführungsgänge von ihm umschlossen werden mussten.

Es werden dabei bei den Monotocardiern die Ausführungsgänge um so länger, je weiter der Schlundring sich vom Munde und vom Pharynx nach hinten entfernt. Sie werden sehr lang bei den mit einem vorstreckbaren Rüssel versehenen Gruppen, wo der Schlundring am Oesophagus weit nach hinten verschoben ist, an das Hinterende des nicht ausstülpbaren Theiles des Rüssels. Die Ausführungsgänge der Speicheldrïsen durchziehen dann diesen Theil des Rüssels in seiner ganzen Länge. Wanderte 
aber der Schlundring rascher nach hinten, als sich die Ausführungsgänge verlängerten, so konnten die Speicheldrüsen vor den Schlundring zu liegen kommen. Bei nachfolgender Verlängerung ihrer Ausführungsgänıre konnten nun aber die Speicheldrüsen sich über den Schlundring hinweg nach hinten verlängern. Dadurch liesse sich das Verhalten der Toxiglossa und Rachiglossa erklären, bei welchen zwar die Speicheldrüsen meist hinter dem Schlundring liegen, bei welchen aber die Ausführungsgänge nicht durch ihn hindurchtreten sollen.

Das saure Secret der Speicheldrüsen gewisser Prosobranchier (Arten von Dolium, Cassis, Cassidaria, Tritonium, Murex) und Opisthobranchier (Pleurobranchus, Pleurobranchidium) enthält zwischen 2,18 und 4,25\% freie Schw efelsäure. Diese räuberischen Thiere bohren mit ihrem Rüssel Thiere an, die durch Kalkskelete geschützt sind (Echinodermen, andere Mollusken). Es ist wahrscheinlich, dass die Schwefelsäure dazu dient, den kohlensauren Kalk in schwefelsauren umzuwandeln, der dann durch die Radula leicht zerrieben werden kann.

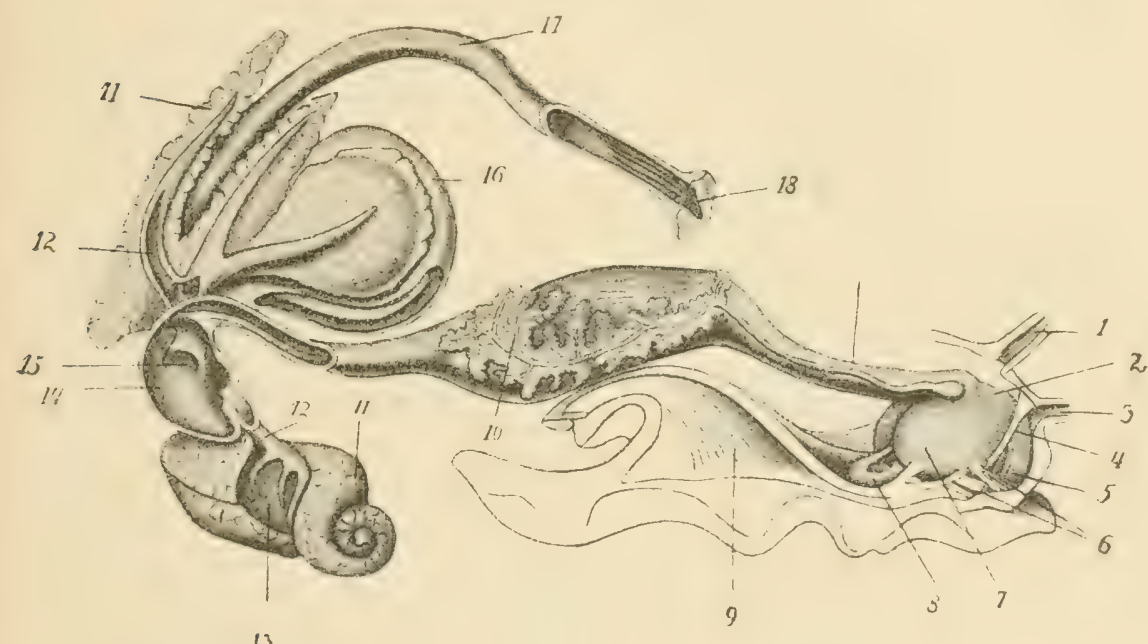

Fig. 538. Darmsystem von Helix, herauspräparirt und von der rechteu Seite gezeichnet, nach Howes. 1 und 3 Tentakel, 2 Constrictor pharyngis, 4 Levator pharyngis, 5 Depressor, 6 Protractor pharyngis, 7 Pharyngealbulbus, 8 Radulascheide, 9 spindelmuskel, in einen Retractor pedis und einen Retractor pharyngis getheilt, 10 Speicheldriisen, 11 Verdauungsdrüse (Leber), 12 Ausführungsgänge derselben (Gallengänge), zum Theil aufgeschnitten, 13 Zwitterdrise, 14 Magen, aufgeschnitten, man sieht in der Tiefe die Mündung der „Gallengänge" 15, 16 Mitteldarm, 17 Euddarm, 18 After.

b) Pulmonata. Ueberall sind zwei Speicheldrüsen (Fig. 538) vorhanden, deren Ausführungsgänge rechts und links von der Austrittsstelle des Oesophagus in den Pharynx münden. Die Speicheldrüsen liegen meist in Form langgestreckter, lappiger, zerrissen aussehender Blätter dem Oesophagus und dem vorderen Abschnitt des Magens auf. 'In einigen Fällen sind sie traubig oder rundlich und compact.

c) Op isthobranchiata. Hier sind die Grössen- und Formverhältnisse der Speicheldrüsen, die fast immer in einem Paar auftreten, noch mannigfaltiger, als bei den Pulmonaten. Mit den in den Pharynx mïndenden Speicheldrüsen sind nicht zu verwechseln die Drïsen, die bei 
manchen Opisthobranchiern in die Mundhöhle münden, und die in einigen Fällen stärker als die Speicheldrüsen entwickelt sind.

D entalium hat keine in den Pharynx mündenden Speicheldrüsen, denn die drüsigen "Backentaschen" münden in die Mundhöhle, und zwei weiter hinten gelegene Divertikel gehören dem Oesophagus an.

Die Cephalopoden besitzen 2 Paar Speicheldrüsen, ein vorderes und ein hinteres. Denkt man sich den (hier senkrecht in den Eingeweidesack emporsteigenden) Vorderdarm in eine derjenigen der Gasteropoden entsprechende horizontale Lage, so liegt das vordere Paar dorsal, das hintere ventral vom Darm. Die beiden hinteren Speicheldrüsen (Fig. 509, 29) sind fast constant vorhanden. Nur bei Cirroteuthis und Loligopsis sollen sie fehlen. Sie liegen am Oesophagus. Aus jeder Drüse entspringt ein Ausführungsgang, der sich mit demjenigen der anderen Seite bald zu einem unpaaren Gange vereinigt, welcher, den Oesophagus begleitend, mit ihm durch den Kopfknorpel hindurchtritt und über der Radula in die Pharyngealhöhle mündet. Gelegentlich verschmelzen (z. B. bei Oegopsiden) die hinteren Speicheldrüsen hinter dem Schlunde, dann ist der Ausführungsgang in seiner ganzen Länge unpaar.

Die vorderen Speicheldrüsen sind besonders bei den Octopoden (Fig. 509, 33) wohl entwickelt und liegen am Pharynx, in den sie ihr Secret durch einen, wie es scheint, überall unpaaren Ausführungsgang entleeren. Bei den Decapoden ist die vordere Speicheldrüse viel kleiner oder rudimentär, meist unpaar und liegt fast immer in der Muskelwand des Pharynx verborgen.

$\mathrm{Nautilus}$ besitzt keine hinteren Speicheldrüsen, wohl aber drüsige Ausstülpungen der Pharyngealhöhle zu heiden Seiten der Zunge, welche vielleicht den vorderen Speicheldrïsen der ührigen ('ephalopoden entsprechen.

Die Cephalopoden (alle?) besitzen ausserdem eine acinöse Z $\mathrm{ung}$, n drüse, welche in den zwischen Zunge und Kiefern gelegenen Abschnitt der Pharyngealhöhle mündet.

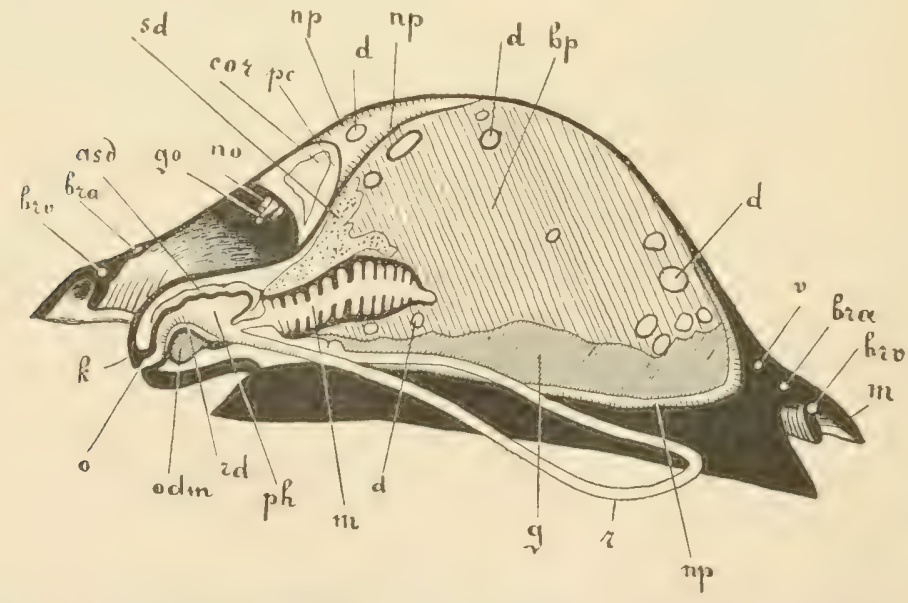

Fig. 539. Medianer Längsschnitt durch Patella, nach RAY LANkester. brv Abführendes Kiemengefäss, bra zuführendes Kiemengefäss, asd Ausführungsgang der Speicheldrüse $s d ; g o$ After, no rechte Nephridialöffnung, sd Speicheldrüse, cor Herz, $p c$ Pericard, $n p$ Niere, $d$ Darm, $h p$ Verdauungsdrüse (Leber), $v$ Blutgefäss, $m$ Mantelsaum, darunter die Kiemenblättchen, $r$ Radulascheide, $g$ Gonade, $m$ Kropf, $p h$ Pharynx, $r d$ Radula, odm Muskelund Knorpelmasse des Zungenappurates, o Mund, $k$ Kopf oder Schnauze. 
Wie schon erwähnt, fehlen den Lamellibranchiern mit dem Pharynx auch die Kiefer, die Zunge und die Speicheldrüsen. Doch führt bei deu $\mathrm{Nuculiden}$, die man aus guten Gründen für ursprüngliche Muschelformen hält, der Mund in einen etwas erweiterten Darmabschnitt, in welchen jederseits eine drüsige Tasche einmündet. Vielleicht entsprechen diese Taschen den später zu besprechenden Schlundsäcken der Chitoniden und Rhipidoglossen.

Eine Bohrschnecke, Natica, welche die Schalen lebender Muscheln durchbohrt, um sich von ihrem Weichkörper zu ernähren, besitzt am Rüssel ein saugnaptühnliches Organ Fig. 480i. Das Epithel der concaren Seite des Organes, welche sich an die zu durchbohrende Schale anlegt, stellt eine Säure absondernde Drüse dar. Die abgesonderte Säure ist wahrscheinlich Schwefelsäure und dient wahrscheinlich zum Auflösen des kohlensauren Kalkes der Muschelschale, der dann sofort wieder in Pulverform als schwefelsaurer Kalk ausgefällt wird.

C) Der Oesophagus (Speiseröhre).

Wir können als Oesophagus denjenigen 'Theil des Darmes bezeichnen, welcher sich zwischen dem Pharynx (oder dem Munde bei den Muscheln) und dem Magen erstreckt, wobei wir unter Magen diejenige Darmerweiterung verstehen, in welche die Mitteldarmdrüse einmündet. Die vordere Grenze des Oesophagus lässt sich immer leicht bestimmen. Sie liegt bei den Muscheln (wo ein Pharynx fehlt) am Mund, bei den Glossophoren aber am hinteren und oberen Ende des Pharynx. Die hintere Grenze des Oesophagus aber lässt sich oft nur willkürlich bestimmen, indem sich der im Ganzen schmale, röhrenförmige Oesophagus oft nur ganz allmählich zum Magen erweitert unter ebenso allmählicher Veränderung der Structur seiner Wandungen, oder indem vor dem Magen Darmerweiterungen vorkommen, von denen sich meist nicht entscheiden lässt, ob sie einen vorderen

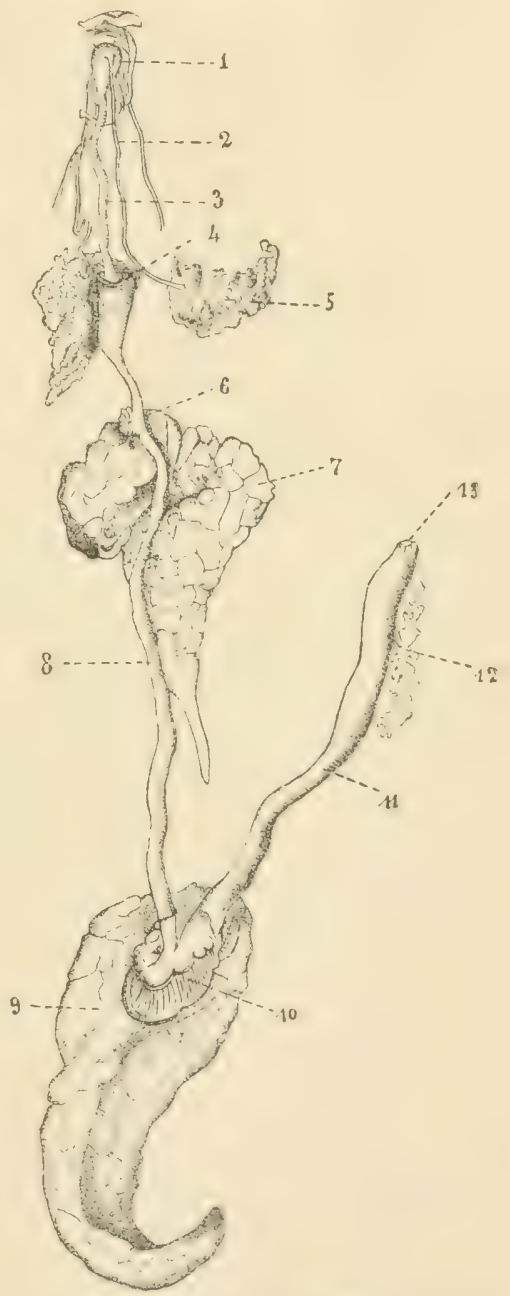

Fig. 540, Darmsystem von Murex trunculus, nach BÉLA HALLER. 1 Pharynx, 2 Ausführungsgänge der Speicheldrüse 5, 3 Oesophagus, 4, 6 und 7 Drüsen des Vorderdarmes 8, 9 Verdaungsdrüse (Leber), 10 Magen, 11 Enddarm, 12 Enddarmdrüse, 13 After. 
gesonderten Abschnitt des Nagens oder einen hinteren erweiterten Abschnitt der Speiseröhre darstellen.

Während der Oesophagus bei den Lamellibranchiern, den Laudpulmonaten, den meisten Opisthobranchiern und den zehnarmigen Cephalopoden als einfaches, innen oft mit Lüngsfalten versehenes und dann erweiterungsfähiges, bewimpertes Rohr zum Magen verläuft, zeigt er bei den anderen Abtheilungen Complicationen, die durch das Auftreten drüsiger Ausstülpungen oder musculöser Erweiterungen bedingt werden.

Bei einzelnen Solenogastres (z. B. Proneomenia) stülpt sich der Darm an der Grenze zwischen dem kurzen Oesophagus und Mitteldarm zu einem mehr oder weniger langen, dorsal vom Pharynx nach vorn verlaufenden unparen, blindgeschlossenen Divertikel ans, welches sich über die Cerebralganglien hinweg bis an das Kopfende erstrecken kann.

Bei Chiton stehen mit dem kurzen Oesophagus zwei seitliche drüsige Schlundsäcke (Zuckerdrüsen) in Verbindung, deren innere Drüsenwand in Form von Zotten gegen das Lumen vorspringt. Das Secret dieser Drüsen wandelt gekochte Stärke in Zucker um.

Aehnliche Schlundsäcke, die mit dem vorderen Theile des Oesophagus communiciren, finden sich auch bei Rhipidoglossen (z. B. Haliotis, Fissurella, Turbo). Ihr Drüsenepithel ragt ebenfalls meist in Form von stark entwickelten Zotten oder Falten in das Lumen vor.

Den zwei seitlichen Schlundsäcken der Chitonen und Rhipidoglossen entspricht wohl der sogenannte Kropf der Docoglossa (Patella), eine sackförmige Erweiterming des Oesophagus, die wegen der Beschaffenheit ihrer Innenwand mit dem Blättermagen eines Wiederkäuers verglichen worden ist (Fig. 539, m). Eine ähnliche Erweiterung des Schlundes findet sich auch bei Cypraeiden und $\mathrm{Naticidae}$, die zu den ursprünglichen Formen der Monotocardier zu zählen sind.

Bei den mit einem Rüssel ausgestatteten Monotocardiern verlängert sich der dünne Oesophagus in dem Maasse, als sich der Rüssel selbst verlängert. An der Spitze des Rüssels findet sich der Mund, dann folgt der oft unansehnliche oder rudimentäre Pharynx und dann der lange Oesophagus, welcher den nicht verschiebbaren Theil des Rüssels in seiner gauzen Länge durchzieht, dann durch den Schlundring hindurchtritt und sich sogar noch weiter darüber hinaus nach hinten verlängern kann. Bei zurückgezogenem Rüssel liegt dann der hintere Theil des Oesophagus in Windungen, bei vorgestrecktem Rüssel tritt er in dessen verschiebbaren oder ausstülpbaren Basaltheil hinein.

Nicht selten zeigt der auf den langgestreckten Theil des Oesophagus, den sogenannten $\mathrm{R}$ üs s eldarm, folgende Abschnitt der carnivoreu Monotocardier eine drüsige Erweiterung. Am meisten aber complicirt sich der Oesophagus bei den Rachiglossen und manchen Toxoglossa, wo sich die genannte Erweiterung als eine grosse, unpaare, compacte Anhangsdrüse vom Darme sondern kann (LeIbLein'sche Drüse, Giftdrüse) und noch weitere Drüsen und Erweiterungen am Oesophagus vorkommen können (Fig. 540).

Man hat es wahrscheinlich gemacht, dass bei gewissen Prosobranchiern schon im Vorderdarm Verdauung und Resorption stattfindet.

Auch bei Pulmonaten und O pisthobranchiern kommt es gelegentlich zu einer vor dem Magen gelegeuen Darmerweiterung (Kropf, Vormagen), und ebenso zeigt der kurze Oesophagus der. Scaph o pod en eine drüsige Erweiterung oder zwei seitliche Drüsendivertikel. 
Während unter den Cephalopoden die Decapoden einen als einfaches, dünnes Rohr aufsteigenden Oesophagus besitzen, ist der Oesophagus der Octopoden mit einer ihm seitlich ansitzenden, als Kropf bezeichneten Tasche (Fig. 509) ausgestattet, welche keine drüsige Wandung besitzt und in dem Falle als Nahrungsreservoir dienen kann, wenn der Magen schon mit Nahrung erfüllt ist. Bei $\mathrm{Nautilus}$ stellt der Kropf eine sehr grosse, den Magen an Grösse übertreffende sackförmige Erweiterung des Oesophagus dar.

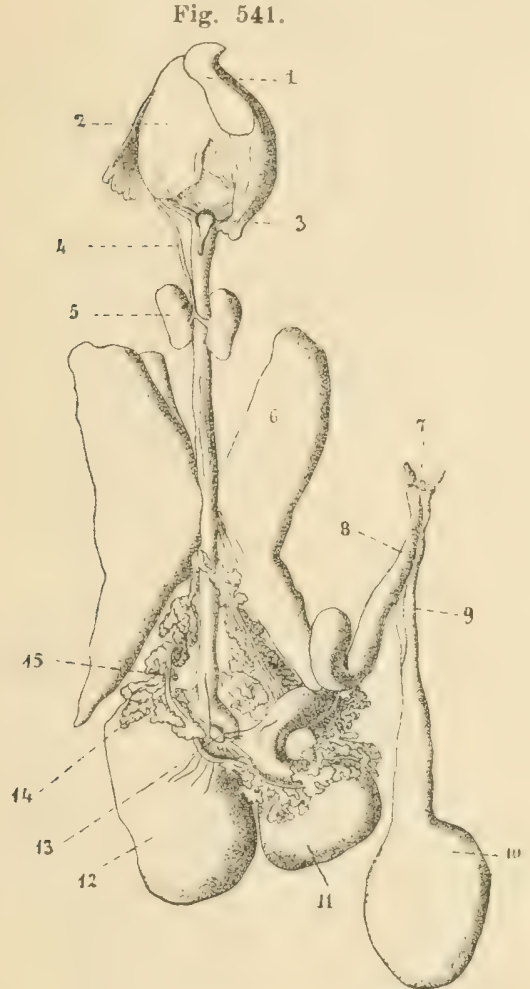

Fig. 542.

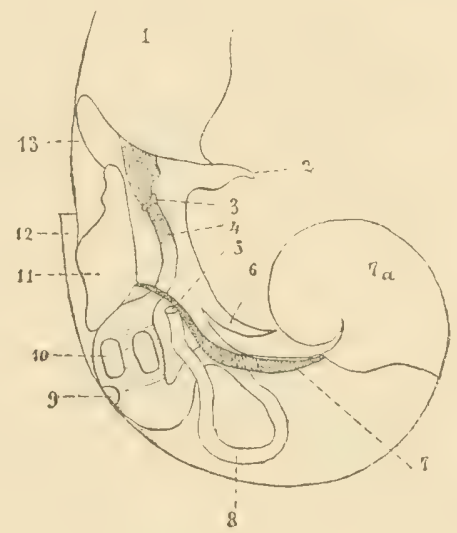

Fig. 542. Skizze der Anatomio von Limacina helicina, von der rechten Seite, nach Entfernung von Mantel, Herz und Niere, nach PeLseneer. 1 Flosse (Parapodium), 2 Fuss, 3 centrales Nervensystem (Schlundring), 4 Oesophagus, 5 After, 6 Spindelmuskel, 7 Ausführungsgang der Zwitterdrüse $7 \mathrm{a}, 8$ Darm, 9 und 10 Platten der Magenbewaffinung, 11 accessorische Drüsen des Geschlechtsapparates, 12 Mantelhöhle, 13 Samenfurche.

Fig. 541. Darmtractus von Sepia, nach Keferstein, 1 Kiefer, 2 Pharynx, 3 hinteres Buccalganglion, 4 Ausführungsgang der Speicheldrüsen 5, 6 Verdauungsdrüse (Leber), 7 After, 8 Euddarm, 9 Ausführungsgang der Farbstoffdrilse (Tintenbeutel) 10, 11 Magenblindsack, 12 Magen, 13 Ganglion gastricum, 14 „Pancreusanhänge" der Ausführungsgänge 15 (Gallengänge) der Verdauungsdrüse.

D) Der Mitteldarm mit dem Magen und der Verdaungsdrüse (Mitteldarmdrüse, Leber).

Der Oesophagus führt in einen erweiterten Abschnitt, den Magen. In den Magen ötfnen sich die Ausführungsgänge einer bei fast allen Mollusken stark entwickelten Mitteldarmdrüse, welche gewöhnlich als Leber, besser als Verda u n g sdrüse bezeichnet wird. Denn diese Drüse spielt durchaus nicht die Rolle der Vertebratenleber, sondern sie übt viehmehr, soweit man bis jetzt darüber unterrichtet ist, eher die Function eines Pancreas oder die vereinigten Functionen der verschiedenen Verdauungsdrüsen des Wirbelthierdarmkanals aus, ohme dass jene bei den 
Wirbelthieren so weitgehende Arbeitstheilung eingetreten wäre. Die Verdauungsdrüse stellt in den meisten Fällen eine reich verzweigte, bald tubulöse, hald acinöse Drïse dar, welche makroskopisch als ein compactes, in Lappen zerfallendes ()rgan von brauner, braungelber oder röthlicher Farbe erscheint. Ihr Driisenepithel besteht aus drei Arten von Zellen: Leberzellen, Fermentzellen und Kalkzellen. Bei zahlreichen Nudibranchiern löst sich die Verdauungsdrüse in sich verästelnde Darmudivertikel auf, die sich fast nach Art der Gastrokanäle oder Darmäste der T'urbellarien im liörper ausbreiten und bis in die Rückenanhänge des Körpers emporsteigen (cladohepatische Nudibranchier).

Unter den Solenogastres besitzt Chaedoderma ein einfaches Mitteldarmdivertikel, welches morphologisch der Verdauungsdrüse der übrigen Mollusken entsprechen dürfte, während bei Proneomenia, Neomenia etc. der gestreckte, gerarle Nitteldarm in seinem ganzen Verlaufe mit drüsigen, dicht hintereinander liegenden, senkrecht stehenden, schmalen Seitentaschen ausgestattet ist.

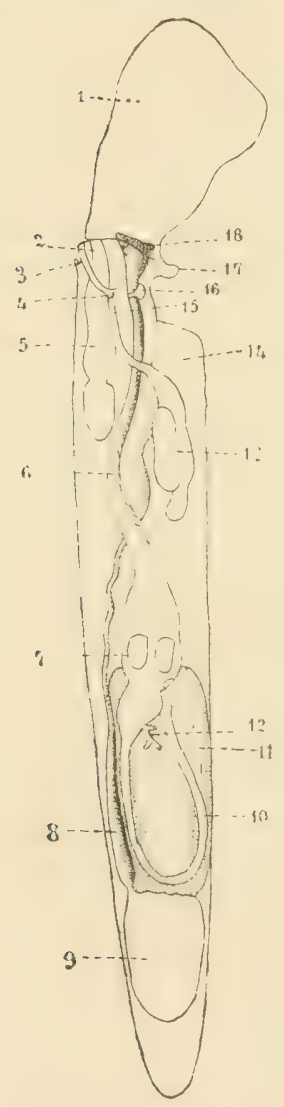

Ein Theil der Mitteldarmdrüse (der der Austrittsstelle dieses Ausführungsganges zunächst gelegene Theil) und das Drüsenepithel des Ausführungsganges derselben können sich bei Cephalopoden in besonderer Weise differenziren und schliesslich ein distinctes Drüsensystem bilden, das man als B a u chspeicheldrüse oder Pancreas bezeichnet hat.

Nicht selten ist der Magen eine einseitige Ausbuchtung der Mitteldarmwand, so dass die Einmündungsstelle des Oesophagus in den Magen (Cardia) der vom Magen in den Dünndarm führenden Oeffnung (Pylorus) mehr oder weniger genähert ist. Es kann dann eine Art directer Verbindung zwischen Cardia und Pylorus bestehen, indem zwischen beiden eine von Längsfalten begrenzte wimpernde Furche oder Rinne verläuft, die sich übrigens auch in die angrenzenden Darmabschnitte fortsetzen kann.

Bei den Cephalopoden mündet der Ausführungsgang der Verdauungsdrüse (der sogenannte Lebergang, Gallengang) nicht direct in den Magen, sondern in eine blindsackartige Ausstülpung desselben, das Spiralcoecum.

Ein Divertikel des Magens sehr vieler La mellibranchier enthält in seinem Lumen eine stabförmige, gallertige Cuticularbildung, den Krystall stil. Entsprechende Bildungen kommen auch bei Prosobranchiern, zumal bei Rhipidoglossen und Toxoglossen vor.

Der Magen vieler Opisthobranchier trägt an seiner Innenwand in verschiedener Weise cuticulare Zähne, Zahnplatten, Kieferplatten etc., welche zur

Fig. 543. Skizze der Anatomie von Clio striata, von der rechten Seite. Das auf dieser Seite liegende Herz, die Niere und der Mantel sind entfernt, nach Pelseneer. 1 Flosse (Parapodium), 2 Penisöffnung, 3 rechter Tentakel, 4 Geschlechtsöffnung, 5 Penis, 6 Oesophagus, 7 Platten der Magenbewaffnung, 8 Ausführungsgang der Gonade, 9 Gonade, 10 Darm, 11 Verdauungsdrüse (Leber), 12 ihre Ausführuugsgänge (abgeschnitten), 13 Anhangsdrüsen des Geschlechtsapparates, 14 Mantelhöhle, 15 Endabschnitt des Ausführungsganges der Gonade, 16 Centralnervensystem (Ganglienring), 17 Fuss, 18 Pharynx. 
weiteren Zerkleinerung der Nihrung dienen. Es ist damn die Muskelwand des Magens stark entwickelt.

Auf rlen Magen folgt als engerer, röhrenförmiger $\Lambda$ bschnitt des Mitteldarmes ler D ün ndarn (Intestinum), welcher gewöhnlich in Windungen oder Schlingen verläuft, die bei den herlivoren und detritivoren Mollusken zahlreicher als bei den räuberischen Weichthieren sind.

Magen, Dünndarm und Verdanungsdrüse bilden zusammen mit einem Theil der Geschlechtsorgane den ganzen oder doch den weitaus grössten 'Theil des Eingeweidesackes, da wo ein solcher' entwickelt ist.

a) Mitteldarm der Amphineuren. Bei Chiton treffen wir die bei den übrigen Mollusken bestehende Sonderung des Mitteldarmes in Magen, Verdauungsdrüse und Dünndarm. Der Magen liegt weit vorn und zeigt eine weite, einseitige Ausbuchtung, die functionell ein Secretreservoir darstellt. Cardia und Pylorus genähert. Die Verdauungsdrüse ist paarig. Die rechte grössere Leber mündet mit vier Mündungen, die linke kleinere mit einer Hauptöffnung in den Magen. Der Dünndarm ist mehr als $4 \mathrm{mal}$ so lang wie der Körper und verläuft in zahlreichen Schlingen von constanter Lage. Chiton ernährt sich von kleinen, sogar mikroskopisch kleinen Algen.

Bei den Solenogastres ist im Gegensatz zu den Chitoniden keine Sonderung des Mitteldarmes in Magen und Dünndarm zu constatiren. Der Mitteldarm verläuft gestreckt und gerade durch den Leib, den er zum grössten 'Theil ausfüllt. Die drüsigen, als "Leberdivertikel" aufgefassten Seitentaschen des Mitteldarmes von Neomenia, Proneomenia etc. kommen dadurch zu Stande, dass von beiden Seiten her schmale, senkrecht und quer stehende Septen (Fig. 544) gegen sein Lumen vorspringen, in welchen Muskelfasern zum rudimentären Fuss heruntersteigen, und in welchen Blutlacunen reichlich vorhanden sind. Bei Proneomenia Sluiteri kann man in der durch die Figur veranschaulichten Weise jederseits Septen erster, zweiter, dritter und vierter Ordnung unterscheiden. Die Septen der rechten alterniren mit den Septen der linken Körperseite. In der dorsalen Mittellinie zieht sich der Mitteldarm zu einer schmalen, in die Geschlechtsdrüse tief einschneidenden, bewimperten Längsfurche aus, und auch medioventral ist der Darm bewimpert.

Fig. 544. Horizontalschnitt durch ein Stück der mittleren Gegend des Körpers von Proneomenia Sluiteri. Man sieht die von rechts und links in die Mittel a $\mathrm{rmh}$ öh le vorragenden S epten erster, zweiter, dritter und vierter Ordnung. In der Tiefe die dorsale Wand des Mitteldarmes und seine Rinne, welche in die $\mathrm{Z}$ witterdrüse einschneidet (vergl. Fig. 437).

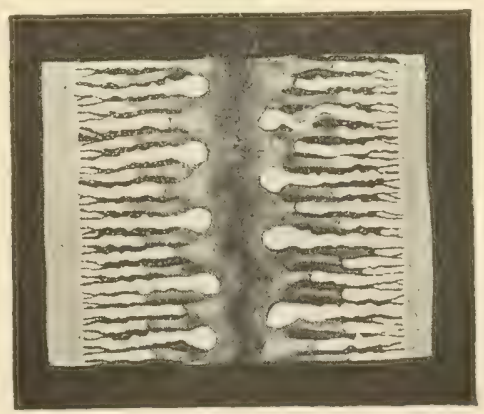

b) Die Verdauungsdrüse der Gaster o poden zerfällt in zwei oder mehrere Lappen, zwischen denen der Magen und die Windungen des Dünndarmes eingebettet sind. Was die Zahl der Mündungen ihrer Ausfïhrungsgänge anbetriftt, so finden sich bald eine, bald zwei, bald mehrere.

Die Wandungen der Verdauungsdrüse reigen dieselbe Schichtenfolge, wie die Darmwandung. Bezüglich der das Drüsenepithel bildenden Ferment-, Leber- und Kalkzellen, besonders auch ihrer physiologischen Be- 
deutung, mus ant die histologischen und physiologischen Originalabhandlungen verwiesen werden.

Bei den $\mathrm{Nudibranchiern} \mathrm{löst} \mathrm{sich,} \mathrm{wie} \mathrm{schon} \mathrm{erwähnt,} \mathrm{die} \mathrm{Ver-}$ dauungsdrüse in ein System von drüsigen Darmästen auf (sogenannte "diffuse Leber"). Greifen wir einen instructiven Fall heraus, so sehen wir bei den Aeolidiern (Beispiel T'ergipes) drei Darmäste aus dem Magen entspringen, zwei vordere seitliche und einen hinteren unpaaren. Diese verästeln sich in der Leibeshöhle, und schliesslich steigen ihre letzten Aeste oder Läppchen in die Rückenanhänge empor. Der Darminhalt kann bis in die letzten Verzweigungen dieser "diffusen Leber" vordringen (Fig. 545).

Man kann übrigens innerhalb der Nudibranchier die Auflösung der compacten Verdaumgsdrüse in eine "diffuse Leber", d. b. die Lockerung, das Freiwerden und die Ausbreitung der in der compacten Drüse dicht aneinanderliegenden Drüsenschläuche fast Schritt für Schritt verfolgen. So bildet bei den 'Tritoniaden die Verdaumgsdrüse eine grosse zusammenhängende Masse. Bei anderen Familien, z. B. den Tethymelibiden, Lomanotiden, Dendronotiden, Bornellidae, Scyllaeidae, sondert sich die Verdauungsdrüse in zwei vordere "Nebenlebern" und eine hintere "Hauptleber", von denen aber Drüsendivertikel abgehen, welche in die Rückenanhänge eintreten. Schliesslich lösen sich auch die Haupt- und Nebenlebern in gesonderte "Leberäste" auf (A e olidier), die in einigen Fällen anastomosiren. Der unpaare, hintere Hauptast der "diffusen Leber" giebt besonders zahlreiche Seitenzweige ab, er erweitert sich häufig schlauchförmig und kann dann einer gestreckten Gallenblase oder einem hinteren Magenblindsack verglichen werden. Bei P h yllirhoë, einer pelagischen Form, die der Rückenanhänge entbehrt, vereinfacht sich die "diffuse Leber" auf 4 unverästelte Blindschläuche, von denen die beiden vorderen getrennt, die beiden hinteren vereinigt in den Magen einmü̈nden (Fig. 403).

Der Magen mancher Opisthobranchier besteht aus zwei durch eine Einschnürung getrennten Abtheilungen. Er trägt bei einigen Formen, z. B. den Bulliden unter den I'etibranchiern, den Pteropodathecosomata, den Tethymelibidae, Bornellidae, Scyllaeidae unter den $\mathrm{Nudibranchiern,} \mathrm{eine} \mathrm{Bewaffnung} \mathrm{mit} \mathrm{harten,} \mathrm{chitinigen}$ Platten, Dornen, Zähnen u. s. w., die auf seiner Innenwand in verschiedener Zahl und Anordnung vorkommen können (Fig. 542, 543).

c) Der Mitteldarm von Dentalium (Fig. 546) besteht aus einem schlingenförmigen, auf sich selbst zurückgebogenen Magenschlauch und einem knäuelförmig aufgewundenen, hinter dem Oesophagus liegenden Dünndarm. In den Magen münden mit weiten Oeffnungen die beiden im oberen Theile des Körpers gelegenen Verdauungsdrüsen, über deren Gestalt die Fig. 546 die beste Auskunft ertheilt.

d) Der unter dem vorderen Schalenmuskel der Lamellibranchier liegende Oesophagus erweitert sich in der vorderen Basis des Fusses zu dem Magen, der etwas in das Innere des Fusses heruntersteigt. Im hinteren Grunde des Magens liegen zwei Oeffnungen, die eine ist der Pylorus und führt in den Dünndarm, der im Innern der Fussbasis in einer geringeren oder grösseren Zahl von Windungen verlänft; die andere führt in ein röhrenförmiges Divertikel, die Krystallstielscheide. In den Magen mündet mit mehreren Oeffnungen die ansehnliche, reich verästelte, acinöse Verdauungsdrüse (Leber), welche mit dem Magen im vordere. Theile der Fusshöhle liegt. Der Magen besitzt gelegentlich 
Fig. 545.

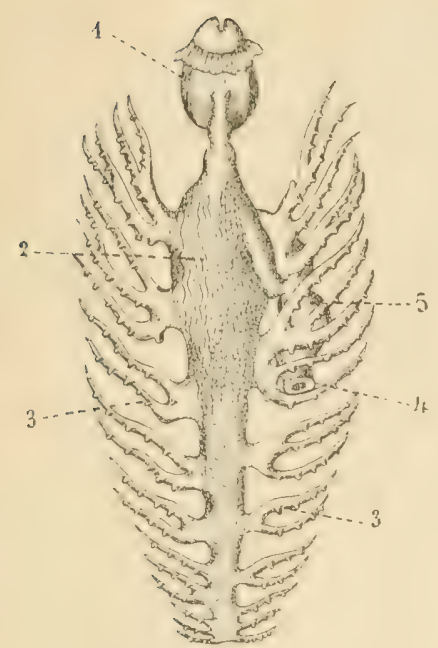

Fig. 545. Darmsystem von Aeolis, nach Soulkyer. 1 Pbarynx, 2 Mlagen, 3 verästelte Verdauungsdriise (Leber), 4 After, 5 Enddarm.

Fig. 546. Darm, Niere und Geschlechtsorgane von Dentalium, von der Hinterseite, nach LACAZEDuthiERs combinirt von LeUCKarT. $a$ Mund, $b$ blattförmige Mundtentakel, $c$ Schnauze, $d$ Eingang zum Pharynx, e Pharynx mit Radula $f$, $g$ Enddarm, $h$ rechte Niere, $i$ After, $l$ rechte Nephridialöfinung, $l$ und $q$ Ausführungsgänge der Verdauungsdrüse $n, m$ und $o$ Gonade, $n$ und $p$ Verdauungsdriise (Leber), $r$ linke Nephridialöffnung, $s$ linke Niere, $t$ Magen, $u$ Pbarynx, $v$ Lappen oder Segel, auf welchen die Fadententakel (Fangfäden) inseriren.
Fig 546 .

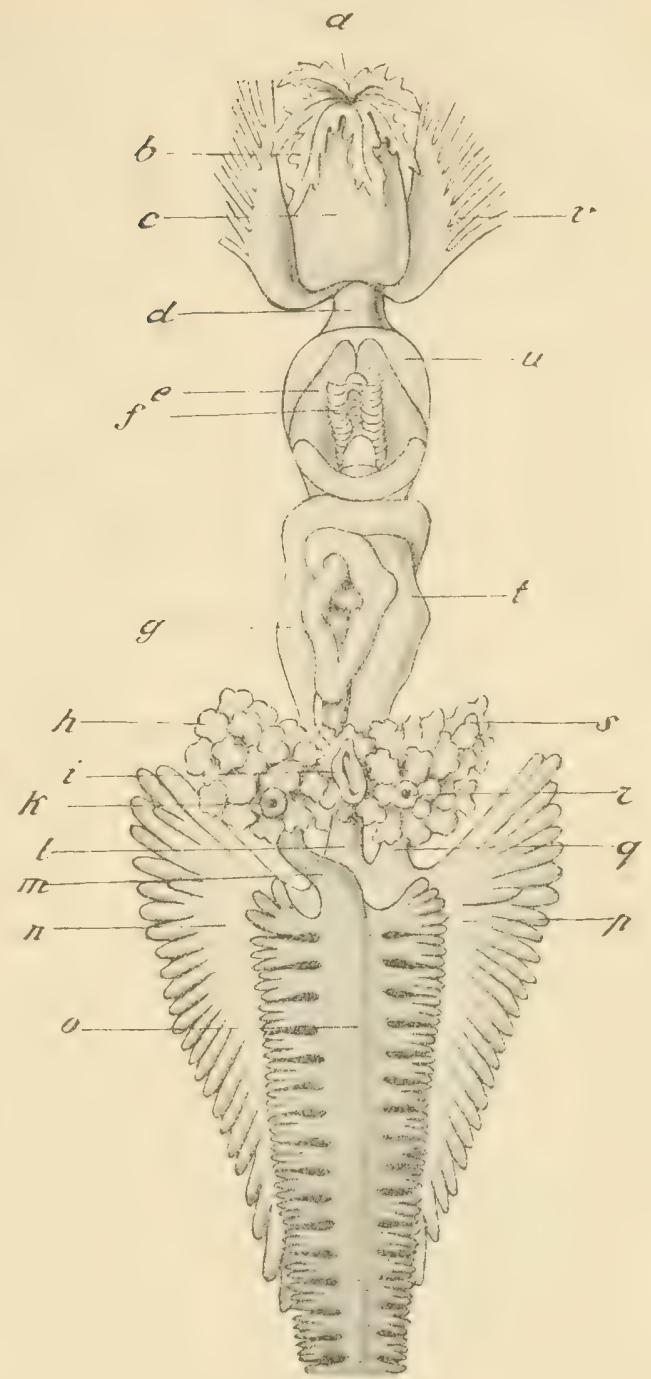

(Pholas, Jouannetia, Teredo) ausser der Krystallstielscheide noch einen zweiten Blindsack. Auf der inneren Magenwand kommt bei allen Muscheln eine verschieden dicke, gallertige Cuticularbildung (dreizackiger Körper, flêche tricuspide) vor, die sich in den ebenfalls gallertigen Krystallstiel fortsetzt. Der Krystallstiel selbst wird von dem Epithel der Scheide, in der er steckt, als Cuticularbildung in concentrischen Schichten abgesondert. Ueber die Rolle dieser gallertigen Bildungen ist in neuester Zeit die recht plausible Ansicht geäussert worden, dass sie dazu dienen, Fremdkörperchen, die mit der Nahrung in den Darm hineingrelaugen, wie z. B. scharfkantige Sandkörnchen, mit einer schleimigen Hülle zu umgeben, um so eine Verletzung der zarten Darmwand zu verhüten und die Fortbewegung der Partikelchen im Darm zu erleichtern. 
Der Krystallstiel ragt mit der Spitze frei ins Darmlumen vor. Er liegt bei einigen Formen nicht in einer gesonderten Scheide, sondern in einer Darmrinne (Najaden, Cardium, Mytilus, Pecten etc.). Dreizackiger Körper und Krystallstiel sind vergängliche Bilduugen, die wahrscheinlich periodisch neu erzeugt werden. Aehnliche Bildungen sind übrigens auch im Magen verschiedener Gasteropoden beobachtet worden. Haliotis hat sogar einen der Krystallstielscheide vergleichbaren Magenblindsack.

Bei den niederen Lamellibranchiern, den $\mathrm{Nuculiden}$ und den Solenomyidae, ist die Krystallstielscheide nur sehr wenig entwickelt oder 0. Schwach entwickelt ist sie auch bei den Arcidae.

Die Septibranchiaten (Poromya, Cuspidaria) unterscheiden sich vor allen anderen Lamellibranchiern durch das Fehlen der Windungen und die daraus resultirende Kürze des Dünndarmes. (Bezïglich des Darmes der Lamellibranchier vergl. Fig. 408, 409, 410, 411, 412.)

e) Der Magen der Cephalopoden liegt immer im dorsalen Theile des Eingeweidesackes als ein Sack mit stark entwickelter Muskelwand. Er besitzt immer einen blindsackförmigen Anhang (Magenb lindsack, Spiralcoecum, Fig. 547, 541) von verschiedener Gestalt und Grösse, in welchen die Verdauungsdrüse (Leber) einmündet. Dieser Blindsack ist ein Reservoir für die Secrete der Verdauungsdrüse. Die Nahrung tritt nie in ihn hinein, und es finden sich sogar an der Stelle, wo der Blindsack in den Magen mündet, Klappenvorrichtungen, welche

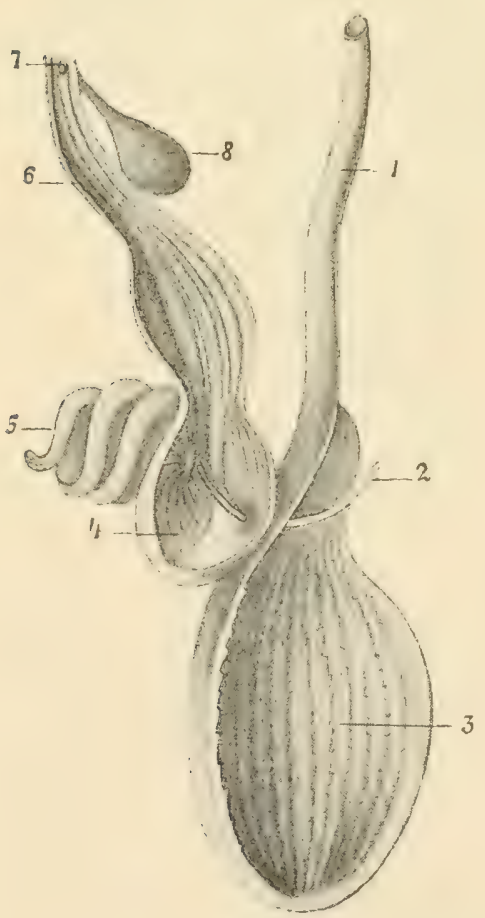
wohl eine Entleerung des im Blindsack angesammelten Secretes in den Magen gestatten, aber einen Eintritt des Mageninhaltes in den Blindsack verhindern.

Bei Nautilus mündet der Blindsack nicht in den Magen, sondern in den Anfangstheil des Dünndarmes und stellt eine kleine, runde Blase mit in das Lumen vorspringenden Lamellen dar. Rundlich oder eiförmig ist er auch bei Se pia und Sepiola, schwach entwickelt bei Rossia, sehr lang und spitz endigend bei Loligo und Sepioteuthis, am blinden Ende mehr oder minder spiralig aufgerollt bei allen $\mathrm{O}$ egopsiden und Octopoden.

Die wohl entwickelte $\mathrm{V}$ erd a ungsdrüse scheint sich auch da paarig anzulegen, wo sie beim erwachsenen Thier unpaar ist. Die ganze, stark baumförmig verästelte Drüse ist von einer gemeinsamen Haut derart umgeben, dass sie äusserlich den Eindruck einer compacten Drüse macht.

Fig. 547. Darmkanal von Loligo sagittata (ohne Pharynx und Speicheldrüsen), zum Theil aufgeschnitten, nach Gegenbadr. 1 Oesophagus, 2 Sonde, in den Pylorus eingeführt, 3 Magen, 4 Magenblindsack mit Spiralcoecum 5, 6 Enddarm, 8 Tintenbeutel, 7 seine Mündung in den Enddarm. 
Die Verdauungsdrüse von $\mathrm{Nautilus}$ besteht aus 5 ( 4 paarigen und 1 unpaaren) Lappen, welche um den Kropf herum liegen. Sie besitzt zwei Ausführungsgänge, welche mit kurzem gemeinsamem Endstück in den Darmblindsack einmünden.

Auch bei den Dibranchiata liegt die Verdauungsdrüse immer ventralwärts vom Magen, in der Umgebung des zum Magen aufsteigenden Oesophagus. Sie ist ungetheilt, rundlich oder eiförmig hei den Octopoden, Oegopsiden und Sepiola. Bei Loligo und Sepioteuthis wird sie von Oesophagus und der Aorta durchbohrt, bei Enoploteuthis durch diese Organe in jhrer dorsalen Hälfte in zwei Zipfel getheilt; ähnlich verhält sich Rossia. Bei Sepia und Spirula ist die Verdauungsdrüse in zwei seitliche Lappen scetheilt, die bei Sepia gesondert sind, bei Spirula aber in ler Mittellinie zusamimenhängen.

Immer sind zwei Ausführungsgänge (Gallengänge) vorhanden, welche, der Medianebene genähert, vom oberen Theil der Verdauungsdrüse entspringen und mit einem vereinigten Endabschnitt oder getrennt in den Magenblindsack münden.

Ueber das sogenannte Pankreas (Bauchspeicheldrüse) der Cephalopoden ist morphologisch Folgendes ermittelt worden. Es ist ursprünglich ein besonders differenzirter Theil der Verdauungsdrüse und liegt bei den Octopoden als ein von dieser durch andere Farbe leicht zu unterscheidender Theil in derjenigen Gegend der Verdaungsdrüse, aus welcher ihre Ausführungsgänge entspringen. Bei Loligo finden wir die Drüse in der stark verdickten Wand der Ausführungsgänge selbst. Sie besteht hier aus zahlreichen drüsigen, anastomosirenden Ausstülpungen des Epithels der Ausführungsgänge in ihre Wand. Bei den übrigen Decapoden brechen diese Drüsenausstülpungen aus der Wand der Ausführungsgänge der Verdauungsdrüse in die umgebende Leibeshöhle vor, und es erscheint dann jeder Ausführungsgang in seiner ganzen Länge von zahlreichen bald traubigen, bald baumförmig verästelten "Pankreasanhängen " besetzt. Das Pankreassecret enthält Diastase und scheint nur einen Theil der Functionen der Verdauungsdrüse auszuführen, nämlich denjenigen, welcher den verdauenden Leistungen der Speicheldrüsen der höheren Wirbelthiere entspricht.

Der D ünndarm, in welchem wohl allgemein bei den Mollusken (wenn auch nicht ausschliesslich) die Resorption der verdauten Nahrung stattfindet, ist bei den (carnivoren) Cephalopoden kurz und macht nur bei Tremoctopus violaceus mehrere Windungen.

\section{E) Der Enddarm (Mastdarm, Rectum)}

ist bei den Mollusken meist kurz. Wo er sich schärfer von dem Dünndarm absetzt, erscheint er diesem gegenüher gewöhnlich dadurch ausgezeichnet, dass er dicker und stärker musculös ist.

Bei der grossen Mehrzahl der Lamellibranchier und bei fast allen Diotocardiern durchbohrt der Enddarm die Herzka m mer, eine Thatsache, welche nehen so vielen anderen für die engere Verwandtschaft dieser beiden Abtheilungen spricht.

Der Enddarm ist bei gewissen Mollusken, nämlich hei den Scap h opoden, bei einigen Prosobranchiern ( $\mathrm{Hur}$ icidae, Purpuridae) und bei den Cephalopoden mit einer Anhangsdrüse, Anal$d r$ ii se ausgestattet, welche besonders bei den Cephalopoden als T in tenbeu tel allgemeiner bekannt ist. 
Die Rectaldrïse von $D$ entalium ist eine verästelte acinöse Drüse, welche nach einer Angabe mit 6 getrennten Ausführungsgängen, nach einer anderen mit einem einzigen in den Enddarm mündet. Man hat im Lumen dieser Drüse Eier und Spermatozoen angetroffen und dabei vermuthet, dass sie zufällig durch die bei Dentalium beobachteten Schluckbewegungen des Enddarmes aus der Mantelhöhle in die Drüse gelangt seien.

Die bei einigen Rachiglossen (Monoceros, Purpura, $\mathrm{M} u \mathrm{rex}$ ) existirende Analdrüse ist immer dunkel gefärbt (braun, violett) und bildet entweder einen vielfach ausgebuchteten Drüsenschlauch oder eine acinöse Drüse mit axialem Ausführungsgang. Immer mündet sie nahe dem After in den Enddarm.

Eine neben dem Rectum gelegene Drüse, die bei Pteropoda thecosomata (Clio, Cavolinia) und Bulloideen beobachtet und als Analdrüse bezeichnet worden ist, bedarf einer näheren Untersuchung.

Der Tintenbe utel der Cephalopoden (Fig. 5 54 ), welcher nur bei Nautilus fehlt, ist eine stark entwickelte Analdrüse. Sie mündet in den Enddarm nahe dem After. Das von ihr abgesonderte Secret, die Tinte oder der Sepiafarlbstofi, bestehend aus ausserst kleinen Pigmentpartikelchen, wird mit Vehemenz aus dem Tintenbeutel und von da lurch den Trichter nach aussen entleert, vertheilt sich rasch im Wasser und bildet um das Thier herum eine Pigmentwolke, welche dasselbe den Augen des Feindes entzieht.

Gestalt und Lage des Tintenbeutels (vergl. auch Fig. 541, 558 und 559). Die typische Lage des Tintenbeutels ist die vor dem Rectum, d. h. in der Schlinge, welche durch den vom Mund aufsteigenden und den zum After heruntersteigenden Schenkel des Darmes gebildet wird. Sehr klein ist der Tintenbeutel bei Spirula, Enoploteuthis und Sepioteuthis. Sowohl in der Reihe der Decapoden, als in der Reihe der Octopoden wird er fortschreitend grösser und lässt dabei immer deutlicher eine Sonderung in einen sackförmigen Theil und einen in den Enddarm vor dem After ausmündenden Ausführungsgang erkennen. Bei den Octopoden liegt der Tintenbeutel in den oberen Theil der Leber eingebettet, im Inneren der musculösen Leberkapsel. In dieser Lage (zwischen Leber und Rectum) finden wir ihn auch noch bei Sepiola. Dann aber sehen wir bei den übrigen Decapoden den Tintenbeutel immer mehr im Eingeweidesack in die Höhe steigen und dabei seinen Ausführungsgang immer mehr verlängern. Schliesslich treffen wir ihn bei Sepia (und den fossilen Dibranchiaten) am obersten Ende des Eingerveidesackes, hinter der Geschlechtsdrüse. Der Ausführungsgang begleitet den Enddarm auf seiner rechten Seite, biegt kurz vor der Einmündung in den Analabschnitt des Rectums um, um von vorn in diesen Abschnitt einzumünden. Aber auch bei Sepia legt sich der Tintenbeutel ontogenetisch als eine vordere Ausstülpung des Rectums an.

Bau des Tintenbeutels von Sepia (Fig. 548 A). Der Tintenbeutel besteht aus drei Theilen: 1) der Farbstoffdr üse, welche den Farbstoff secernirt, 2) dem Farbstoffreservoir mitsammt A us führungsgang, welcher 3) nahe der Einmündung eine Ampulle mit drüsiger Wand bildet. Die Farbstoffdrüse liegt als ein Sack im Grunde des Tintenbentels an seiner vorderen (der Genitaldrüse zugekehrten) Wand. Er ragt nach innen in den übrigen Hohlraum des Tintenbeutels vor, der als Reservoir und Leitungsweg des Farbstoffes dient, 
welcher, in der Farbstoffdrïse bereitet, durch eine Oeffnung in der. Wand dieser Drüse in das Reservoir übertritt. Der Binnenraum der Drüse wird von zahlreichen durchbrochenen, bindegewebigen und reich vascularisirten Lamellen durchsetzt, die selbst wieder miteinander zusammenhängen, so dass daraus ein fast schwammiges Gefüge resultirt. Immer neue Lamellen werden in einem nach unten zurückgebogenen, verengten $\mathrm{Ab}$ schnitt, in der Bildungszone der Drüse, abgekammert, während die ältesten, der Oeffnung der Drüse zunächstliegenden sich ablösen und degeneriren. Alle Lamellen sind von einem Drüsenepithel ausgekleidet, und die Epithelzellen zeigen von der Bildungszone bis zu den ältesten Lamellen alle Stadien der Pigmentbildung. In der Bildungzone sind die jungen Drüsenzellen zuerst ungefärbt. In den successiv darauf folgenden Lamellen aber treten in ihnen immer mehr Pigmentkörnchen auf, die dann an den alten Lamellen in den Binnenraum der Drüse entleert werden, wobei die Zellen selbst sich loslösen und zu Grunde gehen.

Sowohl die Drüse, als das Farbstoffreservoir sind von einer bindegewebigen, vascularisirten Haut umhüllt, welche in der Drïse auch das bindegewebige Gerüst der Lamellen oder Trabekeln bildet.

Der gesammte Tintenbeutel aber ist selbst wieder von einer derben Haut umschlossen, die aus drei Schichten besteht: 1) einer inneren, silberglänzenden Flitterschicht (Argentea), ähnlich der entsprechenden Schicht in der äusseren Haut, 2) einer mittleren Muskelschicht (innere Längs- und äussere Ringmuskeln), 3) einer äusseren Bindegewebsschicht.

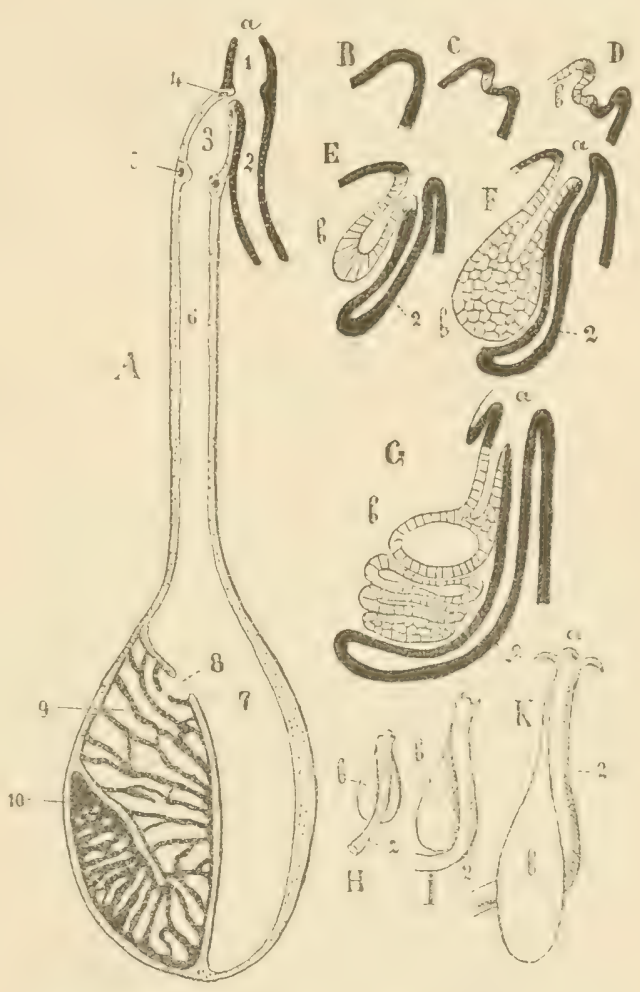

Fig. 548. Morphologie der Farbstoffarüse (Tintenbeutel) der Cephalopoden, nach der Darstellung von P. Giron. A Medianer Längsschnitt durch den Tintenbeutel des erwachsenen Thieres, a After, 1 gemeinsamer Endabschnitt für das Rectum 2 und den Ausführungsgang des Tintenbeutels, 3 Ampulle, 4 und 5 Sphinctermuskeln der Ampulle, 6 Ausführungsgang des Tintenbeutels, 7 Farbstoffreservoir, 8 Mündung der Farbstoffdrüse in das Reservoir, 9 von Lamellen durchsetzter Theil der Farbstoffdrüse, 10 Bildungszone der Lamellen. $\boldsymbol{B}-\boldsymbol{G}$ Verschiedene Stadien der Entwickelung der Farbstoffurüse. $\boldsymbol{B}$ Analpapille. $C$ Einstülpung an der Analpapille. $\boldsymbol{D}$ Am Boden der Einstülpung treten zwei neue Einstülpungen auf, welche immer tiefer werden und von denen die eine die Farbstoffdrüse $b$, die andere das Rectum 2 bildet. Bei $\boldsymbol{F}$ kann man an der Farbstoffdrüse schon die Bildungszone, bei $\boldsymbol{G}$ schon das erste Auftreten der Lamellen und des Ausführungsganges beobachten. $\boldsymbol{H}, \boldsymbol{I}, \boldsymbol{K}$ Veränderung der gegenseitigen Lage von Rectum und Farbstoffdrüse während der Entwickelung, von der Hinterseite (Mantelseite), $\boldsymbol{H}$ Das Rectum liegt hinter dem Tintenbeutel. Dieser verschiebt sich bei $\boldsymbol{I}$ so, dass er bei $\boldsymbol{K}$ hinter (auf die Mantelseite) das IRectum zu liegen kommt. 
Was die Endampulle anbetrifft, so besitzt sie an den beiden verengten Enden nach innen vorspringende, als Klappen fungirende Falten und kann an diesen Stellen durch Muskelsphincter verschlossen werden. Anch die Ampulle selbst bildet an ibrer inneren Obertliche Längsfalten, zwischen denen Drüsenschläuche münden.

Der After der Cephalopoden trägt immer zwei seitliche, vorragende, oft lanzettförmige Anhänge.

Der kurze und verengte Enddarm der Solenogastres öffnet sich in den dorsalen Theil eines am Hinterende des Körpers gelegenen Hohlraumes, in die Kloake, die selbst wieder mit der Aussenwelt durch eine ventrale, sehr erweiterungsfähige Lïngsspalte communicirt, und in welche auch die morphologisch als Nephridien $\mathrm{zu}$ betrachtenden Ausführungsgänge der Geschlechtsorgane münden.

Nachdem der Enddarm der I, a m e llibran chi er das Herz durchsetzt hat, verläuft er direct über den hinteren Schalenmuskel nach hinten, um sich mit dem After in den hinteren und oberen Theil der Mantelhöhle (Analkammer) zu öffinen.

Ueber die Lage des Afters vergl. das Kapitel V „Uebersicht über die Anordnung der Organe der Mantelhöhle".

\section{Cireulationssystem.}

A) Allgemeines.

Alle Mollusken besitzen ein Circulationssystem, das bei einigen Abtheilungen, besonders den Cephalopoden und einigen Prosobranchiern, durch Aushildung eines geschlossenen arteriellen und venösen Gefässsystems einen hohen Grad der Complication erreichen kann. Nirgends fehlt als centrales propulsatorisches (Organ das Herz. Dieses liegt, vou einem Abschnitt der secundären Leiheshöhle, dem Pericard oder Herzbeutel umschlossen, in ursprünglicher Lage median über dem Enddarn. Bei den Lamellibranchiern und Diotocardiern wird es von dem Enddarm durchbohrt. Bei den ührigen Gasteropoden liegt es nehen dem Fnddarm. Es ist immer ein arterielles Herz, d. h. in die Blutbahn eingeschaltet, welche das Blut von den Athmungsorganen in den Körper zurückleitet.

Wo bei symmetrischen Mollusken der Rü̈cken sich zu einem hoheu Fingeweidesack auszieht, in welchen der Darm hinauf- und aus welchem er zum After heruntersteigt, kommt das Her\% (Dentalium, Cephalopoden) hinter den Enddarm zu liegen. Bei den asymmetrischen Gasteropoden hängt die Lage des Iterzens von der des Pallealcomplexes ab. Ist der After und Endilarm mit dem Pallealcomplex an die Vorderseite des Fingeweidesackes verlagert, so liegt das Herz vorn am Lingeweidesack (Prosobranchier, Pulmonaten, einige wenige T'ectibranchier).

Aus dem Ilerzen entspringen im Allgemeinen zwei grosse A r terien (A orten), von denen die eine den Kopftheil, die andere den Fingeweidesack und die in ihm enthaltenen Eingeweide mit Blut versorgt. Nicht selten wurzeln heile mit einem gemeinsamen Stamm im Herzen. Die Arterien ergiessen das Blut bei nicht geschlossenem Kreislauf früher oter später in die primäre Leibeshöhle, d. h. in das Lacunensystem des 
Körpers. Das venöse Blut strömt bald in eigenwandigen Gefässen, bald in wandungslosen Blutkanälen in die Kiemen, wird hier arteriell und fliesst dann durch Vermittelung der Vorkamern (A ria) des Herzens in dieses zurück.

Typisch sind die Vorkammern des Herzens in einem Paare vorhanden, eine Vorkammer rechts und eine Vorkammer links vou der Herzkammer. Dies gilt für alle Mollusken, die mit zwei synımetrischen Kiemen ausgestattet sind. Das arterielle Blut strömt damn aus der linken lieme in die linke Vorkammer und von da in die liammer, aus der rechten lieme in die rechte Vorkammer und von da in die Kammer (Diotocardia zeugobranchia, Lamellibranchia, Cephalopoda dibranchiata). Auch da, wo die Kiemen in grösserer /ahl jederseits in der Kiemenfurche eine Längreihe bilden (Chitoniden), liegt das Herz hinten über dem Enddarm und ist mit einer einzigen rechten und einer einzigen linken Vorkammer versehen. Diese Thatsache scheint mir ebenso sehr dafür zu sprechen, dass den Mollusken ursprünglich nur 2 Ctenidien und nur 2 Vorhöfe zukamen, als die Verhälnisse bei $\mathrm{Nautilus}$ (Cephalopoda tetrabra nchiata) dagegen sprechen. Nautilus mit seinen 2 Paar Kiemen hat nämlich auch 2 Paar Vorhöfe des Herzens.
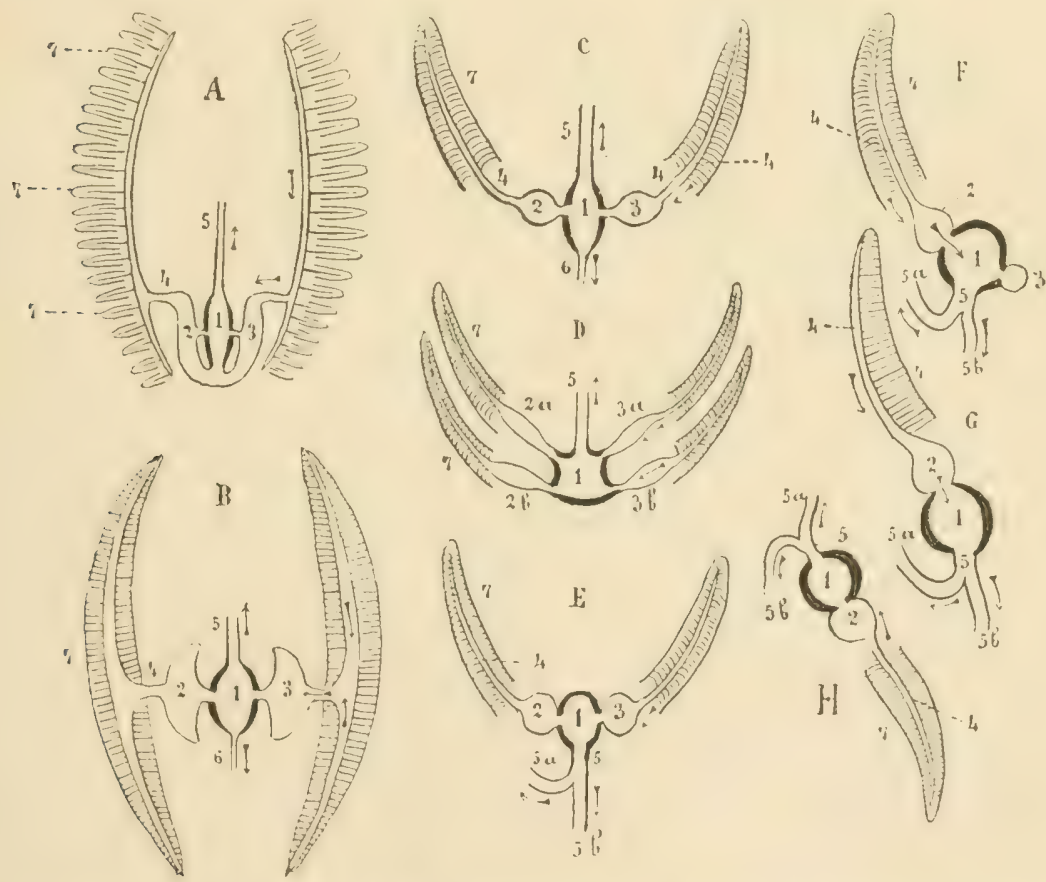

Fig. 549. $\mathbf{1}-\boldsymbol{I}$ Schemata zur Demonstration der Beziehungen zwischen Ctenidien, Herz und Aorta. $d$ Chiton. $\boldsymbol{B}$ Lamellibranchier. (: Dibranchiate Cephalopoden. $1: \boldsymbol{U}$ Tetrabranchiate Cephalopoden. E Prosobranchia diotocardia zougobranchia. I Prosobranchia diotocardia azygobranchia. G Prosobranchia monotocardia. II Opisthobranchi\& tectibranchia. 1 Herzkammer, 2, 3, 2a, 2b, 3a, $3 b$ Vorkammern, 4 Veua branchialis $=$ abführendes Kiemengefäss, 5 Aorta, $5 a$ Aorta cephalica, $5 b$ Aorta visceralis, 6 Aorta posterior vel superior, 7 Ctenidien. 
Bei der grossen Mehrzahl der Gasterop o den ist mit der einen der beiden ursprünglich vorhandenen Kiemen auch der ihr zugehörige Vorhof des Herzens verschwunden. Rewöhulich erhält sich mit der ursprünglich rechten Kieme der ursprünglich rechte Vorhof des Herzens, nämlich bei den Gasteropoden mit rechtsgewundener Schale. Bei ächt linksgewundenen Gasteropoden sind die Verhältnisse umgekehrt.

Es giebt indessen eine ganze Abtheilung von Prosobranchiern, die der Dio tocardier, bei denen sich noch beide Vorhöfe erhalteu haben. Dabei erweist es sich, dass die Vorhöfe des Herzens conservativer sind als die Kiemen, indem sich bei einigen Gruppen die beiden Vorhöfe noch erhalten haben, während die eine Kieme schon geschwunden ist. (Das Nähere weiter unten.)

Wo bei denjenigen Gasteropodev, welche nur eine Vorkammer des Herzens besitzen, der Pallealcomplex an die Vorderseite des Eingerveidesackes verschoben ist, liegen die Athmungsorgane vor dem Herzen und die einzige Vorkammer vor der Herzkammer (Prosobranchiata monotocardia, die meisten Pulmonata, einige wenige Opisthobranchiata). Bei denjenigen Gasteropoden aber, bei welchen sich der Pallealcomplex auf der einen (gewöhnlich der rechten) Kïrperseite befindet, liegt die Kieme hinter dem Herzen und der Vorhof hinter der Ḱammer. Zu diesen gehören fast alle Opisthobranchiaten. Auch bei einigen Pulmonaten, wie Testacella, Onchidium etc., liegt in Folge besonderer Organisationsverhältnisse der Vorhof des Herzens hinter der Kammer.

Das Blut oder besser die Hämolymphe ist eine Flüssigkeit, welche reich an gelösten Eiweissstoffen (Hämocyanin) ist, die zur Ernährung und Athmung dienen. In der Hämolymphe flottiren amöboide Zellen, die Lymphzellen oder Amöhocyten. Selten findet sich Hämoglobin gelöst in der Hämolymphe oder gebunden an besondere Blutkïrperchen. Die Lymphzellen lösen sich entweder aus der Wand localisirter Bl u tdrü se n los, die eine verschiedene Lage haben können, oder ihre Loslösung erfolgt in diffuser Weise in grösseren Gefässbezirken. Ihrem Ursprung nach scheinen sie Bindegewelsszellen darzustellen.

Die II and ung des Herzens und der eigenwandigen Gefässe besteht aus meist dicht verfilzten, glatten Muskelfasern und (am Herzen) einem äusseren Endothel, welches dem Pericard angehört. Ein inneres Endothel fehlt, so dass die Muskelfasern direct vom Blute bespült werden.

Die Wand der Herzkammer ist immer stärker musculös als die der Vorkammern. An der Einnündungsstelle der Vorhöfe in die Kammer finden sich immer in das Lumen vorspringende Kílappen, welche bei der Contraction der Kammer ein Zurückströmen des Blutes in die Vorhöfe verhindern. Ausser diesen Atrioventricularklappen kommen gelegentlich auch Klappen zwischen Kammer und Aorta vor. Klappenvorrichtungen können auch in peripheren Blutbahnen auftreten, da, wo solche Blutbahnen zu contractilen Erweiterungen anschwellen. Beispiel: die Ḱlappe zwischen den Kiemenherzen und den zuführenden Kiemengefässen der Cephalopoden.

Bei verschiedenen Gasteropoden und bei Chiton wurde in der Wand des Herzens ein Netz von Ganglienzellen und Nervenfasern nachgewiesen, welches von zwei Nerven verschiedenen Ursprungs innervirt wird. Der zum Kammerplexus gehende Nerv stammt bei Prosobranchiern aus dem linken Parietalganglion, der zum Vorhof gehende aus dem linken Parietovisceralcomnectiv. Wo 2 Vorhïfe vorhanden sind, werden sie von den Kiemenganglien aus innervirt. 
B) Specielles.

1. Amphineura.

a) Chitonidae (Polyplacophora). Das Herz ist symmetrisch mit zwei seitlichen Vorkammern.

Die Herzkammer und die beiden Vorkammern sind längliche Schläuche. Die Vorkammern verhalten sich zur Herzkammer folgendermaassen. Jede Vorkammer steht ungefähr in der Mitte ihrer Länge mit der Herzkammer in offener Communication. Ausserdem gehen die beiden Vorkammern hinten in einander über, und in diesen vereinigten Abschnitt mündet auch das Hinterende der Herzkammer. Die Kammer liegt der dorsalen Wand des Pericards an und ist an ihr durch ein medianes Endothelband befestigt. Sie setzt sich nach vorn in eine Aorta fort, welche das Blut durch Oeffnungen in ihrer Wand in die Leibeshöhle austreten lässt. Das ganze übrige Circulationssystem, mit Ausnahme der Fussarterien, besteht nicht aus eigenwandigen Gefässen, sondern ist lacunär.

Das venöse Blut sammelt sich aus dem Lacunensystem des Körpers (primäre Leibeshöhle) in einem Längsgang, welcher jederseits unter dem Pleurovisceralstrang verläuft. Aus diesem Längsgang strömt das Blut in die Kiemen, wird hier arteriell und kommt aus den Kiemen in einen zweiten Längsgang zurück, welcher über den Pleurovisceralsträngen verläuft. Aus diesen zwei Längsgängen führen zwei Quergänge in der Gegrend des Herzens das arterielle Blut in dessen Vorkammern (vergl. Fig. 435).

In Fusse liegen lateral und ventral von den Pedalsträngen die zwei Fussarterien, welche wahrscheinlich ihr Blut aus der Aorta beziehen und an das Lacunensystem des Fusses abgeben.

b) Solenogastres. Das Herz findet sich über dem Enddarm auf der Rückenseite des Pericards. Doch liegt es nicht frei in diesem letzteren oder durch ein Endothelband aufgehängt, sondern es ragt einfach von oben her in das Pericard vor, so dass es nur auf seiner Unterseite vom Pericardendothel überzogen ist. Das Vorhandensein von zwei Vorkammern hat sich nicht bestätigt. Das ganze übrige Circulationssystem ist rein lacunär. Grössere Blutgänge liegen in der vorragenden Kante der Hauptsepten, welche in den Mitteldarm vorragen, und blähen sie wulstförmig auf. Auch finden sich gelegentlich grössere Bluttaschen in Falten, welche von der Pharyngealwand in die Pharyngealhöhle vorragen und ansehnliche Bluträume in jenen als Kiemen betrachteten Falten, welche bei Neomenia und Chaetoderma in die Kloake vorragen. An allen diesen Stellen ist das die Bluträume gegen den Darm abschliessende Darmepithel bewimpert, und an allen diesen Stellen findet wohl Athmung statt.

\section{Gasteropoda.}

Verhältniss vou Herzkammer und Vorkammern. Die niedersten Gasteropoden, nämlich die Diotocardier unter den Prosobranchiern, haben ein Herz mit zwei Vorhöfen. Dies gilt nicht nur für die Zygobranchier. (Fissurella, Haliotis etc.), welche zwei Kiemen besitzen, sondern auch für die Azygobranchier (Turboniden, Trochiden, Neritidae), bei denen nur die linke (ursprünglich rechte) Kieme sich erhalten hat. In den rechten, kleineren und rudimentären Vorhof mündet dann keine Kiemenvene mehr, denn diese ist mit der rechten Kieme verschwunden. Bei den Zygobranchiern liegt die längliche Herzkammer in der Längsrichtung des Enddarmes, welcher sie der Länge nach durchbohrt. Bei den Azygobranchiern nimmt der Herzschlauch mit Bezug auf den ihn 
durchbohrenden Enddarm eine quere Lage ein, die linke Torkammer liegt vor, die rechte hinter der Kammer. In die vordere (linke) Vorkammer tritt von vorn her die linke Kiemenvene ein. Denken wir uns nun die hintere (rechte) Vorkammer vollständig geschwunden, wie dies bei allen äbrigen Gasteropoden der Fall ist, so besteht dann das Herz aus einer Kammer und einer vor dieser liegenden Vorkammer, die von der wieder vor ihr liegenden Kieme oder Lunge die Kiemen- resp. die Lungenvene bezieht. Die gegenseitige Lage von Kammer, Vorkammer, Kiemen- resp. Lungenvene und Athmungsorgan ist charakteristisch für die Azygobranchier, Monotocardier und die meisten Pulmonaten.

Die Docoglossen (Patella und Verwandte) haben nur eine Vorkammer des Herzens, dagegen ist die Kammer bei Patella (nicht bei Acmaea) in zwei Abtheilungen getheilt.

Unter den Monotocardiern besitzt, soweit bis jetzt bekannt, nur Cypraea einen (rudimentären) rechten Vorhof, der, mit Ausnahme der Oeffnung in die Herzkammer, allseitig geschlossen ist.

Unter den Pulmonaten giebt es Formen, bei welchen die Vor$\mathrm{kammer}$ hinter der Herzkammer liegt. Diese Lage ist als eine secundär erworbene zu betrachten, hervorgerufen durch die Rückverlagerung des Afters und der Mantelhöhle an das Hinterende des Körpers (Testacella, Onchidium). Bei Daudebardia liegt die Vorkammer noch vor der Herzkammer, trotzdem ist diese Gattung schon (wie übrigens inehrere nackte Lungenschnecken) opisthopneumon, $d . h$. das respiratorische Gefässuetz der Mantelhöhle liegt zum grossen Theil hinter dem Herzen. Bei Testacella liegt auch der Vorhof hinter dem Herzen (vergl. p. 649).

Bei den Opisthobranchiern liegt die Vorkammer hinter der Kammer, dies liängt in Allgemeinen damit zusammen, dass die Kieme im hinteren Körpertheil liegt, oder dass doch da, wo kein ächtes Ctenidium vorhanden ist, wo vielmehr die Athmung durch die Analkiemen oder durch Rückenanhänge oder durch die Haut geschieht, die Kiemenvene von hinten zum Herzen tritt.

Bei einigen Tectibran chiern, z. B. Actaeon, Acera, Gasteropteron, liegt die Kieme ziemlich weit vorn, und es liegt dann der Vorhof mehr rechts seitlich von der Kammer als hinter derselben.

Von besonderer Bedeutung ist - mit Rücksicht auf das nämliche Terhalten der Lamellibranchier - die Thatsache, dass bei vielen Diotocardiern (z. B. Fissurella, Haliotis, Turbonidae, Trochidae, Neritidae, Neritopsidae etc.) die Herzlimmer vom Enddarme durchbohrt wird, während bei allen anderen Gasteropoden der Enddarm am Herzen vorbeiläuft.

Circulation. a) Prosobranchier. Aus der Herzkammer entspringt ein grosses Gefäss, die Aorta. Diese theilt sich bald in 2 Aeste: 1) die vordere oder Kopfaorta (A. cephalica) und 2) die hintere A orta (A. visceralis). Die vordere A orta versorgt den vorderen Körpertheil (Kopf, Pharynx, Rüssel, Oesophagus, Magen, Begattungsorgane) und den Mantel mit Blut und giebt $u$. a. eine wichtige, in den Fuss eindringende Arteria pedalis ab, die sich bald in einzelne, den Fuss der Länge nach durchziehende Arterien auflöst. Bald ist die Kopfaorta reich verästelt, so dass sie sich in zahlreiche feine Gefässe auflöst, die sich in und an den erwähnten Organen ausbreiten, bald öffnen sich die Arterien, ohne sich reich zu verästeln, in arterielle Sinusse. Unter diesen verdient 
besonders der grosse Kopfsinus, in welchen sich z. B. bei Haliotis die vordere Aorta öffnet, erwähnt zu werden. - Die Aorta visceralis versorgt die im Eingeweidesack liegenden Organe, vornehmlich die Verdauungsdrüse, die Geschlechtsdrüsen und den Mitteldarm. Wo sich die Kopfaorta über den durch die centralen Ganglien und ihre Commissuren gebildeten Schlundring hinaus nach vorn fortsetzt, tritt sie durch diesen Schlundring hindurch.

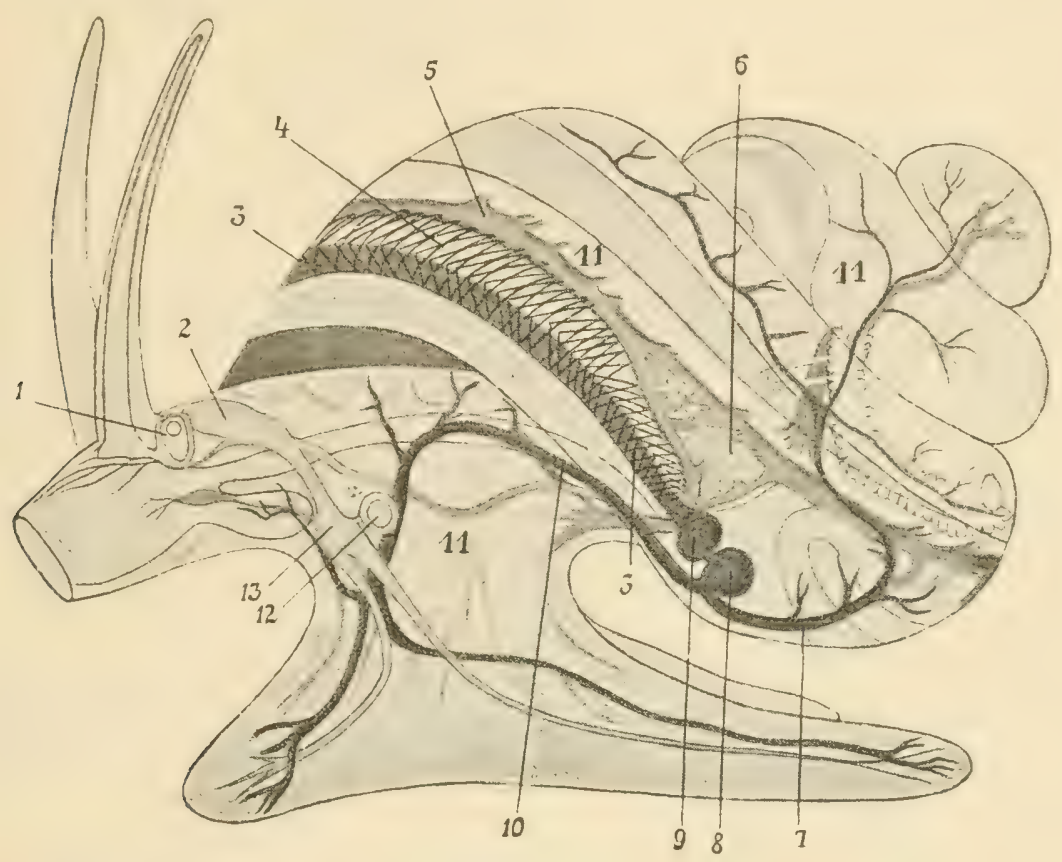

Fig. 550. Gefässsystem von Paludina vivipara, nach LEydig. Das Thier ist von der linken Seite gesehen, 1 Auge, 2 Cerebralganglion, 3 abführendes Kiemengefäss (Kiemenvene), 4 Kieme (Ctenidium), 5 zuführendes Kiemengefäss, 6 Niere, 7 Aorta visceralis, 8 Herzkammer, 9 Vorhof, 10 Aorta cephalica, 11 venöse Sinusse des Körpers, 12 Gehörbläschen, 13 Pedalganglion.

Das venöse Blut sammelt sich im Lückensystem aller Körpertheile und

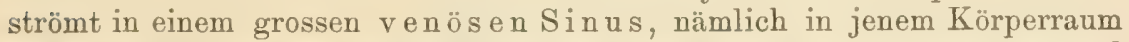
zusammen, in welchem Magen, Speicheldrüsen, Darm, Verdauungsclrüse und Geschlechtsorgane liegen. Dieser Raum oder diese primäre Leiheshöhle ist geräumiger in der Umgebung des Magens, sehr eingeengt aber im eigentlichen Eingeweidesack, wo die Lappen der Verdauungsdrüse, die Wandungen des Darmes und die Geschlechtsdrüsen mit ihren accessorischen Theilen so dicht gedrängt liegen, dass sie nur enge Spalten zwischen sich lassen.

Aus dem grossen venösen Sinus gelangt das Blut im Allgemeinen auf 3 Wegen in das Herz zurück.

1) Ein grosser Theil des venösen Blutes strömt durch Lacunen oder durch Gefässe in die paarige oder unpaare Kiemenarterie (zuführendes Kiemengefäss). Bei der Athmung in der Kieme wird das Blut arteriell und sammelt sich (vergl. das Kapitel über die Athmungsorgane) in einem abführenden Kiemengefäss, welches als Kiemenvene das 
Blut in den Vorhof des Herzens führt. Wo zwei Kiemen vorhanden sind, kommen natürlich auch 2 Kiemenarterien und 2 Kiemenvenen vor, welche letztere das arterielle Blut in 2 Vorhöfe des Herzens ergiessen.

2) Ein anderer Theil des venösen Blutes durchströmt die Niere, sammelt sich aus der Niere wieder in Lacunen oder Gefässen, die zur $\mathrm{K}$ ieme führen, und gelangt schliesslich wieder durch die Kiemenvenen in das Herz. Seltener gelangt das Blut, welches die Niere durchströmt hat, mehr oder weniger direct, also unter Umgehung der Kieme als venöses Blut in den Vorhof, wo es sich mit dem von der Kieme kommenden arteriellen Blute vermischt.

3) Ein gewisser Theil des venösen Blutes ergiesst sich direct, unter Umgehung der Niere sowohl als der Kieme, in die zum Vorhof des Herzens führende Kiemenvene.

So ist also im Herzen dem arteriellen Blut auch venöses beigemischt.

b) Pulmonata. Das Blutgefässsystem (Beisp.: Helix pomatia, Limax, Fig. 551, 552, 477) verhält sich ganz ähnlich wie das der ILonotocardier. Die wichtigste Abweichumg ist durch das Auftreten der Luftathmung bedingt. Verschiedene Venen sammeln das venöse Blut aus dem grossen Leibessinus und dem Lacunensystem und vereinigen sich zu einer grossen Vene, welche den Enddarm begleitet und als Vena circularis in den verdickten und mit der Leibeswand des Nackens verwachsenen Mantelrand verläuft. Aus dieser Vene entspringen zahlreiche, venöse Gefässe, die sich an der Unterseite des Mantels oder, mit anderen Worten, an der Decke der mit Luft erfüllten Mantelhühle (Lunge) ausbreiten und ein zierliches, respiratorisches Gefässnetz erzeugen. In diesem Netz wird das venöse Blut arteriell und wird durch zahlreiche Gefüsse in die grosse Lungenvene (Vena pulmonalis) geleitet, welche dem Rectum annähernd parallel an der Decke der Mantelhöhle nach hinten verläuft, um in den Vorhof des Herzens einzutreten. Die Gefässe des respiratorischen Gefässnetzes

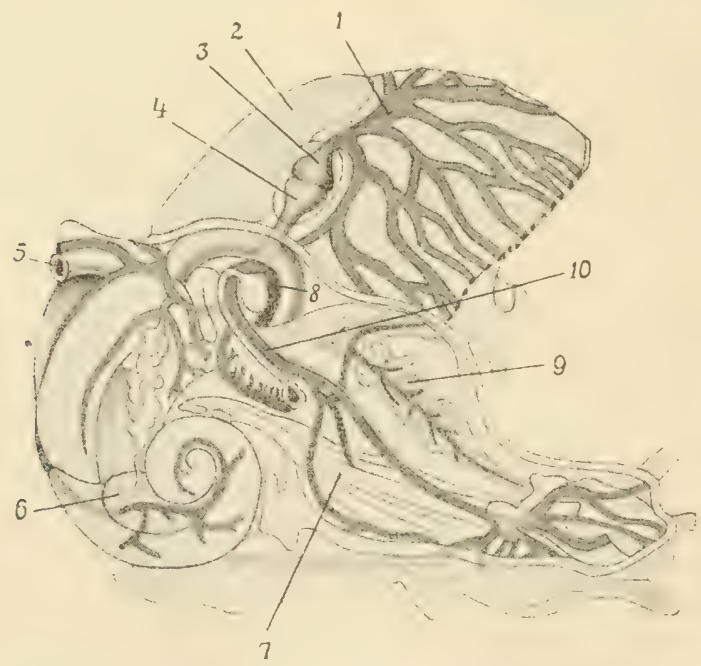

Fig. 551. Lungenvenen, Herz und Arteriensystem von Helix, nach HowEs. Der Mantel (Lungendecke) aufgeschnitten und zurückgeklappt. 1 Lungenvene (abfihrendes Lungengefäss), 2 Niere, 3 Vorhof, 4 Kammer des Herzens, 5 Rectum, durchschnitten, 6 Zwitterdrüse, 7 Spindelmuskel, 8 Aorta visceralis, 9 Speicheldrüsen, 10 Aorta cephalica. 
erheben sich leisten- oder rippenförmig auf der MantelHäche. Das Mantelepithel, welches sie an der der Mantelhöhle zugekehrten Seite überzieht, ist bewimpert.

Die abführenden Lungengefässe, welche in der Gegend der Niere auf der rechten Seite der Lungenvene verlaufen, treten zuerst in die Niere ein und lösen sich in ihr in ein feineres Gefässnetz auf, bevor sie in die Lungenvene einmünden.

Die Kopfaorta tritt nicht durch den Schlundring, sondern zwischen den Pedal- und Visceralganglien hindurch, ein Verhalten, das auch bei den meisten Opisthobranchiern bestehen soll.

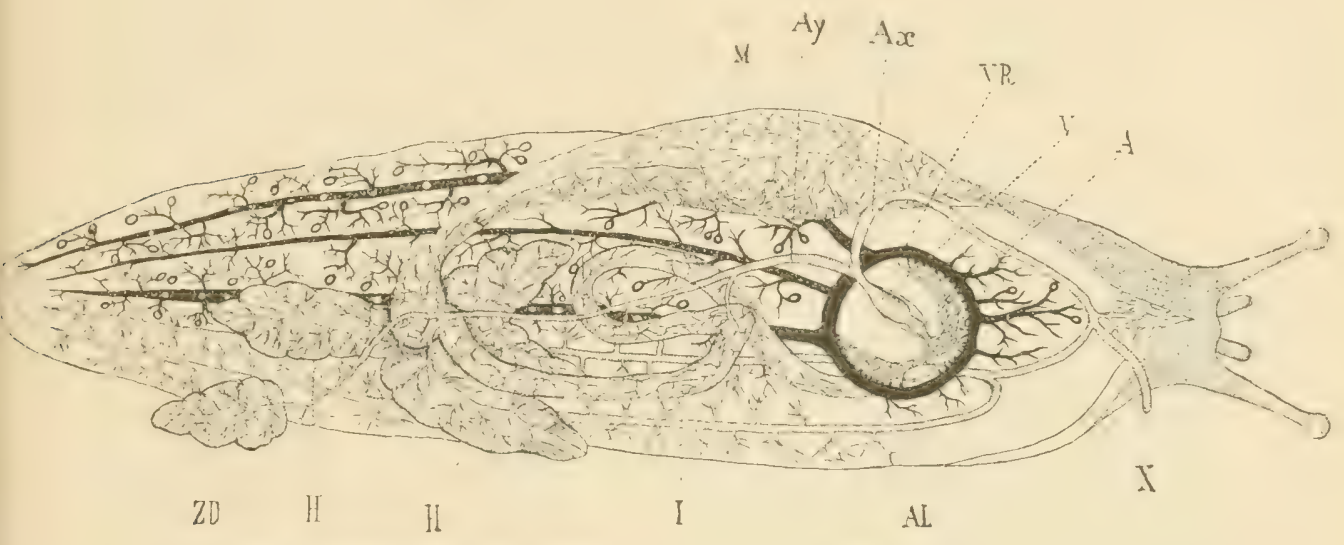

Fig. 552. Gefässsystem von Limax, nach von LEUcKART combinirten Zeichnungen von Delle Chífe und Srmoth. Die Venen, welche das venöse Blut aus dem Körper zur Lunge führen, sind schwarz gehalten. A Vorhof, $V$ Herzkammer, $\Gamma R$ venöser Ringsinus der Lungenhöhle, $A x$ Aorta cephalica, $A y$ Aorta visceralis, $M$ Muskelmagen, $Z D$ Zwitterdrüse, $H$ Verdaungsdrüse, $I$ Darm, $A L$ Athemloch, $X$ Arteria genitalis.

Bei den opisthopne umonen Pulmonaten (z. B. Daudebardia, Testacella), bei denen der kleine oder rudimentäre Eingeweidesack an das Hinterende des Körpers gerückt ist, und bei welchem die sonst im Eingeweidesack eingebetteten Organe (Leber, Geschlechtsorgane) in die über dem Fusse liegende Körperhöhle zurückverlagert sind und also vor dem weit hinten befindlichen Herzen liegen, ist die hintere Aorta stark reducirt, die vordere Aorta dagegen sehr stark entwickelt. Die hintere Aorta versorgt nur die hinteren Leberlappen und die Zwitterdrüse, und es fällt hier der vorderen Aorta (Kopfaorta, A. ascendens) auch die Aufgabe zu, einen Theil jener Organe mit Blut zu versorgen, welche, wie z. B. die vorderen Leberlappen, ein 'Theil der Geschlechtsorgane, sonst in das Verbreitungsgebiet der hinteren Aorta fallen.

Bei Oncidium ist zwar eine der hinteren Aorta entsprechende Arteria visceralis, die sich bald nach dem Ursprung der Aorta aus dem Herzen abzweigt, vorhanden, aber sie nimmt einen nach vorn gerichteten Verlauf.

c) Opisthobranchier. Auch hier sind die Verhältnisse im Wesentlichen wie bei den Prosobranchiern, mit den durch die verschiedene Lage der Kiemen bedingten, zum Theil schon signalisirten Abweichungen.

Zur summarischen Darstellung des Kreislaufes der Tectibranchier wähle ich Gastropteron. Das in ein geräumiges Pericard 
(ingeschlossene $\mathrm{H}$ erz befindet sich rechtsseitig vor und über der Kiemenbasis. Es liegt quer, die stärker musculöse Kammer links, der Vorhof rechts, zwischen Kiemenbasis und Herz. Aus der Kammer entspringt die Aorta, die sich sofort in eine vordere und eine hintere Aorta spaltet. Die vordere Aorta dringt in die Kopfhöhle ein. Die von ihr abgehenden Hauptarterien sind: 1) Die Arterie des Copulationsorganes. 2) Die beiden grossen Fussarterien, von denen jede sich bald wieder in 2 Aeste theilt, nämlich a) die vordere Fussarterie; sie verästelt sich reichlich in den Parapodien; b) die hintere Fussarterie, sie läuft jederseits parallel der Medianlinie im medianen Theil des Fusses nach hinten. 3) Die Arterien der Kopfscheibe. 4) Die Arterien des Schlundkopfes und Oesophagus. 5) Das Vorderende der vorderen Aorta verästelt sich in den den Mund umziehenden Geweben. Folgendes sind die Hauptäste der hinteren Aorta: 1) die Magenarterie; 2) die Leberarterien; 3) die Genitalarterien. Aus allen Theilen des Körpers strömt das venöse Blut in reich verzweigten Bahnen zurück in zwei grosse venöse Sinusse, von denen der eine die Kopfhöhle, der andere die Rumpfhöhle darstellt. Weite, aber kurze Blutkanäle führen das venöse Blut aus diesen Sinussen in die $\mathrm{Niere}$, die ein reiches, venöses Lacunensystem aufweist. Aus der Niere tritt es direct in das $\mathrm{zuführende} \mathrm{Kiemen-}$ gefäss über, wird in der Kieme arteriell, sammelt sich in dem abführenden Kiemengefäss, welches als Kiemenvene nach kurzem Verlauf in den Vorhof des Herzens eintritt.

Nach dieser Darstellung geht alles venöse Blut bei Gastropteron auf seinem Rückwege zum Herzen ersteus durch die Niere und zweitens durch die Kieme, so dass das Herz nur von arteriellem Blut durchströmt wird.

Das scheint aber durchaus nicht bei allen Tectibranchiern der Fall zu sein, denu es wird, um nur ein Beispiel anzuführen, bei Pleurobranchus ein grosser Theil des venösen Blutes aus einem dorsalen Ringsinus durch einen sehr kurzen, aber weiten venösen Gang direct in die Kiemenvene entleert, dicht an der Stelle, wo letztere in den Vorhof einmündet, mit Umgehung sowohl der Niere, als auch der Kieme.

Dorididae. Ohne auf die specielleren Verhältnisse des Kreislaufes einzugehen, sei hier nur erwähnt, dass ein Theil des venösen Blutes direct durch zwei seitliche Gefässe in den Vorhof einmündet. Ein anderer Theil ergiesst sich in einen an der Basis der Kiemenkrone gelegenen inneren venösen circumanalen Ringsinus. Aus diesem steigt das Blut in die Kiemen empor, wird in ihnen arteriell, strömt aus den Kiemen zurückkommend in ein äusseres circumanales Ringgefäss und aus diesem von hinten durch die Kiemenvene in den Vorhof des Herzens (Fig. 475).

$\mathrm{Nudibranchiata.} \mathrm{Das} \mathrm{im} \mathrm{Pericard} \mathrm{eingeschlossene} \mathrm{Herz} \mathrm{liegt} \mathrm{fast}$ immer vor der Körpermitte und in der Nediane des Körpers. Die aus der Eammer ihren Ursprung nehmende Aorta theilt sich in eine vordere und eine hintere Aorta, die sich beide in ein eigenwandiges Arteriensystem auflösen. Die feineren Arterienzweige öffnen sich in das Lacunensystem des Köpers, das hie und da gefässartige Kanäle bilden kann und mit dem grossen Kopf- und Eingeweidesinus in Verbindung steht. Aus dem Lacunensystem der Rückenanhänge oder der Haut sammeln sich, wie es scheint, eigenwandige Venen, welche das arteriell gewordene Blut in den Torhof des Herzens zurïckführen. Meist sind es schliesslich drei "Kiemen- 
venen", die in den binter dem Herzen liegenden Vorhof einmünden, zwei seitliche und eine von hinten kommende mediane, unpaare.

$$
\text { 3. Scaphopoda. }
$$

Das Circulationssystem von Dentalium ist - mit alleiniger Ausnahme des erst ganz kürzlich entdeckten, rudimentären Herzens - vollständig lacunär und besteht aus Kanälen, Sinussen und Lückensystemen, deren specielle Anordnung hier nicht besprochen werden kann.

Das Pericard mit dem Herzen liegt an der Hinterseite des Körpers, dorsalwärts vom After. Denken wir uns den Darm von Dentalium gestreckt und horizontal gelegt, so würde das Herz in typischer Lage auf der Rückenseite des Enddarmes liegen. Das Herz entbehrt der Vorhöfe und stellt eine sackförmige Einstülpung der vorderen Wand des Pericards in die Pericardialhöle dar. Durch feine Spalten steht es mit den benachbarten Blutsinussen des Körpers in Verbindung.

\section{Lamellibranchiat a.}

Herz. Die Regel, welche für fast alle Muscheln gilt, ist die: das Herz ist rom Enddarm durchbohrt, besitzt zwei seitliche Vorhöfe und liegt in einem Pericard.

Es giebt jerloch vereinzelte Ausnahmen von dieser Regel. Bei Nucula, Arca, Anomia liegt die Kammer über (dorsalwärts von) dem End d a rm. In Anbetracht, dass diese Gattungen zu den ursprïnglichen Lamellibranchiern gehören, in Anbetracht ferner, dass das Herz der Amphineuren, Scaphopoden und Cephalopoden ebenfalls über, resp. hinter dem Enddarm liegt, dürfen wir diese dorsale Lage für die ursprüngliche Herzlage der Lamellibranchier halten. Die Durchbohrung des Herzens seitens des Enddarmes ist so entstanden zu denken, dass die Kammer von oben her sich nach unten hin um den Fnddarm herumbog:

Das Herz der erwähnten Muschelgattungen ist ausserdem noch dadurch ausgezeichnet, dass die Kammer in der Querrichtung mehr oder weniger stark ausgezogen ist und zwar so, dass seine beiden seitlichen Enden blasenförmig angeschwollen sind, während der mittlere, über dem Darm verlaufende Verbindungstheil enger und dünner ist. Am weitesten gehen diese Verhältnisse bei Arca $\mathrm{N}$ oa e, wo man von zwei seitlichen Herzkammern sprechen kann, die nicht mehr durch ein einfaches Verbindungsstück zusammenhängen. Die Theilung der Kammer in zwei seitliche Theile hat hier auch eine Theilung der beiden Aorten herbeigeführt. Tmmerhin verbinden sich sowohl die beiden vorderen, als die beiden hinteren Aortenstämme nach relativ kurzem Verlaufe zu einer unpaaren vorderen resp. unpaaren hinteren Aorta.

Haben die erwähnten Gattungen ein über dem Enddarm liegendes Herz, so haben einige specialisirte Formen ein unter dem Enddarm liegendes Herz, z. B. Meleagrina, Ostrea, Teredo. Der Grund dieser Erscheinung dürte in der zunehmenden Entfernung der Kiemenbasis von der ursprünglichen Herzgegend liegen, wobei die Vorhöfe und mit ihnen die Herzkammer mitgezogen wurden. Dabei bleiben aber die Vorhöfe nicht mehr seitlich von der Kammer, sondern sind an ihre Unterseite verzogen, wo sie, miteinander verwachsen, durch eine grössere oder kleinere Oeffnung communiciren. Pinna, A vicula und Perna zeigen uns die aufeinanderfolgenden Stadien der Verlagerung des Herzens an 
die Unterseite des Enddarmes. - Das oben erwähnte Wegrücken der Kiemen aus der ursprünglichen Herzgegend wurde selbst wieder bedingt durch die Verlagerung des immer stärker werdenden ursprünglich hinteren Schalenmuskels nach vorn und unten bis in die Mitte der jederseitigen Schalenklappe. Dass dieser hintere Schalenmuskel bei fortschreitender Reduction und schliesslichem Schwinden des vorderen zu dem einzigen Schliessmuskel der "Monomyarier" geworden ist, wurde schon früher betont.

Auch bei Tere do liegt das Herz auf der Unterseite des Enddarmes. Das hängt damit zusammen, dass sich hier der Enddarm mit dem After dorsalwärts dem Munde genähert hat, während die Kiemen, in ursprünglicher Lage verharrend, das Herz auf der Unterseite des Darmes zurückbehalten haben.

Circulation (Fig. 409). Das Arteriensystem ist eigenwandig und verästelt sich in feine Gefässe, die das Blut in ein Lacunensystem des Körpers entleeren. Das venöse System scheint besonderer eigenwandiger Gefässe zu entbehren, wenn auch die venösen Blutbahnen gefässartige engere oder weitere Kanäle bilden.

Aus der Herzkammer entspringt im Allgemeinen eine vordere und eine hintere Aorta. Die vordere Aorta läuft über dem Darm nach vorn und theilt sich in verschiedene Arterien. Die Arteria visceralis bedient den Darm, die Verdauungsdrüse und die Geschlechtsdrüse; die Fussarterie ernährt den Fuss; die vordere Mantel-

Fig. 553 .

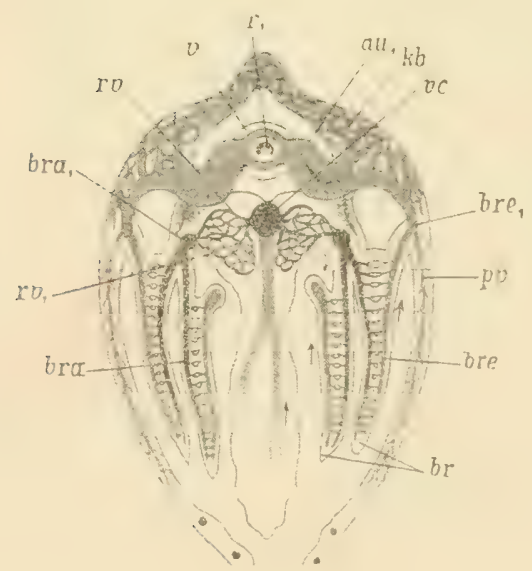

Fig. 554 .

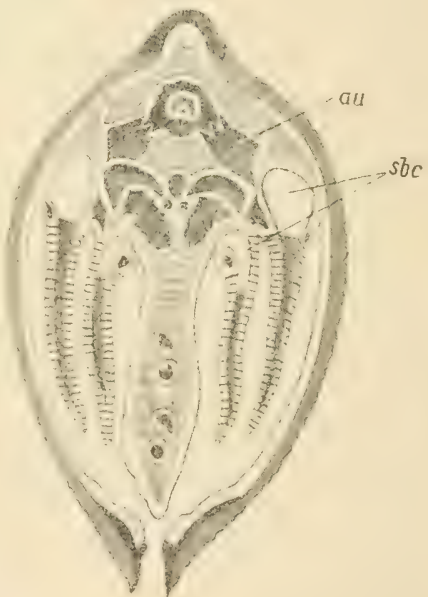

Fig. 553. Querschnitt durch Anodonta, zur Demonstration dos Kiemen- und Nierenkreislaufes, sowie der Kiemenvenen, nach HowEs. br Kiemen, bre ausleitendes Kiemengefäss (Kiemenvene), welches in die grosse, querdurchschnittene, der Kiemenbasis entlang verlaufende Kiemenvene bre, einmündet, $p v$ Mantelvene, $v c$ grosser venöser Körpersinus, $k b$ Pericardialdrüse, $a u_{1}$ Vorhof, $v_{1}$ Rectum, $v$ Herzkammer, $r v$ und $r v_{1}$ Nierengefässe, $b r a_{1}$ grosses, an der Basis der Kieme verlaufendes zufübrendes Kiemengefäss (Kiemenarterie), Ora in die Kieme verlaufender Seitenast desselben. Die venöses Blut führenden Gefässe resp. Sinusse sind schwarz gezeichnet.

Fig. 554. Weiterer Querschnitt durch Anodonta, nach Howes. Die Figur erklärt sich aus Fig. 553. au Vorhof, $s b c$ vom Wasser durchspülte, nit der Nantelhöhle in Communication stehende Räume an der Kiemenbasis $\mathrm{zwischen}$ auf- und absteigender Kiemenlamelle. 
arterie verbreitet sich im vorderen Theil des Mantels und in den Mundlappen.

Die hintere Aorta tritt hinten aus der Kammer aus und verläuft an der Unterseite des Enddarmes. Sie theilt sich bald in zwei grosse, seitliche Hauptarterien, die hinteren Mantelarterien. Die Hauptstämme der vorderen und hinteren Mantelarterien verlaufen jederseits dem freien Mantelrand entlang und gehen ineinander über, so dass sie zusammen die beiden Mantelrandarterien bilden. Aus den Wurzeln der hinteren Mantelarterien entspringen ferner noch kleinere Arterien, welche den Enddarm, das Pericard, den hinteren Schliessmuskel, die Retractoren der Siphonen etc. versorgen. Aus dem Lacunensystem des Körpers sammelt sich das venöse Blut durch zusammenfliessende Blutkanäle schliesslich in einem venösen Längssinus, welcher unter dem Pericard liegt (Fig. 553).

Von hier aus durchströmt der grösste Theil des Blutes das complicirte, venöse Kanalnetz der beiden Nieren, um sich jederseits in einer der Basis der Kieme entlang verlaufenden "Ki e m en a r t e ri e" (zuleitendes Kiemengefäss) zu sammeln und von diesem aus in die beiden Kiemenlamellen einzutreten. Es wird in den Kiemen bei der Athmung arteriell, strömt als arterielles Blut in eine der Kiemenarterie parallel verlaufende „Ki emenvene“ (ableitendes Kiemengefäss) und von dieser in den Vorhof des Herzens.

Ein Theil des venösen Blutes aber gelangt durch directe Verbindungen aus dem venösen Sinus in die Kiemenarterie (mit Umgehung der Nieren) und ein Theil sogar mit Umgehung der Niere direct in das Pericard. Durch diese letztere Communication wird also dem das Herz durchströmenden, aus den Kiemen stammenden arteriellen Blute ein wenig venöses beigemischt.

Nicht bei allen Lamellibranchiern entspringt aus dem Herzen eine vordere und eine hintere Aorta. Gerade in den niederen Gruppen der Protobranchiaten und Filibranchiaten giebt es zahlreiche Formen (Nucula, Solenomya, Anomia, Mytilidae), bei denen aus der Kammer nur ein einziger vorderer Aortenstamm hervorgeht, die aber bald eine Arterie, die Arteria visceralis abgiebt, welche diejenigen Gebiete bedient, die bei den ïbrigen Lamellibranchiern durch die Aorta posterior versorgt werden. Hierin, das heisst in dem Vorhandensein einer einzigen, aus der Kammer entspringenden Aorta, stimmen die erwähnten niederen Muscheln mit Chiton und den Gasteropoden überein. Dass die Aorta bei den Prosobranchiern und den meisten Pulmonaten hinten aus der Herzkammer austritt, ist ein secundäres Verhalten, hervorgerufen durch die Verlagerung des Pallealcomplexes nach vorn.

Es ist noch zu bemerken, dass bei einer sehr specialisirten Muschel, bei Teredo nämlich, die hintere Aorta mit der vorderen verschmilzt, so dass auch hier ein gemeinsamer Aortenstamm die Herzkammer verlässt.

Bei mit Siphonen ausgestatteten Lamellibranchiern kommt an der hinteren Aorta, nahe der Stelle, wo sie aus der Herzkammer austritt, eine musculöse und contractile Erweiterung vor, die. als Bulbus arteriosus bezeichnet worden ist. Sie hat vielleicht die specielle Function, beim Ausstrecken der Siphonen durch Blutschwellung wirksam zu sein. Das Zurückfliessen des Blutes in die Herzkammer bei der Contraction (Systole) des Bulbus arteriosus verhindert eine von seiner vorderen Wand in ihn hineinragende zungenförmige Klappe. 
5. Cephalopoda.

Herz (Fig. 509, 549 und 555). Es muss hier zunächst wieder auf die wichtige Thatsache hingewiesen werden, dass $\mathrm{Nautilus}$ ein Herz mit 4 Vorhöfen, die Decapoden und Octopoden ein Herz mit 2 Vorkammern besitzen. Dieser Unterschied hïngt mit der verschiedenen Zahl der Ctenidien ( 4 bei Nautilus: Tetrabranchiata, 2 bei Decapoden und Octopoden: Dibranchiata) zusammen.

Bei Nautilus ist das Herz ein fast viereckiger, jederseits in zwei Zipfel ausgezogener Sack, und die 4 Vorhöfe, die in die 4 Herzzipfel einmünden, sind langgestreckte Schläuche, welche eher wie erweiterte Kiemenvenen, als wie Vorkammern aussehen.

Die kräftig musculöse Herzkammer der Dibranchiata ist fast überall schlauchförmig verlängert. Bei den Octopoden liegt sie quer, so dass die 2 Vorhöfe in einer Flucht mit ihr liegen. Bei den Oegopsiden liegt sie in der Längsaxe des Körpers, ist also nach unserer Orientirung in dorsoventraler Richtung verlängert, und die Vorhöfe stehen senkrecht zu ihr. Eine Zwischenstellung zwischen Octopoden und Oegopsiden nehmen bezüglich der Lage des Herzens die Myopsiden ein.

Das hier besprochene Herz ist das dem Herzen der übrigen Mollusken entsprechende. Man bezeichnet es als arterielles Herz, zum Unterschied von den venösen Herzen, die weiter unten besprochen werden sollen.

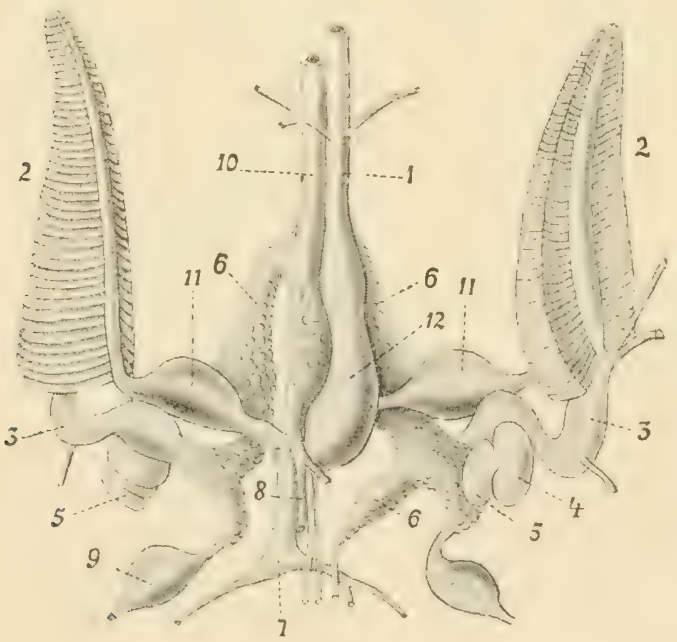

Fig. 555. Circulationssystem, Venenanhänge des $\mathrm{Ne}$ phridialsystems und Kiemen von Sepia officinalis, von vorn, nach Hunter. 1 Aorta cephalicr, 2 Ctenidien, 3 zu den Ctenidien führende Venen, $4 \mathrm{Kie}$ menherzen, 5 Kiemenherzanhang (Pericardialdrüse), 6 Venenanhänge des Nephridialsystems, 7 Aorta abdominalis, 8 Vena abdominalis, 9 seitliche Venen, 10 Vena cephalica, 11 Vorhöfe, 12 Herzkammer.

Circulation. Zunächst muss hier hervorgehoben werden, dass das Blutgefässsystem ein wenigstens theilweise geschlossenes ist. Es existirt nicht nur ein reich verzweigtes, eigenwandiges Arteriensystem, sondern auch ein reich verzweigtes, eigenwandiges Venensystem. Beide gehen an gewissen Körperstellen, z. B. in der Haut und in verschiedenen Muskelschichten, durch ein System von Haargefässen (Capillaren) direct ineinander über. An anderen Stellen aber ergiessen die Arterienzweige das Blut in ein Lückensystem; das venös gewordene Blut sammelt sich aus diesem in Sinussen (besonders in einen peripharyngealen Kopfsinus), um von da aus durch eigenwandige Venen den Kiemen zugeführt zu werden. 
Aus der Herzkammer nehmen zwei Aorten ihren Ursprung, erstens die nach unten (gegen den Kopffuss) verlaufende. A orta cephalica, und zweitens die nach oben gegen die Spitze des Eingeweidesackes verlaufende Aorta abdominalis. Die Aorta cephalica ist viel stärker als die A. abdominalis. Sie giebt in ihrem Verlaufe zunächst Aeste an den Mantel und die vordere Kürperwand ab, versieht den Magen, das Pankreas, die Verdanungsdrüise, den Oesophagus, die Speicheldrüsen und den Trichter mit Arterien. Nachdem sie hierbei den Oesophagus begleitet hat, gabelt sie sich, im Kopfe angekommen, in zwei Aeste, die sich an die Basis der Arme begeben, um sich hier in ebenso viele Arteriae brachiales zu theilen, als Arme vorhanden sind.

Die Aorta abdominalis versieht im Allgemeinen den Enddarm, den Tintenbeutel, die Geschlechtsorgane, den dorsalen Theil der Körperwand und die Flossen, wo solche vorhanden sind, mit Arterien.

Nur bei den $\mathrm{O}$ egopsiden entspringen indessen bloss die zwei erwähnten Aorten aus der Herzkammer. Bei den $\mathrm{Octopoden}$ und MI yopsiden nehmen gewisse Arterien, die zum Verbreitungsgebiet der Aorta abdominalis der Oegopsiden gehören, einen directen Ursprung aus der Herzkammer, so vornehmlich die Arteria genitalis, welche zu der Keimdrüse verläuft, und bei Myopsiden ein feines, als Art. anterior bezeichnetes Gefäss.

An einzelnen Stellen können die Arterien zu kleinen musculösen und contractilen Erweiterungen, peripheren Arterienherzen, anschwellen.

Das Venensystem wollen wir zunächst für Sepia kurz beschreiben. In jedem Arm sammelt sich das venöse Blut (z. Th. durch Capillaren, z. Th. durch Lacunen) in einer der Innenseite der Arme entlang verlaufenden Vene. Alle Armvenen ergiessen ihr Blut in einen die Mundmasse umgebenden ringförmigen Kopfsinus, welcher ïberhaupt das venöse Sammelreservoir für die ganze Kopffussgegend ist. Aus diesem Sinus entspringt die grosse Kopfvene (Vena cephalica), welche auf der Hinterseite des Oesophagus und der Leber in den Eingeweidesack emporsteigt. Sie sammelt auf ihrem Wege venöses Blut aus der Leber, dem Trichter u. s. w. Etwas unter dem Magen theilt sie sich gabelig in die beiden Hohlvenen (Venae cavae), welche in die beiden an der Basis der Kiemen liegenden contractilen Venenherzen einmünden. Aus dem oberen Theil des Eingeweidesackes sammelt sich das Blut in mehreren Abdominalvenen. Die wichtigsten sind folgende. Eine unpaare Vena abdominalis mündet in die Vena cephalica genau an der Stelle, wo sie sich in die Venae cavae theilt. Zwei seitliche Abdominalvenen münden in die Hohlvenen nahe der Stelle, wo sie in die Kiemenherzen eintreten.

Alle diese Venen tragen in der Region des Herzens traubenförmige oder lappige Anhänge, die Venenanhänge. Alle diese Anhänge sind hohl und communiciren überall mit den Venen, so dass sie also reichlich von Blut durchspült werden. Die Höhle, in welche diese Anhänge vorragen, ist die Höhle der $\mathrm{Nierensäcke,} \mathrm{und} \mathrm{das} \mathrm{Epithel,} \mathrm{welches}$ die Venenanhänge überzieht, gehört zur Epithelwand der $\mathrm{Niere}$ (vergl. diese),

Wir sehen also, dass auch hier das aus dem Körper zurückströmende Blut reichlich Gelegenheit hat, in den Venenanhängen die in ihm enthaltenen excretorischen Bestandtheile an die Niere abzugeben.

An den beiden venösen Kiemenherzen finden sich Anhänge, die Pericardialdrüsen, von denen später die Rede sein wird. Die beiden Kiemenherzen dieneu dazu, bei ihrer Contraction das venöse Blut 
in das zuführende Kiemengefäss zu treiben. Das in den Kiemen arteriell gewordene Blut (über den Kiemenkreislauf vergl. p. 670) strömt durch das ausführende Kiemengefäss, die sogenannte $\mathrm{Ki}$ emenvene, in die Vorkammern des Herzens und von da in die Kammern.

Im Gegensatz zu den übrigen Mollusken strömt bei den Cephalopoden das gesammte aus dem Körper zurückkehrende Blut durch die Kiemen, so dass das Herz nur arterielles Blut erhält.

Der weitaus grösste Theil des venösen Blutes kommt (in den Venenanhängen) mit der Niere in Berührung, bevor es in die Kiemen eintritt.

Bei den $\mathrm{O}$ ctopoden zeigt das Venensystem nicht unbeträchtliche Verschiedenheiten. Bei Octopus verlaufen an der Aussenseite eines jeden Armes zwei mit einander durch Anastomosen verbundene Venen, die das venöse Blut der Arme sammeln. An der Basis der Arme verbinden sich diese Venen zunächst paarweise, dann so, dass aus ihrer jederseitigen Verbindung eine laterale Kopfvene hervorgeht.

Die beiden seitlichen Kopfvenen vereinigen sich mit einander zu der grossen, vor dem Trichter hinter dem Oesophagus emporsteigenden Vena cephalica. Die Armvenen ergiessen also hier ihr Blut nicht erst in einen venösen Ringsinus des Kopfes, wie das bei Sepia der Fall war, sondern sie stehen mit der Vena cephalica in directer Verbindung. Nichtsdestoweniger existirt auch bei Octopus ein Kopfsinus. Dieser steht aber nicht in Verbindung mit der Vena cephalica, wohl aber mit einem grossen, den ganzen Eingeweidesack erfüllenden Sinus, welcher nichts anderes ist als die primäre Leibeshöhle, und in der die Eingeweide, vom venösen Blute gebadet, liegen. Aus diesem grossen venösen Sinus strömt das Blut durch zwei grosse und weite Venen, die sogenannten "Peritonealtuben", in den oberen Theil der Aorta cephalica, nahe der Stelle, wo sich diese in die zwei Hohlvenen theilt.

$\mathrm{Nautilus}$ ist vor allem durch das Fehlen der Kiemenherzen ausgezeichnet. Ferner theilt sich jede der beiden Hohlvenen in zwei Aeste, die als zuführende Kiemengefässe zu den Kiemen gehen.

\section{Die Leibeshöhle.}

(Primäre und secundäre Leibeshöhle, Pericard, Pericardialdrüsen.)

Man unterscheidet bei den Mollusken eine primäre und eine secundäre Leibeshöhle. Die erstere stellt im Allgemeinen das Lacủnen- und Sinussystem des Körpers dar, in welches sich die Arterien öffnen, und aus welchem die Venen, wo solche vorhandeu sind, ihr Blut beziehen. Sie ist ohne eigene Epithelwand, d. h. sie wird begrenzt, je nach den örtlichen Verhältnissen, vom angrenzenden Bindegewebe, Nervengewebe, Muskelgewebe, oder auch von Epithelien, die aber, wie das Darmepithel, Körperepithel, Nierenepithel etc., anderen Organen angehören.

Die sogenannte secundäre Leibeshöhle oder das Coelom ist bei der grossen Mehrzahl der Mollusken als Leibeshöhle sehr reducirt und erhält sich meist nur in zwei beschränkten Höhlen, erstens dem Pericard oder Herzbeutel und zweitens der Höhlung der Gonaden (Hoden, Ovarien, Zwitterdrüsen). Sie ist immer allseitig von einer eigenen Epithelwand, dem Endothel 
der Leibeshöhle, a usgekleidet. Sie entspricht der ächten, von einem Endothel ausgekleideten Leibeshöhle, dem Coelom der Anneliden. Wie dieses, steht sie mit den nach aussen leitenden Nephridien (bei den Mollusken gewöhnlich nur in einem Paar vorhanden) durch die Nephridialtrichter in offener Verbindung, so dass also eine Sonde von aussen durch die Niere in die secundäre Leibeshöhle, und zwar in denjenigen Theil derselben eingeführt werden könnte, welcher als Pericard das Herz enthält. Die Rieimlager sind als Wucherungen des Endothels der secundären Leibeshöhle zu betrachten. Im Pericard differenzirt sich ihr Epithel bei sehr vielen Mollusken zu Drüsen, die, als Pericardialdr üsen bezeichnet, wohl neben den Nieren excretorisch thätig sind.

Dass das Lumen der Geschlechtsdrüsen der Mollusken ein Theil einer ïchten Leibeshöhle ist, und dass die Keimlager selbst, d. h. jene Zellcomplexe, welche die Eier und Spermatozoen liefern, Wucherungen der Endothelwand dieser Leibeshöhle darstellen, wäre schon a priori eine berechtigte Suggestion. Nun finden sich aber bei gewissen Mollusken, nämlich bei den Solenogastriden, bei Sepia und bei Nautilus, Verhältnisse, welche diese Auffassung direct stützen. Bei diesen Formen steht nümlich der Geschlechtsdrüsensack in offener Verbindung mit dem übrigen Theil der secundären Leibeshöhle, ist gewissermaassen nur ein unvollständig abgegliederter Abschnitt derselben.

Bei den Solenogastres (Typus Proneomenia) liegt die Zwitterdrüse als ein langgestreckter Schlauch über dem Mitteldarm. Auf dem Querschnitt erscheint dieser Schlauch fast herz- oder nierenförmig, indem er rechts und links nach unten ausgebuchtet ist. Das kommt dadurch zu Stande, dass der Mitteldarm dorsalwärts eine schmale, aber tiefe Längsfurche bildet, welche von unten her in den Zwitterdrüsenschlauch einschneidet. Der Zwitterdrüsensch]anch ist im Innern durch eine Scheidewand, deren Endothelwand die Bildungsstätte der Eier ist, in zwei seitliche Räume getrennt, die selbst wieder von Scheidewänden durchzogen sein können, auf denen die Geschlechtsproducte sich entwickeln. Besonders deutlich ist diese Theilung des Zwitterdrüsenschlauches in zwei seitliche Kammern in seinem hinteren Theile, wo sich die beiden Kammern schliesslich voneinander isoliren und als zwei kurze Leitungskanäle der Geschlechtsproducte getrennt in das Pericard einmünden.

Wenn wir die Verhältnisse der secundären Leibeshöhle von Proneomenia vergleichen mit denen eines Anneliden, so kommen wir zu folgendem Resultat.

In Bereiche des Mitteldarmes fehlt das Rückengefäss. Die Leibeshöhle ist viel weniger geräumig, so dass sie den Darm nur noch auf seiner Rückenseite umgiebt. Sie ist nur als Zwitterdrüsensack entwickelt, dessen Endothelwand die Geschlechtsproducte liefert.

In der Gegend des Enddarmes ist das im dorsalen Mesenterium liegende Rückengefäss als $\mathrm{Herz}$ entwickelt, während die Leibeshöhle hier als Pericard imponirt.

Das Pericard steht durch zwei Kanäle mit der Kloake in Communication, die mit Recht vom morphologischen Gesichtspunkte aus als N ephridien betrachtet werden (vergl. Fig. 556).

Da bei den Solenogastres, Nautilus und Sepia die Genitaldrüsenschläuche oder -säcke als Theile der secundären Leibeshöhle erkannt sind, so folgt daraus, dass sie auch bei allen übrigen Mollusken unter 
diesen Gesichtspunkt fallen, wenn sie auch mit der übrigen secundüren Leibeshöhle nicht mehr in directem Zusammenhang und offener Communication stehen.

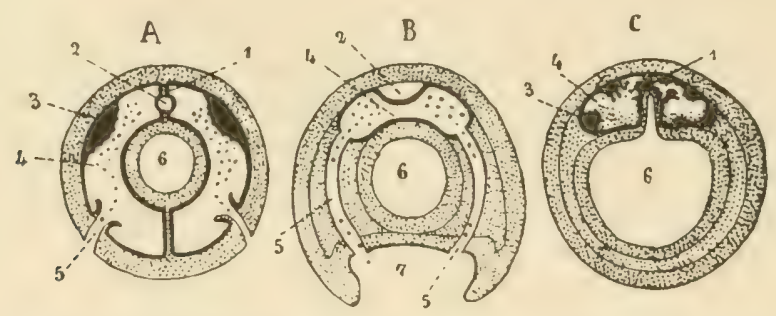

Fig. 556. Schematische Querschnitte durch einen Ringelwurm $\mathcal{A}$ und einen Solenogastriden $\boldsymbol{B}$ und $\boldsymbol{C}$ zur Demonstration der Beziehungen der secundären Leibeshöhle zu Gonaden und Nephridien. $\boldsymbol{B}$ Gegend der Kloake. $\boldsymbol{C}$ Gegend des Mitteldarmes. 1 Dorsales Mesenterium, 2 Rückengefäss resp. Herz, 3 Keimepithel. 4 secundäre Leibeshöhle, in $\boldsymbol{B}$ Pericard, in $\boldsymbol{C}$ Zwitterdrüse, in der secundären Leibeshöhle Geschlechtsproducte, 5 Nephridien, 6 Darm, 7 Kloake.

Bei den Chitoniden ist die secundäre Leibeshöhle in recht ansehnlicher Ausdehnung erhalten. Sie zerfällt in drei, untereinander nicht mehr zusammenhängende Abschnitte. Der eine Abschnitt enthält den Darm und die Verdauungsdrüse (Leber), die also aussen, d. h. gegen die Leibeshöhle zu von einem Endothel überzogen sind. Die Mesenterien, welche ursprünglich den Darm an die Leibeswand befestigten und an welchen das parietale Endothel der Leibeswand sich in das viscerale Endothel des Darmes und der Leber fortsetzte, sind jedoch verschwunden bis auf Reste, die sich am Enddarm erhalten haben. Die beiden übrigen Abschnitte der secundären Leibeshöhle sind: 1) das Pericard, und 2) die Genitaldrïse. Gewisse Bänder, durch welche die drei Abschnitte miteinander verbunden sind, wurden als die eingeschnürten Reste der Communication zwischen den drei Abtheilungen der ursprünglich einheitlichen secundären Leibeshöhle aufgefasst (Fig. 557).

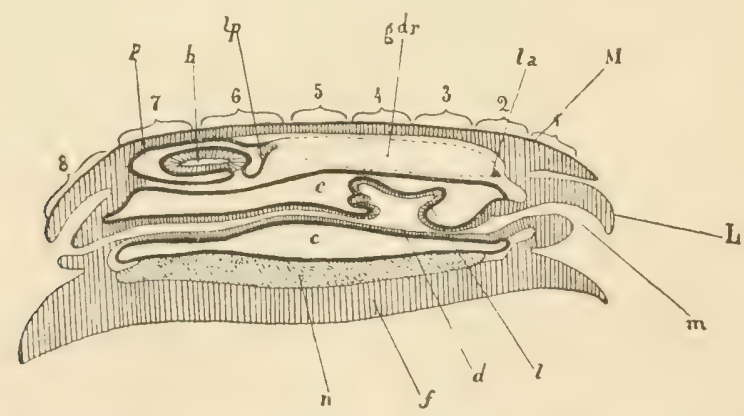

Fig. 557. Schematischer Längsschnitt durch Chiton, zur Demonstration der Beziehungen zwischen den verschiedenen Abtheilungen der secundären Leibeshöhle, nach Haller. 1-8 Lage der 8 Schalenplatten auf dem Rücken, $M$ vorderer Theil des Rückenintegumentes, $L$ Schnauze, $m$ Mund, $l$ Verdauungsdrüse (Leber), $d$ Darm, $f$ Fuss, $n$ Niere, $p$ Pericard, $c$ den Darm umgebender Theil der secundären Leibeshöhle, $h \mathrm{Herz}$, lp Verbindungsband zwischen Pericard und Gonsde, $g d r$ Gonade, la Verbindungsband zwischen Gonade und hinterem Theil der den Darm umgebenden secundären Leibeshöhle. 
Es empfiehlt sich, im Anschluss an die Amphineuren die Cephalopoden zu behandeln. Bei Nautilus und den Decapoden (Beispiel Sepia, Fig. 558) ist im dorsalen Theil des Eingeweidesackes eine gerüumige secundäre Leibeshöhle vorhanden. Sie ist durch ein vorspringendes Septum unvollständig in zwei übereinander liegende Rüume getheilt, von denen der untere als Pericardialraum das Herz mit den von ihm ausgehenden oder zu ihm zurückkehrenden Arterien und Venen, die Kiemenherzen und die Pericardialdrüsen enthält, während der obere den Magen und die Geschlechtsdrüse birgt. Dieser gesammte Raum, welcher auch als Visceropericardialhöhle bezeichnet wird, ist von Endothel ausgekleidet, welches auch die in ihm liegenden Organe überzieht. Er steht durch zwei Oeffnungen (Wimpertrichter) mit den beiden Nierensäcken in Verbindung. Bei Nautilus mündet er ausserdem noch direct durch zwei Kanäle in die Mantelhöhle. Die Oeffnungen dieser Kanäle liegen dicht neben den Nierenöffnungen.

Ist die secundäre Leibeshöhle bei Nautilus und den Decapoden sehr geräumig, so ist sie dagegen bei den $\mathrm{Octo-}$ poden sehr stark reducirt und auf ein enges, aber dickwandiges Kanalsystem eingeschränkt, welches früher als Wassergefässsystem bezeichnet wurde. Die bei Nautilus und den Decapoden in ihr liegenden Organe: arterielles Herz mit zu- und ableitenden Gefässen, Kiemenherzen, Magen, liegen jetzt nicht mehr in ihr, sondern ausserhalb derselben und sind selbstverständlich auch nicht mehr von einem Endothel überzogen. Trotzdem zeigt das erwähnte Kanalsystem der Octopoden noch

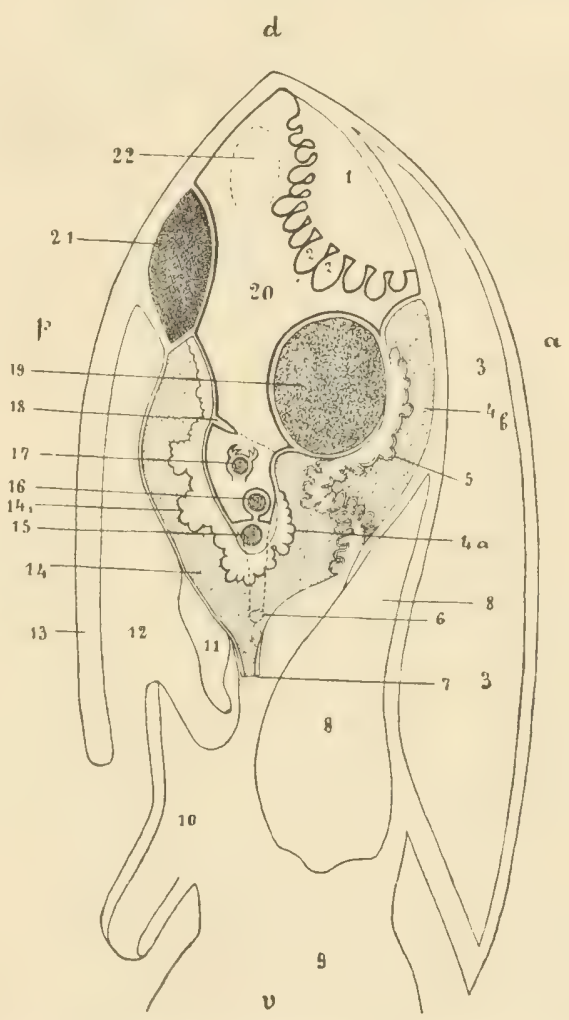

Fig. 558. Schematische Darstellung der secundären Leibeshöhle von Sepia, nach Grobben. Medianer Längsschnitt durch den Körper, in den aber auch Organe eingezeichnet sind, die, weil paarig und symmetrisch, nicht in die Schnittebene fallen. Die Umrisse der secundüren Leibeshöhle sind durch dickere Linien hervorgehoben. 1 Weiblicher Keimkörper mit in die Gonadenhöhle (Ovarialkapsel, Abschnitt der secundären Leibeshöhle) vorragenden Eiern 2, 3 Schale, $4 b$ vorderer Theil des Nierensackes, 5 Pancreasanhänge des Ausführungsganges (Gallenganges) der Verdauungsdriise (Leber), $4 a$ vordere Venenanbänge des Nierensystems, 6 Mündung (Triehter) der Niere in die secundäre Leibeshöhle, 7 Aeussere, d. h. Mantelöffnung der Niere, 8 Verdaungsdrïse (Leber), 9 Kopffuss, 10 Trichter, 11 Ende des Eileiters mit weiblicher Geschlechtsöffnung, 12 Mantelhöhle, 13 Mantel, 14 hinterer Theil des Nierensackes, 15 Darm, 14, hintere Venenanhänge des Nephridialsystems, 16 Herz, 17 Kiemenherz mit Kiemenherzanhang (Pericardialdrüse), 18 Falte, welche die secundäre Leibeshöhle unvollständig in eine obere und in eine untere Abtheilung sondert, 19 Magen, 20 obere Abtheilung der Leibeshöhle (grösstentheils Gonadenhöhle), 21 Pigmentdrüse (Tintenbeutel), 22 Mündung des Eileiters in die Gonadenhöhle; $d$ dorsal, $v$ ventral, $a$ vorn, $p$ hinten. 
die nämlichen morphologisch wichtigen Beziehungen, wie die secundäre Leibeshöhle der Decapoden. Es besteht nämlich jederseits aus drei zusammenmündenden Kanälen, von denen der eine sich in den Nierensack öffnet, der zwoite um die Pericardialdrüse (Kiemenherzanhang) herum sich zu einer flaschenförmigen Kapsel erweitert und der dritte zu der Ge-

$d$

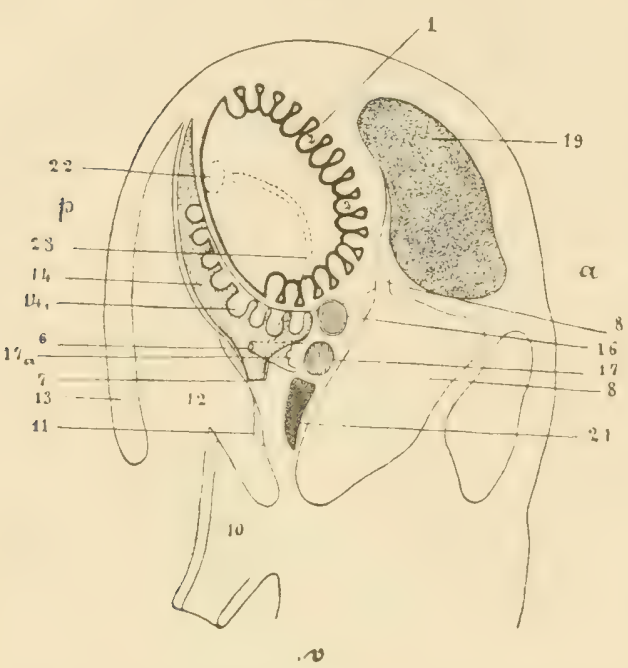

Fig. 559. Eledone moschata. Die Figur ent. spricht der Fig. 558 von Sepia, nach GRoBBEN. 8 Ausführungsgang der Verdauungsdrüse, $17 a$ Pericardialdrüse (Kiemenherzanhang), 23 Wasserkanäle. schlechtsdrüse verläuft, um sich in ihre Wand fortzusetzen. Insofern als bei den Octopoden sogar das Herz aus der zum "Wasserkanalsystem" reducirten secundären Leibeshöhle ausgeschlossen ist, geht diese Reduction hier unter allen Mollusken am weitesten, denn bei allen anderen Mollusken bleibt doch mindestens noch das Herz in einen Theil der secundären Leibeshöhle, in das Pericard, eingeschlossen.

Bei den L amelli branchiern und Gastoropoden erhält sich, abgesehen von der Geschlechtsdrüse, von der secundären Leibeshöhle nur noch das Pericard. Pericard und Gonaden sind aber vollstindig von einander getrennt. Im Pericard liegt bei den $\mathbf{M u}$ scheln ausser dem Herzen noch ein Theil des dieses durchbohrenden Enddarmes, bei den Gasteropoden (abgesehen von denjenigen Diotocardiern, bei denen der Enddarm das Herz durchbohrt) nur das Herz. Selten (z. B. Phyllirhoë) liegt auch der Vorhof nicht mehr im Pericard.

Die Pericardialdrüse ist bei den Mollusken weit verbreitet. Sie ist eine drüsige Differenzirung der Endothelwand des Pericardes und ist vielleicht, wie schon erwähnt, neben der Niere excretorisch thätig. Sie kommt an sehr verschiedenen Stellen des Pericardes vor, ist aber, wie es scheint überall, von dem Blutgefässsystem, zu dem sie in nahe Beziehungen tritt, abgeschlossen. Secrete oder Excrete, die sie liefert, müssen in das Pericard gerathen und kömnen von hier durch die Niere nach aussen entleert werden.

Unter den Prosobranchiern finden wir bei den Diotocardiern die Pericardialdrüse auf dem Vorhofe des Herzens, dessen Wand dendritisch verzweigte Ausstülpungen in die Pericardialhöhle hinein bildet, die vom Pericardialendothel überzogen werden. Wo bei Monotocardierц Pericardialdrüsen vorhanden sind, finden sie sich an der Wand des Pericardes selbst. Aehnliche Lappenbildungen finden sich unter den Opisthobranchiern bei Aplysia und Notarchus an der vorderen Aorta, die an der Pericardwand verläuft, bei Pleurobranchus und Pleurobranchaea an der unteren, bei Doriopsis und Phyllidia an der dorsalen Pericardwand. Die seitlichen Furchen des Pericardes 
von Doris bilden Nischen, die selbst wieder zu Nebennischen ausgeluchtet. sind. Diese Oberflächenvergrösserungen des Pericardialepithels sind ebenfalls als Pericardialdrüsen gedeutet worden.

Unter den Lamellibranchiern sind Pericard i l ldr ü sen viel weiter verbreitet als unter den Gasteropoden, doch fehlen sie gerade den ursprünglichsten Formen (Nucula, Solenomya, Anomia). Die gewöhnlich rostroth gefärbte Drüse tritt in zwei Formen auf. Sie besteht entweder aus drüsigen Vorstülpungen der Endothelwand der Vorhöfe in die Pericardialhöhle hinein oder aus Drüsenschläuchen, die sich a us den vorderen Winkeln des Pericardes in den Mantel hina usstülpen (Keber's Organ, rothbraunes Organ). Die erstere Form findet sich in besonders starker Entwickelung bei Mytilus, Litbodomus und Saxicava, verschieden stark entwickelt bei Dreissena, Unio, Anodonta, Venus, Cardium, Scrobicularia, Solen, Pholas, Teredo, mehr oder weniger rudimentär bei Pecten, Spondylus, Lima, Ostrea. Die zweite Form ist beobachtet bei Unio, Anodonta, Venus, Cardium, Scrobicularia, Solen, Pholas, Montacuta, Dreissensia. Ausserdem kommen Pericardialdrüsen ganz vereinzelt auch noch an anderen Stellen des Pericardes vor, so bei Meleagrina als vorspringende Krausen im hinteren Grunde des Pericardes, bei Chama an der Herzkammer etc.

Die Pericardialdrüse der Ce p halop o den ist der sogenannte Ki e m e nherzanhang. Es ist dies ein vom Peritonealendothel überzogenes Anhangsgebilde der Kiemenherzen, welches in die Visceropericardialhöhle oder bei den Octopoden in einen flaschenförmig erweiterten Theil des (als Abschnitt der secundären Leibeshöhle erkannten) Wasserkanalsystems hineinragt. Bei Sepia ist dieser Anhang kegelförmig. Eine tiefe Spalte an seiner in die Visceropericardialhöhle vorragenden Oberflïche führt in ein reich verzweigtes Kanalsystem, dessen Drüsenepithel eine Fortsetzung des Peritonealepithels ist. Zwischen dieses Kanalsystem dringen vom Kiemenherzen her Bluträume hinein. Die Pericardialdrüse zeigt bei anderen Cephalopoden Variationen in Bau und Form, auf die hier nicht eingetreten werden kann. Nautilus besitzt 2 Paar Pericardialdrüsen, was wieder damit zusammenhängt, dass Nautilus mit 2 Paar Kiemen auch 2 Paar zuführende Gefässe und an den den Kiemenherzen entsprechenden Stellen eben auch 2 Paar Pericardialdrüsen besitzt.

\section{Die Nephridien.}

(Niere, BoJAnus' Organ.)

Die zur Excretion dienenden Organe sind durch den ganzen Stamm der Mollusken hindurch homolog.

Sie bestehen typisch a us zwei symmetrischen Säcken, welche sich einerseits durch diebeiden äusseren Nierenöffnungen in die Mantelhöhle (also nach aussen) öffnen, andererseits durch zwei innere Nierenöffungen (Nierentrichter, Wimpertrichter) mit dem Pericard (also der secundären Leibeshöhle) in Verbindung stehen. Die Nephridien liegen immer in der Nähe des Pericardes. Ihre Wand wird reich vascularisirt, ja es strömt ein grosser Theil des aus dem Körper zurückkehrenden venösen Blutes durch die Nierenwandungen, wo er die Excrete abgiebt, bevor er in die 
Athmungsorgane eintritt. Die Nierenwandungen werden ausschliesslich vom venösen Blute durchströmt.

Die Nephridien erhalten sich paarig bei allen symmetrischen Mollusken und auch noch bei denjenigen Gasteropoden, welche paarige Kiemen und einen doppelten Vorhof des Herzens besitzen (Diotocardier).

Bei allen übrigen Gasteropoden erhält sich mit dem ursprünglich rechten (bei den Prosobranchiern links liegenden) Ctenidium und dem entsprechenden Herzvorhof nur eine (die entsprechende) Niere.

Nautilus, mit vier Kiemen und vier Vorhöfen des Herzens, hat vier Nieren, von denen aber nur zwei mit der Visceropericardialhöhle communiciren.

Aehnliche Beziehungen zwischen Nephridial- und Genitalsystem, wie bei den Würmern, existiren bei den Solenogastriden, wo die $\mathrm{Ne}$ phridien als Ausführungsgänge der Geschlechtsproducte functioniren, welche letztere aus der Zwitterdrüse (Genitalkanımer der secundären Leibeshöhle) in das Pericard übertreten.

Auch noch bei einigen Lamellibranchiern, Diotocardiern und den Scaphopoden existiren Beziehungen zwischen Geschlechtsdrüsen und Nephridien, indem die Geschlechtsdrüsen in die Nephridien münden, so dass ein kürzerer oder längerer Abschnitt dieser letzteren nicht nur als Niere resp. Harnleiter, sondern auch als Ausführungsgang der Geschlechtsproducte functionirt. Bei allen übrigen Mollusken haben sich die Geschlechtswege vollständig von den Harnwegen emancipirt.

A) Amphineura. Die Nieren der Solenogastriden und Chitoniden sind sehr abweichend gebaut.

1) Bei den Solenogastriden entspringen aus dem Pericard 2 Kanäle, welche, den Enddarm umfassend, unter demselben mit einem gemeinsamen Endstück in die Kloake sich öffnen (Fig. 560). Diese Kanäle fungiren sicher als Leitungswege der Geschlechtsproducte. Ebenso sicher entsprechen sie morphologisch den Nieren der übrigen Mollusken,

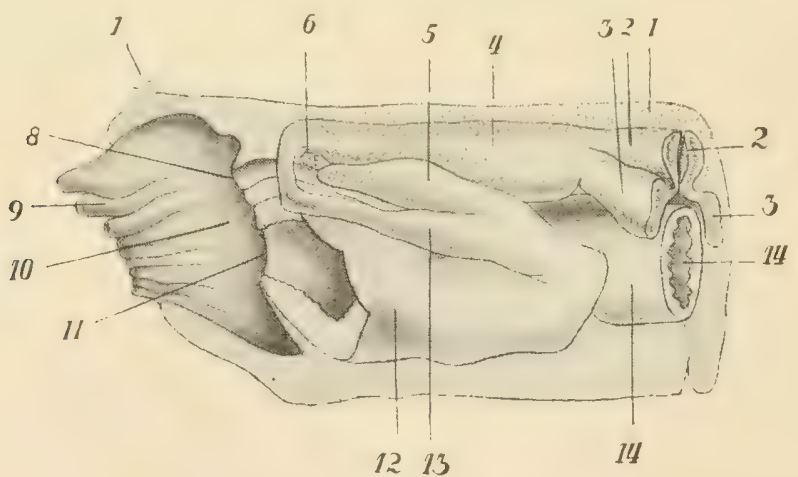

Fig. 560. Paramenia impexa. Hinteres Leibesende; von der rechten Seite ist das Integument wegpräparirt gedacht, ebenso ein Stück der Wandung des rechten Nephridiums, schematisch, nach PrUvoT. 1 Integument, 2 Ovarialtheil der Zwitterdrüse, 3 Hodentheil der Zwitterdrüse, nahe der Stelle, wo letztere in das Pericard 4 einmündet, 5 Drüsenanhang des rechten Nephridiums, 6 dorsale Commissur der Pleurovisceralstränge, 7 als Sinnesknospe gedeutetes Organ, 8 Mündung des Enddarmes in die Kloake, 9 Kieme, 10 Kloake, 11 Mündung der Nephridien in die Kloake, 12 unterer Theil des Nephridiums, 13 oberer Theil des rechten Nephridiums, welcher oben in das Pericard mündet, 14 Enddarm. 
wenn auch ihre excretorische Thätigkeit noch nicht nachgewiesen ist. Sie sind mit einem ausserordentlich hohen Epithel langer, fadenförmiger Drüsenzellen ausgekleidet.

Bei einigen Solenogastriden mündet in jeden Nephridialkanal eine Anhangsdrüse.

2) Bei den Chitoniden fungiren die stark entwickelten paarigen Nephridien ausschliesslich als Excretionsorgane.

Jedes Nephridium (Fig. 561) besteht aus einem weiten Kanal von lang Y-förmiger Gestalt. Die beiden genäherten Schenkel des $Y$ sind nach hinten, der dritte nach vorn gerichtet. Beide Nieren-Y durchziehen in der Längsrichtung jederseits den Kürper in seiner grössten Länge. Der eine der beiden genäherten Schenkel mündet im hinteren Theil der Mantelfurche nach aussen, der andere in das ebenfalls im hinteren Körpertheil gelegene Pericard. So sind äussere Oeffnung und Pericardöffnung der Niere einander genähert. Der dritte Schenkel ist ein vorn blind endigender Kanal. In alle drei Schenkel der Niere münden secundäre Läppchen und gelappte Kanälchen, die besonders am vorderen Schenkel zahlreich sind. Das bewimperte cubische Epithel der Niere ist in den Schenkeln, wie in den Lappen dasselbe. Nur am ausführenden Schenkel der Niere findet sich ein histologisch differenter Endabschnitt.

B) Gasteropoda.

1) Prosobranchia. a) Diotocardia.

Unter allen Gasteropoden besitzt allein $\mathrm{F}$ issurella einen symmetrischen Excretionsapparat in dem Sinne, dass zwei als Excretionsorgane fungirende Nephridien vorhanden sind, die rechts und links vom After in die Mantelhöhle ausmünden. Aber das linke Nephridium ist sehr

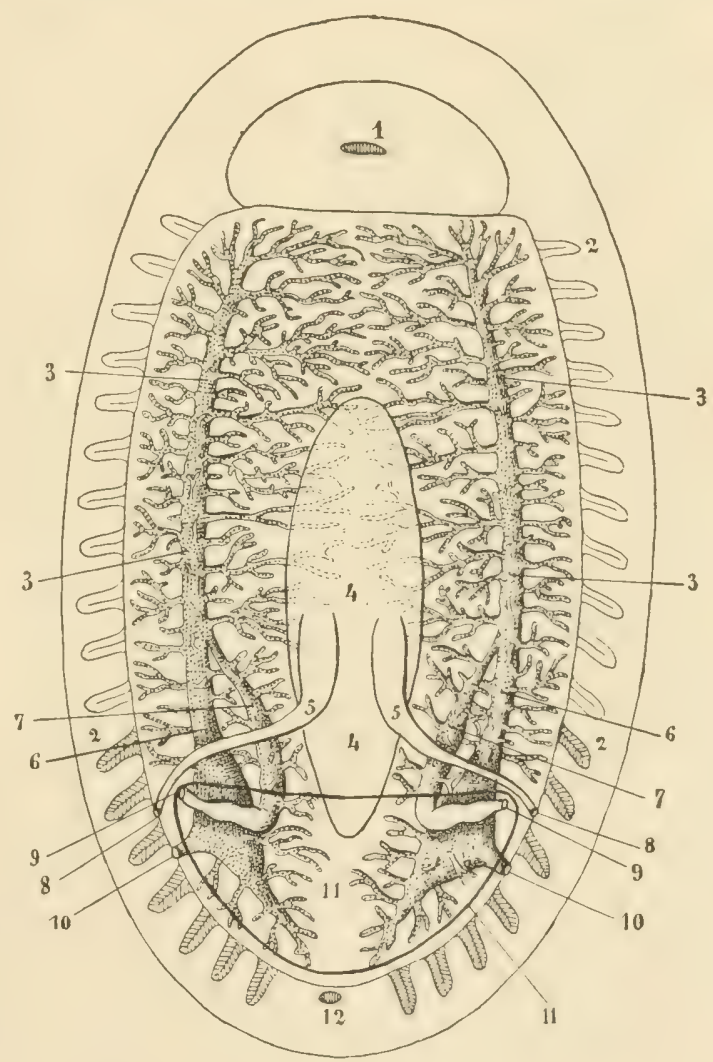

Fig. 561. Nephridial- und Genitalsystem von Chiton, schematisirt, von oben, nach Figuren und Angaben verschiedener Autoren combinirt. 1 Mund, 2 Kiemen, 3 nach rorn verlaufender unparer Schenkel des Nephridiums mit seinen seitlichen Verzweigungen, 4 Gonade, 5 Ausführungsgänge der Gonade, 6 zur äusseren Oeffnung (10) verlaufender Schenkel des Nephridiums, 7 zur Renopericardialöffnung (9) verlaufender Schenkel des Nephridiums, 8 Genitalölfnungen, 9 Renopericardialtrichter, 10 Nephridialöffnung, 11 Pericard nur durch eine Contourlinie angedeutet, 12 Anus. 
reducirt und communicirt nicht mit dem Pericard, während die rechte, stark entwickelte Niere ihre Lappen überall in die Lücken zwischen den Leberlappen, dem Darme und den Geschlechtsorganen hineinschickt. Die Geschlechtsdrüse mündet nicht direct in die Mantelhöhle, sondern durch Vermittelung der rechten Niere.

Auch bei Haliotis, Turbo und Trochus sind noch beide Nephridien vorhanden. Aber das linke Nephridium hat seine excretorische Bedeutung fast ganz verloren, steht aber immer noch sowohl mit dem Pericard, als mit der Mantelhöhle in Communication. Es wird als Papillensack bezeichnet, da seine Wand in Form zahlreicher grosser Papillen in seinen Binnenraum vorspringt. Die Blutlacunen, welche von aussen in die Papillen eindringen, communiciren direct mit den Vorhöfen des Herzens, werden also von arteriellem Blut durchströmt. In diesen Lacunen der Papillen werden Krystalloide (Eiweisskrystalloide?) abgelagert. Man hat die Ansicht geäussert, dass dieser Papillensack dazu diene, Reservenahrungsstoffe (in Form der eben erwähnten Krystalloide) aufzuspeichern und bei Bedürfniss dem Blute zuzuführen.

Das rechte Nephridium ist ausschliesslich excretorisch thätig. Es ist in zwei hintereinander liegende Lappen mit weiter Conmunicationsöffnung getrennt, von denen der vordere unter dem Boden der Mantelhöhle liegt und diesen gegen die Mantelhöhle zu vorwulstet. Auf einem Theil seiner Wandung erhebt sich ein in die Höhle des Nephridialsackes vorragendes, von excretorischem Epithel überzogenes, schwammiges Maschennetz. Die Maschen werden durchsetzt von einem System eigenwandiger Gefässe. Fast alles venöse Körperblut durchströmt, bevor es zu den Kiemen gelangt, dieses in den Nierenwandungen entwickelte Gefässsystem. Das rechte Nephridium steht mit dem Pericard in keinerlei Verbindung.

Die Neritida e haben nur ein rechts vom Herzen gelegenes Nephridium, welches sich durch eine Spalte im Grunde der Mantelhöhle öffnet. Der Nierensack ist im Innern von Trabekeln durchsetzt, von denen viele von der einen Wand zur gegenüberliegenden ziehen. Er hat in Folge dessen ein schwammiges inneres Gefüge. Die Trabekeln sind gegen das Hohlraumsystem des Sackes vom Drüsenepithel ausgekleidet.

P atell a (Fig. 562) hat noch beide Nepridien, und beide functioniren als Excretionsorgane. Die beiden äusseren Oeffnungen liegen zu beiden Seiten des Afters. Die rechte Niere ist aber viel grösser als die linke. Beide liegen auf der rechten Seite des Pericards, und beide communiciren mit ihm durch je eine renopericardiale Oeffnung. Die rechte Niere hat ein schwammiges inneres Gefüge, die linke hingegen besitzt einen einheitlichen Hohlraum, in welchen von der Wand Falten vorragen. Das Balkennetz der rechten Niere wird von einem gegen den Hohlraum der Niere vollständig abgeschlossenen, nicht eigenwandigen Lacumensystem durchzogen, welches das venöse Körperblut durchströmt, bevor es in die Kiemen eintritt. Das Lacunensystem der linken Niere hingegen steht mit dem Vorhof des Herzens in directer Verbindung.

Auch bei $\mathrm{Haliotis}$ und Patella gelangen die Geschlechtsproducte, wie bei Fissurella, aus den Keimdrüsen in die rechte Niere und von da durch die rechte Nierenöffnung nach aussen.

b) Monotocardia. Die Monotocardia haben nur ein einziges, als Excretionsorgan fungirendes Nephridium. Es liegt als eine Tasche unmittelbar hinter der Mantelhöhle auf der rechten Seite des Pericards, unmittelbar unter der Haut. Meist befindet es sich auf der linken Seite des Enddarmes. Seltener (Cassidaria, Tritoniidae) wird die Niere vom 
Rectum durchbohrt, oder es verläuft das Rectum unter der Niere nach vorn. Immer aber finden wir die spaltförmige $\mathbf{M}$ a ntelöffnung der Niere auf der linken Seite des Enddarmes, ganz im Grunde der Mantelhöhle. Diese Lage der Niere und besonders ihrer äusseren Oeffnung hat zu der Annahme geführt, dass die Niere der Monotocardier der linken $\mathrm{Niere}$ der Diotocardier entspreche, eine Ansicht, die um so plausibler erscheint, als bei einzelnen Monotocardiern (z. B. Dolium) eine als Afterniere bezeichnete Drüse vorkommt, welche rechts neben dem After mündet und der rechten Niere der Diotocardier entsprechen dürfte.

Fig. 562. Schematische Darstellung der boiden Nephridien von Patella, nach LANkester. ksa Vorderer, oberer Lappen der grossen rechten Niere $k s l$, $k s i$ unterer subvisceraler Lappen derselben, $k s p$ hinterer Lappen derselben, ff subanaler Tractus des grossen rechten Nephridiums, $g$ Analpapille mit dem zu ihr verlaufenden Rectum, $h$ Papille mit Oeffnung des linken nicht gezeichneten Nephridiums, $f$ idem des rechten, $l$ Pericard, durch eine punktirte Contourlinie angedeutet, rechts die renopericardiale Oeffnung des rechten Nephridiums, dio des linken ist nicht dargestellt.

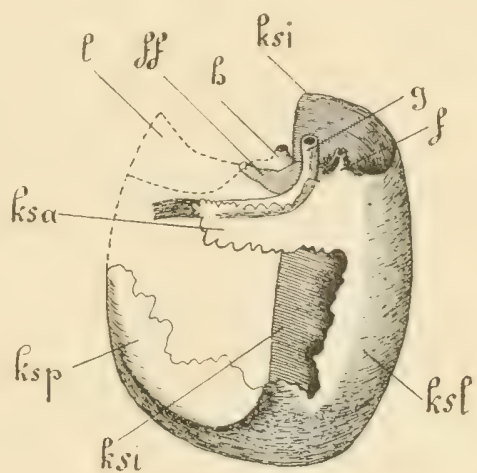

Die Niere steht überall durch einen Kanal (Renopericardialkanal) mit dem Herzbeutel in Verbindung.

Auf den seitlichen Wänden des Nierensackes erheben sich in das Innere vorspringende, vom Drüsenepithel der Niere ausgekleidete Lamellen oder Trabekeln. Diese sind hesonders bei Süsswasserprosobranchiern (mit Ausnahme von Cyclostoma und Valvata) stark entwickelt, durchsetzen die ganze Niere und verleihen ihr ein schwammiges Gefüge. Ueberall durchströmt das venöse Körperblut, sei es in besonderen Gefässen, sei es in Lacunen, den Drüsentheil der Niere, bevor es zu den Kiemen geht. Aber eine offene Communication mit der Nierenhöhle kommt nirgends vor.

Bei den Taenioglossa Proboscidifera zerfällt die Niere in zwei Lappen ron gleicher Structur. Bei Natica, Cypraea bekommen die beiden Lappen schon eine verschiedene Structur, und innerhalb der Stenoglossa accentuirt sich diese Verschiedenheit immer mehr in einer hier nicht näher zu besprechenden Weise.

Paludina und Valvata sind dadurch ausgezeichnet, dass die Niere nicht im hinteren Grunde der Mantelhöhle ausmündet, sondern sich vielmehr in einen am Mantel nach vorn verlaufenden Harnleiter (Ureter) fortsetzt, dessen Oeffnung am Mantelrande liegt.

Gegenüber der oben mitgetheilten Auffassung, dass die einzige Niere der Monotocardier der linken Niere der Diotocardier entspreche, ist in neuester Zeit mit Geschick eine ganz andere Auffassung vertreten worden. Es wird darauf aufmerksam gemacht, dass die linke Niere bei den Diotocardiern immer die kleinere ist, dass sie bei Patella auf die rechte Seite des Pericards gerückt ist, dass sie bei Haliotis, Turbo und Trochus nicht excretorisch thätig ist (Papillensack). Bei Haliotis, Turbo, Trochus und Patella steht das in der Wand der linken Niere entwickelte Lacunensystem direct mit den Vorhöfen in Communication. 
Nun existirt bei den meisten Monotocardiern ein differenter Abschnitt der Niere, welcher als Nephridialdrüse bezeichnet worden ist. Er besteht aus dem an das Pericard angrenzenden Theil der Niere und stellt ein Organ dar, an dem zwei Haupttheile zu unterscheiden sind: 1) Kanäle, die mit wimpernden Epithelzellen ausgekleidet sind und die in die Niere ausmünden. Sie stellen also nur Ausstülpungen der Nierenwand dar, welche in das Organ eindringen; ihr Epithel ist eine Fortsetzung des Nierenepithels. 2) Zwischen diesen Kanälen ist das Organ angefüllt ron Bindegewebszellen und Muskeln und enthält Blutlacunen, besonders eine grosse, welche direct mit dem Vorhof in Verbindung steht. Dieser letztere Theil des Organes spielt vielleicht die Rolle einer Blutdrïse.

Vergleicht man nun die Nephridialdrüse mit der linken, bei Patella auf die rechte Seite des Pericards gerückten Niere der Diotocardier, so ergiebt sich eine auffallende Uebereinstimmung in den Beziehungen zum Vorhof. Man würde sich bloss vorzustellen haben, dass die Scheidewand zwischen den beiden Nieren von Patella verschwunden sei, und dass die linke Niere ihre äussere Oeffnung verloren habe, um das Verhalten der Niere der Monotocardier zu erhalten. Es würde also die Niere der Monotocardier den beiden Nieren der Diotocardier entsprechen, speciell die Nephridialdrüse dem linken, der ïbrige 'Theil der Niere dem rechten Nephridium, die einzige Nierenöffnung der rechten Nierenöffnung der Diotocardier.

Bei Ampullaria würde sich ein Zwischenstadium finden, indem dort die linke (hintere) Niere ihre Mantelöffnung verloren hat, dagegen durch einen Gang mit der rechten Niere in Verbindung steht, die sich ihrerseits in die Mantelhöhle öffnet.

Diese zweite, eben vorgetragene Auffassung trägt der Thatsache keine Rechnung, dass bei den Monotocardiern die Mantelöffnung der Niere, welche der Oeffnung der rechten Diotocardierniere entsprechen soll, auf der linken Seite des Enddarmes liegt. Ferner ist es noch nicht erwiesen, dass die hintere Niere von Ampullaria der linken, die vordere der rechten Diotocardierniere entspricht. Es kann sich hier auch um 2 Abtheilungen einer und derselben Niere handeln. Schliesslich sehen wir, dass die rechte grössere Niere von Patella auf der rechten, die linke kleinere (auf die rechte Seite des Pericards gerückte) auf der linken Seite des Enddarmes resp. Afters in die Mantelhöhle mündet.

Die Entwickelungsgeschichte wird entscheiden, ob eine der beiden vorgetragenen Auffassungen und welche die richtige ist.

2) Pulmonata (Fig. 563). Die Pulmonaten haben nur eine Niere. Sie liegt im Grunde der Mantelhöhle im Mantel zwischen Rectum und Pericard. Der Nierensack weist den sogenannten parenchymatösen Typus auf, indem das excretorische Epithel vou der Wand in zahlreichen Falten oder Lamellen so in die Höhle vorspringt, dass kaum noch ein centraler Raum frei bleibt. Immer communicirt die Niere durch einen wimpernden Kanal (Nierentrichter, Nierenspritze) mit dem Pericard. Die Lagerungsverhältnisse der Niere und die Morphologie des Harnleiters sind schon früher (p. 647) erörtert worden.

3) Opisthobranchiata. Tectibranchiata. Nur eine Niere ist vorhanden in der zu erwartenden Lage auf der rechten Körperseite zwischen Pericard vorn und Enddarm hinten. Sie gehört dem parenchymatösen Typus an und besitzt einen bewimperten Verbindungskanal mit dem Pericard. Sie mündet an der Kiemenbasis vor dem After aus. 
Bei den Pteropoden ist, die zartwandige Niere nicht parenchymatös, sondern ein einfacher, hohler, mit Epithel ausgekleideter Sack, und lässt die Communication mit dem Pericard, dem sie anliegt, nirgends vermissen.

Fig. 563.

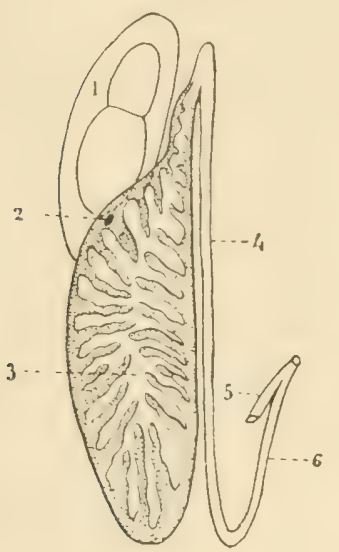

Fig. 563. Nephridium und Pericard von Daudebardia rufa, von oben, schematisch, nach Plate, 1 Pericard, 2 Renopericardialöffnung (Nierentrichter), 3 Nephridium, 4 primärer Harnleiter, 5 Rectum, 6 secundärer Harnleiter.

Fig. 564. Nephridium von Bornella, nach IIANCOCK. 1 Niere, 2 Verbindungsstïck zur Renopericardialöffnung (pyriform vesicle, Nierenspritze), 3 Stück der Pericardwand, 4 Harnleiter, $5 \mathrm{Ne}$ phridialöffnung.
Fig. 564 .

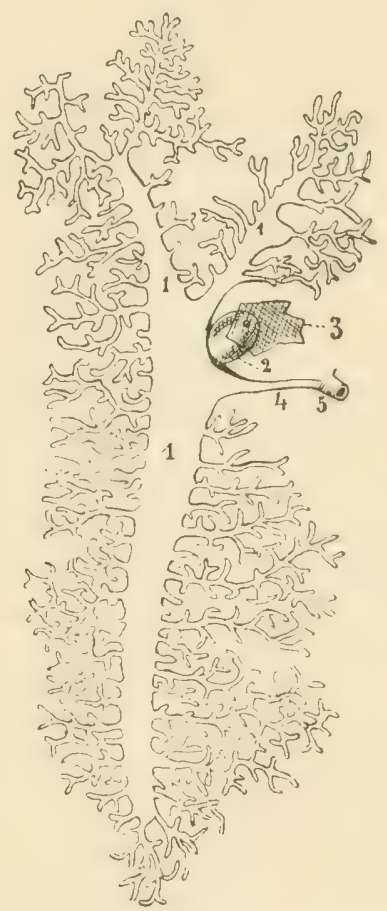

Nudibranchiata (Fig. 564). Die Formverhältnisse der Niere der Nulibranchiata sind auffallend verschieden von denen der Tectibranchiata. Die unpaare Niere hat hier einige Aehnlichkeit mit der paarigen der Chitoniden. Sie stellt einen ziemlich weiten, die Körperhöhle in grösserer oder geringerer Ausdehnung durchziehenden Schlauch (Nierenkammer) dar, in welchen von allen Seiten Verästelungen einmünden. Der Schlauch steht einerseits durch einen kürzeren oder längeren Gang (Nierenspritze, pyriform vesicle) mit dem Pericard in Verbindung, andererseits mündet er durch einen Harnleiter an der Basis der Analpapille oder in deren Nähe nach aussen.

Von Pleurobranchaea, einem Tectibranchiaten, von dem sich die Nudibranchiaten vielleicht herleiten lassen, wird angegeben, dass sie eine Nudibranchiatenniere besitze.

Bei Phyllirhoë fehlen die Verästelungen der Urinkammer, die als ein einfacher, medianer Schlauch vom Pericard nach hinten zieht. Vorn steht sie durch einen Trichter mit dem Pericard, ungefähr in der Mitte seiner Länge durch einen seitlichen Harnleiter mit der Aussenwelt in Verbindung.

C) Scaphopoda (Fig. 546). Dentalium besitzt eine parige und symmetrische Niere, die zu beiden Seiten des Enddarmes liegt. Jedes 
Nephridium besteht aus einem mit kurzen Divertikeln besetzten Sack. Die beiden Nephridien stehen ïber dem After durch einen Verbindungsschlauch miteinander in Communication und öffnen sich durch zwei zu Seiten des Afters gelegene Oeffnungen in die Mantelhöhle. Das Torhandensein von renoyericardialen Oeffnungen wird von allen Beobachtern bestritten, und es wären die Scaphopoden die einzige Molluskengruppe, bei welchen solche Oeffnungen gänzlich fehlen. Von grosser Bedeutung ist, abgesehen von der Symmetrie der Niere, die Thatsache, dass die Geschlechtsproducte aus der Geschlechtsdrüse (durch Platzen der zwischen beiden Organen liegenden Wand?, durch eine Oeffnung?) in die rechte Niere und erst von da durch die rechte Nierenöffnung nach aussen, $d . h$. in die Mantelhöhle gelangen.

Es sei hier noch erwähnt, dass jederseits neben dem After, zwischen diesem und den Nierenöffnungen ein Porus vorkommt, der Wasserporus, dessen Bedeutung noch nicht sicher ermittelt ist. Wenn diese Poren wirklich ins blutführende Lacunensystem des Körpers hineinführen, was früher behauptet wurde und auch neuerdings wieder als möglich hingestellt wird, so wäre dies der einzige Fall einer möglichen directen Wasseraufnahme in das Blut.

D) Lamellibranchiata. Das Nephridium (BoJAnus' Organ) ist immer paarig und symmetrisch und liegt unter dem Pericard, vor dem hinteren Schliessmuskel. Jedes Nephridium stellt einen Schlauch oder Sack dar, welcher einerseits durch einen Nierentrichter in das Pericard, andererseits durch eine äussere Oeffnung in die Mantelhöhle mündet. Diese Communication der Niere mit der Mantelhöhle erfolgt immer über das Cerebrovisceralconnectiv hinweg.

Die niedersten Lamellibranchier (Protobranchier: Nucula, Leda, Solenomya) zeichnen sich in doppelter Weise aus. Erstens ist jedes Nephridium ein einfacher Schlauch, mit freiem, nicht von Trabekeln oder Lamellen durchsetztem Hohlraum. Dieser Schlauch besteht aus zwei hinten in einem Winkel zusammenstossenden und ineinander übergehenden Schenkeln, von denen der eine an seinem vorderen Ende durch den Nierentrichter in das Pericard, der andere an seinem vorderen Ende in die Mantel-

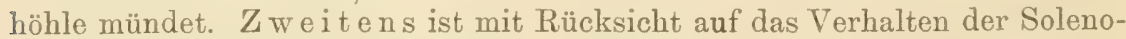
gastriden, niederer Prosobranchier (Fissurella, Haliotis, Patella) und der Scaphopoden die Thatsache wichtig, dass die parige Geschlechtsdrüse nicht direct nach aussen, sondern in die Niere mündet, und zwar in der Nähe ihres Pericardialtrichters.

Auch noch bei anderen Lamellibranchiern existiren Beziehungen zwischen Geschlechtsdrüse und Niere. So mündet die Geschlechtsdrüse der Pectinidae und Anomiidae ebenfalls in die Niere, aber nahe ihrer äusseren Mündung. Bei Arca, Ostrea, Cyclas und Montacuta mündet jederseits die Niere und die Geschlechtsdrüse noch in den Grund einer gemeinsamen Grube (Urogenitalkloake), und bei allen anderen Muscheln existiren getrennte äussere Nephridial- und Geschlechtsöffnungen.

Der einfache Bau der Protobranchiatenniere complicirt sich bei den übrigen Lamellibranchiern nach folgenden Richtungen hin:

1) Der nach aussen mündende Schenkel jedes Nierenschlauches wird zu einem äusseren Hohlraum (Vorhöhle, Aussensack), ohne excretorisches Epithel, welcher den Pericardialschenkel der Niere von aussen umfasst (Fig. 565). Dieser letztere ist allein als excretorischer Nierensack entwickelt. Von seiner Wand ragen von Drüsenepithel überzogene Falten oder Trabekel in seinen Hohlraum vor, welche ihm ein parenchymatöses oder 
schwammiges Gefüge verleihen. Der Nierensack steht mit dem Pericard durch einen kürzeren oder längeren Nierentrichter in Communication.

2) Die beiden Nierensäcke treten mit einander in der Medianebene des Körpers in offene Communication. Am weitesten ist diese Communication bei den am meisten specialisirten Muscheln (Pholadacea, Myacea, Anatinacea, Septibranchia).

Fig. 565. Querschnitt durch den Rumpf von Anodonta, zur $\mathrm{D}_{\theta}$ monstration von Pericard, Herz und Niere. Die Zeichnung ist nach Abbildungen von GriesBaCH combinirt und schematisirt. Nicht alle Theile, welche dargestellt sind, kommen auf einem und demselben Querschnitt vor. 1 Pericard, 2 Herzkammer, 3 Vorlıöfe, 4 Enddarm, 5 venöser Sinus, 6 Renopericardialöffoung (Trichter), 7 Nierensack, Nierenhöhle, 8 Vorhöhle, welche bei 9 durch die Nephridialöffnung in die Mantelhöhle mündet, 10 Genitalöffnung, 11 Fussbasis.

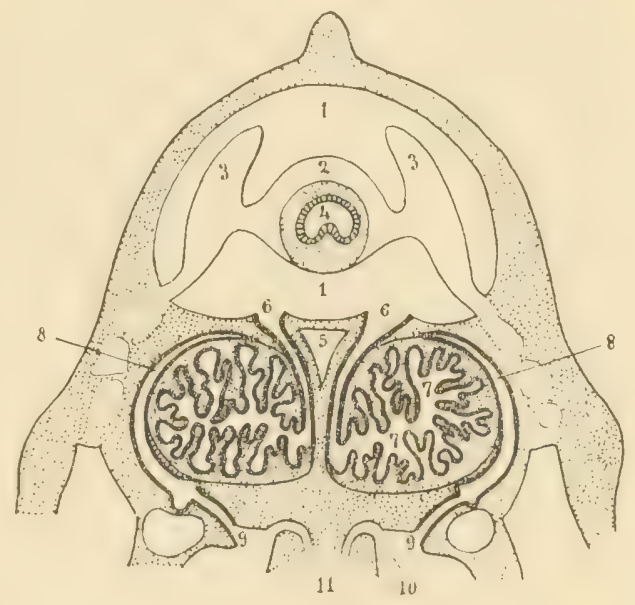

Bei Anomia, wo alles asymmetrisch ist, sind auch die beiden (nicht mit einander communicirenden) Nieren asymmetrisch.

Die Nieren werden von venösem Blut durchströmt, welches zu den Tiewen geht. Die zuführenden Gefässe der Nieren scheinen eigenwandig, die abführenden Kanäle lacunär zu sein. Nirgends besteht eine offene Communication zwischen Blutgefässsystem und Niere.

E) Cephalopoda (Fig. 566 und 567). (Man vergleiche das über die Leibeshöhle und das venöse Blutgefässsystem Gesagte.) Die Cephalopoden haben zwei (Dibranchiata) oder vier (Tetrabranchiata) symmetrische, im hinteren und oberen 'Theil des Eingeweidesackes gelegene, gerüumige Nierensäcke, die in typischer Weise einerseits communiciren mit der secundären Leibeshöhle und andererseits mit der Aussenwelt (Mantelhöhle). Von den zwei Paar Nieren von Nautilus besitzt jedoch nur ein Paar die Leibeshöhletrichter.

An der vorderen Wand der Harnsäcke verlaufen die grossen, zum Herzen zurückkehrenden Körpervenen. Diese Venen stülpen sich gegen die Hühlung der Harusäcke zu den schon früher erwähnten Venenanbängen aus. Das diese Anhänge überziehende Harnsackepithel ist wohl vorzugsweise der Sitz der Excretion. Die Excrete werden in den Harnsack abgeschieden (dessen Wand sonst überall glatt ist) und von da durch den kürzeren oder längeren Harnleiter nach aussen, d. h. in die Mantelhöhle entleert. Die Nierenöffnungen finden sich an der medianen Seite der Kiemenbasis und sind bei Nautilus, den Oegopsiden, Sepioteuthis unter den Myopsiden einfache, schlitzförmige Oeffnungen, bei den übrigen Myopsiden und Octopoden aber an das Ende frei in die Mantelhöhle vorragender Nierenpapillen verlagert.

Die beiden Nierensäcke der Oct op o d en sind vollständig von einander getrennt. Nahe der Stelle, wo jeder Nierensack sich in den Harnleiter 

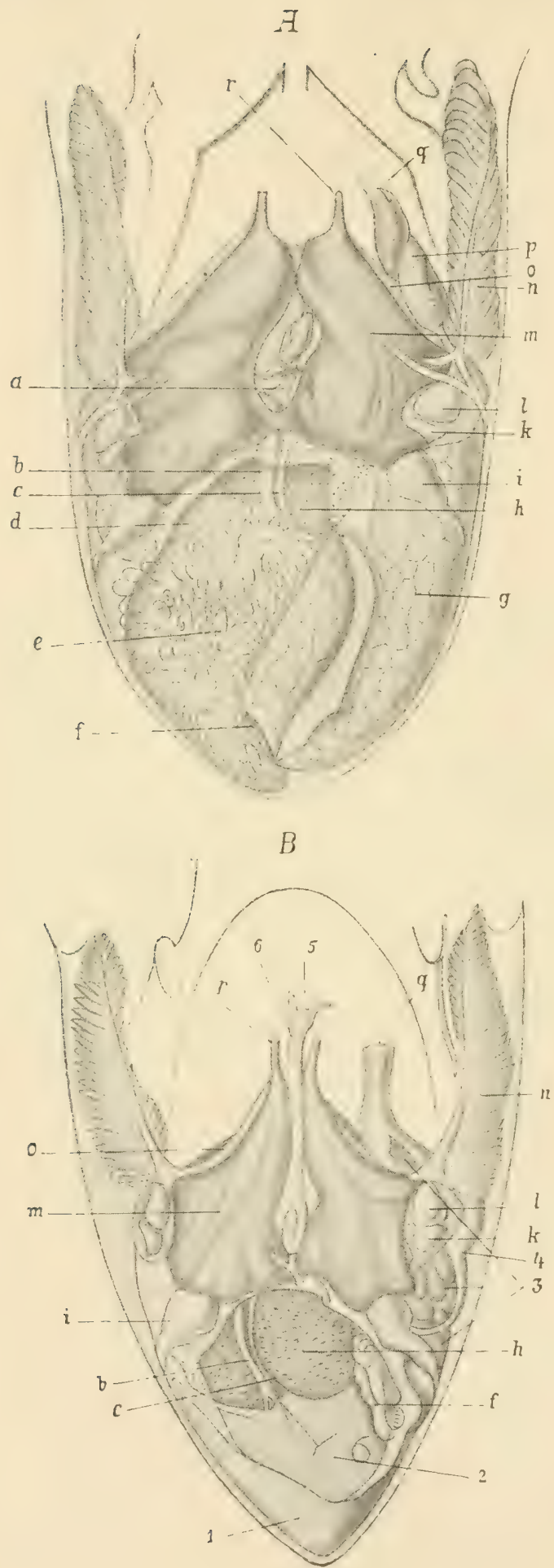

fortsetzt, liegt der Niereutrichter, d. b. jene der Renopericardialöffnung der übrigen Mollusken entsprechende Communication, welche hier in die auf das "Wassergefässsystem" reducirte secundäre Leibeshöhle führt.

Bei den Decapoden stehen die beiden Nierensäcke miteinander in der Medianebene in offener Communication. Solche Communicationen giebt es bei Sepia zwei, eine obere und eine untere. Die untere Communicationsbrücke ist $\mathrm{zu}$ einem grossen Sacke ausgebuchtet, welcher an der Vorderseite der paarigen Nierensäcke bis gegen die obere Spitze des Eingeweidesackes emporsteigt (vergl. Fig. 558). In der Scheidewand zwischen unpaarem vorderen und paarigen hinteren Nierensäcken verlaufen die zum Herzen zurückkehrenden Körpervenen,

Fig. 566. Nierensäcke, Leibeshöhle, Geschlechtsorgane etc. von Sepia. $\boldsymbol{A}$ Weibchen. $\boldsymbol{B}$ Männchen. Der Eingeweidesack ist von hinten gesehen, der Mantel, die Leibeswand, der Tintenbeutel, bei $\boldsymbol{A}$ auch der Enddarm und die Nidamentaldrüsen entfernt, nach GRoBBEN. $a$ Herz, $b$ Genitulvene, $c$ Genitalarterie, $d$ Magen, $e$ weiblicher Keimkörper, $f$ Mündung des Oviductes in die Eierstockshöhle, $g$ Oviduct, $h$ unpaarer vorderer Nierensack, i Abdominalvene, $k$ Kiemenherzanhang (Pericardialdrủse), $l$ Kiemenherz, $m$ paariger hinterer Nierensack, $n$ Kieme, $o$ Kanäle der Leibeshöhle, welche zur Niere führen, $p$ Eileiterdrüse, $q$ weibliche Geschlechtsöffnung, $r$ Nierenöffnungen. In $\boldsymbol{B} 1$ Hode, 2 (die Verweislinie ist etwas zu weit gefihrt) Mündung des männlichen Keimkörpers in die Gonadenböhle (Genitalkapsel), $f$ Mündung des Samenleiters in die männliche Gonadenhöhle, $3 \mathrm{Ab}$ schnitt der Leibesböhle (Bauchfelltasche), welcher das Vas deferens enthält, 5 After, 6 Rectum, $q$ männliche Geschlechtsöffnung. 
die sich hier nicht nur nach hinten, d. h. in den Hohlraum der beiden paarigen Nierensäcke, sondern auch nach vorn, in den Hohlraum des unpaaren Verbindungssackes, zur Bildung der Venenanhänge ausstülpen können. Nahe der Stelle, wo jeder Nierensack sich in den Harnleiter fortsetzt, entspringt aus ihm der renopericardiale Verbindungsgang, welcher sich in den das Herz enthaltenden, dem Pericard der ïbrigen Mollusken entsprechenden Abschnitt der secundären Leibeshöhle öffnet.

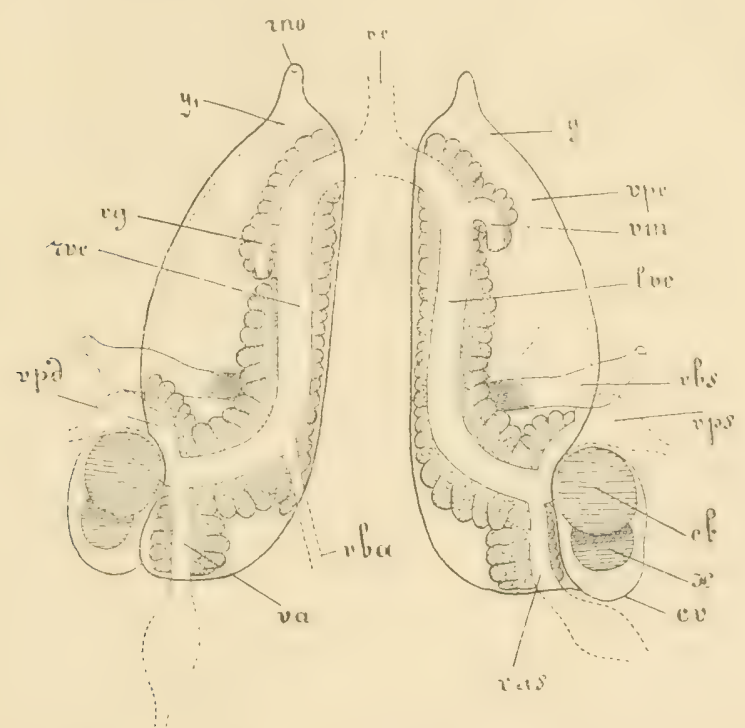

Fig. 567. Schematische Darstellung des paarigen hinteren Nierensackes von Sepia officinalis und der an seiner vorderen Wand verlaufenden Venen mit den ,Venenanhängen", von hinten, nach ViGeurus. $v c$ Vena cava, rno rechte Nephridialöfinuug, $y_{1}$ linke Renopericardialöffnung, die Contouren der Leibeshöhle sind durch eine punktirte Linie angedeutet, $v g$ Vena genitalis, $r v$ rechter Ast der Vena cava, $v p d$ rechte Mantelvene, va rechte Vena abdominalis, vba Vene des Tintenbeutels, vas linke Vena abdominalis, $c v$ Abschnitt der secundären Leibeshöhle (Kiemenherzkapsel), welcher das Kiemenherz $c b$ und den Kiemenherzanhang (Pericardialdrïse) $x$ umgiebt, vps linke Mantelvene; $v b s$ linke Mantelvene, $l v c$ linker Ast der Vena cava cephalica, $v m$ linke Vena genitalis, vpc secundäre Leibesböhle (Visceropericardialsack), $y$ linke Renopericardialöffnung (Nierentrichter).

Die Gestalt der Nierensäcke wird z. Th. wenigstens bedingt durch die Gestalt und Lage der angrenzenden Eingeweide, durch den Reifezustand der Geschlechtsorgane, durch die verschiedene Gestalt dieser Organe im männlichen und weiblichen Geschlecht. Alle Eingeweide, welche von aussen gegen die Nierenwand drücken und dieselbe in verschiedener Weise gegen ihren Hohlraum zu einbuchten, sind selbstverständlich an diesen Stellen vom Epithel der Nierensäcke überzogen. Dasselbe gilt von jenen Organen, welche, wie der Magen, der Magenblindsack, die Ausfïhrungsgänge der Terdanumgsdrüsen bei Decapoden , Tepia, scheinbar i m I n $n$ ern der geräumigen Nierensäicke liegen. Sie liegen in Wirlslichkeit a usserhalb der Nierensäcke, sind nur in sie hineingehängt, ähnlich wie der Darm eines Ringelwurmes, z. B. in Wirklichkeit ausserhalb der Leibeshöhle, von dieser durch das Peritonealendothel vollständig abgeschlossen, liegt. 
Es wurde oben erwähnt, dass von den zwei Paar Nierensäcken von Nautilus nur das eine Paar, nämlich das obere, renopericardiale Oeffnungen besitzt.

Diese Thatsache liess sich für die Ansicht verwerthen, dass die zwei Paar Nierensäcke durch Theilung aus einem einzigen, demjenigen der Dibranchiaten entsprechenden Paar' hervorgegangen seien. In Verfolgung dieses Gedankens wurden auch das untere Kiemenpaar, das untere Paar Vorhöfe u. s. w. als neue Erwerbungen betrachtet. Da auch die Verhältnisse bei Chiton, wo trotz der zahlreichen Kiemenpaare nur zwei Vorhöfe des Herzens vorhanden sind und wo keine Beziehungen zwischen der Zahl der Schalenplatten und der Zahl der Kiemenpaare u. s. w. vorhanden sind, nicht verwerthet werden können, so steht die mehrfach geäusserte Ansicht von einer ursprünglichen Metamerie des Molluskenkörpers auf schwachen Füssen.

\section{Geschlechtsorgane.}

A) Allgemeines.

IIir werden bei der Darstellung der Geschlechtsorgane der Mollusken zu betrachten haben: 1) die Gonaden oder $\mathrm{K}$ eimdrüsen, d. h. jenen wichtigsten Theil, in welchem die Fortpflanzungszellen (Eier und Spermatozoen) gebildet wer(len; 2) die Leitungswege, durch welche die Fortpflanzungszellen nach aussen befördert werden, und 3). die Begattungsorgane.

1) Die Gonaden oder Keimdrüsen sind schon im Abschnitt XVIII als vollständig oder unvollständig abgegliederte Theile der secundiaren Leibeshöhle erkannt und in ihren Bezichungen zu den übrigen Abschnitten dieser Leibeshöhle dargestellt worden.

Die Gonaden sind paarig und symmetrisch (in einem Paar vorhanden) bei den Lamellibranchiern und Solenogastres. Bei allen übrigen Mollusken sind sie unpaar und in der Einzahl vorhanden. In sehr seltenen Fällen (bei einigen nachher zu erwähnenden hermaphroditischen Lamellibranchiern) finden sich 2 Paar Gonaden, nämlich ein Paar weibliche und ein Paar männliche.

Getrennt geschlechtlich sind unter den Amphineuren die Chitoniden und Chaetoderma, zahlreiche Lamellibranchier, die Scaphopoden, unter den Gasteropoden die Prosobranchier (mit Ausnabme einiger Marseniaden und von Valvata) und sämmtliche Cephalopoden. Hermaphroditisch sind unter den Amphineuren Proneomenia, Neomenia und Verwandte, viele Lamellibranchier, unter den Gasteropoden die Pulmonaten, Op is thob ranchier und die Prosobranchiatenfamilie der Marseniaden.

Beim hermaphroditischen 'Zustand gilt als Regel, dass eine und dieselbe Kieindrüse, die $/ \mathrm{w}$ it terd r ï se, sowohl Eier als Spermatozoen erzeugt.

Ausnahmsweise finden sich in einem und demselben Individuum resonderte mäunliche und weibliche Gonaden (Hoden und Ovarien). Das ist, wie schon erwähnt, bei gewissen Muscheln der Fall, nämlich bei den Anatinaceen und Septibranchiern, welche 2 Hoden und 2 Eierstöcke besitzen.

L a ge der Gonaden. Die lauggestreckte, röhrenförmige, durch eine mediane Scheidewand getheilte Zwitterdrüse der Solenogastres 
liegt in der vorderen Verlängerung des Pericards ïber dem I)arm. In ganz ähnlicher Lage, aber nicht in offener Communication mit dem Pericard, fundet sich die Gonade der Chitoniden. Bei den Gasterop od en findet sich die Gonade im Eingeweidesack, und zwar mit Vorliebe im obersten 'Theil desselben, zwischen den Lappen der Verdauungsdrüse. Wo der Eingeweidesack verstreicht, zieht sich die Gonade mit dem Darm und der Verdaumgsdrüse in die über dem Fusse liegende primäre Leibeshöhle zurück. In ähnlicher Lage wie bei den Gasteropoden treffen wir die Scaphopoden-Gonade im dorsalwäts hoch ausgezogenen Eingeweidesack über dem After und über den Nieren. Dasselbe gilt für die $\mathrm{Cephalopoden.} \mathrm{In} \mathrm{typischer} \mathrm{Lage} \mathrm{liegen} \mathrm{die}$ paarigen, vielfach grelappten Geschlechtsdrüsen der M u scheln in der primären Leibeshöhle üher dem musculösen Theil des Fusses, zwischen den Darmwindungen, hinter der "Leber" orler noch zwischen ihre Lappen eindringend und sich wohl auch zu Seiten und unter der Niere ausbreitend.

Das die Gonarlen auskleidende Epithel ist morphologisch Fndothel der secundären Leiheshöhle. Die Fortpflanzumgszellen können entweder ïberall aus dem Gonadenepithel entstehen oder sie entstehen nur (Cephalopoden) an bestimmten, als Keimepithel oder Kieimlager zu bezeichnenden Bezirken des Gonadenepithels. So mag es dam den Anschein haben, als ob die lieimdrüse in oder an einem besonderen Sacke liege, während dieser Sack in Wirklichkeit selbst die Gonare ist und die Kieimdrüse nur das massig entwickelte Keimlager dler Gonade.

Die reifen Fortpflanzungszellen lösen sich von ihrer Bildungsstätte al und fallen in den Hohlraum der Gonaden, d. h. in einen Theil der secundiren Leibeshöhle. Von hier aus werden sie in verschiedener Weise nach aussen geleitet.

2) L e it u n g s we ge. Die Gonaden haben entweder ihre besonderen A usführungsgänge (Chitoniden, Monotocardier, Pulmonata, Opisthobranchiata, Cephalopoda, viele Lamellibranchier), oder sie benutzen die Nephridien als Leitungswege. Im letzteren Falle gelangen die Geschlechtsproducte entweder direct in die Niere und von da durch die Nierenöftumg nach aussen (viele Diotocardier, die Scaphoporlen, manche Lamellibranchier), oder sie gelangen zuerst in das Pericard und aus diesem durch die Nephridien nach aussen (Solenogastres). In dem Falle, wo die Gonaden in die Niere münden, kann ihre Einmündungsstelle in sehr verschierlenen Bezirken dieser letzteren liegen. Die Conade mündet bald in den proximalen (durch den Nierentrichter mit dem Pericard communicirenden), meist zum Nierensack erweiterten Theil des Nephridiums, bald in den distalen, nach aussen mündenden Theil (Harnleiter), bald in eine wenig tiefe Urogenitalkloake.

Man kann folgende Reihe aufstellen:

a) Die Gonade mündet in das Pericard (Solenogastres).

b) Die Gonade mündet in den proximalen oder Pericardtheil der Niere.

c) Die Gonade mündet in den distalen ober Harnleitertheil der Niere.

d) Die Gonade mündet in eine Urogenitalkloake.

e) Die Gonade mündet gesondert von der Niere nach aussen.

Wo paarige Gonaden vorhanden sind, sind die Leitungswege paarig (Solenogastres, Lamellibranchier). Wo eine einzige unpaare Gonade vorhauden ist, lommt a) ein einziger Ausführungsgang vor, oder wird 
ein einziger Y,eitungsweg (Nicre) benutzt (Gasteropoden, Scaphoporlen, Cephalopoden etc.); dieser Leitumgsweg ist damn immer asymmetrisch und meist rechtsseitig. b) Ein paariger Leitungsweg bei unpaarer Keimdrüse findet sich bei den Chitonen und vielen Cephalopoden.

ITo die Geschlechtsdrüsen mit besonderen Ausführungsgängen wach aussen münden, können sich an dieseu verschiedene Abschnitte, Anhangstaschen, accessorische Drüsen, Begattungsapparate etc. differenziren, welche vornehmlich bei den Puhmonaten, ()pisthobranchiern und Cephaloyoden die Leitungswege $\mathrm{zu}$ einem complicirten Apparate gestalten. Im männlichen Geschlecht wird die Complication vorwiegend bedingt durch das Auftreten von Begattungsorganen, von Drüsen, welche die Kapseln von Spermatophoren bilden, von Samenblasen etc.; im weiblichen Geschlecht durch das Auftreten von Eiweissdrüsen, Schalendrüsen, Receptacula seminis, einer Vagina etc. Da bei hermaphroditischen Mollusken beirle Reihen von Complicationen an einem und demselben Geschlechtsapparat zugleich auftreten, so resultirt daraus die höchste Complication dieses Apparates bei den (hermaphroditischen) Pulmonaten und opisthobranchiern.

3) Begattungsorgane fehlen bei zahlreichen Mollusken, so bei den Amphineuren (siche weiter unten), fast allen Diotocardiern, den Scaphopoden und allen Lamellibranchiern. Sie sind vorhanden bei den Monotocardiern, den Pulmonata, Opisthobranchiata und Cephalopoda. Bei den Gasteropoden handelt es sich um in der Nackengegend, auf der rechten Seite, liegende männliche Apparate, die bald aus einem frei volragenden, nusculösen Penis bestehen, bald ein aus der Geschlechtsiffinung vorstrecklares orler vorstülpbares Organ darstellen. Bei den Cephalopoden ist es ein bestinmter, in hesonderer, bisweilen sehr auffälliger Weise, modificirter (he ctocoty lis irter) Arm des Mämnchens, welcher bei der C'opulation eine mehr oder weniger wichtige Rolle spielt.

\section{B) Specielles.}

a) Gonaden. 1) Amphineuren. Die langgestreckte Zwitterdrüse von Proneomenia und Verwandten haben wir als paarig bezeichnet. Sie ist in der That durch eine mediane, in vielfachen Falten verlaufende Scheidewand mehr oder weniger deutlich in zwei seitliche Röhren getheilt. Im unteren, dem Darme anliegenden Theil einer jeden Röhre entstehen aus dem Keimepithel die Spermatozoen, im oberen die Eier. Hinten trennen sich diese beiden Röhren auf eine kürzere oder längere Strecke, um als paarige, gesonderte Kanäle in das Vorderende des Pericards zu münden.

Die männliche oder weibliche Gonade der Chitoniden liegt als ein unpaarer, langer Sack auf der Rückenseite des Darmes vor und z. Th. noch unter dem Pericard. Beim Ovarium ragen von der Epithelwand zahlreiche birnförmige Schläuche (Fig. 568) in die Ovarialhöhle vor. Ein jeder solcher Schlauch stellt ein gestieltes Follikel mit von den Follikelzellen umgebener Eizelle dar. Es finden sich solche Follikel in allen Grössen und Entwickelungsstadien. Jedes Ei ist anfangs eine einfache Ovarialepithelzelle, die sich durch besondere Grösse von den benachbarten Epithelzellen unterscheidet. Indem sie wächst und immer dotterreicher wird, senkt sie sich unter das Ovarialepithel in die Tiefe, stülpt dasselbe zu gleicher Zeit gegen die Ovarialhöhle vor und bildet so ein junges Follikel. Auch die Wrandung des sackförmigen Hodens erhebt sich in seinen Binnen- 
raum hinein in Form zahlreicher Falten, an denen das Epithel mehrschichtig wird und die Mutterzellen der Spermatozoen liefert.

Dass die Gonade von Chiton zwei Ausführungsgänge hat, lässt vermuthen, dass sie selbst ursprïnglich parig war. Die beiden Ausführungsgänge, d. h. die beiden Samenleiter beim Männchen und die beiden Eileiter beim Weibchen, münden jederseits in die Mantelfurche, etwas vor der Nierenöffnung (Fig. 561).

2) Grasteropoda. Die Gonaden der Prosobranchier bieten geringes vergleichend-anatomisches Interesse. Bei den $\mathrm{Pulmonata}$ und Opisthobranchiata ist die Keimdrüse eine Zwitterdrüse, in welcher Spermatozoen und Eier gleichzeitig erzengt werden. Die Zwitterdrüse der Pulmonaten ist ein vielfach gelapptes oder aus zahlreichen zusammenmündenden Divertikeln bestehendes Organ, in welcher, überall durcheinander vermengt,

Spermatozoen und Eier entstehen, die in früheren oder späteren Bilduugsstadien sich von der Wand loslösen und dann frei in der Gonadenhöhle liegen. Auch die ansehnliche, in

Fig. 568. Schnitt durch die Wand des 0variums von Chiton, nach HALLER, schematisirt. 1 Eier auf verschiedenen Entwickelungsstadien, 2 Keimepithel, 3 Eisäcke, Eischläuche, 4 Follikelepithel, 5 vom Ei verlassener Eischlauch.

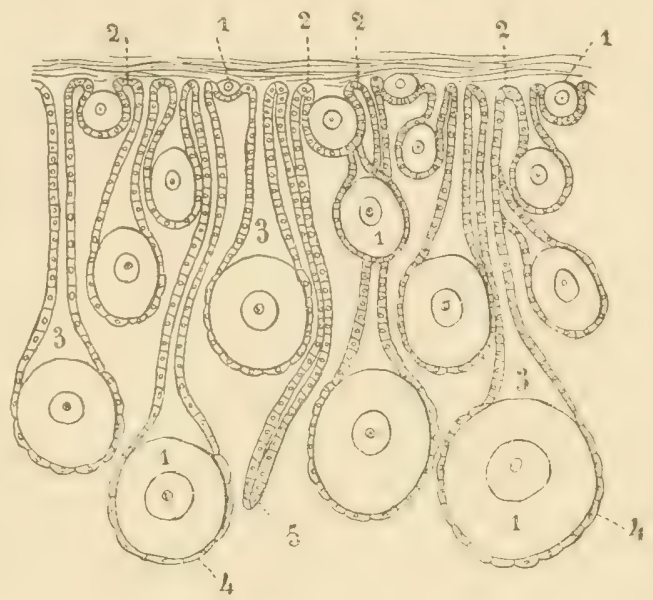

ihren gröberen Formverhältnissen sehr variable Zwitterdrïse der Tectibranchiata verhält sich ganz ähnlich. Sie liegt im hinteren Körpertheil an der Verdauungsdrüse, zwischen deren Lappen sie eindringen kann, und weist selbst mehr oder minder deutliche Lappen auf, die wieder aus Lappen zweiter Ordnung, Bläschen oder Acini bestehen. In allen Acini werden gleichzeitig Spermatozoen und Eier gebildet. Nur bei Pleurobranchaea und Verwandten finden sich Verhältnisse, welche dadurch an die gleich zu besprechenden Verhältnisse der Nudibranchiaten erinnern, dass die Stellen, wo die Spermatozoen, und diejenigen, wo die Eier entstehen, in der Zwitterdrüse localisirt sind. Die Acini zerfallen nämlich in männliche und weibliche, indem die einen nur Spermatozoen, die anderen nur Eier liefern. Das scheint auch bei einzelnen $\mathrm{Nudibranchiern} \mathrm{(Amphorinia,}$ Capellinia) der Fall zu sein. Bei der grossen Mehrzahl der Nudibranchier aber kommt eine räumliche Sonderung der männlichen und weiblichen Keimbezirke dadurch zu Stande, dass die Endacini nur Eier erzengen, aber

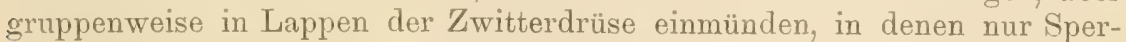
matozoen erzeugt werden. Aus allen Lappen entspringen Ausführungsgänge, die, sich miteinander vereinigend, schliesslich den Zwittergang bilden. Die Zwitterdrüse stellt so ein im grösseren hinteren Theil der primären Leibeshöhle ansehnlich ausgebreitetes Organ dar, welches, wo eine compacte Verdauungsdrüse vorhanden ist, diese überzieht. Phyllirhoë 
hat 2-6 (meistens 3) gesonderte, kugelige Acini, deren lange und dünne Ausführungsgänge sich zu einem Zwitterdrüsengang vereinigen (Fig. 576).

Die Zwitterdrüse der Pteropoda (Tectibranchia natantia) liegt immer im oberen (dorsalen) Theil des Eingeweidesackes und ist bald ein traubiges, bald ein aus zusammenmündenden Röhrenfollikeln oder zuzammengedrïckten, dicht aneinander liegenden Fächern bestehendes Organ. Immer entstehen die Eier in dem peripheren Theil der Acini, Röhren oder Fächer, während die Spermatozoen in dem centralen, dem Ausführungsgang zugekehrten Theile sich bilden. Beide Abschnitte sind meist von einander durch eine Membran geschieden, welche die Eier durchbrechen müssen, $u m$ in den Zwittergang zu gelangen. Die Pteropoden scheinen übrigens protandrisch hermaphroditisch zu sein, d. h. es werden zuerst die Spermatozoen und erst nachher die Eier gebildet, ein Verhalten, welches auch bei vielen anderen hermaphroditischen Mollusken beobachtet wurde.

3) Die Gonade (Hode, Ovarium) der Scaphopoden ist ein geräumiger, mit seitlichen Divertikeln versehener, langgestreckter Sack, welcher über dem After der Hinterseite des Körpers (Eingeweidesack) entlang in die Höhe steigt. In der Abtheilung der Solenopoden (Siphonodentalium etc.) erstreckt sich ein grosser Theil der Gonade in den Mantel hinein. Bei jungen Thieren ist die Gonade allseitig geschlossen, beim erwachsenen Thiere scheint ihre Wand mit der Wand der rechten Niere zu verschmelzen und in der so entstandenen Scheidewand durch Durchbruch eine Communication zwischen Gonade und rechtem Nephridium aufzutreten.

4) Die Gonade der Lamellibranchier stellt jederseits eine in der primären Leibeshöhle liegrende, die übrigen Eingeweide umgehende and z. Th. zwischen sie eindringende Masse dar, welche aus reich verzweigten Schläuchen oder Lappen besteht. In einigen Fällen (Anomiidae, Mytilidae) erstreckt sich die Gonade jederseits in den Mantel hinein. In anderen (Axinus, Montacuta) buchtet sie die Leibeswand gegen die Mantelhöhle vor, in der Weise, dass verästelte Auswüchse vom Körper in die Mantelhöhle vorragen, welche in ihrem Innern die Gonadenschläuche enthalten.

Die meisten Lamellibranchier sind getrennt-geschlechtlich. Was den Hermaphroditismus der Muscheln anbetrifft, so giebt es 1) ganze hermaphroditische Gruppen: die am meisten specialisirten Muscheln, die Anatinaceen und Septibranchier, sind hermaphroditisch. 2) Es giebt Familien mit einzelnen hermaphroditischen Gattungen: Cyclas, Pisidium, Entovalva. 3) Es giebt Gattungen mit einzelnen hermaphroditischen Arten: gewisse Arten der Gattungen Ostrea, Pecten, Cardium. 4) Gewisse sonst getrenntgeschlechtliche Arten sind gelegentlich hermaphroditisch: Anodonta. Der Hermaphroditismus scheint immer in dem Sinne incomplet zu sein, dass Spermatozoen und Eier nicht gleichzeitig zur Reife gelangen.

Bei den Anatinaceen und Septibranchiern existirt jederseits eine männliche und eine von ihr vollständig getrennte weibliche Gonade. Bei allen übrigen hermaphroditischen Muscheln hingegen ist die jederseitige Geschlechtsdrüse eine Zwitterdrüse.

5) Die Cephalopoden sind durchgängig getrennt-geschlechtlich. Dass ihre Gonadensäcke einen Theil der secundären Leibeshöhle darstellen, mit der sie in offener Communication stehen, wurde schon erörtert.

Es findet sich immer eine einzige unpaare Gonade, welche überall im obersten Theile des Eingeweidesackes liegt. Sie stellt einen verschieden gestalteten Sack dar (eine Bauchfelltasche oder eine Genital- 
kapsel), welcher allseitig von einem häufig in grosser Ausdehnung wimpernden Epithel ausgekleidet ist, das nichts anderes als Peritonealepithel der secundären Leibeshöhle ist. Aber nicht an der ganzen Wand des Gonadensackes liefert dieses Peritonealepithel das Keimlager, sondern nur an der vorderen der Schale zugekehrten Seite. Hier bildet das Keimlager das, was man als Eierstock oder Hode im engeren Sinne bezeichnet, und man sagt dann, dass der Eierstock oder der Hode in eine Bauchfelltasche, oder in eine Ovarialkapsel, oder in eine Hodenkapsel eingeschlossen sei, oder in sie vorspringe oder hineinhänge. In Wirklichkeit aber ist der ganze Apparat eine Gonade, in welcher die Bildungsstätte der Fortpflanzungszellen auf die vordere Wand localisirt ist.

So erklärt es sich, dass Hode und Ovarium scheinbar nicht eigene Ausführungsgänge besitzen, sondern vielmehr ihre Geschlechtsproducte zuerst in die Hoden- resp. Ovarialkapsel entleeren, von wo sie durch die Ansführungsgünge dieser letzteren (Eileiter, Samenleiter) nach aussen, d. h. in die Mantelhöhle entleert werden. Da aber in Wirklichkeit die ganze Gonadentasche der Geschlechtsdrüse einer Schnecke oder einer Muschel entspricht, so fallen die Fortpflanzungsproducte auch nur in die Höhle dieser Geschlechtsdrüse (Hoden-, Ovarialkapsel) und werden von da durch Eileiter oder Samenleiter nach aussen entleert, welche vollständig den Ei- und Samenleitern der Gasteropoden, Lamellibranchier und Chitoniden entsprechen.

Es existirt aber noch eine andere Communication der Gonadenhöhle mit der Aussenwelt, denn es steht ja bei den Cephalopoden die Gonadenhöhle mit dem übrigen Theil der secundären Leibeshöhle in offener Communication, mag derselbe als Visceropericardialhöhle gerüumig (Decapoden) oder als Wasserkanalsystem sehr eingeengt sein (Octopoden). Dieser andere Theil der Leibeshöhle steht aber seinerseits durch die Nephridien mit der Mantelhöhle in Verbindung.

Einmal communicirt somit die Gonadenhöhle durch die Eileiter resp. Samenleiter direct mit der Mantelhöhle, ein andermal indirect durch Vermittelung 1) der Visceropericardialhöhle oder des Wasserkanalsystems, und 2) der Nephridien. Dieser zweite Communicationsweg wird jedoch nie zur Entleerung der Geschlechtsproducte benutzt.

Das weibliche Keimlager, Ovariallager (Eierstock im engeren Sinne) findet sich immer an der vorderen Wand der Gonade und zeigt sehr verschiedene Bauverhältnisse (Fig. 569). Wir können immer 1) die Eier und 2) die eiertragende Gonadenwand unterscheiden. Die Eier sind gestielt und ragen von der eiertragenden Wand in den Hohlraum der Gonade (in die Höhle der Ovarialkapsel) vor. Bei den grössten und ältesten Eiern ist das Ei von einem Follikelepithel umgeben und dieses selbst wieder von dem allgemeinen Epithel der Gonadenwand, welches auch die Stiele überzieht. Jedes $\mathrm{Ei}$ hat einen besonderen Stiel. Die jüngsten Eier ragen wie Höcker an der eiertragenden Wand vor, sie werden gestielt, indem sie wachsen, aus der eiertragenden Wand hervorquellen und mit ihr durch einen Strang in Verbindung bleiben. (Es herrschen also ganz ähnliche Verhältnisse wie bei Chiton.) Sind die Eier reif, so fallen sie unter Platzen der Follikel in die Gonadenhöhle und gelangen von da durch die Eileiter nach aussen.

Bei Nautilus (Fig. 569 A) und Eledone ist die ganze Gonadenwand mit Ausnahme der hinteren Fläche eiertragend und mit einfach gestielten Eiern besetzt. Auch bei Argonauta (Fig. 569 B) und Tremoctopus ist die ganze Ovarialkapsel mit Ausnahme der hinteren Wand eiertragend, aber 
die eiertragende Flaiche sluingt (zum Zwecke der Oberfächenvergrösserung) in Form zahlreicher ziemlich verzweigter Bäumchen in die Gonadenhöhle vor. An den Stämmen, Aesten und Zweigen sitzen die einfach gestielten Eier. Bei Parasira (Tremoctopus) catenulata ist ein centraler Hof von über 20 grösseren Eierbäumchen von einem Kranze kleinerer Bäumchen umgeben. Bei Octopus erhebt sich auf der vorderen Wand der Gonade ein einziger, aber überaus reich verzweigter Eierbaum (C). Bei Sepia, Sepiola, Rossia wölbt sich die eiertragende Fläche in Form eines Wulstes auf der vorderen Gonadenwand vor. Dieser Wulst wird bei Loligo zu einer vorspringenden, schmalen Falte, deren freier Rand sich in Filamente fortsetzt, die allseitig mit einfach gestielten Eiern besetzt sind. Bei den Oegopsiden (Ommastrephes [Fig. 569 D], Onychoteuthis, Thysanoteuthis) bleibt der Eierträger nur noch an seinem unteren und oberen Ende an der Gonadenwand suspendirt und durchzieht im übrigen als ein allseitig freier, allseitig mit gestielten Eiern besetzter, spindelförmiger Körper die Gonadenhöhle.
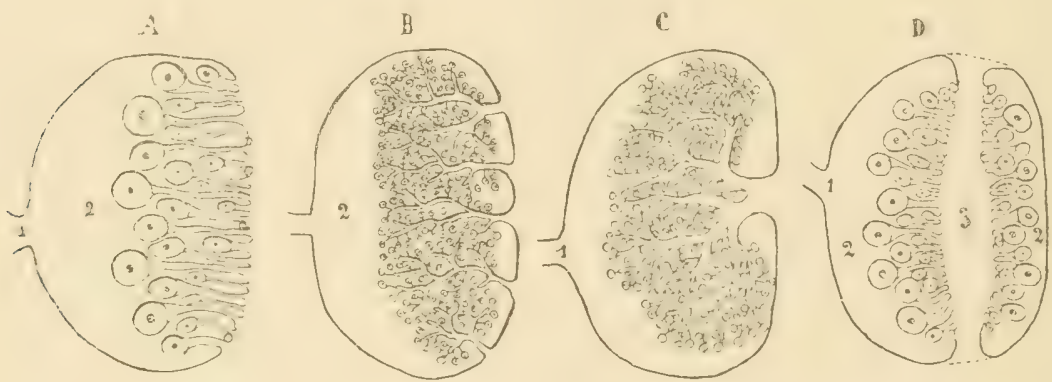

Fig. 569. $\boldsymbol{A}-\boldsymbol{D}$ Vier Schemata weiblicher Gonaden von Cephalopoden. $\boldsymbol{A}$ Typus Nautilus. $B$ Typus Argonauta. $C$ Typus 0ctopus. $D$ Typus Ommastrephes. 1 Mündung des Eileiters in die Gonade, 2 Gonadenhöhle (ein Abschnitt der secundären Leibeshöhle), 3 Eierträger.

Bei Octopus und Eledone stehen alle Eier in einem und demselben Ovarium auf dem nämlichen Reifestadium.

Eigenthümlich ist eine Umbildung des Follikelepithels bei den der Reife nahen Ovarialeiern der Cephalopoden. Dasselbe erfährt nämlich eine ausserordentliche Oberflächenvergrösserung, die dadurch zum Ausdruck kommt, dass es in Form zahlreicher, bald netzförmig verbundener, bald neben einander in der Längsrichtung des Eies verlaufender Falten tief in den Eidotter des von ihm umschlossenen Eies vordringt. Vielleicht steht diese Einrichtung mit der Ernährung des Eies in Zusammenhang.

Das männliche Keimlager (Keimkörper, Hode im engeren Sinne) stellt ein verschieden gestaltetes (oft kugeliges oder eiförmiges), compactes Organ dar, welches gewöhnlich frei in der Gonadenhöhle liegt, an deren vorderer Wand durch ein dünnes Ligament (Mesorchium), in welchem die Genitalarterie verläuft, aufgehängt. Der Keimkörper ist ïberall von Epithel überzogen, welches sich über das Mesorchium hinweg in das Epithel der Gonadenwand (Endothel der Hodenkapsel) fortsetzt. An der vom Mesorchium abgewandten Oberfläche des Keimkörpers liegt eine trichterförmige Vertiefung (Fig. 570 A), gegen welche von allen Seiten die den männlichen Keimkörper bildenden röhrenförmigen Hodenkanäle convergiren, um in sie auszumünden. In den Hodenkanälen, zwischen 
denen nur spärliches Bindegewebe vorkommt, entstehen die Spermatozoen und werden darauf durch die gemeinsame Vertiefung, in welche die Hodenkanäle münden, in die Gonadenhöhle befördert und von da durch den Samenleiter nach aussen. Die Hodenkanäle besitzen ursprünglich ein mehrschichtiges Keimepithel, welches die Spermatozoen liefert und welches an der gemeinsamen Mündung in das äussere Epithel des männlichen Keimkörpers, somit in das Epithel des Gonadensackes übergeht.
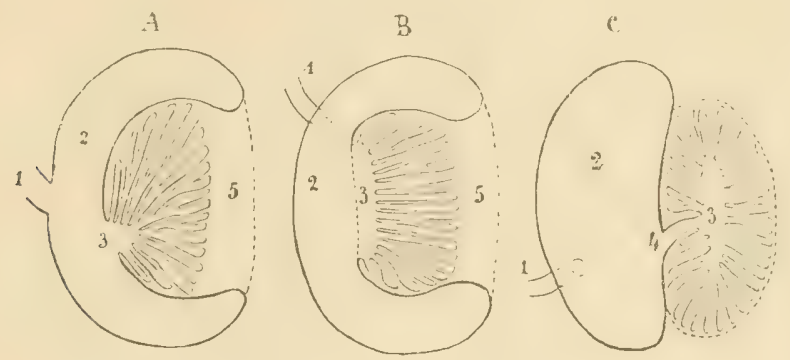

Fig. 570. A, B. C Drei Schemata niännlicher Gonaden von Cephalopoden. $\boldsymbol{A}$ Gewöhnlicher Typus. $\boldsymbol{B}$ Loligo. $\boldsymbol{C}$ Sepia, 1 Samenleiter, 2 Gonadenhöhle, 3 gemeinsamer Raum, in welchen die Hodenkanälchen münden und welcher sich selbst wieder in die Gonadenhöhle öfinet, bei Sepia $C$ durch Vermittelung eines Kanales 4, 5 Aufhängeband des männlichen Keimkörpers an der vorderen Gonadenwand.

Diese Schilderung gilt für den männlichen Keimkörper der meisten Cephalopoden. Loligo (B) weicht insofern ab, als die trichterförmige Oeffnung, in welche alle Hodenkanälchen einmünden, ersetzt ist durch eine Längsfurche, in welche, von allen Seiten her convergirend, die Hodenkanälchen ausmünden. Bei Sepia (C) findet sich kein Aufhängeband des Keimkörpers, sondern letzterer liegt unmittelbar vor der vorderen Wand der Gonade, also nicht in der Gonadenhöhle suspendirt, sondern ausserhalb dieser Höhle. Der Keimkörper besitzt hier einen centralen Gang, in welchen die von allen Seiten convergirenden, d. h. mit Bezug auf den Gang radiär gestellten Samenkanälchen einmünden. Dieser Gang öffnet sich selbst wieder durch einen Ausführungskanal (Fig. 570 C, 4) in die Gonadenhöhle, aus welcher der Samenleiter die Spermatozoen nach aussen leitet.

Die Spermatozoen der Mollusken haben die so weit verbreitete Stecknadelform. Bei zahlreichen Prosobranchierarten kommen bei einem und demselben Individuum zwei verschiedene Formen von Spermatozoen vor, die als haarförmige und w urmförmige bezeichnet worden sind. Man hat diese Erscheinung bald im Sinne eines sich entwickelnden Hermaphroditismus, bald im Sinne eines verloren gegangenen Hermaphroditismus deuten wollen, wobei die wurmförmigen Spermatozoen im ersteren Falle als beginnende Eier, im letzteren Falle als Rudimente von Eiern betrachtet wurden. Doch fehlt durchaus eine sichere Grundlage für solche Ansichten.

Was die Erage anbetrifft, ob bei den Mollusken der hermaphroditische oder der getrennt-geschlechtliche Zustand der ursprüngliche sei, so ist die Wahrscheinlichkeit für die letztere Alternative grösser. Von den 5 Klassen der Mollusken sind zwei durchwegs getrenntgeschlechtlich: die Scaphopoden und Cephalopden. Unter den Amphineuren 
sind die Chitoniden, die wir im Anschluss an neuere Forscher für weniger specialisirt als die Solenogastren halten, getrennt-geschlechtlich. Unter den Lamellibranchiaten herrscht bei den mit Recht als ursprünglich geltenden Protobranchiern (wenn wir ganz davon absehen, dass überhaupt die meisten Muscheln getrennt-geschlechtlich sind) Trennung der Geschlechter. Unter den Gasteropoden sind die Prosobranchier getrenntgeschlechtlich, speciell auch die Diotocardier, die mit Recht allgemein * als die niedersten und am wenigsten specialisirten Schnecken gelten.

b) Die Leitungswege. Auf den Modus der Ausleitung der Geschlechtsproducte, welcher bei den Amphineuren, Scaphopoden, Lamellibranchiern besteht, brauchen wir nicht zurückzukommen, da die betreffenden wichtigen Verhältnisse schon im allgemeinen Theil dieses Kapitels, z. Th. auch schon im Kapitel "Nephridialsystem" besprochen worden sind. Wir haben es hier somit nur mit den z. Th. sehr complicirten Leitungswegen der Gasteropoden und Cephalopoden zu thun.

1) Gasteropoda. Eine $\mathrm{Suggestion}$ von allgemeinerem morphologischen Interesse möge zuerst Platz finden. Wir haben gesehen, dass bei gewissen Diotocardiern: Haliotis, Fissurella und bei Patella die Geschlechtsproducte durch die rechte Niere entleert werden. Wir haben ferner bemerkt, dass die Ansichten darüber getheilt sind, ob die einzige Niere der Monotocardier der linken oder der rechten Niere der Diotocardier oder beiden zusammen entspricht. Wenn die Ansicht, dass die Niere der Monotocardier der linken Niere der Diotocardier entspricht, richtig ist, so drängt sich von selbst die suggestive Frage auf, ob sich die rechte Niere der Diotocardier (durch welche bei Haliotis, Fissurella, Patella, auch bei Turbo (?), Trochus (?) die Geschlechtsproducte entleert werden) bei Monotocardiern nicht in irgend einer Weise erhalten habe. Ferner die weitere Frage, ob es nicht die bei den Monotocardiern auf der rechten Seite des Enddarmes oder Afters liegende Genitalöffnung ist, welche der rechtsseitigen Nierenöffnung der Diotocardier entspricht, wobei die Niere sich nur als Leitungsweg der Geschlechtsproducte erhalten hätte. Bei den Pulmonaten und Opisthobranchiern ist die Geschlechtsöffnung aus der Mantelhöhle hinausgerückt und hat sich, wohl in Zusammenhang mit der Ausbildung der Begattungsapparate, weit nach vorn an die rechte Seite des Nackens verschoben. Sie ist in Folge dessen bei weiteren Lageveränderungen des Pallealcomplexes, ja des ganzen Eingeweidesackes, nicht nothwendigerweise betheiligt, und wir würden verstehen, weshalb bei Daudebardia und Testacella die gemeinsame Geschlechtsöffnung, bei Onchidium die männliche Geschlechtsöffnung weit vorn auf der rechten Körperseite liegt, obgleich der Pallealcomplex ganz nach hinten verlagert ist.

Auch bei Opisthobranchiern liegt die einfache oder (secundär) doppelte Geschlechtsöffnung rechtsseitig am Körper vor dem After, ja vor der Niere. Diese Lage würde sich, wie uns scheint, nur unter der Voraussetzung einer Zurückverschiebung des Pallealcomplexes erklären lassen, an welcher die vom Pallealcomplex emancipirte Geschlechtsöffnung sich nicht betheiligte und so vor die zurückverlagerte After- und Nierenöffnung zu liegen kam.

Monotocardier. Gegenüber den Diotocardiern, denen Begattungsorgane (mit Ausnahme der Neritidae) fehlen, zeichnen sich die Monotocardier im männlichen Geschlecht durch den Besitz eines Begattungs- 
organes oder Penis aus. Dieser Penis findet sich nicht an der Stelle, wo ursprüuglich die Geschlechtsöffnung liegt, nämlich nicht in der Mantelhöhle. Hier könnte er nicht functioniren. Er findet sich in der That in freier Lage auf der rechten Seite des Kopfes oder Nackens (Fig. 454) als ein dehnbarer, frei vorragender, oft ansehnliche Dimensionen erreichender musculüser Anhang. Trotzdem verharrt die männliche Geschlechtsöffnung bei sehr vielen, vielleicht den meisten Monotocardiern an der ursprünglichen Stelle in der Mantelhöhle rechts neben dem Rectum. Von dieser Oeffnung an aber zieht dann eine wimpernde Furche am Boden der Athemhöhle und auf der rechten Seite des Nackens nach vorn gegen die Basis des Penis, um sich an diesem ebenfalls als eine tiefe Furche bis an seine Spitze fortzusetzen. In dieser Furche wird der Samen von der Geschlechtsöffnung zum Penis geleitet. In einigen Fällen aber schliesst sich die Samenrinne zu einem Kanal, und dann wird der Penis zu einem hoblen Rohr, in welches der Samenleiter einmündet. Dann ist die äussere Geschlechtsöffnung von ihrer ursprünglichen Stelle weit nach vorn verlagert. Der aus dem Hoden entspringende Samenleiter verlituft meist unter Bildung von Windungen der Spindelseite der Schale entlang. Besondere Anhangsorgane fehlen dem Vas deferens, höchstens dass es in seinem Verlaufe sich zu einer sogenannten Samenblase erweitert.

Im weiblichen Geschlecht verbleibt die Genitalöffnung in der Mantelhöhle, wo sie rechts neben dem Enddarm hinter dem After liegt. Der Leitungsweg bleibt im Allgemeinen ziemlich einfach, er weist gewöhnlich folgende aufeinanderfolgende Abschnitte auf: 1) einen aus dem Ovarium entspringenden Eileiter ( $\mathrm{viduct}$ ), der sich in seinem Verlaufe zu einem oder mehreren Samenbehältern (Receptacula seminis) ausbuchten kann. Der Eileiter setzt sich in einen erweiterten Abschnitt mit dicker, drüsiger Wand fort, den Uterus, in welchem die Eier mit Eiweiss ausgestattet werden und ihre Schale bekommen. Der Uterus mündet durch Vermittelung einer kurzen, musculösen Scheide (Vagina) an der weiblichen Geschlechtsöffnung nach aussen. Bei Paludina kommt eine gesonderte, in den Eileiter mündende $\mathrm{E} i \mathrm{w}$ iss drüse vor.

Bei den zwitterigen Prosobranchiern (Valvata, einige Marseniaden: Marsenina, Onchidiopsis) ist eine Zwitterdrüse vorhanden. Aus dieser Zwitterdrüse entspringt entweder ein Zwittergang, der sich dann in ein Vas deferens und in einen Oviduct spaltet, oder es sind Vas deferens und Oviduct von Anfang an getrennt. Das Vas deferens verläuft, so wie im männlichen Geschlecht der getrennt-geschlechtlichen Prosobranchier, zum Penis, der Oviduct zu der weiblichen Geschlechtsöffnung. Beide Leitungswege weisen grössere Complicationen (Anhangsdrüsen etc.) auf, als bei den übrigen Prosobranchiern.

Opisthobranchiata und Pulmonata. Die Leitungswege gestalten sich hier ausserordentlich complicirt, sowohl durch Gliederung in aufeinander folgende Abschnitte, als durch Ausbildung von verschiedenen Anhangsorganen.

Wir wollen die Darstellung, die sich nur auf die wichtigsten Punkte erstrecken kann, beginnen mit einem bei den Cephalaspiden unter den Tectibranchien verbreiteten Typus.

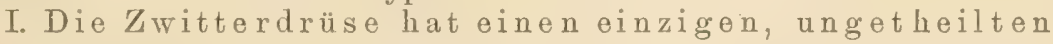
Ausführungsgang, welcher durch eine einzige Greschlechtsöffnung nach aussen mündet. Aus dieser Oeff nug treten die befruchteten Eier direct nach aussen, wïhrend die Spermatozoen von dieser Oeffnung in einer 
wimpernden, in der Mantelhöhle verlaufenden Samenfurchezu dem ingeringerer oder grösserer Entfernung vor der Geschlechtsöffung weit vorn in der Nähe des rechten Tentakels befindlichen Penis befördert werden.

Denken wir uns den Hoden eines männlichen Monotocardiers zu einer Zwitterdrüse umgewandelt, das Vas deferens zu einem Zwittergang; so wïrde im Wesentlichen der eben skizzirte Zustand hergestellt sein.

Als Beleg für diesen Zustand wählen wir Gasteropteron (Fig. 571). Andere Cephalaspiden (Doridium, Philine, Scaphander, Bulla) und sämmtliche Pteropoda verhalten sich ganz ähnlich.

Aus der im hinteren Körpertheil zwischen den Leberlappen liegenden $\mathrm{Z}$ witterdrüse entspringt ein Zwittergang, welcher nach längerem, gewundenem Verlauf in einen kurzen, sehr stark erweiterten Endabschnitt einmündet, der als Uterus oder Geschlechtskloake bezeichnet wird. Diese Geschlechtskloake mündet vor der Kiemenbasis durch die Geschlechtsöffnung nach aussen. In die Kloake münden: 1) der gemeinsame Ausführungsgang von zwei Drüsen, von denen die eine als Eiweissdrüse die Eier mit Eiweiss versorgt, während die andere, die Nidamental- oder Schalendrüse, die äussere schützende Hülle der Eier liefert; 2) der Ausführungsgang einer kugligen Blase (Receptaculum seminis, Swaminerdan's Blase), welche bei der Begattung die Spermatozoen aufnimmt. Von der ungefähr

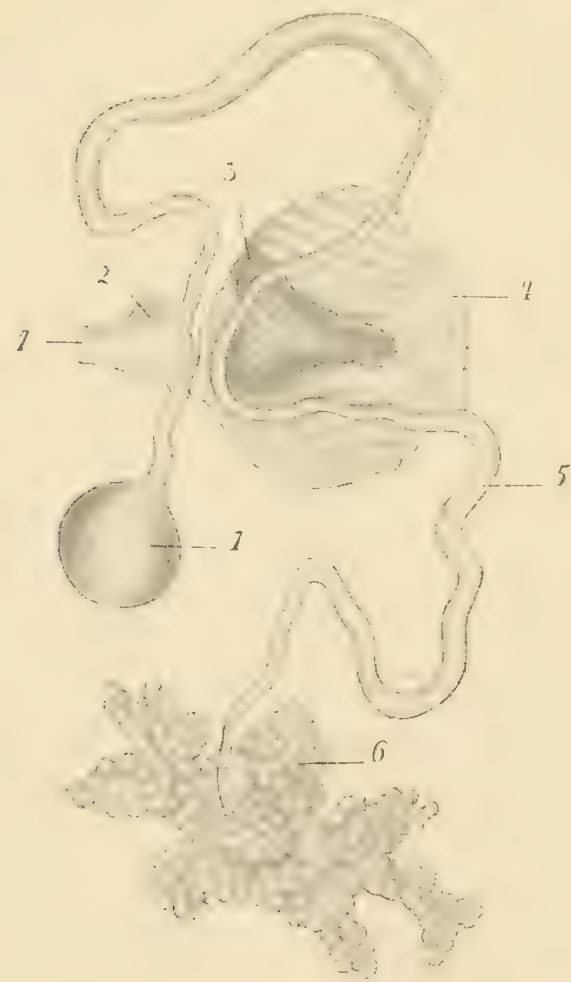
in der Mitte der Körperlänge rechtsseitig liegenden Geschlechtsöffnung setzt sich die Samenrine nach vorn zum $\mathrm{Pen}$ is fort. Dieser letztere ist in eine besondere Scheide eingeschlossen, aus welcher er vorgestreckt und in welche er durch einen Rückziehmuskel zurückgezogen werden kann. In den Penis mündet eine als Prostata bezeichnete Drüse. Der Penis liegt rechts vorn am Körper an der Grenze von Kopf und Fuss. Seine Scheide liegt im Ruhezustande in der Kopfhöhle neben der Buccalmasse.

Die ausserordentlich complicirten Verhältnisse des Leitungsapparates von Aplysia und Acera sind von den hier besprochenen nicht wesentlich verschieden. Der Zwittergang macht, in der Gegend der Eiweissdrüse angelangt, eine auf sich selbst zurïcklaufende Schlinge, deren beide Schenkel

Fig. 571. Geschlechtsorgane von Gasteropteron Jifeckelii, nach VAYssière, Samenfurche und Penis sind nicht gezeichnet, 1 Gemeinsame Geschlechtsöffnung, 2 Geschlechtskloake, 3 Eiweissdrüse, 4 Nidamentaldrüse, 5 Zwittergang, 6 Zwitterdrüse. 
in spiraligen Windungen die Eiweissdrüse umfassen. Der Penis ist ohne Prostata.

II. Typus. Aus der Zwitterdrüse entspingt ein Zwittergang, der sich aber bald in zwei Gänge theilt: 1) in das Vas deferens oder den Samenleiter und 2) in den Oviduct oder den Eileiter. Das Vas deferens geht zum männlichen Begattungsapparat, der Oviduct zur weiblichen Geschlechtsöffnung. Die männliche Oeffnung mit dem Penis liegt vor der weiblichen, von dieser gesondert, beide auf der rechten Seite, die männliche weit vorn am Kopf oder Nacken.

Diesen zweiten Typus könnte man sich aus dem ersten so entstanden denken, dass nicht nur der gemeinsame Ausführungsgang der Zwitterdrüse sich in einen männlichen und in einen weiblichen Kanal theilte, sondern sich auch in Fortsetzung des männlichen Kanales die Samenfurche zu einem Kanale schloss.

Wie der Zwittergang beim II. Typus in einen männlichen und in einen weiblichen getheilt ist, so sind auch die Anhangsgebilde so vertheilt, dass die männlichen in das Vas deferens, die weiblichen in den Oviduct münden.

Zu diesem zweiten Typus gehören unter den Pulmonaten die Basommatophoren, ferner einzelne Daudebardiaarten (D. Saulcyi, hier liegen die beiden Oeffnungen dicht nebeneinander), die Onchidien und Vaqinuliden. Bei diesen beiden letzteren Gruppen ist die weibliche Geschlechtsöffnung den an das Hinterende des Körpers verlagerten Theilen des ursprünglichen Pallealcomplexes gefolgt und liegt ganz hinten neben dem After. Die männliche Geschlechtsöffnung aber hat ihre Lage ganz vorn am Kopfe hinter dem rechten Kopftentakel beibehalten. So liegen hier die beiden Geschlechtsöffnungen an den entgegengesetzten Körperenden. Unter den Opisthobranchiern findet sich der zweite Typus z. B. bei Oscanius (Tectibranchiata) repräsentirt.

Als Beispiele wähle ich Lymnaeus stagnalis und Onchidium.

Lymnaeus (Fig. 572). Aus der hoch oben im Eingeweidesack der "Leber" eingelagerten $Z$ witterdrüs e entspringt ein dünner $Z_{w}$ itter $\mathrm{g}$ ang, welcher sich bald in einen männlichen und einen weiblichen Gang spaltet. Der männliche Gang erweitert sich zunächst zu einem abgeplatteten Sack, dam zu einer grösseren birnförmigen Drïisenblase (Prostata). Aus dieser Blase setzt er sich als ein dünnes, langes $\mathrm{V}$ a s deferens fort, welches zum Theil in der Fussmusculatur verläuft und schliesslich in den männlichen Begattungsapparat einmündet. Dieser stellt nur das erweiterte, ausstülpbare und musculöse Ende des Vas deferens selbst dar. Das Vas deferens bildet zunächst einen kleinen Penisschlauch, und dieser ragt mit einer Papille in den darauf folgenden grossen Schlauch (Penisscheide) vor, welcher bei der Begattung nach aussen umgekrempelt wird. An den grossen Schlauch setzen sich Protractoren, an den kleinen Retractoren an; der kleinere allein tritt mit seiner Papille bei der Begattung in die Vulva ein.

In den weiblichen Gang mündet sofort nach seiner Trennung vom mämnlichen eine $\mathbf{E}$ iweissdrüse ein. Dann wird er zu dem krausenartig gefalteten Uterus und setzt sich dann als Oviduct in einen grossen birnförmigen $\mathrm{K}$ örper fort, der sich bis zur weiblichen Geschlechtsöftinung zur $\mathrm{V}$ ag in a verjüngt. In den Oviduct mündet eine 
seitliche Anhangsdrüse, die als Nidamentaldrüse bezeichnet worden ist, in die Vagina der Ausführungsgang des kugligen Receptaculum seminis.

Onchidium celticum (Fig. 573). Zwitterdrüse und weibliche Anhangsdrüsen liegen im hintersten Körpertheil zwischen den Leberlappen

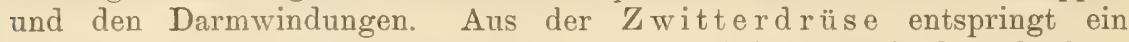
$Z_{w i t t e r g a n g}$, welcher an einer Stelle ein seitliches Blindsäckchen trägt, und welcher in ein Organ von unregelmässiger Gestalt, den Uterus,

Fig. 572 .

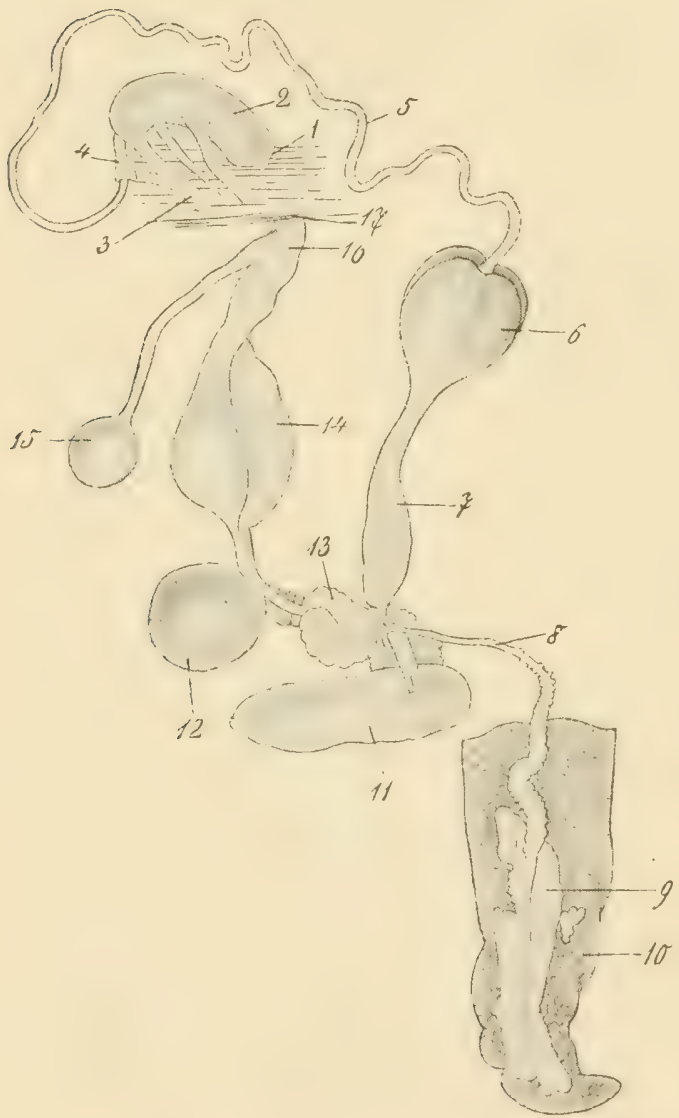

Fig. 573.

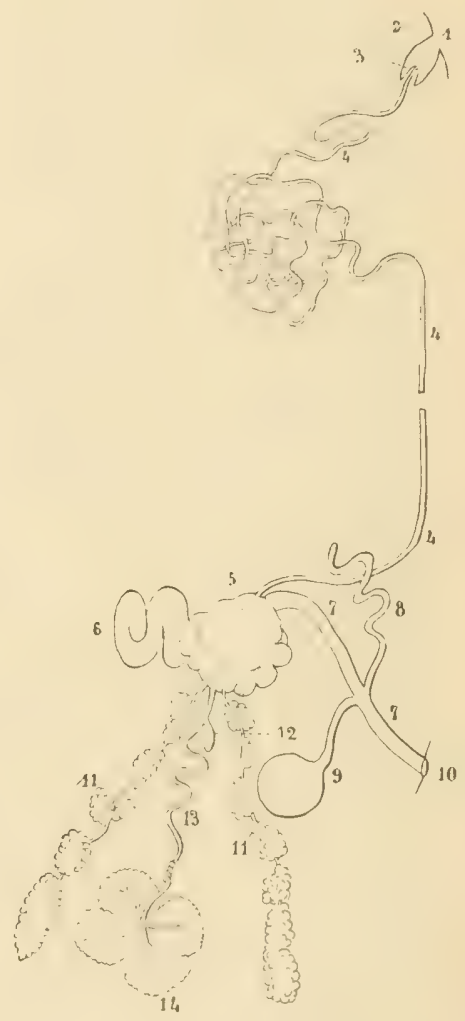

Fig. 572. Geschlechtsorgane von Lymnaeus stagnalis, nach BaudELoT. 1 Männliche Geschlechtsöffnung, 2 grosser Penisschlauch (Penisscheide), 3 Protractoren, 4 kleiner Penis schlauch, 5 Vas deferens, 6 Prostata, 7 abgeplattete Erweiterung des Vas deferens, 8 Zwittergang, 9 Zwitterdrüse, 10 Stück der Verdauungsdrüse (Leber), 11 Eiweissdrüse, 12 Nidamentaldrüse, 13 Uterus, 14 birnförmiger Körper, 15 Receptaculum seminis, 16 Vagina, 17 weibliche Geschlechtsöffnung.

Fig. 573. Geschlechtsorgane von Oncidium celticum, combinirt nach der Darstellung von JoYEUX-LAfFUIE; etwas schematisirt, das Vas deferens nur zum Theil gezeichnet. 1 Männliche Geschlechtsöffnung, 2 Penisscheide (Praeputium), 3 Penispapille (Eichel), 4 Vas deferens, 5 Uterus, die Samenrinne im Uterus durch punktirte Linien angedeutet, 6 Uterusblindsack, 7 Eileiter und Vagina, 8 Coecalanhang, 9 Receptaculum seminis, 10 weibliche Genitalöffnung, 11 Eiweissdrüsen, 12 Blindsäckchen des Zwitterganges 13, 14 Zwitterdrüse. 
einmündet. Im Innern des Uterus grenzen zwei vorspringende Falten eine Rinne ab. Legen sich die Ränder der beiden Falten aneinander, so wird die Rinne zu einem Rohr. Diese Rinne verläuft von der Einmündungsstelle des Zwitterganges bis zur Austrittsstelle des Samenleiters aus dem Uterus und dient nur zur Beförderung des Samens. Der übrige weitere Theil des Uterus dient als Eileiter und Eireservoir, er trägt einen grossen blindsackförmigen Anhang, und in ihn münden die Austührungsgënge der beiden vielfach gelappten Eiweissdrüsen.

Ein Vergleich mit Lymnaeus zeigt also, dass bei $\mathrm{O} n \mathrm{chidium}$ die Trennung der männlichen und weiblichen Leitungswege sich nicht so weit erstreckt, wie bei Lymnaeus, indem das Vas deferens im Uterustheil des Leitungsweges nur unvollkommen als Rinne gesondert ist. Die vollständige Trennung erfolgt hier, wie bei den Landpulmonaten, erst am Ende des Uterus. Der dünne Samenleiter (Vas deferens) tritt nach rechts in die Leibeswand ein, in welcher er der rechten Längsfurche zwischen Fuss und Rücken entlang nach vorn verläuft, um vorn im Körper wieder in die primäre Leibeshöhle einzutreten, in derselben sich in sehr zahlreiche Windungen zu legen und schliesslich in den Begattungsapparat einzutreten. Dieser besteht wie bei Lymnaeus aus einer grösseren ausstülpbaren Enderweiterung, in welche das Vas deferens in Form einer Papille (Eichel) vorragt. Durch Blutstauung wird diese als Penisscheide oder Praeputium bezeichnete Enderweiterung aus der Geschlechtsöffnung ansgestulpt, durch einen Retractor zurückgezogen. Bei anderen Onchidiumarten complicirt sich der Begattungsapparat durch das Auftreten einer accessorischen Penisdrüse und einer verschieden gestalteten knorpeligen Bewaffnung.

Der am Ende des Uterus vom Vas deferens sich trennende Eileiter ist zugleich auch V a ina. Er stellt ein einfaches Rohr dar, welches sich rechts neben dem After durch die weibliche Geschlechtsöffnung nach aussen öffnet. Ungefähr in der Mitte seiner Länge steht er mit dem stielfürmigen Ansführungsgang einer kugligen Blase, des R e ce p ta c ul u m seminis (Bursa copulatrix) und mit einem langen, drüsigen Coecala $h$ a $\mathrm{ng}$ in Verbindung.

III. Ein dritter Typus findet sich bei den Stylommatophoren unter den Pulmonaten, ferner bei allen Nudibranchiaten und einigen Tectibranchiern (z. B. Pleurobranchaea). A us der Zwitterdrüse entspringt ein Zwittergang, welcher sich wie beim zweiten Typus früher oder später in einen männlichen und in einen weiblichen Gang spaltet. Diese münden aber nicht mit getrennten äusseren Oeffnungen nach aussen, sondern vereinigen. sich wieder in einem gemeinsamen Atrium genitale oder einer Geschlechtskloake. Man kann sich diesen dritten Typus aus dem zweiten so entstanden denken, dass sich die männliche und weibliche Geschlechtsöffnung einander genähert und schliesslich in einander geöffnet haben.

Als Beispiele wähle ich Helix pomatia und Pleurobranchaea Meckelii.

Helix pomatia (Fig. 574). Aus der Zwitterdrüse entspringt ein zickzackförmig gewundener enger $\mathrm{Z}_{\mathrm{w}} \mathrm{ittergang}$, welcher in den krausenförmigen, langgestreckten "Ut e r u s" übergeht. Das gestreckte Band, welchem die gefaltete Uteruskrause der Länge nach aufsitzt, ist der Samenleitertheil, die Krause der weibliche Leitungstheil des sogenannten Uterus. Der Samenkanal ist aber in Wirklichkeit nur eine Rinne des 
Uterus, von dessen Hohlraum durch zwei gegenüberliegende vorspringende Falten, deren Ränder sich übereinander schieben, getrennt. Ein als Prostata betrachtetes drüsiges Längsband begleitet den Samenleitertheil. Da, wo der Zwittergang in den Uterus übergeht, mündet die ansehnliche zungenförmige Eiweissdrüse. Am Ende des Uterus trennen sich männlicher und weiblicher Leitungsweg vollkommen. Das dünne Vas deferens läuft in Windungen zum Begattungsapparat, der seinerseits in

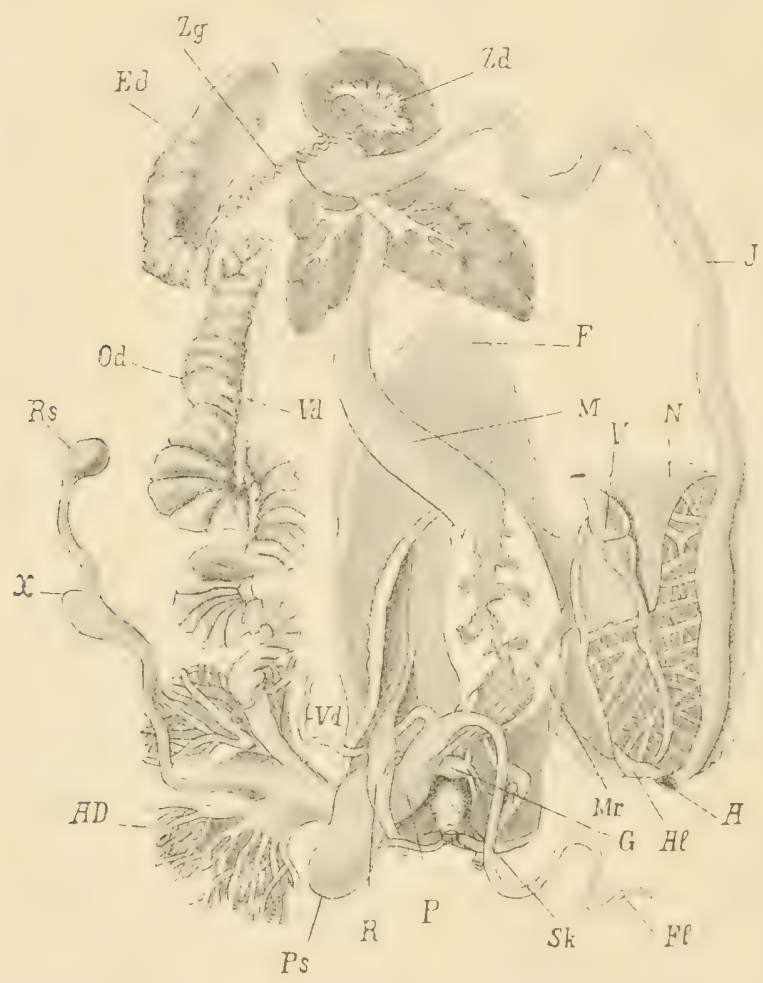

Fig. 574. Anatomie von Helix pomatia, nach Leuckart, Wandiafeln. Die Schale ist entfernt, der Mantel auf die linke Seite gelegt, die Organe des Eingeweidesackes und Kopfes isolirt und auseinandergelegt. Links (in der Figur) die Geschlechtsorgane. $L$ Verdauungsdrüse (Leber), Zd Zwitterdrüse, $J$ Darm, $N$ Niere, $V$ Herzkammer, $M$ Vormagen, $F$ Fuss, $A$ After, $A l$ Mantelrand in der Gegend des Athemloches, $M r$ Rückziehmuskel, $G$ Cerebralganglion, $F l$ Flagellum, Sk Schlundkopf (Pharynx), $P$ Penis, $R$ Fühlerretractor, $P S$ Pfeilsack, $A d$ fingerförmige Drüse, $Y d$ V as deferens, $X$ seitliche Ausbuchtung des Stieles des Receptaculum seminis $R s$, Od Eileitertheil des Uterus, Ed Eiweissdrüse, $Z g$ Zwittergang.

die Geschlechtskloake mündet. Der Begattungsapparat besteht aus dem vorstülpbaren Penis. Wo das Vas deferens in den Penis einmündet, trägt dieser einen langen, geisselförmigen, hohlen Anhang, das Flag elI um, dessen Drüsenepithel vielleicht die Substanz der Spermatophorenhülle liefert. An der nämlichen Stelle setzt sich ein Rückziehmuskel des Penis an. Der kurze Oviduct mündet mit einem erweiterten Abschnitt in die Geschlechtskloake. Anhangsorgane des erweiterten Abschnittes sind: 1) das langgestielte, dem Uterus eng anliegende, birnförmige 
Receptaculum seminis, dessen Stiel eine bisweilen rudimentäre seitliche Ausbuchtung aufweist; 2) zwei quastenförmige Organe, die fing erförmigen Drüsen, deren milchiges, Kalkconcretionen enthaltendes Secret wahrscheinlich zur Bildung der äusseren Eihülle beiträgt; 3 ) in unmittelbarster Nähe der Kloake der Pfeilsack, welcher einen spitzen, kalkigen Stab, den Liebespfeil, enthält, der als Reizmittel bei der Begattung in die Gewebe des mitcopulirenden Individums vorgestossen wird.

Fig. 575 .

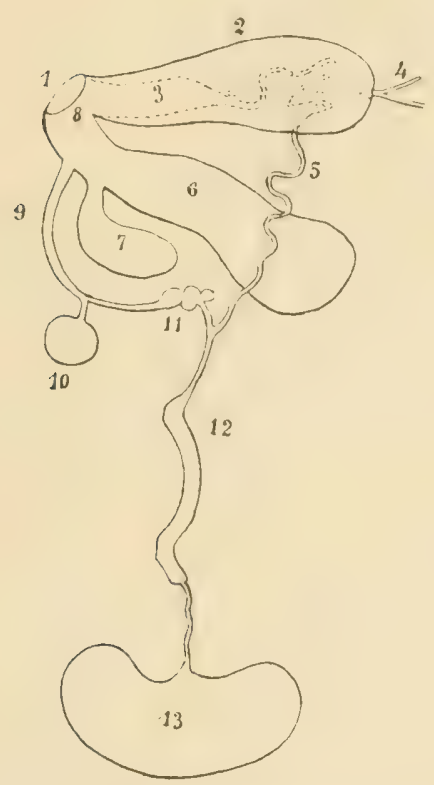

Fig. 576 .

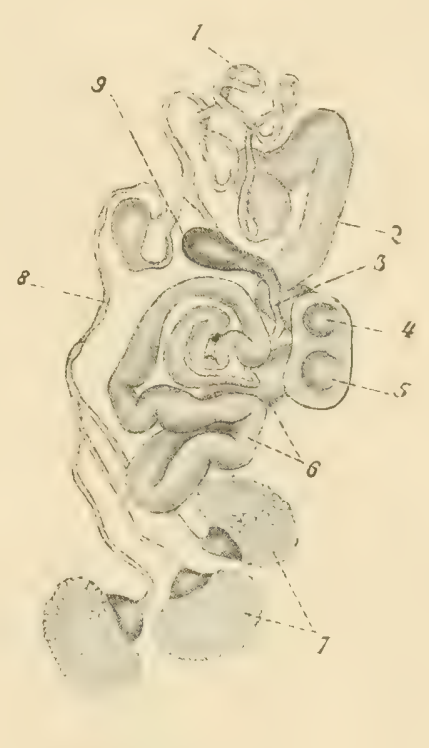

Fig. 575. Geschlechtsorgane von Pleurobranchaea Meckelii, nach Mazzarelur. 1 Gemeinsame Geschlechtsöffnung, 2 Penisscheide, 3 Penis, 4 Rückziehmuskel desselben, 5 Vas deferens, 6 Nidamentaldrüse, 7 Eiweissdrüse, 8 Geschlechtskloake, 9 Eileiter, 10 Receptaculum seminis, 11 Erweiterungen und Blindsack des Oviductes, 12 Zwittergang, 13 Zwitterdriise.

Fig. 576. Geschlechtsorgane von Phyllirhoë, nach SovlEyet. 1 Vas deferens, 2 Penis, 3 Oviduct, 4 männliche, 5 weibliche Geschlechtsöffnung, 6 Vagina, 7 Zwitterdrüse, 8 Zwittergang, 9 Receptaculum seminis.

Die gemeinsame äussere Geschlechtsöffnung liegt in der Nackengegend hinter dem rechten Augententakel.

Pleurobranchaea Meckelii (Fig. 575). Der aus der Zwitterdrüse entspringende $\mathrm{Z}$ wittergang bildet in seinem Verlaufe eine langgestreckte Erweiterung (Ampulle) und theilt sich dann in den männlichen und in den weiblichen Leitungsweg. Das Vas deferens verläuft in Windungen zur Penisscheide, tritt in dieselbe ein, windet sich in ihr fast nach Art einer Uhrspirale auf und bildet dann die als Penis bezeichnete ausstülpbare Erweiterung, die durch einen Rückziehmuskel eingestülpt werden kann. Der Oviduct nimmt einen kürzeren Verlauf, in welchem er den kurzen Austührungsgang eines kugeligen Receptaculum seminis aufnimmt. Der erweiterte, mit dem Penis in die Genitalkloake einmündende Endabschnitt des Oviductes (Vagina) 
empfängt den Ausführungsgang der Eiweissdrüse und der $\mathrm{Nida}$ mentaldrüse (Schalendruse, Schleimdrüse), welche letztere als das. Homologon der fingerförmigen Drüse von Helix betrachtet wird.

Die Leitungswege der $\mathrm{Nudibranchier}$ stimmen im Grossen und Ganzen mit denen von Pleurobranchaea überein. Im Einzelnen herrscht freilich eine unerschöpfliche Mannigfaltigkeit. Fast immer vereinigen sich die männlichen und weiblichen Leitungswege schliesslich im Grunde einer Genitalkloake, welche oft auf einer Papille vorn auf der rechten Seite liegt. Selten sind weibliche und männliche Oeffnung getrennt, liegen dann aber dicht nebeneinander. Der Penis ist oft und in mannigfaltiger Weise bewaffnet. Wir geben die Abbildung des Geschlechtsapparates von Phyllirhoë (Fig. 576). Für das Verständniss genügt die Figurenerklärung.

Die wichtige Frage nach dem gegenseitigen Verhältnisse der 3 Typen ron Leitungswegen der Geschlechtsproducte bei den hermaphroditischen Schnecken ist vielfach discutirt, aber nicht gelöst worden. Auch die ontogenetischen Untersuchungen haben bis jetzt noch zu keinem sicheren Resultate geführt. Man weiss also noch nicht, ob der einheitliche hermaphroditische Gang durch Verschmelzung getrennter männlicher und weiblicher Gänge, oder ob der männliche und weil)liche Gang durch Spaltung eines ursprünglich einheitlichen hermaphroditischen Ganges entstanden ist. Die Schwierigkeit ist um so grösser, als die genetische Deutung der Zwitterdriise unsicher ist.

Die Begattung ist bei den hermaphroditischen Gasteropoden eine gegenseitige. Doch ist es sicher, dass wenigstens bei Pulmonaten bei ausbleibender Begattung Selbstbefruchtung eintreten kann. Der Zwittergang trägt nämlich nicht selten ein oder zwei seitliche Blindsäckchen, sogenannte Samenblasen oder Vesiculae seminales, in welchen das eigene Sperma aufgespeichert wird und bei ausbleibender Fremdbefruchtung zur Befruchtung der eigenen Eier verwendet werden kann. Eier und Sperma werden häufig nicht zu gleicher Zeit reif.

2) Cephalopoda. Obschon die Gonade bei allen heute lebenden Cephalopoden mpaar ist, so sind doch die Leitungswege der Geschlechtsproducte ursprünglich in beiden Geschlechtern prarig. Paarig (in einem. Paar vorhanden) sind die Geschlechtsleiter im weiblichen Geschlecht bei Nautilus, den Oegopsiden und Octopoden; im männlichen Geschlecht kommt ein doppelter Samenleiter nur bei Nautilus und bei Philonexis (Tremoctopus) carenae vor. Bei Nautilus, welcher also in beiden Geschlechtern paarige Leitungswege besitzt, ist in beiden Geschlechtern der linke rudimentär und fungirt nicht mehr als solcher. Er stellt die sogenannte "birnförmige Blase" dar, welche einerseits an das Herz und das Unterende der Gonade befestigt ist, andererseits an der Basis der unteren Kieme in die Mantelhöhle mündet.

Wo nur ein Leitungsweg vorhanden ist, so ist es in beiden Geschlechtern der linksseitige, so bei Loligo, Sepia, Sepiola, Rossia, Sepioteuthis, Chiroteuthis, Cirrhoteuthis etc.

Die Geschlechtsleiter entspringen an der Wand der als Theil der sccundiren Leibeshöhle erkannten Gonadenhöhle (Bauchfelltasche, Genitalkapsel) und münden in die Mantelhöhle zu Seiten des Afters zwischen Nephridialöffnung und Kiemenbasis. 
Männliche Leitungswege, Samenleiter. Am männlichen Leitungsweg können wir da, wo er, wie z. B. bei Sepia (Fig. 577), sich stärker complicirt, 4 Hauptabschnitte unterscheiden. Aus der Hodenkapsel entspringt ein in dicht aneinander liegenden Windungen verlaufendes $\mathrm{V}$ as deferens. Dieses erweitert sich zu einer Samenblase (Vesicula sem in a lis), deren ausserordentlich stark entwickeltes und reich gefaltetes

Fig. 577 .

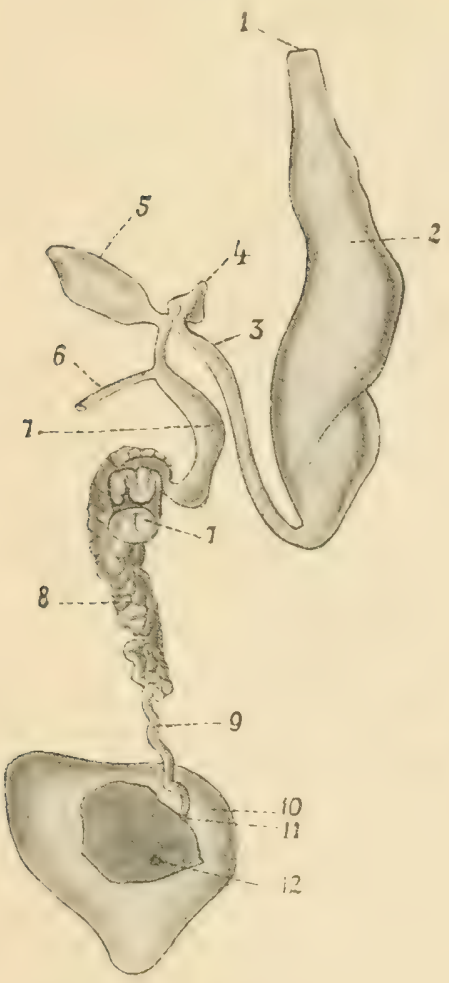

Fig. 578 .

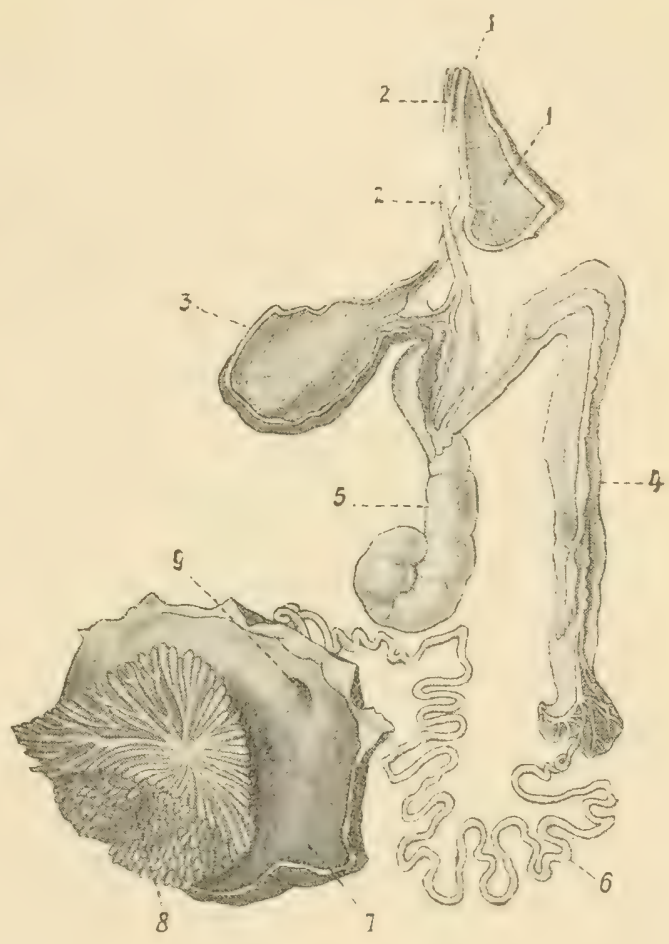

Fig. 577. Männliche Geschlechtsorgane von Sepia officinalis. 1 Geschlechtsöffnung, 2 Spermatophorensack, 3 Vas efferens, 4 Blindsack, 5 Prostata, 6 Kanälchen, welches in den den männlichen Leitungsweg umgebenden Abschnitt der Leibeshöble mündet, 7 Vesicula seminalis, 8 und 9 Vas deferens, 10 Gonade, ein Stück ihrer hinteren Wand weggeschnitten; man blickt in die Gonadenhöhle und erkennt an ihrer vorderen Wand die Mündung des männlichen Keimkörpers, 11 Mündung des Samenleiters in die Gonadenhöhle.

Fig. 578. Männliche Geschlechtsorgane von Octopus vulgaris, nach Cuvier. 1 Penis, 2 Muskel, durchschnitten, 3 Spermatophorensack, 4 Vesicula seminalis, 5 Prostata, 6 Vas deferens, 7 geöffneter Gonadensack, an dessen vorderer Wand die Hodenkanälchen des Keimkörpers 8 sichtbar sind, 9 Mündung des Samenleiters in den Gonadensack.

Drüsmepithel eine wichtige Rolle bei der Spermatophorenbildung spielt. Die Samenblase setzt sich als dünnes $\mathrm{V}$ as efferens zum letzten Abschnitt, der Spermatophorentasche (NEEDHAM'sche Tasche) fort, welche als Reservoir für die Spermatophoren dient. Sie ist von flaschenförmiger Gestalt und ragt mit dem dem Halse einer Flasche entsprechenden Theile, an dessen Ende sich die männliche Geschlechts- 
öffnung befindet, frei in die Mantelhöhle vor. In das Vas efferens münden 2 Anhangsorgane: 1) die Prostata, eine eiförmige Drüse mit kurzem Ausführungsgang; und 2) ein einfacher seitlicher, nicht drüsiger Blindsack. Die Prostata betheiligt sich, wie die Vesicula seminalis, an der Bildung der Spermatophoren. Prostata, Blindsack und Vesicula seminalis bilden in natürlicher Lage ein Convolut, welches in einem besonderen Abschnitt der secundären Leibeshöhle, in einer besonderen „Bauchfelltasche" liegt. Merkwürdigerweise steht das Vas efferens mit dieser Bauchfelltasche durch ein euges Röhrchen in offener Communication.

Verglichen mit Sepia, unterscheidet sich der männliche ausführende Apparat von Octopus (Fig. 578) vorwiegend durch das Fehlen eines gesonderten Vas efferens. Die lange Vesicula seminalis mündet in die mächtige Prostata nahe der Stelle, wo diese selbst in den Spermatophorensack sich öffnet. Diese Stelle liegt nicht im Grunde, sondern am Halse des Spermatophorensackes, da, wo sich dieser zu dem langen, fleischigen, mit seinem Endstück in die Mantelhöhle vorragenden Penis auszieht. Der Penis ist mit einem seitlichen Blindsack ausgestattet.

Es wurde oben erwähnt, dass, soviel man bis jetzt weiss, nur zwei lebende Cephalopoden parrige münnliche Leitungswege besitzeu, nämlich Nautilus und Philonexis carenae. Bei Nautilus ist der linke rudimentär. $\mathrm{Ob}$ aber die beiden Samenleiter von Philonexis carenae den beiden muthmaasslich den Cephalopoden ursprünglich zukommenden entsprechen, ist sehr zweifelhaft. Die beiden sehr verschieden gebauten Vasa deferentia von Philonexis, die aus der Hodenkapsel entspringen, vereinigen sich nämlich später wieder. Ausserdem liegen beide linksseitig. Auffallend ist auch, dass der Spermatophorensack eine doppelte Oeffnung hat, dass also die Geschlechtsöffnung doppelt ist.

Weibliche Geschlechtsorgane. Sepia (Fig. 579). Der complicirte ausführende Aplarat besteht aus zwei vollständig voneinander getrennten und gesondert in die Mantelhöhle mündenden Partien: 1) dem unpaaren (linksseitigen) Oviduct, dessen Lage und Mündung der des Samenleiters beim Männchen entspricht, und 2) den Nidamentaldrüs en. Die beiden grossen Nidamentaldrüisen liegen als birnförmige Organe dicht unter der Körperhaut im hinteren Theil des Eingeweidesackes, symmetrisch zu beiden Seiten des hinter ihnen heruntersteigenden Ausführungsganges des Tintenbeutels. Sie münden an ihrer ventralen Spitze in die Mantelhöhle. Jeder Drüsensack erscheint in symmetrischer Weise durch hintereinander liegende, von beiden Seiten vorspringende Drüsenlamellen gefächert. Die Fächer zwischen den Drüsenlamellen öffnen sich in den centralen, spaltförmigen Ausführungsgang. Diese Structur spiegelt sich auch in dem äusseren Aussehen einer jeden Drüse wieder. Ausser diesen beiden Nidamentaldrüsen existirt noch eine accessorische $\mathrm{Nida}$ mentaldrüse, welche unter und vor den ersteren liegt. Sie ist ziegelroth gefärbt und besteht aus einem Mittelstück und zwei Seitenlappen. Sie wird aus zahlreichen geschlängelten Drüsenkanälchen gebildet, die sich in einem Drüsenfeld in die Mantelhöhle öffnen, welches zwischen dem Mittel- und Seitenlappen in Form einer Bucht eingestülpt ist. Da in dieser Bucht jederseits auch die Mündung der grossen Nidamentaldrüse liegt, so vermischt sich in ihr das Secret beider Drüsenarten.

Der aus dem Ovarialsack entspringende Oviduct ist zur Zeit der Brunst mit Eiern so angefüllt, dass er hauptsächlich in seinem sich in den Ovarialsack öffnenden Theil weit ausgedehnt ist. Bevor er sich an derselben Stelle und in ähnlicher Weise, wie der Samenleiter im männ- 
lichen Geschlecht, durch ein frei in die Mantelhöhle rorragendes Stück nach aussen öffnet, steht or mit einer zweilappigen oder herzförmigen Anhangsdrüse (Eileiterdrüse) in Verbindung, welche die Structur der Nidamentaldrïsen wiederholt. Auch der Endabschnitt (von der Eileiterdrüse bis zur Mündung des Oviductes) ist drüsig, indem zwei symmetrische Reihen von senkrechten Drüsenblättchen von seiner Wand in sein Lumen vorragen.

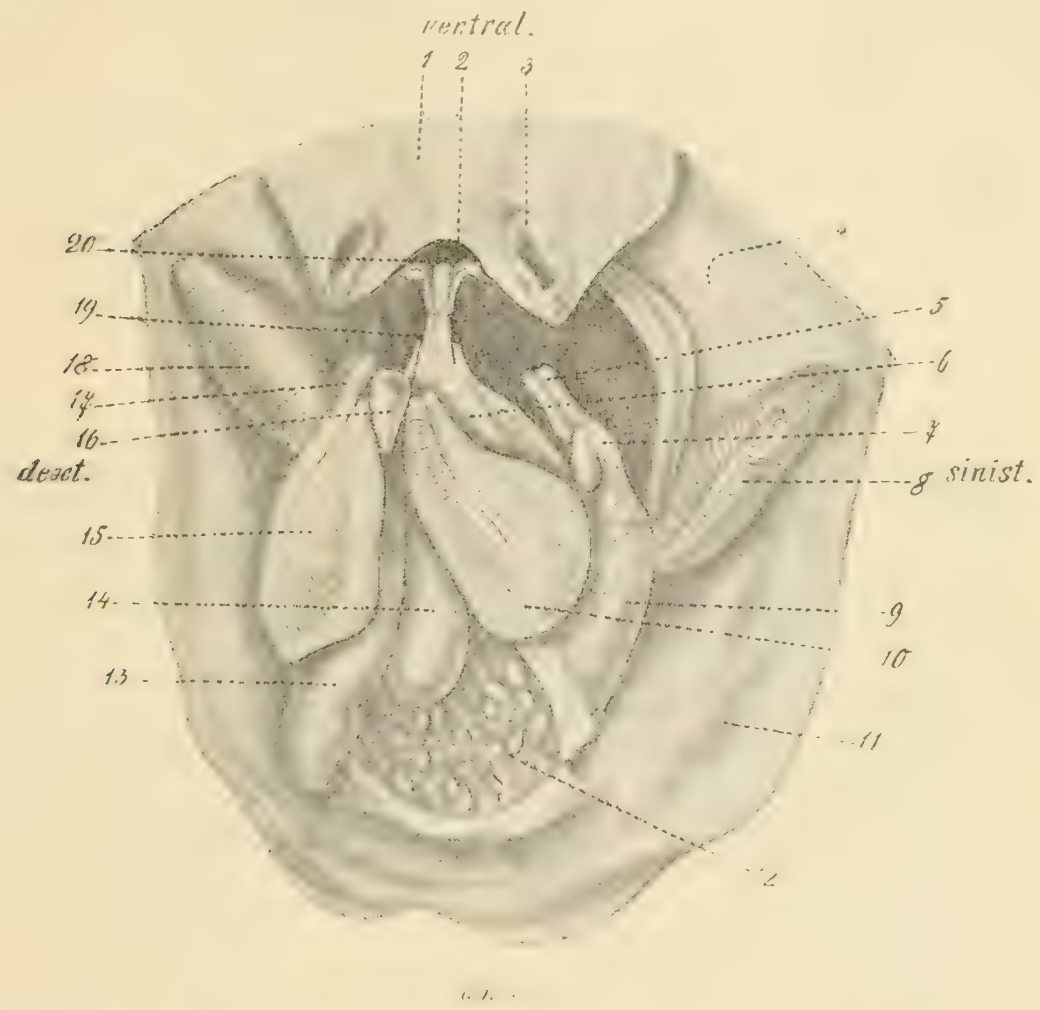

Fig. 579. Weibliche Geschlechtsorgane von Sepia officinalis, im Wesentlichen nach Brock. Die Mantelhöble ist geöffnet, das hintere Integument des Eingeweidesackes wegpräparirt, der Tintenbeutel etwas bei Seite gelegt, der Oviduct blossgelegt. Ansicht des blossgelegten Organcomplexes von hinten. 1 Trichter, 2 Rand der dorsalen Trichteröffnung, 3 Schliessknorpel, 4 linkes Ganglion stellare, 5 drüsiger Endabschnitt des Oviductes mit weiblicher Geschlechtsöffnung, 6 linker Seitenlappen der accessorischen Nidamentaldrüse, 7 Eileiterdrüse, 8 linke Kieme, 9 Oviduct, mit durchschimmernden Eiern erfüllt, 10 linke Nidamentaldrüse, 11 Mantel, 12 Ovarialsack, von hinten geöffnet, man sieht an seiner vorderen Wand die gestielten Ovarialeier, 13 Tintenbeutel (Pigmentdrüse), 14 Magen, 15 rechte Nidamentaldrüse, 16 Mittelstück der accessorischen Nidamentaldrüse, 17 rechter Seitenlappen der accessorischen Nidamentaldrüse, 18 rechte Kieme, 19 rechte Nierenöffnung, 20 After.

Die Secrete der Nidamentaldrüsen, accessorischen Nidamentaldrüsen und Eileiterdrüsen liefern die äusseren Eihüllen, mit welchen die austretenden Ovarialeier umhiillt werden. 
Um nun noch die ganze Klasse der Cephalopoden kurz zu berücksichtigen, möge erwähnt werden, dass $\mathrm{Nidamentaldrüsen} \mathrm{vorkommen:}$ 1) bei den Dibranchiaten (Nautilus); 2) unter den Decapoden bei den Myopsiden (Sepia, Sepiola, Rossia, Loligo, Sepioteuthis etc.), bei einigen Oigopsiden (Ommastrephes, Onychoteuthis, Thysanoteuthis). Sie fehlen bei den Octopoden und einem Theil der Oigopsiden (Enoploteuthis, Chiroteuthis, Owenia).

$\mathrm{Nautilus}$ unterscheidet sich von allen anderen lebenden Cephalopoden dadurch, dass er 1) nur eine Nidamentaldrüse besitzt, und 2) dass sie nicht im Eingeweidesack liegt, sondern im Mantel.

Accessorische Nidamentaldrüsen kommen nur bei den Myopsiden vor. Die beiden Drüsen sind entweder gesondert (Rossia, Loligo, Sepioteuthis), oder mit einander verschmolzen (Sepia, Sepiola).

Eileiterdrüsen sind bei allen Cephalopoden vorhanden, in wechselnder Lage und mit mannigfaltiger Modification im Bau.

Auch als Receptacula seminis fungirende Ausstülpungen des Oviductes kommen gelegentlich vor (Tremoctopus, Parasira).

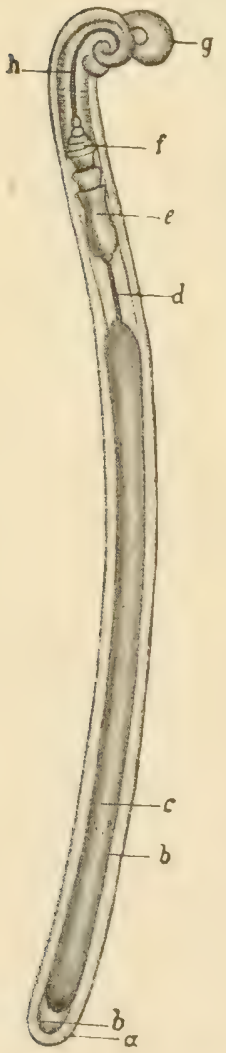

Bei allen Cephalopoden werden gewisse Quantitäten von Spermatozoen in äusserst complicirte Hüllen, sogenannte Spermat o phoren, gewickelt. Die Substanz dieser grossen, fadenförmigen Spermatophoren wird in der Prostata und Vesicula seminalis geliefert. Welches aber der Mechanismus ist, durch welchen ein so complicirtes Etuis, wie die Spermatophore eines ist, hergestellt wird, ist zur Zeit noch unermittelt. Die Spermatophoren platzen bei Berührung, oder wenn sie ins Wasser gelangen, an ganz bestimmten Stellen und spritzen ihren Spermatozoeninhalt heraus. Zur Zeit der Brunst ist die Spermatophorentasche dicht erfüllt mit Spermatophoren. Bei Philonexis carenae wird jedoch eine einzige, sehr lange Spermatophore erzeugt.

c) Die Begattungsapparate. Hectocotylie der Cephalopoden. Die Begattungsapparate der Gasteropoda und der in die Mantelhöhle vorragende Penis gewisser Cephalopoden sind schon im vorhergehenden Abschnitt behandelt worden.

Wir wollen hier eine der merkwürdigsten und die räthselhafteste Erscheinung innerhalb der Cephalopodenklasse besprechen, die Hectocotylie. Diese Erscheinung besteht in der Umwandlung eines Mundarmes des Männchens zu einem Begattungsorgan und Spermatophorenträger, dem sogenannten Hectocotylus, welcher sich bei der Begattung vollständig loslöst und in die Mantelhöhle des Weibchens gelangt.

Fig. 580. Spermatophore ron Sepia, nach MrLne Edwards, a Aeusseres Etuis, $b$ inneres Etuis, $c$ Spermatozoensack, $d, e, f, h, g$ verschiedene Theile des Ejaculationsapparates. 
Die typische Hectocotylie (Fig. 581) ist beschränkt auf die Octopodengattungen Argonauta, Philonexis und Tremoctopus., Der umgewandelte Arm ist bei Tremoctopus und Philonexis (Parasira) der dritte rechte, bei Argonauta der dritte linke. Er ist anfänglich in einem aussen pigmentirten Sückchen eingeschlossen (Fig. 581 A, welches durch Platzen den Arm frei werden lässt, der dann seine besondere Gestalt deutlich erkennen lässt (B). Die Falten, welche das Säckchen bildeten, schlagen sich zurück und bilden nun eine neue, die Spermatophoren aufnehmende Tasche, welche nun innen pigmentirt ist. Eine Oeffnung führt aus dieser Tasche in eine Samenblase, die im Innern des Hectocotylus liegt und sich in einen dünnen, langen Ausführungsgang fortsetzt, welcher den Arm seiner ganzen Länge nach durchzieht und an seinem Ende nach aussen mündet. Das Endstück des Armes ist zu einem langen, fadenförmigen Penis umgewandelt, welcher anfangs ebenso in einem besonderen Säckchen eingeschlossen liegt, wie der ganze Arm in der Hectocotylustasche. Bei ausgestülptem Penis bleibt das Säckchen als ein Anhang an seiner Basis zurück.
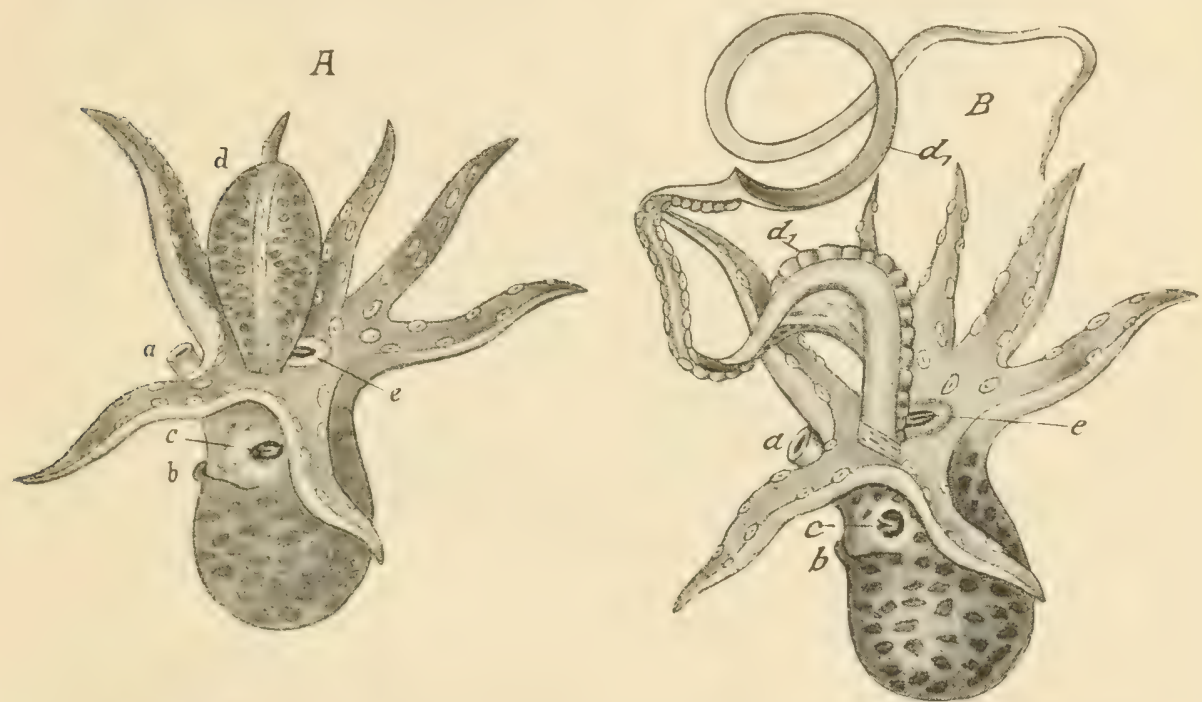

Fig. 581. Männchen von Argonauta argo, nach H. MülLER (Weibchen, Fig. 419 u. 420). $\boldsymbol{A}$ Mit in das Säckchen $\boldsymbol{d}$ eingeschlossenem Hectocotylus. $\boldsymbol{B}$ Mit freiem Hectocotylus. a Trichter, $b$ Rand der Mantelfalte, $c$ linkes Auge, $d$ Säckcben, $d_{1}$ Hectocotylus, $e$ Mund.

Die Spermatophoren können aus der inneu pigmentirten Samentasche in die Samenblase gelangen und von da durch den Ausführungsgang, welcher an der Spitze des Penis mündet, entleert werden.

Es ist wahrscheinlich, dass die Hectocotylus-tragenden Cephalopoden bei der Begattung sich Mund gegen Mund mit ihren Armen umfassen und dass sich dabei der Hectocotylus ablöst und in irgend einer Weise in die Mantelhöhle des Weibchens eindringt. Man findet wenigstens häufig losgelöste Hectocotyli, bis zu 4 Stück zugleich, in der Mantelhöhle der Weibchen.

Unerklärt ist: 1) in welcher speciellen Weise der Hectocotylus die Eier des Weibchens befruchtet, und 2) wie die Spermatophoren in den Hectocotylus gelangen. 
Abgesehen von dem durch die Ausbildung des Hectocotylus bedingten geschlechtlichen Dimorphismus, sind Männchen und Weibchen bei den erwähnten Gattungen auch sonst verschieden. Die Männchen sind viel kleiner, und bei Argonauta ist nur das Weibchen beschalt.

Es ist höchst wahrscheinlich, dass der abgelöste Hectocotylus wieder regenerirt werden kann.

Während nun nur bei den drei erwähnten Gattungen ein ächter, sich Ioslösender Hectocotylus zur Ausbildung gelangt, so ist doch für alle übrigen Cephalopoden (auch für Nautilus, vergl. p. 693) der Nachweis erbracht worden, dass im männlichen Geschlecht immer ein bestimmter Arm oder Theil des Kopffusses in irgend einer Weise modificirt ist,

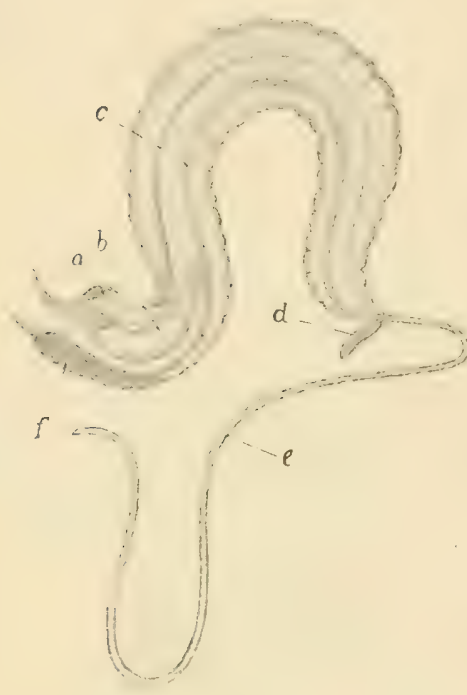
irgend welche, oft wenig auffallende Merkmale besitzt, die den anderen Armen nicht zukommen. Man nennt nun den betreffenden Arm den hectocotylisirten Arm. Wenn auch der Gedanke nahe liegt, dass dieser Arm bei der Begattung irgend eine Rolle spiele, so ist diese Rolle zur Zeit doch ganz unerklärt, und es handelt sich eben nur um eine Vermuthung. Ja, man kann. sich nicht einmal vorstellen, in welcher Weise z. B. bei Sepia und Nautilus der hectocotylisirte Arm bei der Begattung sich bethätigen könnte. Das constante Auftreten eines hectocotylisirten Armes

Fig. 582. Hectocotylus von Philonexis (Octopus) carenae, nach LeUckART. a Spermatophorentasche, $b$ Samenblase, $c$ Ausführungsgang der Samenblase, $d$ Anhang $=$ Rest des Penissäckchens, $e$ Penis, $f$ Saugnäpfe.

ist um so räthselhafter, als durchaus nicht immer derselbe Arm hectocotylisirt ist. Bei den Octopoden ist es im Allgemeinen der dritte der rechten Seite, doch bei dem Subgenus Scaeurgus von Octopus und bei Argonauta der dritte der linken Seite. Bei den Decapoden ist der hectocotylisirte Arm meist der vierte der linken Seite, doch kann es im Genus Enoploteuthis auch der vierte rechte und sogar bei einer und derselben Ommastrephesart bald der vierte der linken, bald der vierte der rechten Seite sein. Bei Sepiola und Rossia ist der erste Arm hectocotylisirt. Schliesslich können sogar die beiden Arme eines Paares hectocotylisirt sein, so bei Idiosepius und Spirula die des vierten, bei Rossia die des ersten Paares.

Der Unterschied in der Grösse, welcher zwischen Männchen und Weibchen der mit einem ächten Hectocotylus ausgestatteten Formen erwähnt wurde, zeigt sich, doch nicht in demselben Maasse, auch bei manchen anderen Cephalopoden. Das Männchen ist etwas kleiner als das Weibchen. 


\section{Parasitische Schnecken.}

1) Thyca ectoconcha (Fig. 583) heisst eine zu den Prosobranchiern gehörende Schnecke, welche an einem Seestern, Linckia multiforis, schmarotzt. Die Hauptzüge ihrer Organisation werden durch den in Fig. 583 dargestellten Längsschnitt, in welchen verschiedene seitlich liegende Organe eingezeichnet sind, illustrirt. Die Schneckenorganisation ist durch den Parasitismus noch wenig beeinflusst. Das Thier besitzt eine Schale, deren Gestalt an eine phrygische Mütze erinnert. In der Mantelhöhle liegt die Kieme. Auch Darm- und Nervensystem bieten nichts Auffallendes. Augen und Gehörorgane sind vorhanden. Es existirt eine kurze, aber kräftige Schnauze mit musculösem Schlundkopf, welche zwischen den Kalkstücken des Integumentes im Gewebe des Seesternes steckt. Eine Radula fehlt. Die Basis der Schnauze wird umgeben von einer musculösen Scheibe, die aus einem vorderen und einem hinteren Theile besteht. Diese Scheibe, der sogenannte Scheinfuss, ist das Haftorgan, vermittelst dessen die Schnecke dem Integument des Wohnthieres so fest aufsitzt, dass sie nur gewaltsam und nicht ohne zu zerbrechen losgetrennt werden kann. Es existirt ein Fussrudiment $(f s)$ ohne Deckel.

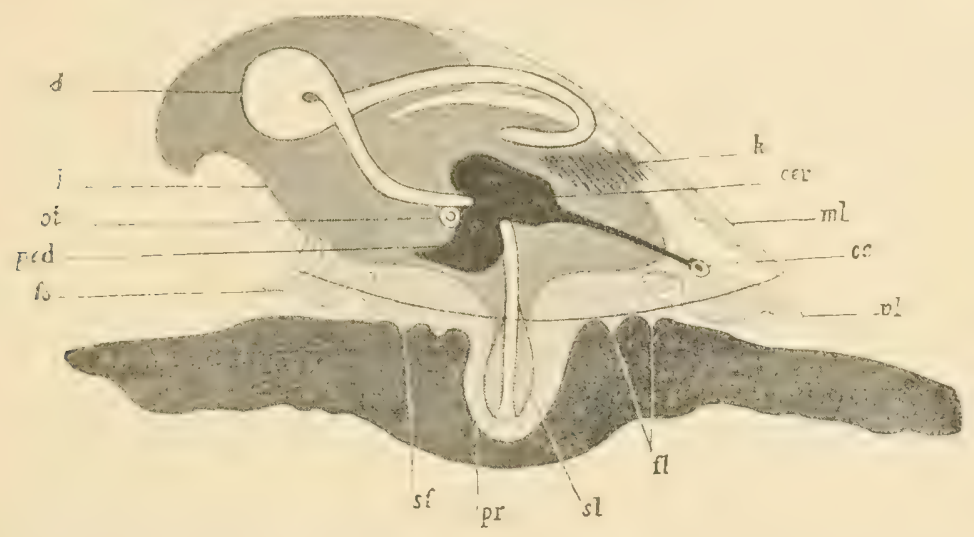

Fig. 583. Längsschnitt durch Thyca ectoconcha, nach P. und F. SARAsin. Es sind auch einige nicht in der Schnittebene liegende Organe eingetragen. cer Cerebralganglien, $d$ Darm, $f$ Falten, $f \delta$ Fuss, $k$ Kieme, $l$ Leber, $m l$ Mantel, oc Auge, ot Otocyste, ped Pedalganglien, $p r$ Proboscis, $s f$ Scheinfuss, sl Schlundkopf, $v l$ Kopffalte.

2) Etwas stärker modificirt ist die Schneckenorganisation bei Stilifer Linckiae (Fig. 584), welcher auf der männlichen Seesternart schmarotzt. Der Parasit steckt ganz iu der Kalkschicht des Integumentes des Wirthes, an welchem er pathologische kugelige Anschwellungen hervorruft und dessen Peritoneum er gegen die Leibeshöhle zu kugelig vortreibt. Mit der Aussenwelt communicirt die Schnecke nur durch eine kleine Oeffnung an der Spitze der Anschwellung. Die so im Integumente des Wirthes festsitzende Schnecke ist allseitig von einer flejschigen Hïlle $(\mathrm{sm})$ wie von einem Sacke umschlossen. Diese Hülle ist nur an der Stelle, wo die Spitze der rechtsgewundenen Schale liegt, von einer Oeffnung durchbrochen, die der Lage nach der oben erwähnten Oeffnung an der Spitze der pathologischen Auftreibung entspricht. Die Hülle wird als Scheinmantel 
bezeichnet und entspricht morphologisch dem stark vergrösserten und auf die Schale zurückgeschlagenen Scheinfusse von Thyca. Daneben existiren ein ächter Mantel, eine Kieme, ein rudimentärer, deckelloser Fuss, Augen, Gehörorgane und ein typisches Prosobranchiernervensystem. Die Ausbildung des sonderbaren Scheinmantels hat offenbar die Bedeutung, dass, trotzdem die Schnecke tief im Integumente des Wohnthieres steckt,

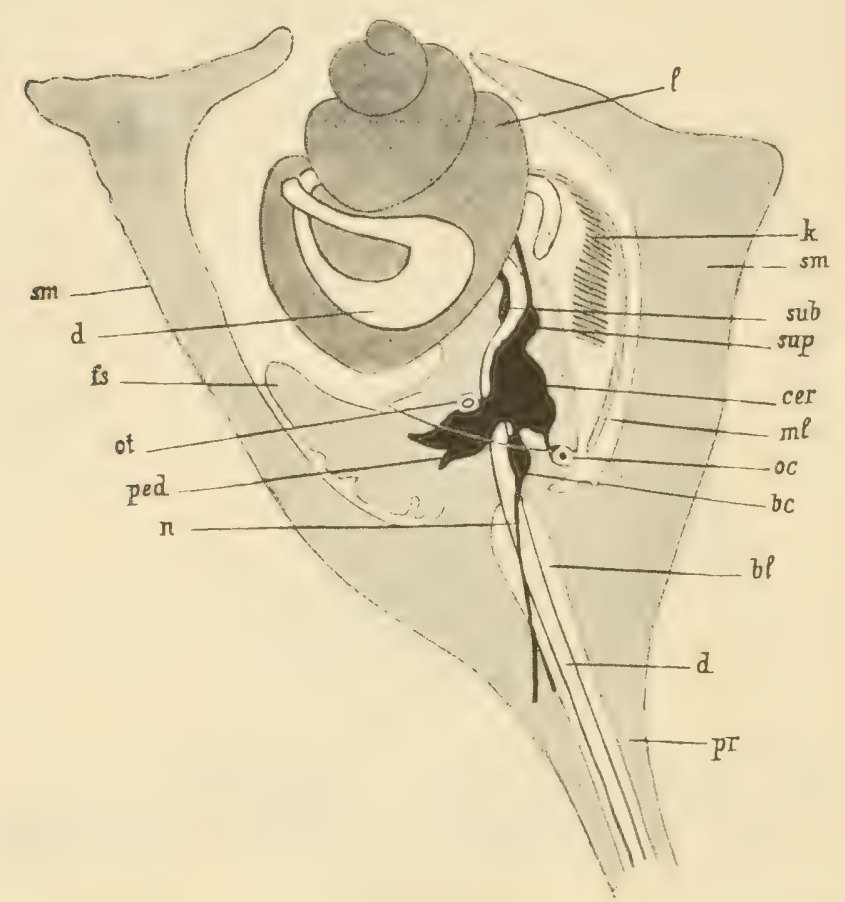

Fig. 584. Längsschnitt durch Stilifer Linckiae, nach P. und F. SARAsin. $b c$ Buccalganglien, $b l$ Blutraum, cer Cerebralganglien, $d$ Darm, $f s$ Fuss, $k$ Kieme, $l$ Leber, $m l$ Mantel, $n$ Rüsselnerv, oc Auge, ot Otocyste, ped Pedalganglien, $p r$ Proboscis, sm Scheinmantel, sub Subintestinalganglion, sup Supraintestinalganglion.

doch eine Communication mit der Aussenwelt erhalten bleibt. Athemwasser kann in die Athemhöhle gelangen und wieder abfliessen; Fäcalmassen und Geschlechtsproducte, vielleicht Larven, können in den vom Scheinmantel umschlossenen Raum gelangen und von da durch dessen Oeffnung nach aussen entleert werden. Die Geschlechter sind getrennt. Die Schnauze ist zu einem sehr langen, rüsselartigen Rohr verlängert, welches in die blutreichen Gewebe des Seesternintegumentes eindringt und aus ihnen die der Schnecke nöthige Nahrung bezieht. Schlundkopf und Radula fehlen.

3) Sind die beiden bis jetzt besprochenen Parasiten typische Schnecken und als solche wenigstens bei genauerer Untersuchung leicht kenntlich, so ist bei zwei weiteren Parasitenarten die Schneckenorganisation so stark modificirt, dass man sie schwerlich für Schnecken oder überhaupt 
für Mollusken halten würde, wenn nicht wenigstens von der einen Form festgestellt wäre, dass ihre Larven Schneckenlarven sind. Die Organisation dieser beiden Parasiten ist bei der Unkenntniss oder unvollständigen Kenntniss ihrer Entwickelung und bei dem Fehlen zur typischen Schneckenorganisation überleitender Zwischenformen schwer zu entziffern.
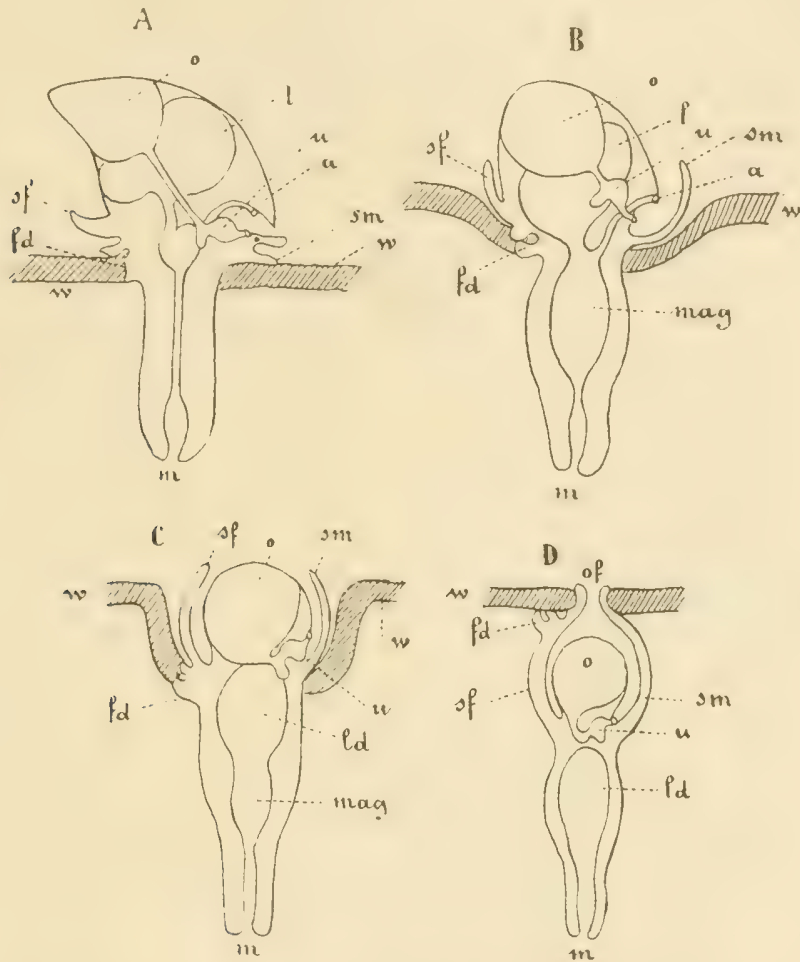

Fig. 585. A, $\boldsymbol{B}, \boldsymbol{C}, \boldsymbol{D}$ Hypothetische $\mathrm{Zwischenstadien} \mathrm{zwischen} \mathrm{Thyca} \mathrm{und} \mathrm{Stilifer}$ einerseits und Entocolax (Fig. 586) andererseits, nach Schiemenz. a After, $d$ Darm, $f d$ Fussdrüse, $l$ Leber (Verdauungsdrüse), $l d$ Leberdarm, $m$ Mund, mag Magen, o Ovarium, of Oeffnung des Scheinmantels, sf Scheinfuss, $s m$ Scheinmantel, $u$ Uterus, $w$ Körperwand des Wirthes.

Entocolax Ludwigii lebt endoparasitisch in der Leibeshöhle oiner Holothurie (Myriotrochus Rinkii), mit dem einen Ende des wurmförmigen Körpers an der Leibeswand der Holothurie befestigt. Die in Fig. 586 schematisch dargestellte Organisation wurde wohl in zutreffender Weise durch Annahme einiger hypothetischer Zwischenstadien interpretirt, durch welche eine Thy c a-oder Stilifer-ähnliche Schnecke, zum Endoparasitismus übergehend, zu einer Entocolax-ähnlichen Form würde. Fig. 585 A zeigt das erste Stadium, das noch lebhaft an Thyca erinnert und noch ectoparasitisch ist, Fig. 585 B, C, D sind weitere Stadien. In dem Maasse, als die Schnecke endoparasitisch wird und die Beziehungen zur Aussenwelt aufgiebt, verschwinden die Sinnesorgane, die Schale, die Mantelhöhle mit der Kieme. Der Magen bildet sich, als besonderer Abschnitt des Darmes, zurück, die Verdauungsdrüse (Leber) wird zu einem 
einfachen, unverzweigten Sack des Darmes, welcher seinen Enddarm und After einbüsst. Jeglicher Zerkleinerungsapparat am Eingang des Darmes wird entbehrlich. Der Scheinmantel wird immer grösser und umhüllt den immer kleiner und rudimentär werdenden Eingeweidesack, weIcher schliesslich nur noch die Geschlechtsorgane heherbergt. Auf Stadium D ragt das ganze Thier schon frei in die Leibeshöhle des Wirthes vor, befestigt an seiner Leileswand durch einen verlagerten Theil des Scheinfusses und mit der Aussenwelt nur noch durch die Oeffnung des Scheinmantels communicirend. Wird auch diese letzte Beziehung zur Aussenwelt aufgegeben, d. h. rückt auch der ganze Scheinmantel mit seiner Oeffnung in die Leibeshöhle des Wirthes, so haben wir eine Form vor uns, welche dem. endoparasitischen Entocolax Ludwigii (Fig. 586) entspricht. Bei

Fig. 586 .

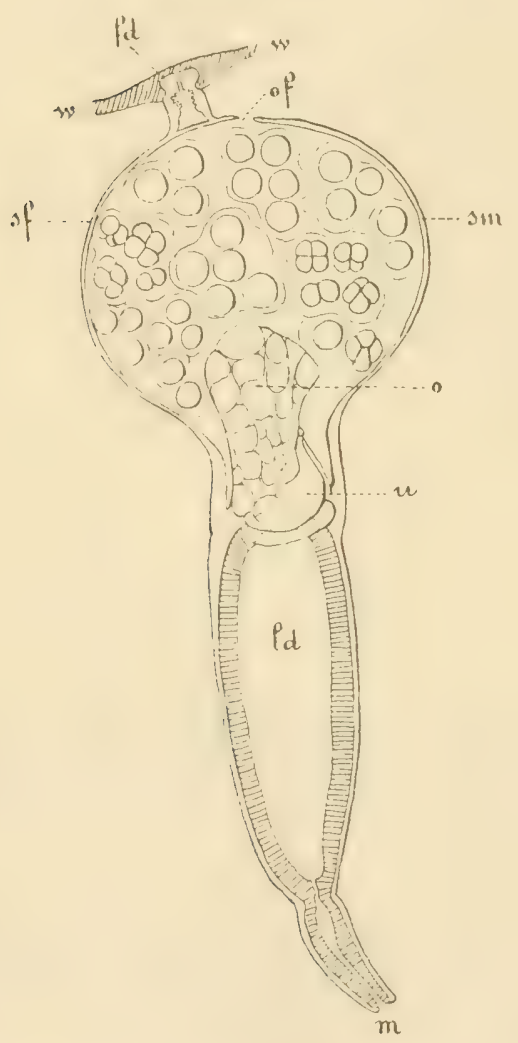

Fig. 587.

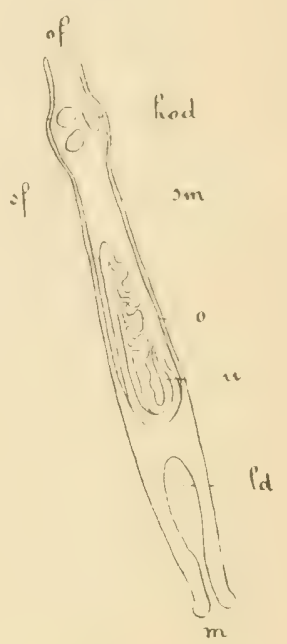

Fig. 586. Entocolax Ludwigii, Skizze nach VoIGT. Buchstabenbezeichnungen, die Interpretation von ScBIEMENZ erläuternd, wie in der vorhergehenden Figur.

Fig. 587. Entoconcha mirabilis, Skizze von Schtemenz nach Baur. Die Buchstabenbezeichnungen (wie in Fig. 585) erläutern die Schiemenz'sche Interpretation der Organisation. hod Hoden?.

dieser Form dient die rom Scheinmantel umschlossene Höhle, in welche der mit einem Receptaculum seminis ausgestattete Eileiter ausmündet, als Behälter für die befruchteten Eier, deren erste Furchungsstadien bei dem einzig bekanut gewordenen (weiblichen) Exemplar in ihr angetroffen wurden.

4) Noch stärker deformirt als Entocolax ist Entoconcha $\mathrm{m}$ irabilis, ein Endoparasit, welcher in einer Holothurie, Synapta digitata, gefunden worden ist. Der Körper des Parasiten stellt einen langen, wurmförmigen, gewundenen Schlanch dar, der mit dem einen Ende am 
Darm des Wirthes befestigt ist, während der Schlauch im Uebrigen frei in der Leibeshöhle flottirt. Die Organisation des Thieres ist noch nicht genügend untersucht. Fig. 587 stellt dieselbe in sehr vereinfachter und schematischer Weise dar und soll dazu dienen, einen Vergleich mit Entocolax zu ermöglichen. Ob dieser Vergleich, für den wir auf die Figurenerklärung verweisen, zutreffend ist, steht vor der Hand dahin. Vor allem ist bis jetzt keine Ausmündung des Ovariums in den als Höhlung des Scheinmantels gedeuteten Brutraum, der mit (in der Figur nicht dargestellten) Embryonen erfüllt ist, beobachtet worden. In einer in der Nähe des befestigten Endes des Schlauches befindlichen Erweiterung des Schlauches findet sich eine Anzahl von freiliegenden "Hodenbläschen ", über deren wirkliche Bedeutung nur neue Untersuchungen Aufklärung bringen können.

Die im Brutraume von Entoconcha enthaltenen Embryonen zeigen im Allgemeinen den Bau von Gasteropodenlarven. Sie besitzen eine spiralig gewundene Schale, in welche der Körper zurückgezogen werden kann, ein Operculum, ein kleines Velum, die Anlagen von zwei Tentakeln, zwei Gehörbläschen, einen Fuss, einen Darm, der nach dem einen (späteren) Beobachter nur aus Mund, Pharynx, Oesophagus und Leberrudiment bestehen soll, während er nach dem älteren Beobachter complet ist, und ferner eine Kiemenhöhle mit in Querreihen stehenden langen Wimpern. Weiter ist über die Entwickelung und Lebensgeschichte von Entocolax nichts bekannt.

Ueber parasitische Larven von Lamellibranchiern (Unionidae) wird im ontogenetischen Abschnitte einiges mitgetheilt werden.

\section{Festsitzende Schneeken.}

Von mehreren Formen festsitzender Schnecken, welche bekannt sind, möge hier nur Vermetus, dessen innere Organisation genauer untersucht wurde, kurz besprochen werden. Vermetus besitzt eine Schale, welche, anstatt zu dem bekannten Schneckengehäuse aufgewunden zu sein, eine Kalkröhre darstellt, die sich vom Meeresboden, mit welchem ihre Spitze verkittet ist, frei erhebt. Die Schale hat grosse Aehnlichkeit mit den kalkigen Wohnröhren von Röhrenwürmern, z. B. von Serpula. Die Larve aber besitzt eine typisch gewundene Schale, und auch beim jungen Thier, das sich festgeheftet hat, ist die Schale noch spiralig gewunden. Bei fortschreitendem Wachsthum aber berühren sich die Windungen der Schale nicht mehr, und die Schale wächst schliesslich röhrenförmig aus.

Die typische Organisation der Prosobranchia monotocardia, zu denen Vermetus gehört, erscheint durch die festsitzende Lebensweise wenig beeinflusst. Entsprechend der Form der Schale ist der Eingeweidesack sehr langgestreckt, fast wurmförmig. Darm, Circulationssystem, Niere, Mantel, Kieme, Nervensystem sind typisch entwickelt. Die Geschlechter sind getrennt, es fehlen Copulationsorgane, die bei der festsitzenden Lebensweise keine Rolle spielen können. Der Kopf ist wohlentwickelt und der kräftige Pharynx wohlbewaffnet. Wenn das Thier (nicht zu stark) gereizt wird, so soll es sich nicht sofort, wie dies andere Schnecken thun, in die Schale zurückziehen, sondern zubeissen. Der Fuss ist stempelförmig, cylindrisch abgestutzt, unter dem Kopf nach vorn gerichtet. $\mathrm{Da}$ er als Locomotionsorgan functionslos ist, dient er als Träger des Operculums nur zum Verschliessen der Schale und, wohl vermittelst 
der Fussdrüse, zur Erzeugung von Schleim. Vermetus soll in der That copiöse Schleimmassen absonderu, dieselben eine Zeit lang schleierartig im Wasser ausgespannt halten und sodann sammt allem, was daran kleben bleibt, verschlucken. Das Thier soll sich in dieser Weise die zu seiner Ernährung dienenden kleinen Organismen fischen.

\section{Ontogenie.}
A) Amphineura.

1. Ontogenie von Chiton Polii (Fig. 588). Das Ei besitzt wenig Nahrungsdotter. Die Furchung ist eine totale und etwas inäquale. Es bildet sich eine Cölogastrula durch Invagination. a) Der Blastoporus der Gastrula larve bezeichnet das Hinterende der Larve. Ein Paar Entodermzellen nahe dem Rückenrande des Blastoporus zeichnen sich durch besondere Grösse aus. Man sieht auf dem Längsschnitt dorsal- und ventralwärts im Ectoderm je zwei Zellen mit grösserem Kern; sie gehören einem zweizeiligen Ring von Zellen an, auf dem sich der präorale Wimperkranz entwickelt, welcher bei den Mollusken als Velum bezeichnet wird (Fig. 588 A).

b) Auf einem weiteren Stadium erscheint der Blastoporus etwas gegen die Bauchseite verschoben, und es beginnt an seinem Rande eine Einwucherung von Ectodermzellen: Beginn der Bildung des ectodermalen Stomodaeums. Am hinteren und oberen Rande des Blastoporus zeigt der abgebildete Schnitt eine zwischen Futoderm und Ectoderm liegende Zelle, wohl eine Mesodermzelle (B).

c) Die Larve streckt sich in die Länge; durch fortgesetzte Einwucherung von Ectodermzellen bildet sich ein deutliches, durch den Blastoporus in den Urdarm führendes Stomodaeum (embryonaler Schlund), welches sich noch weiter auf die Bauchsoite in der Richtung nach vorn verschiebt $(\mathrm{C})$.

d) Fig. $588 \mathrm{G}$ stellt einen schief, von vorn und oben nach hinten und unten geführten, das Stomodaeum interessirenden Schnitt durch eine etwas ältere Larve dar und zeigt zu den Seiten des Blastoporus die ersten Mesodermzellen. Diese stammen wahrscheinlich vom Entoderm ab und treten symmetrisch zu beiden Seiten des Blastoporus a uf.

e) Ein Medianschnitt durch ein nächstes Stadium (D) lässt in der Mittelebene noch keine Mesodermzellen erkennen. Dagegen erscheint jetzt der Mund auf der Bauchseite nach vorn bis ganz an den Wimperkranz oder das Velum verschoben, dessen doppelte Zellenreihe sich sehr dentlich erkennen lässt.

f) Querschnitt eines älteren Stadiums (H). Die Mesodermzellen haben sich vermehrt und sind in zwei Gruppen zu Seiten des Stomodaeums, zwischen Ecto- und Entoderm, angeordnet.

g) Auf einem folgenden Stadium, welches uns Fig. 588 E im Längsschnitt vorführt, zeigt die Larve vor allem eine stärkere Entwickelung des Mesoderms, in welchem ein Hohlraum, die L eibeshöhle, aufgetreten ist. Eine nach hinten gerichtete Ausstülpung des Stomodaeums stellt die erste Anlage der Radulascheide dar. Hinter dem Munde ist, offenbar von Ectoderm gebildet, eine sackförmige Einstülpung aufgetreten, 

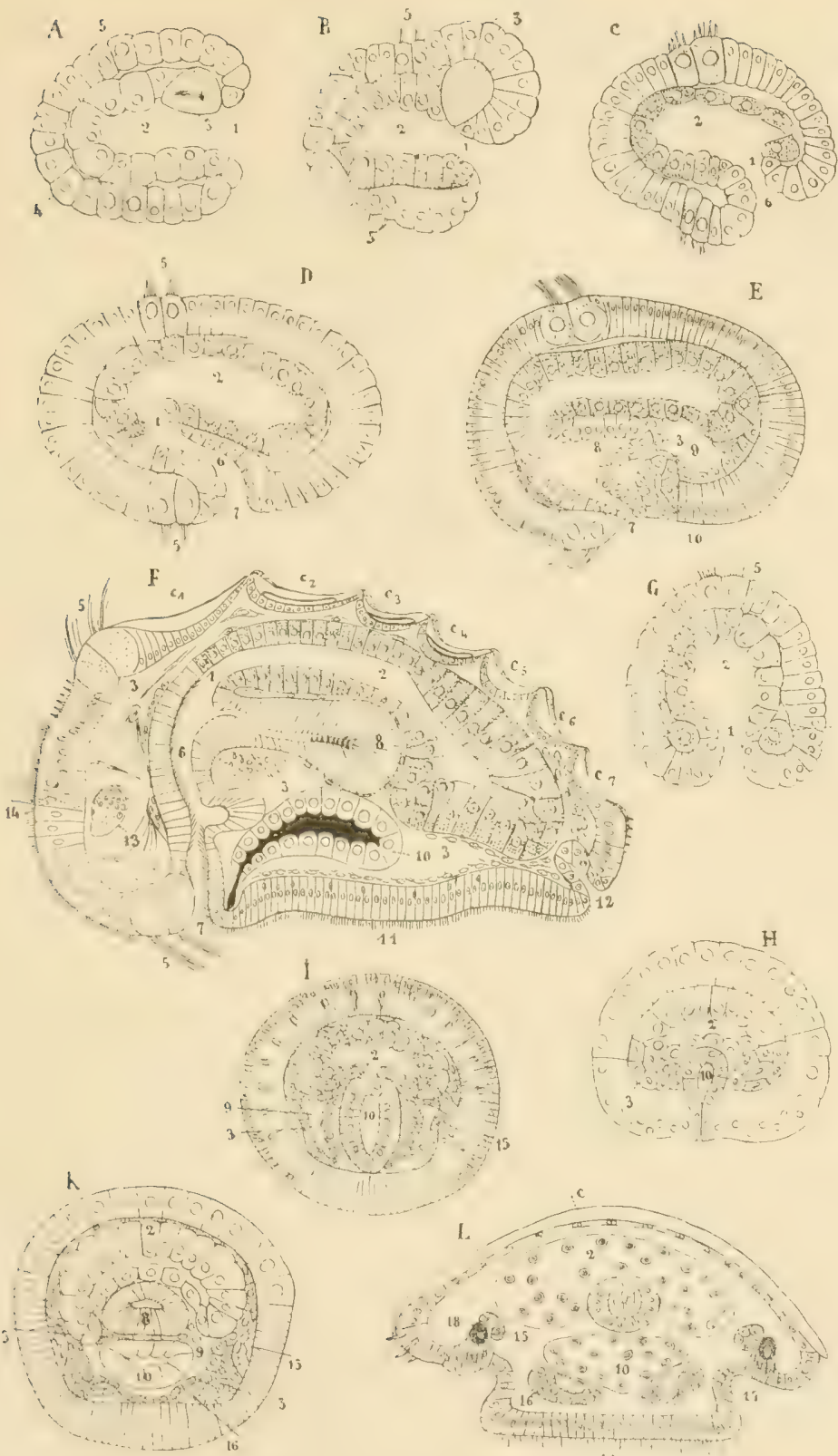

E

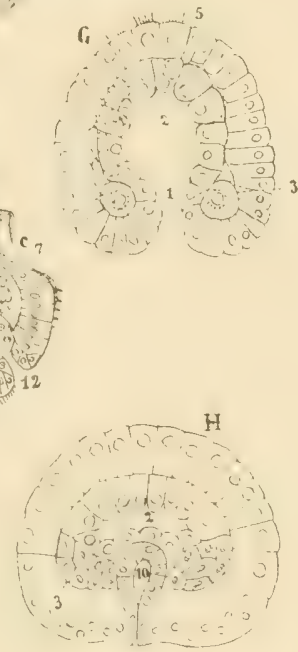

Fig. 588. Entwickelung von Chiton Polii, nach Kowalevsky. $\boldsymbol{A}-\boldsymbol{F}$ Sechs Entwickelungsstadien von der Gastrula bis zum jungen Chiton auf annähernd medianen Längsschnitten. $G$ Frontalschnitt durch Stadium $C$ schief vom oberen Theil des Velum nach dem Blastoporus. $\boldsymbol{H}, \boldsymbol{I}, \boldsymbol{K}, \boldsymbol{L}$ Querschnitte von vier Entwickelungsstadien hinter dem Munde. 1 Blastoporus, 2 Urdarm, Mitteldarm, 3 Mesoderm, 4 Ectoderm, 5 Velum, prïoraler Wimperkranz, 6 Stomodaeum, Schlund, 7 Mund, 8 Radulascheide, 9 Leibeshöhle, 10 Fussdrüse, in Fig. I Oesophagus, 11 Fuss, 12 After mit Proctodaeum, 13 Cerebralganglion, 14 Scheitelschopf, 15 Pleurovisceralstränge, 16 Pedalstränge, 17 Mantelfurche, 18 Auge, $c$ Schale, $c_{1}-c_{7}$ die 7 zuerst angelegten Schalenstiicke. 


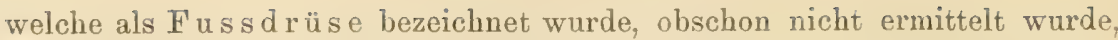
was aus ihr beim erwachsenen Thier wird.

h) Durch das Auftreten der Leibeshöhle werden die Zellen des Mesoderms in zwei Lagen geschieden, von denen die innere, das viscerale Blatt, sich dem Darm, das äussere oder parietale Blatt dem Ectoderm anlegt (vergl. Querschnitt Fig. 588 I). Rechts und links zeigt sich in der Tiefe des Ectoderms auf dem Querschnitt die Anlage der Pleurovisceralstränge. In ähnlicher Weise entstehen die Pedalstränge und vorn, in dem vom präoralen Wimperkranze umsäumten Scheitelfelde die Anlage des supraösophagealen Centralnervensystems als Scheitelplatte, d. h. als Verdickung des Ectoderms, welche ein Büschel längerer Wimperhaare trägt.

i) Auf späteren Stadien (F, K, L) löst sich das Centralnervensystem mit den Pleurovisceral- und den Pedalsträngen vom Ectoderm los und bekommt seine mesodermale Lage. Auf dem Rücken treten als Cuticularbildungen die Anlagen von 7 Schalenplatten auf. Die achte, hinterste entsteht erst später. Eine hintere Einstülpung des Ectoderms stellt offenbar die Anlage des Proctodaeums (embryonaler Enddarm mit After) dar. In der Radulascheide treten die ersten Radulazähne auf. Das ganze Scheitelfeld und die Gegend des Fusses bedeckt sich mit Wimpern. Im dorsalen Ectoderm treten an den schalenlosen Stellen die ersten Kalkstachelchen auf. Im hinteren Körpertheile stellt eine dichte Ansammlung von Mesodermelementen offenbar eine mesodermale Bildungszone dar.

Auf diesem Stadium verlässt die Larve die Eihülle, um frei herumzuschwimmen und sich nach Rückbildung des Wimperkranzes bald in einen zu Boden sinkenden jungen Chiton umzuwandeln. Während dieser Umwandlung treten vorn am Körper ventral zwei seitliche larvale Augen auf. Die Entwickelung des Circulationssystems, der Nephridien, Geschlechtsorgane und Ctenidien wurde nicht verfolgt.

2. Solenogastres. Was die Ontogenie der Solenogastriden anbetrifft, so liegt bis jetzt bloss eine noch recht unvollständige Mittheilung über die Entwickelung von Dondersia banyulensis vor, welche gerade hinreicht, das Verlangen nach einer genaueren Kenntniss noch zu vergrössern. Die Furchung ist eine inäquale totale und verläuft unter Micromerenbildung. Der Vorgang der Gastrulation scheint die Mitte zu halten zwischen Epibolie und Invagination. Der Blastoporus bezeichnet das hintere Leibesende der Larve, die durch 2 Ringfurchen in 3 hintereinander liegende Regionen zerfällt. Die vordere besteht aus zwei Zellringen und entspricht offenbar einem Scheitelfeld. Sie ist theilweise bewimpert, trägt in der Mitte eine Gruppe längerer Wimperhaare, unter welchen bald eines als Flagellum prädominirt. Die zweite, aus einem einzigen Zellenring bestehende Region trägt einen Ring langer Cilien und stellt offenbar das Velum dar. Die dritte Region besteht aus 2 kurzbewimperten Zellenreihen, von denen die hintere den Blastoporus umgrenzt. Bei einer älteren Larve erscheint ein hinterer Theil der Larve in eine Einstülpung des vorderen Theiles zurückgezogen. Nur aus diesem hinteren Theil, dem Embryonalzapfen, soll der ganze Körper der Dondersia oder doch weitaus der grösste Theil desselben hervorgehen. Am Embryonalzapfen treten zunächst beiderseits der Mittellinie 3 Paare hintereinander liegender, einander dachziegelförmig bedeckender Spicula, die noch in ihren Bildungszellen enthalten sind, auf. Sie brechen sodann nach aussen durch, und ihre Zahl vermehrt sich dadurch, dass vorn 
immer neue Paare hinzutreten. Der Embryonalzapfen verlängert sich und bekommt eine ventrale Krümmung. Der Vorderkörper mit dem Velum und dem Scheitelfeld reducirt sich und erscheint schliesslich nur noch als eine Art Kragen am Vorderende des Körpers. Die Larve sinkt zu Boden und wirft den ganzen Vorderkörper mit dem Velum und dem Scheitelfeld ab. (Aehnliche Erscheinungen, Abwerfen oder Resorption von Larventheilen, die bei der Larve eine grosse Rolle gespielt, stark functionirt haben, sind im Thierreich weit verbreitet, man vergl. die Abschnitte über die Ontogenie der Würmer [z. B. Nemertinen, Phoronis etc.]. der Arthropoden [z. B. Insectenmetamorphose], der Echinodermen u. s. w.).
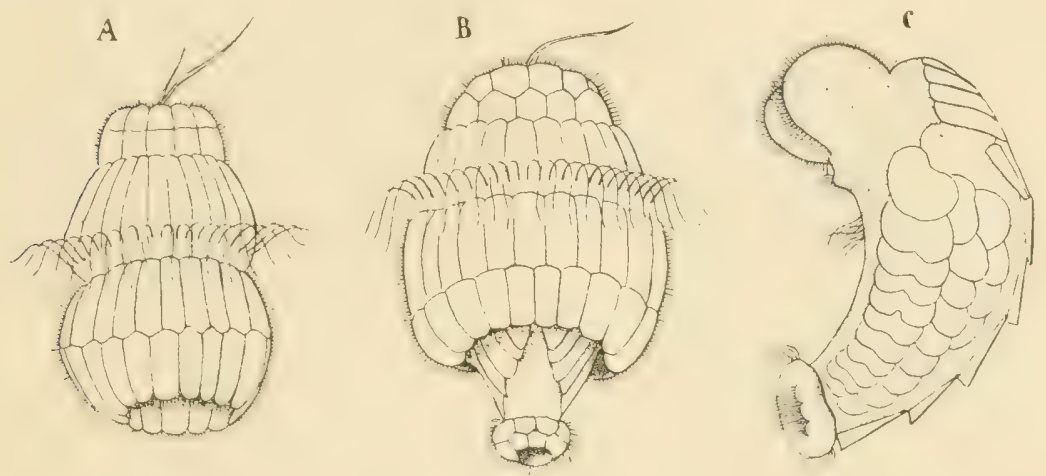

Fig. 589. Dondersia banyulensis. $\boldsymbol{A} 36$ Stunden alte Larve. $\boldsymbol{B} 100$ Stunden alte Larve. $C$ Junge Dondersia unmittelbar nach der Verwandlung (7. Tag), nach Pruvot.

A uf dem Rücken der jungen Dondersia lassen sich jetzt 7 hintereinander liegende, dachziegelförmig nur wenig ïbereinandergreifende Kalkplatten unterscheiden, welche a us rechteckigen, nebeneinander gelagerten Spi$\mathrm{cula}$ bestehen (Fig. 589 C). Diese Beobachtung ist von grosser Bedeutung mit Rücksicht auf die Chitonschale, die beim erwachsenen Thier aus 8 , bei der älteren Larve aber nur aus 7 Schalenstücken besteht. Sollte es sich sicher herausstellen, dass die Solenogastriden ein Chitonstadium durchlaufen, so würde dadurch die Auffassung, dass sie viel mehr specialisirte Thiere als die Polyplacophoren und von Chiton-ähnlichen Formen abzuleiten sind, eine fast entscheidende Stütze erhalten.

Ausser den 8 dorsalen Kallkplatten besitzt die junge Dondersia noch zahlreiche kreisförmige Kalkspicula, welche die Seitentheile bedecken, Die Bauchseite ist nackt. Ein Mund fehlt noch, die Entodermmasse ist noch nicht hohl, jederseits zwischen Entoderm und Haut findet sich ein solider Mesodermstreifen.

\section{B) Gasteropoda.}

Wir wählen zur Darstellung der Gasteropodenentwickelung die neuerdings wieder sehr genau untersuchte Entwickelung von Paludina vivi p a ra (Fig. 590-592), welche im Innern des Mutterthieres verläuft. Das Ei ist relativ arm an Nahrungsdotter. Durch Invagination bildet sich eine Coelogastrula, deren Blastoporus das Hinterende des Keimes hezeichnet und zum After wird. Es bildet sich kein Proctodaeum. 
Der ganze Darm vom Magen bis zum After geht aus dem Entoderm hervor. Das Mesoderm legt sich als ventrale hohle Ausstülpung des Urdarmes an, welche sich bald vom Darme losschnürt und als eine nach vorn in zwei Zipfel auslaufende Blase $z w i s c h e n$ Darm und Ectoderm in der Furchungshöhle liegt (Fig. 590 A, B, C). Diese Blase dehnt sich rechts und links um den Darm herum nach dem Rücken aus, um den Darm schliesslich dorsalwärts ganz zu umwachsen. Ihre äussere Zellwand, welche sich dem Ectoderm anlegt, stellt das partietale, die innere Wand, welche sich dem Darm anlegt, das viscerale Blatt des Mesoderms dar. Rasch lockert sich der Zusammenhang der Mesodermzellen (Fig. 590 D); sie nehmen Spindelgestalt an und erfüllen schliesslich als ein zelliges Maschenwerk die Furchungshöhle.
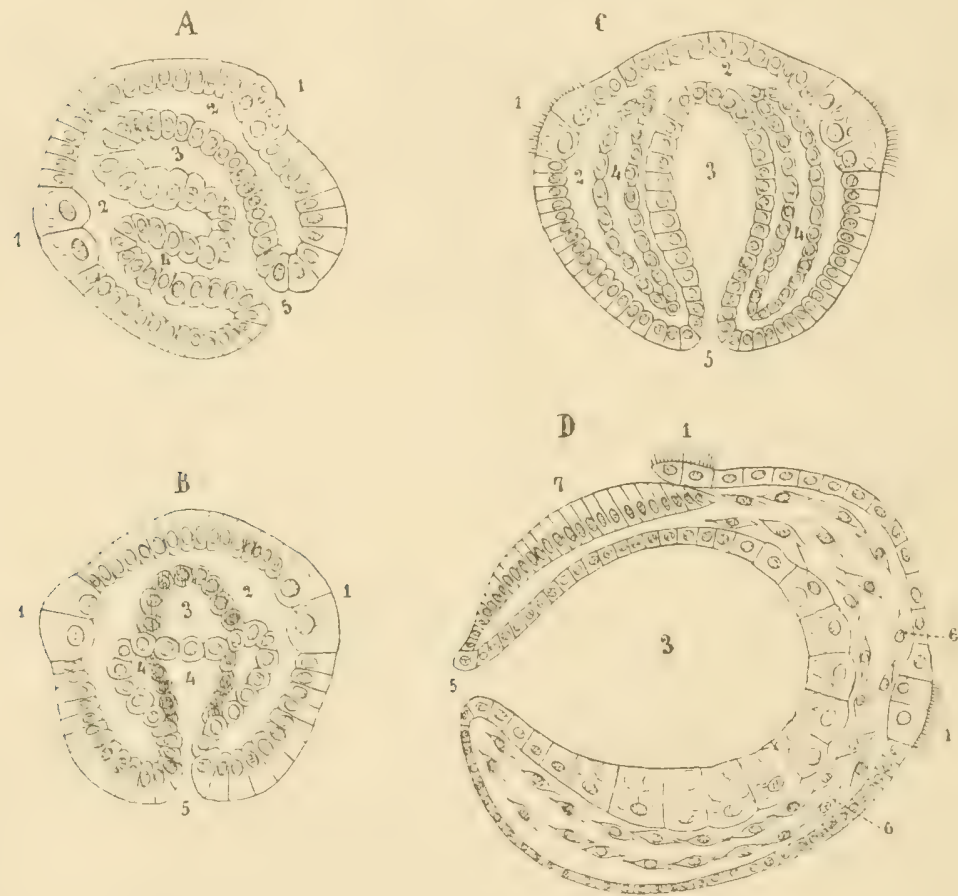

Fig. 590. Entwickelung von Paludina vivipara, nach v. Ertanger. $\boldsymbol{A}$ und $\boldsymbol{B}$ Stadium nach der Gastrula, mit Anlage des Mesoderms und Coeloms als Ausstülpung des Urdarms, $\boldsymbol{A}$ Im medianen optischen Längsschnitt. $\boldsymbol{B} \mathrm{Im}$ horizontalen optischen Längsschnitt. $C$ Horizontaler optischer Längsschnitt durch einen Embryo, bei welchem sich der Coelomsack ganz vom Darm getrennt hat. $\boldsymbol{D}$ Sagittaler optischer Längsschnitt durch einen Embryo, dessen Mesoderm sich schon aufgelöst hat und in Spindelzellen zerfallen ist. 1 Velum, 2 Furchungshöhle, 3 Urdarm, 4 Coelom, 5 Blastoporus, 6 Mesodermzellen, 7 Schalendrüse.

Inzwischen ist das Velum aufgetreten. Dorsalwärts zwischen dem Velum und dem After stülpt sich die Schalendrüse ein. Der Oesophagus bildet sich durch eine Einstülpung des Ectoderms, welche sich bald mit dem Mitteldarm in Verbindung setzt. Indem sich auch eine paarige Urniere anlegt, gelangt eine typische Molluskentrochophora 
zur Ausbildung, welche anfänglich ganz symmetrisch ist, und bei welcher der After hinten in der Mediane liegt.

Nachdem sich der Oesophagus gebildet hat, ballen sich jederseits unter dem Darm Mesodermzellen zu einem Zellhaufen zusammen, in welchem bald eine Höhlung auftritt. So entstehen zwei "Säcke, welche in der Mittellinie zusammenrücken, bis sie aneinanderstossen und zu einem einheitlichen verschmelzen, dessen paariger Ursprung noch eine Zeit lang durch ein mittleres Septum documentirt wird. Der auf solche Weise ent-
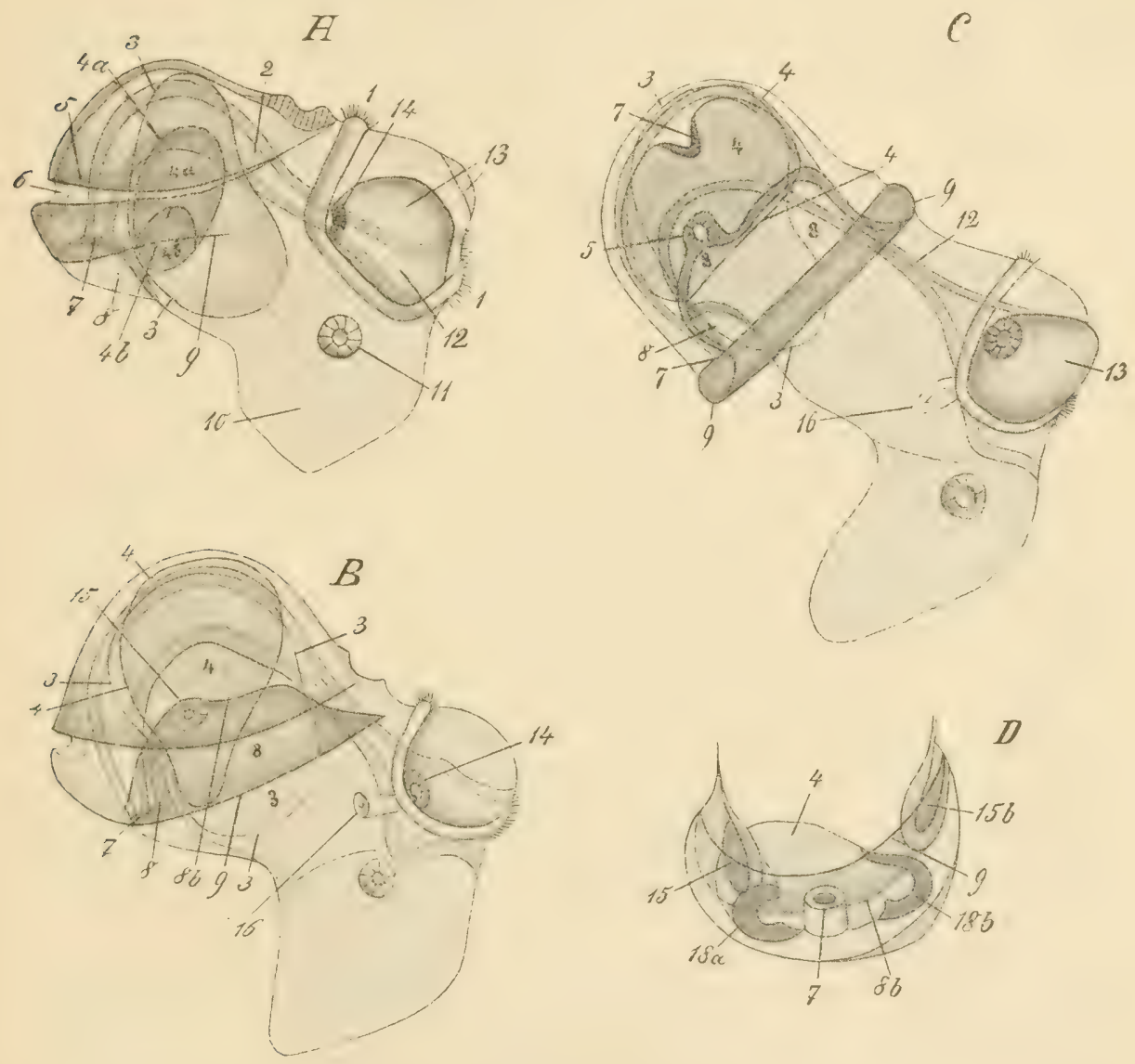

Fig. 591. Entwickelung von Paludina vivipara, nach v. ERLANGER, A Ansicht von der rechten Seite eines Embryo, bei welchem das Pericard durch ein Septum in zwei Theile getheilt ist. $\boldsymbol{B}$ Dieselbe Ansicht eines etwas älteren Embryo mit einheitlichem Pericard. $C$ Dieselbe Ansicht eines älteren Embryo, bei welchem die erste Anlage des Herzens aufgetreten ist. $\boldsymbol{D}$ Ventrale Ansicht des Hinterendes eines Embryos, bei welchem die Asymmetrie des Eingeweidesackes aufzutreten beginnt. Der After liegt noch median, aber die Mantelhöhle ist rechts (in der Figur links) schon tiefer. 1 Velum, 2 Mitteldarm, 3 Verdauungsdrüse (Leber), 4 Pericard, $4 a$ und $4 b$ die durch ein Septum getrennten Abtheilungen des Pericards, 5 freier Rand der Schale, 6 Schalenfalz, 7 After, 8 Mantelhöhle, $8 b$ Grund der Mantelhöhle = Basis der Mantelfalte, 9 freier Rand des Mantels, 10 Fuss, 11 Gehörorgan, 12 Schlund, 13 Kopffühler, 14 Auge, 15 Ausführungsgang des (anfänglich) rechten Nephridiums, $15 b$ rudimentärer Ausführungsgang der (anfänglich) linken Niere, 16 Uniere, 17 Herzanlage, $18 a$ rechte, $18 b$ rudimentäre linke Niere. 


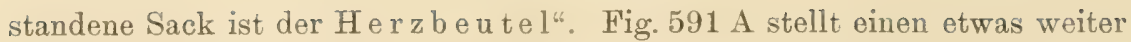
entwickelten Embryo von der rechten Seite gesehen dar. Unter und hinter dem Munde erkennt man schon die vorragende Fussanlage, an welcher rechts und links durch Einstülpung des Ectoderms die Ge$\mathrm{h}$ örblase entstanden ist. Im Scheitelfeld stellt rechts und links eine Hervorragung die Anlage der Fühler dar, an deren Basis die Anlagen der $\mathrm{A} u \mathrm{~g}$ en als Ectodermgruben auftreten. Die Schalendrüse hat eine $\mathrm{Schale}$ abgesondert. Durch stärkeres Wachsthum des von der Schale bedeckten Körpertheils ist der After gegen die Bauchseite verschoben. Unmittelbar hinter dem After wölbt sich das Ectoderm vor zur Anlage der Mantelfalte, so dass der After in den Grund einer noch seichten Grube, der Anlage der Mantel- oder Kiemenhöhle, zu liegen kommt. Es ist von grosser Wichtigkeit, zu constatiren, dass auf diesem äusserlich noch symmetrischen Stadium die Mantelhöhle und der After hinten am Körper liegt. Der Vorderdarm (Oesophagus) hat sich stark verlängert. Am Magen hat sich ventralwärts die Verdauungsdrüse in Form eines weiten Sackes ausgestülpt, steht aber mit ihm noch durch eine weite Oeffnung in Verbindung. Das Pericard, welches immer noch die Scheidewand zeigt, hat sich schon etwas von unten auf die rechte Seite des Magens verschoben. Es erfolgt nun die Anlage des definitiven Nephridiums in folgender Weise (Fig. 591 D). In jedem Abschnitt des Pericards (der linke ist kleiner als der rechte) bildet sich eine Ausstülpung der Pericardwand. Die rechte Ausstülpung wird zum secernirenden Abschnit der bleibenden Niere, der linke bildet sich zurück, muss aber als ein vorübergehend auftretendes Rudiment der (ursprünglich) linken Niere betrachtet werden. Die unter dem Pericard gelegene Mantelhöhle dringt rechts und links pericardwärts in Form eines Zipfels vor. Der fortwachsende rechte Zipfel setzt sich mit der Anlage der rechten Niere in Verbindung und bildet den A usführungsgang derselben. Der linke wächst nicht weiter und verbindet sich nicht mit dem linken Nierenrudiment.

Ein weiteres Stadium ist in Fig. 591 B von der rechten Seite abgebildet. Die wichtigsten Veränderungen sind: Die Augengrube hat sich als Augenblase abgeschnürt. Die $\mathbf{M}$ antelfalte ist weiter nach vorn gewachsen und rechtsseitig tiefer geworden. Das einheitliche Pericard ist ganz auf die rechte Seite des Magens gerückt und findet sich über dem nach vorn und unten umbiegenden Enddarm. Der Körper ist schon asymmetrisch.

Auf dem folgenden Stadium, Fig. $591 \mathrm{C}$, ist die hintere und dorsale Körperregion schon deutlich vom Körper abgesetzt als Eingeweidebruchsack; die diese Region bedeckende Schale hat sich bedeutend vergrössert. Die Mantelfalte ist viel breiter und die Mantelhöhle viel tiefer geworden und liegt grösstentheils auf der rechten Körverseite. Die schlingenformige Krümmung des Darmes ist viel mehr ausgesprochen. An der hinteren und dorsalen Seite des Pericards senkt sich die Pericardwand in Form einer Rinne ein, die sich bald zu einem Rohre schliesst, der Anlage des Herzens. Die beiden Oeffnungen der Röhre, an welchen die Herzwand in die Pericardwand übergeht, communiciren mit der Leibeshöhle. Die Herzröhre schnürt sich in der Mitte ein, ihr vorderer Abschnitt wird zum Vorhof und Anfang der Kiemenvene, ihr hinterer Abschnitt zur Herzkammer und zum Anfang der Körperaorta.

Fig. 592 A zeigt einen etwas älteren Embryo, welcher schon die Gestalt der erwachsenen Schnecke besitzt. Das Velum ist reducirt; eine ventrale 
Ausbuchtung des vorderen Schlundabschnittes stellt die Anlage der Radulascheide dar. Herzkammer und Vorhof sind deutlich unterscheidbar. Am Fusse hat eine Ectodermeinsenkung das junge Operculum gebildet. Die rechtsseitige Mantelhöhle, in welche der Enddarm mündet, erstreckt sich jetzt auch nach links auf die Vorderund Dorsalseite des scharf abgesetzten Eingeweidesackes. Die Kieme tritt in Gestalt von Höckern an der Innenfläche der Mantelböhle auf, das Os phra di um links von der Kieme als ein ectodermaler Höcker.

Fig. 592 B zeigt uns endlich einen Embryo, bei welchem die Mantelhöhle schon die vorderständige Lage am Eingeweidesack eingenommen hat. Ctenidium und Osphradium haben sich weiter entwickelt. Das
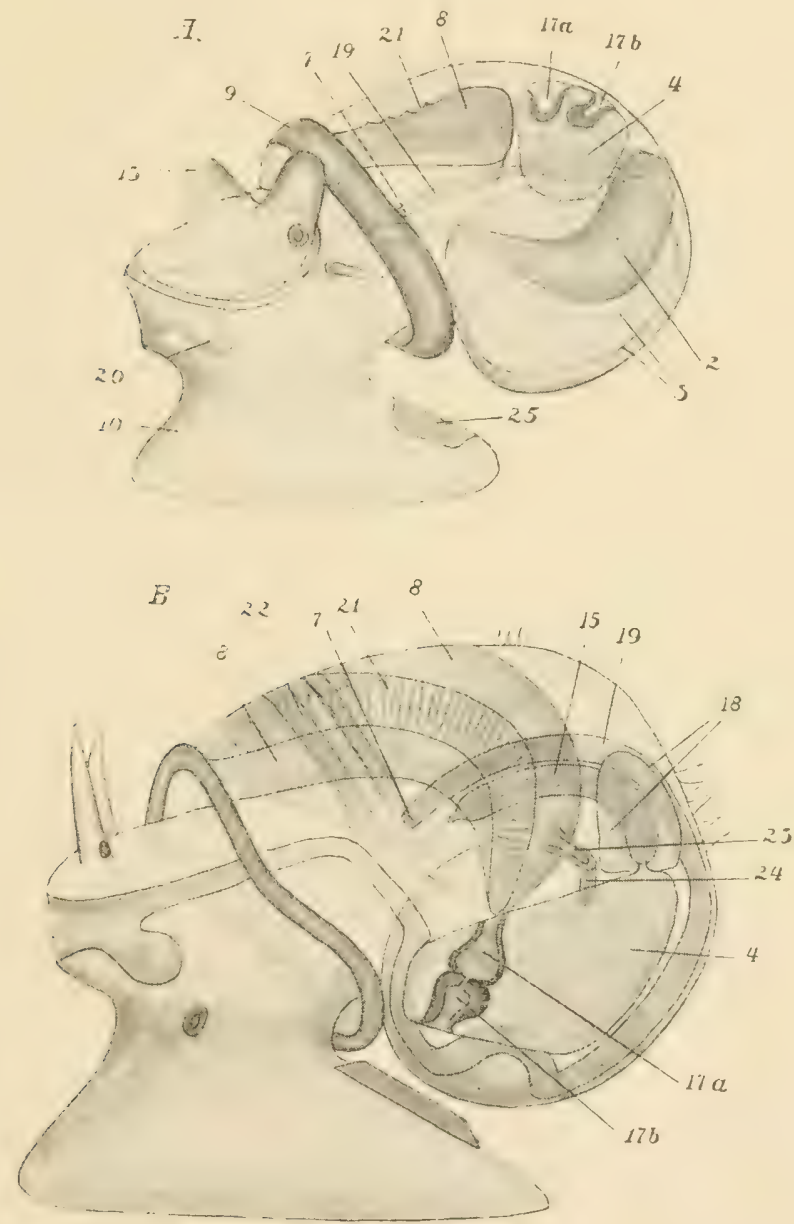

Fig. 592. Entwickelung ron Paludina vivipara, nach v. ErLANGfr. $\boldsymbol{A}$ Ansicht eines Embryo, bei welchem die erste Anlage der Kieme aufgetreten ist. $\boldsymbol{B}$ Ansicht eines nahezu reifen Embryos. Beide Ansichten von der linken Seite. Bezeichnungen wie in Fig. 591. Herner: 17a Vorhof, 176 Kammer des Herzens, 18 Nephridium, 19 Enddarm, 20 Anlage des Radulasackes, 21 Kiemenanlage, 22 Osphradium (SpenGeL's Organ), 23 Anlage des Geschlechtsganges, 24 Anluge der Gonade. 
Velum ist nur noch auf Schnitten als reducirtes Organ nachweisbar. Das Stadium ist wichtig wegen der Anlage der Geschlechtsorgane, die in beiden Geschlechtern identisch ist. Eine Ausstülpung der (mesodermalen) Herzbeutelwand, welche sich von dieser sondert, stellt die Anlage der Gonade dar, während eine dieser entgegenwachsende Ausstülpung des Grundes der Mantelhöhle die (ectodermale) Anlage des Geschlechtsleiters darstellt. Letzterer entsteht auf der einen Seite des Afters in derselben Weise, wie der Ausführungsgang der bleibenden Niere auf der anderen Seite, und es bestätigt somit die Ontogenie die Vermuthung, zu der wir auf vergleichend-anatomischem Wege (pag. 816) gekommen sind, dass der Geschlechtsleiter der Monotocardier einem Theil der rechten, ursprünglich und beim jungen Embryo linken (bei den Monotocardiern scheinbar fehlenden) Niere der Diotocardier entspreche.

Die Gefässe entstehen sehr frühzeitig als Lückenräume zwischen Mesoderm und Ectoderm resp. Entoderm, welche von Mesodermzellen umwachsen werden und erst secundär mit dem Herzen in Verbindung treten.

Alle Ganglien des Nervensystems: die Cerebral-, Pleural-, Pedal- und Parietalganglien und das Visceralganglion entstehen gesondert voneinander als Ectodermverdickungen, die sich vom Ectoderm durch Delamination abschnüren. Erst secundär treten sie durch auswachsende Nervenfasem miteinander in Verbindung. Die Parietalganglien speciell entstehen rechts und links am Mittelkörper, rücken aber bald, bei der Verschiebung der Organe des Eingeweidesackes, das eine über, das andere unter den Darm. Die Anlage des Visceralganglions soll dorsal vom Enddarm auftreten und erst später unter denselben zu liegen kommen.

Die hier kurz citirten Beobachtungen über die Entwickelung von Paludina sind nach vielen Richtungen von grösster Bedeutung, indem sie die Resultate der vergleichend-anatomischen Forschung auf das unzweideutigste erhärten. Wir heben noch Folgendes hervor:

1) Die Art der Entstehung des Pericards ist der Auffassung desselben als einer secundären Leibeshöhle sehr giunstig. Von Wichtigkeit ist, dass das Pericard, anfänglich paarig, durch eine später schwindende Scheidewand in zwei seitliche Hälften getrennt ist.

2) Die Thatsache, dass die Gonade als eine Ausstülpung des Pericards sich anlegt, erhärtet die vergleichend-anatomisch gewonnene Ansicht, dass auch die Gonadenhöhle eine secundäre Leibeshöhle ist.

3) Der After und die Mantelhöhle liegen anfänglich symmetrisch hinten am Körper und kommen erst durch asymmetrisches Wachsthum zuerst auf die rechte Seite des Eingeweidesackes und schliesslich an seine Vorderseite zu liegen.

Die Entwickelung der übrigen Gasteropoden wollen wir nicht eingehend besprechen. IVir verweisen auf das Litteraturverzeichniss. Im Allgemeinen ist der Nahrungsdotter im Ei etwas reichlicher vorhanden als bei der lebendig gebürenden Paludina, wo die ïberaus geringe Menge desselben offenbar mit den günstigen Ernährungsbedingungen der Embryonen in Zusammenhang steht.

Der Blastoporus entspricht der Lage nach der Stelle des späteren Mundes, oft, vielleicht sogar in der Mehrzahl der Fälle, bleibt er offen, wobei aber doch der Oesophagus durch Einsenkung von Ectodermzellen entsteht.

Die Anlage des Mesoderms bei Paludina, in Form einer Ausstülpung des Urdarmes, steht bis jetzt bei den Mollusken vereinzelt da. Sie steht 
wohl mit der Dotterarmuth in Zusammenhang. Bei den übrigen Gasteropoden nimmt das Mesoderm in schon für die anderen Mollusken beschriebener Weise seinen Ursprung aus zwei symmetrischen, grossen Urmesodermzellen am hinteren Rande des Blastoporus, die mehr das Aussehen von Entoderm- als von Ectodermzellen haben und frühzeitig in die Furchungshöhle rücken.

Ueberall bildet sich eine Veligerlarve, d. h. eine Trochophora mit Molluskencharakteren: 1) der dorsalen Schalendrüse mit der Embryonalschale, und 2) der ventralen Fussanlage.

Doch ist der Habitus dieser Veligerlarve in verschiedenen Abtheilungen oft recht verschieden, was vorwiegend mit der Ernährungsund Lebensweise der Embryonen oder Larven zusammenhängt.

Fing 593

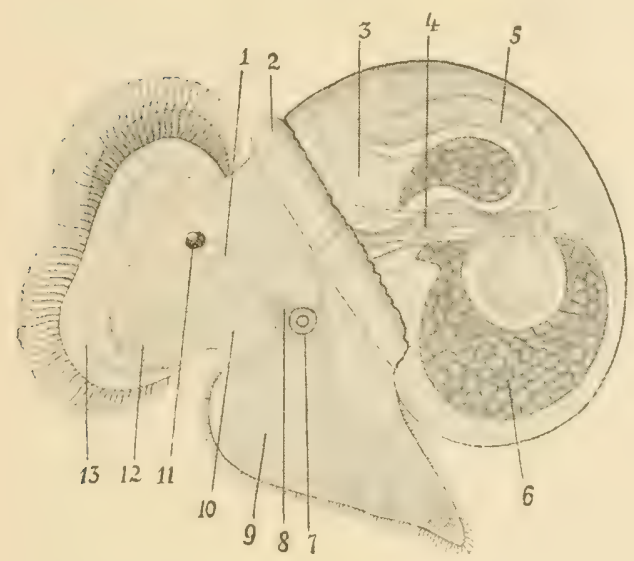

Fig. 594 .

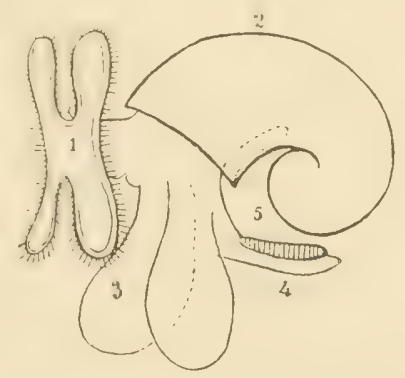

Fig. 594. Larve von Cymbulia (Pteropode), von der linken Seite, nach Gegenbaur. I Velum, 2 Schale, 3 Parapodien (Flossen), 4 F'uss mit Deckel 5.

Fig. 593. Larve von Oncidium celticum, von der linken Seite, nach Joyeux-LAFfuIE. 1 Cerebralganglion, 2 Mantelrand, 3 Anlage der Gonade, 4 larvaler Schalenmuskel, 5 Enddarm, 6 Anlage der Verdauungsdrüse, 7 Gehörorgan, 8 Pedalganglion, 9 Fuss, 10 Schlund, 11 Auge, 12 verzweigte Muskelzellen des Velums, 13 Velum.

Bei den marinen Gasteropoden, also der grossen Mehrzahl der Prosobranchier incl. Heteropoden), der Pulmonatengattung Oncidium und allen Opisthobranchiern, verlässt der Embryo frühzeitig als junge, freischwimmende Veligerlarve die Eihülle. Bei allen diesen Formen ist der präorale Wimperkranz stark ausgebildet. Meist wölbt sich der Ectodermboden des Wimperkranzes nach aussen vor, so dass dieser letztere von einem deutlichen Ringwulst getragen wird. Ja, es wächst jederseits der Ringwulst zu einem grösseren oder kleineren Lappen aus, welcher an seinem Rande die kräftigen und langen Cilien trägt und gelegentlich selbst wieder in einen oberen und unteren Lappen sich ausziehen kann. Das ist das ächte Velum der freischwimmenden Gasteropodenlarven, ihr einziges Bewegungsorgan. In seinem Inneren spannen sich von Wrand zu Wand contractile Mesodermzellen (Muskelzellen) aus, die ihm einen hohen Grad von Contractilität verleihen. Bei den älteren Larven kann der Kopf mitsammt dem Velum in die Schale zuriickgezogen werden. 
Es ist wahrscheinlich, dass das Velum bei der Larve auch respiratorisch thätig ist, vielleicht sogar vermöge seiner Contractilität propulsatorisch für die Leibesflüssigkeit wirkt.

Bei den Süsswasser- und Landgasteropoden — sofern sie nicht lebendig-gebärend sind - verharrt der Embryo längere Zeit in der Eihülle und verlässt dieselbe erst als junge Schnecke, nachdem sich die Larvenorgane (Velum, Urniere, Kopfblase, Fussblase oder Podocyste) schon in der Eihülle zurückgebildet haben. Auch bei diesen Formen ist die im Ei enthaltene Masse von Nahrungsdotter nicht sehr ansehnlich, dagegen wird in die Eikapsel mit dem Ei eine ansehnliche Masse von Eiweiss abgelagert, welches dem sich entwickelnden Embryo zur Nahrung dient, sei es, dass es durch dessen Körperwand diffundirt oder dass es vom Embryo verschluckt wird. Die Eikapseln sind immer gross, in einzelnen Fällen, z. B. bei tropischen Landschnecken, sehr gross, bis zur Grösse kleiner Vogeleier; aber ihre Grösse wird nicht, wie etwa bei den Cephalopoden, bedingt durch die Grösse des enthaltenen Eies, sondern durch die Masse des Eiweisses, in welches das kleine Ei eingebettet ist. Die reife Eikapsel enthält in ihrem Inneren schon eine ansehnliche junge Schnecke mit wohlentwickelter Schale.

Bei den Land- und Süsswasserschnecken kann also das Velum nicht als Bewegungsorgan dienen; es ist als solches reducirt auf einen einfachen Wimperring oder auf zwei seitliche Wimperstreifen. Bei den Embryonen einzelner Landschnecken wurde es völlig vermisst. Dagegen tritt eine ursprüngliche Nebenfunction, die respiratorische und die propulsatorische, in den Vordergrund. Die Nackengegend wölbt sich nämlich sehr stark vor und bildet die bisweilen enorme Kopfblase (Fig. 595), welche regelmässige Pulsationen ausführt. In ähnlicher Weise ist häufig der hintere Fussabschnitt zu einer pulsirenden Fussblase oder Podocyste erweitert. Kopfblase und Fussblase und ähnliche "Larvenherzen" bilden sich gegen das Ende des Embryonallebens zurück.

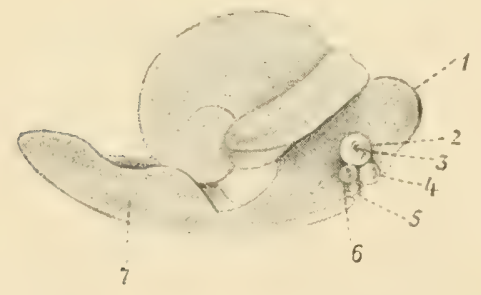

Fig. 595. $4 \mathrm{~mm}$ grosser Embryo von Helix Waltoni, von der rechten Seite, nach P. und F. SARAsin. 1 Kopfblase, 2 oberer Tentakel (Augententakel), 3 Auge, 4 unterer Tentakel, 5 Mundlappen, 6 Sinnesplatte, 7 Podocyste.

Die embryonale Schale erhält sich bei den Gasteropoden entweder zeitlebens, oder sie wird frühzeitig abgeworfen und durch die Anlage der definitiven ersetzt. Bisweilen gelangt sogar eine zweite vergängliche Schale zur Entwickelung.

Es muss nochmals betont werden, dass auch die Nacktschnecken, zu welcher natürlichen Gasteropodenabtheilung sie auch gehören mögen, ein typisches Veligerstadium durchlaufen, dass sie auf den älteren Veligerstadien eimen reutlich al)gesetzten, aufgewundenen Eingeweidesack mit entsprechender Schale und meist auch am Hinterfuss ein Operculum besitzen.

Bei den Larven der gymnosomen Pteropoden entwickeln sich am Körper 3 postorale accessorische Wimperkränze. 
C) Scaphopoda.

Ontogenie von Dentalium. Die Furchung führt zur Bildung einer Coeloblastula, und es entsteht durch Einstülpung eine Coelogastrula. Der Blastoporus liegt anfangs ganz hinten auf der Bauchseite und verschiebt sich, ganz ähnlich wie bei Chiton, nur allmählich auf der Bauchseite weiter nach vorn. Durch Einsenkung des Ectoderms entsteht das Stomodaeum, wobei aber der Blastoporus stets offen bleibt. Es bildet sich eine typische Molluskentrochophora aus, doch wurde die Urniere nicht beobachtet. Das Velum stellt einen dicken Ringwulst am Körper der gestreckt eiförmigen Larve dar. Dieser Ringwulst besteht aus drei Ringen sehr grosser Ectodermzellen, von denen jeder einen Kranz langer Wimpern trägt. Die Schalendrüse breitet sich frühzeitig aus, und ihr seitlicher Rand beginnt frühzeitig als Mantelfalte ventralwärts und nach hinten auszuwachsen. Die freien Ränder der beiden Mantelfalten rerschmelzen später unter dem Körper. Der After bildet sich erst sehr spät. Besonders genau wurde untersucht die Entwickelung des Cerebralund des Pedalganglions, sowie der Gehör-

Fig. 596. 37 Stunden alte Larve von Dentalium, von hinten und unten, pach Kowalevsky. 1 Scheitelschopf, 2 Anlagen der Gehirnganglien (Scheitelröhren), 3 Velum, aus drei Ringsreihen von Wimpern bestehend, 4 Mund (unter dem Velarwulst verborgen), 5 Mantelfalte.

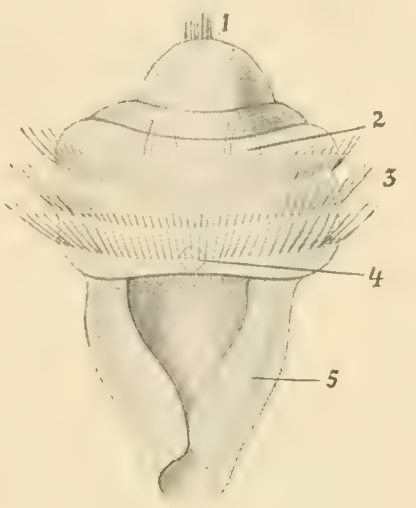

organe. Ventralwärts auf dem Scheitelfelde, vor dem Velum und hinter dem Wimper'schoyf bilden sich zwei symmetrische Einstülpungen des Ectoderms, die Scheitelsäcke oder Scheitelröhren. Diese Scheitelsäcke schnüren sich später vom Ectoderm ab, verlieren allmählich ihr immer enger werdendes Lumen, während ihre Wandung sich durch Zellwucherung verdickt und mehrschichtig wird. Die so entstehenden zwei Zellmassen verbinden sich in der Mittellinie vor und über dem Schlunde zum jungen Cerebralganglion. Die Otocysten entstehen jederseits an der Basis der Fussanlage als ein ectodermales Epithelgrübchen, das sich sofort in Form eines Epithelbläschens vom Ectoderm loslöst. Dicht unter den Gehörbläschen wuchern jederseits Ectodermzellen in die Tiefe und bilden jederseits eine ectodermale Zellenmasse, die sich vom Ectoderm loslüst uml, in das Fussmesoderm einsinkend, mit der gegenüberliegenden Zellmasse zum jungen Fussganglion verschmilzt.

D) Lamellibranchiata.

1. Entwickelung von Teredo (Fig. 597-598). Die Furchung ist eine totale inäquale. Die Gastrulabildung geschieht durch Epibolie. Die Gastrula (Fig. 597 A, B) besteht 1) aus zwei grossen Entodermzellen Macromeren), einer diesen dicht aufsitzenden Haube von Ectodermzellen (Micromeren) und aus zwei symmetrischen, mittelgrossen Urmesodermzellen am hinteren Rande des Blastoporus. Der Blastoporus verschliesst sich - indem die Ectodermzellen unter fortgesetzten Theilungen 
die Entodermzellen vollständig umwachsen - in der Richtung von hinten nach vorn, wobei die beiden Urmesodermzellen vom Ectoderm überwachsen werden und zwischen dieses und das Entoderm zu liegen kommen (Fig. 597 C). Etwas vor der Mitte der Bauchseite entsteht durch Ectodermeinstülpung ein Blindsack, das Stomodaeum (D). Das Ectoderm hebt sich von dem zweizelligen Mesoderm ab, so dass zwischen beiden nachträglich eine Furchungshöhle, oder die primäre Leibeshöhle, auftritt. Es bildet sich ein doppelreihiger, präoraler Wimperkranz (D, E). Von den zwei grossen Entodermzellen schnüren sich durch Theilung kleinere ab. An der ganzen Oberfläche des Keimlings treten Wimpern auf, mit alleiniger Ausnahme der hinteren Rückenfläche, wo sich die cylindrisch werdenden Ectodermzellen grubenförmig zur Bildung der Schalendrüse ( $F$ ) einsenken. Diese sondert als erste Anlage der Schale ein einheitliches, cuticulares Häutchen ab. Die Entodermzellen beginnen sich zu einer Darmwand zu gruppiren. Nach Anlage des ersten Schalenhäutchens verstreicht die Schalendrüse wieder, sie breitet sich aus. Es
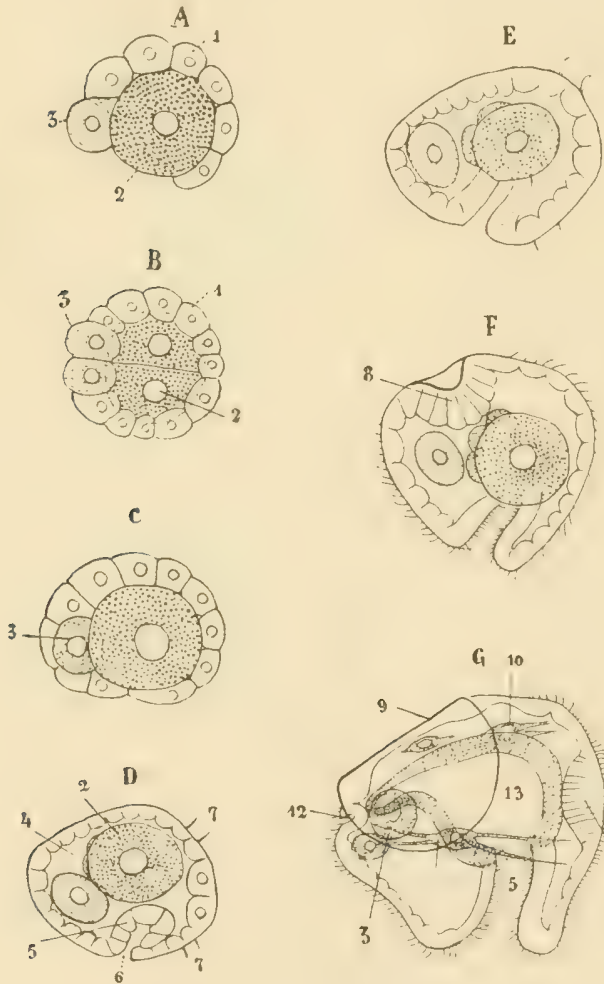
lässt sich nur noch ihr Rand als Wulst unter dem Schalenrande erkennen. Jetzt bildet das Entoderm einen hohlkugelförmigen Mitteldarm, in welchen der Oesophagus durchbricht. Von den beiden Urmesodermzellen haben sich jederseits zwei bis drei kleinere Zellen abgetheilt. Die dünne, cuticulare Schale wird durch Auftreten einer mediodorsalen Grenzlinie zweiklappig.

Fig. 597. $A-G$ Entwickelungsstadien on Teredo, nach Hatscheк. $\boldsymbol{d}, \boldsymbol{C}, \boldsymbol{D}, \boldsymbol{E}, \boldsymbol{F}$ $\boldsymbol{G}$ Von der rechten Seite. $\boldsymbol{B}$ Im optischen Horizontalschnitt. 1 Ectoderm, 2 Macromeren = Entodermzellen, 3 Urmesoderm. zellen, 4 Furchungshöhle, 5 Stomodaeun (Schlund), 6 Mund, 7 präoraler Wimperkranz, 8 Schalendrüse, 9 Schale, 10 Larvale Muskelzellen, 11 Scheitelplatte mit Scheitelschopf, 12 Analeinstülpung, After, 15 entodermaler Mitteldarm.

Ein weiteres Stadium ist zunächst durch das Auftreten einer hinteren, kleinen Ectodermeinstülpung ausgezeichnet, welche als Proctodaeum den Enddarm und After liefert. Im Scheitelfeld ist eine Ectodermverdickung, die Scheitelplatte, entstanden, welche 3 Geisseln trägt. Einzelne Mesodermzellen werden zu Muskelzellen (Fig. 597 G).

Das nächste Stadium kann man als dasjenige der Trochophoralarve bezeichnen. Die Larve unterscheidet sich von einer typischen 
Annelidentrochophora nur durch den Besitz der Schale, welche jetzt schon den grössten Theil des Körpers bedeckt, und durch den Mantel, welcher sich jederseits, zuerst hinten, als Falte gebildet hat und dessen Bildung und Wachsthum von hinten nach vorn fortschreitet. Die hinter dem Scheitelfelde gelegene Region des Körpers hat sich jederseits zu einer breiten Falte ausgedehnt, welche sich nach aussen über die Schale gelegt hat. Die Scheitelplatte ist mehrschichtig geworden, das Proctodaeum gegen den Mitteldarm durchgebrochen. Die Urmesodermzellen haben jederseits einen kurzen Mesodermstreifen erzeugt. Am Vorderende eines jeden Mesodermstreifens hat sich ein länglicher Körper mit kanalartigem, später wimperndem Lumen gebildet, welcher sich nach aussen öffnet, die Urniere. Am Mitteldarm zeigt sich die Anlage der Verdauungsdrüse als parige, halbliugelförmige Ausstiilpung. Die allgemeine Bewimperung des Körpers ist verschwunden. Es erhalten sich noch Wimpern auf der Scheitelplatte und in der Analgegend. Der doppelte, präorale Wimperkranz tritt jetzt sehr deutlich hervor, und es hat sich zu ihm noch ein postoraler Wimperkranz hinzugesellt. Die Region zwischen dem präoralen und dem postoralen Kranze langer Wimpern trägt ebenfalls Cilien und bildet eine adorale Wimperzone.

Ein weiteres Entwickelungsstadium ist in Fig. 598 abgebildet. Wir erkennen die Anlage des Pedalganglions als Ectodermverdickung auf der Bauchseite und die Anlage der $\mathrm{Ki}$ eme in Form einer verdickten

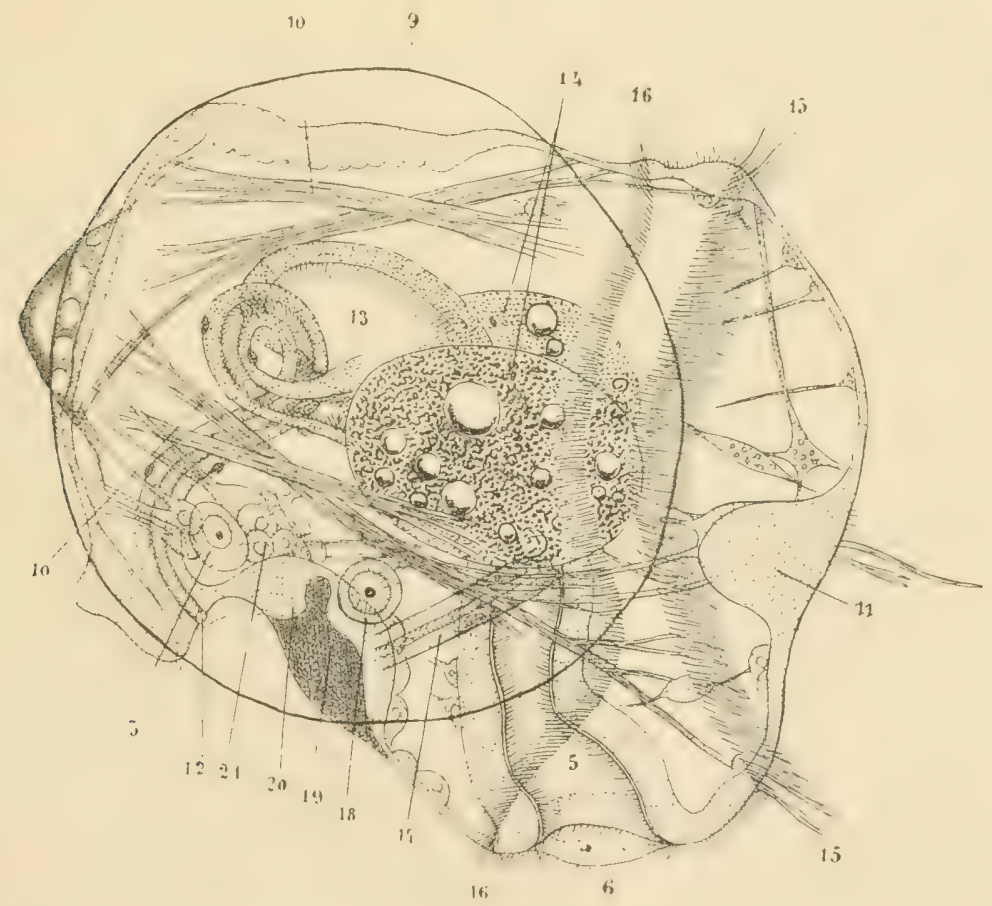

Fig. 598. Aeltere Larve von Teredo, von der rechten Seite, nach HatscheK. Bezeichnungen wio in Fig. 597; ausserdem: 14 Anlagen der Verdauungsdrüse (Leber), 15 präoraler Wimperkranz (Velum), 16 postoraler Wimperkranz, 17 Urniere, 18 Gehörbläschen, 19 Anlage des Pedalganglions, 20 Kiemenanlage, 21 Mesodermstreifen. 
Epithelleiste. Der Magen hat nach hinten einen Blindsack gebildet und der enge Mitteldarmabschnitt hat sich in eine Schlinge gelegt. Durch Einstülpung des Ectoderms und nachherige Loslösung sind zwischen Mund und After die zwei Otolithen führenden Gehörbläschen entstanden. Das Mesoderm besteht aus verästelten Muskelzellen, verästelten Bindegewebszellen, den Urnieren und den noch undifferenzirten Zellen der Mesodermstreifen.

Von weiteren Entwickelungsvorgängen wurden folgende beobachtet. Die ventrale Ectodermverdickung, welche die Anlage des Pedalganglions darstellt, rundet sich ab und löst sich vom Ectoderm los, indem sie zugleich von den sich lebhaft vermehrenden Zellen der Mesodermstreifen, die sich vor ihr zu einer medianen Zellmasse vereinen, umwachsen wird. In der vorderen Bauchregion wächst das Ectoderm hervor, um mitsammt der die Hervorwölbung bewirkenden, wuchernden und sich vergrössernden medianen Masse von Mesodermzellen die Anlage des Fusses zu bilden. In der vorwachsenden Kiemenfalte brechen Kiemenspalten durch, zuerst eine einzige, dann vor dieser eine neue. Die weitere Metamorphose der Larve ist nicht bekannt.

Die Entwickelung der übrigen Meeresmuscheln verläuft ganz ähnlich wie die von Teredo, und es gelangt eine ganz übereinstimmende Larve zur Ausbildung. Alle Meeresmuscheln zeichnen sich speciell dadurch aus (Teredo, Ostrea, Modiolaria, Cardium, Montacuta etc.), dass der Wimperkranz sehr stark entwickelt ist, und dass er sogar meist von einer kragenförmigen Verbreiterung der Haut, dem Velum, getragen wird, welches in zwei seitliche Lappen getheilt ist. Das Velum kann aus der Schale vorgestreckt und in sie zurückgezogen werden und stellt, dank dem Kranz kräftiger Wimpern, den es trägt, das Bewegungsorgan dieser freischwimmenden Muschellarven dar.

Unter den Süsswassermuscheln giebt es nur eine Form, D reis s e a polymorpha, deren Larven freischwimmend sind und ein gut entwickeltes Velum tragen. Diese Form soll erst in (geologisch gesprochen) jüngster Zeit aus einer Meeresmuschel zu einer Süsswassermuschel geworden sein.

Bei den übrigen Süsswassermuscheln finden sich besondere Verhältnisse. So entwickeln sich die Eier von Pisidium und Cyclas in besonderen Brutkapseln in den Kiemen des Mutterthieres und verlassen dasselbe erst als junge Muscheln. Das Trochophorastadium wird zwar noch durchlaufen, aber das Velum bleibt, als locomotorisch functionslos, rudimentär.

2. Ontogenie von Cyclas cornea (Fig. 599 und 600). Wir wollen nur die Punkte hervorheben, in denen die Ontogenie von Cyclas von derjenigen von Teredo abweicht, und solche Beobachtungen eitiren, welche die an Teredo angestellten ergänzen. Die Blastula besteht aus einer Haube kleinerer Zellen (Ectodermzellen) und einem Boden von drei grossen Zellen, einer sehr grossen Urentodermzelle und zwei symmetrischen Urmesodermzellen. Die Urentodermzelle liefert durch Theilung eine Scheibe von Entodermzellen. Die beiden Urmesodermzellen werden von den Ectodermzellen überwachsen, so dass sie in die Furchungshöhle gelangen. Das Entoderm stïlpt sich in der Weise ein, dass ein schlitzförmiger Blastoporus entsteht, welcher von der Gegend des späteren Mundes bis zur Gegend des späteren Afters reicht. Der Blastoporus schliesst sich vollständig. Der Oesophagus entsteht durch Ectodermeinstül)ung. Es bildet sich eine Molluskentrochophora mit Schalendrüse, Fussanlage, Stomodaeum, 
Nagen, Mitteldarm, After, Urniere und Scheitelplatte. Das Velum ist auf ein zu Seiten des Mundes liegendes Wimperfeld (Fig. 599 A) reducirt, was damit in Zusammenhang steht, dass die Trochophora von Cyclas nicht freischwimmend ist; denn die Eier von Cyclas machen ihre ganze Entwickelung in den Kiemen der Mutterthiere durch. Oberhalb der Scheitelplatte sind die Ectodermzellen gross und flach, sie bilden eine hervorgewölbte Kopfblase. Das Mesoderm besteht: 1) aus zerstreuten Zellen, die unter dem Ectoderm der Kopfhöhle, im Fuss, am Darm und
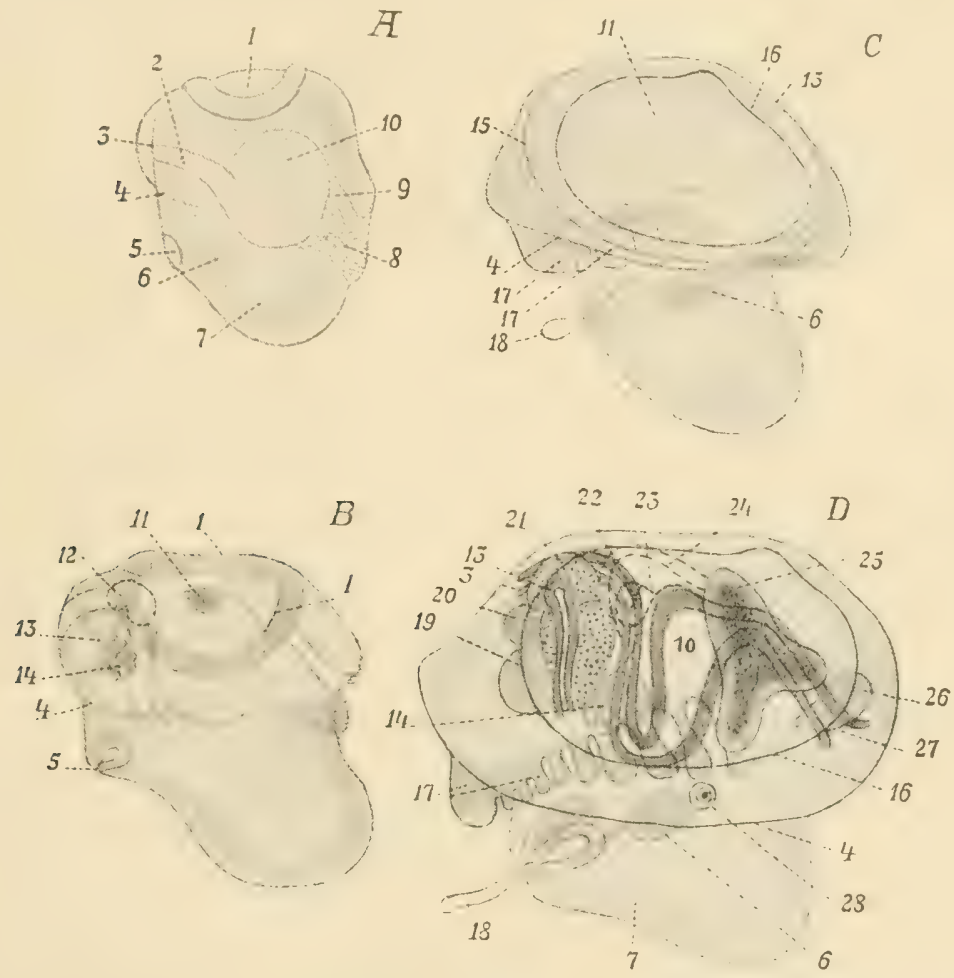

Fig. 599. $\boldsymbol{A}-\boldsymbol{C}$ Vier Entwickelungsstadien von Cyclas cornea, von der rechten Seite, nach Ziegler. 1 Schalenhäutchen, 2 Enddarm, 3 After, 4 freier Rand des Mantelwulstes oder der Mantelfalte, 5 Byssushöhle mit anliegender Byssusdrüse, 6 Anlage des Pedalganglions, 7 Fuss, 8 Velarfeld, 9 Oesophagus, 10 Magen, 11 Kalkschale, 12 Pericard, 13 Niere, 14 Anlage der Gonade, 15 Rand des Schalenhäutchens, 16 Rand der Kalkschale, 17 Kiemenanlage, 18 Byssusfaden, 19 Visceralganglion, 20 hinterer Schliessmuskel, 21 driisiger Abschnitt der Niere, 22 laterale Wand des Pericardialbläschens, 24 mediane Wand des Pericardialbläschens, 25 Verdauungsdrüse (Leber), 26 Cerebralganglion, 27 Mund, 28 Gehörbläschen.

namentlich am Oesophagus liegen, wo sie schon zu Muskelzellen umgebildet sind, und 2) aus zwei Mesodermstreifen, welche zu Seiten des Darmes liegen. Die Pedalganglien entstehen zusammen mit der paarigen Anlage der Byssusdrüs e aus Verdickungen des Ectoderms am Hinterende des Fusses. Die Gehörbläschen entstehen durch Einstïlpung des Ectoderms. Der Mantel legt sich von hinten nach vorn fortschreitend als ein Wulst an, der immer weiter ventralwärts herunter- 
wächst. Zugleich breitet sich die sich abflachende, an ihrem Rande das zarte Schalenhäutchen absondernde Schalendrüse aus. Unter dem Schalenhäutchen tritt jederseits, von einem kleinen, runden Bezirk seitlich von der dorsalen Medianlinie ausgehend, die Anlage der definitiven Schalenklappe auf (B). Die Verdauungsdrüse (Leber) legt sich als zwei seitliche, kugelige Ausstülpungen der Magenwand an. Die Gonaden entstehen aus grösseren und auch sonst differenten Zellen der Mesodermstreifen, welche sich sehr frühzeitig unterscheiden lassen. Im vorderen und dorsalen Theile eines jeden Mesodermstreifens ungrenzt eine Gruppe von Mesodermzellen einen anfangs kleinen Hohlraum, welcher immer grösser wird. Die so gebildeten zwei Bläschen, deren Hohlraum die secundäre Leibeshöhle darstellt, liefern das Pericard. Hinter ihnen gruppiren sich Mesodermzellen so, dass jederseits ein Strang, und aus diesem durch Auftreten eines Lumens ein Kanal, die Anlage des Nephridiums, entsteht, welches sich sofort mit dem Pericardialbläschen in offene Verbindung setzt und, ectodermwärts weiter wachsend, sich bald auch nach

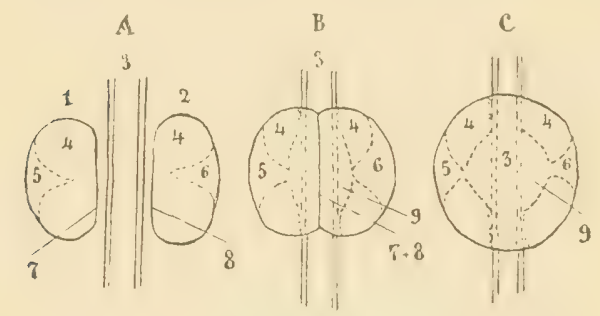

\begin{abstract}
Fig. $600 . \quad \boldsymbol{A}-\boldsymbol{C}$ Schematische Darstellung der Entwickelung des Pericards und Herzens von Cyclas cornea, nach der Darstellung von Ziegler. 1 und 2 Die beiden seitlichen Pericardialbläschen, 3 Enddarm, 4 Pericardialhöhle, 5 und 6 Einstülpungen der lateralen Pericardwand $=$ Anlagen der beiden seitlichen Vorhöfe, 7 und 8 mediale Wände der beiden seitlichen Pericardialbläschen, bei $\boldsymbol{B}$ theilweise
\end{abstract} zu einem medianen Septum verschmolzen (über und unter dem Darm), welches in $\boldsymbol{C}$ verschwunden ist, 9 Anlage der Herzkammer.

aussen öffnet. Die beiden Pericardialbläschen verlängern sich nach hinten und oben. Ein jedes zerfällt durch eine Einschnürung in zwei hintereinander liegende Bläschen, die aber dorsalwärts miteinander communiciren (Fig. 600 A). Die beiden pericardialen Doppelbläschen wachsen einander über dem Enddarm entgegen, um schliesslich in der dorsalen Medianebene zu verschmelzen (B). In ähnlicher Weise verschmelzen sie unter dem Enddarm. Die innere Wand der Pericardialbläschen wird zur Wandung der Herzkam er (C), die laterale zur Wand des Vorhofes. An der Stelle der Einschnürung des jederseitigen Pericardialbläschens bildet sich die Communicationsspalte zwischen Vorhof und Herzkammer und die Atrioventricularklappe.

Das Visceralganglion entsteht am hinteren Ende der Mantelrinne aus einer Ectodermverdickung. Die Pleurovisceralconnective bilden sich wahrscheinlich in ihrer ganzen Länge durch Abschnürung vom Ectoderm. Die $\mathrm{Ki}$ eme entsteht jederseits als eine Falte am dorsalen Rand der inneren Mantelfäche. Ihre Bildung schreitet von hinten nach vorn fort. Von vorn nach hinten treten an der Kiemenfalte von unten nach oben ziehende Rinnen auf, und zwar sowohl an der Innen- wie an der Aussenfläche und so, dass sie einander gegenüberliegen. Die inneren und äusseren Rinnen stossen zusammen, verschmelzen, und an ihrer Verschmelzungsstelle entstehen durch Durchbruch Spalten.

3. Die Entwickelung der Unioniden (Anodonta, Unio) wird stark beeinflusst durch die parasitische Lebensweise ihrer Larven. 
Die befruchteten Eier gelangen in das äussere Kiemenblatt der Kiemen der Weibchen, wo sie ihre erste Entwickelung durchmachen. Die Furchung führt zur Bildung einer Coeloblastula, an welcher sehr frühzeitig die Anlage der Schalendrüse als ein eingekrümmtes Schild grosser und hoher Zellen der Wandung der Blastula auftritt. Die Bildung des Urdarmes erfolgt - was wohl mit der späteren parasitischen Lebensweise der Larve im Zusammenhange steht sehr spät und zwar durch Invagination. Schon bevor diese Invagination stattfindet, hat sich das Mesoderm angelegt, dessen 2 Urzellen im Blastocöl an der Stelle liegen, wo später die Darmeinstülpung auftritt.

Fig. 601. Glochidium-Larve von Anodonta, aus dem äusseren Kiemenblatt des Weibchens. A. Von unten bei geöfineten Schalenklappen, nach ScHierHozz. $\boldsymbol{B}$ Im optischen Querschnitt, nach Flemming, 1 Sinnesborsten, 2 Klebfaden, 3 Schalenaufsatz, 4 Scheinmantel, 5 Seitengruben, 6 Nundbucht, 7 Fusswulst, 8 Wimperschild, 9 embryonaler Schliessmuskel, 10 Schale.
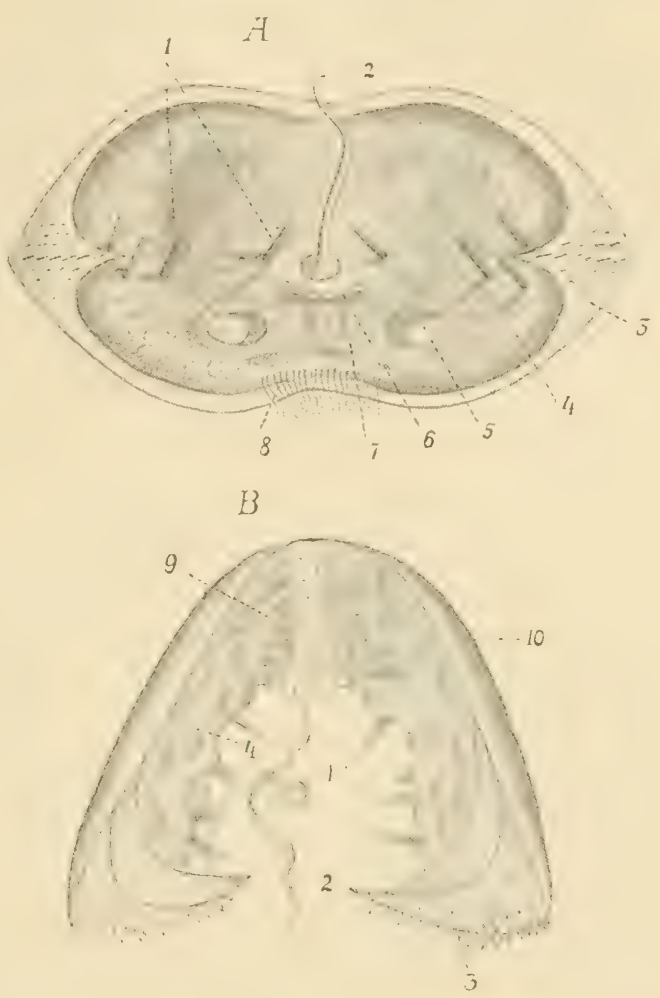

Die als GIochidium parasiticum bezeichneten Embryonen haben auf dem letzten Stadium der Entwickelung, welches sie, bevor sie geboren werden, in den Kiemen der Mutterthiere erreichen, folgenden Bau (Fig. 601). Sie sind bilateral-symmetrisch, haben eine zweiklappige Schale. Jeder Schalenklappe sitzt an ihrem ventralen Rande ein dreieckiger Schalena ufsatz auf, der aussen mit kurzen Stacheln und Dornen besetzt ist. Zwischen den beiden nach innen stark concaven Schalenklappen liegt der Weichkörper, welcher die Schale von innen so auskleidet, dass seine ventrale Epithelschicht - fälschlicherweise - als Mantel bezeichnet werden konnte. Sie mag als Scheinmantel bezeichnet werden. Betrachten wir diesen Scheinmantel von unten bei aufgeklappter Schale, so sehen wir, dass er jederseits 4 mit langen Sinneshaaren ausgestattete Sinneszellen besitzt, von denen je 3 in der Nähe des Schalenaufsatzes und die vierte der Mittellinie genähert liegen. Zwischen den beiden inneren Sinneszellen in der Mittellinie ragt aus der Mündung einer K le bfadendrüse ein langer Klebfaden hervor. Hinter der Klehfadendrüse findet sich: 1) die Mundbucht; 2) eine kleine Hervorwölbung, der Fusswulst; 3) zu beiden Seiten die wimpernden Seitengruben und 4) zu hinterst der Wimperschild. Zwischen dem Mantel und der Schale 
zieht der embryonale Schliessmuskel quer von der einen zu der anderen Schalenklappe. Ausserdem finden sich nur noch vereinzelte Muskelfasern und die Mitteldarmanlage als ein Epithelbläschen, welches sich vollständig vom Ectoderm losgeschnürt hat und ohne irgendwelche Communication mit der Aussenwelt ist.

Die so beschaffenen Embryonen werden von den Muscheln aus den Kiemen nach aussen entleert, wobei sie, die bis jetzt in die Eischalen eingeschlossen waren, frei werden. Sie lassen ihre Klebfäden im Wasser flottiren. Streichen Fische an solchen abgelegten Embryonen vorbei, so haben letztere Gelegenheit, durch Zusammenklappen der Schale vermittelst der Schalenaufsätze sich an der Fischhaut anzuklammern und die Dornen der Schalenaufsätze in sie einzubohren. Die Embryonen von Anodonta siedeln sich mit Vorliebe an den Flossen, diejenigen von Unio an den Kiemen der Fische an. Das Epithel der Fische beginnt an den inficirten Stellen zu wuchern und umwächst nach einigen Stunden den Parasiten vollständig. Eine Wucherung des embryonalen Scheinmantels jeder Schalenhälfte, der pilzförmige Körper, senkt sich in das Gewebe des Wirthes ein und dient wahrscheinlich zur Ernährung des Embryos. Während des endoparasitischen Lebens, das mehrere Wochen dauert, vollzieht sich die Umwandlung des Embryos in die junge Muschel. Dabei werden Larvenorgane resorbirt und dienen so ebenfalls zur Ernährung: zuerst die Sinneszellen, dam die Klebfadendrüse mit dem Reste des Klebfadens, ferner der Schliessmuskel und ganz zuletzt der Scheinmantel. Die Anlagen des definitiven Mantels und der definitiven Schale treten auf. Die Mitteldarmblase setzt sich mit der Mundbucht in Verbindung; der Fusswulst wächst zum zungenförmigen Fuss aus, und es tritt an ihm durch Epitheleinstülpung die rudimentäre Byssusdrüse auf. Während des parasitischen Lebens treten ferner, in ähnlicher Weise wie bei anderen Muscheln, auf: die Anlagen der inneren Kiemeblätter, der Verdauungsdrüse, der Nephridien, des Herzens, der Cerebral-, Pedal- und Visceralganglien und der Gehörbläschen.

Im Laufe der letzten Woche des Parasitismus wird die durch Wucherung der Gewebe des Wirthes gebildete, den Parasiten umgebende Kapselwand dünner, und schliesslich wird der Parasit durch Bersten dieser Wand frei und fällt als junge Muschel auf den Grund des Wassers. Es fehlen ihr nur noch die Geschlechtsorgane, das äussere Blatt der Kiemen und die Mundlappen.

\section{E) Cephalopoda.}

Ueber die Entwickelung der Tetrabranchiata (Nautilus) ist nichts bekannt.

Dibranchiata. Das Ei ist gewöhnlich sehr gross und enthält, ähnlich den Haifisch-, Reptilien- und Vogeleiern, eine sehr ansehnliche Masse von Nahrungsdotter. Es gehört zum Typus der telolecithalen, meroblastischen Eier und wird von einer Eikapsel umhüllt. (Zahlreiche Eikapseln können miteinander zu Schnüren, Strängen etc. verkittet werden.) Die partielle $\mathrm{Furchung}$ vollzieht sich demgemäss am animalen Pole des Eies und führt hier zur Bildung einer Keimscheibe (Blastoderm).

Ontogenie von Sepia. Das Blastoderm wächst nur sehr langsam um den Dotter herum, so dass im Bezirk der ursprünglichen Keimscheibe schon längst alle äusseren Organe des Embryos kenntlich sind, während am gegenüberliegenden Pol der Dotter noch nackt zu Tage tritt. 
Mit Bezug auf das erwachsene Thier ist der Keim so zu orientiren, dass die Mitte der Keimscheibe (der animale Pol) dorsal liegt, der obersten Spitze des Eingeweidesackes entspricht, während die Nahrungsdottermasse eine ventrale Lage hat.
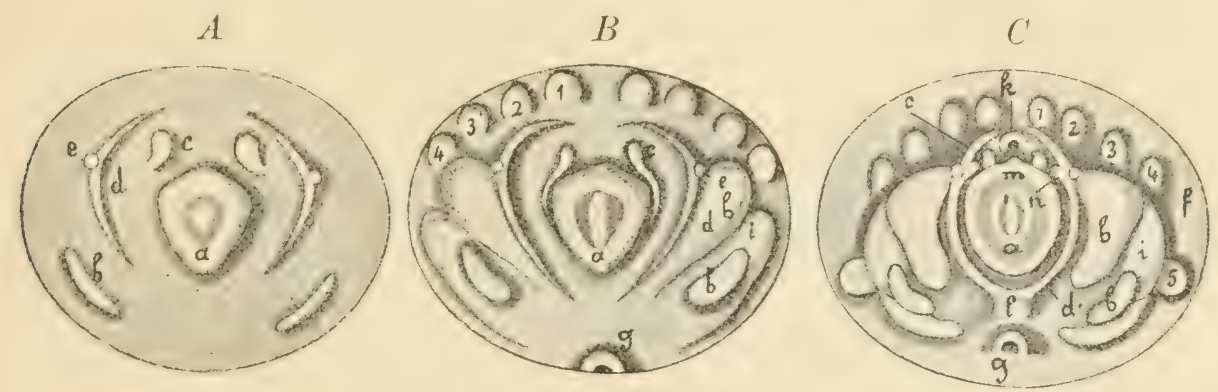

$D$
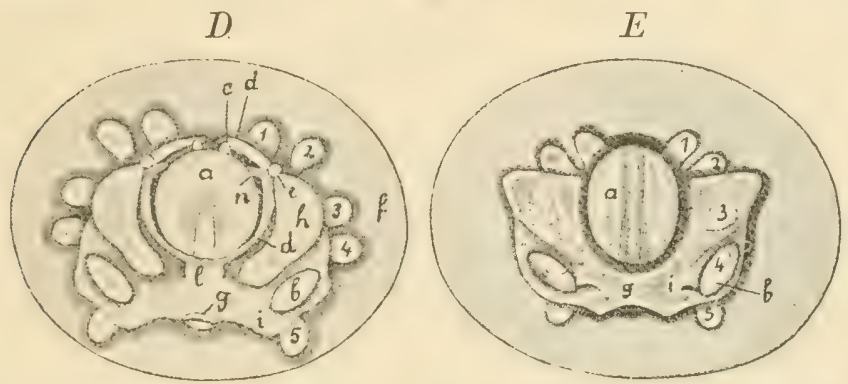

Fig. 602. Ontogenie von Sepia, nach Koelliker. $\boldsymbol{A}-\boldsymbol{E}$ Fünf Entwickelungsstadien. Man sieht die dem Dotter aufliegende Keimscheibe von ihrer freien Oberfläche, deren Centrum der dorsalen Spitze des Eiugeweidesackes der erwachsenen Sepia entspricht. Die Vorderseite des Embryos ist in den Figuren nach unten gekehrt. a Eingeweidesack mit Mantel, $b$ Augenanlagen, $c$ Kiemenanlagen, $d$ Trichterhälften, $e$ Anlage des Trichterknorpels des Mantelschliessapparates, $f$ peripherer Theil des Blastoderms, welcher, den Dotter allseitig umwachsend, den Dottersack bildet, $g$ Mund, $h$ hinterer Kopflappen, $i$ vorderer Kopflappen, k After, 5 vorderes oder erstes Armpar, 4, 3, 2, 1 zweites, drittes, viertes und hinterstes Armpar.

Stadium I (Fig. 602 A). An der Keimscheibe tritt in der Mitte eine oval-rhombische Hervorwölbung auf, die Anlage des Eing ew eidesackes und IIantels. Vor dieser jederseits ein bohnenförmiges Hügelchen, die Anlage des A u ges. Jederseits hinter dem Auge zieht sich eine langgestreckte, schmale, leistenförmige Erhabenheit im Bogen nach hinten. Ungefähr in der Mitte ihrer Länge bildet sich dicht an ihrer Aussenseite ein kleiner Höcker, die Anlage des Trichterknorpels. Der vor diesem Höcker gelegene Theil der Längsleiste wird zu dem vo m Trichter z u m Nackenknorpel gehenden Muskel, der hintere Theil (welcher hinter dem Mantel liegt) stellt die parige Anlage des Trichters selbst dar. Zwischen den beiden Trichteranlagen, hinter dem Mantel, erheben sich symmetrisch zwei weitere Höcker, die Anlagen der Ki e m en. Eine Grube im Centrum der Anlage des Eingeweidesackes wurde als Anlage einer Schalendrüse (?) gedeutet.

Stadium II (Fig. 602 B und 603 A). Die erwähnten Anlagen wölben sich stärker vor und heben sich deutlicher ab. Als Höcker treten an der Aussen- und Hinterseite der Trichteranlagen zuerst die 
Anlagen der beiden binteren Armpa are, dann die Anlagen eines dritten und vierten Paares auf. Es zeigt sich die erste Andeutung des Kopfes jederseits in Form einer doppelten, grösseren Anschwellung. Jederseits trägt die äussere und vordere Kopfanschwellung die Augenanlage. Der Embryo bedeckt sich mit Wimpern. Ganz vorn in der Medianlinie zeigt sich der Mund, d. h. die äussere Oeffnung des sich einsenkenden Stomodaeums.

Stadium III (Fig. 602 C). Die ganze Embryonalanlage hat sich dorsalwärts mehr hervorgewölbt und vom Dotter abgesetzt. Am Dotter hat sich das Blastoderm, bestehend aus 2 Schichten, dem Ectoderm aussen und der Dotterhaut innen, weiter gegen den ventralen (vegetativen) Pol ausgebreitet. Am hinteren Rande der Anlage des Eingeweidesackes ist die Mantelfalte schon derart vorgewachsen, dass sie eine kleine Mantelhöhle und theilweise schon die Kiemenanlagen bedeckt. In dem Raume zwischen den Kiemen und den Trichteranlagen bat sich durch Einstülpung das Proctodaeum gebildet, dessen Oeffnung, der After, zu erkennen ist. Es zeigt sich die Anlage des fünften Armpaares.

Stadium IV (Fig. 602 D und 603 F, G). Der Eingeweidesack ist gewölbter. An seiner Basis besitzt er ringsherum einen freien Mantelrand. Die Kiemen sind tiefer in die vergrösserte hinterständige Mantelhöhle hineingerückt. Auch die Trichteranlagen liegen jetzt dicht am Mantel, sie haben sich hinten bis fast zur Berührung genähert. Die Armanlagen sind von hinten weiter nach vorn um die Kopfanlagen herum gerückt. Indem sich die ganze Embryonalanlage wieder stärker emporgewölbt und vom Dotter deutlicher abgesetzt hat, rücken die Armanlagen näher aneinander und unter die Kopfanlagen. Der After ist schon von der Mantelfalte bedeckt.

Stadium V (Fig. $602 \mathrm{E}$ und $603 \mathrm{~B}, \mathrm{H}$ ). Indem sich die Arme unter den Kopfanlagen, die selbst von beiden Seiten her miteinander verschmolzen sind, einander noch mehr (gegen die Axe des ganzen Keimes zu) genähert haben, bilden sie jetzt schon einen ziemlich engen Kranz auf der Bauchseite des Embryos, derart, dass bei der Betrachtung von der Rückenseite einige von ihnen vom Kopfe verdeckt erscheinen. Die Folge davon ist ferner, dass sich jetzt der Embryo, der schon als junge Sepia kenntlich ist, vom darunterliegenden Dotter scharf abgeschnürt hat. Die Trichteranlagen sind an ihrem freien Rande miteinander verschmolzen und ganz ins Innere der Mantelhöhle gerückt.

Stadium VI (Fig. 603 C). Die Anlagen des Kopfes und der Arme haben sich jetzt zum Kopffuss angeordnet. Der Embryo stellt jetzt etwas vom Dotter durchaus Besonderes dar und hängt nun an demselben, statt, wie früher, auf ihm zu liegen. Das Blastoderm umwächst schliesslich den Dotter vollständig und bildet so einen Dottersack.

Dieser Dottersack ist anfänglich 4-5mal grösser als der Embryo. In dem Maasse, als der Embryo nun auf Kosten des Dotters wächst und sich weiter entwickelt, wird der Dottersack kleiner, so dass er beim Ausschlüpfen des Embryos nur noch ein Drittel so gross ist, wie dieser (Fig. 603 D).

Mit Bezug auf den Dottersack ist ferner noch zu bemerken, dass er zu keiner Zeit mit dem Darm in Communication steht. Was die Vertheilung des Dotters in dem sich entwickelnden Embryo anbetrifft, so wird die Dottermasse in dem Maasse, als sich der Embryo abschnürt, in zwei Theile geschieden, einen inneren (im Innern des Embryos liegenden) und einen äusseren (den Dottersack erfüllenden). Beide sind durch den 
aus dem Kopffuss nach unten vorragenden Dottersackstiel hindurch miteinander verbunden. Der innere Dotter findet sich im Embryo in drei ungleich grossen Portionen. Die grösste erfüllt den Eingeweidesack, eine
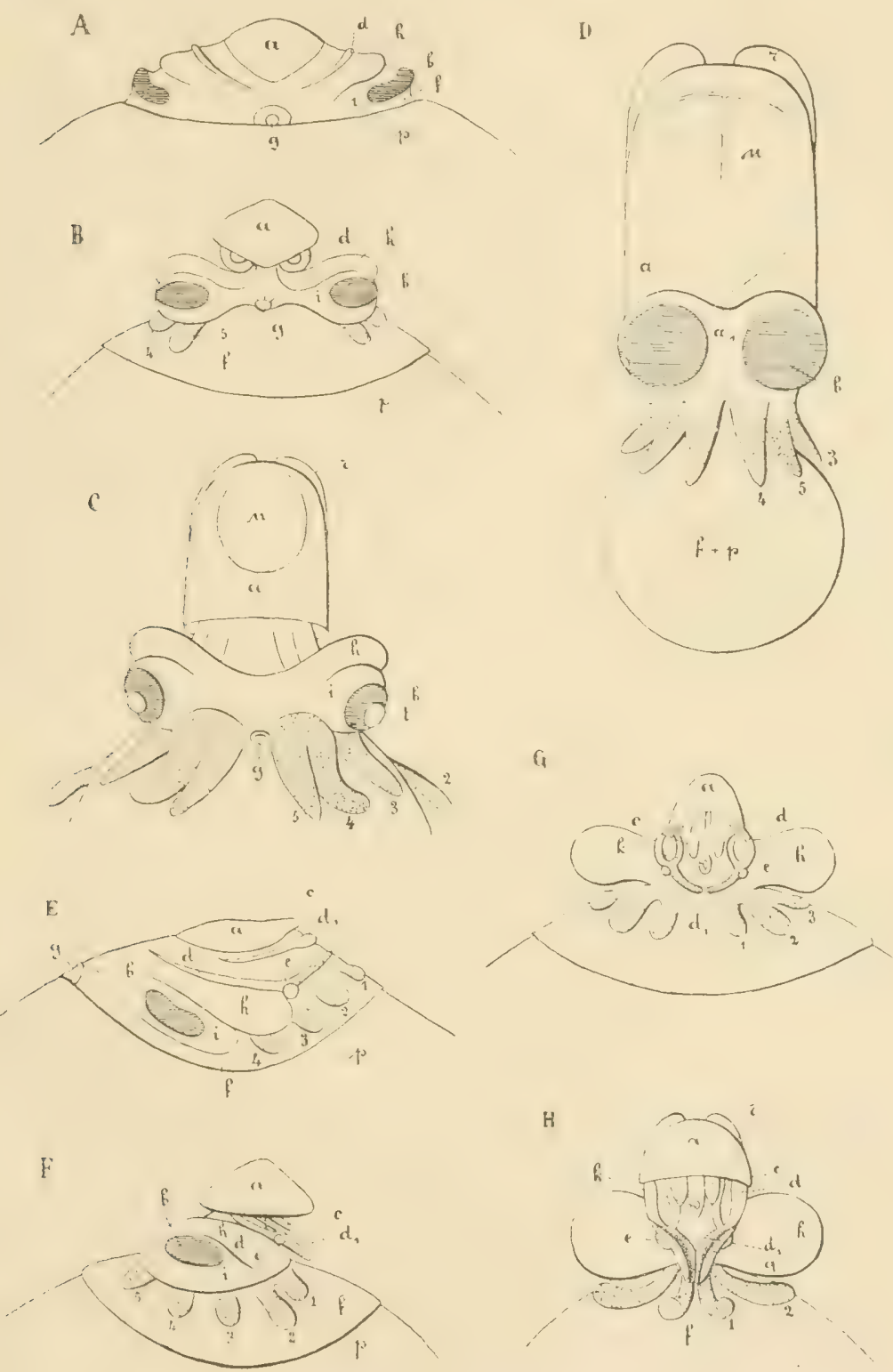

Fig. 603. Verschiedene Stadien der Entwickelung von Sepia, nach KoeLliker. $\boldsymbol{A}, \boldsymbol{B}, \boldsymbol{C}, \boldsymbol{D}$ von vorn; $\boldsymbol{E}$ und $\boldsymbol{F}^{\prime}$ von der linken Seite; $\boldsymbol{G}$ und $\boldsymbol{H}$ von hinten. Bezeichnungen wie in Fig. 602; ferner: d Anlage des Trichter-Nackenmuskels (Collaris), $d_{1}$ paarige Anlage des eigentlichen Trichters, $p$ Dotter, $a_{1}$ Mantelrand, $t$ Augeneinstülpung?, u. Gegend der Schale oder Schulpe, $q$ umgesehlagener Rand der beiden Trichteranlagen, $r$ Flossen. Bei $\boldsymbol{G}$ ist die Mantelfalte in die Höhe gehoben, bei $\boldsymbol{H}$ abgeschnitten. 
ansehnliche Portion erfüllt den Kopffuss; beide sind durch eine enge im Halstheil liegende Portion verbunden.

Loligo und Argon a ta haben einen kleineren Dottersack, welcher frühzeitiger als bei Sepia vom Blastoderm umwachsen wird. Der Dottersack wird bei Argonauta schon ganz in den Körper aufgenommen, bevor dieser sich ventralwärts ganz verschlossen hat.

Noch geringer ist die Menge des Nahrungsdotters bei einem Cephalopoden (Ommatostrephes?), dessen Laich pelagisch flottirt. Die Furchung ist zwar auch hier eine partielle, discoidale, aber der Nahrungsdotter wird schon vom Blastoderm fast vollständig umwachsen, bevor am Keime irgendwelche Organe entwickelt sind, und es bildet sich kein äusserer Dottersack.

Wir verzichten auf eine Darstellung der Bildung der Keimblätter, der Entwickelung der inneren Organe und der inneren Differenzirung äusserlich sichtbarer Organe. Die Resultate der verschiedenen Untersuchungen sind so widersprechend und theilweise so lückenhaft, dass neue Untersuchungen dringend geboten sind. Die Entwickelung des Auges ist schon 1). 750 geschildert und die Entwickelung des Enddarmes und Tintenbeutels p. 777 illustrirt worden.

Zum Schlusse mögen zwei wichtige Thatsachen aus der Entwickelung der Dibranchiaten besonders betont werden. 1) Wichtig für die Auffassung der Arme als Theile des Fusses. Die Anlagen der Arme treten hinter den Kopfanlagen auf und schieben sich erst secundär um den Kopf herum und unter denselben. Der Mund liegt aber noch auf ganz späten Stadien am Vorderende des Armkranzes (Fig. 603 C). 2) Der Trichter entsteht aus zwei seitlichen, getrennten Anlagen, die erst secundär an ihrem freien Rande verwachsen. Wichtig mit Hinblick auf die bei Nautilus zeitlebens bestehende Tremnung der beiden Trichterlappen. Bezüglich der Auffassung des Trichters als Epipodium vergl. p. 691.

Es muss noch auf das Fehlen eines Velums bei den Cephalopodenembryonen hingewiesen werden. Dasselbe findet seine Erklärung in der directen Entwickelung dieser Mollusken im Innern von Eikapseln, auf Kosten einer grossen Masse von Nahrungsdotter.

Dringend nöthig sind Untersuchungen über die Entwickelung der Schale und über die Natur des als Schalendrüse bezeichneten Organes.

\section{Phylogenie.}

Wir wollen uns hier kurz fassen. Directe Anknüpfungspunkte des Molluskenstammes an andere Abtheilungen des Thierreiches sind zur Zeit nicht bekannt. Ueber den Ursprung der Mollusken steht subjectiven Ansichten Thür und Thor offen. Unsere subjective Ansicht ist die, dass die Mollusken von turbellarienähnlichen Thieren abstammen, welche sich durch den Erwerb eines Enddarmes, eines Herzens und wenigstens theilweise Umwandlung von Gonadenhöhlungen zu einer secundären, ursplüinglich paarigen Leibeshöhle ron der Organisation der heute bekannten Platoden entfernt hatten. Die Uebereinstimmung im Nervensystem der niederen Mollusken (Chiton, Solenngastres, zum Theil auch Diotocardier) mit demjenigen der Platoden ist eine ganz auffüllige: Strickleiternervensystem mit Hauptstämmen, welche in ihrer ganzen Länge einen Besatz von Ganglienzellen aufweisen. Pleurovisceralstränge $=$ Seitenstränge der Platoden; Pedalstränge $=$ ventrale Lüngsnervenstämme der Platoden. Wenn 
eine solche hypothetische Stammform zum Schutze des Körpers eine Rückenschale, vielleicht zunächst in Gestalt einer derben Cuticula mit eingelagerten Kalkkörperchen, absonderte, so war die nothwenige Folge davon die Ausbildung der typischen Molluskenorganisation: Die Ausbildung der Schale entfremdete einen grossen Theil der Körperoberfläche der ursprünglichen respiratorischen Function und führte zur Ausbildung localisirter Kiemen, die durch das Mittel der Ausbildung einer Mantelfalte sich unter den für die nothwendig zarthäutigen Organe äusserst nützlichen Schutz der Schale begeben konnten. Schwund der Musculatur an der von der Schale bedeckten Rückenseite und damit Schwund der dorsalen Längsnervenstämme. Stärkere Ausbildung der schon bei den Planarien stärker entwickelten Musculatur der Bauchseite = Bildung des Fusses mit seiner flachen Kriechsohle. Umwandlung eines Theiles der dorsoventralen Musculatur zu einem Schalenmuskel.

Bei dieser Ableitung der Mollusken wäre die charakteristische Molluskenlarve - ohne dass wir sie auf die Annelidentrochophora zu beziehen brauchten - in folgender Weise zu erklären. Sie entspricht der Turbellarienlarve (MüLLER'sche Larve der Polycladen etc.), in welche Molluskencharaktere zurïckverlegt sind: Schalendrüse, Schale, After, Fuss. Der präorale Wimperkranz (das Velum) der Molluskenlarve entspricht dem nämlichen Gebilde der Turbellarienlarven. Die Urniere der Molluskenlarve entspricht einem vereinfachten Turbellarien-Wassergefässsystem, während sowohl die bleibenden Nephridien, als Ei- und Samenleiter morphologisch mit Leitungswegen der Geschlechtsproducte bei den Turbellarien zu homologisiren sind.

\section{Uebersicht der wichtigsten Litteratur.}

Zusammenfassende Werke. Handbücher. Schriften allgemeineren Inhaltes. Untersuchungen, die sich über alle odermehrereklassen erstrecken.

Boll. Beiträge zur vergleich. Histologie des Molluskentypus. Arch. für mikr. Anat. Supplementband. 1869.

H. G. Bronn. Die Klassen und Ordnungen des Thierreiches. Bd. III: MIalacozoa. I. Malacozoa acephala. 1862. II. Nalacozoa cephalophora, von W. Keferstein. 1862-1866.

G. Cuvier. Mémoires pour servir à l'histoire et ì l'anatomie des Mollusques. Paris 1817.

G. B. Deshayes. Traité élémentaire de Conchyliologie. 3 vol. Paris 1839-1857.

Derselbe. Histoire naturelle des Mollusques (Exploration de l' Algérie). 1848.

Eydoux et Sonleyet. Voyage autour du monde sur la corvette la Bonite. Histoire naturelle: Zoologie. Paris 1852.

Paul Fischer. Manuel de Conchyliologie et de Paléontologie conchyliologique. Histoire naturelle des Mollusques vivants et fossiles. 2 vol. Paris 1887.

H. von Jhering. Vergleichende Anatomie des Nervensystems und Phylogenie der Mollustien. Leipzig $187 \%$.

Kober, Beiträge zur Anatomie und Physiologie der Weichthiere. Königsberg 1851.

E. Ray Lankester. Mollusca, in: Encyclopaedia britannica. 9 ed. vol. 16.1883.

R. Louckart. Zoologische Untersuchungen. Ileft 3. Giessen 1854.

Poli. Testacea utriusque Siciliae eorumque historia et anatome. $3 \mathrm{Bd}$. 1791-1795.

H. Simroth. Ueber einige Tagesfragen der Malacozoologie, hauptsächlich Convergenzerscheinungen betreffend, in: Zeitschr. Naturw. Halle. 62. Bd. 1889.

J. Thiele. Die Stammesverwandtschaft der Mollusken. Ein Beitrag zur Phylogenie der Thiere. Jenaische Zeitschr. f. Naturisisensch. 25. Bd. 1891.

S. P. Woodward. A Manual of the Mollusca. Verschiedene Auflagen. 


\section{Amphineura.}

L. Graff. Anatomie des Chaetoderma nitidulum, Zeitschr. f. wiss. Zoologie. 26. Bd. 1876.

Derselbe. Neomenia und Chaetoderma. Zeitschr. $f$. wiss. Zoologie. 28. Bd. 187 .

B. Haller. Die Organisation der Chitonen der Adria. Arb. aus dem zool. Instit. in Wien. I. Theil, Bd. 4, 1882; II. Theil, Bd. 5, 1883.

G. A. Hansen. Anatom. Beskrivelse of Chaetoderma nitidulum. Nyt magaz. for naturvidenskab. Bd. 22. 1877.

Derselbe. Neomenia, Proneomenia und Chaetoderma, in: Bergen. MIus. Aarster. f. 1888.

J. Heuscher. Zur Anatomie und Histologie von Proneomenia Sluiteri, unter der Presse.

A. A. W. Hubrecht. Proneomenia Sluiteri. Niederl. Arch, für Zool. Suppl.-Band I. 1881. Derselbe. A contribution to the morphology of Amphineura. Quart. Journal Microsc. Soc. vol. 22. 1882.

Derselbe. Dondersia festiva gen, et spec. nov,, in: Donders Festbundel. Nederl. Tijdschr. Geneesk. 1888.

J. Koren und D. C. Danielssen. Descriptions of new species belonging to the genus Solenopus, with some observations on their organisation. Ann. Nat. Hist. (5) vol. 3, 1879.

A. Kowalevsky und A. F. Marion. Contributions à l'histoire des Solénogastres ou Aplacophores, in: Ann. Mus. H. N. Marseille. Tome 3. 1889.

A. Th. จ. Middendorff. Beiträge zu einer Malacuzoologia rossica. I. Beschreibung und Anatomie neuer oder für Russland neuer Chitonen. Mém. de l'dcad. St. Pétersbourg. tome VI. 1849.

G. Pruvot. Sur l'organisation de quelques Néoméniens des côtes de France, in: Archives de Zoologie expérim. $2^{0}$. vol. 9. 1891.

A. Sedgwick. On certain points in the anatomy of Chiton. Proceed. Roy. Soc. No. 217. Dec. 1881.

T. Tullberg. Neonenia a new genus of invertebrate animals. Svenska Vet. Akad. Handl. $B d$. 3. 1875 .

Axel Wirén. Studien über die Solenogastres. I. MTonographie des Chaetoderma nitidulum Lovén, in: Kongl. Svenska Vetenskaps-dkademiens Handlingar. vol. 24. Stockholm 1892.

Ausserdem Arbeiten von van Bemmelen, Dall, Pelseneer etc.

$$
\text { Gasteropoda. }
$$

Alder und Hancock. A monograph of the British Nudibranchiate BIollusca. London 1850 -1851 .

R. Bergh. Beiträge zu einer Monographie der Polyceraden, I. II. III., in: Verhandl, der k. k. Zoolog. Botan. Gesellschaft zu Wien. Bd. 29, 30, 33. 1879-1883.

Derselbe. Ueber die Verwandtschaftsbeziehungen der Onchidien. Morph. Jahrb. 10. Bd. 1884.

Derselbe. Report on the Nudibranchiata of the Chall. Exped. Report Chall. Zool. vol. 10. 1884.

Derselbe. Die Titiscanien, eine Familie der rhipidoglossen Gasteropoden. Mit 3 Taf. Morph. Jahrb. 16. Bd. 1890.

Derselbe. Die Marseniaden, in: Zool. Jahrbücher. Bd. 1. 1886, und in: Senper. Reisen im Archipel der Philippinen. 2. Th. Wissensch. Resultate. Suppl.-Heft 3. 1886.

Derselbe. Die cladohepatischen Nudibranchien, in: Zool. Jahrbücher. Abth. für Systematik. Bd. 5. 1891 .

Derselbe. Die cryptobranchiaten Dorididen, in: Zool. Jahrbücher von Spengel. Abth. für Systematik. 6. Bd. 1891.

Ausserdem zahlreiche Monographien verschiedener Familien, Gattungen und Arten von Opisthobranchiaten in verschiedenen Zeitschriften.

J. E. V. Boas. Spolia atlantica. Bidrag til Pteropodernes Morfologi og Systematil samt til Kundskaben om deres geografiske Udbredelse, in: Danske Vid. Selsk. Skr. (6). Bd. 4. 1886.

Derselbe. Zur Systematik und Biologie der Pteropuden, in: Zoolog. Jahrbücher. 1. Bd. 1886.

L. Boutan. Recherches sur l'anatomie et le développement de la Fissurelle, in: Arch. Z Expér. (2). Tome 3bis. 1886.

E. L. Bouvier. Système nerveux, morphologie générale et classification des Gastéropodes prosobranches. Ann. Sc. Nat. (7). Tome 3, 1887.

E. Claparède. Anatomie und Entwickelungsgeschichte der Neritina Auviatilis. Müller's Archiv. 1857.

P. Garnault. Recherches anatomiques et histologiques sur le Cyclostoma elegans. Bordeaux, in: Arch. Soc. Linn. Bordeaux 1887. 
C. Gegenbaur. Untersuchungen ïber. Pteropoden und Heteropoden. Leipzig 1853

R. J. Harvey Gibson. Anatomy and physiology of Patella vulgata. Part 1. Anatomy, in: Trans. Royal Soc. Edinburgh. vol. 32.1887.

B. Haller. Untersuchungen über marine Rhipidoglossen. I. Studie Morph. Jahrb. Bd. 9. 1883. II. Studie. Bu. 11. 1886

Derselbe. Die Morphologie der Prosobranchier, gesammelt auf einer Erdumsegelung durch die Kïnigl. ital. Corcette "Tettor Pisani". I. Jlorph. Jahrb. 14. Bd. 1888. II. ibid. 16. $B d .1890$.

Huxley. On the morphology of the cephalous Mollusca as illustrated by the anatomy of certain Heteropoda and Pteropoda etc. Philos. Transactions. 1853.

J. Joyeux-Laffuio. Organisation et développement de l'Oncidie (Onchidium celticum Cuv.). Arch. Zool. expérimentale. Tome 10. 1882.

H. de Lacaze-Duthiers. Histoire et monographie du Pleurobranche orangé. Ann. Sc, nat. 1 seri. Tiome 11 18.j!?

Derselbe. Mémoire sur la Pourpre, in: Annales des Sciences nat. (4). Tome 12.1859.

Derselbe. Mémoire sur le système nerveux de l'Haliotide, in: Ann. des Sciences nat. (4). Tome 12.1859.

Derselbe. Mémoire sur l'anatomie et l'embryogénie des Vermets. Ann. Scienc. nat. 4. série. Tome 13. 1860.

Derselbe. Histoire de la Testacella, in: Arch. Zool. expér. (2). Tome 5.1888.

A. Lang. Versuch einer Erklërung der Asymmetrie der Gasteropoden, in: Vierteljahrsschrift d. Naturf. Gesellsch. Zürich 36. Bd. 1891.

Fr. Leydig. Ueber Paludina vivipara. Zeitschr. f. wiss. Zool. 2. Bd. 1850.

Milne Edwards. Note sur la classification naturelle des Mollusques Gastéropodes. Ann. Sciences nat. 1848

G. Moquin-Tandon. Recherches anatomiques sur l'ombrelle de la mediterranée. Ann. Scienc. nat. 5 ser. vol. IIV. 1875

H Müller und C. Gegenbaur. Ueber Phyllirhö̈ bucephalum. Müll, Arch. 1858.

A. Nalepa. Beitrüge zur Anatomie der Stylommatophoren. Sitz-Ber. Akad. Wien. 87. Bu. 1883 .

Nordmann. Monographie de Tergipes Edwardsii. Mém. Acad. Imp. St. Pétersbourg. Tom. II. 1843.

J. Paneth. Beiträge zur Histologie der Pteropoden und Heteropoden. Archiv für mikrosk. Anat. 24. Bd. 1884.

J. I. Peck. On the anatomy and histology of Cymbutiopsis calceola. 4. Taf., in: Studies Biol. Labor. Johns Hopl. Univ. vol. 4.

Paul Pelseneer. Report on the Pteropoda collected by H. M. S. Challenger during etc. Pt. 1, 2, 3, in: Report Challenger. Zoology. Pt. 58. 1887, Pt. 56. 1888, Pt. 65. 1888.

Derselbe. The cephalic appendages of the gymnosomatous Pteropoda, and especially of Clione, in: Quart. Journ. Microsc. Science (2). vol. 25. 1885.

L. Plate. Studien über opisthopneumone Irungenschnecken. I. Daudebardia und Testacella. Zool. Jahrbücher. Abth. für Anatomie und Ontogenie. 4. Bd. 1891.

Quatrefages. Mémoire sur les Gastropodes phlebentères. Ann. Scienc. nat. Tome III und IV. 1844 und 1845 .

Rang et Souleyot. Histoire naturelle des Mollusques Ptéropodes. Paris 1852.

B. Sharp. Beiträge zu Anatomie von Ancylus fuviatilis (O.F. Müll.) und Ancylus lacustris (Geoffroy). Inaug.-Dissert. Würaburg 1883.

H. Simroth. Veber die Bevegung und das Bevegungsorgan des Cyclostoma elegans und der einheimischen Schnecken überhaupt. Zeitschr. f. wiss. Zool. 36. Ba. 1881.

Derselbe. Versuch einer Naturgeschichte der deutschen Nacktschnecken und ihrer europäischen Veriandten. Zeitschr. f. wiss. Zoologie. 42. Bd. 1885.

Ausserdem zahlreiche Arbeiten ïber Pulmonaten in verschiedenen Zeitschriften.

S. Trinchese. Materiali per la fauna maritima italiana. Aeolididae e famiglie affini. Atti accad. Lincei. (3). Mem, vol. 11. 1883.

Troschel. Beiträge zur Kenntniss der Pteropoden. Arch. $f$. Naturg. Tom. XX. 1854.

M. Vayssièro. Recherches anatomiques sur les Mollusques de la famille des Bullidés. Ann. Hist. Nat Zool. (6). Tome 9. 1880.

Derselbe Recherches anatomiques sur les genres Pelta (Runcina) et Tylodina. Ann. Sc. Nat. (6). Tome 15. 1883.

Derselbe. Recherches zoologiques et anatomiques sur les Mollusques opisthobranches du golfe de Marseille. 1. partie Tectibranches. Ann. Mus. Hist. N. Marseille. Tome 2. Hém. 3. 1885. 2. partie. Ibid. Tome 3. Hém. No. 4. 1888.

Nicolas Wagner. Die virbellosen Thiere des veeissen Meeres. 1 Bd. Leipzig. fol. 1885.

R. Wegmann. Contribution is l'histoire naturelle des Haliotides. Arch. Z. expér. (2). Tome 2. 1884. 
Derselbe. Note sur l'arganisation de la Patella vulgata L., in: Recueil. Z. Suisse. Tome 4. 1887.

Emile Yung. Contributions à l'histoire physiologique de l'escargot (Helix ponatia), in: Mém. Cour. Acad. Belg. Tome 49. 1887.

Scaphopoda.

Herm. Fol. Sur l'anatomie microscopique du Dentale, 4 pl. Arch. Zool. expér. (2). T. 7. 1889.

H. de Lacaze-Duthiers. Histoire de l'organisation et du développement du Dentale Annales des Sciences naturelles. IV. Sér. Tome VI, VII und VIII. 1856, 1857, 1858.

L. Plate. Bemerkungen zur Organisation der Dentalien. Z. Anzeiger, 11. Jahrg. 1888. Ueber das Herz der Dentalien. Ibid. 14 Jahrg. 1891.

M. Sars. Om Siphonodentalium vitreum etc. Christiania 1861.

Lamellibranchiat a.

Ernst Egger. Jouannetia Cumingi Son. Eine morphol. Untersuchung. Arbeit. Zool. Instit. IIüzburg. 8 lid. 1887.

Garner. On the anatomy of the lamellibranchiate Conchifera. Transact of the Zool. Soc. London. Tome II. 1841.

H. de Lacaze-Dathiers. Mémoire sur l'organisation de l'Anomie. Annales des Sciences nat. (4). Bd. 2. 1854.

Derselbe. Morphologie des Acéphales. 1. Mlém. Anatomie de l'Arrosoir (Aspergillum dichotomum). Arch. Zool. expérien. (2). Tome 1. 1883.

Loydig. Anatomie und Entwickelung von Cyclas. Mïller's Archiv. 1835.

H. A. Meyer und Moebius. Fiana der Kieler Bucht. Leipzig 1865.

Paul Pelseneer. Report on the anatomy of the deep-sea Mollusca collected by $H$. M. S. Challenger. Rep. Challenger, Zool. Pt. 74. 1888.

Derselbe. Contribution à l'étude des Lamellibranches, in: Archives de Biologie. Tome XI. 1891.

A. de Quatrefages. Mémoire sur le genre Taret. Annales des Sciences naturelles (3). vol. 11. 1849.

$$
\text { Cephalopoda. }
$$

A. G. Bourne. The differences between the males and females of the pearly Nautilus. Nature. vol. 28.1883.

J. Brock. Studien über die Vemvandtschaftsverhältnisse der dibranchiaten Cephalopoden. Habilit. Erlangen 1879.

Derselbe. Versuch einer Phylogenie der dibranchiaten Cephalopoden, in: Morph. Jahrbuch. 6. $B d .1880$

Derselbe. Zur Anatomie und Systematik der Cephalopoden. Zeitschr. f. wiss. Zool. 36. Bd. 1882.

Delle Chiaje. Memorie su' Cefalopodi. Memorie sulla storia e notomia degli animali senza vertebre del regno di Napoli. Napoli 1829.

Fèrussac et d'Orbigny. Histoire naturelle générale et particulière des Céphalopodes acétabulifères vivants et fossiles. Paris 1835-1845.

Lèon Fredericq. Recherches sur la physiologie du Poulpe commun (Octopus vulgaris), in: Arch. Zool expérim. Tome 7. 1879.

Carl Grobben. Zur Kenntniss der Morphologie und Vervandtschaftsverhältnisse der Cephalopoden. Arb, Z. Inst. Wien. 7. Bd. 1886.

H. von Jhering. Ueber die Verwandtschaftsbeziehungen der Cephalopoden. Zeitschr. $f$. wiss. Zool. 35. Bd. 1880.

Van der Hoeven. Beitrag zur Kenutniss von Nautilus. (Holländisch.) Amsterdam 1856.

Will. E. Hoyle. Observations on the anatomy of a rare Cephalopod (Gonatus Fabricii), in: Proc. Z. Soc. London. 1889. II.

H. Müller Ueber das Männchen von Argonauta argo und die Hectocotylen. Zeitschr. $f$. wiss. Zoolog. 1855.

R. Owen. Memoir on the pearly Nautilus etc. London 1832.

Derselbe. Description of some new and rare Cephalopoda. Transact. Zool. Societ. London. vol. II. 1841

Derselbe. Art. Cephalopoda. Todd's Cyclopaedia etc. vol. 1. London 1836.

Derselbe. Sugplementary Observations on the Anatomy of Spirula australis Lam., in: Ann. of Nat. Hist. (5). vol. 3. No. 13.1879.

I. B. Verany. Mollusques méditerranéens observés, décrits, figurés et chromolithographiés d'après le vivant. 1. Partie. Cephalopodes de la Méditerranée. Génes 1847-1851. 
Vorany et Vogt. Mémoires sur les Hectocotyles etc. Ann. des Sciences Nat. 17. 1852.

W. J. Vigelius. Untersuchungen an. Thysanoteuthis rhombus Frosch. Ein Beitrag zur Anatomie der Cephalopoden. Mitth. Zool. Station zu Neapel. 2. Bd. 1880.

F. Ernest Weiss. On some oigopsid cuttle fishes, in: Q. Journ. Micr. Sc. (2). vol. 29.

Sehriften über einzelne Organe oder Organgruppen.

Integument, Mantel, Schale, Mundlappen.

Félix Bernard. Recherches sur les organes palléaux des Gastéropodes prosobranches. Thèse. Paris 1890. Auch in: Annales des Sciences naturelles.

F. Blochmann. Ueber die Drüsen des Mantelrandes bei Aplysia und veruandten Formen. Zeitschr. f. wissensch. Zool. 38. Bd. 1883.

Jos. Blumrich. Das Integument der Chitonen. Mit einer Vorbemerkung von Prof. Hatschek, in: Zeitschr. f. wiss. Zoologie. 52. Bd. 1891.

Bowerbank. On the structure of the shells of molluscous and conchiferous animals. Trans. of Micr. Soc. I. London 1844.

W. Carpenter. On the microscopic stmucture of shells. Report 13, 14, 17. Meeting British Assoc. London 1846, 1847, 1848.

E. Ehrenbaum. Untersuchungen über die Structur und Bildung der Schale der in der Kieler Bucht häufig vorkommenden Muscheln. Zeitschr. f. wiss, Zool. 41. Bd. 1884.

P. Girod. Recherches sur la peau des Cephaloporles. Arch. Zool. expérinent (2). vol 1. 1883.

H. Meckel. Mikrographie einiger Drïsenapparate der niederen Thiere. Müller's Archiv. 1846.

Felix Müller. Ueber die Schalenbildung bei Lamellibranchiaten, in: Zool. Beiträge von A. Schneider. 1. Bd. 1885.

R. Owen. On the relative positions to their constructors of the chambered shells of Cephalopods. Proc. Zool. Soc. London. 1878. Part 4. London 1879.

Bernhard Rawitz. Der Mantelrand der Acephalen. 1. Theil. Ostracea. Jenaische Zeitschr. f. Naturwiss, 22. Bd. 1888. 2. Theil. Arcacea, Mytilacea, Unionacea. 1bid. 24. Bd. 1890.

G. Steinmann. Torlüufige Mittheilung über die Organisation der Ammoniten, in: Ber. Nat. Ges. Freiturg. 4. Bd 1889.

G. Steinmann und L. Döderlein. Elemente der Paläontologie. Leipzig 1890.

Johannes Thiele. Die Mundlappen der Lamellibranchiaten, in: Zeitschr. $f$. wiss. Zoologie. 44. $B d .1886$.

T. Tullberg. Studien über den Bau und das Wachsthum des Hummerpanzers und der Molluskenschalen, in: Kongl. Svensk. Vetensk. Akad. Handling. 19. Bd. 1882.

Karl A. Zittel. Handbuch der Paläontologie. I. Abth. Paläozoologie. II. Band. Mollusca und Arthropoda. München und Leipzig 1881-1885.

\section{Musculatur, Fuss, Fussdrüsen, Wasseraufnahme.}

Th. Barrois. Les glandes du pied et les pores aquifères des Lamellibranches. Lille 1885.

J. Carrière. Die Drüsen im Fusse der Lamellibranchiaten, in: Arbeit. aus d. zool. Institut Wiirzburg. 5. Bd. 1879

Derselbe. Die Fussdrïsen der Prosobranchier und das Wassergefässsystem der Lamellibranchier und Gasteropoden, in: Archiv f. mikrosk. Anatomie. 21. Bd. 1882.

C. Grobben. Zur Morphologie des Fusses der Heteropoden. Arb. Zool. Inst. Wien. 7. Bd. 1887.

A. Fleischmann. Die Bewegung des Fusses der Lamellibranchiaten. Zeitschr. f. wiss. Zoologie, 42. Bd. 1885 .

Georg Kalide. Beitrag zur Kenntniss der Musculatur der Heteropoden und Pteropoden, zugleich ein Beitrag zur Morphologie des Molluskenfusses. Zeitschr. f. wiss. Zool. 46. Bd. 1888.

J. H. List. Zur Kenntniss der Drïsen in Fusse von Tethys fimbriata L., in: Zeitschr. $f_{\text {. }}$ viss. Zool. 45. Bd. 1887.

Paul Pelseneer. Sur la valeur morphologique des bras et la composition du système nerveux central des Céphalopodes. Arch. Biol. Tome 8. 1888.

Derselbe. Sur l'épipodium des Mollusques. 1. in: Bull. Scientif. France et Belg. 19. Bd. 1888. 2. note ibid. 2\%. Bd. 1890. 3. note ibid. 23. Bd. 1891.

Bernhard Rawitz. Die Fussdrïse der Opisthobranchier, in: Abhandl. Akad. Berlin. 1887.

Lndwig Reichel. Ueber die Bildung des Byssus der Lamellibranchiaten. Zool. Beiträge, Schneider. 2. $B d .1888$

P. Schiemenz. Veber die Wasseraufnahme bei Lamellibranchiaten und Gasteropoden (einschliesstich Pteropoden). Nitth. Zool. Station Neapel. 5. Bd. 1884. 2. Therl. 1bid. 7. Bd. 1887. Hier auch die ganze übrige Litteratur.

Jap. Steenstrup. Hectocotylus dannelsen hos Octopods etc. $\hbar$. Dansk. Tidensk. Selskabs Slerifter. 1856. 
Niervensystem.

L. Böhmig. Beiträge zur Kienntniss des Centralnervensystems einiger pulmonaten Gasteropoden. Inaug.-Diss. Leipzig 1883.

E. L Bouvier. Système uerveux, morphologie générale et classificution des Gastéropodes prosobranches. Annales des Sciences nat. (7). Tome 3. 1887.

Louis Boutan. Contribution à l'étude de la masse nerveuse ventrale (cordons pallí-visceraux) et de la collerette de la Fissurelle. Arch. Zool, expérim. (2). T'ome 6.1889.

J. Brock. Zur Neurologie der Prosobranchier. Zeitschr. f. wiss. Zool. 48. Bd. 1889.

0. Bütschli. Bemerkungen über die wahrscheinliche Herleitung der Asymmetrie der Gasteropoden, spec. der Asymmetrie im Nervensystem der Prosobranchier, in: Morph. Jahrb. 12. $B d .1886$.

Chéron. Recherches sur le système nerveux des Céphalopodes dibranchiaux, in: Annales des Sciences nat. (5). Tome 5. 1866.

Karl Drost. Ueber das Nervensystem und die Sinnesepithelien der Herzmuschel (Cardium edule) etc. Morph. Jahrbuch. $12 \mathrm{Bd} .1886$.

Duvernoy. Mémoires sur le système nerveux des Mollusques acéphales, in: Hémoires de l'Académie des Sciences. T. 24.

B. Haller. Zur Kenntniss der Muriciden. Eine vergl,anat. Studie. I. Theil. Anatomie des Nervensystems. Denkschr. math-nuturv. Klasse Akad. Wissensch. Wien. 45. Bd. 1882.

Derselbe. Untersuchungen über marine Rhipidoglassen. II. Textur des Centralnervensystems und seiner Hüllen. Morph. Jahrb. 11. Bd. 1885.

H. von Jhering. Vergleichende Anatomie des Nervensystems und Phylogenie der Mollusken. Leipzig 1877.

Lacaze-Duthiers Du système nerveux des Mollusques gastéropodes pulmonés aquatiques. Arch. de Zool. éxp. Tome I. 1872.

Bernhard Rawitz. Das centrale Nervensystem der Acephalen. Jenaische Zeitschr. f. Naturuiss. 20. Bd. 1887.

Paul Pelseneer. Sur la valcur morphologique des bras et la composition du système nerveux central des Céphalopodes. Arch. Biol. Tome 8. 1888.

Derselbe. Recherches sur le système nerveux des Ptíropodes, in: Arch. Biol. Tome 7. 1887.

C. Semper. Ueber Sehorgane vom Typus der Wirbelthieraugen. Wiesbaden 1877.

H. Simroth. Das Fussnervensystem von Paludina vivipara. Zeitschr. f. wiss. Zool. 35. Bd. 1880.

Derselbe. Ueber das Nervensystem und die Bexegung der deutschen Binnenschnecken. Progr. d. Realschule 2. Ordnung Leipzig. No. 503. 1882.

J. W. Spengel. Die Geruchsorgane und das Nervensystem der Mollusken. Zeitschr. $f$. wiss. Zool. Bd. 35. 1881.

\section{Sinnes organe.}

Félix Bernard, Recherches sur les organes palléaux des Gastéropodes prosobranches. Ann. des Sciences nat. (7). Tome 9. 1890. Enthält eine Untersuchung des Gasteropodenosphradiums.

J. Brock. Ueber die sogenannten Augen von Tridacna und das Vorkommen von Pseudochlorophyllkörpern im Gefösssystem der Muscheln. Zeitschr. f. wiss. Zool. 46. Bd. 1888.

0. Bütschli. Notiz zur Morphologie des Auges der Muscheln. Festschr. 500-jährig. Bestand Ruperto-Carola v. Nat-Med. Ver. Heidelberg. Nat. Theil. 1886

Justus Carrière. Die Sehorgane der Thiere vergleichend-anatomisch dargestellt. München und Leipzig 1885.

Derselbe. Ueber Molluskenaugen. Arch. f. milkrosk. Anat. 33. Bd. 1889.

C. Claus. Das Gehörorgan der Heteropoden. Arch. $f$. milerosk. Anat. 12. Bd. 1875.

P. Fraisse. Ueber Molluskenaugen mit embryonalem Typus. Zeitschr. $f$. viss. Zool. 35. Bd. 1881.

W. Flemming. Untersuchungen über Sinnesepithelien der Mollusken. Arch. f. milsr. Anat. Tom. VI. 1870.

H. Grenacher. Abhandlungen zur vergleichenden Anatomie des Auges. I. Die Retina der Cephalopoden, in: Abhandl. Naturf. Gesellsch. z. Halle. 16. Bd. 1884. II. Das Auge der Heteropoden. Ibid. 17. Bd 1886.

V. Hensen. Ueber das Auge einiger Cephalophoren. Zeitschr. f. wiss. Zool. Bd. XV. 1865.

C. Hilger. Beitrüge zur Kenntniss des Gasteropodenauges. Morph. Jahrb. 10. Ba. 1884.

Lacaze-Duthiers. Otocystes ou capsules auditives des Mollusques (Gastéropodes). Arch. $d$. Zool. éxp. Tome I. 1872.

E. Ray Lankester and A. G. Bourne. On the existence of Spengel's olfactory organ and of paired genital ducts in the pearly Nautilus. Quart. Journal Micr. Science. vol. 23. 1883. 
F. Leydig. Ueber das Gehörorgan der Gasteropoden, in: Archiv f. mikrosk. Anatomie. 7. Bd. 1871 .

H. N. Moseley. On the presence of eyes in the shells of certain Chitonidae and on the structure of these organs, in: Quarterly Journal Micr. Sc. (2). vol. 25. 1885.

$\mathrm{Ph}$. Owsjannikow und Kowalevsky. Ueber das Centralorgan und das Gehörorgan der Cephalopoden. St. Petersburg 1867.

W. Patten. Eyes of Molluscs and Arthropods, in: Nitth Zool. Stat. Neapel. 6. Bd. 1886.

Paul Pelseneor. Sur l'oeil de quelques Mollusques gastéropodes, und: Les organes des sens chez les Mollusques, in: Annales Société Belge Microsc. Memoires. Tome 16. 1891.

Rawitz. Siehe oben unter Integument.

P. B. Sarasin, Ueber drei Sinnesorgane und die Fussdriise einiger Gasteropoden. Arbeit. Zool.-zoot. Inst. Würzburg. 6, Bd. 1883.

B. Sharp. On the visual organs in Lamellibranchiata. Mitth. Zool. Station in Neapel. 5. Bd. 1884.

D. Sochaczewer. Das Riechorgan der Landpulmonaten. Zeitschr. f. wiss. Zool. 35. Bd. 1880.

J. E. Tenison-Woods. On the anatomy and life history of Mollusca peculiar to Australia, in: Proceed. R. Soc. N. S. Wales. vol. 22. 1889. Schalenaugen bei Gasteropoden.

Johs. Thiole. Die abdominalen Sinnesorgane der Lamellibranchier. Zeitschr. f. wiss. Zool. 48. $B d$. 1889 .

Darm, Tinten beutel.

D. Barfurth. Ueber den Bau und die Thätigkeit der Gasteropodenleber, in: Archiv. f. mikr. Anatomie. 22. Bd. 1883.

Th. Barrois. Le stylet crystallin des Lamellibranches. Revue biol. du Nord de la France. 1. Ani. T. 2. 1890 .

Em. Bourquelot. Recherches sur les phénomènes de la digestion chez les Mollusques céphalo. podes. Arch. de Zool. éxp. 1885.

J. Frenzel. Mikrographie der Mitteldarmdrüse (Leber) der Mollusken. I. AUgemeine Morphologie und Physiologie des Drïsenepithels, in: Nova acta Acad. Leop.-Carol. 48. Bd. 1886.

Heinrich Maria Gartenauer. Ueber den Darmkanal einiger einheimischen Gasteropoden. Inaug.-Diss. Strassburg 1875.

Patrick Geddes. On the mechanism of the odontophore in certain Mollusca, in: Trans. Zool. Soc. London. vol. 10. Part 11. 1879.

Paul Girod. Recherches sur la poche du noir des Céphalopodes des côtes de France. Archives de Zool. expérim. vol. $X .1882$.

Macdonald. General classification of the Gasteropoda. Trans, of the Linn. Soc. of London. T. IXIII. 1860.

Panceri. Gli organi e la secrezione dell' acido solforico nei Gasteropodi con un appendice etc. Atti della $R$. Accad. delle scienze fisiche. Tom. IV. 1869.

R. Rössler. Die Bildung der Radula bei den cephalophoren Mollusken. Zeitschr. f. wiss. Zool. $B d .41 .1885$

C. Semper. Zum feineren Bau der Molluskenzunge. Zeitschr. f. wiss. Zool. Bd. 9. 1868.

H. Troschel. Das Gebiss der Schnecken. 1. Bd. Berlin 1856-1863.

W. J. Vigelius. Vergleichend-anatomische Untersuchungen über das sogenannte Pankreas der Cephalopoden. Verhandl. k. Akad. Wetensch. Amsterdam. Deel 22.1881.

$$
\text { Respirationsorgane, Circulationssystem. }
$$

Félix Bernard. Recherches sur les organes palléaux des Gastéropodes prosobranches. Thèse. Paris 1890.

Bojanus. Ueber die Athem- und Kreislaufswerkzeuge der zweischaligen Muscheln. Isis 1817, 1820,1827

L. Cuénot. Études sur le sang et les glandes lymphatiques dans la série animale. 2. partie. Invertebrés, in: Archives de Zoologie expérim. 2. série. vol. 9. 1891.

Carl Grobben. Ueber den Bulbus arteriosus und die Aortenlilappen der Lamellibranchiaten, in: Arbeiten a.d. Zoologischen Institute der Universität Wien. 9. Bd. 1891.

W. A. Herdman. On the structure and function of the cerata or dorsal papillae in some nudibranchiate Mollusca. Quarterly Journ. Microsc. Science. vol. 31 . P. 1.

I. Joubin. Structure et développement de la branchie de quelques Céphalopodes des côtes de Hrance. Archives de Zool. expérim. (2). vol. 3. 1885.

Langer. Ueber das Gefässsystem der Teichmuschel. Denkschriften der Wiener Akademie. 1855 und 1856.

A. Ménégaux. Recherches sur la circulation des Lamellibranches marins. Besançon 1890. 
K. Mitsukuri. On the structure and significance of some aberrant forms of Lamellibranchiate gills. Quart. Journal Mierosc. Sc. N. S. 21.1881.

H. L. Osborn. On the gill in some forms of prosobranchiate Mollusca. Stud. biol. Labor. J. Hopkins Univ. vol. 3. 1884.

R. Holman Peck. The structure of the Lamellibranchiate gill. Quart. Journ. of Micr. Science. 1876.

c. Posner. Ueber den Bau der Najadenkieme, Arch. f. mikrosk. Anat. Tom. II. 1875.

$$
\text { Secundäre Leibeshöhle, Nephridien, Geschlechtsorgane. }
$$

Baudelot. Recherches sur l'appareil génér. des Mollusques gastéropodes. Ann. Sc. nat. sér. IV. Tome IIX, 1862.

Th. Behme. Beiträge zur Anatomie und Entwickelungsgeschichte des Harnapparates der Lungenschnecken, in: Arch. Naturg. 55. Jahrg. 1889.

J. Brock. Ueber die Geschlechtsorgane der Cephalopoden. Erster Beitrag, in: Zeitschr. $f$. wiss. Zool. 32. Bd. 1879.

J. T. Cunningham. The renal organs (Nephridia) of Patella. Quart. Journal Alicrosc. Science. vol. 23. 1883.

Derselbe. Note on the structure and relations of the kidney in Aplysia. Mitth. Zool. Station in Neapel. 4. Bd. 1883.

C. Grobben. Morphol. Studien über den Harn- und Geschlechtsapparat, sowie die Leibeshöhle der Cephalopoden Arb. Zool. Inst. Wien. 5. Bd. 1884.

Derselbe. Ueber die Pericardialdrïse der Lamellibranchiaten. Ein Beitrag zur Kenntniss der Anatomie dieser Molluskenklasse. Arb. Zool. Inst. Wien. 7. Bd. 1888.

Derselbe. Die Pericardialdrüsen der Gastcropoden, in: Arbeiten aus dem Zoolog. Institute der Univ. Wien. Bd. 9. 1890.

A. C. Haddon. On the generative and urinary alucts in Chiton, in: Proceed. Roy. Dublin Soc. (2). vol. 4. 1885.

B. Haller. Beiträge zur Kenntniss der Niere der Prosobranchier. Morph. Jahrb. 11. Bd. 1885.

A. Hancock. On the stmucture and homologies of the renal organ in the Molluscs. Transact. of the Linn. Soc. vol. XXIV.

P. P. C. Hook. Les organes de la génération de l'huitre. Tijdschr. Nederl. Dierk. Vereen. Suppl. D. 1. 1883.

H. von Jhering. Ueber den uropneustischen Apparat der Heliceen. Zeitschr. f. wiss. Zool. 41. $B d, 1884$.

J. Kollmann. Ueber Verbindungen zwischen Cölom und Nephridium. Baseler Festschrift zum Würzburger Jubiläum. 1882.

A. Kowalevsky. Ein Beitrag zur Kenntniss der Excretionsorgane. Biol. Centralblatt. 9. Bd. 1889.

E. Ray Lankester. On the originally bilateral character of the renal organs of Prosobranchia and on the homologies of the yolk sacc of Cephalopoda. Ann. of Nat. Hist. (5). 7 vol. 1881 .

Derselbe. Observations on the Pondsnail etc. Quart. Journ. Microsc. Science. Tome XIV. 1874.

E. Ray Lankester and A. Bourne. On the existence of Spengel's olfactory organ and of paired genital ducts in the pearly Nautilus. Quart. Journal of Microsc. Science. vol. XXIII. 1883.

G. F. Mazzarelli Intorno all' anatomia dell' apparato riproduttore delle Aplysiae del golfo di Napoli. $Z$. Anz. 12. Bd. 1889.

Derselbe Intorno all' apparato riprodultore di alcuni Tectibranchi (Pleurobranchaea, Oscanius, Acera), in: Zool. Anzeiger. 14. Jahrg. 1891.

0. Nüsslin. Beiträge zur Anatomie und Physiologie der Pulmonaten. Habilitationsschrift (Carlsruhe). Tübingen 1879.

R. Owen. On the external und structural characters of the male Spirula australis. Proceed. Zool. Soc. London 1880.

Rémy Perrier. Recherches sur l'anatomie et l'histologie du rein des Gastéropodes prosobranches, in: Annales Sciences natur. (7). T. 8. 1890.

Walter M. Rankin. Ueber das Bojanus'sche Organ der Teichmuschel (Anodonta cygnea Lam.), in: Jenaische Zeitschrift für Naturuissensch. 24. Bd. 1890.

A. Schmidt. Der Geschlechtsapparat der Stylommatophoren etc. Abh. des Nat. Vereins für Sachsen und Thïringen. 1. Bd. 1885.

P. Stepanoff. Ucber Geschlechtsorgane und Entwickelung von Ancylus fluviatilis. St. Petersburg 1866. 
W. J. Vigelius. Bijdrage tot de Krenuis van het excretorisch Systeem der Cephalopoden. Acad. Proefschrift. Leiden 1879.

Derselbe. Ueber das Excretionsystem der Cephalopoden. Niederl. Arch. f. Zool. 5. Bd. 1880 .

Parasitische Schnecken.

Albert Baur. Beiträge zur Naturgeschichte der Synapta. III. Die Eingenceideschnecke in der Leibeshöhle der Synapta digitata, in: Nova Acta Academ. Caes, Leop. Tom. XXXI. 1864.

Max Braun. Zusammenfassender Bericht im Centralbl. f. Bakteriologie u. Parasitenkunde. 5. $B d .1889$.

Johannes Müller. Ueber. Synapta digitata und iiber die Erzeugung von Schnecken in Holothurien. Berlin 1852.

Paul und Fritz Sarasin. Ueber zwei parasitische Schnecken, in: Erg. Forsch. Ceylon 1884 -1886 . 1. Bd. 1887.

P. Schiemenz. Parasitische Schnecken. Kritisches Referat, in: Biol. Centralblatt. 9, Bd. $1889 / 1890$.

Walter Voigt. Entocolax Luduigii, ein neuer seltsamer Parasit aus einer Holothurie, in : Zeitschr. f. wiss. Zool. 47. Bd. 1888.

Ontogenie.

F. Blochmann. Ueber die Entwiclelung von Neritina fluviatilis Mitll, I., in: Zeitschr. $f$. wiss. Zoologie. 36. Bd. 1881.

Derselbe. Beiträge zur Lenntniss der Entwickelung der Gasteropoden. Zeitschr. t. wiss. Zoologie. 38. Bd. 1883.

W. K. Brooks. The development of the Squid. (Loligo Pealii Lesueur). Annivers. Mem. Boston Soc. Nat. Hist. Boston 1880.

$\mathrm{R}$ von Erlanger. Zur Entwickelung von Paludina vivipara. I u. II, in: Morphologisches Jahrbuch von Gegenbaur. 17. Bd. 1891.

Fermann Fol. Études sur le développement des Mollusques. I. Sur le développement des Ptéropodes, in: Archives de Zool. expérim. Tome IV. 1875. II. Sür le développement embryonnaire et lavvaire des Hétcropodes. Ibid. Tome V. 1876. III. Sur le développement des Gastéropodes pulmonés. Ibid. Tome VIII. 1879/80.

H. Grenacher. Zur Entwickelungsgeschichte der Cephalopoden, zugleich ein Beitrag zur Morphologie der höheren Mollusken, in: Zeitschr. für uiss. Zoologie. 24. Bd. 1874.

C A. Haddon. Notes on the Development of Mollusca. Quart. Journal Microsc. Science. vol. 22.1882.

B. Fiatschek. Ueber Entrvickelungsgeschichte von Teredo, in: Arb. a. d. Zool. Instit. d. Universität Wien. Tom. III. Heft 1. 1880.

R. Horst. Embryogénie de l'huitre. Tijglschr. Nederl. Dierk. Ver. Suppl. Deel 1. 1884. Derselbe. Development of the european Oyster. Quart. Journ. Microsc. Science. 188\%.

A. Kölliker. Entwickelungsgeschichte der Cephalopoden. Zürich 1844.

A. Kowalevsky. Fitude sur l'embryogenie du Dentale, in: Annales du Nusée d' histoire naturelle de Marseille. Zoologie. T'ome 1. 1883.

l) erselbe. Embryogénie du Chiton Polii (Philippi) avec quelques remarques sur le développement des autres Chitons. Ann. Mus. N. H. Marseille. Tome 1. No. 5.

A. Krohn. Beiträge zur Entuickelungsgeschichte der Pteropoden und Heteropoden. Leipzig 1860 .

E. Ray Lankester. On the developmental history of the Mollusca. Philos. Transact. London. 1875.

Derselbe. Observations on the development of the Cephalopoda. Quart. Journ. Microsc. Science. vol. TV. N. S. 1875.

S. Lovén. Beiträge zur Kenntniss der Entwickelung der Mollusca acephala lamellibranchiata. Stockholm 1879.

J. Playfair Mac Murrich. A contribution to the embryology of the prosobranch Gasteropods. Stud. Biol. Lab. J. Hopkins Univ. vol. 3. 1886.

William Patten. The embryology of Patella, in: Arbeit. Zool. Inst. Wien. 6, Bd. 1885.

G. Pruvot. Sur le développement d'un Solénogastre, in: Comptes rend. Acad. Paris. Tome 111 1890.

Carl Rabl. Ueber die Entuickelung der Tellerschnecke, in: Morph. Jahrb. 5. Bd. 1879. Derselbe. Die Ontogenie der Süsswasserpulmonaten. Jenaische Zeitschrift. 9. Bd. 1875.

Derselbe. Ueber die Entwickelungsgeschichte der Malermuschel. Jenaische Zeitschrift. 10. Bd. 1876.

W. Salensky. Litudes sur le déveloplement du Vermet, in: Arch. Biol. Tome 6. 1887. l)erselbe Beiträge zur Entuichelungsgeschichte der Prosobranchier. Zeitschr. für wiss. Zoologie. 22. Bd. 1872. 
P. B. Sarasin. Entwiclelungsgeschichte der Bithynia tentaculata. Arb. Zool.-zoot. Institut Würzlurg. 6. Bd. 1882.

Paul und Fritz Sarasin. Aus der Entwickelungsgeschichte von Helix Waltonii. Ergebn. Nat. Frorsch. Ceylon 1884-1886. 1. Bd. Wiesbaden 1888.

P. Schiemenz. Zusammenfassende Darstellung der Beobachtungen von Eisig, Rouzaud, Jourdain, Brock, Kitotz etc. über die Entuickelung der Genitalorgane der Gasteropoden. Biol. Centralblatt. 7. Bd. 1888.

C. Schierholz. Ueber Entuickelung der Unioniden, in: Denleschriften Akad. Wien. 55. Bd. 1888.

F. Schmidt. Beitrag zur Kenntniss der postembryonalen Entwickelung der Najaden, in: Archiv für Naturgeschichte. 51 Jahrg. 1885.

M. Ussow. Untersuchungen über die Entvickelung der Cephalopoden. Arch. Biologie. Tome 2. 1881.

L. Vialleton. Recherches sur les premières phases du développenent de la Seiche. Annal. Sc. Nat. (7). Tome 6 (auch Thèse). 1888.

Wladimir Wolfson. Die embryonale Entwickelung des Lymnaeus stagnalis. Bullet. Acad. Imp. Sc. St. Pétersbourg. 26. Jahrg 1880

H. E. Ziegler. Die Entwickelung von Cyclas cornea Lam. Zeitschr. f. wiss. Zool. 41. Bd. 1885 .

\section{Zu Abschnitt XIX und XX.}

R. von Erlanger. On the paired Nephridia of Prosobranchs, the homologies of the only remaining Nephridium of most Prosobranchs, and the Relations of the Nephridia to the gonad and genital duct., in: Quart. Journ. Microsc. Science (N. S.) CXYXII. vol. XXXIII. Part 4. Juni 1892.

Trochus, Turbo und Haliotis besitzen nur eine linksseitige, Fissurella, Emarginula, Puncturella, Patella und Tectura haben überhaupt keine Renopericardialöffnung. Bei allen Diotocardiern (auch bei Trochus) werden die Geschlechtsproducte durch das rechte Nephridium entleert. Die einzige Niere der Monotocardier ist in der That die linke der Diotocardier. Die rechte der Diotocardier erhält sich in ihrem ausleitenden Theil bei den Monotocardiern als Geschlechtsleiter, in ihrem secernirenden Theil vielleicht (?) als die "Nephridialdrüse".

\section{Anhang.}

\section{Rhodope Veranii.}

Der Körper dieses kleinen, bis $4 \mathrm{~mm}$ langen Thierchens ist gestreckt spindelförmig, äusserlich bilateral-symmetrisch. Das Körperepithel ist überall bewimpert. Es existirt ein Hautmuskelschlauch. Nach innen vom Hautmuskelschlauch, dem Bindegewebe (Parenchym) eingebettet, finden sich zahlreiche, unregelmässig geformte $\mathrm{K}$ alkkörperchen. Darmkanal. Der Mund liegt am Vorderende und führt in eine erweiterte Mund-oder Schlundhöhle, in deren Anfangsstück zwei traubenförmige Speicheldrüsen münden. Eine Radula und Kiefer fehlen. Ein verengter Abschnitt, der Oesophagus, setzt die Schlundhöhle mit dem schlauchförmigen, den Körper der Länge nach durchziehenden Mittel- 
darm in Verbindung. Dieser Mitteldarm, welcher eine gut entwickelte Muskelwand besitzt, setzt sich vorn, über der Einmündungsstelle des Oesophagus, in ein über das Gehirn nach vorn verlaufendes Divertikel fort. Eine gesonderte Verdauungsdrüse fehlt. Am Ende des zweiten Körperdrittels geht von der rechten Seite des Mitteldarmes ein kurzer und düner, bewimperter Enddarm ab, der rechtsseitig mit dem After nach aussen mündet.

Das Nervensystem besteht aus 2 über dem Schlunde liegenden, dicht aneinander gelagerten und fast eine einzige Masse bildenden Ganglienparen und einem unter dem Schlund, etwas asymmetrisch links liegenden Ganglion. Die beiden Ganglien eines jeden oberen Ganglienpares sind miteinander durch $\mathrm{Quercommissuren,} \mathrm{das}$ hintere dorsale Paar mit dem unteren Ganglion durch zwei den Schlund umgreifende Counective verbunden. Von den Nerven sind zwei seitlich nach hinten verlaufende am stärksten ausgebildet. Sie entspringen aus dem hinteren oberen Ganglienpaar, welchem ein Paar A u gen und ein Paar wimpernde, einen Otolithen enthaltende, Gehörbläschen angelagert sind.

Geschlechtsorgane. Rhodope ist hermaphroditisch. Die Gonaden bestehen aus etwa 20 auf der Bauchseite der hinteren zwei Körperdrittel liegenden Follikeln, von denen die vorderen Eier, die hinteren Spermatozoen bilden. Die Ausführungsgänge aller Follikel sollen sich zu einem gemeinsamen Gang verbinden. Ist dies wirklich der Fall, so stellen alle Gonadenfollikel zusammen eine $\mathrm{Z}$ witterdrïse dar. Der Zwittergang, welcher nach vorn verläuft, soll sich vorn wieder spalten in den Oviduct und das Vas deferens. Letzteres führt zum musculösen Penis, welcher aus der rechts vorn liegenden männlichen Geschlechtsöffnung vorgestreckt werden kann. Mit dem Oviduct steht in Verbindung eine Vesica seminalis und eine Drüse (Eiweissdrüse, Nidamentaldrüse). Die weibliche Geschlechtsöffnung soll, von der männlichen gesondert, hinter dieser auf der rechten Seite liegen.

Ein gesondertes Blutgefässsystem wurde nicht beobachtet. Dagegen ist eine wohlentwickelte Leibeshöhle vorhanden, erfüllt von farbloser, ernährender Flüssigkeit, in welcher Blutkörperchen suspendirt sind.

Besondere Athmungsorgane fehlen.

Das Nephridialsystem wurde folgendermaassen beschrieben: Rechts vor dem After, zwischen diesem und den Geschlechtsöffnungen, liegt die äussere Nephridialöffnung. Sie führt vermittelst eines kurzen, bewimperten Kanales in eine geräumige $\mathrm{Ni}$ eren $\mathrm{k}$ a m mer, welche eine Erweiterung eines Längskanales darstellt. Stellenweise ist die Nierenkammer zur Bildung kurzer Blindsäckchen ausgebuchtet. In die Nierenkammer münden 9 oder 10 kleine, flaschenförmige Organe, welche ganz an die Excretionsivimperzellen der Plathelminthen erinnern. Am Boden einer jeden Flasche, deren Hals in die Nierenkammer mündet, erhebt sich nämlich eine Wimperflamme.

Die Entwickelung ist eine directe. Auf keinem Stadium findet sich irgend eine Andeutung einer Schalendrüse oder einer Schale oder eines Fusses.

Systematische Stellung. Rhodope wird von den einen Forschern zu den Turbellarien (in die Nähe der Rhabdocölen), von den anderen zu den Mollusken (in die Nähe der Nudibranchier) gestellt, 
während dritte geneigt sind, in ihr eine Zwischenform zwischen diesen beiden Abtheilungen zu erblicken.

Es scheint uns nun, dass nur ein einziger Punkt angeführt werden kann, welcher für eine Verwandtschaft mit den Turbellarien spricht, nämlich das Vorhandensein der wimpernden Excretionszellen im Nephridialsystem. Im Uebrigen aber erscheint uns eine Ableitung des Nephridialsystems von Rhodope mit seiner Urinkammer und rechtsseitigen Nephridialöffnung von demjenigen der Nudibranchier viel plausibler, als eine Ableitung vom Wassergefässsystem der Plathelminthen. Das Vorhandensein eines Enddarmes und Afters, eines unteren Schlundganglions (Pedalganglion?) spricht sebr gegen die Verwandtschaft mit den Turbellarien. Der Hinweis auf den ganz vereinzelten Fall von Microstoma lineare (vergl. p. 145-146) mit seiner unteren Schlundcommissur ist doch gewiss nicht iiberzeugend. Der Geschlechtsapparat von Rhodope ist viel mehr nach dem Typus desjenigen der Nudibranchier als nach demjenigen der Turbellarien gebaut.

Gegen die Verwandtschaft mit den Mollusken sprechen gewiss auch schwerwiegende Bedenken: vor allem das Fehlen des Herzens und das vollständige Fehlen der Schale und des Fusses, selbst beim Embryo. Die Frage ist die, ob man es für möglich hält, dass ein Mollusk, welcher den Fuss, die Kiemen, die Schale u. s. w. eingebüsst hat (und solche Formen giebt es, vergl. Phyllirrhoë), sich auch noch unter Einbusse des Herzens so weit von der typischen Molluskenorganisation entfernen konnte, dass diese Organe selbst nicht einmal mehr in der Entwickelung vorübergehend auftreten. Hält man dies für möglich, so wird man in der Asymmetrie von Rhodope, zumal in der besonderen Lage der Geschlechts-, Nephridial- und Afteröffnung auf der rechten Körperseite, Welche ganz mit derjenigen der Nudibranchier übereinstimmt, ein ausserordentlich bedentungsvolles Moment erblicken, welches schwer zn Gunsten der Molluskenverwandtschaft in die Wagschale fällt.

Dass Rhodope eine vermittelnde Stellung zwischen Turbellarien und Mollusken einnehme, daran ist wohl nicht im Ernste zu denken.

\section{Litteratur.}

L. von Graff. Ueber Rhodope Veranï Koell. (= Sidonia elegans M. Schultze), in: Morph. Jahrbuch. 8. Bd. 1883.

A. Koelliker. Rhodope, nuovo genere di Gasteropodi. Giornale dell' Istituto P. Lombardo di scienze e. c. Tomo 16. Milano 1847.

s. Trinchese. Nuove osservazioni sulla Rhodope Veranii (Kooll.). Rendic. dell' Accad. di Napoli. 1887. 





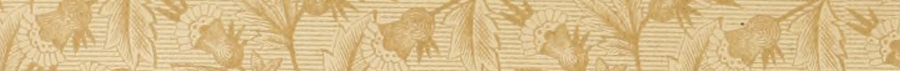


